$12 / 1^{-14}-95050$

DOE/EH-0445

\title{
HUMAN RADIATION EXPERIMENTS: \\ The Department of Energy Roadmap to the Story and the Records
}

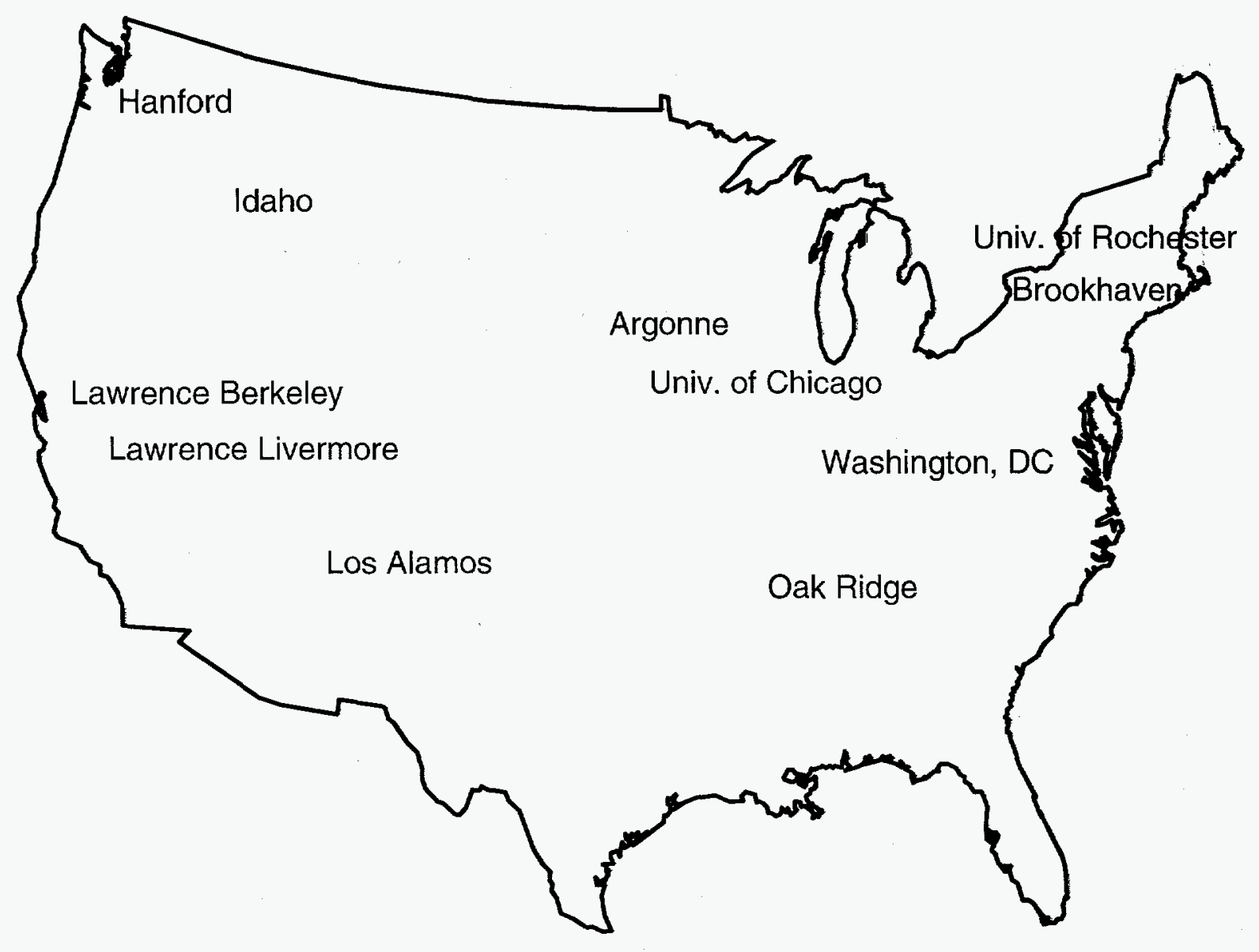

United States Department of Energy Assistant Secretary for Environment, Safety, and Health February 1995 
This report has been reproduced directly from the best available copy.

Available to DOE and DOE Contractors from the Office of Scientific and Technical Information, P.O. Box 62, Oak Ridge, TN 37831; prices available from (615) 576-8401.

Available to the public from the U.S. Department of Commerce, Technology Administration, National Technical Information Service, Springfield, VA 2216I, (703) 487-4650.

Cover photo: Cobalt-60 teletherapy conducted for cancer treatment at the Oak Ridge Institute for Nuclear Science (1972). 
HUMAN RADIATION EXPERIMENTS:

The Department of Energy Roadmap

to the Story and the Records

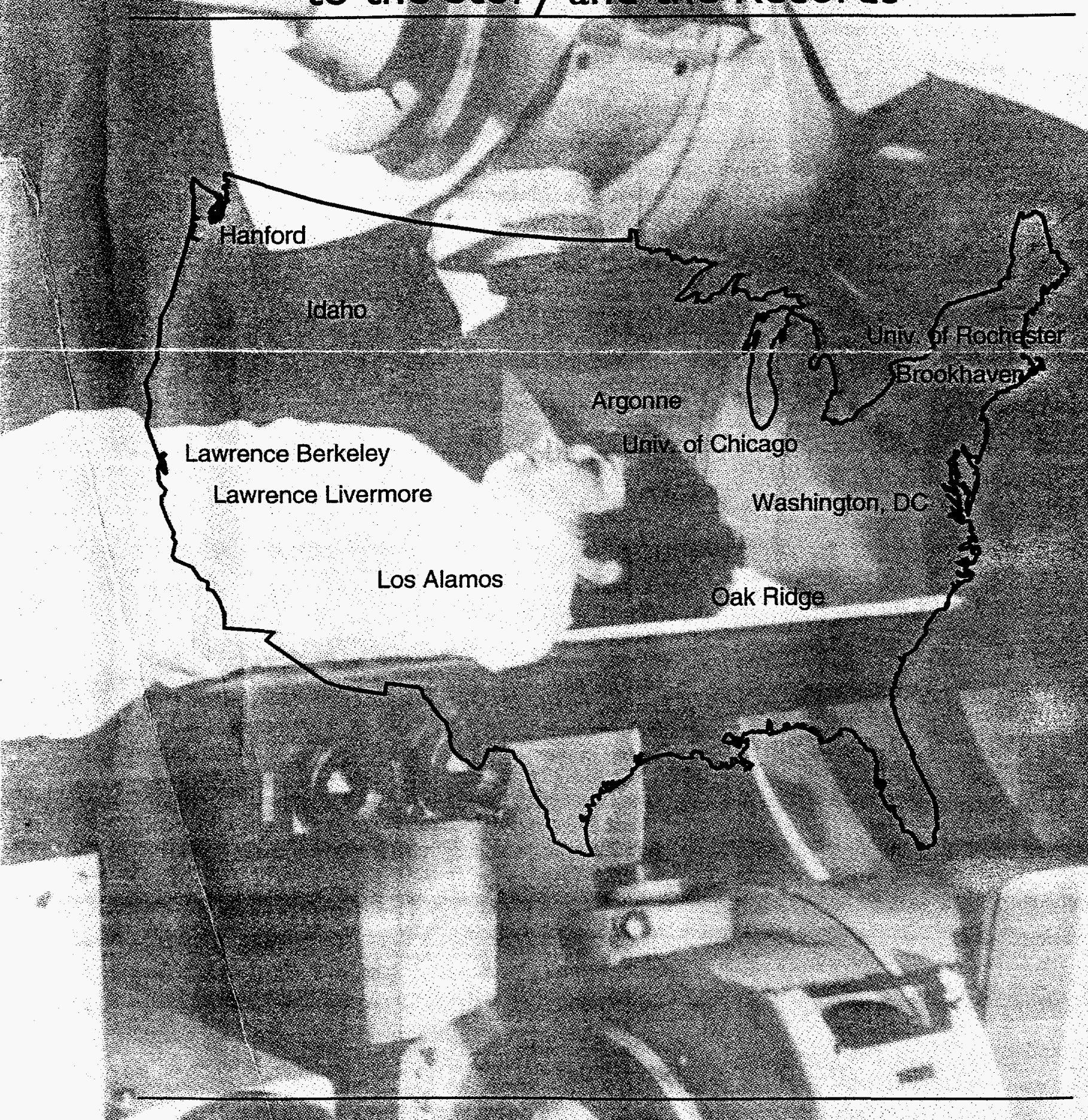

United States Departement of Energy Assistant Secretary for Environment, Safety, and Health MISTER February 1995 


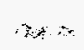

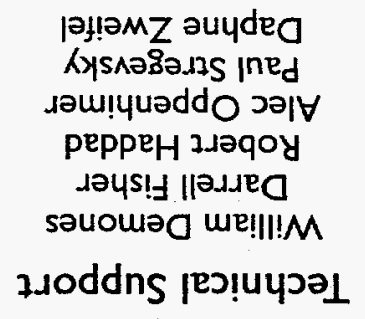

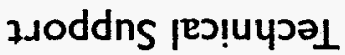

S키이 키!!ura zuezs!

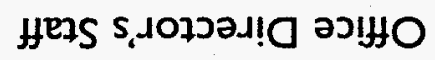

$$
\begin{aligned}
& \text { !)su!!j!!Z qog } \\
& \text { IInus \#2W }
\end{aligned}
$$

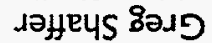

$$
\begin{aligned}
& \text { ә5०Y पәत्र } \\
& \text { دouाted әuu!! } \\
& \text { mวอిped d!!l4d } \\
& \text { पבJEW KE XY ES! } \\
& \text { pun'BOH WOL }
\end{aligned}
$$

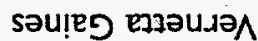

$$
\begin{aligned}
& \text { ueag uप이 } \\
& \text { S!ARO EPUEM }
\end{aligned}
$$

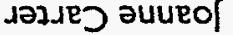

$$
\begin{aligned}
& \text { ueuryong \गए। } \\
& \text { uə| } \forall \text { 티도 }
\end{aligned}
$$

دОวכә.!! Kandəa '

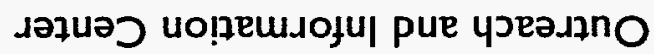

$$
\begin{aligned}
& \text { әә乡n人 ןецग!W } \\
& \text { נәэ|рәрә|рu!पs Кpu! } \\
& \text { !e||!d E7! دd } \\
& \text { ว8ిEAESUEW URE| } \\
& \text { ||כגנEH P!AeO }
\end{aligned}
$$

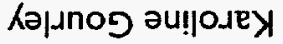

$$
\begin{aligned}
& \text { دəus!f WOJ } \\
& \text { ssə8ి..ng uos } \hat{i}_{\forall} \forall
\end{aligned}
$$

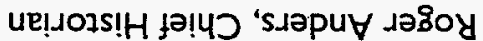

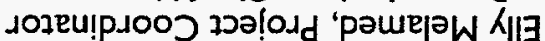

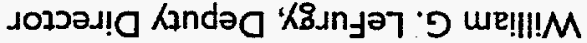

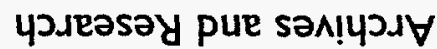

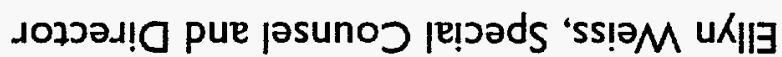

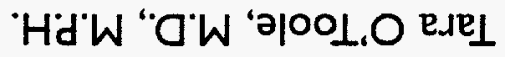




\section{DISCLAIMER}

Portions of this document may be illegible electronic image products. Images are produced from the best available original document. 


\section{Foreword}

$\mathrm{O}$ n December 7,1993, U.S. Secretary of Energy Hazel R. O'Leary announced her Openness Initiative; the scope of its ramifications has only begun to become fully apparent in the succeeding year. The determination to conduct the public's business in an open and fully accountable manner has required profound change in an agency whose institutional birth was in the most secret of wartime programs, the Manhattan Project.

Over the past several decades, the American people's trust in our institutions of government has greatly eroded. Many complex factors have contributed to this erosion, not least among them the secrecy associated with our Cold War nuclear competition with the Soviet Union. Without judging the historical necessity of secrecy, and in recognition that even today some activities require national security classification, it is a fact that the ability of the Government to perform its post-Cold War missions is greatly impeded by pervasive public distrust of its motives and competence. The commitment to openness, of which

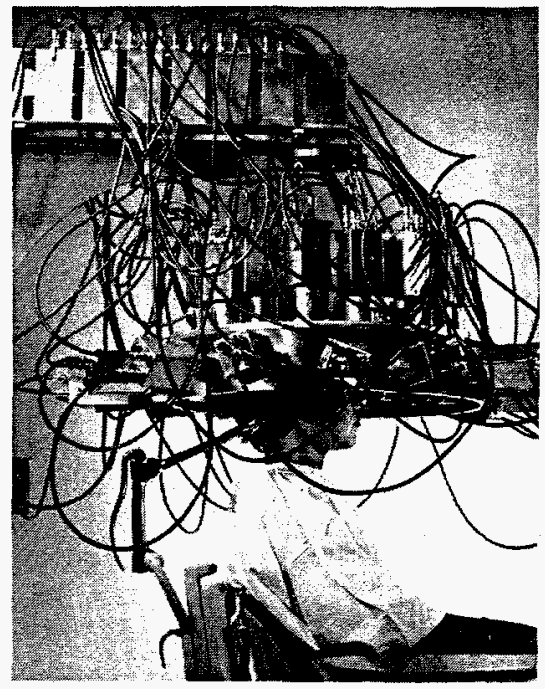

Positron emitter detector (circa 1962) used to detect brain tumors at Brookhaven National Laboratory. this proiect is a very visible element, is a deliberate effort to rebuild that basic level of trust between the American people and their government that is necessary for a democracy to function.

Well over 200 people in Washington, D.C. and around the country have devoted all or most of their time during the past year to the effort to find, declassify if necessary, evaluate, and make publicly accessible and usable the U.S. Department of Energy's (DOE's) records related to human experimentation with radiation. This project extends beyond the records of the experiments themselves to include records in the custody of DOE and important private institutions that illuminate the considerations that drove human-subject research. It has called on the expertise of historians, archivists, health professionals, declassifiers, records managers, lawyers, and researchers of various kinds. In addition, the advice and comments of a number of academic and government historians and archivists has been sought and is gratefully acknowledged. While the work is still ongoing, it has reached a stage at which substantial progress can be reported, as it is in the following pages.

It would be unrealistic to imagine that we will ever find every document that bears on the story of human radiation experimentation in which the Manhattan Project, the Atomic Energy Commission, and DOE have been involved, considering that 3.2 million cubic feet of records still survive in dozens of locations from coast to coast, many of which are poorly catalogued, if at all. The goal of this publication is not to have the final word, but to leave behind a roadmap that will enable the public, historians, and policy makers, as well as those who participated in experiments as subject or researcher, to come to a better understanding of this aspect of the history of the atomic age.

For me and those with whom I have been privileged to work, this has been an opportunity to contribute to our country's understanding of its past and transition to its future. My sincere gratitude is extended to all of those who helped, from Washington to Berkeley and many points between.

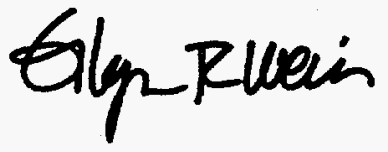

Ellyn R. Weiss, Director

U.S. Department of Energy, Office of Human Radiation Experiments

February 1995 


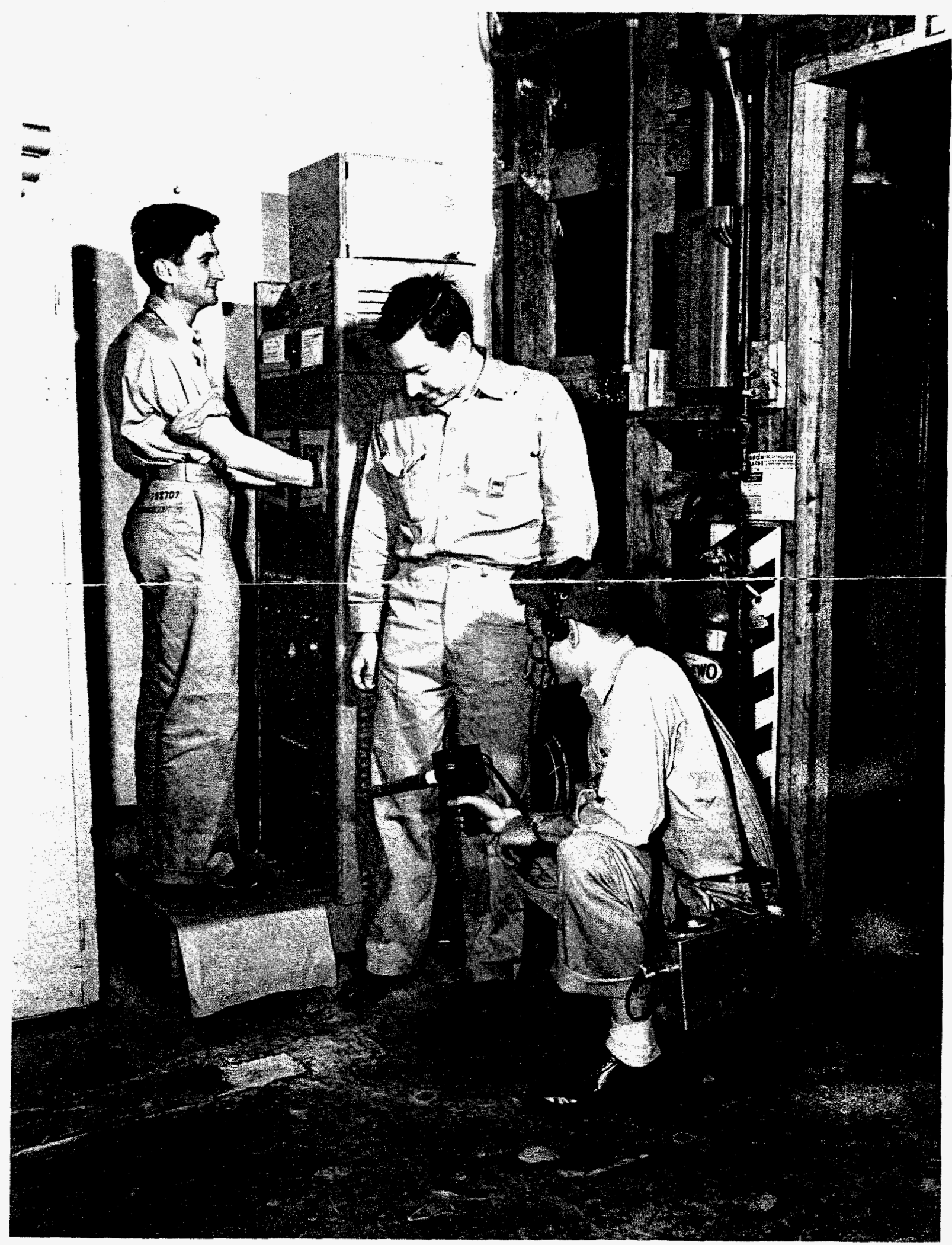

Oak Ridge National Laboratory workers checking for radioactive contaminants (circa 1950). 
T

HESE ACKNOWLEDGMENTS must begin with

Secretary Hazel R. O'Leary, who conceived this project and whose personal commitment to openness ensured that the necessary resources and attention were always forthcoming. Dr. Tara O'Toole, Assistant Secretary for Environment, Safety and Health, generously shared her expertise and provided a strong and supportive administrative environment.

We also gratefully acknowledge the help of Glenn Podonsky, Lesley Gasperow, Sandra Fox, Virginia Johnson, and the staff of the Office of Security Evaluations; Martha DeMarre, Fanny Bryant, and the staff of the Coordination and Information Center; and Norma Wilson, Becky Dobbs, and others from Pacific Northwest Laboratory. Loretta Hefner of Lawrence Berkeley Laboratory, along with an able and eager staff, provided invaluable assistance.

This work could not have been accomplished without the support and coordination of the primary DOE field and laboratory contacts: Jack Bartley, Bruce Church, Max Creamer, Richard Dickson, Barbara Fitzgerald, Shirley Fry, Ken Groves, Erskine Hicks, Ed Jascewsky, Ralph Kopenhaver, Deborah Maresca, Alan McMillan, Thomas Row, Gene Runkel, Gary Sanders, Robert Schlenker, Yvonne Sherman, L.P. Singh, Judy Stroud, James Ware, and Michael Yesley.

The project also recognizes the important contributions of the following people:

- Dave Anglen

- Tom L. Baccus, Trina Baker, Neil Barss, Robert Baumgardner, Tom Bell, Anna Berge, Barton Bernstein, Gabrielle Boudreau, Barbara Brooks, Peter Brush, Joanne Burrows

- Pepin Carolan, Nong Chen, Marjorie Ciarlante, Carolyn Clark, Margo J. Clark, Lynn V. Cline, Frank Cooling, Jim Cooper, Jeannie Cuevas

- Cheryl Dawson, Ross Decker, Denise Diggin, Jerry Dummer

- Connie Eimer, Patricia Barbosa-Ekman
- Dion Farganis, Lenora Flowers, Guy Fringer

- Steve Galson, Vanessa Gamble, Michael Giberson, Robert Gruber, Paul Guthals

- Bart Hacker, Perry Hall, Hal Halpern, Victoria Harden, Zena Hardin, Pat Heinig, Roger Heusser, Richard Hewlett, Karen Holmes, Mary Hones, Thomas Hudson

- Bruce Jones, Pat Jones, Rick Jones, Geoffrey Judge

- Bonnie Kapus, Hannah King, Judy Krumm, Tom Kunkle

- Robert Landazuri, Georgette Lane, Lowell Langford, Marsha Lawn

- Robert Martensen, Brian Martin, Priscilla McMillan, Carol McKay, Roger Meade, Bill Moss

- Jerome Nashorn, Gary Novak

- Rick Oborn, John Ost

- John Parascandola, Gayle Peters, Don Peterson

- Charles Reeves, Dan Reicher, Chris Reilly, David Rothman, William G. Rothstein, Carol Rueter

- Shannon Savage, Jeanne Schauble, Berta Schreiber, Pat Schuette, Marion B. Scroger, GayLa Sessoms, Mike Smith, Lynne Snyder, Heather Stockwell, John Stoner, Susan Storch, Cliff Strader

- Dennis Trailor

- George Voelz

- Samuel Walker, Mary Ann Wallace, Denise Walters, Ashleigh Waring, Spencer Weart, Suzanne White

- Jeanne Young

- Nancy Zinn, Steve Zobel, Mark Zweifel.

Thanks also are due to the staffs of R.O.W. Sciences, Inc., and COMPA Industries, Inc. 


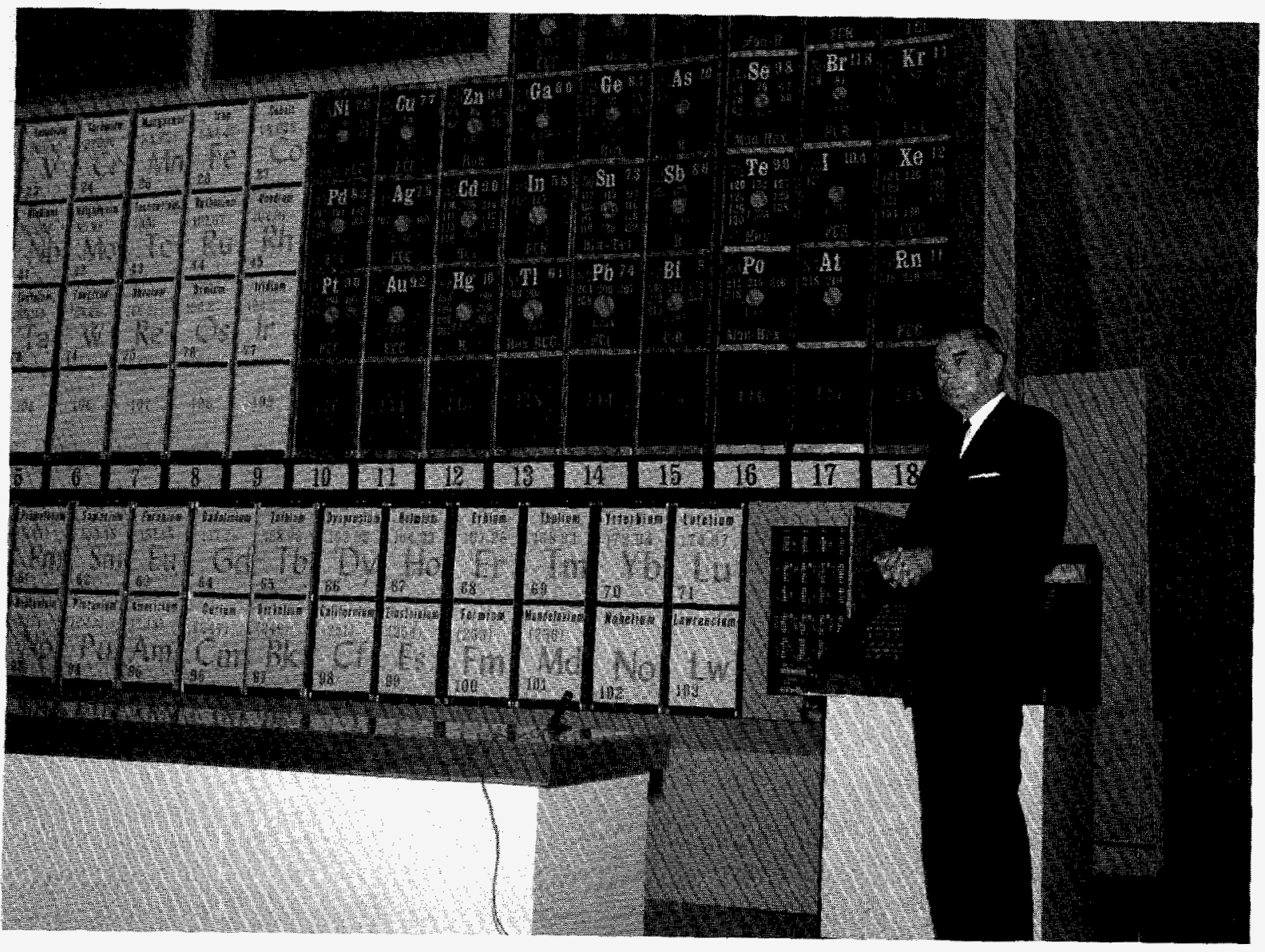

Glenn T. Seaborg, discoverer of plutonium and Chairman of the AEC, 1961-1971. 
Foreword

Acknowledgments $\checkmark$

List of Photographs

Chapter I. Overview of the DOE Project

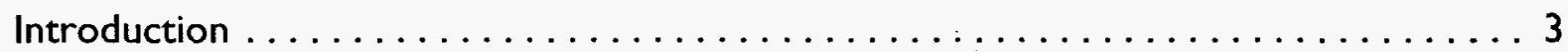

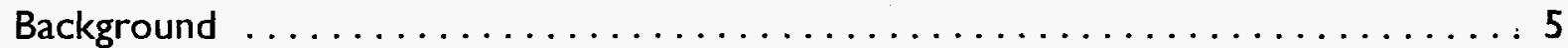

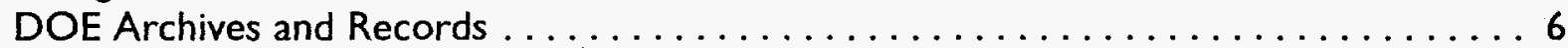

DOE Strategy for Finding Experiment Information ................ 8

Information as an Engine for Democratic Government $\ldots \ldots \ldots \ldots \ldots \ldots \ldots$.

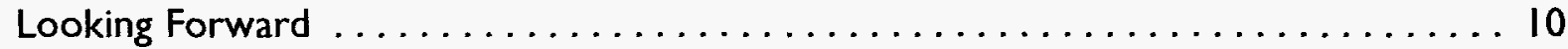

Chapter 2. Narratives and Records Series Descriptions ............... 13

\section{Institutional Areas}

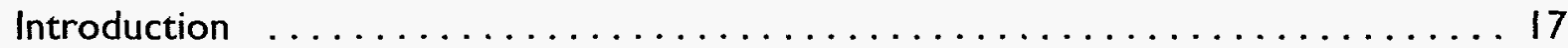

DOE Predecessor Agencies and Human Radiation Experimentation:

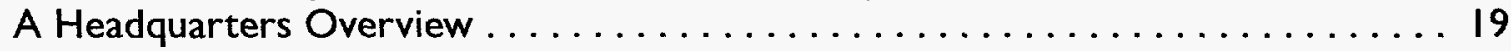

Argonne National Laboratory . . . . . . . . . . . . . . . . . . . . 47

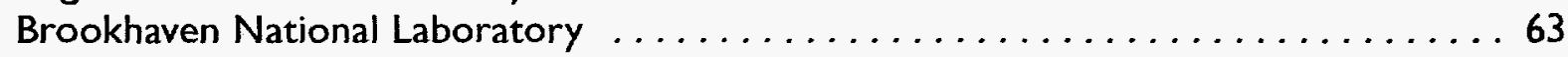

Hanford Sites .......................................... 74

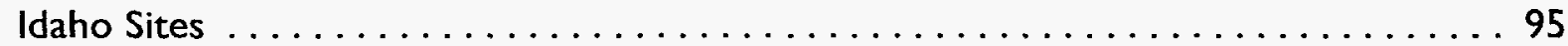

Lawrence Berkeley Laboratory ........................... 108

Lawrence Livermore National Laboratory $\ldots \ldots \ldots \ldots \ldots \ldots \ldots \ldots \ldots \ldots \ldots \ldots$

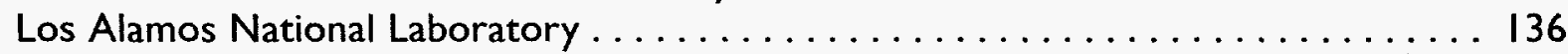

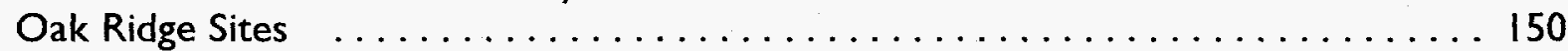

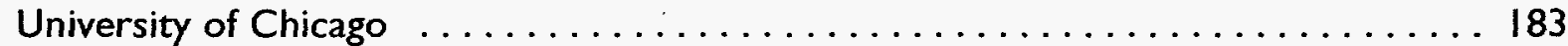

University of Rochester ............................... 189

National Archives and Records Administration $\ldots \ldots \ldots \ldots \ldots \ldots \ldots . \ldots . \ldots 194$

\section{Topical Areas}

Introduction .................................... 202

Radiation, Biomedical Science, and Isotope Distribution $\ldots \ldots \ldots \ldots \ldots \ldots . \ldots 203$

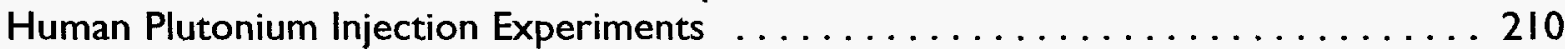

Environmental Releases of Radiation ........................ 214 
Chapter 3. Human Radiation Experiments Associated with DOE or Predecessor Agencies ........................ 223

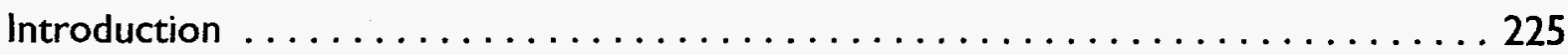

Criteria for Listing Experiments . . . . . . . . . . . . . . . . . 225

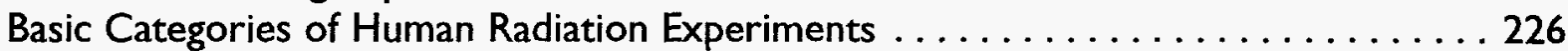

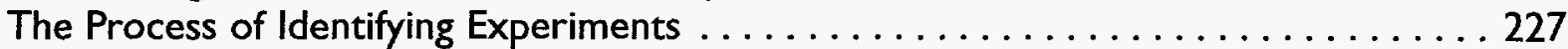

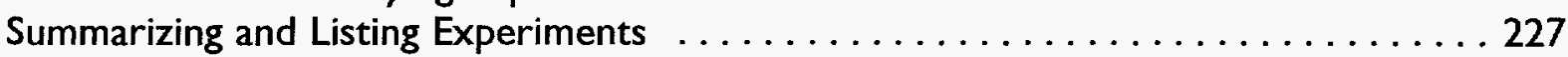

Challenges . . . . . . . . . . . . . . . . . . . . . . . 227

\section{List of Experiments}

Plutonium Injection Experiments . . . . . . . . . . . . . . . . . 229

Argonne National Laboratory . . . . . . . . . . . . . . . . . . . . 229

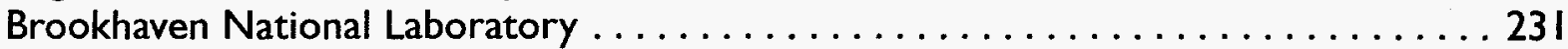

Hanford Sites .................................... 237

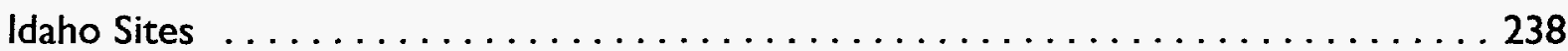

Lawrence Berkeley Laboratory . . . . . . . . . . . . . . . . . . . . 239

Lawrence Livermore National Laboratory . . . . . . . . . . . . . . . . . . . 249

Los Alamos National Laboratory . . . . . . . . . . . . . . . . . . . 251

Oak Ridge Sites . . . . . . . . . . . . . . . . . . . . . . . . . . . . 259

University of Chicago-Argonne Cancer Research Hospital . . . . . . . . . . . 268

University of Rochester . . . . . . . . . . . . . . . . . . . . . 279

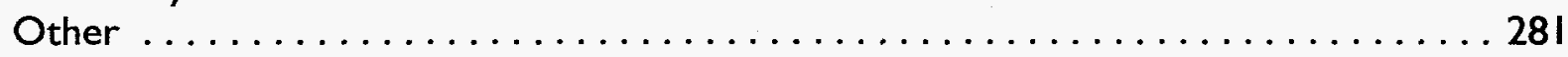

\section{Appendices}

Abbreviations and Acronyms . . . . . . . . . . . . . . . . . . .

Radiation Terms ................................... 295

List of Experiments from American Nuclear Guinea Pigs:

Three Decades of Radiation Experiments on U.S. Citizens (Markey Report) . . . 279

Select Bibliography . . . . . . . . . . . . . . . . . . . . . . . . . . 299 
1. Wright Langham being placed in the first whole body radiation counter at Los Alamos ..................... 3

2. Medical activities at Brookhaven National Laboratory (circa 1965) $\ldots \ldots \ldots \ldots \ldots .4$

3. A horizontal rotational scanner used to detect the quantity

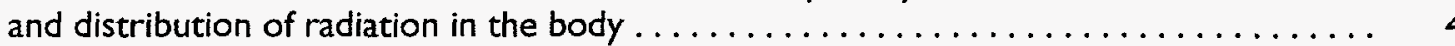

4. Los Alamos chemist Wright Langham and a "plastic man"

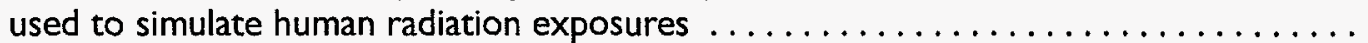

5. A whole body counter (circa 1964) at the Berkeley Donner Laboratory.

Such counters were used in human radiation tracer studies and for

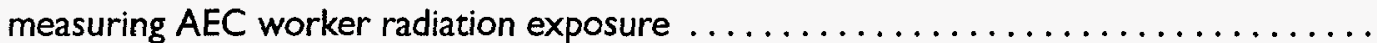

6. Oak Ridge National Laboratory workers turning in their pocket dosimeters (circa 1950). Various types of dosimeters were worn by workers to measure radiation doses and prevent excessive exposure. . . . . . . . . . . . . . . . . . . . .

7. A positron emitter detector at Brookhaven National Laboratory (circa 1965).

8. Eariy treatment for Parkinson's disease at the Berkeley Donner Laboratory (circa 1965)

9. Donner Laboratory carbon-14 metabolic study apparatus.

10. Oak Ridge National Laboratory workers checking for radioactive contaminants (circa 1950).

II. Oak Ridge technicians measuring air monitor samples for radiation.

12. Brookhaven National Laboratory used "phantoms" such as the mannequin on this wheeled table to approximate human radiation exposures ......

13. A Brookhaven technician demonstrating fast-neutron detection equipment $\ldots \ldots \ldots 26$

14. Brookhaven Low-Level Whole Body Counting Facility (circa 1968). . . . . . . . . 27

15. A patient prepared for treatment with charged atomic particles at Lawrence Radiation Laboratory (now Lawrence Berkeley Laboratory)

16. Clinical test of an artificial kidney developed by Argonne National Laboratory (circa 1970).

17. A subscale model of the nuclear reactor used for medical research and treatment at Brookhaven National Laboratory

18. A patient receiving treatment at Brookhaven Medical Department Hospital (circa 1961).

19. Study of carbohydrate-lipid metabolism at Brookhaven.

20. A parkinsonian patient (left) before and during administration of L-dopa at Brookhaven. Radioactive materials were useful in the development of L-dopa ........

21. A facility at Hanford for treating persons injured by embedded radioactive particles (circa 1967). In this shielded operating cell, a mock patient is flanked by a surgeon

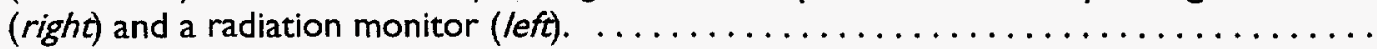

22. A Richland, WA, child participating in a program to measure radiation typically present in the body. This 1960 s project took place at Pacific Northwest Laboratory. .... 
23. Measuring intentional radiation release at the ldaho experimental dairy farm (1964). . . 96

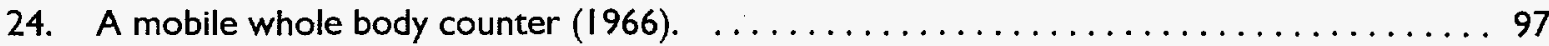

25. Respiration analysis using injected radioactive tracers at Donner Laboratory (circa 1968).

26. A patient under a positron camera. The camera was a diagnostic tool developed at Donner Laboratory, Berkeley, to photograph radioactive tracer concentrations. Unlike a whole body scanner, this device photographs a single, specific area of the body. ..................... 109

27. A kidney examination using a scintillation camera at Donner Laboratory, Berkeley . . . .110

28. Early use of a Geiger-Müller counter to test thyroid function at Lawrence Radiation Laboratory ................................

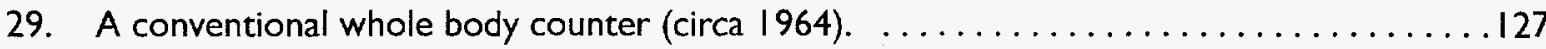

30. Wright Langham (left) introduces the "plastic man" to Los Alamos Director Norris Bradbury. The figure was used to simulate human radiation exposures. . . . . . . . I 37

31. A whole body radiation counter at Los Alamos (circa 1958). . . . . . . . . . . I 139

32. A counter being used at Los Alamos to measure plutonium in the lung. $\ldots \ldots \ldots \ldots \ldots$

33. An Oak Ridge National Laboratory employee having a blood test to detect radiation exposure (circa 1950).

34. Aerial view of the Oak Ridge $X-10$ facility (1945), which served as a pilot for the Hanford plutonium production reactors. After World War II, the facility produced isotopes for national distribution $\ldots \ldots \ldots \ldots \ldots \ldots \ldots \ldots \ldots \ldots$

35. Oak Ridge health physics technicians monitoring a cafeteria for radiation.

36. Cobalt- 60 teletherapy conducted for cancer treatment at the Oak Ridge Institute for Nuclear Science $(1972) \ldots \ldots \ldots \ldots \ldots \ldots \ldots \ldots \ldots \ldots$. . . . . . . . . . . . . . . . . .

37. The automatic contouring system used at Argonne Cancer Research Hospital to determine how much radiation will penetrate to cancer tumors . . . . . . . . . . . .

38. An AEC inspector checking radiation equipment for safety at Oakland Navy Hospital (circa 1973)

39. Joseph Hamilton (left) conducting one of the first isotope metabolism studies during the 1930s. The study took place at the Lawrence Radiation Laboratory (now Lawrence Berkeley Laboratory).

40. Oak Ridge technicians reading dosimeters to detect worker radiation exposures. . . ..204

41. An Oak Ridge isotope worker (right) and a health physics technician (circa 1950) .....205

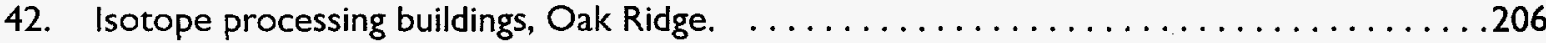

43. Production of isotopes at Oak Ridge National Laboratory, ca. $1946 \ldots \ldots \ldots \ldots \ldots .207$

44. Measuring beta radiation from a sample of phosphorus-32 at Oak Ridge . . . . . ..207

45. Early method of handling radioactive sources at Los Alamos $\ldots \ldots \ldots \ldots \ldots \ldots \ldots .208$

46. Experimental cardiac pacemaker powered by plutonium, ca. 1968 . . . . . . . . 209

47. Telegram from University of Rochester notifying Los Alamos

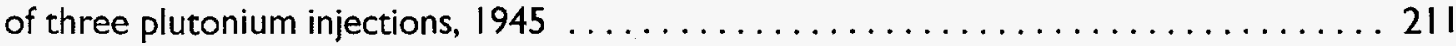

48. Plutonium separation building ("canyon") at Hanford $\ldots \ldots \ldots \ldots \ldots \ldots \ldots \ldots \ldots \ldots \ldots \ldots$ 
49. (top and bottom) A Los Alamos Radioactive Lanthanum (RaLa) test in Bayo Canyon. . . 218

50. Measuring intentional radiation releases at the Idaho experimental dairy farm (circa 1964).

51. Checking radioactivity after a Controlled Environmental

Radioiodine Test (CERT) in 1966

52. A nuclear reactor sitting on a test cell pad prior to preliminary tests at the Nevada Test Site (circa 1968). This Phoebus 2 design was part of the Rover project to develop a nuclear-propelled rocket capable of interplanetary travel.

53. Separating radioactive carbon from material bombarded in the Oak Ridge nuclear reactor

54. The first patient to receive boron neutron capture therapy at Brookhaven National Laboratory (1951). The patient is under the blanket visible in the mirror (top center). . . 225

55. Diagnostic test of iodine-131 thyroid uptake at Brookhaven National Laboratory. 227 


\section{Chapter I:}

\section{Overview of the DOE Project}

Introduction $\ldots \ldots \ldots \ldots \ldots \ldots \ldots \ldots \ldots \ldots \ldots \ldots \ldots \ldots \ldots \ldots \ldots$

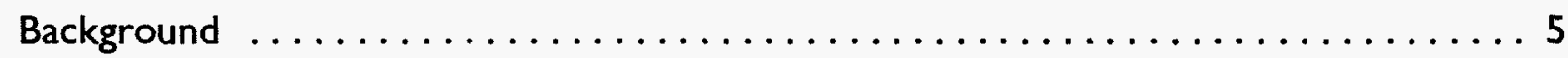

DOE Archives and Records $\ldots \ldots \ldots \ldots \ldots \ldots \ldots \ldots \ldots \ldots \ldots \ldots \ldots \ldots \ldots \ldots$

DOE Strategy for Finding Experiment Information $\ldots \ldots \ldots \ldots \ldots \ldots \ldots$

Information as an Engine for Democratic Government $\ldots \ldots \ldots \ldots \ldots \ldots \ldots$

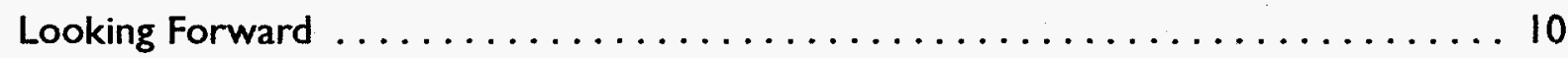




\section{Chapter I. Overview of the DOE Project}

\section{Introduction}

O N APRIL 10, 1945, medical staff of the U.S. Manhattan Engineer District in Oak Ridge, $\mathrm{TN}$, injected plutonium into the victim of a car accident. American scientists had only recently begun producing plutonium, and thousands of workers were laboring to produce the quantities required for the first atomic bombs. While aware that plutonium was hazardous, project officials were uncertain how much exposure would cause harm. Desire for information about human metabolism and retention of plutonium led to this first injection in Oak Ridge. Over the next 2 years, 17 other people also received plutonium injections.

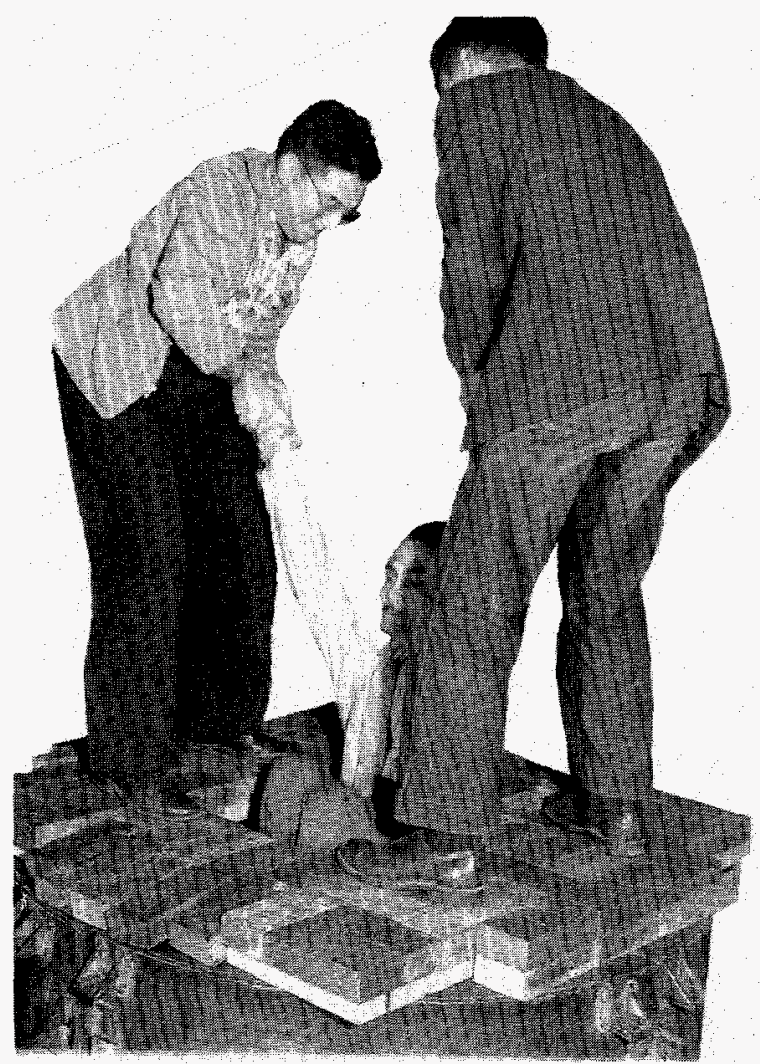

Figure 1. Wright Langham being placed in the first whole body radiation counter at Los Alamos.
The Manhattan Project and its postwar successor, the U.S. Atomic Energy Commission (AEC), also carried out human experiments with uranium, polonium, americium, and other radioactive substances. Radiation tests continued after the war; some of these studies took place under AEC supervision and had direct defense-related applications. The agency also sponsored substantial programs in the medical applications of radiation and in basic biomedical research. In addition, independent physicians and researchers at universities and hospitals conducted many postwar human radiation studies to develop the techniques of present-day nuclear medicine.

The role of the U.S. Government in conducting or sponsoring human radiation experiments has become the subject of public debate. Questions have been raised about the purpose, extent, and health consequences of these studies, and about how subjects were selected. The extent to which subjects provided informed consent is also under scrutiny. To respond to these questions, the Clinton administration has directed the U.S. Department of Energy (DOE), along with other Federal agencies, to retrieve and inventory all records that document human radiation experiments. Many such records are now publicly available and will permit an open accounting and understanding of what took place.

The American people want to know if their Government used appropriate policies and practices when these radiation experiments took place.

This report summarizes the Department's ongoing search for records about human radiation experiments. It is also a roadmap to the large universe of pertinent $D O E$ information. DOE is working to instill greater openness-consistent with national security and other appropriate considerations-throughout its operations. A key aspect of this effort is opening DOE's historical records to independent research and analysis. 


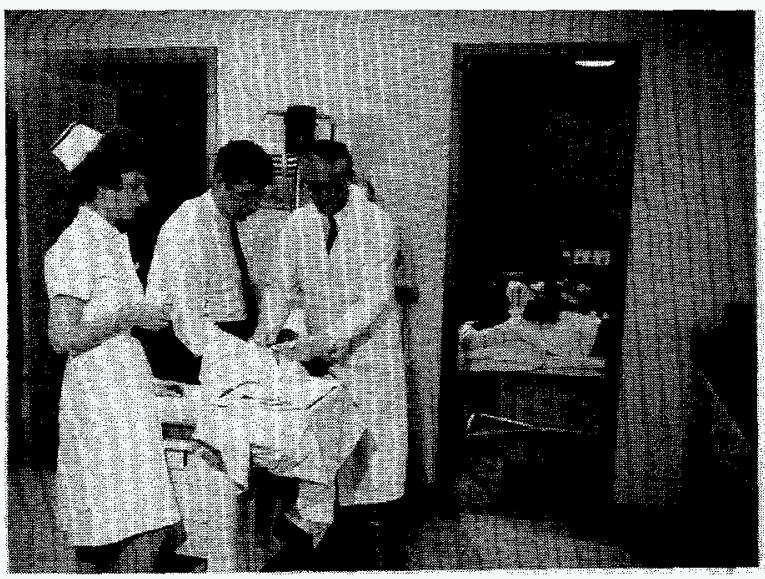

Figure 2. Medical activities at Brookhaven National Laboratory (circa 1965).

Why the concern over events that took place as long ago as $\mathbf{5 0}$ years? Some individuals are concerned that they or family members may have been involved in experimental activities. Most broadly, however, the issue is trust. The American people want to know if their Government used appropriate policies and practices when these radiation experiments took place. People also want to know if their Government is now truly committed to opening its records.

This project is a prototype for the larger job of identifying, preserving, and making available the historical record of the American nuclear age.

Issues associated with DOE records range beyond human radiation experiments. DOE is currently involved in extensive environmental management and cleanup activities that require historical documentation of site activities. Ongoing independent health studies require information about site emissions and worker exposures to hazardous material. The end of the Cold War has also spurred interest in nuclear weapons development and related programs. The records that document these stories are, like those for human radiation experimentation, contained within 3.2 million cubic feet of DOE records. This project is a prototype for the larger job of identifying, preserving, and making available the historical record of the American nuclear age.
The effort to bring these records under intellectual control now allows unprecedented access to an important subset of DOE records.

Three categories of information are presented here:

- Narrative summaries of the major DOE facilities associated with human radiation experiments-These summaries present facts, establish context, and discuss the most useful sources of pertinent information.

- Records series descriptions-These descriptions summarize the content of records collections that contain important experiment-related documentation. Record series for each site follow the corresponding narrative.

- Descriptions of individual human radiation experiments-Criteria based on White House guidance (described below) were used to decide which events and activities fit the definition of human radiation experiments. In gathering and presenting these categories of information, detailed analysis and judgment have deliberately been avoided. A Presidential advisory committee is now evaluating the ethics of human radiation experiments, and DOE is providing information to support that work.

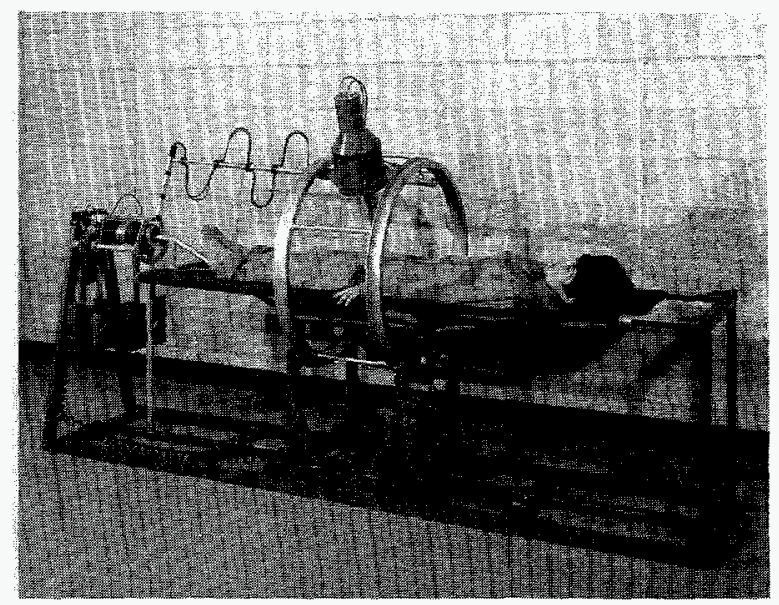

Figure 3. A horizontal rotational scanner used to detect the quantity and distribution of radiation in the body. 
This project has identified an enormous volume of historical records. Some records were classified and are newly available to the public through declassification. Other records contain personal privacy information that has been appropriately withheld pursuant to Federal law. Most of these records, however, were neither secret nor otherwise restricted. As a practical matter, access to them was inhibited because they were disorganized, poorly catalogued, and scattered across holding areas, offices, and records centers from coast to coast. The effort to bring these records under intellectual controlto describe what is where-now allows unprecedented access to an important subset of DOE records.

\section{Backgroune}

At a December 1993 press conference, Secretary of Energy Hazel R. O'Leary released documents describing previously secret U.S. nuclear tests, facts about bomb-grade plutonium, and information about fusion energy. The Secretary also made available some documents related to human radiation experiments, particularly the 1945-1947 injections of 18 human subjects with plutonium. She committed DOE to the collection and review of historical data about the experiments and undertook to release as much information as legally possible.

Secretary O'Leary committed the Department of Energy to the collection and review of historical data about human radiation experiments.

Facts about human radiation experiments were not unknown before the December press conference. Postwar scientific journals had published details about many such experiments, including the plutonium injections. Information about the plutonium experiments first received widespread public attention during the mid-1970s. Congressman Edward Markey (D-Mass) issued a report in 1986 entitled American Nuclear Guinea Pigs: Three Decades of Radiation Experiments on U.S. Citizens. This report discussed the plutonium injections and about 30 other experiments.
Moreover, a month before the Secretary's press conference, the Albuquerque Tribune had published a lengthy series by reporter Eileen Welsome on the injections, which was ultimately awarded a Pulitzer Prize.

The Secretary also made available some documents related to human radiation experiments, particularly the 1945-1947 injections of eighteen human subjects with plutonium.

Nonetheless, the Secretary's public discussion of the issue generated intense public interest. Media accounts of other experiments soon followed, including use of radioactive materials at a Massachusetts school for the retarded and at a Vanderbilt University maternity clinic. These accounts spurred further public interest and calls for a full account of human radiation studies.

Shortly after the December press conference, DOE set up a toll-free hotline-soon expanded to include other Federal agencies and departments - to gather inquiries and information from persons about possible radiation experiments. Calls to the interagency helpline eventually exceeded 20,000 . Hundreds of letters also arrived daily from the public.Apart from DOE, agencies potentially involved in human radiation studies included the Department of Defense, the Department of Veterans Affairs, the Department of Health and Human Services, the National Aeronautics and Space Administration, and the Central Intelligence Agency. President Clinton established a Cabinet-level Human Radiation Interagency Working Group in January 1994 to coordinate the Federal government's response. The administration also issued a directive for Government-wide records inventory and retrieval. This activity were to focus on:

Experiments on individuals involving intentional exposure to ionizing radiation. This category does not include common and routine clinical practices, such as established diagnosis and treatment methods, involving incidental exposures to ionizing radiation; 
and

Experiments involving intentional environmental releases of radiation that (I) were designed to test human health effects of ionizing radiation; or (2) were designed to test the extent of human exposure to ionizing radiation.

Specified releases of radiation to the environment were also included in the directive, such as a series of tests at Los Alamos, tests at the Dugway Proving Ground, and a 1949 release at Hanford called the "Green Run." (All of these releases are discussed in Chapter 2.)

In addition, the President issued an Executive Order establishing an independent Advisory Committee on Human Radiation Experiments, which was to provide expert advice and recommendations regarding the studies in question. The order directed the committee to consider three specific issues:

I. Had there been a clear medical or scientific purpose for the experiments?

2. Was appropriate medical follow-up conducted?

3. Did the design and administration of the experiments meet the ethical and scientific standards, including standards of informed consent, which prevailed at the time of the experiments and that exist today?

Federal agencies were directed to provide the committee with the historical records and other information needed to complete its work.

In January 1994, DOE set up an interim headquarters group under the Assistant Secretary for Environmenc, Safety, and Health to coordinate the search for historical records. Shortly thereafter, the agency established an Office of Human Radiation Experiments (OHRE), which assumed responsibility for the records search, liaison with the advisory committee, and written and telephone inquiries from the public.

\section{DOE Archives and Records}

FROM THE 1940s to the present, the U.S. nuclear program has depended on a national network of laboratories and other specialized sites. Today, over $\mathbf{4 0}$ such sites exist in more than a dozen states. Private companies operating under special Federal contracts have managed most of these facilities. While DOE directs and oversees the activities of these contractors, sites have historically enjoyed substantial autonomy. This arrangement began with the Manhattan Project's decision to rely on the technical skills and infrastructure already in place at the Nation's universities and in private industry. The result was a highly decentralized organization. From a recordkeeping standpoint, this resulted in limited central files-that is, discrete, comprehensive collections of documents for specific missions and functions. Instead, a proliferation of nonstandardized filing practices took root throughout the organization.

The President issued an Executive Order establishing an independent Advisory Committee on Human Radiation Experiments, which was to provide expert advice and recommendations regarding the studies in question.

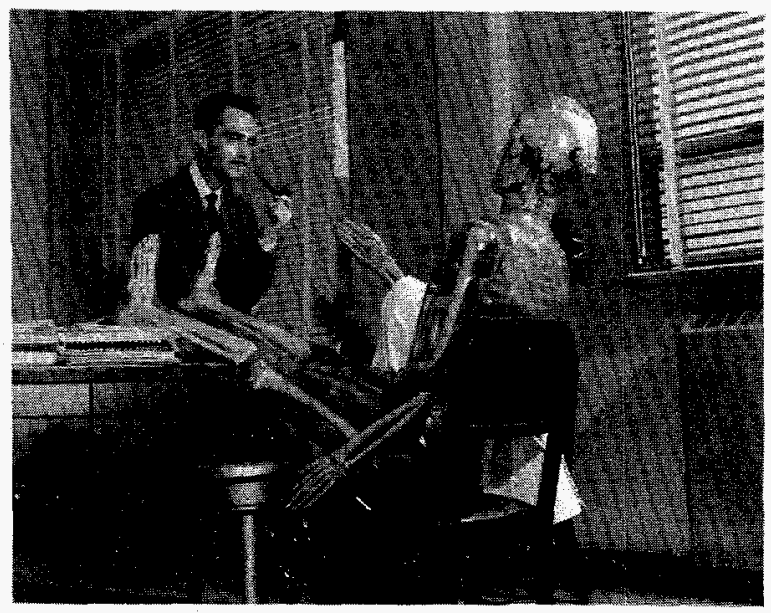

Figure 4. Los Alamos chemist Wright Langham and a "plastic man" used to simulate human radiation exposures.

Other influences worked against effective records management. The U.S. nuclear program underwent rapid and continual growth in the decades after 1945; in the push to expand programs, records had a low priority. Modern technological programs consist of many projects that 
change over time, and documentation of such volatile work is often difficult to manage and preserve. Records and decisions about them are typically decentralized, resulting in idiosyncratic approaches to documentation. Persuasive evidence of this phenomena is presented in $A$ Study of Documents at Department of Energy National Laboratories: Final Report, issued in 1982 by the American Institute of Physics.

Despite these factors, a large volume of DOErelated information dating from the early 1940s to the present has survived. Agency headquarters, field, and contractor organizations have custody of an estimated 3.2 million cubic feet of paper files. These organizations also have an undetermined, although presumably large, volume of information in pictorial, cartographic, and electronic formats. DOE has also transferred some records with historical value to the $\mathrm{Na}$ tional Archives and Records Administration (NARA) for permanent preservation.

Use of DOE records is, however, difficult. One reason is that the agency created and kept its files for purposes other than research. From the researcher's perspective, document content, arrangement, and location are consequently less than ideal. The primary barrier to using DOE records, however, is that they are not under intellectual control. In other words, systematic knowledge about where specific records are or what records are available for a particular organization or topic is spotty at best. The 1988 NARA report entitled Evaluation of the Records Management Program of the Department of Energy documented long-term problems in several key areas. Singled out for particular notice was a shortcoming in complying with Federal records standards for inventorying (describing what exists) and scheduling (identifying what to save and what to destroy). This problem lies at the heart of the lack of intellectual control.

Additional issues pertinent to DOE records are security classification and other access restrictions. From its wartime origins until only recently, the U.S. nuclear program was cloaked in secrecy. According to dictates of the 1946 and 1954 Atomic Energy Acts, many documents were "born classified," and required specially qualified personnel to review each page of each document before declassification. Congress orig- inally established these stringent restrictions to prevent adversaries from obtaining nuclear weapons information. The result, however, was the systematic classification of millions of documents. While classification guidelines have been modified over time, declassification still requires a laborious page-by-page review. (Most records relating to human radiation experiments are now unclassified; relevant classified records have received top priority for review and release.)

Agency headquarters, field, and contractor organizations have custody of an estimated 3.2 million cubic feet of paper files.

DOE has been working to make more information available since the late 1980 s. Environment, safety, and health concerns, particularly questions about potential health effects associated with past site operations, drove much of the initial effort. Various epidemiological and other health studies of site workers and of nearby communities are now underway through the Centers for Disease Control and Prevention $(C D C)$ and state health departments. This research requires historical information, some of which is classified. DOE and the related government health organizations, however, are committed to making the documentary basis of site health studies open to the public.

This approach raised two important questions: What kinds of specific information-including classified information-existed for each site under study? And, what was the best mechanism to make this information available within restrictions imposed by law?

The answers to these questions were based upon fundamental information and records management concepts. DOE, as owner of the information, would work with CDC and other stakeholders to conduct an inventory of appropriate records at relevant sites. The Department would incorporate the inventory results into written guides for distribution to the public. Among other functions, CDC and DOE would use the guides to target specific collections with access restrictions and set priorities for declassification review. 
Many documents were "born classified," and required specially qualified personnel to review each page of each document before declassification.

The search for human experimentation records uses the same fundamental approach. Compatibility of the approaches makes an eventual merger of DOE environment, safety, and health information into a single Internet-based data collection possible. This would significantly enhance public access and ensure the long-term management and preservation of historical records.

\section{DOE Strategy for Finding Experiment Information}

DOE HAD TWO GOALS in planning to find and make available human radiation experiment records:

1. Address the short-term information needs of the Advisory Committee on Human Radiation Experiments and other stakeholders.

2. Meet long-term objectives to manage and preserve DOE records with value to historians and other researchers.

To meet these goals, DOE has made a commitment to locate records relating to human subject research and bring them under intellectual control. This requires an inventory to establish what kinds of records are available, where they are, and what information they contain. This process identifies the universe of records and helps identify files relevant to a particular research topic. Intellectual control also helps establish priorities for declassification review and physical transfer to archival repositories for permanent preservation.

The Office of Environment, Safety, and Health distributed records search guidance throughout the Department in early 1994. This guidance, along with subsequent updates issued by the Office of Human Radiation Experiments, outlined the basic tasks required of DOE offices and contractor organizations.

The guidance mandated a logical, phased approach using established archival and records management procedures. It called for nine steps:

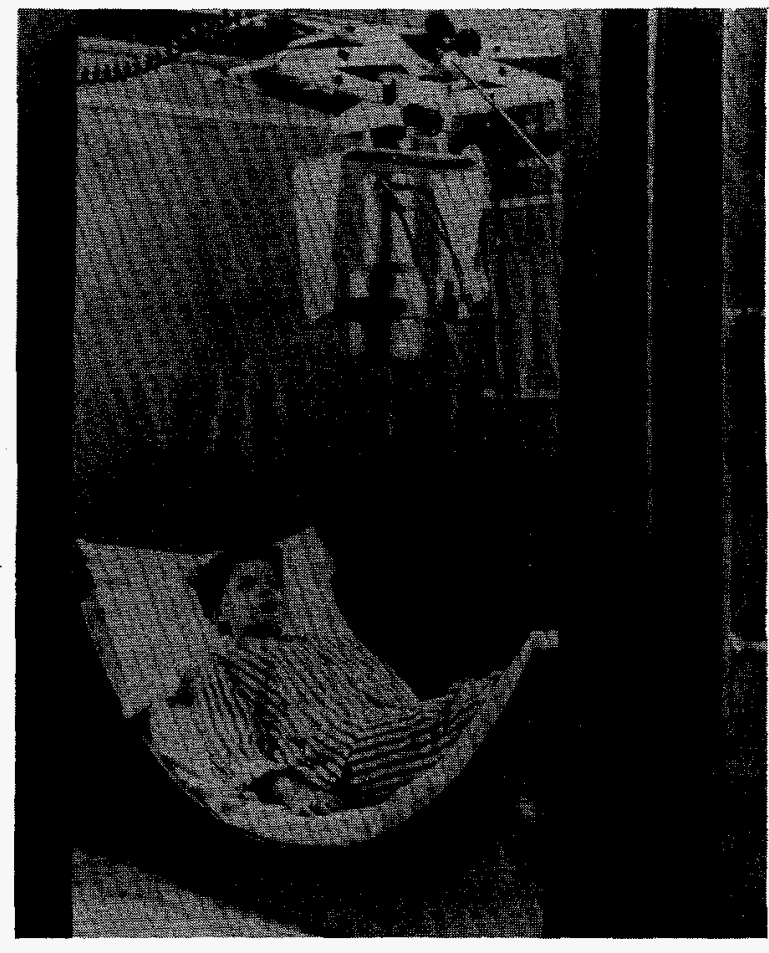

Figure 5. A whole body counter (circa 1964) at the Berkeley Donner Laboratory. Such counters were used in human radiation tracer studies and for measuring AEC worker radiation exposure.

(1) Identify human radiation experiments conducted, sponsored, or facilitated by DOE or predecessor agencies;

2 Find all bodies of site records that describe experiments and the organizational context in which they occurred;

3) Identify records as individual series (such as reports, contracts, or correspondence files);

(4) Gather basic information about the records to complete an inventory form for each series;

(6) Copy selected significant documents;

(- Ensure that site information is accurate by conducting verification and other quality assurance measures;

- Conduct declassification review for series containing classified material;

8 Compile the inventory information into a publicly available database; and

( ) Use the database to find specific records quickly, and to effectively manage and preserve records throughout DOE. 
Each DOE Operations Office and site associated with past human radiation experiments established an interdisciplinary team to perform this work under the direction of the headquarters Office of Human Radiation Experiments.

This guidance for this project used established archival and records management procedures.

DOE has used a three-phased oversight approach for this process:

- First, the Office of Human Radiation Experiments issued detailed written guidance and held meetings to discuss the guidance. Each site has also submitted periodic progress reports.

- Second, each important site has been visited at least twice by interdisciplinary headquarters teams to provide focused guidance in identifying and describing both records and individual experiments.

- Third, quality assurance is implemented through cross-checking information from different sources and audit visits to verify inventory coverage and accuracy.

Given the volume of extant records, priorities were established for sites as well as records. Initial research revealed that most activities associated with human experiments took place at the sites described in Chapter 2. Most effort has focused on these places. Since the greatest interest is in experiments prior to 1974 (the year in which broadly applicable guidelines for the protection of human research subjects were adopted) attention has been concentrated on inactive records. These contain most information that is more than 10 years old.

The DOE strategy for finding and making available complete information on human radiation experiments centers on the records series concept. A series consists of the following:

File units or documents arranged according to a filing system or kept together because they relate to a particular subject or function, result from the same activity, document a specific kind of transaction, take a particular physical form, or have some other relationship arising out of their creation, receipt, or use.

A group of records filed together, or that relate to a common topic, typically form a series. Organizations often create a series for a specific purpose or to serve a single function, such as recording official actions, compiling personnel data, or tracking funds.

Records series arranged the way they were originally kept provide the most valuable historical information. Original arrangement maintains file integrity as evidence of the nature of an entity and its activities. This helps researchers answer broad questions about the organization, its functions, and its members. Documents existing apart from their series have less value, as the contextual information provided by the rest of the file is absent. Consequently, the procedure established by the DOE guidance stressed the need to find and describe complete records series-to work from the bottom up, as it were.

On the other hand, there is also demand for specific information about human radiation experiments. To get this information, the series descriptions are used to target more detailed searches for individual documents. Such documents are copied, marked with details about where they came from (provenanced), and sent to the Coordination and Information Center (ClC) in Las Vegas. The $\mathrm{ClC}$ scans and indexes each document into computer files. About 13,000 documents, comprising more than 150,000 pages, were placed in this human experimentation collection during 1994. As the inventory and related search activities continue, additional documents will be added. These documents are being made available for public access on the Internet computer network. An Internet Home Page on the World Wide Web (http://www.eh.doe.gov/ohre/home.htm) also provides additional information, including a large bibliography of published reports and pertinent congressional testimony. This information will be fully searchable by personal names, places, terms, and many other keywords. 
Intormatrom as an Engine for Democraté Govemment

While priority has been given to establishing control over records relating to human radiation experiments, it is recognized that DOE records serve a broader public interest. The conceptual framework for this proposition, contained in the 1985 Report of the Committee on the Records of Government, outlines the need for organized and accessible Government records to:

- document the history and intent of public policy;

- ensure accountability for programs and activities;

- preserve basic data needed to review past scientific research and conduct new research;

- ensure effective administration of public programs; and

- form the basis of a national history and an understanding of society and culture.

These documents are being made available for public access on the Internet computer network.

The approach represented by this project is also linked to broader ideas about improving government:

Transparency-Simplifying appropriate access to government information lets citizens see what agencies have done (or have not done). This is essential to building trust and confidence in tasks assigned to government.

Public Involvement-People need to have adequate information to participate in reviewing issues, presenting options, and making decisions.

Shared History -Vibrant, meaningful history depends on access to a wide knowledge base. Current debates on why the atomic bomb was used on Japan, for example, draw extensively on diverse archival sources. As we move deeper into historical analysis of the Cold War, even broader access to government records will be needed.

Lessons Learned-In assessing government's role, people need information by which to judge the success of government activities. The same information is needed in coping with unintended consequences of past actions.

Competition-Knowledge of specific programs and their relative success stimulates competition for current government services. Such information allows private enterprises-or other government entitiesto propose alternate approaches.

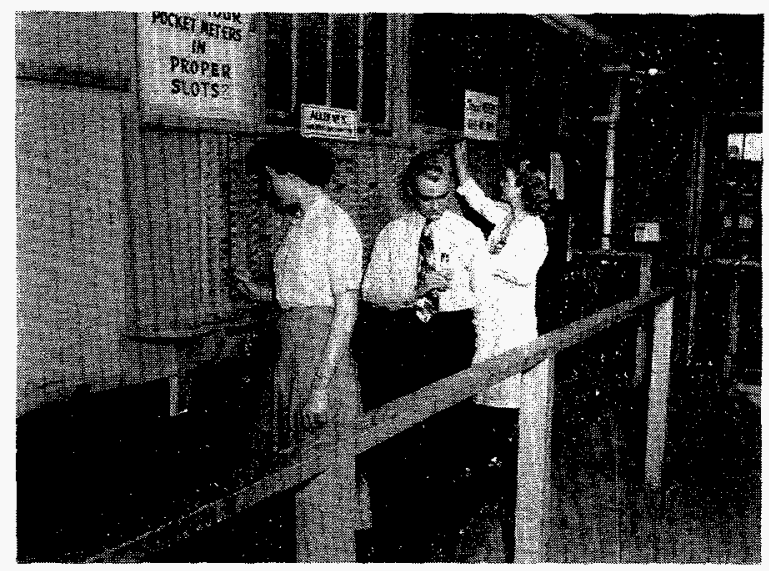

Figure 6. Oak Ridge National Laboratory workers turning in their pocket dosimeters (circa 1950). Various types of dosimeters were worn by workers to measure radiation doses and prevent excessive exposure.

\section{Looking Forward}

OVER THE LAST YEAR, DOE has tried to uncover as much information as possible about human radiation experiments. Scores of citizen inquiries and accounts have been received and entered into a computer database. DOE and its contractor organizations have reviewed their records holdings for pertinent information. Thousands of documents have been made public and an unprecedented number of records have been declassified and released. Individual experiments have been researched, described, and publicized. DOE has also assisted the Advisory Committee on Human Radiation Experiments in fincling specific information. These efforts will lead to enhanced public understanding about the 
experiments and about the Cold War era overall.

The report is intended for a wide audience, including policy makers, historians, scientists, journalists, public interest groups, those who may have been involved in human radiation research, and the public.

This report summarizes DOE's work for the year and aims to expand public understanding still farther. It is a guide - a roadmap - to an enormously complex history documented in millions of documents, some of which are, or were until recently, restricted under national security classification. The report is intended for a wide audience, including policy makers, historians, scientists, jour nalists, public interest groups, those who may have been involved in human radiation research, and the public.

As noted above, openness is an ongoing process. More documents will almost certainly be found, as will new series, although we believe that through an iterative and logical process, most of the important records relevant to human radiation experiments have been identified. Yet, while the documents collected at the $\mathrm{CIC}$ and placed on the Internet are easily accessible, original documents in records series may prove more difficult to obtain because of declassification issues, Privacy Act restrictions, and some site-specific constraints.

Despite such limitations, however, this process offers a first glimpse into Cold War historical records, and a first step in preserving these records and opening them to the public. 


\section{Chapter 2:}

\section{Narratives and Records Series Descriptions}

\section{Institutional Areas}

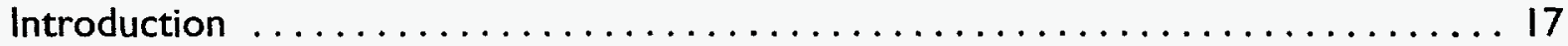

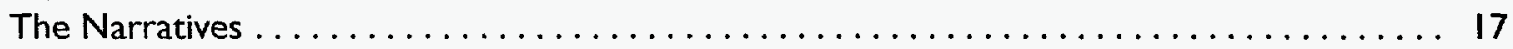

The Records Series Descriptions $\ldots \ldots \ldots \ldots \ldots \ldots \ldots \ldots \ldots \ldots \ldots \ldots \ldots \ldots, 17$

DOE Predecessor Agencies and Human Radiation Experimentation:

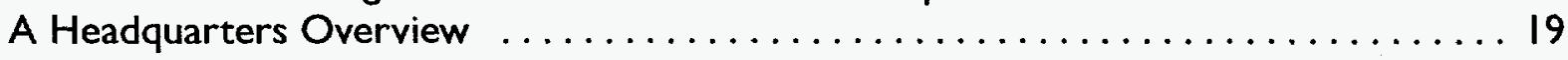

Introduction ............................................. 19

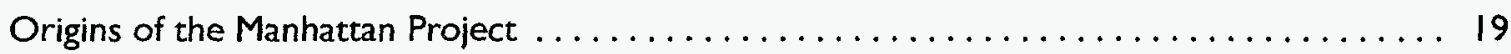

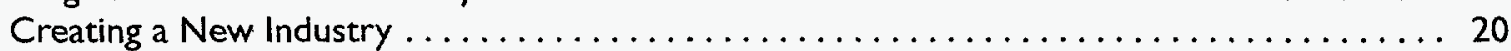

Wartime Medical Problems ..................................... 20

The Plutonium Injection Experiments $\ldots \ldots \ldots \ldots \ldots \ldots \ldots \ldots \ldots \ldots \ldots \ldots \ldots, 20$

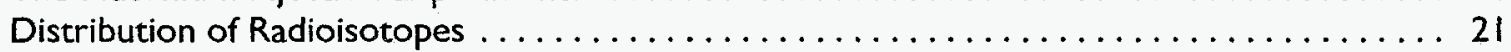

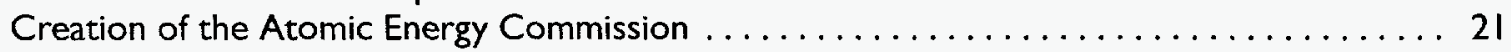

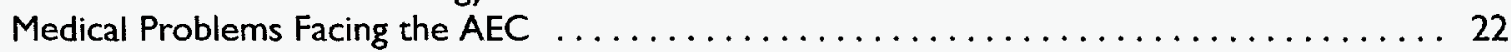

The AEC and Human Radiation Experimentation, 1940s-1950s . . . . . . . . . . . 22

The AEC and Human Subject Consent, 1940s-1950s ......................... 23

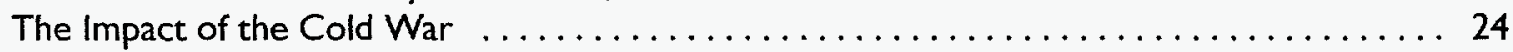

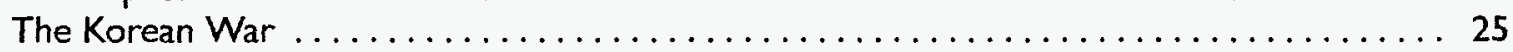

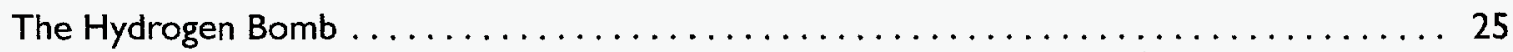

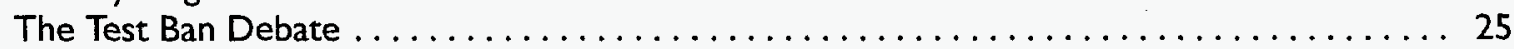

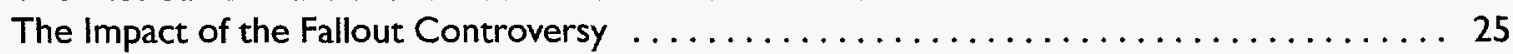

The AEC in Transition . . . . . . . . . . . . . . . . . . . . . . . . . . . . . . . . . . . . . 26

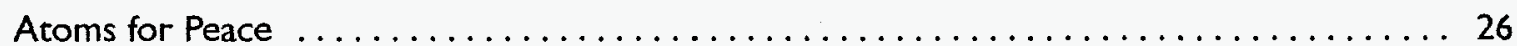

Building a Commercial Nuclear Power Industry ...................... 27

The AEC and Human Radiation Experiments, 1960-1970s ................. 27

Radioisotopes and Nuclear Medicine $\ldots \ldots \ldots \ldots \ldots \ldots \ldots \ldots \ldots \ldots, \ldots \ldots, 28$

Biomedical Research and Institutional Decision Making $\ldots \ldots \ldots \ldots \ldots \ldots \ldots \ldots \ldots 28$

The AEC and Subject Consent, 1960s-1970s ........................ 28

Controversies Over Radioactive Effluents, Thermal Pollution, and Reactor Safety ........ 29

Impact of the Energy Crisis .................................... 29

The Energy Research and Development Administration ...................... 30

The U.S. Department of Energy $\ldots \ldots \ldots \ldots \ldots \ldots \ldots \ldots \ldots \ldots \ldots \ldots \ldots \ldots \ldots, \ldots \ldots \ldots$

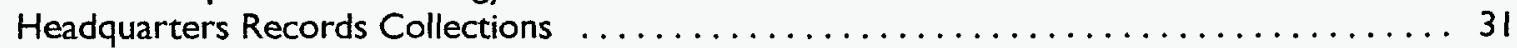




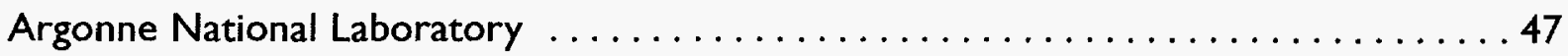

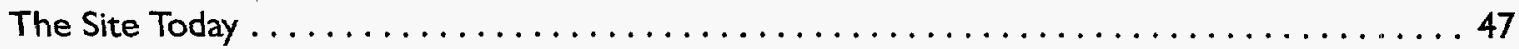

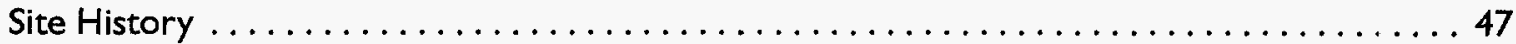

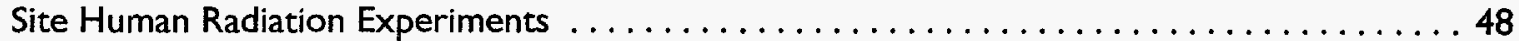

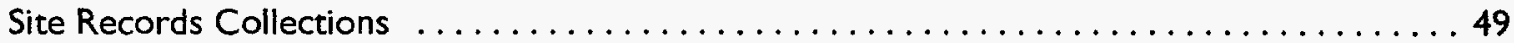

Brookhaven National Laboratory . . . . . . . . . . . . . . . . . . . 63

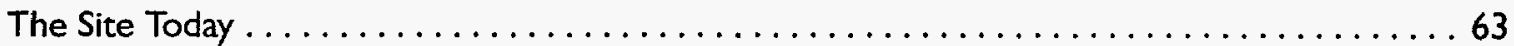

Site History . . . . . . . . . . . . . . . . . . . . . . . . . . . . . . 63

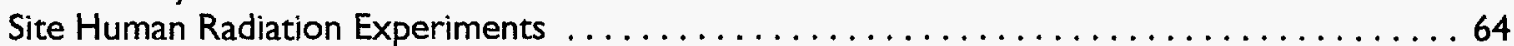

Site Records Collections .....................................66 66

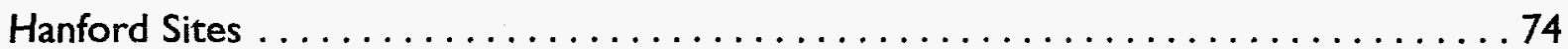

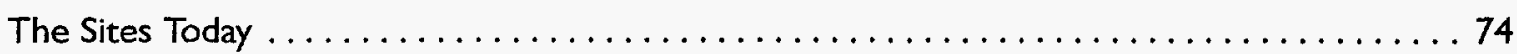

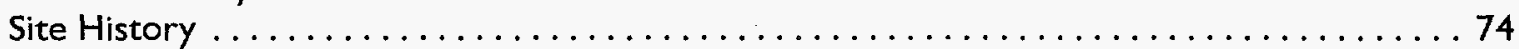

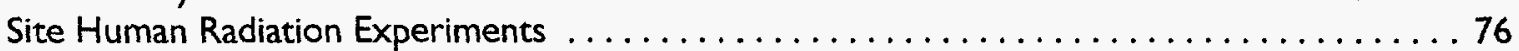

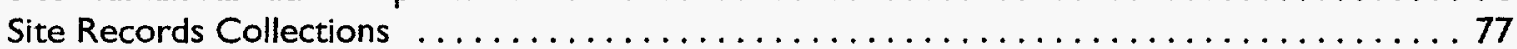

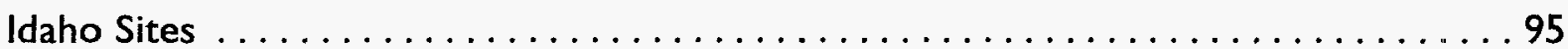

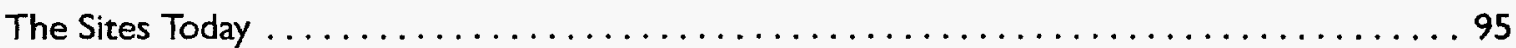

Site History . . . . . . . . . . . . . . . . . . . . . . . . . . . . . . 95

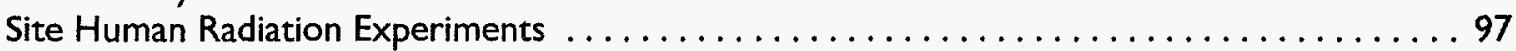

Site Records Collections $\ldots \ldots \ldots \ldots \ldots \ldots \ldots \ldots \ldots \ldots \ldots \ldots \ldots \ldots \ldots \ldots$

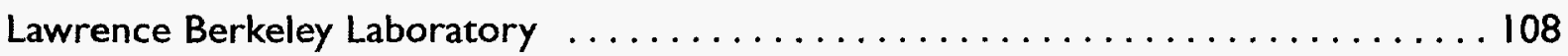

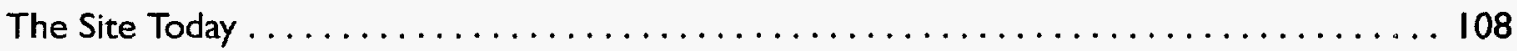

Site History . ................................... 108

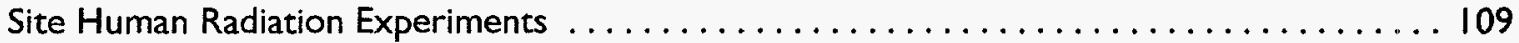

Site Records Collections $\ldots \ldots \ldots \ldots \ldots \ldots \ldots \ldots \ldots \ldots \ldots \ldots \ldots \ldots \ldots \ldots \ldots \ldots$

Lawrence Livermore National Laboratory $\ldots \ldots \ldots \ldots \ldots \ldots \ldots \ldots \ldots \ldots$

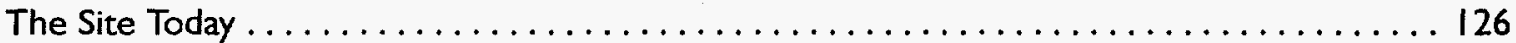

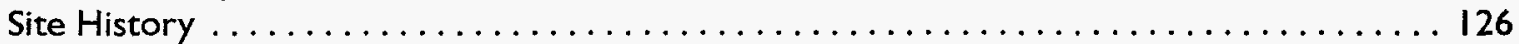

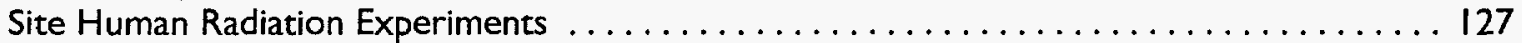

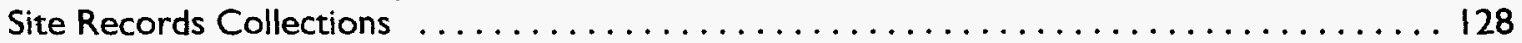

Los Alamos National Laboratory . . . . . . . . . . . . . . . . 136

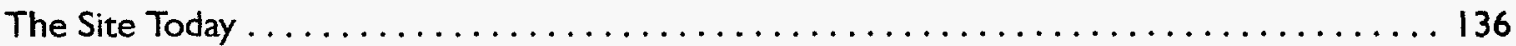

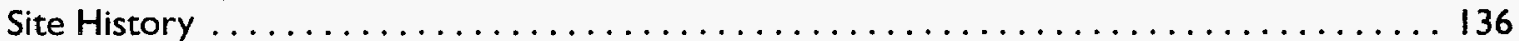

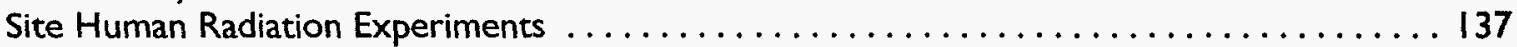

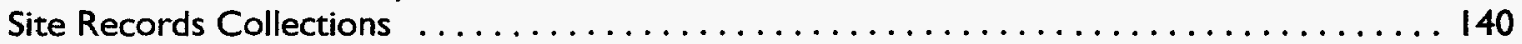




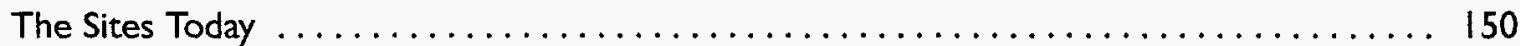

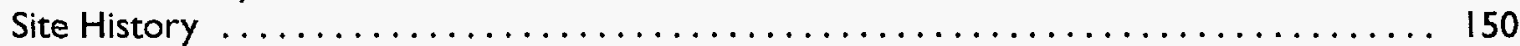

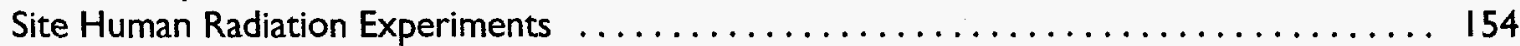

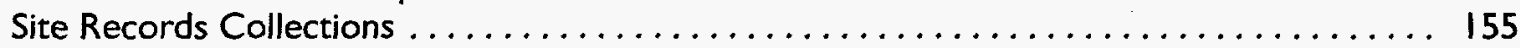

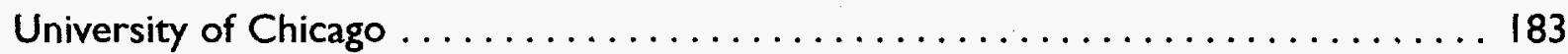

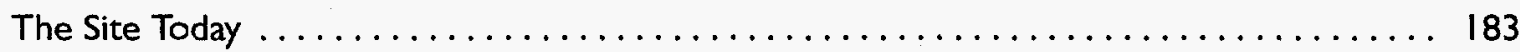

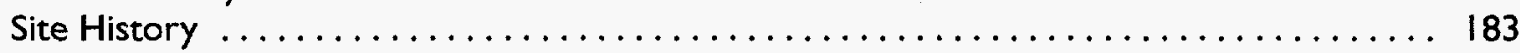

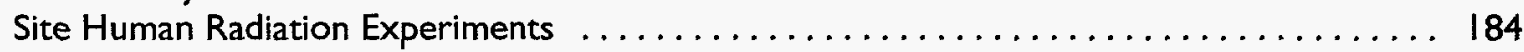

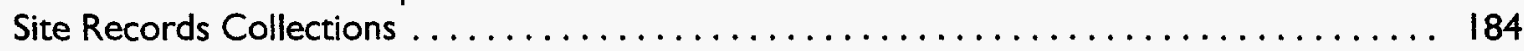

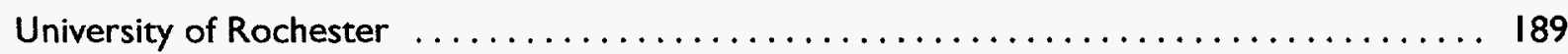

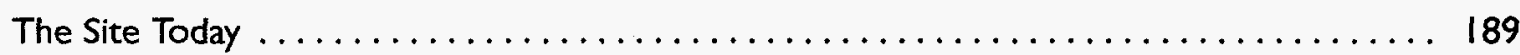

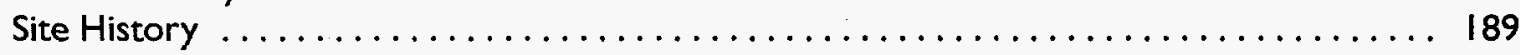

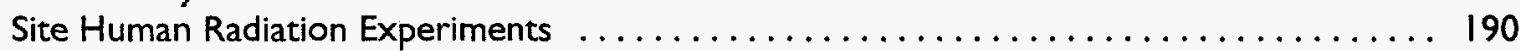

Site Records Collections ................................ 191

National Archives and Records Administration $\ldots \ldots \ldots \ldots \ldots \ldots \ldots \ldots$

\section{Topical Areas}

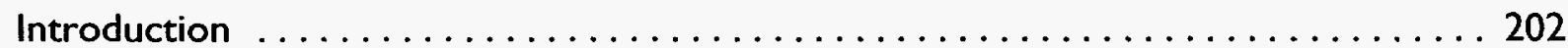

Radiation, Biomedical Science, and Isotope Distribution . . . . . . . . . . 203

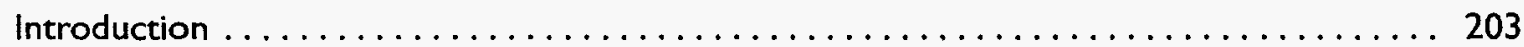

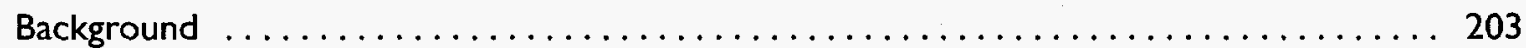

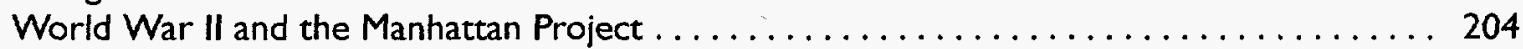

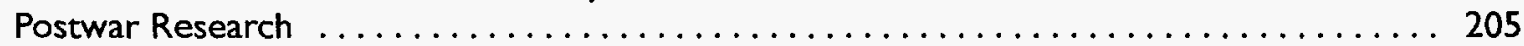

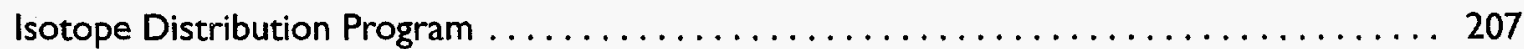

Other Aspects of Biomedical Research . . . . . . . . . . . . . . . . . . . 209

Human Plutonium Injection Experiments $\ldots \ldots \ldots \ldots \ldots \ldots \ldots \ldots \ldots \ldots \ldots$

The Manhattan Project and Plutonium Health Hazards .................... 210

The Experiments, Part I ...................................... 210

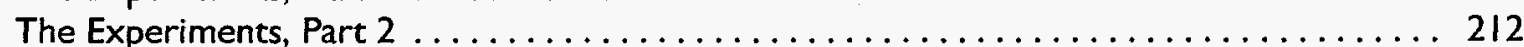

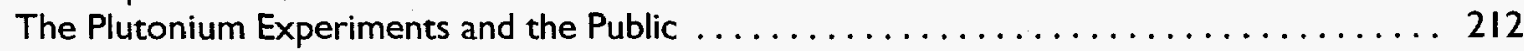

Environmental Releases of Radiation $\ldots \ldots \ldots \ldots \ldots \ldots \ldots \ldots \ldots \ldots \ldots \ldots$

Introduction . ........................................ 214

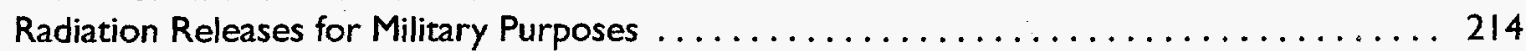

Radiation Releases for Nonmilitary Purposes ....................... 219 


\section{Chapter 2. Narratives and Records Series Descriptions}

\section{Institutional Areas}

\section{intreduction}

$\mathbf{T}$ HIS CHAPTER CONTAINS two kinds of information. The first consists of brief narrative histories that discuss the involvement of the Department of Energy (DOE) and its predecessor agencies with human radiation experiments. These histories cover agency headquarters elements and the various field sites that had significant involvement in experiment activities.

The second category of information is series descriptions for groups of original records that are pertinent to either individual experiments or to the organizational context in which they took place. Since many of these records still reside at DOE sites, series descriptions are appended to the narrative for each facility. Where records are not in the custody of DOE, they are listed under their custodial organization (such as the National Archives).

\section{The Narratives}

Narratives are included for nine different DOE organizations and facilities, past and present. Two universities that operated under contract with the Government are also discussed. These organizations had the most significant involvement in human radiation experiments sponsored or conducted by DOE and its predecessors. Summaries of the sites' current activities, their history, and their role in experimentation are provided. This summary approach was adopted for both conceptual and practical reasons. Conceptually, DOE's task was to find pertinent records and make them available. Judgements drawn from this material are made by independent bodies, including the Advisory Committee on Human Radiation Experiments.

From a practical perspective, summary narratives also present useful contextual information for the records series descriptions. Archivists typically use "scope and background statements" in published finding aids to help researchers better understand an organization's records. It is, for example, important to know when an organization began, what its purpose was, what its principal parts were, and how it changed over the years. Such information helps researchers plan a records search.

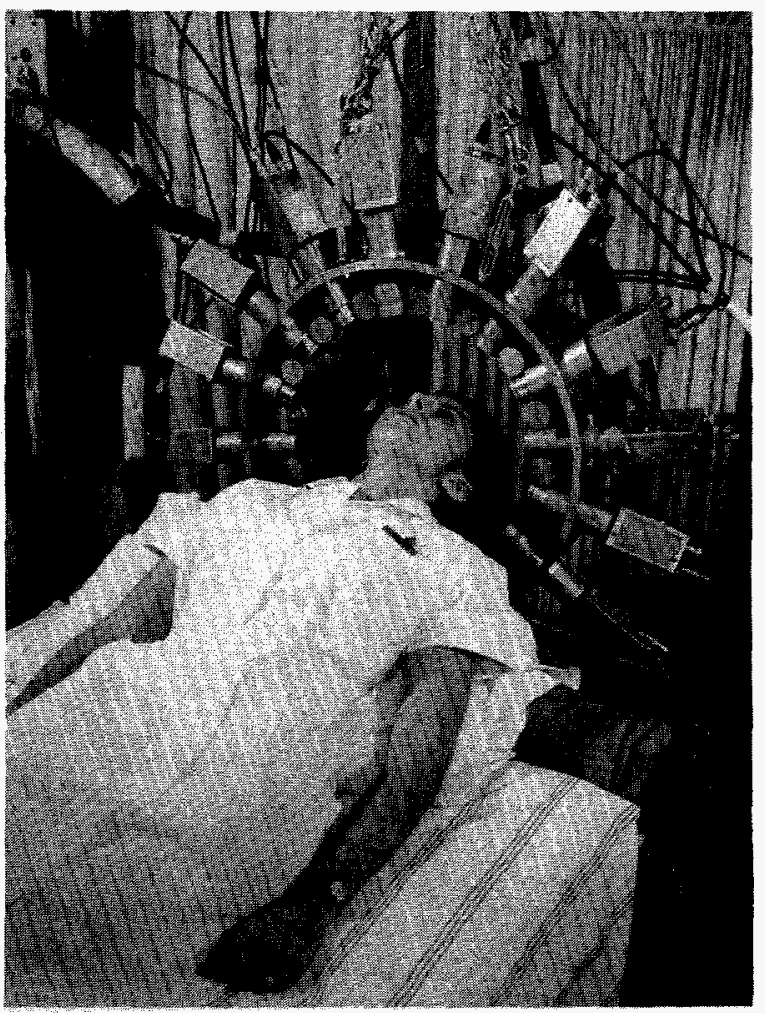

Figure 7. A positron emitter detector at Brookhaven National Laboratory (circa 1965).

\section{The Records Series Descriptions}

Records series are groups of related files, such as a hospital's medical records or a laboratory's research notebooks. A series can be small (one binder or notebook), large ( $100+$ boxes of files), or any size in between. The determining factor is how the records were created and maintained. Records series descriptions are a technique for effectively cataloging large collections. Such a catalog provides intellectual control: it tells people where specific records are and what is in them. For many years, the National Archives and Records Administration (NARA) and other 
archival institutions have used the concept of records series to manage historical records.

DOE chose to develop records series descriptions for human radiation experiment-related records because it was the best method for quickly gaining control over the Department's vast holdings. Dozens of DOE records collections spread around the Nation may have useful information. Often, a document by document search was required. A requisite for the assignment of national priorities for the search was to gain an overview of the records universe and identify the most important collections. DOE also recognized that the credibility of the search is enhanced by leaving behind a record of what was done and a means for others to take it further. The series will permit independent record searches, provide long-term public access, and aid in transferring DOE records to archival custody.

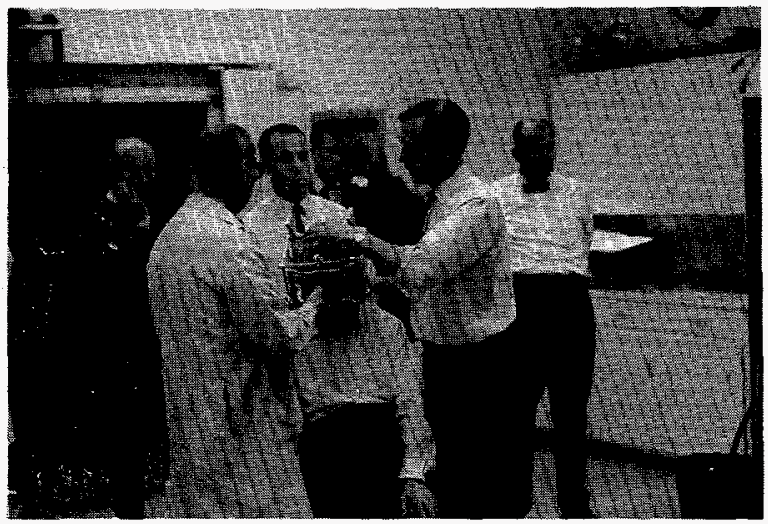

Figure 8. Early treatment for Parkinson's disease at the Berkeley Donner Laboratory (circa 1965).

In compiling the series descriptions, the intention was to cover as many collections relating to human radiation experiments as possible. Some collections may have eluded the search. If new materials are found, they will be added to the listings below and their availability publicized.

It is recognized that there are inconsistencies in the records series. These differences reflect varying histories, cultures, and recordkeeping practices throughout the agency. The goal is to present uniform and accurate information about each series. We encourage individuals to give us more and better information: this listing will be updated through a sustained dialog with its users.
The listed records series have been culled from the larger DOE records universe. For example, records relating to occupational radiation exposures, plant production emissions, nuclear weapons testing, waste management, environmental monitoring, general administration, and many other topics have not routinely been included. While occasionally the project scope expanded to include documents requested by the Advisory Committee, the search focused on activities relating to human radiation experiments and intentional radiation releases as defined in the January 1994 White House guidance.

Dozens of DOE records collections spread around the Nation may have useful information.

The difference between document collections and records series is important. Part of the DOE project has involved copying significant individual documents and providing them to interested parties, including the Advisory Committee. A collection containing electronic document images and indexes has been created, consisting of about 150,000 pages. This collection is available on the Internet through the DOE/OHRE Home Page. (World Wide Web address:

http://www.eh.doe.gov/ohre/home.htm) Users should understand that these individual documents represent only a fraction of the records covered by the series descriptions. Researchers may wish to use both the special document collection and the original files.

Finally, it should be understood that the records represented by the series descriptions are not instantly accessible. Most are still kept in agency warehouses and basements, and some contain classified documents that will require declassification before they are publicly available. Other restrictions, such as personal privacy, may also apply to some files. Those wishing to use records described in this guide-except those in the legal custody of the National Archives and Records Administration-should contact the DOE Office of Human Radiation Experiments at (202) 254-5020. We will work with the custodial organizations to facilitate access. Note that records at NARA are typically open for use; some files are classified, but DOE is systematically reviewing those files for declassification. 
DOE Predecessor Agencies and Human Radiation Experiments: A Headquarters Overview

\section{Introduction}

DOE INHERITED a legacy of human radiation experiments from predecessor agencies, including the Manhattan Engineer District (MED) and the Atomic Energy Commission (AEC). The Manhattan Project engaged in human radiation experimentation as part of its mission to build the atomic bomb. This mission included studying the health effects and hazards posed by nuclear energy. The AEC, postwar successor to the MED, had jurisdiction over both peaceful and military nuclear development and investigated related biomedical issues.

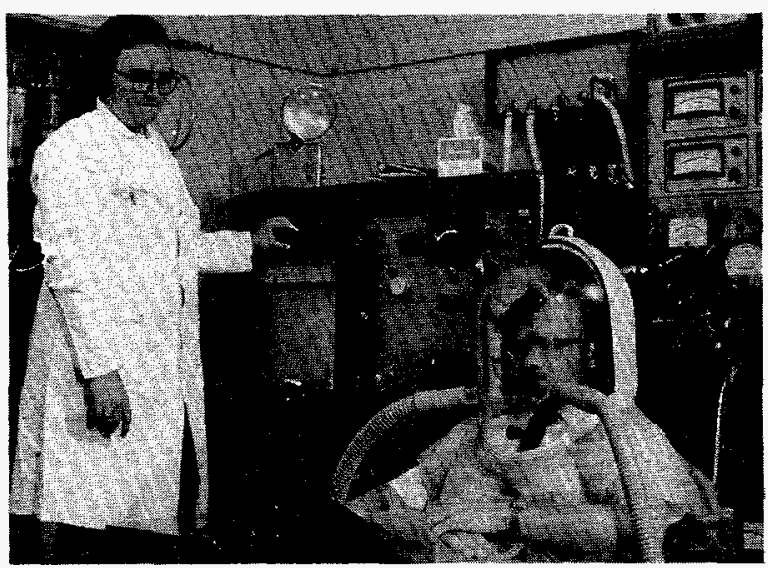

Figure 9. Donner Laboratory carbon-14 metabolic study apparatus.

Shortly after the war's end, cancer research assumed a prominent place on the national agenda. At the direction of Congress, the AEC funded considerable research into cancer diagnosis and therapy. After the AEC was abolished in 1975, the Energy Research and Development Administration (ERDA) briefly had responsibility for all AEC functions except those related to nuclear regulation, which devolved upon the Nuclear Regulatory Commission (NRC). DOE came into existence in 1977 and in turn assumed responsibility for nuclear biomedical research and weapons production.
The Manhattan Project engaged in human radiation experimentation as part of its mission to build the atomic bomb.

Attempts to understand radiation and its impact on the human body began shortly after the discovery of $x$ rays in 1895 . The Federal government, however, did not sponsor human radiation experimentation until the Manhattan Project was on the verge of building the atomic bomb. This project required development of a new industry that created hazardous radioactive materials, some of which did not exist until the war effort. MED biomedical researchers began research and experimentation with animals to establish exposure standards for the workers. Yet animal experimentation proved incapable of providing all needed data. The Manhattan Project leadership therefore authorized studies with radioactive materials in human subjects.

\section{Origins of the Manhattan Project}

In December 1938, while conducting experiments in their Berlin laboratory, German scientists Otto Hahn and Fritz Strassman discovered that uranium could be broken into two lighter elements while releasing energy. Scientists soon realized that this "fission" process could release enormous amounts of energy, providing the basis for a weapon of unprecedented explosive power. American scientists quickly grasped this possibility when news of the discovery of fission crossed the Atlantic.

A month after Nazi Germany invaded Poland, Albert Einstein wrote President Roosevelt urging the President to launch a program to build atomic weapons. Spurred by the possibility that the Germans could already be working on an atomic bomb, Roosevelt organized an advisory committee that began considering how to separate the fissionable isotope of uranium from uranium ore. Soon after Glenn Seaborg of the University of California and his colleagues discovered plutonium in 1941, the committee expanded its scope to explore the feasibility of large-scale production of this second fissionable metal. 
The uranium and plutonium projects began slowly due to the great technical and logistical problems involved. In June 1942, Vannevar Bush and James B. Conant, who led the bomb project, recommended that the country commit all possible resources to production of an atomic bomb. Bush and Conant further suggested that the Army run the project. Roosevelt agreed, and in August 1942 the Army Corps of Engineers established the Manhattan Project to build an atomic bomb as quickly as possible.

\section{Creating a New Industry}

The task called for creation of an enterprise greater in scope and complexity than any single contemporary private industry on "a pressing, almost desperate time schedule." Moreover, the project would incorporate new industrial processes and would have to deal with radioactivity on a previously unknown scale. Nevertheless, given the exigencies of wartime, the leader of the Manhattan Engineer District, General Leslie Groves, decided to bypass pilot plant stage and go directly to full production.

The task called for the creation of an enterprise greater in scope and complexity than any single contemporary private industry on "a pressing, almost desperate time schedule."

Unsure which (if any) would succeed, the Manhat$\tan$ Project simultaneously pursued three methods to produce the fissionable isotope of uranium: electromagnetic separation, gaseous diffusion, and thermal diffusion. Plants for all three were built at Oak Ridge, a thinly settled area in eastern Tennessee selected by the Government as an atomic reservation. Hanford, a large arid tract in eastern Washington bounded by the Columbia River, was selected for the plutonium project. Nuclear reactors, a plutonium separation plant, and a variety of associated facilities were constructed there. These sites were chosen for their access to water and power and for their remoteness, which enhanced security. Virtual ar. mies of workers moved into Oak Ridge and Hanford to construct and operate plants. To design a weapon, the Manhattan Project built a separate research laboratory at Los Alamos, NM.

\section{Wartime Medical Problems}

Creating the atomic bomb involved many unique and little-understood health hazards. The most novel was radiation. Scientists knew that radiation was hazardous; for example, the health effects suffered by radium dial painters earlier in the century had been well documented. What was not known was how much radiation would harm workers.

But the plutonium work, which produced highly radioactive and toxic materials, presented the greatest hazards.

Other hazards included chemical agents, highvoltage electricity, and the potential for explosions in experimental work that involved the use of gas and liquids under great pressure. To protect workers from these hazards, the Manhattan Project organized a Medical Section.

The Medical Section's most immediate problem was to identify and control the hazards associated with the various production processes. Data were collected on the potentially damaging effects of radioactive and toxic materials. The medical personnel provided advice on the design of plants and production processes and prepared to treat cases of radiation and chemical poisoning. Because the Manhattan Project oversaw entire communities at Oak Ridge, Hanford and Los Alamos, the Medical Section also ran clinical medicine programs to treat a variety of routine health problems. But the plutonium work, which produced highly radioactive and toxic materials, presented the greatest hazards.

\section{The Plutonium Injection Experiments}

Most project medical research involved experimentation with animals through programs established at the University of Rochester and elsewhere. Manhattan Project researchers, however, also used humans as research subjects; the most widely known example of this is the plutonium injection experiments.

As early as January 1944, Glenn Seaborg warned that "the physiological hazards" of plutonium might "be very great" and suggested that" a program to trace the course of plutonium in the 
body should begin as soon as possible." Animal studies had shown plutonium to be toxic and that different species excreted it from the body at different rates. Project physicians therefore wanted human data to obtain reliable information for the establishment of exposure levels for workers. In presenting these considerations to Los Alamos laboratory director J. Robert Oppenheimer on March 26, 1945, Louis Hempelmann asked that the MED "help make arrangements for a human tracer experiment." Such arrangements were made, and a series of human experiments began in 1945. (See the section, "Human Plutonium Injection Experiments," under Topical Areas later in this chapter.)

Other human radiation experimentation was conducted under the Manhattan Project. In the mid-1940s, University of Rochester researchers gave five patients radioactive polonium to obtain excretion data. Rochester researchers also injected six patients with uranium salts to investigate the metabolism of uranium by the body and to observe its effect on kidney function. To detect radiation skin effects, MED contractor researchers in Tennessee also exposed 10 subjects to beta radiation. (Individual experiments are detailed in Chapter 3.)

\section{Distribution of Radioisotopes}

The Manhattan Project also assisted postwar radiation experiments by non-Government physicians and researchers. In 1946, Oak Ridge began shipping radioisotopes to private physicians and other researchers. This distribution made radioisotopes available in far greater quantities and at much lower cost than previously. The isotope distribution program was the earliest, and for many years the most successful, aspect of the postwar promotion of "the peaceful atom." Researchers used isotopes to study the body's metabolic processes and to conduct experimental treatments for diseases, principally cancer. Some of this work involved experimentation with human subjects. The same distribution program provided isotopes to agency and contractor researchers.

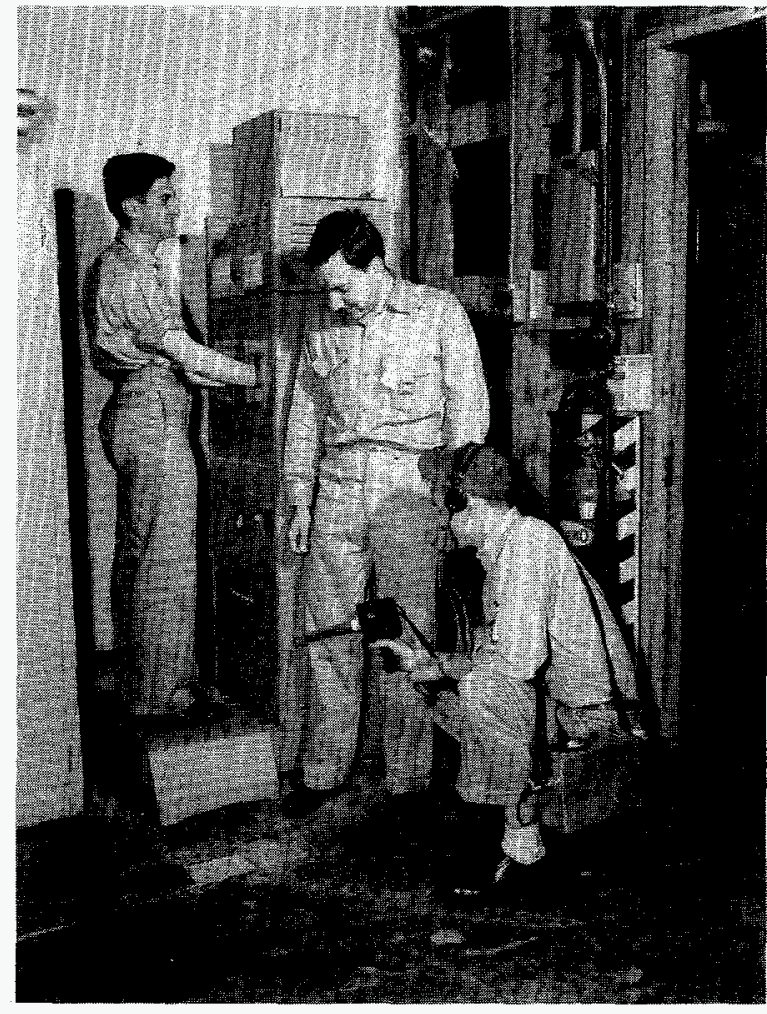

Figure 10. Oak Ridge National Laboratory workers checking for radioactive contaminants (circa 1950).

\section{Creation of the Atomic Energy Commission}

Because the atomic bomb was a wartime military project, the Manhattan Project had built its facilities behind a curtain of secrecy. It was only with the bombing of Japan that the American public learned about the project. After the war, President Truman submitted legislation to Congress to set up a permanent atomic energy program under military control. After vigorous debate, however, Congress decided to charge a civilian agency with atomic energy and weapons development. The Atomic Energy Act of 1946 created the Atomic Energy Commission (AEC) to oversee both peaceful and military development of the atom. The law also created the joint Committee on Atomic Energy to provide congressional oversight. Reflecting increasing tensions with the Soviet Union, the Atomic Energy Act ordered the AEC to develop atomic energy "subject at all times to the paramount objective of ensuring the common defense and security." In its early years, the AEC's overriding task was the development of a nuclear weapons arsenal. 
In January 1947, the AEC inherited the programs of the Manhattan Project. Coming to the agency were 254 officers; 1,688 enlisted men; 3,950 Government workers; 37,800 contractor employees; and plants and laboratories worth over $\$ 1$ billion. The major facilities included the Los Alamos laboratory, the Oak Ridge enriched-uranium production plants, and the Hanford plutonium production complex. The AEC also assumed responsibility for uranium mining and refining activities. In addition, nonmilitary atomic research laboratories were under development at Argonne, near Chicago; Brookhaven on Long Island; and Oak Ridge.

Some information, such as medical research and treatment with radioisotopes, was openly available. Despite these exceptions, most atomic energy activities remained behind a congressionally mandated wall of secrecy.

The Atomic Energy Act of 1946 gave the agency responsibility for atomic energy activities from weapons production to scientific and medical research. The act also placed security restrictions on most information pertinent to atomicenergy development. Legally mandated classification restrictions applied to biomedical information associated with uranium or plutonium production, weapons production, or weapons design. Some information, such as medical research and treatment with radioisotopes, was openly available. Despite these exceptions, most atomic energy activities remained behind a congressionally mandated wall of secrecy.

The Manhattan Project had used a small headquarters staff to oversee the operation of atomic energy facilities throughout the country. The AEC continued this practice, leaving substantial responsibility with agency and contractor field facilities. In some areas, such as weapons research and development, the AEC commissioners maintained central management control. In other areas, such as biomedical research, the AEC exercised less management oversight.

\section{Medical Problems Facing the AEC}

During the war, the Manhattan Project medical program gained only preliminary information about the hazards of radioactive substances. There was a desire to find out much more about how uranium, plutonium, and other fission products acted in the human body: What amounts of radioactive dusts and gases were harmful to man? Exactly how toxic were uranium, plutonium, and their compounds? What was the most hazardous means by which radioactive substances were introduced into the body-by ingestion, by inhalation, or by skin absorption? Physicians had no means available to stop or delay radiation injuries, nor did they possess therapeutic measures to treat injury from radioactive substances. To address these issues, an organizational unit to do the work was required.

\section{The AEC and Human Radiation Experimentation, 1940s-1950s}

The Atomic Energy Act mandated four AEC program divisions: military applications, production, research, and engineering. This arrangement left the agency temporarily without an organization to oversee biomedical research, but the AEC extended ongoing research on an interim basis. An Advisory Committee on Biology and Medicine was established in 1947, and a Division of Biology and Medicine in 1948. The AEC charged the new division with overseeing biomedical research programs, including human experimentation. Until the closed communities of Los Alamos, Oak Ridge, and Hanford were opened, the division also supervised clinical medicine programs for the treatment of resident workers and their families. By fiscal year 1949, the division was managing an operating budget of $\$ 14.6$ million.

Although the AEC biomedical division was charged with protecting the public from the hazards of atomic energy, its initial focus continued to be upon atomic workers. Thus, one area of human subject research in which the AEC built upon precedents was investigation of the biomedical hazards of uranium, plutonium, and fission products. Biomedical research projects devoted to investigating these hazards were authorized at the Argonne, Brookhaven, and Los Alamos Laboratories, and at the University of Rochester, the University of California (Berkeley and Los Angeles), Columbia University, and Case Western Reserve University. Most of these research projects involved experimentation with animals. 
Another area in which the AEC built upon Manhattan Project foundations was isotope distribution, headquartered in Oak Ridge. The AEC stimulated private research with radioisotopes by providing funding to private physicians and researchers. The isotope distribution program was the AEC's first significant peaceful application of nuclear science, and the agency vigorously promoted it. By the end of 1954, Oak Ridge had made 64,202 shipments of radioisotopes, most to non-Government institutions. Some of this research involved human subjects.

\section{Popular and scientific interest in the po- tential uses for radiation in cancer treat- ment was growing.}

In other areas, the AEC broke new ground. Perhaps, the most visible of these was the use of radiation in cancer therapy. Popular and scientific interest in the potential uses for radiation in cancer treatment was growing as the AEC came into being. In 1948, Congress gave the AEC $\$ 5$ million for the express purpose of developing a cancer research program. With the funds, the AEC built cancer research hospitals at the University of Chicago, Brookhaven Laboratory, and the Oak Ridge Institute of Nuclear Studies.

Cancer therapy was not the only new area of AEC sponsored or supported human radiation studies in the late 1940s and 1950s. Calibration of improved radiation measuring equipment involved volunteers ingesting small amounts of radioactive material. The AEC also sponsored human $\mathrm{x}$-ray tests and studies of skin absorption of radioactive substances, and also began studying radium dial painters and other groups who ingested radium before World War II.

\section{The AEC and Human Subject Consent, 1940s-1950s}

To establish guidance for private research using radioisotopes on people, the AEC looked to its Subcommittee on Human Applications. The subcommittee, part of the larger Committee on Isotope Distribution, drew up a list of radioisotopes deemed safe for use in humans. The subcommittee also compiled lists of medical schools, hospitals, clinics, and other institutions qualified to con- duct human radioisotope research. After the subcommittee reviewed an institution's qualifications and granted approval for use of an isotope in human research, the subcommittee expected each institution to form a local use committee to monitor individual research projects. This procedure limited AEC oversight of the clinical procedures and ethical practices of individual private physicians who used radioisotopes for human subject research. There was no requirement imposed by the AEC that private researchers obtain consent from subjects.

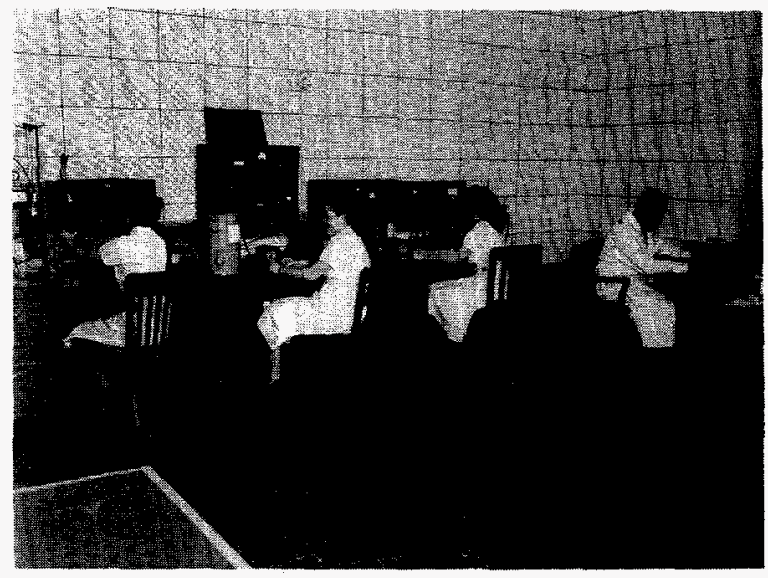

Figure 11. Oak Ridge technicians measuring air monitor samples for radiation.

Ethical issues were, however, considered in the context of research performed directly by AEC employees or in AEC-owned, contractor-operated facilities. In an April 1947 letter to Stafford Warren, chairman of the Interim Medical Advisory Committee, AEC General Manager Carroll Wilson stated that radiation should not be administered to medical patients unless there was "expectation that it may have therapeutic effect." Any human experimentation would have to be susceptible of proof from official records that the patient was "in an understanding state of mind, was clearly informed of the nature of the treatment and its possible effects, and expressed his willingness to receive the treatment."

While written consent from the patient was not required, doctors were instructed to attest that the subject had willingly consented. Wilson's directive applied to AEC officials and to employees of its contractor-operated facilities. 
The record does not show that the AEC distributed or enforced Wilson's policy. Indeed, the directive was quickly superseded. During March 1951, Shields Warren, the first director of the AEC Division of Biology and Medicine, listed "guiding principles" for human experimentation for a Los Alamos Laboratory official. Warren drew upon another Wilson letter, a report from the AEC's Medical Board of Review, minutes of the September 1948 meeting of the Advisory Committee on Biology and Medicine, and his own experiences. Warren did not mention or refer to Wilson's April 1947 directive. Warren's principles for human subject research included five requirements:

I. There must be hope of therapeutic benefit;

2. There must be a provision requiring written informed consent;

3. The subject would have the right to revoke consent at any time during an experiment;

4. The research must require only limited use of classification or secrecy; and

5. Any experimental work involving humans, including self-experimentation, would have to be supervised by a physician.

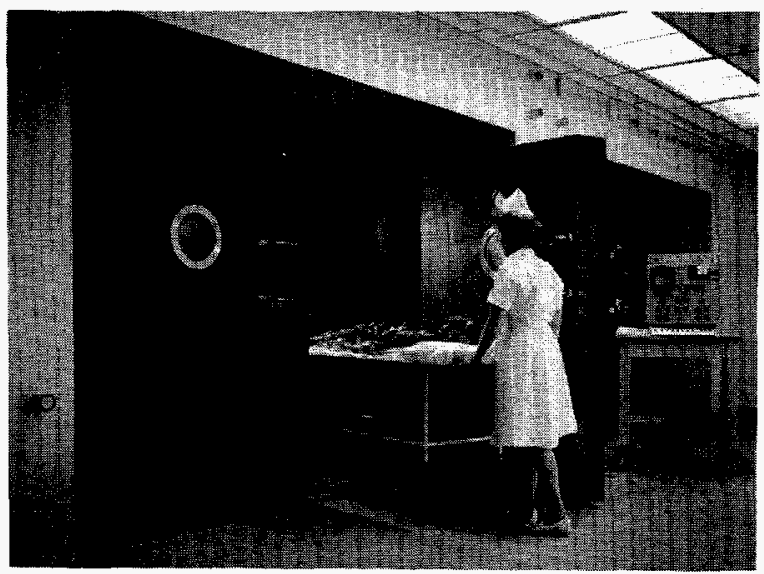

Figure 12. Brookhaven National Laboratory used "phantoms" such as the mannequin on this wheeled table to approximate human radiation exposures.

Charles Dunham, who replaced Warren as Division of Biology and Medicine head, modified this policy. Thomas Shipman, the Los Alamos Health Division leader, wrote Dunham in 1956, noting widespread ignorance of Warren's human experimentation policy. Shipman, who was propos- ing research on normal volunteers, confessed that he had heard about the policy but had never seen it in writing. In his response to Shipman's request for guidance, Dunham did not require that experiments carry some prospect of therapeutic benefit for the subject, but did mandate that all subjects provide informed consent. Dunham also added two provisions:

1. Radioactive substances must be used in amounts judged small enough to avoid harming subjects; and

2. Approval for human experimentation must be obtained by a senior medical officer.

Like Warren before him, Dunham did not refer to Wilson's April 1947 directive.

These letters suggest that the AEC lacked a firmly established policy regarding human radiation experiments during the 1940s and 1950s and used different policies at different times. On their face, these policies appear to be strict regarding both expected therapeutic benefit and written consent. What is not clear, except by negative inference, is whether any effort was made to widely distribute and enforce the policies. No documents have been found indicating that the AEC did either.

There was no requirement imposed by the $A E C$ that private researchers obtain consent from subjects.

\section{The Impact of the Cold War}

The five AEC commissioners devoted most of their attention to problems other than human radiation experiments. Throughout the agency's first years, the commissioners attended mostly to military applications, particularly weapons development. Increasing Cold War tensions spurred the nuclear arms race, and by 1949 the agency was on the front line of the Cold War. The international event having the greatest impact on AEC activities was Soviet detonation of a nuclear device in August 1949. This occurred before it was expected and caused a secret Government debate over whether to develop a hydrogen, or "super," bomb. Truman concluded the debate during January 1950, when he ordered the AEC to build the super bomb, whose 
explosive power promised a "quantum jump" over atomic bombs. To produce the tritium required for the hydrogen bomb program, the AEC built a new production reactor facility near Aiken, SC, known as the Savannah River plant. In response to debates over the adequacy of the scientific resources devoted to hydrogen weapons development, the AEC also built a second weapons research laboratory at Livermore, CA, which, like Los Alamos, was administered by the University of California.

The Cold War spurred other AEC activities, including those related to radiological warfare. Unlike atomic bombs, which achieve their destructive power from explosive effect, radiological warfare would cause damage by the direct dispersal of radioactive material on a targeted area. By 1951, the agency had concluded that the limitations of such weapons outweighed their usefulness; this decision was based partially on field tests. Cold War competition with the Soviet Union also contributed to the agency's decision to conduct the Green Run test at Hanford in 1949. The Green Run, occurring soon after the first Soviet atomic detonation, was an intentional release of radioactive material to test methods for monitoring the Soviet nuclear program.

\section{The Korean War}

International tensions increased when the Korean War broke out in June 1950. This conflict spurred the first deployment of nuclear weapons overseas, vast expansion of AEC production facilities, and establishment of a continental nuclear weapons testing facility at the Nevada Test Site. By the mid-1950s, the AEC operated I 3 nuclear production reactors and 12 gaseous diffusion plants for producing fissionable uranium. Both the Hanford and Oak Ridge plants were enlarged and new production complexes were constructed at Paducah, KY, and Portsmouth, $\mathrm{OH}$.

\section{The Hydrogen Bomb}

The Korean war ended in July 1953, but the AEC's intensive programs to refine nuclear weapons continued. Atmospheric nuclear tests were conducted in Nevada during 1951, 1952, 1953, 1955, 1957, and 1958; and at the Pacific proving grounds during 1951, 1952, 1954, 1956. and 1958. The most important tests were the Castle series of 1954, which took place in the
Pacific. Soon after the series, the AEC possessed a hydrogen weapon and a new plan to produce mass quantities of a few weapons types. Bravo, the first Castle shot, also ultimately affected agency biomedical programs.

The Cold War spurred other AEC activities, including those related to radiological warfare.

Los Alamos scientists fired the Bravo shot during March 1954. The blast size and amount of radioactive fallout were far greater than planned for: Bravo fallout contaminated 7,000 square miles, some of it with very high radiation. Fallout descended upon the military and scientific task force conducting the test series, Marshallese islanders, and the crew of a Japanese fishing vessel, the Lucky Dragon.

\section{The Test Ban Debate}

These fallout incidents, combined with the large number of atmospheric weapons tests conducted by both the United States and the Soviet Union, sparked public debate in the United States over a proposed test ban. A closely related debate also followed over the health hazards posed to the public by atmospheric nuclear testing. AEC assertions that fallout posed little threat to Americans were challenged, and public controversy raged until President Kennedy signed a limited test-ban agreement with the Soviet Union in August 1963. The treaty prohibited testing in the atmosphere, underwater, and in outer space.

\section{The Impact of the Fallout Controversy}

The fallout debate had caught the AEC unprepared and the Division of Biology and Medicine in a difficult position. Biomedical research into the hazards of fallout would take years to bear fruit, yet there was an urgent demand for information. To provide answers, the division gathered data from all relevant ongoing research projects, including one called Project Sunshine. This project had begun as an evaluation of the hazards associated with nuclear war and grew into a worldwide investigation of radioactive fallout levels in the environment and in human beings. Work in this area included collecting 
human tissues and samples of plants and animals from around the world.

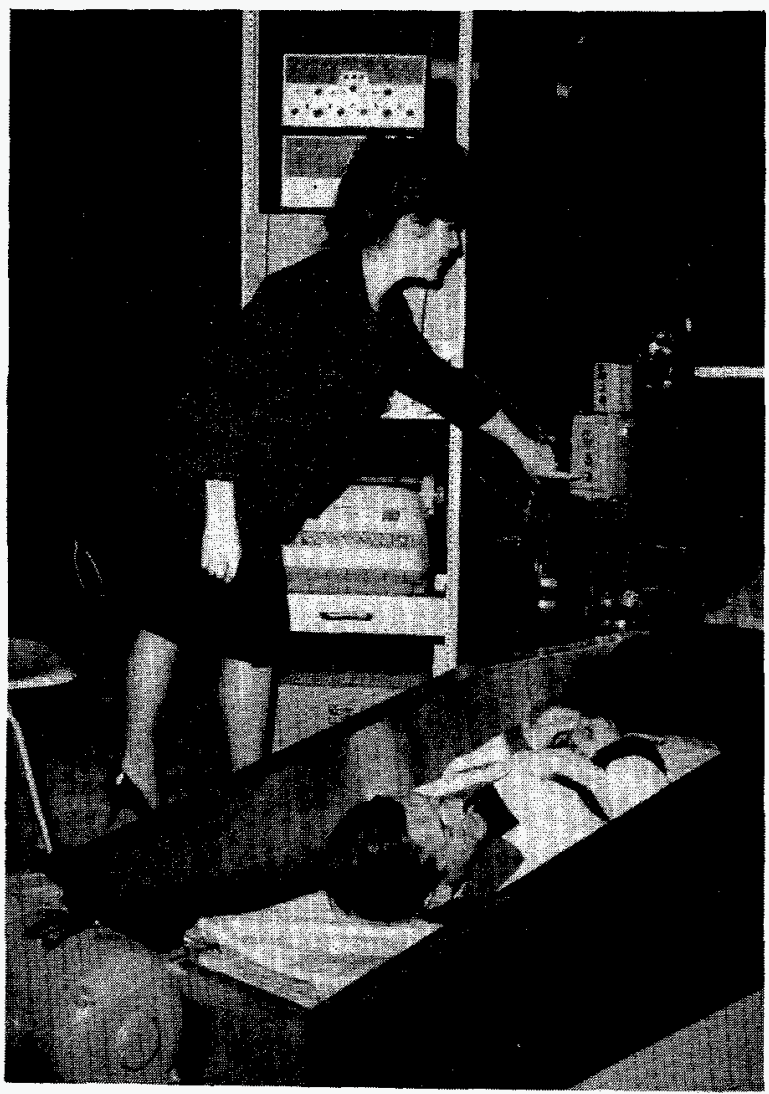

Figure 13. A Brookhaven technician demonstrating fast-neutron detection equipment

The fallout controversy compelled the AEC to focus more attention on questions related to public protection. It also gave greater public visibility to AEC biomedical research. The joint Committee on Atomic Energy pushed the agency to place greater resources into investigating the health effects of fallout. As a result, in 1958, the AEC nearly doubled its prior level of spending on biomedical programs over a 5-year period. The director of the Division of Biology and Medicine, Charles Dunham, stated that this effort would require "studies on human subjects," because data from animal experiments could not be applied directly to human experience. Dunham stated that human experiments were safe because of technical advances that allowed the use of radioactivity in very small amounts. These experiments required special equipment found in hospitals or large medical centers. Dunham urged the agency to expand its contractual support for human experiments at such institutions and increase funding for work in AEC-owned clinical facilities.

The director of the Division of Biology and Medicine stated that this effort would require "studies on human subjects," because data from animal experiments could not be applied directly to human experience.

During the 1950s, AEC contractor researchers participated in work in which subjects were injected with small amounts of radioactive strontium, calcium, or other substances to help determine the efficiency of chelating agents in removing radiation from the body. The fallout controversy imparted greater urgency to other AECsponsored research efforts to learn about human retention and excretion of radioactive materials. In the 1960s, the agency conducted tests in which human subjects were exposed to environmental releases of radioiodine to provide data on its absorption by the human body.

\section{The AEC in Transition}

By the time the United States signed the Limited Test Ban Treaty in 1963, the AEC's production and research efforts had created a nuclear weapons stockpile that met the military's needs. Accordingly, President Johnson in 1964 instructed the $A E C$ to reduce production activities. This resulted in the gradual shutdown of eight Hanford production reactors, two Savannah River production reactors, and two Oak Ridge gaseous diffusion plants. The remaining gaseous diffusion plants were run at a reduced rate. Weapons research did not cease, but both the Los Alamos and the Livermore Laboratories diversified some of their effort into other activities. Nuclear weapon testing, although now performed underground, continued at a steady pace.

The AEC reached a crossroads in 1963. Up to that time, the problems of the military atom had commanded the most time, attention, and energy from agency leaders. Over the next 10 years, the problems of the peaceful atom drew increasing negative attention to the AEC.

\section{Atoms for Peace}

Always anxious to promote the peaceful atom, the AEC was unable to do so effectively until after Congress amended the Atomic Energy Act 
in 1954. The 1954 Act encouraged private participation in atomic energy development, giving the AEC authority to remove entire topical areas of nuclear science and technology from secrecy restrictions. This law permitted the agency to foster a commercial nuclear power industry and to participate in international peaceful atomic energy activities. Both meshed with President Eisenhower's desire to reap practical benefits from America's lead in nuclear technology. Eisenhower proposed atomic energy development under United Nations auspices in his heralded "Atoms for Peace" speech. As a result, the AEC actively participated in the creation of the International Atomic Energy Agency, helped build research reactors abroad and, over a 10 year period, helped to organize three international peaceful atomic energy conferences in Geneva, Switzerland.

The 1954 Act gave the Atomic Energy Commission authority to remove entire topical areas of nuclear science and technology from secrecy restrictions.

At home, the AEC also promoted potential peaceful atomic energy applications. Among them were medical uses of radioactive tracers, fusion research, nuclear-powered rockets, nuclear batteries, and nuclear canal excavation. Many of these ambitious ideas never came to fruition. The largest single effort, however, was the push to develop a commercial nuclear power infrastructure.

\section{Building a Commercial Nuclear Power Industry}

In 1955, the AEC launched the Power Demonstration Reactor Program, designed to transform nuclear reactors into commercial electric power generators. Offering private industry financial and other assistance to design and build power reactors, the AEC attracted cooperation in building first-generation experimental power reactors, all of which were more expensive than comparable fossil-fuel-fired electric generating plants. In the expectation that power reactors would soon become economically competitive and that the utility industry would invest heavily in the new technology, the agency geared up its staff to license private utilities to construct and operate nuclear power reactors, a mission mandated by the 1954 Atomic Energy Act.

By 1965, however, the program was languishing. Only 12 power reactors were then in operation in the country, and of those, industry had built only three with wholly private funds. All others had required substantial governmental financial assistance to attract industry participation. The goal of making reactors economically competitive with fossil-fuel-fired power plants had not yet been realized, 10 years after initiation of the program. In 1966-1967, however, industry suddenly ordered 50 nuclear power plants, and commercial nuclear power continued to grow robustly for another decade.

\section{The AEC and Human Radiation Experiments, 1960-1970s}

As the AEC devoted more time to the peaceful atom, its biomedical research program continued along lines set earlier. This included substantial research into fallout and the occupational hazards of atomic energy. During the 1960s, the Division of Biology and Medicine gradually devoted greater resources to the hazards of the peaceful atom. Some of this research involved human radiation experiments.

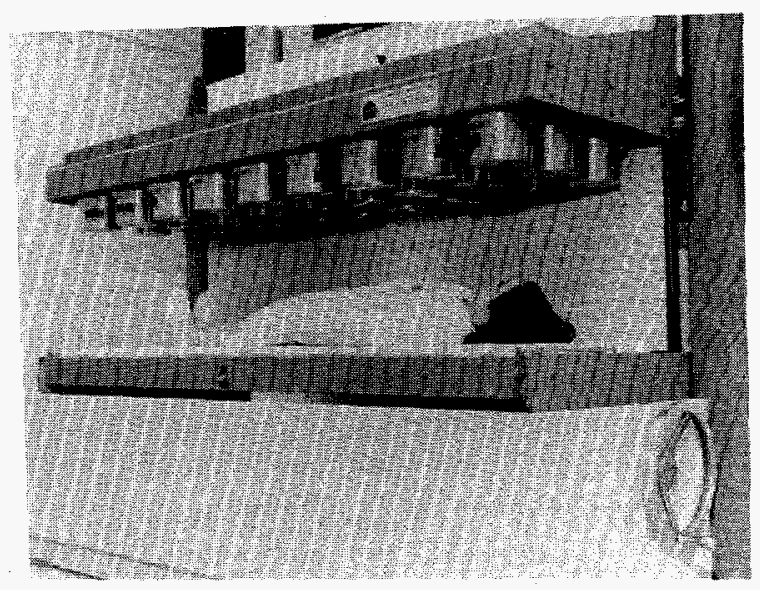

Figure 14. Brookhaven Low-Level Whole Body Counting Facility (circa 1968).

In the 1960s and 1970s, researchers in AECowned and private facilities expanded into new areas. The AEC funded experimentation in which prisoners in Oregon and Washington were 
administered radiation from $x$ rays to obtain data on radiation effects upon testicular cells. Contractor researchers used particle accelerator beams and total body neutron activation analysis in other human radiation experiments.

\section{Radioisotopes and Nuclear Medicine}

The direct applications of nuclear science and technology to medicine grew rapidly after World War II. By the early 1960s, the Government had made one-half million shipments of radioisotopes to physicians and other users. Nuclear medicine had become an accepted field of specialty and most human radiation experimentation was, in fact, being conducted by private physicians and private hospitals. The agency placed radioisotope licensing activities under its regulatory staff. All other radioisotope programs were the responsibility of officials charged with overseeing promotional activities.

The Atomic Energy Commission funded experimentation in which prisoners in Oregon and Washington were administered radiation from $x$ rays to obtain data on radiation effects upon testicular cells.

\section{Biomedical Research and Institutional Decision Making}

By the 1960s, the Division of Biology and Medicine had systematized a decision-making process for biomedical research projects and proposals, including those which involved human subject research. The Division of Biology and Medicine approved most biomedical research through an annual budget cycle. Proposals for new research originated with doctors and scientists in AEC contractor laboratories or in AEC-funded university research projects. The proposals were drafted on a Proposal and Authorization for Research or Development form, also known as Form 189, which contained project descriptions, justifications, and cost estimates. After laboratory directors and university project leaders approved them, completed Form 189s were forwarded to the Division of Biology and Medicine, where they were reviewed by the branch chief who oversaw research in that discipline. Costs were then rolled into a consolidated division budget request. At that level, individual projects were no longer identified.

\section{By 1970, the Atomic Energy Commission encouraged its sites to form institutional review boards to review human subject research projects.}

When the division director and his senior managers approved the consolidated budget and the research that it would fund, the budget went to the AEC general manager and commissioners for approval. Approval at this stage was given for spending levels, not for individual research projects, or even for groups of them. By approving the Division of Biology and Medicine budget, and incorporating it into the agency budget submitted to Congress, the AEC general manager and commissioners authorized the biomedical research that it would fund.

The agency used the Advisory Committee on Biology and Medicine to provide advice on general biomedical research and health policies and programs. Except for a short period in the early years of the agency, the committee did not review individual research projects. Although the committee in theory presented its recommendations to the AEC commissioners, in practice the committee functioned as an advisor to the division director.

Occasionally, the agency did consider biomedical research programs or projects outside the budget review process. This was generally limited to programs or projects considered controversial or unusually expensive. For these projects, the division director would incorporate project proposals and recommendations into an agency decision paper and seek approval of the paper through the agency's formal policy decision process.

The AEC and Subject Consent, 1960s-1970s

The U.S. National Institutes of Health (NIH) adopted formal guidelines for the protection of human subjects in 1966. The Division of Biology and Medicine informed AEC facilities of this and some sites chose to apply elements of the guidelines, although there was not yet a requirement 
to do so. By 1970, the AEC encouraged its sites to form institutional review boards to review human subject research projects. The NIH guidelines required informed consent from subjects before experimentation and required that subjects be told that they could withdraw consent to experimentation at any time. Many local institutional review boards formed at AEC laboratories did require written consent from subjects.

\section{Controversies Over Radioactive Effluents, Thermal Pollution, and Reactor Safety}

The quieting of the fallout issue caused by the cessation of atmospheric nuclear testing in 1963 did not end the debate over the health effects of radiation. By the late 1960s, issues were raised about the potential environmental impacts of radioactive emissions from nuclear power plants. The agency maintained, however, that its authority did not extend to environmental impacts. The AEC was eventually directed by court order to consider the full range of environmental impacts of nuclear power plants during the licensing process. Compelled by this decision to strengthen its environmental assessment capability, the agency renamed the Division of Biology and Medicine the Division of Biomedical and Environmental Research and channeled more funds and scientific effort into environmental research.

Another public controversy erupted during the early 1970s, again over nuclear power plants. Critics charged that plant safety devices would not prevent a catastrophic meltdown of a nuclear reactor core, which could spread radioactive contamination over hundreds of square miles. The AEC was unable to provide conclusive proof of the adequacy of safety systems. A formal hearing on this subject gave national publicity to critics of the agency, raised significant questions about nuclear reactor safety, and revealed that the AEC had been less than forthcoming about reactor safety problems.

By 1973, the AEC was severely buffeted by controversy. Critics asserted that the agency had sacrificed its responsibility to regulate the atom in the public interest to its desire to promote nuclear science and technology. Many charged that the agency faced an inherent conflict of interest between its roles of regulating and promoting the atom. Sentiment grew for abolishing the agency and vesting protection of public safety in an independent regulatory agency.

\section{Impact of the Energy Crisis}

The AEC faced credibility problems as the country faced an energy crisis. Energy problems had started with the northeast power blackout of 1965, which had interrupted electric power for nearly 30 million people. Over the next 2 years, 20 other major power failures occurred across the nation. By decade's end, many sensed that an energy crisis was approaching and expected greater Federal action to solve the problem. The oil embargo of 1973-1974 deepened the sense of crisis.

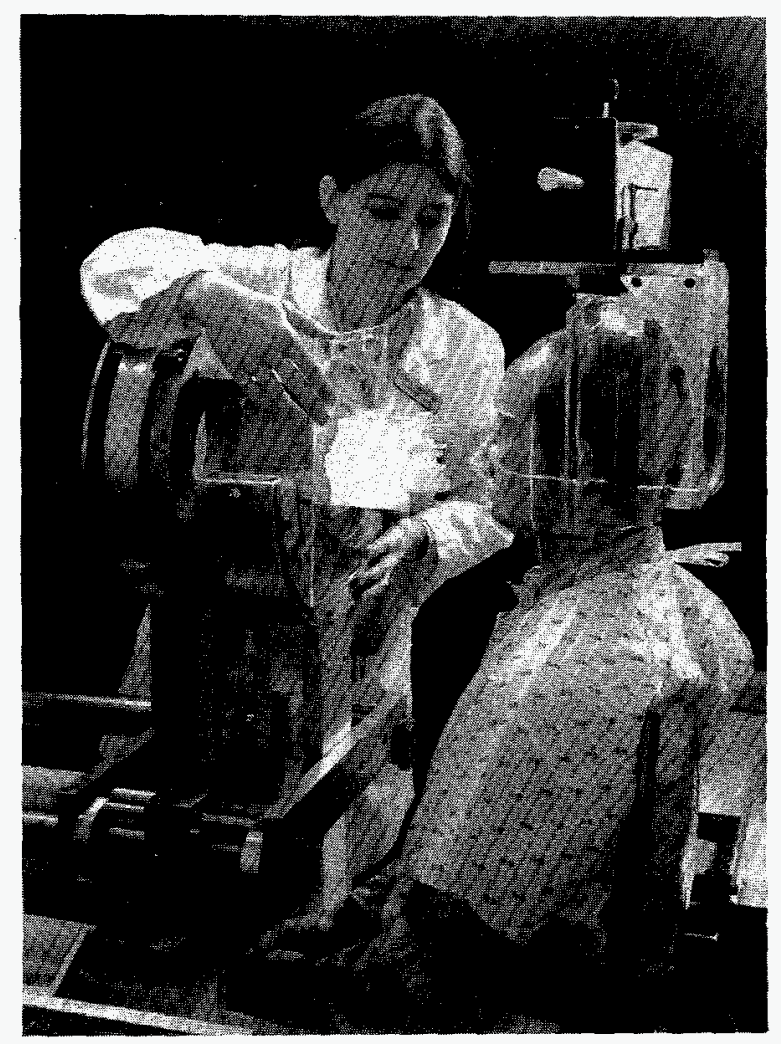

Figure 15. A patient prepared for treatment with charged atomic particles at Lawrence Radiation Laboratory (now Lawrence Berkeley Laboratory).

One result of the energy crisis was a movement to unify scattered Federal energy programs under a single organization. In 1973, President Nixon unsuccessfully proposed a Department of Energy and Natural Resources. Then, in late 1974, Congress passed the Energy Reorganization Act of 
1974, which abolished the AEC and established the Energy Research and Development Administration (ERDA), a single energy research agency, and another agency, the Nuclear Regulatory Commission, which was given the AEC's regulatory functions. ERDA also inherited the nuclear development and weapons-related programs of the AEC.

\section{The Energy Research and Development Administration}

ERDA had a much broader energy mission than did the AEC. The new agency conducted energy research and development in wind, solar, geothermal, and fossil-fuel energy technologies as well as nuclear energy technologies. ERDA also began comprehensive Federal energy research and development planning, publishing annual research and development plans. In addition, the agency created a new solar energy research institute. The bulk of ERDA's facilities, personnel, and contractors, however, came from the AEC.

In 1974, the Government adopted uniform regulations requiring independent institutional review boards to approve all experiments and requiring written informed consent.

ERDA inherited the AEC biomedical research programs, facilities, and its Division of Biomedical and Environmental Research, as well as its weapons research and production missions. In 1974, the Government adopted uniform regulations for all Federal agencies involved in human experimentation, including ERDA. These regulations required independent institutional review boards to approve all experiments before they took place. All subjects also had to provide written evidence of informed consent.

The most controversial biomedical problem ERDA inherited involved the wartime plutonium injection experiments. By now, documents related to the experiments had been declassified, although knowledge about them was largely confined to biomedical circles. In 1967, Patricia Durbin, a radiobiologist at the Lawrence Radiation Laboratory, learned that several patients injected in 1945 were still alive. She urged that the AEC examine them to obtain additional data about the retention and excretion of plutonium.

The University of Rochester, which still operated under an AEC biomedical research contract, was authorized in 1973 to conduct medical examinations of three of the four surviving subjects. While official agency policy mandated full disclosure, the three were not told that they had been injected with plutonium nor was the reason for their reexamination revealed. After learning of this, the AEC commissioners ordered an investigation and directed that full disclosure be made to the subjects. The AEC did not, however, reveal the experiments to the public. ERDA officials later published detailed information about the experiments in 1976.

\section{The U.S. Department of Energy}

ERDA had little time to build energy research and development programs. The perceptions that the Nation was in an energy crisis deepened, fueled by a natural gas shortage that closed plants, businesses, and schools in New England during the severe winter of 1976-1977. Spurred by the crisis, President Carter sent a proposal to Congress in 1977 to unify Federal energy policy planning and research and development units in one Cabinet-level department. Congress acted on the proposal promptly, and the Department of Energy (DOE) came into existence in October 1977.

The Department of Energy absorbed the Federal Power Commission, the Federal Energy Administration, and other smaller energy programs as well as all ERDA facilities, laboratories, production plants, and its division of biomedical and environmental research. The Department also became responsible for nuclear and other energy technology development, for nuclear weapons development, and for energy-related biomedical and environmental research, including human radiation experimentation activities. DOE inherited ERDA's radiation research activities and the regulations that the agency had promulgated to protect human subjects. Biomedical research activities were assigned to the office of energy research. By this time, predecessor agencies had established a legacy of research in biomedical research, including human radiation experiments. 


\section{Headquarters Records Collections}

DOE headquarters records are rich and comparatively easy to find and use. The Department has custody of most AEC and ERDA headquarters records, while nearly all Manhattan Project headquarters records have been transferred to the National Archives and Records Administration. AEC records are extraordinarily valuable, covering agency activities in a breadth and depth seldom found in government records collections. All records for AEC regulatory activities are in the custody of the Nuclear Regulatory Commission.

For material pertinent to human radiation experiments, the records of the AEC Secretary (1958-1975) and of its Division of Biology and Medicine are the most valuable. Both document AEC decision-making on biomedical issues and agency oversight over biomedical programs. Beyond the institutional context of human radiation experiments, both collections contain some documentation about individual clinical experiments and both contain crucial documentation about the AEC's 1974 investigation of the plutonium injection experiments.

Most AEC headquarters records are in the custody of archivists or historians and are preserved either in the DOE History Division or Office of Human Radiation Experiments. Recently DOE has transferred some important AEC records to the National Archives, including portions of the AEC Secretary's files (1946-1958) and of the Division of Biology and Medicine files. DOE will transfer additional AEC records to the National Archives in the future. More recent records are in the custody of DOE program offices and are, at this time, more difficult to access. The agency is, however, working to bring these records under intellectual control.
There are limitations on documentary access due to classification and privacy. Although most AEC biomedical program data-including information about human radiation experimentswas never classified, it may be intermixed with other information or documents which were, or are, classified. DOE has recently devoted substantial resources to declassifying $A E C$ records, but researchers may still encounter classified headquarters documentation. Researchers may request declassification reviews of collections, or portions of them. Few headquarters records have privacy restrictions. Researchers can also request that such documents be released to them, with the deletion of information which would identify individuals.

Department of Energy headquarters records are rich and comparatively easy to find and use.

AEC headquarters records are divided between National Archives and DOE custody. Because some AEC headquarters units operated out of Oak Ridge in the agency's early days, some AEC headquarters records are stored in Oak Ridge in DOE custody or in Atlanta in National Archives custody. The series described in the portion of Chapter 2 dealing with Oak Ridge, contain some headquarters records. 


\section{Atomic Energy Commission}

\section{SERIES TITL OHice of the Secretary (Secretatat Records). Corresoondence files}

INCLUSIVE DATES 1958-1975

ARRANGEMENT AEC Subject/Numeric Filing System (subject files)

Chronological order (Commission meeting minutes)

VOLUME 435 cubic feet

DESCRIPTION These files were compiled by the Secretary to the U.S. Atomic Energy Commission (AEC) to create the official record of Commission decisions and actions. They contain documentation on agency policies, origins, structure, functions, missions, controversies, and activities at the highest level of the agency. The Department of Energy has custody of portions of the Secretary's files pertaining to promotional matters. They document agency policy formulation on budgets, nuclear weapons programs, nuclear reactor programs, special nuclear materials production programs, biomedical programs, environmental programs, contracts, security matters, and organizational problems. They contain information on agency policies and standards for human subject research. They also contain letter reports of Advisory Committee on Biology and Medicine meetings, reports and meeting minutes of other advisory committees, and documentation on the AEC's 1974 investigation of the plutonium injection experiments. The series includes AEC information and division staff paper, letters, and memorandums showing implementation of policy decisions, excerpts of minutes of formal Commission meetings, and complete minutes of Commission meetings. Collection numbers $6,8,9,10,20$.

RESTRICTIONS This series contains privacy material and classified information.

LOCATION OF DOE Germantown Building, Room F-036

RECORDS 19901 Germantown Road

Germantown, MD 20585 


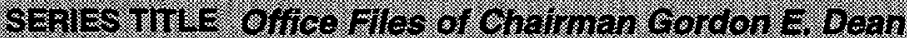

INCLUSIVE DATES $1949-1953$

ARRANGEMENT Chronological

VOLUME 4 cubic feet

DESCRIPTION The Dean office files consist of a typescript copy of Dean's office diary and a set of his reader files. They were compiled by Dean's secretary and document the issues and problems that came before Dean as an AEC commissioner and as AEC chairman. The major subjects covered are AEC weapons programs, expansion of special nuclear materials production programs, the hydrogen bomb program, security problems such as atom spy cases, and AEC budget and personnel matters. The diary contains scattered entries on biomedical policies, programs, and activities. The Dean office files include diary materials, letters, memorandums, and reports. A folder title inventory is available. Collection number 1110 .

RESTRICTIONS This series contains privacy material and a small amount of classified information.

LOCATION OF DOE Germantown Building, Room F-036

RECORDS 19901 Germantown Road

Germantown, MD 20585

\section{SEAIES TILE OFree Fles of Commissionor Whard if L Lbbr}

INCLUSIVE DATES $1946 ; 1954-1966 ; 1969$

ARRANGEMENT Subject

VOLUME 11 cubic feet

DESCRIPTION The Libby office files were created by Libby's office staff and they primarily document his service as an AEC commissioner. One box of materials consists of classified documents compiled by Libby after he left the AEC. The series documents top agency policy formulation and includes files on nuclear weapons programs, Project Sunshine, agency basic research programs, biomedical programs, and radioisotopes programs. The Sunshine files ( 2 boxes) document Libby's leadership of the project. The Libby office files include memorandums, letters, reports, handwritten notes and calculations, clippings, and published articles. Save for a set of reader files, they are arranged by a subject filing system devised by Libby's staff. A folder title inventory is available. Collection number 1114.

RESTRICTIONS This series contains privacy material and a small amount of classified information.

LOCATION OF DOE Germantown Building, Room F-036

RECORDS 19901 Germantown Road

Germantown, MD 20585 


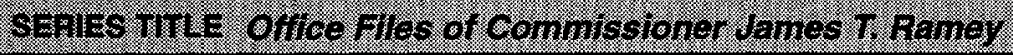

INCLUSIVE DATES 1962-1973

ARRANGEMENT Subject

VOLUME 68 cubic feet

DESCRIPTION The Ramey office files were compiled by his office staff and document his services as an AEC commissioner. They capture top agency policy formulation on matters in which Ramey was most interested. These include civilian nuclear power programs, regulatory programs, nuclear desalting programs, and the liquid metal fast breeder reactor program. They also contain files on the artificial heart program, cancer research, and research in AEC laboratories. The Ramey office files consist of correspondence files of memorandums, letters, reports, meeting notes and minutes, news clippings, handwritten notes, and published reports. They are arranged by a subject filing system devised by Ramey's staff. A folder title inventory is available. Collection number 326741.

RESTRICTIONS This series contains privacy material and a small amount of classified information.

LOCATION OF Washington National Records Center

RECORDS Suitland, MD 20409

\section{SERIES TTLE Ofice Itles or Chamman Dixy Lee Ray}

INCLUSIVE DATES 1972-1975

ARRANGEMENT Subject

VOLUME 30 cubic feet

DESCRIPTION The Ray office files were compiled by her staff to document her tenure as AEC commissioner and as AEC chairman. They document top agency policy formulation and include materials on civilian nuclear power programs, reactor safety programs, the liquid metal fast breeder program, Plowshare programs, and nuclear weapons programs. They also contain files on biomedical research, nuclear medicine, laboratory research activities, and minutes and reports of meetings of AEC advisory committees. The Ray office files consist of correspondence files of memorandums, letters, reports, meeting notes and minutes, news clippings, handwritten notes, and published reports. They are arranged by a subject filing system used by the AEC chairman's office. A folder title inventory is available. Collection number 326765 .

RESTRICTIONS This series contains privacy material and a small amount of classified information.

LOCATION OF Washington National Records Center

RECORDS Suitland, MD 20409 


\section{SERIES THLE OHCe Files or Chatman James ri. Sohlosinger}

INCLUSIVE DATES 1971-1974

ARRANGEMENT Subject

VOLUME 35 cubic feet

DESCRIPTION The Schlesinger office files were compiled by his office staff to document his tenure as AEC chairman. They capture top agency policy formulation and include material on Schlesinger's reorganization of agency operational and regulatory activities. They include files on laboratory and other research programs, civilian nuclear power programs, reactor safety programs, the liquid metal fast breeder reactor program, nuclear weapons programs and other national security matters. They also contain minutes and reports of meetings of AEC advisory committees. The Schlesinger office files consist of correspondence files of memorandums, letters, reports, meeting minutes and notes, news clippings, handwritten notes, and published reports. A folder title inventory is available. Collection number 326765 .

RESTRICTIONS This series contains privacy material and a small amount of classified information.

LOCATION OF Washington National Records Center

RECORDS Suitland, MD 20409

\section{SEAIES TILE Office FIles or Chatrman clem $T$. Soaborg}

INCLUSIVE DATES 1961-1971

ARRANGEMENT AEC Subject/Numeric Filing System

VOLUME 250 cubic feet

DESCRIPTION The Seaborg office files were compiled by the chairman's office staff and document Seaborg's tenure as AEC chairman. They capture top agency policy formulation and contain files on virtually all subjects that came before Seaborg including nuclear test ban negotiations, nuclear weapons programs, the fallout controversy, civilian nuclear power programs, basic research programs, laboratory research programs, special nuclear materials programs, the liquid metal fast breeder reactor program, and others. They include files on the formulation of biomedical policies and on biomedical programs and activities as well as reports of the Advisory Committee on Biology and Medicine and Seaborg's correspondence with the committee. The Seaborg office files consist of correspondence files of memorandums, letters, reports, meeting notes and minutes, news clippings, handwritten notes, and published documents. A folder title listing is available. Collection number 326766.

RESTRICTIONS This series contains privacy material and classified information.

LOCATION OF Washington National Records Center

RECORDS Suitland, MD 20409 
SEnIES TITE Flles or the Eeneral Manager's Ohloe

INCLUSIVE DATES 1947-1975

ARRANGEMENT Subject

VOLUME 184 cubic feet

DESCRIPTION The General Manager's office files were largely compiled by deputy general managers and assistant general managers so the General Manager's office files largely document policy implementation by these officials. The series includes documentation on Atoms for Peace programs, civilian nuclear power programs, security matters, agency organization and management, special nuclear materials production programs, and nuclear waste programs. It contains a few files on biomedical programs. It is an important source for program council meeting minutes, which contain information on early agency policy formulation pertaining to biomedical and other programs. The series also contains the office diaries of general managers Carroll L. Wilson and Marion W. Boyer and of deputy general managers Walter Williams and Carlton Shugg. The diaries may contain scattered references to biomedical programs and activities. Other files which may contain references to biomedical programs and activities are the office reader files and chairman and commissioner memorandum files. The general manager's office files consist of correspondence files of memorandums, letters, reports, meeting notes and minutes, news clippings, handwritten notes, and technical reports. A folder title inventory is available. Collection number 1135 .

RESTRICTIONS This series contains privacy material and classified information.

LOCATION OF DOE Germantown Building, Room F-036

RECORDS 19901 Germantown Road

Germantown, MD 20585

SERES TILE Diviston of Blology and Mediche, Central Correspondence and helated files

INCLUSIVE DATES 1947-1974

ARRANGEMENT AEC Subject/Numeric Filing System

VOLUME 53 cubic feet

DESCRIPTION The Division of Biology and Medicine (DBM) files were compiled to document the implementation of agency biomedical policies and programs. Most were compiled by a central mail room unit. They include documentation on biomedical research programs at agency laboratories, university biomedical research funded by the $A E C$, the 1950 s fallout controversy, Project Sunshine, biomedical activities at nuclear weapons tests, and the 1974 investigation of the plutonium injection experiments. The division files consist of correspondence files of memorandums, letters, staff papers, contracts, reports, meeting minutes, handwritten notes, and published reports. They are organized into several individual collections. They include a complete set of minutes of the meetings of the Advisory Committee on Biology and Medicine, a statutory body which provided advice to the division director. A folder title inventory is available. Collection numbers 1129, 1132, 1133, 1194, 1353, 1709.

RESTRICTIONS This series contains privacy material and classified information.

LOCATION OF DOE Germantown Building, Room F-036

RECORDS 19901 Germantown Road

Germantown, MD 20585 


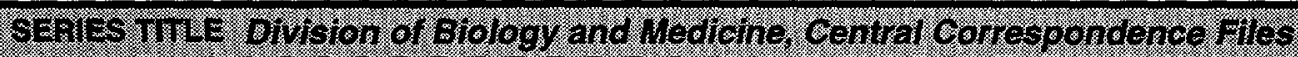

INCLUSIVE DATES 1956-1975

ARRANGEMENT AEC Subject/Numeric Filing System

VOLUME 37 cubic feet

DESCRIPTION These Division of Biology and Medicine (DBM) files were compiled by a central mail room unit. They include documentation on biomedical research programs at agency laboratories, university biomedical research funded by the AEC, the 1950s fallout controversy, the thermal pollution controversy, and the AEC's implementation of the National Environmental Policy Act. The series consists primarily of subject files of correspondence for the years $1970,1971,1973$, and 1975. The series contains memorandums, letters, staff papers, contracts, reports, handwritten notes, and published reports. Collection numbers 7239, 6586, 6793, 7249, 7723.

RESTRICTIONS This series contains a small amount of classified information.

LOCATION OF DOE Germantown Building, Room G-017

RECORDS 19901 Germantown Road

Germantown, MD 20585

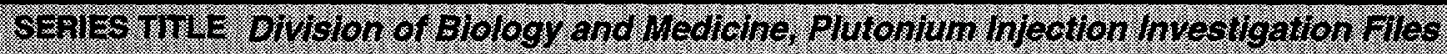

INCLUSIVE DATES Ca.1945-1988

ARRANGEMENT Numerically by human subjects case number (Medical files)

Subject (case files)

VOLUME 3.3 cubic feet

DESCRIPTION The records were created or collected by AEC staff during the 1974 investigation of the plutonium injections. They document information on persons who were injected with plutonium between 1945 and 1947 and provide information on the measurement of the plutonium excretion rate and the plutonium body content of several subjects by the staff of Argonne National Laboratory many years after injection. The files also contain medical information relating to health status at the time of injection, medical status at the time of measurement in the mid 1970s, and death certificates for those deceased. They contain documentation relevant to the 1972-1974 search and contact efforts, and to the scientific investigations conducted as part of the Argonne National Laboratory follow-up efforts. The follow-up studies focused on three persons who were alive in the 1970 s and four persons who had died. For the living subjects the purpose was to determine the excretion rate long after injection. For the decreased subjects, the purpose was to determine the amount of plutonium retained by the body at the time of death and to evaluate the degree to which the plutonium had redistributed within the skeleton. The files contain original records created by AEC/division and Argonne staff, ANL's copies of records created by others before Argonne's followup studies. The series consists of patient records, letters, memorandums, reports, handwritten notes, and charts. No index is available. Collection number OHRE 1.

RESTRICTIONS This series contains privacy material.

LOCATION OF U.S. DOE, Office of Human Radiation Experiments

RECORDS $1726 \mathrm{M}$ Street NW, Suite 200

Washington, DC 20036 


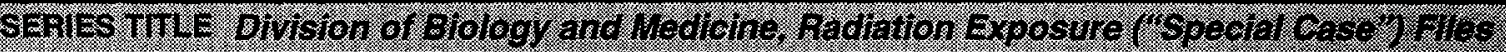

INCLUSIVE DATES 1945-1962

ARRANGEMENT AEC Subject/Numeric Filing System

VOLUME 4 cubic feet

DESCRIPTION This series consists entirely of files which document exposures of individuals and groups to radiation. Most seem to be occupational or accidental exposures. The series includes files on exposures of named individuals, the Marshallese Islanders in 1954 , the Lucky Dragon crew in 1954, radium cases, and weapons testing personnel. The series was consolidated into a special collection by the AEC Division of Biology and Medicine. The series contains letters, memorandums, reports, and telegrams. A folder title listing is available. Collection number 326783.

RESTRICTIONS This series contains a small amount of classified information.

LOCATION OF DOE Germantown Building, Room G-017

RECORDS 19901 Germantown Road

Germantown, MD 20585 


\section{SERIES TTLE Otfice of the Cenoral Counsel, Centrat Corrossondence Fibs}

INCLUSIVE DATES $\mathrm{ca} .1947-\mathrm{Ca} .1977$

ARRANGEMENT AEC Subject/Numeric Filing System

VOLUME approximately 210 cubic feet

DESCRIPTION The series consists of central correspondence files compiled by the General Counsel to advise the AEC commissioners on legal and policy issues. Some files which were once a part of the series have been destroyed. The remaining files document General Counsel advice on issues such as weapons testing, compliance with the National Environmental Policy Act, land acquisition, and other matters. The files may contain documentation on biomedical policy, including General Counsel advice on procedures and ethics for human subject research. Access to some documents may be restricted due to attorney-client privilege. The series contains correspondence files of letters, memorandums, AEC staff papers, handwritten notes, and reports. No folder title inventory or listing is available. No collection number.

RESTRICTIONS This series contains privacy material and a small amount of classified information.

LOCATION OF James Forrestal Building, Room 7E-054

RECORDS 1000 Independence Avenue, SW

Washington, DC 20585

\section{SERIES TILL Ofrice of the General Counsel, Contract Filos}

INCLUSIVE DATES ca. 1947-ca. 1977

ARRANGEMENT Name of institution

VOLUME approximately 145 cubic feet

DESCRIPTION The series is primarily composed of information copies of contracts sent to the General Counsel's Office. It includes information about activities covered under contracts, but does not appear to include General Counsel's opinion about the contents. It does not include copies of all AEC contracts, but does include copies of AEC contracts with University of California (Berkeley and Los Angeles) and Brookhaven. The series consists of copies of contracts, modifications to them, and correspondence pertaining to contracts. No folder title inventory or listing is available. No collection number.

RESTRICTIONS This series contains privacy material and a small amount of classified information.

LOCATION OF James Forrestal Building, Room 7E-054

RECORDS 1000 independence Avenue SW

Washington, DC 20585 


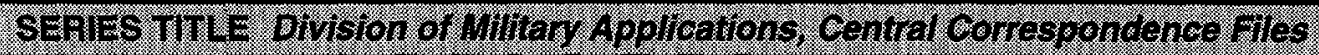

INCLUSIVE DATES 1947-1974

ARRANGEMENT AEC Subject/Numeric Filing System

VOLUME 43 cubic feet, exclusive of films

DESCRIPTION The Division of Military Application (DMA) files were compiled by a central mail facility to document the organization's role in implementing policy decisions pertaining to nuclear weapons testing, nuclear weapons accidents, and the 1969 Rocky Flats plant fire. They contain a few scattered documents on radiological warfare activities. The DMA files consist of correspondence files of memorandums, letters, staff papers, reports, and handwritten notes. They are organized into several collections and most are arranged according to the agency's Subject/Numeric Filing System. A folder title inventory is available. Collection numbers 1178, 1179, 1185, 1188, 1189, 1336.

RESTRICTIONS This series contains classified information.

LOCATION OF DOE Germantown Building, Room F-036

RECORDS 19901 Germantown Road Germantown, MD 20585

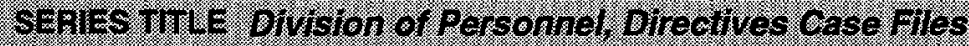

INCLUSIVE DATES $1947-1971$

ARRANGEMENT Numbered directive

VOLUME 33 cubic feet

DESCRIPTION The series contains regulations covering most agency activities. The regulations were issued in different series such as GM (General Manager) Bulletins or AEC Manual Chapters. The directives also include official statements of responsibilities and authorities for most AEC program offices. The series consists of copies of official regulations and the documentation pertaining to them. A folder title listing is available. Collection numbers $4802,6578,6286,5674$.

RESTRICTIONS This series contains a small amount of classified information.

LOCATION OF DOE Germantown Building, Room G-017

RECORDS 19901 Germantown Road

Germantown, MD 20585 
INCLUSIVE DATES 1948-1974

ARRANGEMENT AEC Subject/Numeric Filing System

VOLUME 4 cubic feet

DESCRIPTION The series documents the organization and management of AEC advisory committees, including the Advisory Committee on Biology and Medicine, the Advisory Committee on Isotopes and Radiation Development, and the Advisory Committee on Medical Use of Isotopes. It does not include minutes of meetings of the committee or reports of committee meetings. The series consists of correspondence files of letters and memorandums. A folder title listing is available. Collection number 6693.

LOCATION OF DOE Germantown Building, Room G017

RECORDS 19901 Germantown Road

Germantown, MD 20585

\section{SERIISS TITLE Qfice Files of L Joe Deal}

INCLUSIVE DATES $1945-1981$

ARRANGEMENT Subject

VOLUME 14 cubic feet

DESCRIPTION The Deal office files are comprised of materials assembled by Deal during his service in Atomic Energy Commission, Energy Research and Development Administration, and Department of Energy organizations with responsibilities for biomedical research and operational safety matters. They include extensive documentation on nuclear weapons testing activities and their health effects. They also include documentation on other operational safety matters. The Deal office files consist of correspondence files of letters, memorandums, reports, handwritten notes, and charts. They are arranged by a subject filing system devised by Deal's secretary. A folder title inventory is available. Collection number 1368.

RESTRICTIONS This series contains a small amount of classified information.

LOCATION OF DOE Germantown Building, Room F036

RECORDS 19901 Germantown Road

Germantown, MD 20585 


\section{SERIES TILE Otice Tiles of Thomas WectaW}

INCLUSIVE DATES 1949-1986

ARRANGEMENT Subject

VOLUME 23 cubic feet

DESCRIPTION The McCraw office files consist of materials assembled by McCraw during his service in Atomic Energy Commission, Energy Research and Development Administration, and Department of Energy organizations with responsibility for biomedical and operational safety activities. They contain extensive documentation on safety of nuclear weapons testing and health effects of weapons testing. They also include files on the fallout controversy of the 1950s, the nuclear rocket program, and advisony committee on biology and medicine meetings. The office files consist of letters, memorandums, reports, handwritten notes, meeting minutes, and charts. A folder title inventory is available. Collection number 1320 .

RESTRICTIONS This series contains classified information.

LOCATION OF DOE Germantown Building, Room F-036

RECORDS 19901 Germantown Road

Germantown, MD 20585

SERES TILE FIeld Office Progress Reports

INCLUSIVE DATES 1947-1963

ARRANGEMENT Field site

VOLUME 10 cubic feet

DESCRIPTION The series documents construction, routine operations, and extraordinary activities at AEC field sites such as Hanford, Oak Ridge, and Savannah River. Virtually all early $A E C$ field activities are documented by this series. It contains materials on subjects such as weapons production, special nuclear materials production, aircraft nuclear propulsion, and reactor development. The Hanford weekly report for the first week of December 1949 contains a reference to the Green Run. The series consists entirely of periodic progress reports. A folder title inventory is available. Collection number 1708.

RESTRICTIONS This series is entirely classified.

LOCATION OF DOE Germantown Building, Room F-036

RECORDS 19901 Germantown Road

Germantown, MD 20585 


\section{SERIES TILE ReVodic Progreso heports}

INCLUSIVE DATES $1947-1965 ; 1967-1968$

ARRANGEMENT Chronological

VOLUME 20 cubic feet

DESCRIPTION The series consists of periodic reports of activities of some Atomic Energy Commission headquarters organizations and of activities overseen by the agency's major operations offices. It also contains some General Manager's monthly reports of activities and some monthly reports to the agency's General Advisory Committee. Runs of these reports vary considerably in time periods covered. Many reports were compiled by the AEC's Division of Finance to help AEC commissioners trace construction activities and the implementation of policy decisions. The series includes reports of biomedical activities as well as of weapon, reactor development, and other activities. The series consists of monthly and weekly reports arranged by organizational unit or chronologically. A folder title inventory is available. Collection number 1342.

RESTRICTIONS This series contains classified information.

LOCATION OF DOE Germantown Building, Room F-036

RECORDS 19901 Germantown Road

Germantown, MD 20585

\section{SERIES TIUE Program Reports to Joint Commitee on Atomic Errergy}

\section{INCLUSIVE DATES 1947-1973}

ARRANGEMENT Chronological

VOLUME 1 cubic foot

DESCRIPTION The series contains a partial set of quarterly progress reports to the Joint Committee on Atomic Energy. In the reports, the AEC described agency progress and major activities in biomedical, basic research, reactor development, and other program areas. A few contain information on radiological warfare activities. The AEC placed material on agency progress and major activities in weapons and production programs into separate parts of the quarterly reports, which were stored and maintained separately. Some of these weapons and production sections are in this series. The series consists entirely of reports, which are arranged chronologically. A folder title inventory is available. Collection number 1172.

RESTRICTIONS This series is entirely classified.

LOCATION OF DOE Germantown Building, Room F-036

RECORDS 19901 Germantown Road

Germantown, MD 20585 
INCLUSIVE DATES 1953-1964

ARRANGEMENT Chronological

VOLUME 1 cubic foot

DESCRIPTION The series contains a partial set of quarterly progress reports to the Joint Committee on Atomic Energy. In the reports the AEC described agency progress and major activities in biomedical, basic research, reactor development, and other programs. The AEC placed material on agency progress and major activities in weapons and production programs into separate parts of the quarterly reports, which were stored and maintained separately. None of the separate weapons and productions sections are included in this series. This series consists entirely of reports, which are arranged chronologically. A folder title inventory is available. Collection number 1378.

RESTRICTIONS This series is entirely classified.

LOCATION OF DOE Germantown Building, Room F-036

RECORDS 19901 Germantown Road

Germantown, MD 20585 


\section{U.S. Energy Research and Development Administration}

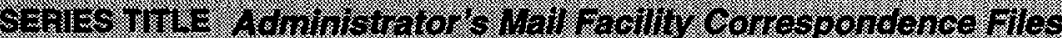

INCLUSIVE DATES 1975-1977

ARRANGEMENT ERDA Subject/Numeric Filing System

VOLUME 115 cubic feet

DESCRIPTION The series consists of files compiled to capture the official decisions, policies, actions, and activities of the agency's top official. The series contains a section on biomedical programs and policies which include materials on controversial matters as well as routine biomedical program activities. The series contains letters, memorandums, briefing charts, reports, and meeting notes. A folder title listing is available. Collection numbers $1216,1217,1218,1220,1221,1223$.

RESTRICTIONS This series contains a small amount of classified information.

LOCATION OF Washington National Records Center

RECORDS Suitland, MD 20409 


\section{U.S. Department of Energy}

\section{SERIES TTILE OTfes of heath and ETVTrommental Reseahah.} Fesearch and bevelosment rioject Case Fils

INCLUSIVE DATES 1954-1990

ARRANGEMENT Contract

VOLUME 40 cubic feet

DESCRIPTION This series documents biomedical research performed under contract to DOE and DOE predecessor agencies. Some of the files were originally part of the AEC Division of Biology and Medicine files. The research was performed by individuals, such as Hymer Friedell and Lester Van Middlesworth, and institutions such as Vanderbilt University, Massachusetts General Hospital, and the Universities of Rochester, Cincinnati, and Washington. The series contains letter and other reports of research, contrasts, memorandums, and documentation related to conferences and symposia. A folder title listing is available. Collection numbers $3267716,326801,430848$, 4308413, 434879, 4348746, 4348676, 434802, 4348778, 4348925, 4348959, 43490341, 43490207, 4348921, 4348932, 4349022, 43490346, 434805, 4308620, $430872,4348638,4348687,434803,434849,4348446,4348447,4348448,4348449$, $4348450,4348410,4308619,4308618,3268624,4348710,4348711,4348712$, $4348747,4348748,4348749,4348750,4348751,4348677,4348178,4348679$, 4348926, 4348927, 4348960, 43490342, 43490208, 43490209, 4348922, 4348923, $4348933,43490226,43490267,43490228,43490341,4348623,4348624,4348623$, 4348626, 4348627, 434871, 434872, 434873, 434874, 434875, 434876, 430871, $4348669,4348688,4348689,4348690$.

LOCATION OF Washington National Records Center

RECORDS Suitland, MD 20409

\section{SEAIESTILE Ofice of Healh and Envirominentil Research.} Research and Develo ment Project Case Flles

INCLUSIVE DATES 1957-1979

ARRANGEMENT Contract

VOLUME 87 cubic feet

DESCRIPTION The series documents biomedical research performed under contract to DOE and DOE predecessor agencies. Most appear to have been on ecological or environmental topics, although some human subject research may be documented in the series. Some of the files were originally created by the AEC Division of Biology and Medicine. The series contains letter and other reports of research, contracts, memorandums, and documentation related to conferences and symposia. A folder title listing is available. Collection numbers $6115,6187,6203,6246,6655,7155,430851,430854$, $430853,7358,7507,4348455,4308412$, 4348224, 326825, 4348680, 4348765, 4348766, 4348764, 93078G, 7724, 4348518, 4348519, 430847, 4348444, 4348445, 434804.

LOCATION OF DOE Germantown Building, Room G-017

RECORDS 19901 Germantown Road

Germantown, MD 20585 


\section{The Site Today}

ARGONNE NATIONAL LABORATORY (ANL) is a multiprogram research laboratory near Chicago, IL. Argonne undertakes basic and applied research and conducts experimental and theoretical programs in the physical, life, and environmental sciences. The Laboratory also operates programs for advanced fission reactors and other technologies.

Argonne runs 25 major research facilities, among them four particle accelerators, a fossilenergy laboratory, and a national storage-battery test facility. In 1992, Argonne employed a staff of more than 4,600 and had an operating budget of more than $\$ 390$ million. The University of Chicago operates the Laboratory for the U.S. Department of Energy.

\section{Site History}

Argonne evolved from the Metallurgical Laboratory, which the Office of Scientific Research and Development (predecessor to the Manhattan Engineer District) organized to support the atomic bomb project. Early in 1942, Arthur Holly Compton, the scientist-administrator responsible for the project's plutonium studies, decided to consolidate his Columbia and Princeton University research groups at the University of Chicago. Compton also moved Glenn Seaborg's plutonium chemistry research from the University of California to Chicago. This consolidation of scientific resources formed the Metallurgical Laboratory, or Met Lab as it became known.

The Met Lab's primary job was to design nuclear reactors and chemical processes for plutonium production. Met Lab scientists focused their initial work on achieving a self-sustaining nuclear chain reaction. Led by Enrico Fermi, this goal was achieved on December 2, 1942, when the world's first sustained nuclear chain reaction took place under Stagg Field in Chicago.

The laboratory subsequently built and operated small research reactors outside Chicago in the Argonne Forest Preserve. In 1943, the Met Lab worked with E. I. du Pont de Nemours Company to design a reactor pilot plant in Oak Ridge and in building the full-scale plutonium production reactors at Hanford, WA.

The Met Lab was organized around four groups: a nuclear physics division; a chemistry division; a plutonium separation division; and, after July 1942, a health division. The health division was established to study the unique occupational hazards associated with the project. The plutonium production reactors would produce unprecedented radiation, and there was a pressing need to devise protective measures for laboratory employees. These measures were tied to collecting radiation exposure data and conducting experiments into the metabolism and toxicology of radioactive substances.

Although Compton received directives from the Manhattan Project for laboratory program work, the Met Lab was an integral part of the University of Chicago. The laboratory was housed in university buildings on the campus, and Compton held a university appointment as dean of the Physical Sciences Department. Many other scientists on the Met Lab staff were likewise members of the university faculty. The university kept direct control of the facility's administrative matters, and the laboratory's administrative officer reported to the university's business manager, not to Compton. By the fall of 1943, crucial activity in the plutonium project had shifted from Chicago to Oak Ridge and Hanford. The Met Lab became a vital part of the du Pont team that was building the Oak Ridge pilot reactor and the full-scale Hanford production reactors.

Met Lab scientists focused their initial work on achieving a self-sustaining nuclear chain reaction.

The Manhattan District formed Argonne National Laboratory (ANL) in 1946. Argonne drew many of its staff and facilities from the Met Lab, and the University of Chicago continued as the laboratory operating contractor. The Laboratory moved its operations to the current DuPage County site during the early 1950s. Postwar activities focused on thermal reactor research, and later on design 
of a breeder reactor that would create new supplies of nuclear fuel while it operated.

Walter Zinn was the first ANL director. He organized the Laboratory into divisions of chemistry, biology, radiological physics, medicine, metallurgy, hazard evaluations, mass spectroscopy, instrument research, instrument fabrication, information, and patents. Three of these divisions had missions that touched on biomedical research. The biology division investigated the effect of radiation on plants and animals. A medical division provided routine health services to laboratory employees and conducted research into the toxic and radiological effects of heavy metals. The radiological physics division conducted routine monitoring programs, set general radiation safety standards for laboratory personnel, kept all personnel radiation exposure records, and worked on new radiation monitoring instruments.

Under Zinn, Argonne gained preeminence in reactor development, and the AEC briefly considered placing all agency reactor work at the laboratory. Zinn and other Argonne scientists played an important role in selecting a proving ground in Idaho to build the breeder and other experimental reactors. Argonne designed a pressurized water reactor as the prototype propulsion unit for the nation's first nuclear submarine. ANL also designed the heavy-water moderated and cooled reactors used as production units at the AEC Savannah River plant.

Argonne National Laboratory and its predecessor, the Met Lab, participated in clinical human radiation experiments.

During the 1960s Argonne hoped to lead in the development of commercial breeder reactors. In 1963, the AEC authorized Argonne to design a Fast Reactor Test Facility. In late 1965, however, the project was canceled, and by the late 1960s Argonne was exploring alternative energy sources and environmental science. As the Laboratory diversified, it reorganized units with duties related to biomedical research. During the late 1960s and early 1970s, the AEC built a Center for Human Radiobiology (CHR) at Argonne to study individuals exposed to internal radiation; most of the people followed were dial painters who had ingested radium before World War II. Laboratory administrators placed the $\mathrm{CHR}$ in the Radiological and Environmental Research Division.

\section{Site Human Radiation Experiments}

ANL and its predecessor, the Met Lab, participated in clinical human radiation experiments. The most noteworthy were the plutonium injections at the University of Chicago's Billings Hospital during 1945. The Met Lab also analyzed excretion data from subjects, and analyzed tissues taken at autopsies from subjects who died from preexisting ailments shortly after the injections.

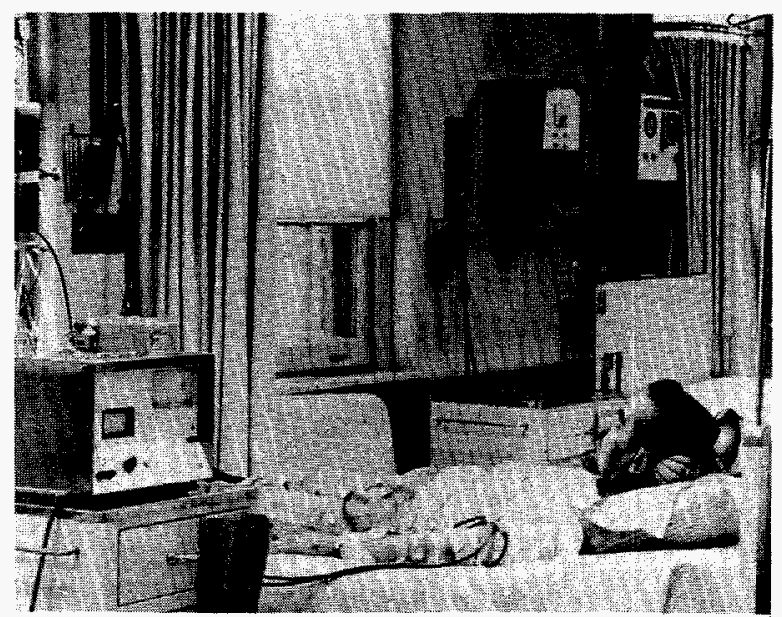

Figure 16. Clinical test of an artificial kidney developed by Argonne National Laboratory (circa 1970).

Met Lab scientists took part in another experiment to learn how best to measure plutonium: in 1946, six Met Lab employees volunteered to drink a solution containing a small amount of plutonium. The gastrointestinal absorption and fecal excretion rates of the ingested plutonium were then measured.

The Laboratory appears to have conducted few other clinical experiments. Known experiments include late 1940s studies involving radioactive phosphorus tracers to study human metabolism and radioactive arsenic to treat cancer. During the 1950s, ANL administered radioactive sodium to subjects. In the early 1960s, laboratory scientists prepared tritiated thymidine for collaborating scientists who used it to inject hospitalized cancer patients. The Laboratory also worked with staff at the separate Argonne Cancer 
Research Hospital (as described later in the University of Chicago narrative).

The primary ANL human research project focused on the adverse health effects of radium deposited in the bodies of pre-war radium dial painters. This research involved medical, epidemiological, and dosimetric follow-up studies. These estimated the radiation doses received by the dial painters and linked these doses to adverse health effects, providing data crucial to the establishment of internal radiation occupational exposure limits.

Argonne has valuable records collections documenting activities pertinent to human radiation experiments.

Argonne moved beyond the radium studies and became involved in follow-up examinations of the survivors of the plutonium injection experiments. When Patricia Durbin learned in the late 1960s that four of the subjects injected with plutonium were still alive, she urged the AEC to do follow-up examinations. The Center for Human Radiobiology was authorized by the AEC to initiate the follow-up studies in 1973. In accordance with instructions from AEC Headquarters, the subjects were not initially informed of the true reason for the examinations. These events are described more fully below in the discussion of the plutonium injections.

\section{Site Records Collections}

Argonne has valuable records collections documenting activities pertinent to human radiation experiments. Although the laboratory has transferred one older collection of records to the National Archives and Records Administration, it retains many original records, some of which date from the Metallurgical Laboratory. The laboratory has some intellectual control over them, and users will have an easier time here than at some other sites. The Center for Human Radiobiology has the richest collections, containing detailed documentation on the effects of radiation on radium dial painters and other groups exposed to radiation outside the laboratory. These collections also document evolving biomedical knowledge about the health effects of radiation.

Researchers will find some Argonne records, including a large collection of laboratory notebooks, classified. Other restrictions may also apply. Many notebooks dating from the Met Lab, for example, are contaminated with radioactivity and must be copied before use. As noted, a collection of older, classified Argonne records has been transferred to the National Archives in College Park, MD. Researchers must await its declassification before these records are openly available. 


\section{Argonne National Laboratory}

SERIES TTLE Laboratory Director's Flles

INCLUSIVE DATES ca. 1950-ca. 1990

ARRANGEMENT Subject

VOLUME 80 cubic feet

DESCRIPTION This series consists of records held in storage for the Office of the Director and documents the range of activities in which the Laboratory has been involved such as reactor development and high-energy physics research. The records include files related to human health research such as information on the development of an artificial kidney and files related to the Institutional Review Board. The series contains administrative records and correspondence files, reviews, and reports.

RESTRICTIONS This series contains privacy material.

LOCATION OF Argonne National Laboratory

RECORDS Records Holding Center, Building 4

Argonne, IL 60439

Federal Records Center

7358 South Pulaski

Chicago, IL 60629

SERIES TIILE Wealh ETrects of Expos Sure to Internally Deposited Radroactivity

INCLUSIVE DATES ca. 1915-ca. 1993

ARRANGEMENT Subject

VOLUME approximately 1,500 cubic feet

DESCRIPTION These records were created, identified, or collected by the staff of the Center for Human Radiobiology. They document efforts to locate persons with prior occupational, iatrogenic or experimental exposures to internally deposited radioactivity; the results of those efforts; and the results of dosimetric, medical, and epidemiological follow-up of the subjects over a period of years following first contact. The follow-up studies were focused primarily on radium, but included exposures to other radio elements and radioactive substances that emitted alpha particles. Among these were thorium, plutonium, americium, and thorotrast. This series is broken down into subseries according to the type of radioactivity involved or to distinguish the follow-up of a clearly defined experimental exposure from the follow-up of other radium exposure. The subseries are: Austin Brues; Occupational and latrogenic Exposure to Radium; Elgin State Hospital Follow-up of Experimental Exposure to Radium; Occupational Exposure to Thorium; and Other Radioelements and Circumstances of Exposure.

RESTRICTIONS This series contains privacy material.

LOCATION OF Argonne National Laboratory

RECORDS Environmental Research Division

Building 202, Room A354

Argonne, IL 60439 


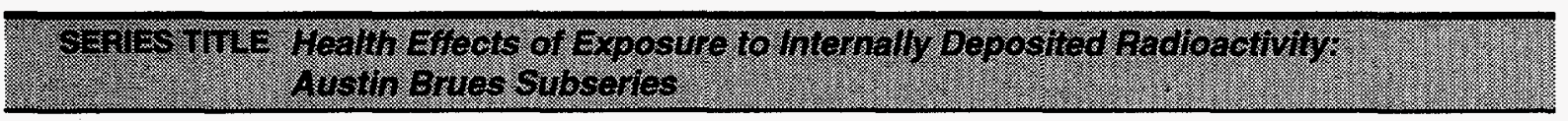

INCLUSIVE DATES 1943-1982

ARRANGEMENT Subject

VOLUME 3 cubic feet

DESCRIPTION This subseries contains materials assembled by Austin Brues during his tenure as director of the Argonne Biology Division and its successors, while he was a staff member of those divisions, as Medical Director of the Center for Human Radiobiology, and after his retirement. The subseries documents Brues's professional medical research interests and activities. It has material on the state of knowledge about the health effects of radiation and some material on the hazards of beryllium and plutonium. These records were maintained by Austin Brues and were incorporated into the collection of the Center for Human Radiobiology in the late 1980s and early 1990s because they document the activities of the early Argonne Laboratory and of the Center for Human Radiobiology. The subseries contains letters, memorandums, reports, professional papers, published articles, news clippings, graphics, and charts. It also includes correspondence with private physicians and with Manhattan Engineer District and Atomic Energy Commission officials. (See Miscellaneous Austin Brues Material.)

RESTRICTIONS This series contains privacy material.

LOCATION OF Argonne National Laboratory

RECORDS Environmental Research Division

Building 202, Room A354

Argonne, IL 60439 


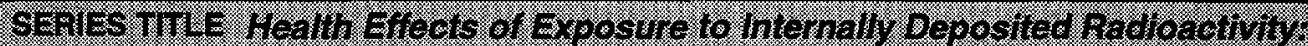

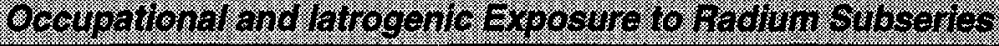

INCLUSIVE DATES 1915-1993

ARRANGEMENT Subject Numerical (case files)

VOLUME approximately 1,470 cubic feet

DESCRIPTION These records were created or collected by the staff of the Center for Human Radiobiology. They document efforts to locate persons with prior occupational or iatrogenic exposure to radium including the study of the radium dial painters. They include records of these follow-up efforts including notes and correspondence; records of medical examinations of subjects conducted by physicians employed by the Center for Human Radiobiology; other medical records released by the subjects to the Center; records of medical tests carried out on the subjects (e.g., blood chemistry, diagnostic radiography, bone densitometry); records of the measurement of radioactivity in the bodies of the subjects; records of the measurement of radioactivity in tissues of the subjects (e.g., teeth supplied by the subjects, or if the subject was examined after death, of bone samples and soft tissue); records of the measurement of radioactivity in the urine or feces of subjects; records of request for the willing of the body for scientific study after death and of consent for those subjects who granted permission; records of request for exhumation of (long) dead subjects and of consent by next-of-kin who granted permission; records of consent of living subjects to participate in the study; budget proposals to DOE; materials prepared for presentation to review committees and comments received from them; published papers; records compiled by employers such as personnel records and workplace radiation surveys; $x$-ray films from diagnostic $x$-ray examination; raw data from analytical procedures; various schedules; and other pertinent information.

RESTRICTIONS This series contains privacy material.

LOCATION OF Argonne National Laboratory

RECORDS Environmental Research Division

Building 202, Room A354

Argonne, IL 60439 


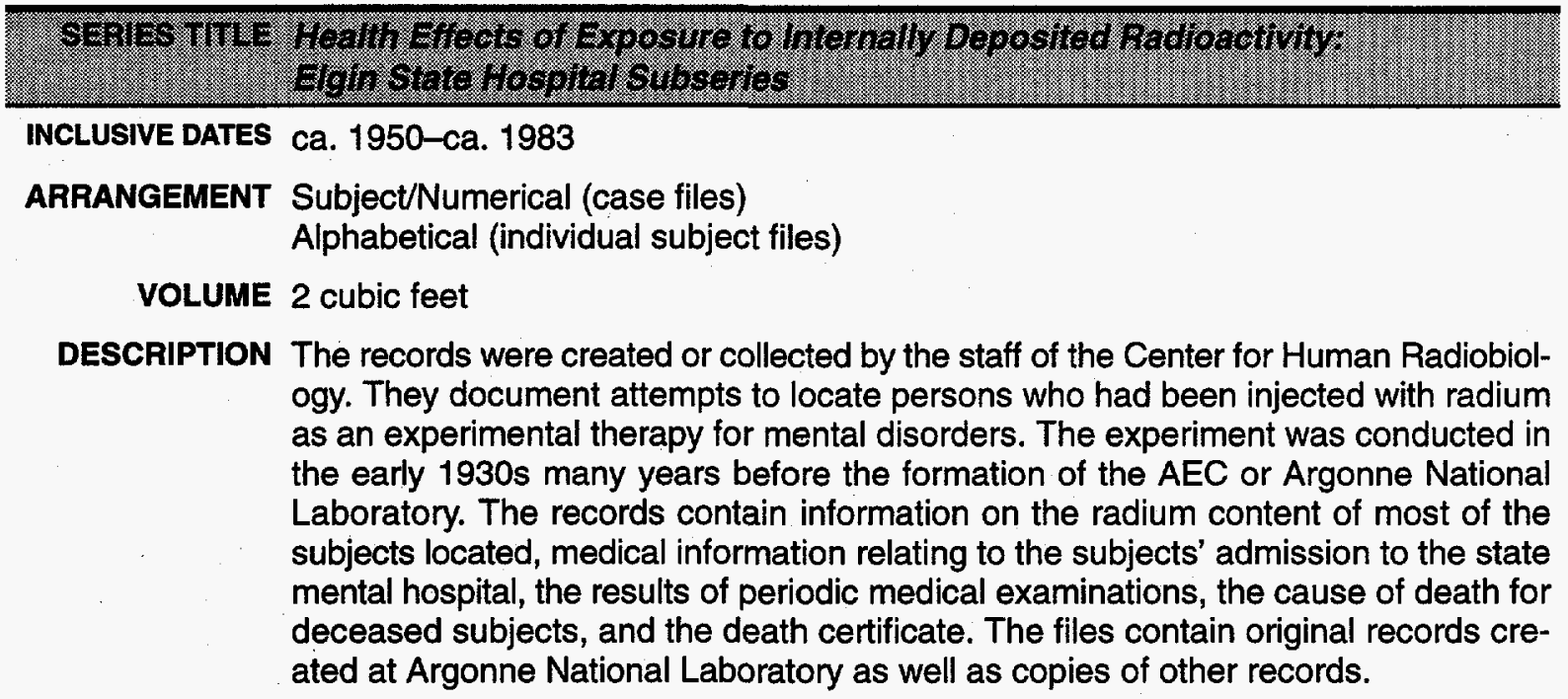

RESTRICTIONS This series contains privacy material.

LOCATION OF Argonne National Laboratory

RECORDS Environmental Research Division

Building 202, Room A354

Argonne, IL 60439

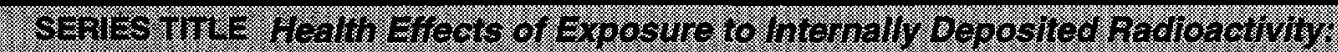
occupational Exposure to Thomin Subsetles

INCLUSIVE DATES ca. 1935-ca. 1985

ARRANGEMENT Subject

Numerical (case files)

VOLUME approximately 20 cubic feet

DESCRIPTION These records contain information on the follow-up study of thorium deposited in humans where exposure was incidental to thorium refining and gas mantle manufacturing operations. This work was funded by the Nuclear Regulatory Commission under the title "Health Effects of Industrial Exposure to Thorium." The efforts of the Center for Human Radiobiology were similar to those described in the subseries Occupational and latrogenic Exposure to Radium and consequently the types of records are similar. Some specific differences were the absence of a full skeletal diagnostic $x$-ray examination, the absence of bone densitometry, and the addition of lung function testing. (See Health Effects of Exposure to Internal Radioactivity: Occupational and latrogenic Exposure to Radium Subseries)
\end{abstract}

RESTRICTIONS This series contains privacy material.

LOCATION OF Argonne National Laboratory

RECORDS Environmental Research Division

Building 202, Room A354

Argonne, IL 60439 


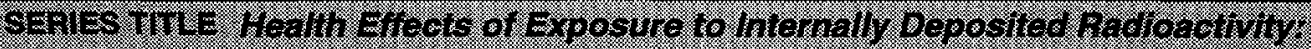

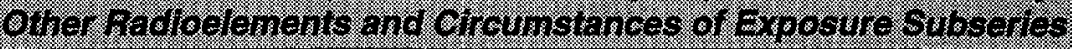

INCLUSIVE DATES ca. 1945-1985

ARRANGEMENT Subject

Numerical (case files)

VOLUME approximately 5 cubic feet

DESCRIPTION These records were created or collected by the staff of the Center for Human Radiobiology in the course of dosimetric work on persons exposed to a variety of radioactivity including incidental exposure, self employment, or medical procedures that involved use of a radiographic contrast medium called thorotrast. They include records of the measurement of radioactivity in the people and their excreta, plus any medical information that the subjects may have authorized for release to Argonne. Such radioelements and substances as protactinium, thorotrast, plutonium, americium, and strontium were among those included in this work. They also include any past records pertinent to the subject matter (e.g., the radioactivity associated with thorotrast).

RESTRICTIONS This series contains privacy material.

LOCATION OF Argonne National Laboratory

RECORDS Environmental Research Division

Building 202, Room A354

Argonne, IL 60439

INCLUSIVE DATES ca. 1989-ca. 1993

ARRANGEMENT Subject

VOLUME 5 cubic feet

DESCRIPTION This series consists of administrative records from the closing years of the Center for Human Radiobiology and document the management and closeout of the project during this period. The records include material transmitted to the Environmental Research Division when responsibility for the Center was transferred to that Division from the Division of Biological and Medical Research in 1991, as well as records generated thereafter.

RESTRICTIONS This series contains privacy material.

LOCATION OF Argonne National Laboratory

RECORDS Environmental Research Division

Building 203, ER Division Office

Argonne, IL 60439 
INCLUSIVE DATES ca. 1915-ca. 1993

ARRANGEMENT Subject

VOLUME 20 cubic feet

DESCRIPTION These are records stored in the Center for Human Radiobiology archives that are not covered by the other records series descriptions. They include miscellaneous administrative and scientific records: for example, two 1944 notebooks from the Metallurgical Laboratory provide log sheets of information on occupational radiation exposure and data on personnel measurements made such as blood samples drawn from the employees to monitor blood reactions to the radiation environment. The records also include extensive information on a study of lung cancer mortality in the state of Pennsylvania, carried out by the Center in the late 1980 s for the Department of Energy.

RESTRICTIONS This series contains privacy material.

LOCATION OF Argonne National Laboratory

RECORDS Environmental Research Division

Building 202, Room A354

Argonne, IL 60439

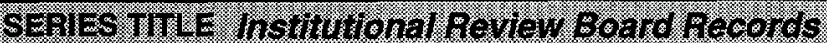

INCLUSIVE DATES 1971-present

ARRANGEMENT Chronological (Legal Dept.)

Subject (Medical Dept.)

VOLUME approximately 3 cubic feet

DESCRIPTION This series consists of the records of the Argonne Institutional Review Board. Two sets of records are maintained, one by the Committee Secretary for the Legal Department and the other by the Committee Chairman for the Medical Department. The records contain minutes of meetings; correspondence between members; memos; letters confirming the appointment of the Chairman and members; materials submitted to the Committee for review; and a variety of other information considered pertinent to the interests or functioning of the Committee. The records include brief information on all research projects submitted to the IRB for review. These projects have been funded by a variety of sources, including the Department of Energy and its predecessors, the National Institutes of Health, the Nuclear Regulatory Commission, the Veterans Administration, and the International Atomic Energy Agency.

RESTRICTIONS This series contains privacy material.

LOCATION OF Argonne National Laboratory

RECORDS Legal Department, Building 201, Second Floor

Medical Department, Building 201, First Floor

Argonne, IL 60439 
INCLUSIVE DATES ca. 1970-ca. 1992

ARRANGEMENT Subject

VOLUME approximately 0.3 cubic foot

DESCRIPTION Consist of administrative documents, progress reports, grant proposals, award recommendations, publication reprints, and miscellaneous research records of work carried out in the nuclear medicine program. The records have information that helps to define the scope of the nuclear medicine program and the significant collaborations with medical institutions who conducted human subject experiments with materials produced at Argonne.

RESTRICTIONS This series contains privacy material.

LOCATION OF Argonne National Laboratory

RECORDS Chemistry Division

Office Building 200

Argonne, IL 60439

INCLUSIVE DATES ca. 1892-ca. 1982

ARRANGEMENT Subject (correspondence files) Author (reprints)

VOLUME 40 cubic feet

DESCRIPTION These are records created and collected by Austin Brues during his lifetime. Brues was the first director of the Argonne National Laboratory Biology Division and a member of the Metallurgical Laboratory staff. They are the residuum of a larger collection that was reviewed by members of the Center for Human Radiobiology in the late 1980 s and early 1990s. The staff of the Center selected items for integration into its own collection and destroyed others that were considered irrelevant. This series includes correspondence files containing letters, memorandums, notes, trip reports, and lectures. The series also includes an extensive collection of journal article reprints related to Brues' professional interests in the health effects of radiation and biology, laboratory notebooks, slides, and photographs. A folder title listing is available to this series. (See Health Effects of Internally Deposited Radioactivity: Austin Brues Subseries.)

LOCATION OF Argonne National Laboratory

RECORDS Environmental Research Division

Building 202, Room A354

Argonne, IL 60439 
INCLUSIVE DATES ca. 1985-ca. 1992

ARRANGEMENT Subject

VOLUME 6 cubic feet

DESCRIPTION This series contains information about the measurement of lead in vivo by an external irradiation method. The concentration of lead in bone of the tibia was measured in $\mathbf{5 1}$ military personnel by directing an external beam of $x$ rays at the leg and measuring the scattered radiation. The work was part of a study to evaluate the effects of lead exposure among artillerymen when firing weapons, sponsored by the U.S. Army Research and Development Command. The study and its results are described more fully in a report entitled Lead Exposures and Biological Response Among U.S. Army Artillerymen, released by the Army Medical Research and Development Command. Included in this series are administrative, research, data, analysis, and reporting records.

RESTRICTIONS This series contains privacy material.

LOCATION OF Argonne National Laboratory

RECORDS Center for Mechanistic Biology and Biotechnology

Building 202, Room B273

Argonne, IL 60439

\section{SERES TTLE Metab.olsm and Dosimetry or hadon}

\section{INCLUSIVE DATES 1982}

ARRANGEMENT Subject

VOLUME approximately 0.3 cubic foot

DESCRIPTION This series contains administrative and research records, including data, from a pilot study done by Argonne in response to growing awareness that radon contributed more to natural background radiation than had been recognized. There was speculation that radon daughters might contribute to the risk of certain illnesses but little was known about radon's distribution or retention in the body. Six employees of the Center for Human Radiobiology stayed overnight in the home of a coworker where mildly elevated levels of radon gas had been found. They were then measured for radon content and exhalation rate at Argonne.

RESTRICTIONS This series contains privacy material.

LOCATION OF Argonne National Laboratory

RECORDS Environmental Research Division

Building 202, Room A354

Argonne, IL 60439 


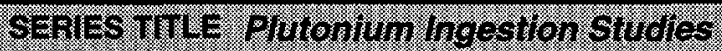

INCLUSIVE DATES 1946

ARRANGEMENT Alphabetical by name of employee (radiation protection records) Subject and chronological (committee files)

VOLUME approximately 0.3 cubic foot

DESCRIPTION These records consist of occupational radiation exposure data and a Metallurgical Laboratory internal memo describing the research and its context, and presenting results. The records provide information on a human radiation experiment involving the ingestion of a plutonium containing solution by six employees of the Metallurgical Laboratory on May 13, 1946.

RESTRICTIONS This series contains privacy material.

LOCATION OF Argonne National Laboratory

RECORDS Environment, Safety and Health Division, Building 201

Argonne, IL 60439
Argonne National Laboratory

Records Holding Center, Building 4

Argonne, IL 60439

\section{SERIES TITL Radlation Protechon hecords}

INCLUSIVE DATES

ca. 1945-present

ARRANGEMENT (See subseries descriptions)

VOLUME approximately 155 cubic feet

DESCRIPTION The records in this series are from the radiation protection program of Argonne, and to some extent, of the Metallurgical Laboratory. The series consists of four subseries: Bioassay, Internal Dosimetry, Personnel Monitoring, and Administrative.

RESTRICTIONS This series contains privacy material.

LOCATION OF Argonne National Laboratory

RECORDS Argonne, IL 60439 
SERIES TILE Radibton Protection Records: Broassay Subsertes

INCLUSIVE DATES ca. 1945-ca. 1987

ARRANGEMENT Chronological (logbooks)

Alphabetical by name (cards)

VOLUME 20 cubic feet

DESCRIPTION These records consist of approximately 80 logbooks from the bioassay programs of the Metallurgical Laboratory and Argonne National Laboratory plus record cards which summarize the data in the logbooks. These records give the type and amount of radioactivity in biological samples from the employees and other persons for which sample analyses were requested, as part of the radiation protection or assay programs of the Met Lab, Argonne, or the requesting institution. The logbook entries identify the sample type; the person submitting it; the type of radioactivity, radioisotope, or radioelement for which the radiochemical analysis is being carried out; and raw data on the results of measurements made. There may be some brief explanatory information on the reason for the analysis, and codes were generally used to distinguish routine, special request, repeat samples, etc., from one another. Notebook Number 1, also marked as Metallurgical Laboratory Notebook 596C, contains the data for the plutonium ingestion experiment that was initiated May 13,1946, at the Metallurgical Laboratory. The notebooks also contain information on exposures to employees that occurred through routine and accidental operations. It is unknown whether the notebooks provide analyses for samples, other than those already noted, that are from subjects in human experiments. The summary record cards provide duplicate information on the May 13, 1946, experiment and other samples.

RESTRICTIONS This series contains privacy material.

LOCATION OF Argonne National Laboratory

RECORDS Records Holding Center, Building 4

Argonne, IL 60439

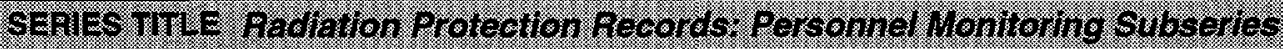

INCLUSIVE DATES ca. 1945-present

ARRANGEMENT Alphabetical by name

VOLUME 50 cubic feet

DESCRIPTION This series consists of exposure records for employees who were issued personnel monitoring badges for the measurement of external radiation exposure.

RESTRICTIONS This series contains privacy material.

LOCATION OF Argonne National Laboratory

RECORDS Environment, Safety and Health Division

Personnel Monitoring Group

Building 202, R Wing

Argonne, IL 60439 
ARRANGEMENT Subject

VOLUME 60 cubic feet

DESCRIPTION These are administrative records of the radiation protection program at Argonne. They consist of routine reports, review documents, and correspondence. These records contain information about research activities that involved radiation, as seen from the perspective of the radiation protection staff who provided support through the issuance of personnel dosimetry badges, review of designs, follow-up on accidents that occurred, etc.

RESTRICTIONS This series contains privacy material.

LOCATION OF Argonne National Laboratory

RECORDS Argonne Records Holding Center, Building 4 Argonne, IL 60439

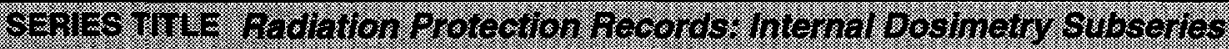

INCLUSIVE DATES ca. 1950-present

ARRANGEMENT Chronological (correspondence and subject files)

Alphabetical (individual exposures)

VOLUME approximately 25 cubic feet

DESCRIPTION This series consists of records of the occupational internal dosimetry program at Argonne National Laboratory, excluding the bioassay records in the Bioassay Subseries. The records include computer listings of data, subject matter files on accidental radiation exposures, records of exposure for individual employees by name, correspondence, etc. The records include dose values for employees who were subjects in the National Cancer Institute supported study of dose interactions between passive smoke and radon gas. It is unknown whether the records contain information on other studies in which employees participated as subjects.

RESTRICTIONS This series contains privacy material.

LOCATION OF Argonne National Laboratory

RECORDS Environment, Safety and Health Division

Dosimetry and Analytical Services Section

Building 200, F Wing

Argonne, IL 60439 


\section{SERIES TILE hadon and Passve smoking}

INCLUSIVE DATES 1985-1990

ARRANGEMENT None

VOLUME approximately 5 cubic feet

DESCRIPTION This series consists of administrative and research records, including data, relating to the exposure of human subjects to radon daughter products in an exposure chamber. A proposal was made and funded by the National Cancer Institute to study the possible modification of radon daughter exposure at home from passive smoking. In order to interpret data collected by body counting in the field, it was necessary to establish a method for distinguishing between radon daughter products deposited in the lungs and those deposited on the skin and clothing. To do so, Argonne employees were exposed in a chamber containing radon gas and daughter products and then measured in a whole body counter to determine radon daughter uptake. In some cases subjects breathed air free of radon and radon daughter products; in others they breathed air in the room. By combining different exposure regimes it was possible to gain understanding of the division of radon daughter product activity between the clothing, skin, and lungs.

RESTRICTIONS This series contains privacy material.

LOCATION OF Argonne National Laboratory

RECORDS Environmental Research Division

Building 202, Room A354

Argonne, IL 60439

\section{SERIES MTLE $A$ ML Techmical herorts}

INCLUSIVE DATES 1946-present

ARRANGEMENT Alphanumeric by report number

VOLUME 208 cubic feet

DESCRIPTION This series consists of scientific and technical reports created by ANL employees and their subcontractors to fulfill contractual requirements. These records document research and development performed by or for ANL. They include topical, progress (quarterly, semiannual, and annual), final, administrative, and special-interest reports, and conference proceedings. Progress reports of divisions that conducted biomedical, human health, and environmental research are part of this series. Copies of most of these reports are also available from DOE's Office of Scientific and Technical Information (OSTI). These reports provide descriptions of work that was completed or in progress during the reporting period and include progress reports issued by the Center for Human Radiobiology on the follow-up of humans exposed to radioactivity. Some classified technical reports exist at the Laboratory and are maintained separately.

RESTRICTIONS This series contains privacy material.

LOCATION OF Argonne National Laboratory

RECORDS Technical Information Services Department

Building 316, Room A136

Argonne, IL 60439 


\section{SERIES TTLE WML Technical Wo tebooks}

INCLUSIVE DATES 1943-present

ARRANGEMENT Alphanumeric

VOLUME 294 cubic feet

DESCRIPTION This series consists of technical notebooks issued by Argonne National Laboratory and its predecessor, the Metallurgical Laboratory, to employees and contractors to record experimental procedures and data; scientific and technical ideas and concepts; lecture and seminar notes; and other information. Also included are several logbooks which, in addition to use as finding aids for the technical notebooks, provide information on the history of the notebooks, (e.g., when issued, names of users, when returned, when declassified, and other information). The logbooks provide information on the organizational structure of the Metallurgical Laboratory. These records occasionally identify subjects or hospital patients. They were the working documents of the holders and therefore describe what projects they were working on, and what they thought important. For example, a notebook of R.S. Stone contains mention of the need to gain information on plutonium metabolism from humans, and seems to anticipate the plutonium injection experiments that were carried out at various locations during 1945-1947. Some classified laboratory notebooks exist and are maintained separately.

RESTRICTIONS This series contains privacy material; some notebooks have radioactive contamination.

LOCATION OF Argonne National Laboratory

RECORDS Technical Information Services Department

Information and Publishing Division

Building 316, Room A136

Argonne, IL 60439

\section{SERIEG TITLE Argonne NeWs}

INCLUSIVE DATES 1951-present

ARRANGEMENT Chronological

VOLUME 5 cubic feet

DESCRIPTION This series consists of a complete set of the Argonne News, a periodic news publication of Argonne National Laboratory. Argonne News prints articles on research conducted at the Laboratory, articles on Argonne history, and articles on general subjects of human interest. Some articles discuss the work of investigators known to have been engaged in human subjects research, such as an article describing a visit of Marshallese islanders to Argonne for whole body counting.

LOCATION OF Argonne National Laboratory

RECORDS Office of Public Affairs

Building 201, Second Floor

Argonne, IL 60439 


\section{The Site Today}

BROOKHAVEN NATIONAL LABORATORY (BNL) is a multiprogram research laboratory owned by DOE and located on 5,300 acres on Long Island near Upton, NY. The laboratory is managed and operated by a consortium of universities known as Associated Universities, Inc., (AUI) under contract with DOE. Approximately 3,300 employees work at BNL along with over 4,000 annual visiting researchers. With an annual budget of about $\$ 400$ million, the Laboratory conducts basic and applied research in the physical, biomedical, and environmental sciences, as well as in selected energy technologies.

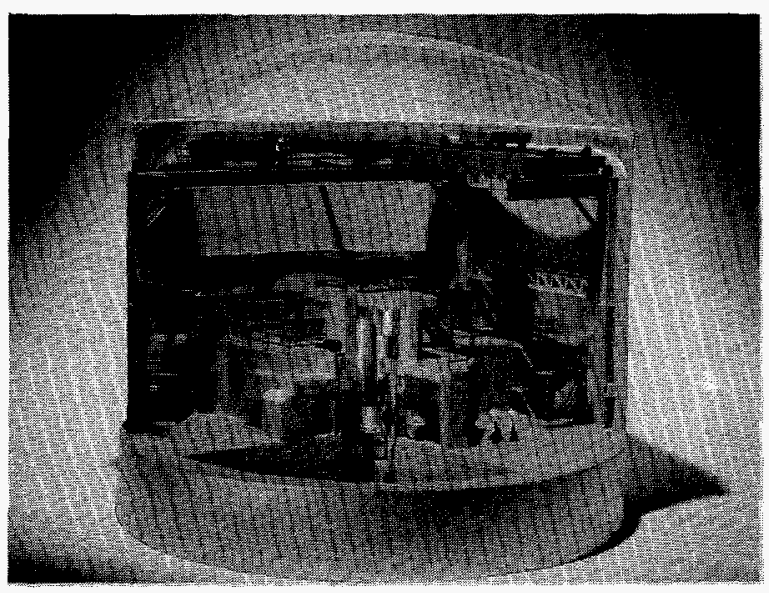

Figure 17. A subscale model of the nuclear reactor used for medical research and treatment at Brookhaven National Laboratory.

Brookhaven was unburdened with the secrecy restrictions placed on many facilities with wartime legacies.

Brookhaven is the location of several "big machines." The Alternating Gradient Synchrotron is a particle accelerator used to probe the essential structure of matter. A High Flux Beam Reactor produces neutron beams for use in various research efforts. The National Synchrotron Light Source is the world's largest facility for scientific research using imaging $x$-ray, ultraviolet, and infrared radiation. A Scanning Transmission Electron Microscope permits detailed study of atomic structures. A Relativistic Heavy lon Collider, opening shortly, will accelerate ions to the speed necessary to simulate conditions involved in the creation of the universe.

\section{Site History}

AUI proposed the creation of Brookhaven in 1946 as a laboratory to facilitate cooperation between universities and the Federal government in performing research in physics and nuclear science. Camp Upton, an Army training center and rehabilitation hospital, was selected as the site. In 1947, the AEC negotiated a contract with AUI to operate the Laboratory. Brookhaven was one of the first facilities dedicated to nuclear research in peacetime. As a result, it was unburdened with

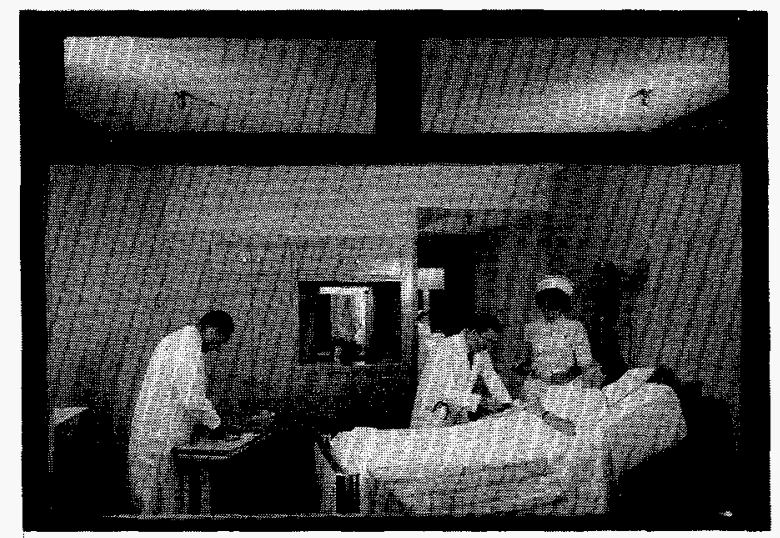

Figure 18. A patient receiving treatment at Brookhaven Medical Department Hospital (circa 1961).

the secrecy restrictions placed on many facilities with wartime legacies.

Brookhaven's Graphite Research Reactor, which opened in 1950, was one of the world's first nuclear reactors available for nondefense research. Two years later, the Cosmotron began operation, eventually becoming the first particle accelerator to achieve one billion electron volts. A Tandem Van de Graaff electrostatic accelerator also was built and used to study the mechanics of nuclear reactions and the structural compounds of nuclei. The Alternating Gradient Synchrotron began operations in 1960 and strongly influenced research that led to three Nobel Prizes in high-energy physics. 
Brookhaven researchers have also worked in various other fields. Laboratory chemists doing solar neutrino experiments during the 1960 s prompted reconsideration of stellar evolution theories. The laboratory has studied energy production and conservation, including the use of natural thermal storage in building construction. Brookhaven also conducts special materials research and has played an important role in nuclear reactor safety research.

Health and biology activities have been a continuing element of the Laboratory's program. During the 1960s, Brookhaven physician George Cotzias used the drug L-dopa to successfully treat Parkinson's disease. The medical department has monitored the health of Marshall Islanders exposed to radioactive fallout from the 1954 Castle-Bravo nuclear weapons test on the Bikini Atoll. Since then, Brookhaven physicians and health physicists have made annual trips to the islands to monitor the health of exposed persons.

\section{Site Human Radiation Experiments}

The Brookhaven Medical Department has performed much human research. As at other sites, the department's initial role was to provide occupational medical services. A major clinical research program began at Brookhaven in 1948, when Congress appropriated funds to the AEC specifically for cancer research.

A major clinical research program began at Brookhaven in 1948.

The first patients came to the Brookhaven hospital in 1949. From the outset, the Laboratory's Medical Department used the hospital for experimental diagnosis, treatment, and research.

One of the major experimental programs, begun in 1951, was boron neutron capture therapy (BNCT). Boron compounds were injected into patients with untreatable brain tumors, and the patients were positioned by a reactor port to receive neutron beams. Since boron attracts (or "captures") neutrons, it was hoped that the technique would allow larger doses of radiation to be applied to tumors without damaging healthy tissue. The treatment was not successful and the clinical program ended in 1961 after treating 45 patients. Changes in technology have recently led to renewed interest in $\mathrm{BNCT}$. In September 1994, a Brookhaven research facility closed to patients for over 2 decades was recommissioned and a modified version of the technique was used on one patient under an approved protocol.

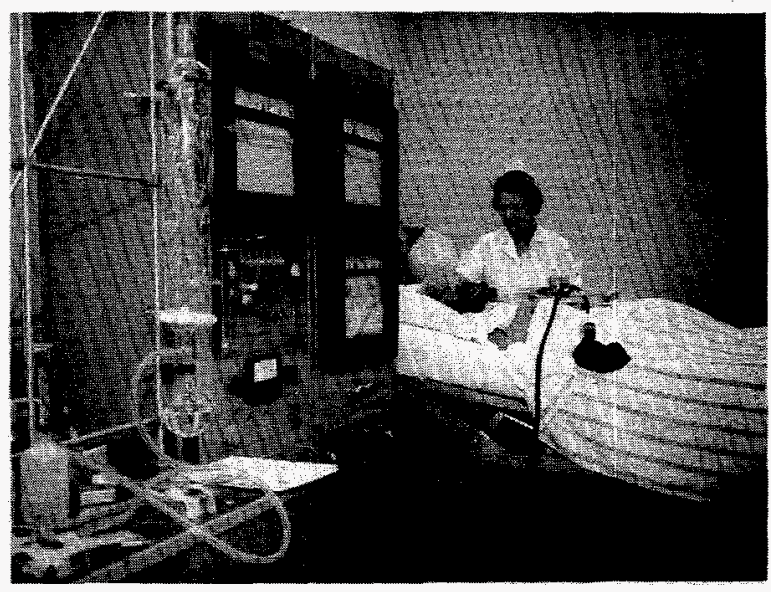

Figure 19. Study of carbohydrate-lipid metabolism at Brookhaven.

Some of the first Brookhaven patients participated in studies involving the use of iodine-131. From 1949 through 1961, researchers used iodine-131 to treat cancer and Graves' Disease; in tracer doses for in vivo thyroid counting; and as a label for serum albumin to detect blood plasma turnover rates. Brookhaven researchers also used carbon-14 to study metabolic pathways and the interrelationships of carbohydrate and fat metabolism with glucose oxidation. Most of the laboratory's studies had a link to cancer research.

The Medical Department has also worked in areas other than cancer research. During the 1950s and 1960s, the department did diabetes research; other investigations focused upon the effect of radiation on humans, animals, and plants. Isotope tracers were given to Brookhaven hospital patients for metabolic studies. In the early 1950s, the department did experiments on children with a degenerative kidney disease by using sodium- 24 and radioiodinated human gamma globulin. The experiments were performed to study the effect of these radioactive agents on the kidney and kidney functions. Brookhaven has also used radioactive thymidine, a constituent of DNA that carries the genes, to measure the life span of various kinds of cells. Individual site experiments are detailed in Chapter 3. 


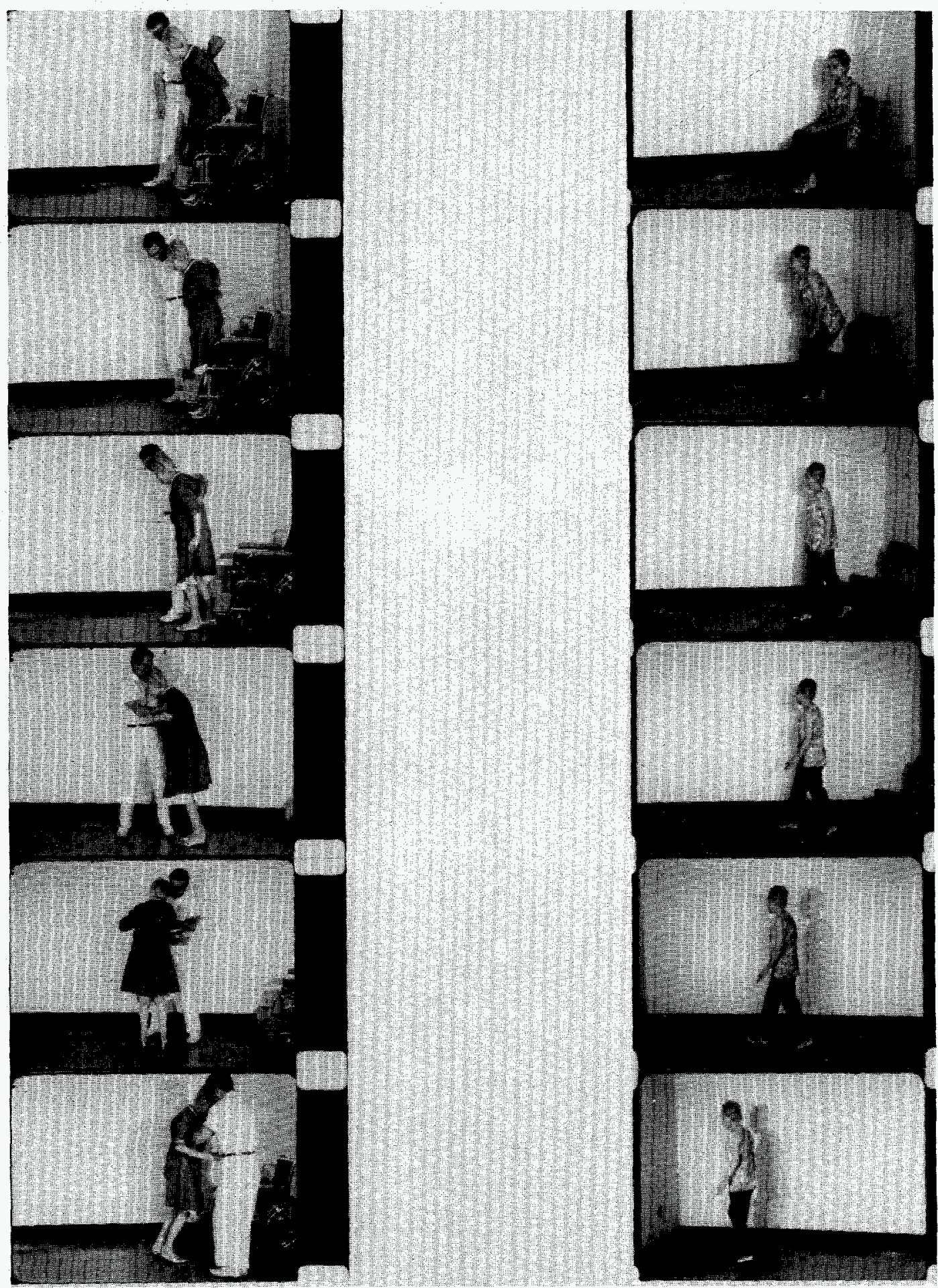

Figure 20. A parkinsonian patient before (/eft) and during administration of L-dopa at Brookhaven. Radioactive materials were useful in the development of L-dopa. 
The Brookhaven hospital closed in 1974, as did the two other AEC cancer research hospitals. Nonclinical biomedical research has continued, and currently includes studies of cancer, bone disease, and the effects of exposure to radiation and other energy-related agents. Major studies of brain structure and the processes associated with cocaine and alcohol addiction are also in progress.

\section{Site Records Collections}

Brookhaven has good documentation for its role in human radiation experiments. Most of these files are in the custody of the BNL Clinical Research Center. They include periodic reports of the Medical Research Center, minutes and agendas for clinical oversight committees, and Proposal and Authorization for Research or Development Forms (Form I89). Also extant are various indexes and listings documenting hospital treatments and research activities. Perhaps the most significant record series are those that cover study protocols and human subjects research policies.
There are, however, some gaps in the documentation. Few programmatic records exist for the boron-neutron capture therapy treatments at the facility during the 1950s and 1960s. A complete picture of site practices and polices for patient selection, informed consent, and experiment authorization is lacking. Moreover, Brookhaven has yet to bring its records fully under intellectual control through an effective records program. The records that have been found to date remain in laboratory custody and there are some limitations on access. 


\section{Brookhaven National Laboratory (BNL)}

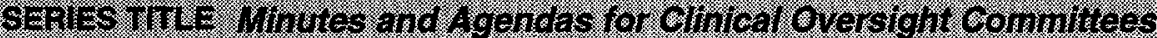

INCLUSIVE DATES 1952-1994

ARRANGEMENT Record type; chronologically thereunder

VOLUME 5 cubic feet

DESCRIPTION These are the minutes and agendas for clinical oversight committees, which include the Executive Committee, Governing Body, Medical Records Committee, Patient Care Committee, Infection Control Committee, Medical Staff Committee, and Medical Care Evaluation Committee. The Medical Records Committee spans the period between 1955 to 1968 . The sections are divided by year and each year contains: memorandums of committee membership; committee meeting minutes; and BNL Hospital Clinical and Statistical Summary Sheets which have sample forms, draft forms including one on Authorization for Release of Clinical Information, proposed rules and regulations, captions for isotope index cards, evaluation of patient laboratory forms, and samples of approved patient consent forms. The Governing Body records begin in 1957 and contain bylaws and minutes of the governing board of the medical research center hospital of BNL; memorandums; forms for initiation and review of the clinical investigative program; forms for administration of radioisotopes to humans; and draft medical records. The Medical Staff Committee operated from 1960 to 1974, and was superseded by the Executive Committee, which is documented by instructions for the operation of the hospital; bylaws, rules, and regulations for the medical staff; memorandums relating to compliance with the policies of accreditation associations, including the Federal regulations on health insurance for the aged. Medical Care Evaluation Committee records are from 1971 and contain information on patient care evaluations.

RESTRICTIONS This series contains privacy material.

LOCATION OF Brookhaven National Laboratory

RECORDS Clinical Research Center

Building 490

Upton, NY 11973 
SERIES TITL James hobertsor Flles

INCLUSIVE DATES ca. 1950-ca. 1974

ARRANGEMENT Record type
VOLUME 17 cubic feet
DESCRIPTION This material consists of records maint
tenure at BNL from 1950-1974. Robet
Division and, after leaving BNL, as head
tal Research in Washington, DC. Include
logical and subject files, as well as sever
files discuss various aspects of Rob
professional activities. Topics discussed
topes, operation of the BNL hospital, p
involvement with other projects and
Weapons Project. The patient data refer
son's disease patients, and growth horm
and observation logs and often contains
signs, and other indicators.
RESTRICTIONS This series contains privacy material.
LOCATION OF Brookhaven National Laboratory
RECORDS Clinical Research Center
Building 490
Upton, NY 11973

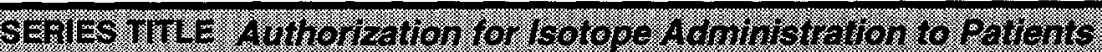

INCLUSIVE DATES 1957-1962

ARRANGEMENT · Alphabetical by patient

VOLUME 0.25 cubic foot

DESCRIPTION These forms pertain to patients receiving isotopes. There are a few handwritten memos dispersed throughout this series from physicians concerning the isotope administration forms. Each form contains personal information about the patient and other information including: diagnosis, expected longevity, reproductive status, BNL physician, and isotope to be administered. The forms also have an approval date and are signed by the chairman of the Medical Department. In addition, for some patients there are addenda to the request for authorization to use isotopes.

RESTRICTIONS This series contains privacy material.

LOCATION OF Brookhaven National Laboratory

RECORDS Clinical Research Center

Building 490

Upton, NY 11973 


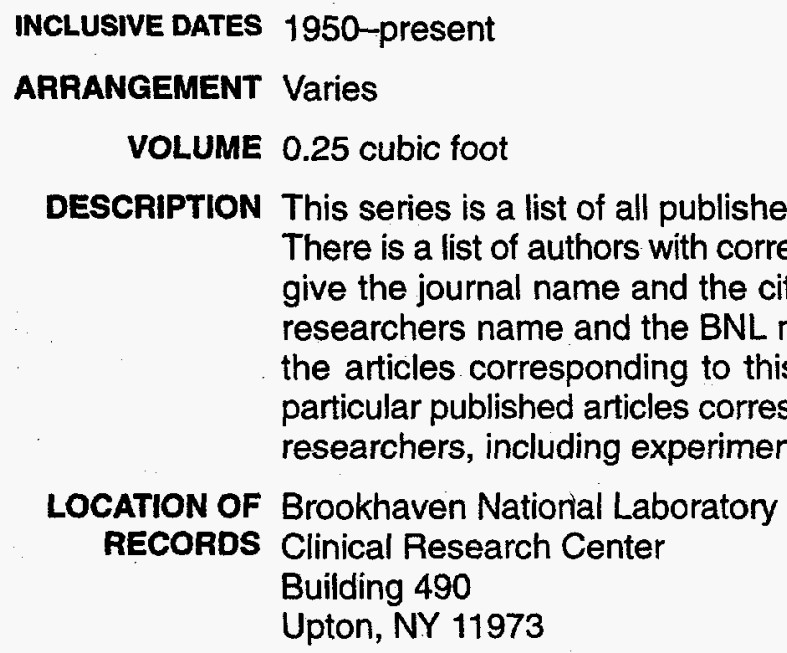

LOCATION OF Brookhaven National Laboratory

RECORDS Clinical Research Center

Building 490

Upton, NY 11973

DESCRIPTION This series is a list of all published articles by members of the Medical Department. There is a list of authors with corresponding BNL reprint numbers. Some of the pages give the journal name and the citation but most have only the title of the study, the researchers name and the BNL number. The BNL Clinical Research Center has all the articles corresponding to this list of publications. The list is an aid in locating particular published articles corresponding to any research activity conducted by BNL researchers, including experiments involving human subjects.

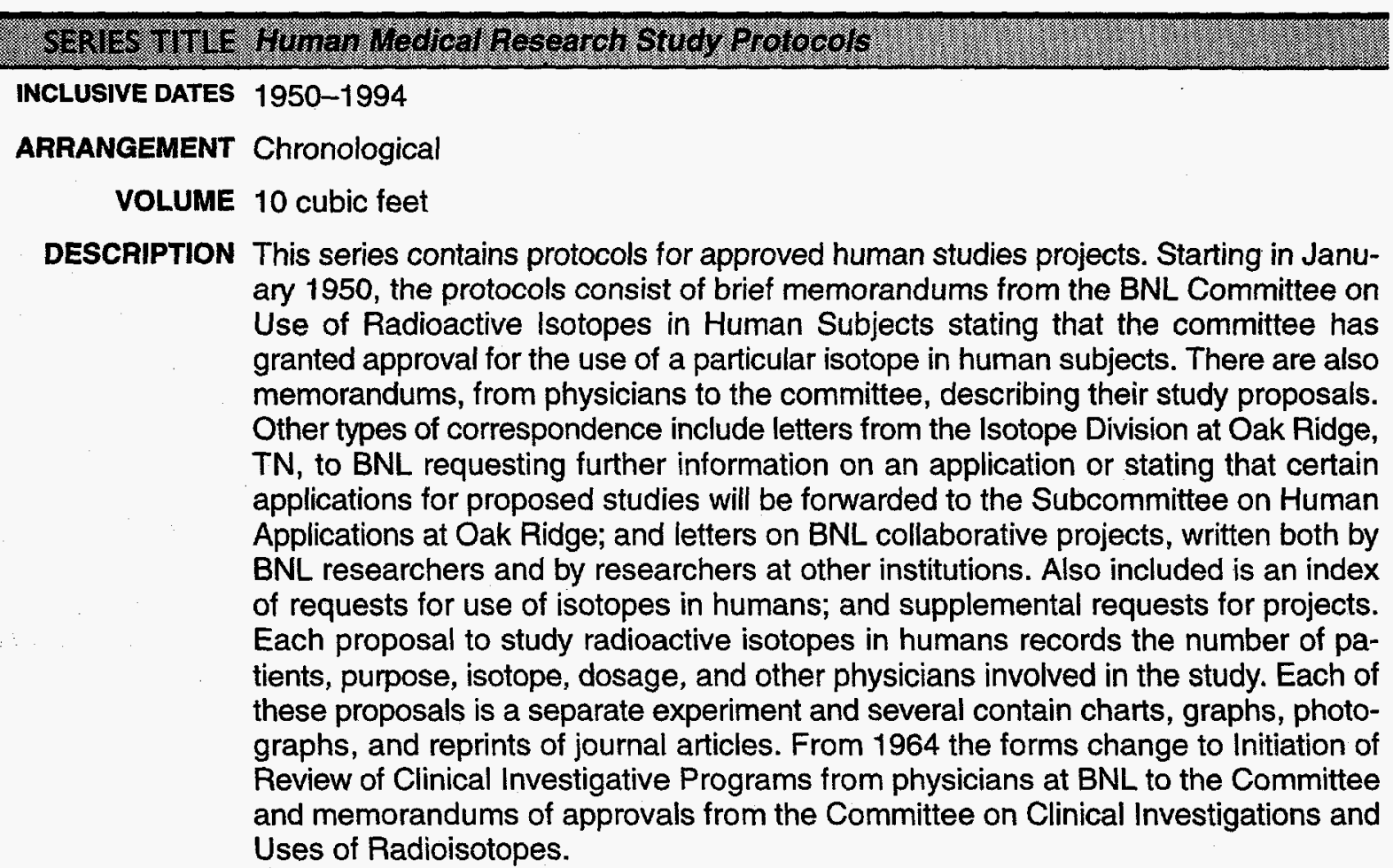

LOCATION OF Brookhaven National Laboratory

RECORDS Clinical Research Center

Building 490

Upton, NY 11973 


\section{SERIES TITLE fruman Subjects Research Pollictes}

INCLUSIVE DATES 1947-1963; 1970-1973

ARRANGEMENT Chronological

VOLUME 0.25 cubic foot

DESCRIPTION These records consist of two subgroups. The earlier group pertains to the implementation of human subjects research policies at the Brookhaven Medical Research Center. Included are minutes and agendas for medical staff meetings; AEC isotope circulars; correspondence with AEC program offices, including the Isotopes Branch and the Division of Biology and Medicine; and internal BNL memorandums. Subjects covered include policies regarding relations with local doctors, AEC policies for use of isotopes on human subjects; medical research programs; and establishment and operation of the local isotopes committee. The primary subject pertains to establishment of the Brookhaven Clinical Investigation Radioisotope Committee in compliance with Department of Health, Education, and Welfare requirements for institutional review of proposed human studies.

\section{LOCATION OF Brookhaven National Laboratory \\ RECORDS Clinical Research Center \\ Building 490 \\ Upton, NY 11973}

\section{SERIES TITLE Isotope hdex cards \\ INCLUSIVE DATES 1950-1957 \\ ARRANGEMENT Index type \\ VOLUME 0.25 cubic foot \\ DESCRIPTION This series consists of two indexes relating to BNL hospital patients. The first is a collection of 5 - by 9 -inch orange cards filed by isotope name (e.g., boron, carbon, iodine). Included is patient surname, unit number, sex, age, number of times adminis- tered, doctor, and general remarks. The second index is labeled "Log of Radioactive Administrations to Patients," and is filed chronologically by date of administration. Included is the name of patient, isotope, dose, and how administered (e.g., tracer, therapeutic, intraperitoneal, intravenous).}

RESTRICTIONS This series contains privacy material.

LOCATION OF Brookhaven National Laboratory

RECORDS Clinical Research Center

Building 490

Upton, NY 11973 


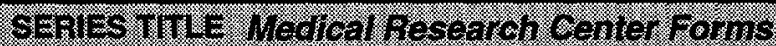

INCLUSIVE DATES 1949-present

ARRANGEMENT None

VOLUME 0.25 cubic foot

DESCRIPTION This series contains a variety of Medical Research Center forms. Most of these are blank. The forms include: hospital forms, medical record forms, dietary forms, pharmacy forms, industrial medicine forms, research forms, clinical chemistry forms, and microbiology forms. Other documents include charts; forms for progress notes; $x$-ray exam requests and reports; occupational therapy requests; nurses admission reports and notes; supply forms; temperature and pulse charts; adverse drug reactions; nuclear medicine examination requests; release of clinical information; applications for participation in a clinical research program; history and physical examination forms; discharge summaries; isotope radiation summaries; consent on admission to hospital forms; internal isotope radiation summaries; and consent for procedure, study, or drug under clinical investigation.

RESTRICTIONS This series contains privacy material.

LOCATION OF Brookhaven National Laboratory

RECORDS Clinical Research Center

Building 490

Upton, NY 11973

SERIES TTLE Ouarterly and Amulal heports of the Medical Research center

INCLUSIVE DATES 1948-1963

ARRANGEMENT Chronological

VOLUME 0.5 cubic foot

DESCRIPTION This series consists of three bound volumes of the quarterly and annual reports, which are medical, scientific and administrative progress reports of the Medical Research Center. Each report has a general introduction and then is divided into the divisions of the Medical Center. Divisions include Medical Practice, Division of Pathology, Hospital Division, Division of Bacteriology, Division of Biochemistry, Division of Physiology, Division of Industrial Medicine, Genetics, Division of Physiology, and the Division of Medical Physics. Not all of these divisions are represented in each progress report. Some progress reports also have the activities of the Associated Universities, a list of officers and scientific staff, list of publications and papers presented. Some progress reports contain organizational charts, discussions of advisory committees and major facilities. Each of the sections contains information on research, medical, and scientific activities. The sections contain information on animal and human experimentation.

LOCATION OF Brookhaven National Laboratory

RECORDS Clinical Research Center

Building 490

Upton, NY 11973 


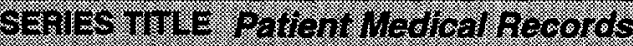

INCLUSIVE DATES 1949-1994

ARRANGEMENT Numeric

VOLUME approximately 370 cubic feet

DESCRIPTION Each patient treated at the Medical Research Center has a file containing medical records; there are about 13,000 individual files. The Medical Center treated a variety of cancers; mostly they specialized in brain tumors and thyroid carcinoma. The files contain personal information on the patient; the treating physician's notes, laboratory records, consent forms, medical follow-up notes, a list of the types of radiation the person was exposed to, hospital authorization forms, autopsy records, order forms, medication forms, photographs, charts, and graphs. Most files also contain a correspondence section that contains copies of letters between the medical staff and the patient, or, in the case of children, the patient's parents.

RESTRICTIONS This series contains privacy material.

LOCATION OF Brookhaven National Laboratory

RECORDS Clinical Research Center

Building 490

Upton, NY 11973

\section{SERES TITLE Physician holex Cards}

INCLUSIVE DATES 1949-1969

ARRANGEMENT Alphabetical by physician

VOLUME 0.25 cubic foot

DESCRIPTION Each card has the physician's name, the unit number, the patient's names, and treatment results. Posting to the cards was incomplete to $1 / 1 / 56$, but from $1 / 1 / 56$ to $12 / 31 / 65$ posting occurred on a regular basis. From 1965 to 1967 indexing was incomplete. Five additional categories of cards are also present. These categories cover diseases and each contains a few cards with patient information. Categories are asthma, bronchitis, granulomatous, fiberglass, small airways, emphysema, and deformities. These cards contain names and other patient information.

RESTRICTIONS This series contains privacy material.

LOCATION OF Brookhaven National Laboratory

RECORDS Clinical Research Center

Building 490

Upton, NY 11973 


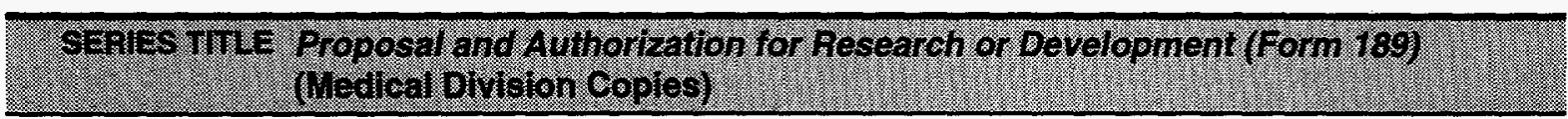

INCLUSIVE DATES 1950-ca. 1977

ARRANGEMENT Chronological

VOLUME 2 cubic feet

DESCRIPTION These forms were used by BNL (as well as other DOE contractors) to propose research projects and receive funding from $A E C / D O E$ program offices. Included for each project is title, date, contractor/laboratory, location, contract number, budget number, classification, progress reporting method, person in charge, status, purpose/need/scope (narrative description), related projects, accomplishments (ongoing project), expected results, and anticipated problems. Multiple forms for different years are present for ongoing projects.

LOCATION OF Brookhaven National Laboratory

RECORDS Clinical Research Center

Building 490

Upton, NY 11973 


\section{The Sites Today}

THE HANFORD RESERVATION OCcupies 560 square miles in southeastern Washington state. More than 18,000 people work at Hanford, and the site has an annual budget of more than $\$ 1$ billion. The DOE Richland Operations Office oversees several major contractors at Hanford: The Westinghouse Hanford Company provides operations and engineering services, the Hanford Environmental Health Foundation supplies occupational health services, and ICF Kaiser Hanford Company provides architect-engineer and construction services. Bechtel Hanford, Inc., is the site environmental remediation contractor. Waste management and environmental restoration are now the largest part of the site's activities.

Battelle Memorial Institute manages Pacific Northwest Laboratory (PNL), a DOE multiprogram National Laboratory. PNL employs more than 4,800 people, has an annual budget of over $\$ 500$ million, and supports energy, environmental, educational, and national security missions.

Formerly a remote agricultural area, Hanford accommodated 50,000 people at the height of construction.

\section{Site History}

Manhattan Project officials selected the Hanford reservation in 1943 for the production of plutonium. This required the construction of nuclear reactors ("piles"), plutonium separation facilities ("canyons"), fuel fabrication plants, and many associated facilities, including those required to house thousands of war workers. The site offered abundant water from the Columbia River, electrical power, and isolation. Consistent with the Manhattan Project's practice of employing private industry to construct and operate the atomic bomb development complex, E.I. du Pont de Nemours and Company constructed and operated the facility. Building began in 1943 and within 2 years an enormous complex was in place. Formerly a remote agricultural area, Hanford accommodated 50,000 people at the height of construction.
Waste management and environmental restoration are now the largest part of the site's activities.

Late in 1942, the MED viewed the reactor process as promising for production of fissionable material. In December, Enrico Fermi and his colleagues at the University of Chicago Metallurgical Laboratory achieved the first sustained nuclear chain reaction with a stacked pile of graphite and uranium. It was understood that largescale production would generate extensive heat, radioactivity, and toxic chemical waste. In part because of these hazards, a pilot production reactor was built at Oak Ridge rather than the more populated Chicago site. Du Pont's construction of the pilot, known as the $X-10$ reactor, began in early 1943.

Even before construction began on the $X-10$ reactor, the Government decided to locate fullscale production at a place even more remote

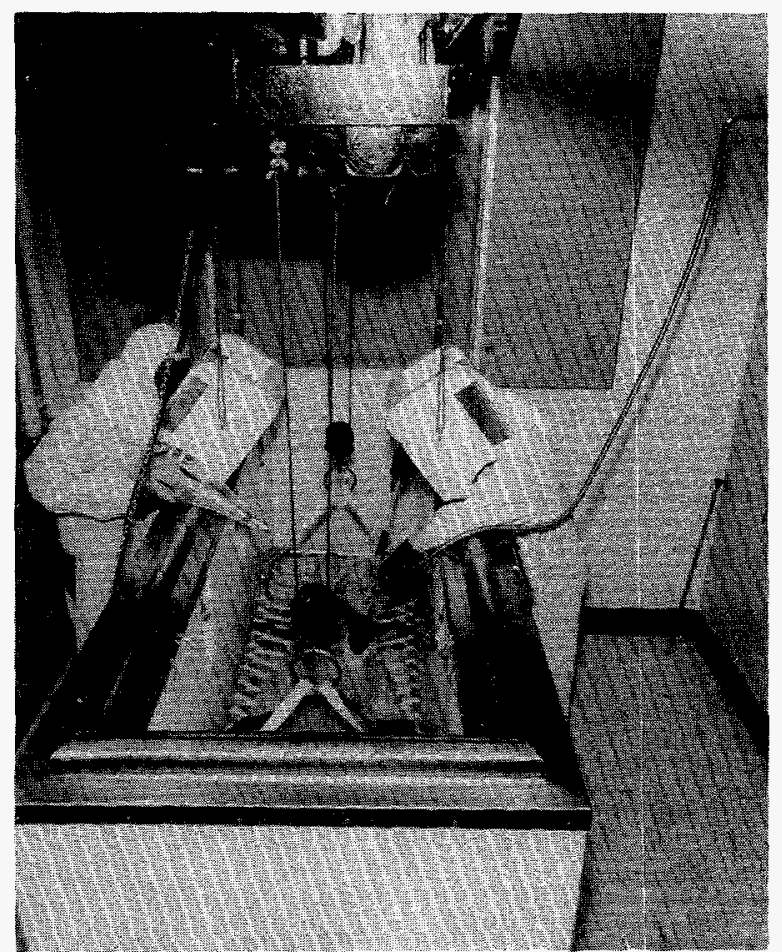

Figure 21. A facility at Hanford for treating persons injured by embedded radioactive particles (circa 1967). In this shielded operating cell, a mock patient is flanked by a surgeon (right) and a radiation monitor (left). 
than Oak Ridge: Hanford. Pressing to meet tight deadlines, du Pont was directed to begin work on the full-scale production facilities, known as the Hanford Engineering Works. By the end of 1944, the first Hanford reactor, the $B$ reactor, began operating. Chemical separation plants needed to extract plutonium from irradiated slugs were finished shortly afterward, and the site was operationally complete by early 1945. In a few months, Hanford had produced the plutonium for both the Alamagordo test device and the Nagasaki bomb.

During the war, du Pont established its own clinical and occupational medical programs, with the Manhattan Project Medical Section exercising only general supervision. In addition, du Pont conducted various kinds of research and development at Hanford. Substantial work went into programs to develop effective means of monitoring personnel for radiation exposure. This included the development of personnel dosimetry indicators (film badges, for example) and methods to interpret indicator data. Because operation of its facilities caused substantial radioactive emissions, Hanford also worked on stack and environmental monitoring programs. Environmental monitoring focused on the site environs, including the Columbia River.

It was understood that large-scale plutonium production would generate extensive heat, radioactivity, and toxic chemical waste.

After the war du Pont did not continue as prime Hanford contractor; General Electric acquired the managing and operating contract in 1946 and assumed responsibility for producing plutonium. The site also conducted a variety of research projects. Hanford Laboratories conducted research on the biological effects of radioactive material, using animals as experimental subjects. The laboratories also studied the effects of radioiodine, which was emitted as a waste product from the chemical separation process.

In 1949, Hanford initiated a tissue sampling program to analyze the deposition of plutonium in humans. Bone, liver, and lung tissue were obtained during autopsies and studied to learn the amount, origin, and effect of resident plutonium. This sampling program grew into the current U.S. Transuranium Registry, now administered by Washington State University. The registry studies the distribution, concentration, and retention of transuranic elements (elements heavier than uranium) in deceased workers with occupational plutonium exposures; participation is voluntary. During the early 1950s, Hanford conducted innovative inhalation toxicology studies and was the first to demonstrate the production of a lung tumor by plutonium in animal studies.

In December 1949, about 8,000 curies of radioactive iodine and about $20,000 \mathrm{cu}$ ries of radioactive xenon were intentionally released from a separation plant stack.

Nuclear weapons production releases and weapons testing raised biomedical questions and stimulated additional research at Hanford. In 1959, Hanford began feeding strontium- 90 to miniature swine and pygmy goats to study biological effects. Other studies focused on fetal and juvenile mammal metabolism and the effects of tritium on biological systems. This and related work led to the establishment of a radiotoxicology center and an ecology group at Pacific Northwest Laboratory during the 1960s. Hanford also used these and related organizations to study the fate of radionuclides in the environment.

In December 1949, about 8,000 curies of radioactive iodine and about 20,000 curies of radioactive xenon were intentionally released from a separation plant stack. The rationale for the release, undertaken shortly after the first Soviet atomic bomb test and known as the Green Run for its use of highly radioactive "green" fuel, was to obtain information for monitoring Soviet nuclear activities. (For more on this event and other Hanford intentional releases, see the narrative on Environmental Releases of Radiation, later in this chapter). Apart from the Green Run, radioactivity was routinely released into the environment as a by-product of processing activities. Filters and other emission reduction devices were installed during the late 1940s and early 
1950s, resulting in a marked decline in radioactive emissions from the site.

Hanford production facilities expanded from 1947 to 1953 to meet Cold War demands for more nuclear weapons. In the immediate postwar period, General Electric built five new production reactors at the site. Ultimately, nine production reactors were built along the Columbia River. During the 1960s, as the U.S. nuclear arsenal grew to formidable levels and the atmospheric test-ban treaty limited weapons testing, six of the Hanford reactors were closed. To promote civilian nuclear power and to help meet plutonium production needs, the AEC built the Hanford N Reactor to produce both plutonium and electricity.

The AEC took other initiatives to promote diversification at Hanford. In 1964, hoping to establish an economic base less dependent on weaponsrelated activities, the agency committed to use multiple contractors at the site. Battelle Memorial Institute of Columbus, $\mathrm{OH}$, was one of the first contractors selected. In 1965, Battelle contracted to run the Hanford Laboratories, newly designated as Pacific Northwest Laboratory. PNL soon began a design study for the Fast Flux Test Facility (FFTF) to test fuels and materials considered for use in fast breeder power reactors. Construction of the FFTF at Hanford began in 1970 and took 12 years to complete.

All of Hanford's production reactors and processing canyons have been shut down; today, most of the site's resources are devoted to managing the environmental legacy left by decades of plutonium production. The potential health consequences associated with the operation of the complex remains a serious concern among many who live, or have lived, near the site. As a result, Hanford is currently involved in several healthrelated activities, including:

- Hanford Environmental Dose Reconstruction Project (HEDR)-The U.S. Centers for Disease Control and Prevention, National Center for Environmental Health (NCEH), manages this study. The goal is to estimate the radiation doses from Hanford emissions to offsite populations. An independent Technical Steering Panel of scientists and public representatives directs the objectives and methodology of this study.
- Hanford Thyroid Disease Study-NCEH also manages this study, with the assistance of the Fred Hutchinson Cancer Research Center. The study's purpose is to determine the risk of thyroid disease among persons who were exposed to radioactive air emissions from the Hanford site between 1944 and 1957.

- Hanford Health Information NetworkWashington, Oregon, and Idaho state health agencies sponsor this project in collaboration with nine Indian nations. The Network distributes information about the known and potential health effects of exposure to radiation released from Hanford from 1944 to 1972. There are information and service centers in each state, a Tribal Service Program, and a resource center serving those who have moved from the region. The project operates a toll-free Hanford Health Information Line, connects people with referral resources, and is establishing a Hanford Health Information Archives to gather and preserve individual health histories and experiences.

All of Hanford's production reactors and processing canyons have been shut down; today, most of the site's resources are devoted to managing the environmental legacy left by decades of plutonium production.

\section{Site Human Radiation Experiments}

During the 1950s, human tritium absorption and radioiron studies were conducted at Hanford. The subjects of these experiments included site employees and medical patients. The controversy over nuclear fallout also stimulated work at Hanford, including studies of radionuclide metabolism and radiation health effects. Examples include research involving employee ingestion of iodine-131 in cow's milk. During the early 1960s, two employee volunteers were exposed to iodine- $|3|$ for measuring doses received through the air. 


\section{Site Records Collections}

The Hanford sites are complex and present a formidable records challenge. Diversification of operations has resulted in records in the custody of several different organizations. The Richland Operations Office has custody of many records kept by the site's Federal managers under the MED, AEC, ERDA, and DOE. In addition, the Operations Office has custody of du Pont, General Electric, and Hanford Environmental Health Foundation records.

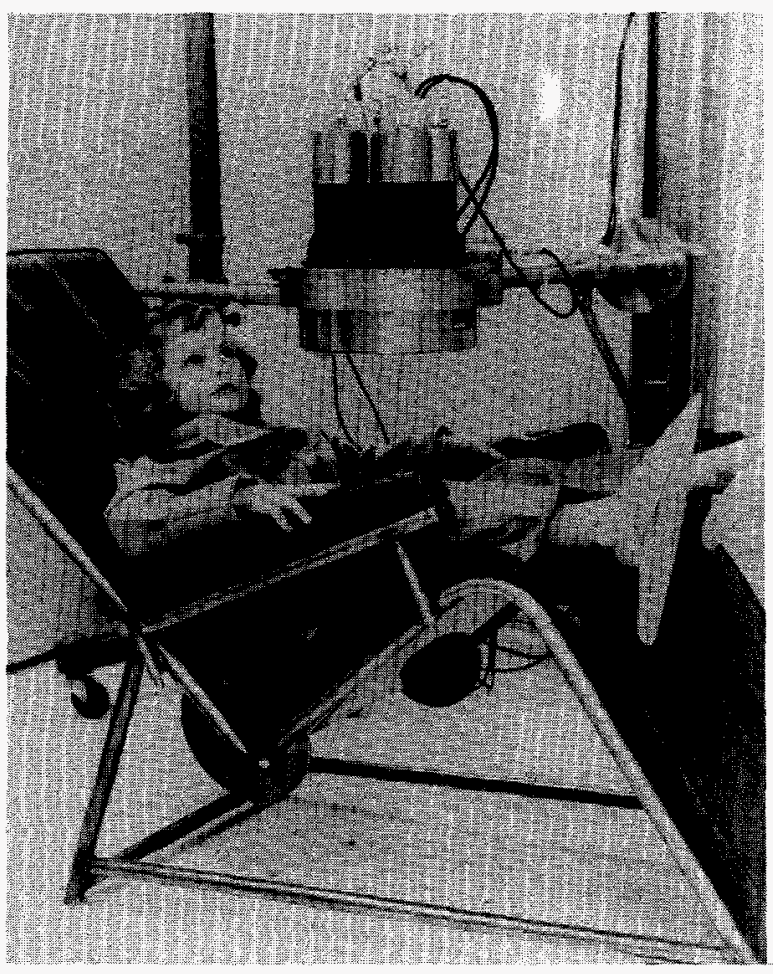

Figure 22. A Richland, WA, child participating in a program to measure radiation typically present in the body. This 1960 s project took place at Pacific Northwest Laboratory.

The Operations Office now controls its records through a box-level electronic database (known as the Records Holding Area Management Information System, or MIS). While this system is potentially useful for research, it does not use the records series concept. Thus, in contrast to the situation at most DOE sites, identifying bodies of records associated with specific functions or organizations is difficult. Reconstructing records series by using MIS is possible, but the volume of material and the generality of the descriptions complicates this task. The series descriptions listed below represent an effort by OHRE staff to reconstruct collections of records with the most value for studying human radiation experiments. Researchers may wish to use these descriptions in conjunction with MIS. OHRE will continue working with the Operations Office to improve series-level control.

The Hanford sites are complex and present a formidable records challenge.

Pacific Northwest Laboratory has custody of its own records and the records of its predecessor, General Electric. PNL has some intellectual control over its records, and identification of series is easier than for the Operations Office records.

Hanford organizations are not accustomed to providing archival reference services, and the records controls that are in place were designed to meet internal needs. Improving access to all site records, including those currently in Hanford custody, is a goal of this project. 


\section{Richland Operations Office}

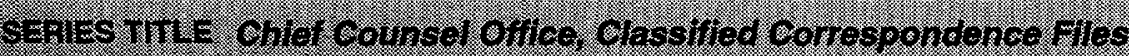

INCLUSIVE DATES 1947-1955; 1965-1971

ARRANGEMENT Subject

VOLUME 1 cubic foot

DESCRIPTION The series was compiled to document activities of the Office of Chief Counsel. It includes documents regarding patent declassification and application for classified subjects, reactor inspection records, contracts with special contractors, monthly reports of the Chief Counsel's Office activities, and a contract negotiation and procedure manual. It contains file of correspondence regarding special claims for injury from radiation exposure. The series consists of legal memorandums, contracts, memos, letters, reports, and applications. A box index is available. Box number 001772.

RESTRICTIONS This series is entirely classified.

LOCATION OF Hanford Records Holding Area

RECORDS 715 Swift Blvd.

Richland, WA 99352

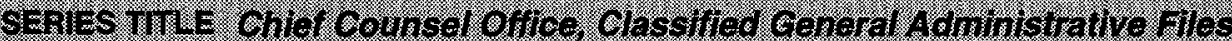

INCLUSIVE DATES 1946-1963

ARRANGEMENT Subject

VOLUME 4 cubic feet

DESCRIPTION This series was compiled as part of a central filing system for basic reference materials. It includes files on contracts, monthly reports of Office of Chief Counsel activities; reactor inspection reports; patent applications; special claims for injury; declassification procedures; photographs of the sites and facilities; Richland site selection criteria; and reports of activities at other sites. Box B00491 contains records of special claims made against Hanford for injury due to irradiation. The series includes reports, photos, negatives, memorandums, letters, press releases, manuals, and applications. A box index is available. Box numbers B00491, 041223, $008715,002488$.

RESTRICTIONS This series is entirely classified.

LOCATION OF Hanford Records Holding Area

RECORDS 715 Swift Blvd.

Richland, WA 99352 


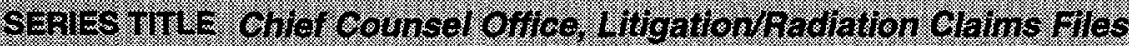

INCLUSIVE DATES $1957-1983$

ARRANGEMENT Litigation subject

VOLUME 20 cubic feet

DESCRIPTION This series documents the litigation activities of the Office of Chief Counsel. It contains various litigation case files and materials on radiation claims against contractors, Workmen's Compensation cases, transcripts of public hearings, and investigative case reports. The series contains letters, memorandums, reports, legal documents, working papers, interrogatories, and charts. $A$ box index is available. Box numbers 024757, 072689, 072709, 072909, 072943, 072910, 072945, 072949, 079007, 079307, 079308, 079403, 079405, 079406, 079440, 103076, 103077, 103080, $103081,103082$.

LOCATION OF Hanford Records Holding Area

RECORDS 712 Swift Blvd. Richland, WA 99352

\section{SERIES TILE Chief Counsel Office. Unctassifed Corresoondence}

INCLUSIVE DATES 1943-1973

ARRANGEMENT Subject

VOLUME 9 cubic feet

DESCRIPTION This series documents the activities of legal counsel in advising Hanford Facility management on law, legal policy, and contract interpretation. It includes material on General Electric activities, patent matters, personnel clearance matters, the Manhattan District History, community management, the hospitals, leases, and land disposal. The series consists of graphs, charts, correspondence, court transcripts, hearing exhibits, trial preparation documents, police reports, and leases. A box index is available. Box numbers 001768, 002464, 002845, 002970, 003425, 007218, 029235, $030733,079006$.

LOCATION OF Hanford Records Holding Area

RECORDS 715 Swift Blvd.

Richland, WA 99352 


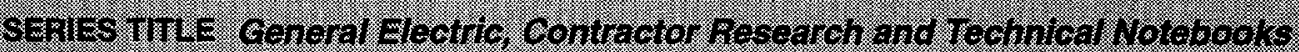

\author{
INCLUSIVE DATES 1952-1962 \\ ARRANGEMENT Chronological \\ VOLUME 42 cubic feet

\section{LOCATION OF Records Holding Area \\ RECORDS 715 Swift Blvd. \\ Richland, WA 99352}

DESCRIPTION This series documents GE experiments and research initiatives. In particular the series contains information on animal research, plant study, radiological study, aquatic biology, chemistry, electrochemistry research on plutonium, environmental research, and other projects. The series contains laboratory notebooks used to record data, observations, and notes. A box index is available. Box numbers (G)67573, 67574, $67604,67605,68379,84029,84030,84031,84584,84587,84588,84589,84590$, $84591,84592,84593,84703,84704,85157,85158,85159,85160,85478,85479$, $85480,85481,85488,85491,85492,85493,85537,85541,85542,85543,85544$, $85545,85546,85547,85553,85554,85559,85596$.

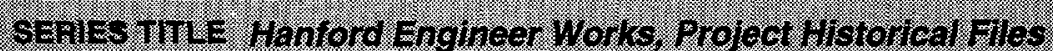

\author{
INCLUSIVE DATES $1943-1947$
}

ARRANGEMENT Subject

VOLUME 1 cubic foot

DESCRIPTION The series documents the early history of the Manhattan District, particularly the Hanford Piles Project. It includes the diaries of Col. F. T. Matthias, the Manhattan District history book, and the Hanford Engineering Works project history. The Matthais diaries contain information related to meetings with $\mathrm{D}$. Cooksey and $\mathrm{Dr}$. Joseph Hamilton of the Lawrence Radiation Laboratory. The series consists of correspondence, manuscript drafts, descriptions of experiments, photographs, project completion reports, and military diaries of day to day operations. A box index is available. Box number $\mathrm{C00309.}$

LOCATION OF Records Holding Area

RECORDS 715 Swift Blvd.

Richland, WA 99352 


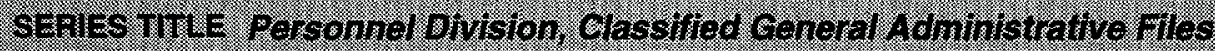

INCLUSIVE DATES 1943-1976

ARRANGEMENT Subject

VOLUME 2 cubic feet

DESCRIPTION This series documents the general administrative activities of the personnel division. It includes reference materials, annual reports, organizational charts for specific contractors and reactor operations, and studies of plant operations. It also contains reports on Richland diversification plans and summaries of plant operations. The series consist of organizational charts, studies, reports, graphs, letters, memorandums, and technical data. A box index is available. Box numbers 046073, C00327.

RESTRICTIONS This series is entirely classified.

LOCATION OF Records Holding Area

RECORDS 715 Swift Blvd.

Richland, WA 99352

\section{SERIES TILE Plans \& Budgot Division, Classified Report Filos}

INCLUSIVE DATES 1943-1961

ARRANGEMENT Chronological

VOLUME 11 cubic feet

DESCRIPTION The series documents the entire range of operations office activities. It includes Construction Engineering Operation monthly reports, Hanford Works monthly reports, manager's data books, du Pont monthly reports, and Hanford management books. Many reports include sections on medical division, health instruments, and biology division activities. The manager's data books include sections on personal injury claims, accidental and occupational fatalities, as well as organization charts. Box 003094 contains important histories of early Hanford medical programs. The series consists of formal reports and data books. $A$ box index is available. Box numbers B00213, B00670, B00672, B00674, 001603, 002061, 002436, 002437, 002815, $003094,001604$.

RESTRICTIONS This series is entirely classified.

LOCATION OF Records Holding Area

RECORDS 715 Swift Blvd.

Richland, WA 99352 


\section{SERIESTITL PRocuroment DWTSIon Files}

INCLUSIVE DATES $1965-1991$

ARRANGEMENT Subject

VOLUME 22 cubic feet

DESCRIPTION This series documents oversight of contract negotiations and patent clearances at Hanford by the Contract Administration Division, earlier called the Contract and Procurement Division. It includes information of the Westinghouse Hanford, Hanford Environmental Health Foundation, General Electric, University of Arkansas, University of Oregon, Flow Research Inc., Pacific Northwest Laboratories, and Battelle Northwest contracts, as well as, patent clearance requests. The series consists of memorandums, letters, and requests for patent clearances with supporting drawings and articles, contracts, authorization letters, policies and procedures, and technical reports. A box index is available. Box numbers 027205, 027252, 027254, 027255, 041242, 043046, 043051, 066889, 079080, 079446, 085597, 085599, 085600, 085651, 085731, 085859, 085862, 094630, 115477, 038169, 040963, 038170.

LOCATION OF Records Holding Area

RECORDS 715 Swift Blvd.

Richland, WA 99352

INCLUSIVE DATES 1963-1969

ARRANGEMENT Subject

VOLUME 3 cubic feet

DESCRIPTION This series documents the functions and responsibilities for the contract manager branch. It includes contracts and correspondence pertaining to contracts, USGS Bureau of reclamation (Yakima) central warehouse upgrades, Bonneville Power Administration contracts, environmental studies, Richland audit reports, and AEC policies for operating contracts. The series consists of invoices, meeting notes, contracts, letters, memorandums, architectural drawings, floor plans, and published material. A box index is available. Box numbers 103205, 103209, 103214.

LOCATION OF Records Holding Area

RECORDS 715 Swift Blvd.

Richland, WA 99352 
INCLUSIVE DATES 1943-1973

ARRANGEMENT Subject

VOLUME 49 cubic feet

DESCRIPTION This series documents operations office oversight of production reactor operations. It includes documentation on reactor operating problems such as graphite expansion, cost of operations, plutonium production, reactor safety, reactor waste, chemical processing activities, and cost analyses of production reactor shutdown. It contains files on accidental exposure and cancer treatment, Columbia River pollution, Building 234 design, fallout data collection, heavy water production, and RaLa production at Richland and Los Alamos. The cancer treatment file is a Medicine Health and Safety (MH\&S) 3-8 Special Case file that includes correspondence about the treatment of cancer patients using the Richland whole body counter. The series consists of letters, memorandums, reports, TWXs, charts, graphs, handwritten notes, and meeting minutes. The records are arranged according to several subject filing systems, one of which is the AEC numeric filing system. A box index is available. Box numbers A00601, A00739, B00125, C00361, 001418, 001607, 002421, 002461, 002876, 003085, 007532, 007541, 007545, 008748, 008751, 008784, 009920, 010478, $015200,015202,015203,015204,015227,015237,015270,016211,016250$, 022746, 022749, 024721, 024722, 027216, 027256, 027260, 028732, 028766, $029363,030750,030751,030755,030758,030760,033273,038287,039230$, $039231,039270,046093,046220$.

RESTRICTIONS This series contains classified information.

LOCATION OF Records Holding Area

RECORDS 715 Swift Blvd.

Richland, WA 99352 


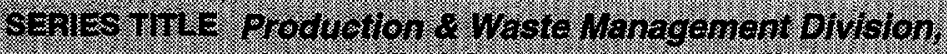

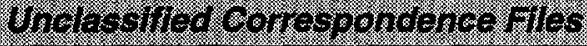

INCLUSIVE DATES 1958-1973

ARRANGEMENT Subject

VOLUME 11 cubic feet

DESCRIPTION The series documents the activities of the Hanford Chemical Processing Department which produced various chemical and physical forms of plutonium, manufactured weapons components, and produced various isotopes. It includes materials on environmental impact statements, US AEC Material Status Reports, loan of materials to institutions, nuclear material transfers, leasing policies, waste management practices. Within the series there is a sub-series regarding grants and loans of plutonium which was overseen by P.A. Craig, Supply Coordinator. The series consists of letters, memorandums, reports, completed forms, and photographs. A box index is available. Box numbers 018776, 028710, 033286, 033287, 033297, 066594, 079168, 079169, $079172,079401,085618$.

\section{LOCATION OF Records Holding Area}

RECORDS 715 Swift Blvd.

Richland, WA 99352

INCLUSIVE DATES 1958-1976

ARRANGEMENT Subject

VOLUME 3 cubic feet

DESCRIPTION This series documents various projects and studies of the Research and Development Division. It includes studies on the effects of the nuclear facilities on the Columbia River, waste disposal by the Federal Water Pollution Control Administration, earthquakes, and chemical discharges into the river. It also includes reports on isotope production, and studies on Hanford diversification. The series consists of letters, memorandums, reports, technical data, meeting minutes, and technical reports. A box index is available. Box numbers 009042, $017264,039235$.

RESTRICTIONS This series is entirely classified.

LOCATION OF Records Holding Area

RECORDS 715 Swift Blvd.

Richland, WA 99352 


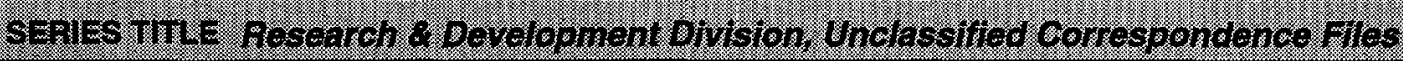

INCLUSIVE DATES 1958-1982

ARRANGEMENT Subject

VOLUME 7.8 cubic feet

DESCRIPTION This series documents the division's major responsibilities and activities. Documentation was compiled as part of the division's investigation of site environmental problems. The series includes material on environmental research and activities, special research studies, and activities which the division oversaw, such as the transfer of control of activities among site contractors. It also contains documentation on thermal effects studies and of the effect of reactor operations on the Columbia River. The series contains memorandums, letters, directives, proposals, scientific data, technical notebooks, and reports. A box index is available. Box numbers 007400,028738 , 029361, 046088, 046111, 046116, 072771, 079392.

\section{LOCATION OF Records Holding Area}

RECORDS 715 Swift Blvd.

Richland, WA 99352

\section{SERESTHE Research Prsonor Study Fles}

INCLUSIVE DĀTES 1963-1976

ARRANGEMENT Project

VOLUME 1.5 cubic feet

DESCRIPTION This series documents the research project whereby prisoners in Oregon and Washington participated in testicular irradiation studies. It is a medical research project case file reflecting the history of the project from initiation to completion. The series consists of contracts, letters, memorandums, annual reports, publications, renewal proposals, and consent forms. An electronic finding aid is available. Box number 046264.

RESTRICTIONS This series contains privacy material.

LOCATION OF Records Holding Area

RECORDS 715 Swift Blvd.

Richland, WA 99352 


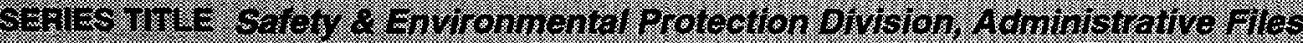

INCLUSIVE DATES $1957-1981$

ARRANGEMENT Subject

VOLUME 4 cubic feet

DESCRIPTION This series documents the division's activities and responsibilities. It includes material on radioactive contaminants discharged to ground; radioactive liquid wastes, radiation exposures (unintentional incidents, accidents, and occupational exposures); stack emissions; air pollutant emissions reporting; discharges into, and sampling of, the Columbia River; dosimetry management; employee safety and health complaints; health and safety inspections; and emergency preparedness. It does not seem to contain information on clinical experimentation but may have data on intentional releases. The series consists of reports, photographs, memorandums, letters, maps, charts, blueprints, phone conversation logs, stack emissions status reports, and environmental impact statements. A box index is available. Box numbers 024284 , 066842, 094557, 103015.

LOCATION OF Records Holding Area

RECORDS 715 Swift Blvd.

Richland, WA 99352 


\section{Hanford Environmental Health Foundation}

INCLUSIVE DATES 1969-1992

ARRANGEMENT Chronological

VOLUME 1 cubic foot

DESCRIPTION This series documents the administration of the foundation. It includes materials on organizational activities, security and safeguards directives, files related to the consent, use, and follow-up studies of diethylenetriamine penatacetic acid (DPT), United Nuclear Corporation employee files documenting training and welfare programs, and documentation on emergency medical services and emergency preparedness guidelines. The series consists of organizational reports, medical reports, letters, memorandums, graphs, and charts. Box number 099501.

LOCATION OF Hanford Records Holding Area

RECORDS 712 Swift Blvd.

Richland, WA 99352

INCLUSIVE DATES 1964-1971

ARRANGEMENT Subject

VOLUME 1 cubic foot

DESCRIPTION This series documents foundation administration. It includes security appraisals and correspondence; contracts; industrial safety and fire protection functional appraisals; records management appraisals; occupational medicine appraisals; Environmental Health Science (EHS) appraisals; Richland Operations Office appraisals. It also contains a W. D. Norwood letter book, and medical director's office and personal correspondence. The series consists of letters, memorandums, reports, and notebooks. Box number 030247.

LOCATION OF Hanford Records Holding Area

RECORDS 712 Swift Blvd.

Richland, WA 99352 


\section{Pacific Northwest Laboratory (PNL)}

\section{SERIES TITLE Director's Office Correspondence with AEC, ERDA, \& DOE}

INCLUSIVE DATES 1965-present

ARRANGEMENT PNL Subject Filing System

VOLUME 6 cubic feet

DESCRIPTION The series documents the administration and management of the laboratory. It includes correspondence files between the PNL Director and the AEC, ERDA, and DOE Richland General Management. The series consists of contracts and related documentation, letters, memorandums, and reports. An electronic finding aid is available.

RESTRICTIONS This series contains privacy material.

LOCATION OF Pacific Northwest Laboratory

RECORDS Richland, WA 99352

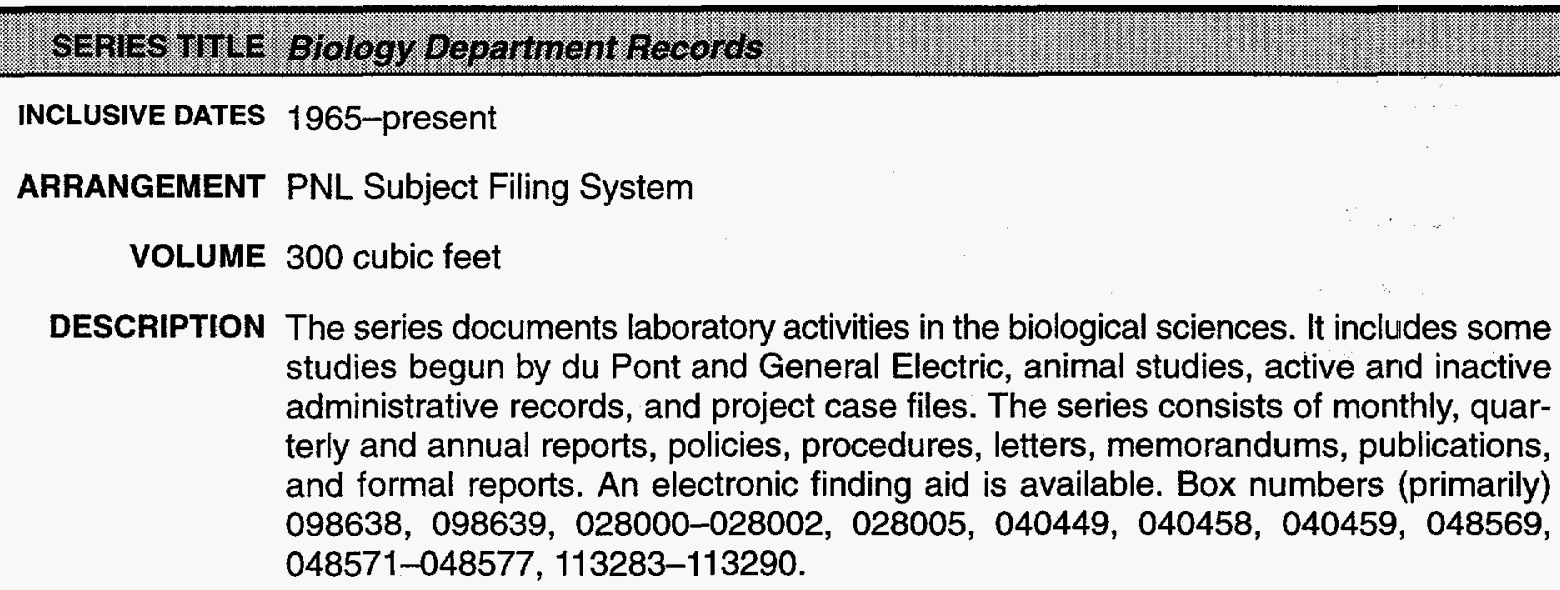

DESCRIPTION The series documents laboratory activities in the biological sciences. It includes some studies begun by du Pont and General Electric, animal studies, active and inactive administrative records, and project case files. The series consists of monthly, quarterly and annual reports, policies, procedures, letters, memorandums, publications, and formal reports. An electronic finding aid is available. Box numbers (primarily) 098638, 098639, 028000-028002, 028005, 040449, 040458, 040459, 048569, 048571-048577, 113283-113290.

RESTRICTIONS This series contains privacy material.

LOCATION OF Pacific Northwest Laboratory

RECORDS Richland, WA 99352 
INCLUSIVE DATES 1944-1964

ARRANGEMENT Subject

VOLUME 100 cubic feet

DESCRIPTION The series documents the biological and biomedical research activities of du Pont and General Electric. It includes records of the Health Instruments Division, material on the Green Run, and files on animal, fish, and vegetation studies. The series consists of monthly, quarterly, and annual reports; policies; procedures; letters; memorandums; Laboratory notebooks; publications; and formal reports. An electronic finding aid is available. Box numbers (primarily) 069551-069556, 080573, 107734-107742, $113295,065548-065557$.

RESTRICTIONS This series contains privacy material.

LOCATION OF Pacific Northwest Laboratory

RECORDS Richland, WA 99352

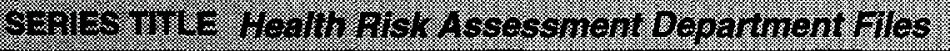

INCLUSIVE DATES 1965-1994

ARRANGEMENT PNL Subject Filing System

VOLUME 100 cubic feet

DESCRIPTION The series consists of administrative and project records received or generated by the department. The administrative records are maintained by organization and the research records as project case files. The research records are primarily "paper" studies of data collected by other organizations. The series consists of letters, memorandums, reports, computer printouts, and laboratory notebooks. An electronic finding aid is available. Box numbers (primarily) 119430, 126610, 129400-129404, 129456, 129457, 124714-124720.

RESTRICTIONS This series contains privacy material.

LOCATION OF Pacific Northwest Laboratory

RECORDS Richland, WA 99352 


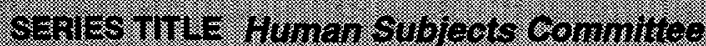

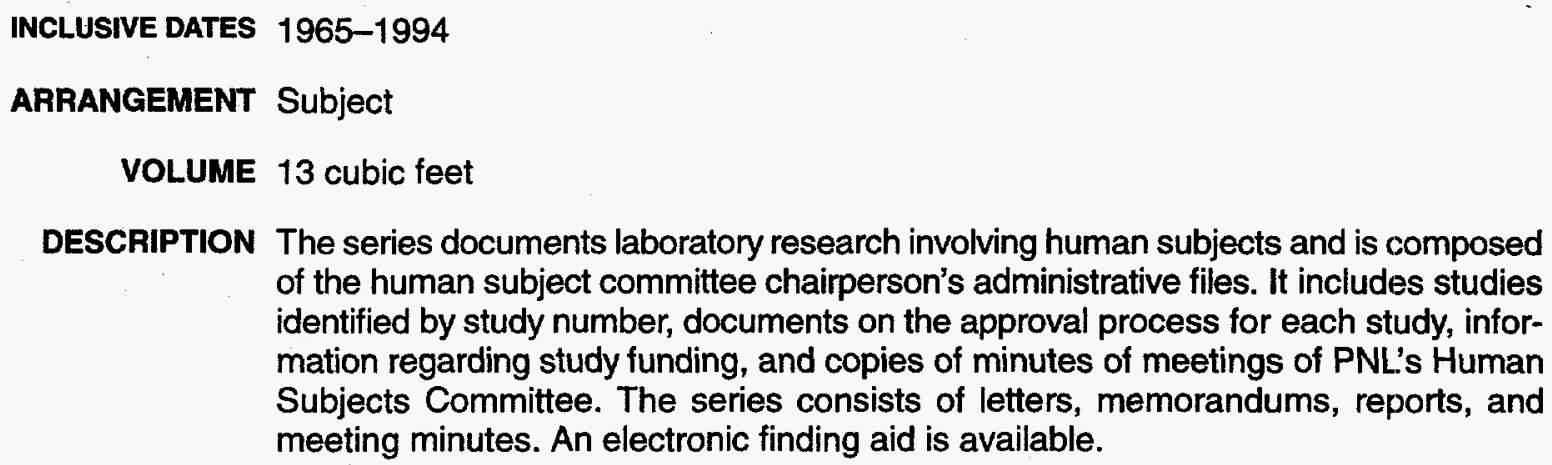

DESCRIPTION The series documents laboratory research involving human subjects and is composed of the human subject committee chairperson's administrative files. It includes studies identified by study number, documents on the approval process for each study, information regarding study funding, and copies of minutes of meetings of PNL.'s Human Subjects Committee. The series consists of letters, memorandums, reports, and meeting minutes. An electronic finding aid is available.

LOCATION OF Pacific Northwest Laboratory

RECORDS Richland, WA 99352

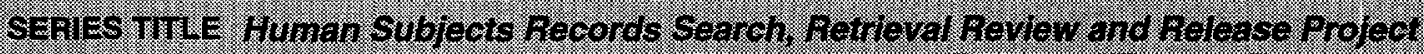

INCLUSIVE DATES 1993-present

ARRANGement Project Case File

VOLUME 15 cubic feet

DESCRIPTION This series documents the Human Subjects Records Search, Retrieval, Review \& Release Project. It includes master and redacted copies of documents pertinent to human radiation experiments, documentation about record searches, and DOE-PNL correspondence. It contains documentation on the following human radiation experiments: a tritium study, the Walla Walla prisoner study, a promethium study, and Hanford intentional releases of radiation. The series consists of notes, drafts, indexes, finding aids, reference material, reports, articles, oral histories, letters, and memorandums. An electronic finding aid is available.

RESTRICTIONS This series contains privacy material.

LOCATION OF Pacific Northwest Laboratory

RECORDS Richland, WA 99352 
INCLUSIVE DATES 1965-1971

ARRANGEMENT By school and thereunder by name/number assigned to each person

VOLUME 27 cubic feet

DESCRIPTION The series was compiled to document a study of the influences of diet on radioactivity in people and was conducted at schools in the Richland area. It includes material on another study to analyze the amounts of certain foods consumed by local families and schoolchildren. The series contains analyses of significant pathways through drinking water, locally grown beef, river fish, and game birds, for radioactivity to reach the body. The series consists of diet charts, whole body counter results, printouts, and photos at local schools. A database is maintained of the documents in each box of records. Box numbers (primarily) 027860-027875, 050200-050213.

RESTRICTIONS This series contains privacy material.

LOCATION OF Pacific Northwest Laboratory

RECORDS Richland, WA 99352

INCLUSIVE DATES $1987-1994$

ARRANGEMENT Project task

VOLUME 165 cubic feet

DESCRIPTION This series documents the projects' efforts to develop estimates of radiation doses that local populations received from nuclear operations at Hanford. It includes material on project scope, organization, and administration; the development of computer and other models for dose reconstruction; analyses of most hazardous radioisotopes and their transport through the environment into the body; site environmental monitoring, local food habits and life styles; and detailed information about types and amounts of Hanford radiation releases. The series consists of computer software, memorandums, letters, notes, charts, graphs, preliminary drafts, final reports, database files, comments from the Technical Steering Panel in which panel members provided direction to the project, minutes of meetings, and comments received from the public concerning the research project. An electronic finding aid is available.

RESTRICTIONS This series contains privacy material.

LOCATION OF Pacific Northwest Laboratory

RECORDS Richland, WA 99352 


\section{SEFICS TILE Hantoral htentionat a tmospherio Releases}

INCLUSIVE DATES 1944-1963

ARRANGEMENT Document number

VOLUME 1 cubic foot

DESCRIPTION The series documents the intentional release of radiation to the environment at Hanford. It includes planning and other documentation from the site Health Division, materials on the Green Run, and documentation about the 1962 and 1963 intentional releases. These records were used by the Hanford Environmental Dose Reconstruction (HEDR) Project. The series consists of formal reports, quarterly reports, monthly reports, and prerelease planning documents. An electronic finding aid is available.

LOCATION OF Pacific Northwest Laboratory

RECORDS Richland, WA 99352

\section{SERES TILL Recorss on the Iraclation Effects in the Human Testis}

INCLUSIVE DATES $1963-1970$

ARRANGEMENT Subject

VOLUME 1 cubic foot

DESCRIPTION This series documents the Study of Irradiation Effects in the Human Testis (also known as the Walla Walla Prisoner Study). It contains documentation on General Electric's and PNL's technical assistance in the study which was conducted by the University of Washington. The series consists of laboratory notebooks, drawings, sketches, letters, memorandums, photographs, reports, copies of journal articles, and blank consent forms. An electronic finding aid is available. Box number 094367.

LOCATION OF Pacific Northwest Laboratory

RECORDS Richland, WA 99352 


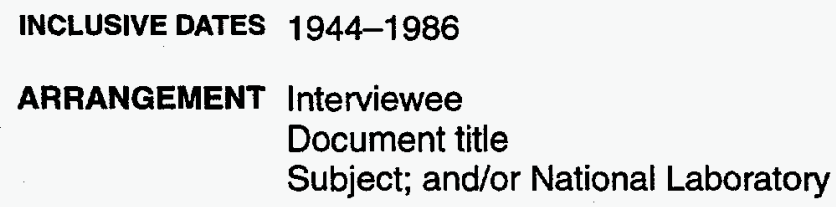

VOLUME 22 cubic feet

DESCRIPTION The series was compiled by Stannard in the preparation of "Radioactivity and Health: A History," a work on the history of radioactivity from before World War II to the 1970s. It includes information on human subjects experiments and on animal studies at sites throughout the United States. The series consists of donated documents, reports, articles, tapes of oral history interviews, and transcripts of oral history interviews. An electronic index is available.

RESTRICTIONS This series contains privacy material.

LOCATION OF Pacific Northwest Laboratory

RECORDS Richland, WA 99352

\section{SERIES TITL Milstorical Collection of Hanford Documents}

INCLUSIVE DATES 1944-1965

ARRANGEMENT Document

Number

VOLUME 200 cubic feet

DESCRIPTION The series documents radiation protection, monitoring, and release activities at Hanford. It includes documents pertaining to research projects, radiation protection, and radiation monitoring at the Hanford Site from the Manhattan Engineer District through 1965, the Green Run, and other intentional releases. The series consists of letters, memorandums, formal reports, internal reports, organizational charts, laboratory notebooks, and finding aids, such as handwritten document number issue books and a card catalogue for documents issued between 1944 and 1964. The majority of these documents have been reviewed for relevancy to the Hanford Environmental Dose Reconstruction Project and applicable documents were declassified (or declassified with deletions) for use by that project.

RESTRICTIONS This series contains privacy material and a small amount of classified information.

LOCATION OF Pacific Northwest Laboratory

RECORDS Richland, WA 99352 


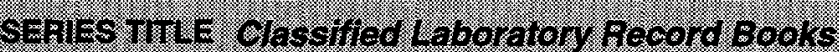

INCLUSIVE DATES 1965-1994

ARRANGEMENT Numerical

VOLUME 50 cubic feet

DESCRIPTION The series documents classified scientific and technical research of the Laboratory. The record books are used to record observations/data chronologically, describe (narrative or sketch) experimental apparatus, equipment, and any procedures, data sheets, etc., that are used. The series consists entirely of Laboratory record books. An electronic finding aid is available.

RESTRICTIONS This series contains classified information.

LOCATION OF Pacific Northwest Laboratory

RECORDS Richland, WA 99352

\section{SERIES TILE Undassifed Laboratow Record Books}

INCLUSIVE DATES $1965-1994$

ARRANGEMENT Numerical

VOLUME 450 cubic feet

DESCRIPTION The series documents biomedical, scientific, and other research of the Laboratory. The record books are used to record observations/data chronologically, describe (narrative or sketch) experimental apparatus, equipment, and any procedures, data sheets, etc., that are used. The series consists entirely of Laboratory record books. An electronic finding aid is available.

LOCATION OF Pacific Northwest Laboratory

RECORDS Richland, WA 99352 


\section{The Sites Today}

THE IDAHO SITES consist of three major facilities on 890 square miles in southeastern Idaho, about $\mathbf{5 0}$ miles west of Idaho Falls. The Idaho National Engineering Laboratory (INEL) is a multiprogram laboratory whose mission focuses upon advanced energy and environment engineering technology. A Naval Reactors Facility functions as a proving ground for prototype naval propulsion reactors. The Argonne National Laboratory West Facility (ANL-W) is a test area for Argonne National Laboratory experimental reactors. With I I,000 employees and a \$I billion annual budget, the facilities together represent Idaho's second-largest employer. The Atomic Energy Commission originally established the site as a nuclear reactor proving ground, and 52 reactors of many different design types have been built there. As of October 1994, seven reactors were operating or in standby condition.

Fifty-two reactors of many different design types have been built at Idaho.

Three DOE offices each manage a portion of the Idaho complex. The Idaho Operations Office oversees INEL activities, the Idaho Branch Office of Pittsburgh Naval Reactors directs the Naval Reactors Facility, and the Chicago Operations Office oversees ANL-W. DOE recently awarded a 5-year management contract to Lockheed Idaho Technologies Company to operate INEL. The Westinghouse Electric Corporation operates the Naval Reactors Facility, and the University of Chicago runs ANL-W. Site focus has shifted from reactor development to management of radioactive waste, storage of spent nuclear fuel, remediation activities, environmental restoration, technology transfer, and research and development activities.

\section{Site History}

The Idaho National Engineering Laboratory (INEL)-In need of a remote site to work with experimental civilian and military reactors, the AEC in 1949 created a National Reactor Testing
Station at a former U.S. Navy gun testing range in Idaho. The first reactor built at the site was the Experimental Breeder Reactor (EBR-1). In 1951, EBR-1 became the first nuclear reactor to produce electricity from nuclear fission. The main purpose for the reactor, however, was to show the feasibility of "breeding," or creating additional nuclear fuel during routine reactor operation. The AEC then anticipated shortages of the uranium ore needed for reactor fuel. EBR-1 demonstrated the first breeding of nuclear fuel in June 1953. During the 1950s, the AEC built a series of experimental reactors at INEL, including five Boiling Water Reactor Experiment (BORAX) reactors. These reactors generated power by running a turbine on steam directly generated in the reactor. The BORAX-I reactor was built in 1953 to examine the behavior of boiling-water reactors during abnormal changes in power and temperature. During 1954, most of the fuel plates in the reactor core were melted during an experiment. Another BORAX reactor, BORAX-III, became the first reactor to light an American town when it provided electricity for Arco, Idaho in 1955. The BORAX reactors laid the groundwork for the commercialization of boiling-water power reactors.

As the AEC began to encourage the creation of a commercial nuclear power industry after 1955 , it conducted reactor research programs to gather data to confirm its assumption that reactors could safely generate electricity. At the time, scientists were concerned that a runaway nuclear chain reaction (excursion) would be the most likely cause of a serious reactor accident. The AEC built four reactors at INEL to carry out the Special Power Excursion Reactor Tests (SPERT). The tests pushed reactors to extreme limits, including intentionally destructive tests in which planned nuclear excursions were allowed to damage reactor cores. These tests released limited amounts of radioactive materials to the environment. SPERT program data contributed to the development of procedures to prevent reactor excursions. The last SPERT reactor (SPERT IV) was shut down in 1970. 
The longest-lived INEL reactor project was the Loss of Fluid Test Facility (LOFT). Started in the early 1960 s, the LOFT project originally intended to force a fuel meltdown to test reactor core performance. In 1967, AEC changed the purpose of the project to test reactor emergency core-cooling systems. In conjunction with the revised LOFT project, INEL conducted the "semiscale" tests in 1970. The semiscale apparatus consisted of a small reactor mockup equipped with an emergency core-cooling system. Tests suggested that water in the emergency core-cooling system did not circulate as designed. Critics argued that the test proved that emergency cooling systems would not work and that commercial reactors were at risk of releasing catastrophic amounts of radioactivity to the environment. The semiscale tests were a key event in the U.S. debate over the safety of commercial nuclear power plants. LOFT was shut down in 1986.

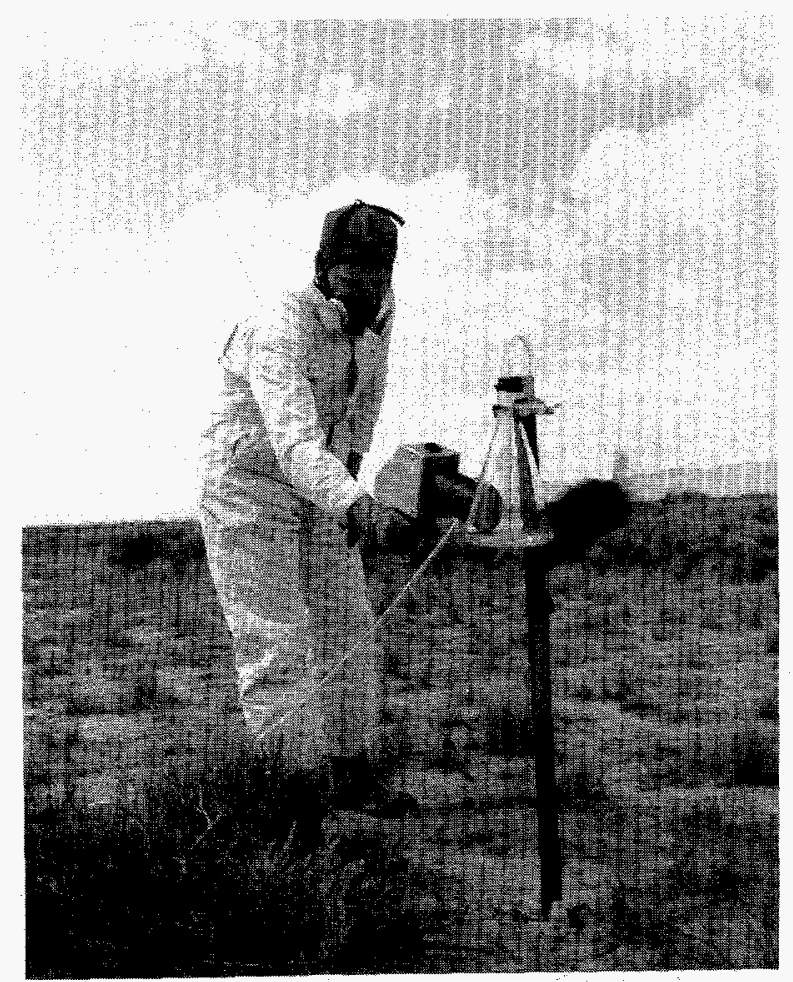

Figure 23. Measuring intentional radiation release at the Idaho experimental dairy farm (1964).

INEL also operated experimental military reac tors. During the early 1950s, the U.S. Air Force tested nuclear propulsion systems. This effort was part of the Aircraft Nuclear Propulsion program, which aimed to develop a reactor small enough to be mounted in an airplane. Three reactor assemblies, designated as the Heat Transfer Reactor Experiments (HTRE), were used to evaluate reactor control systems, test advanced fuels and moderators, and assess the feasibility of a nuclear-powered aircraft. The aircraft reactor program was canceled in 1961.

The Idaho Operations Office now manages the Radioactive Waste Management Complex, which examines, sorts, processes, and stores transuranic waste and low-level waste.

The U.S. Army, too, built experimental reactors at INEL. One such reactor, the Stationary LowPower Reactor No. I (SL-1), was a portable reactor for use in providing power in remote areas. The SL-1 suffered a catastrophic power excursion in 1961, killing three technicians.

The AEC built the Idaho Chemical Processing Plant (ICPP) at INEL to recover enriched uranium for use as nuclear fuel. The ICPP. was originally designed in the early 1950s as a 5-year demonstration facility, It quickly became the principal facility for receiving, storing, reprocessing, and managing nuclear materials from reactors in the U.S. and other countries. The ICPP also operated facilities to manage high-level radioactive wastes. The waste calcining facilities have been used to convert liquid radioactive wastes into a solid granular form for storage. Since 1963, the ICPP has converted more than six million gallons of high-level radioactive liquid waste to granular solid form.

The Idaho Operations Office now manages the Radioactive Waste Management Complex, which examines, sorts, processes, and stores transuranic waste and low-level waste. The complex consists of a 97-acre subsurface disposal area and a 57-acre transuranic storage area.

The Naval Reactors Facility - Experimental reactors for the Navy were also built at the Idaho site, but the Naval Nuclear Propulsion Program, a joint AEC-Navy program, maintained its own 
oversight over the reactors and operated them with its own contractors. The Naval Reactors Facility was built in the early 1950s and has tested prototype reactors for submarines and surface ships. The first prototype Naval reactor was produced to help design the reactor for the first nuclear submarine, the U.S.S. Nautilus, which was launched in 1955, In 1958 two prototype Naval reactors were constructed in designing the first nuclear-powered aircraft carrier, the U.S.S. Enterprise, which went to sea in 196I. In 1965, a third prototype facility, S5G, was built to study enhanced reactor safety and allow quieter submarine operation.

The Argonne National Laboratory West facility-The ANL-W opened in 1964. It is operated as an adjunct to Argonne National Laboratory. This facility houses several experimental reactors and other laboratory facilities. The chief focus has been liquid metal-cooled reactors, safety studies, and reactor core designs. Reactors built at the facility include the Experimental Breeder Reactor II and the Zero Power Plutonium Reactor.

\section{Site Human Radiation Experiments}

Two human radiation experiments have been identified that were performed by the ldaho Operations Office Health and Safety Division (known originally as the Health Services Laboratory). Several other experiments involving intentional releases of radioactivity to the environment were also conducted at INEL. Various groups sponsored these tests, including the AEC and its contractors, and other Federal organizations.

Two human radiation experiments have been identified that were performed by the Idaho Operations Office Health and Safety Division.

The first human radiation experiment was the Controlled Environmental Radioiodine Tests (CERT), which were designed to develop models for predicting the movement of radioiodine through the milk-to-human food chain (Figure 26). During these tests, known amounts of iodine-13I were released into the environment on 23 occasions from 1963 to 1968. From 1963 to 1966 , some human volunteers inhaled air and ingested milk containing radioiodine to obtain data on the transport of radioiodine to and through the body. The purpose of this program, which was part of the AEC's investigation of fallout effects, was to develop mathematical models for predicting the movement of radioiodine through the food chain to man.

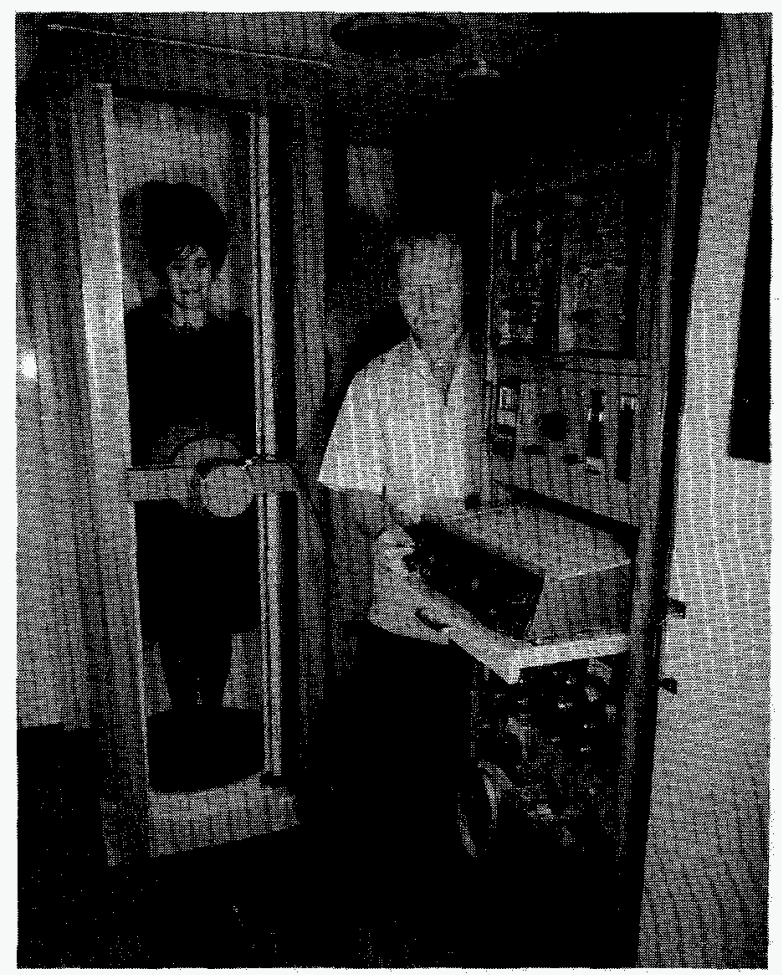

Figure 24. A mobile whole body counter (1966).

The second human radiation experiment involved administration of radioactive material to subjects for testing and calibrating whole body radiation counters. These tests took place from 1965 to 1972 and involved about 18 AEC employees as subjects. The subjects swallowed plastic capsules containing radioactive material, or inhaled radioactive noble gases. Whole body counting equipment was then used to measure and trace the isotopes.

Experiments involving intentional radiation releases to the environment also included tests associated with reactor development and safety, burning of contaminated solvents, and diffusion of gases. These experiments took place from 1955 to 1977. None of these releases involved deliberate exposure of human subjects to radiation. 
Some tests did, however, result in movement of airborne radioactive material offsite. Individual site experiments are discussed in Chapter 3.

\section{Site Records Collections}

INEL has custody of records dating from the beginning of the site in 1949. Many inactive records are stored at the Federal Records Center in Seattle but some are maintained onsite. Most inactive records onsite are kept at the Central Facilities Area. INEL has custody of the records created by the site managing contractors and by the Idaho Operations Office of the AEC, ERDA, and DOE. Some important records are in the custody of the Radiological and Environmental Sciences Laboratory of INEL. Records created by the Naval reactors program and by ANL-W are controlled by these respective organizations. Some records are stored at sites in Idaho Falls, at the Idaho Falls Center for Higher Education (University Place), and at the Willow Creek Building of Lockland Idaho Technologies Company.

INEL has records transfer sheets that contain some information about the contents of individual boxes of inactive records. This information is maintained in hard copy and on the computerized Automated Document System (ADOCS), which has a limited search capability. Because records holding information is maintained on a box-by-box basis, similar to the system used at Hanford, records series have to be reconstructed. These series descriptions represent a joint effort by Idaho and OHRE to reconstruct and describe the most important collections.

Information in these series covers the full range of human experimentation done at Idaho.

Information in these series covers the full range of human experimentation done at Idaho. There is also a small amount of material on environmental releases that were not designed to test the health effects of radiation or the effect of human exposure to radiation. While these releases are beyond the scope of the definition of human experimentation, they were identified during the search. Specifically included are some records associated with the INEL Historical Dose Evaluation which studied radiation dose levels associated with releases and accidents. 


\section{Idaho National Engineering Laboratory (INEL)}

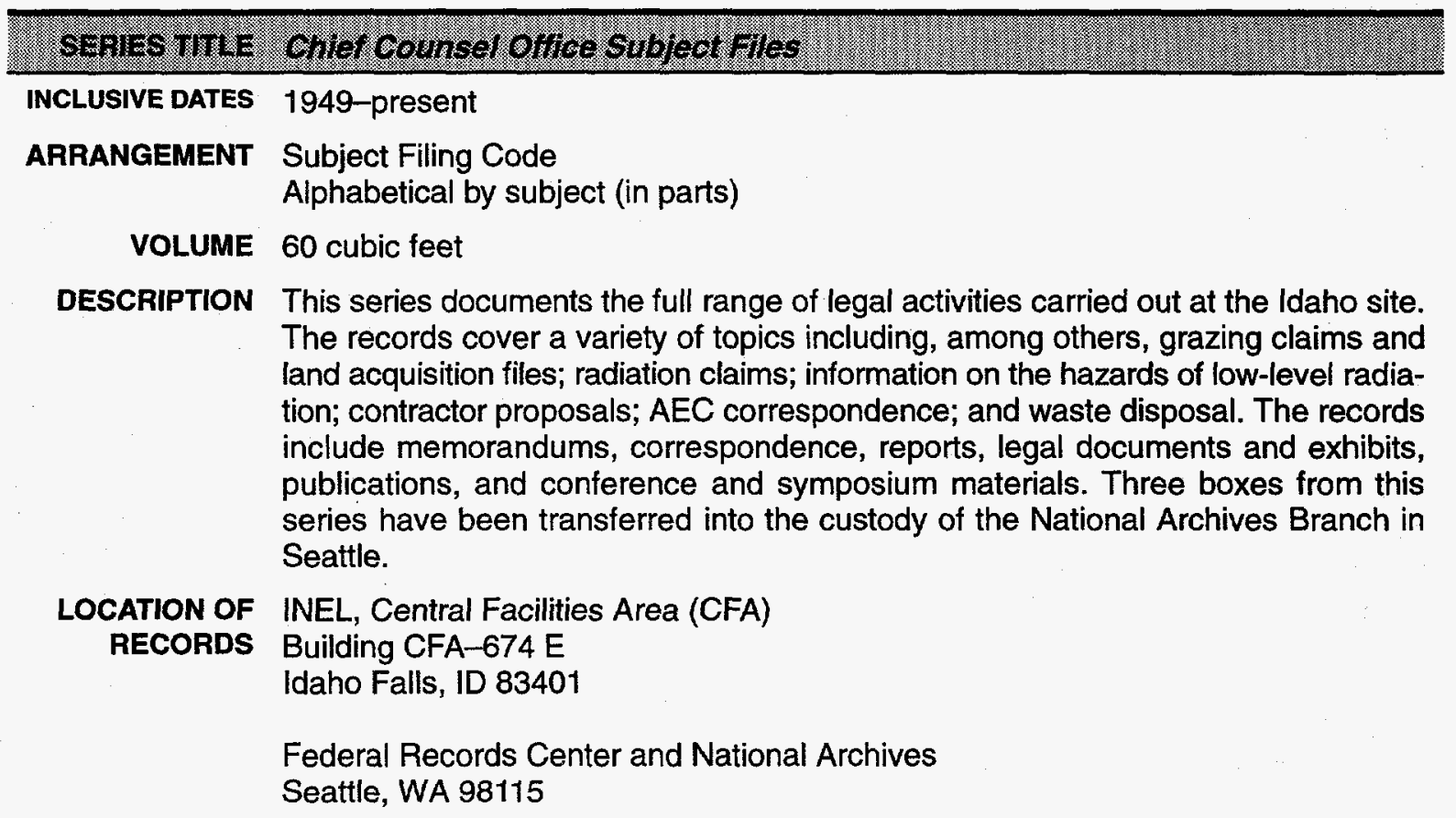

INCLUSIVE DATES 1947-present

ARRANGEMENT Alphabetical

VOLUME 915 cubic feet

DESCRIPTION This series consists of the medical records of each past and present employee of the Idaho National Engineering Laboratory. The records have been microfilmed and the hard copies sent to the Federal Records Center in Seattle, Washington. The microfilmed records are maintained by the Idaho National Engineering Laboratory, Office of Occupational Medicine. This series includes the records of volunteers who are known to have participated in human radiation experimentation.

RESTRICTIONS This series contains privacy material.

LOCATION OF Office of Occupational Medicine

RECORDS Willow Creek Building Idaho Falls, ID 83401
Federal Records Center

Seattle, WA 98115 


\title{
SERIES TILE OecUpational Bostinethy Reeords
}

\author{
INCLUSIVE DATES 1947-present
}

ARRANGEMENT Alphabetical by subject

VOLUME 71.5 cubic feet

DESCRIPTION These records contain the results of whole body counts, urinalysis tests, and thyroid counts measuring personnel for exposure to ionizing radiation. They also contain a calibration history for the whole body counting equipment. The records include: occupational radiation records; bioassay records; whole body count records; individual personnel records; and record storage receipts dating back to the late 1940s. There are bound notebooks containing log entries of whole body counts, including personnel names, dates, and comments; raw spectra data; viewgraphs of whole body counts, etc. There are also logbooks containing entries that show the name of the subject, date, and a comments section for the whole body count which notes the experiment or study for which the count was performed. Raw spectra data of whole body counts are also noted. The majority of the records are on microfiche and have been sent to the Federal Records Center (FRC), Seattle. There are a few records from 1990 to the present retained onsite. Most of the records have been entered into an electronic database.

RESTRICTIONS This series contains privacy material.

LOCATION OF INEL, Operational Dosimetry Unit Offices

RECORDS Central Facilities, CFA-690

Room 205, Room 11, Room 115, and Records Storage Vault

INEL, Central Facilities Area, CFA 674-E

Federal Records Center

Seattle, WA 98115

INCLUSIVE DATES $1958-1972$

ARRANGEMENT Numerical filing system

VOLUME 5 cubic feet

DESCRIPTION These files, also known as "J.R. Horan Letter Files," are subject-based files which contain correspondence, reports, reprints, news clippings, interview transcripts, and raw data. Horan was the director for many years of the Health and Safety Division. Subjects include radium, film dosimetry, accidents, radiological assistance, water quality, structural studies, contamination and decontamination, radiation exposure, and contamination control. There is one file on John Gofman and Arthur Tamplin regarding their criticism of the Atomic Energy Commission in the 1970s.

LOCATION OF Federal Records Center

RECORDS Seattle, WA 98115 


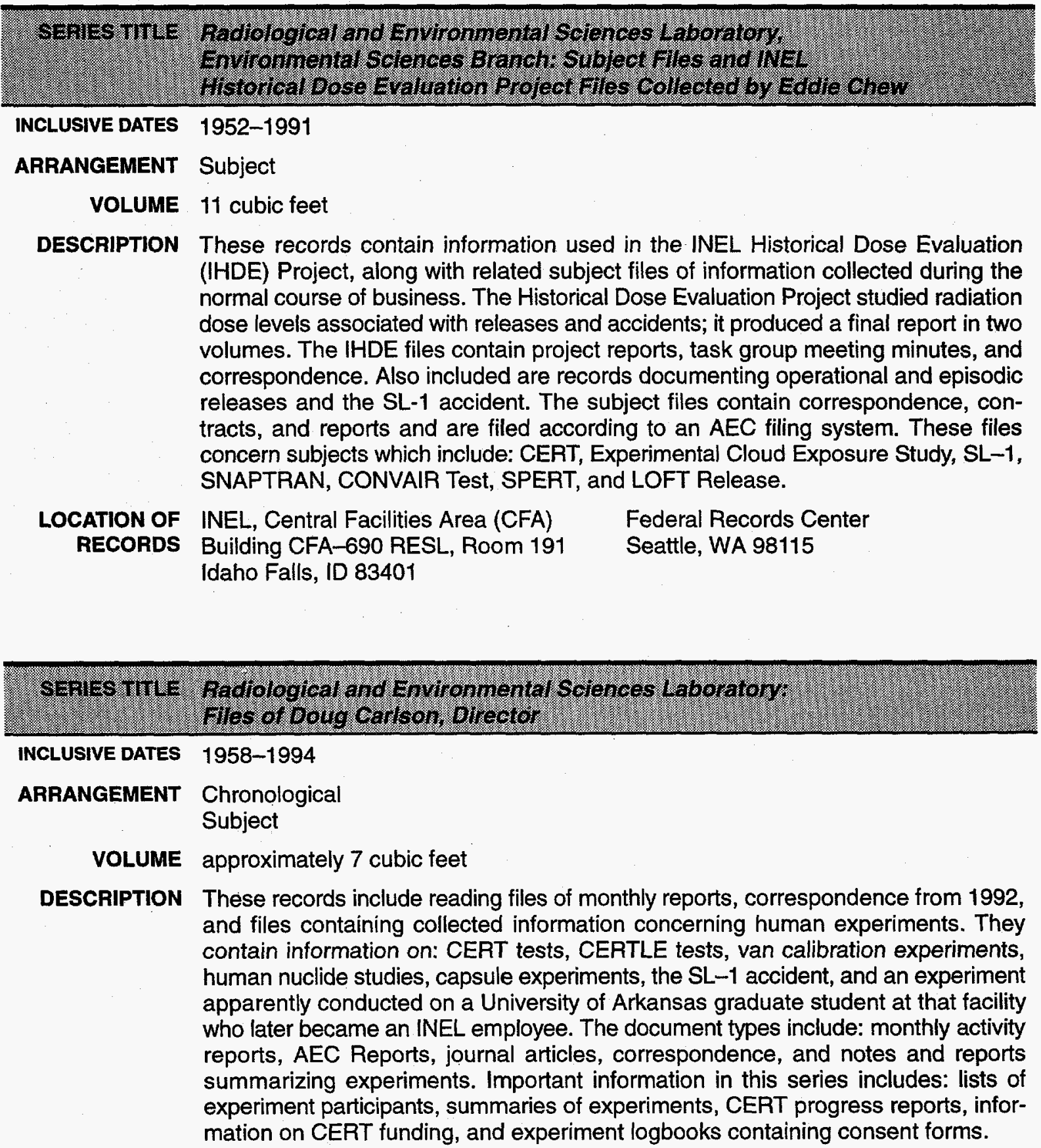

RESTRICTIONS This series contains privacy material.

LOCATION OF INEL, Central Facilities Area (CFA)

RECORDS Office of the Director

Federal Records Center

Building RESL CFA-690

Seattle, WA 98115

Idaho Falls, ID 83401 


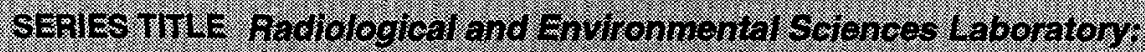
Whole Eody Gounting Records Collected by Dale G. Olsen

INCLUSIVE DATES 1961-1994

ARRANGEMENT Chronological Subject

VOLUME approximately 4 cubic feet

DESCRIPTION These records include the journal articles, dectapes and dectape logs, reports on bioassay techniques, and whole body counting logbooks kept in the office of the Branch Chief of the Laboratory Accreditation Program. The logbooks record whole body counts conducted by Dale Olsen and others. One logbook entitled "Human Ingestion Capsule" contains information on body counts of people who voluntarily swallowed capsules containing radioisotopes. This log includes 10 signed consent forms.

RESTRICTIONS This series contains privacy material.

LOCATION OF INEL, Central Facilities Area (CFA)

RECORDS Building RESL CFA-690, Room 115 Idaho Falls, ID 83401
Federal Records Center

Seattle, WA 98115

(cabinet DOELAP, drawer \#4 and adjacent bookcase)

\section{SERES TITLE Papers Speeches and PWblications Rlles of Clavde W SII}

INCLUSIVE DATES $1955-1980$

ARRANGEMENT Chronological

VOLUME 5 cubic feet

DESCRIPTION This series contains the records of Claude Sill, who was chief of the Analytical Chemistry Branch at Idaho, part of the Health and Safety Division, for approximately 27 years. He worked for DOE from 1951 to 1980 and is currently employed by Lockheed Idaho Technologies Co., as a principal scientist. His branch provided analytic bioassay services for all contractors at ldaho and he was responsible for the whole body counters. He and his staff actively published and participated in professional meetings and these records include speeches at health physics and bioassay meetings and publications in a variety of journals and proceedings. He also has some logbooks and loose paper files. His records include accounts of his involvement in the Controlled Environmental Radioiodine Test (CERT) and use of humans for the calibration of analytical equipment. He also has in his collection an article on considerations when using human volunteers in experiments with radioisotopes.

RESTRICTIONS This series contains privacy material.

LOCATION OF INEL, Test Reactor Area

RECORDS Building TRA 604, Alpha Wing,

Rooms 111,118

Idaho Falls, ID 83401
Federal Records Center

Seattle, WA 98115 


\section{SERIES TITLE SHe Contractor Ceneral Wanagers Correspondence and hepons Filos}

\section{INCLUSIVE DATES $1975-1986$}

ARRANGEMENT (Multiple filing systems)

VOLUME 25 cubic feet

DESCRIPTION This series is composed of the records of the general managers of site contractors for the Idaho National Engineering Laboratory and some of their employees. There are two contractors included here who managed the site. The first is Aerojet Nuclear Company (ANC) which managed the site from 1971 until 1976, and the second is EG\&G which managed the site from 1976 until 1994. The records consist of incoming and outgoing correspondence with the U.S. Atomic Energy Commission and with its successor, the U.S. Energy Research and Development Administration. Also included are internal memorandums, annual reports, project descriptions, engineering design papers and proposals, operating procedures, operating reports, procedural guidelines, and minutes of weekly managers meetings. A few subject files deal with issues of safety and risk assessment and the Accident Investigation Committee. The general managers whose records comprise the bulk of the material are C. K. Leeper, who was general manager for ANC, and J.O. Zane, who worked for both ANC and EG\&G. Zane's files include some created before he became general manager. Also included are the records of Gary Marx, who was the manager of the Department of Planning and Budgets for EG\&G. His records include copies of correspondence and reports, arranged by department, and his budget presentations. There is one box of correspondence of J.R. Dubay of Material, Plant Services, and Engineering. General manager files for an earlier period have not been located and may have been destroyed.

LOCATION OF Federal Records Center

RECORDS Seattle, WA 98115 
INCLUSIVE DATES 1969-1985

ARRANGEMENT Chronological

Author

VOLUME 13 cubic feet

DESCRIPTION This series consists of office copies of correspondence and reports generated by and collected by their authors. The individuals who kept these files worked in the Health and Safety Division, and its successor divisions, over a long period of time. Their files record the various changes in contractors and organizational structure within an office that performed essentially the same function over this period. The contractor health and safety offices were concerned primarily with health safety and security issues that arose out of the day-to-day hazards of work on the site. Types of documents in this series include: memos, letters, route slips, weekly and monthly reports, safety anomaly reports, photographs, safety manuals, maps, plans, organization charts, and log books. They cover many safety related subjects including: bus accidents, pest control, decontamination, safety reviews, dosimetry, whole body counting, radiation protection, LOFT, and budgets. At least two letters discuss the planned human iodine-131 skin absorption experiment. The individuals whose files are collected in this series include: J. W. McCaslin, J. L. Clark, Lamar J. Johnson, Richard B. O'Brien, D. P. Halls, and Bryce L. Rich.

LOCATION OF Federal Records Center

RECORDS Seattle, WA 98115

\section{SERIES TILE Contractor Nedical and Bloassay fecords}

INCLUSIVE DATES 1951-1989

ARRANGEMENT Alphabetical (medical records)

Chronological (bioassay records)

VOLUME 11 cubic feet

DESCRIPTION This series contains bioassay and medical records from the Science and Technology Branch's Operational Dosimetry Organizations and the Quality Assurance, Safety, and Security-Industrial Safety-Medical Departments of the Idaho National Engineering Laboratory. The medical records were kept for personnel working under various DOE contractors during this period, including ENICO, AS\&S, Industrial Safety, Allied Chemical Corporation, Aerojet, and Idaho Nuclear Corporation. Document types included in the series are bioassays and medical records of individuals from 1951 to 1989. Bioassay records are kept by analysis number which are roughly chronological. Medical records include physical examinations of employees, medical tests, and other medical information and are kept alphabetically by employee last name.

RESTRICTIONS These records contain privacy material.

LOCATION OF Federal Records Center

RECORDS Seattle, WA 98115 


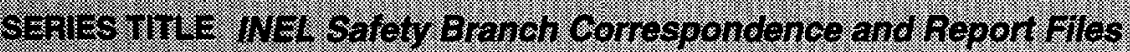

INCLUSIVE DATES 1962-1981

ARRANGEMENT Document type and date

VOLUME 7 cubic feet

DESCRIPTION These records document the safety monitoring by the following safety branches of the Idaho National Engineering Laboratory from 1960 to 1974: Idaho Nuclear Company Health and Safety, Directors Office of Health and Safety; EG\&G Idaho, Safety Division; EG\&G Idaho, Technical Safety Support Division; EG\&G Idaho, Safety Support; EG\&G Idaho, System Safety Development Center, Safety and Environmental Programs; and related safety branches of Aerojet Nuclear Company. The types of documents in this series include logbooks of instrument calibrations; Aerojet Nuclear Company correspondence of W.D. Hanson, P.B. Anderson, and others; industrial hygiene and safety correspondence (log of letters, subjects include safety issues, hazardous material disposal and spills, and equipment safety monitoring); health and safety equipment assessments; Governor's Committee on Radiation Directives and related correspondence; annual safety surveys and appraisals; D.P. Hall's, T. Stickley's, and J.W. McCaslin's letters; and EG\&G Idaho Interoffice Correspondence, letter logs, and document review forms. A rough box content listing is available.

LOCATION OF Federal Record Center

RECORDS Seattle, WA 98115

INCLUSIVE DATES 1974-1976

ARRANGEMENT Chronological

VOLUME 1 cubic foot

DESCRIPTION This series contains auto-radiographs of fallout collection plates of the Idaho National Engineering Laboratory gas stacks and soil samples. The series includes request forms from E.B. Tycz of the Environmental Safety Division for analysis by the Analytical Chemistry Branch of the Aerojet Nuclear Company, together with the plates of gas fallout from the stacks and deposition samples from the soil. Exposure time and date are marked on each plate as well as a tracking number generated by the Spectroscopy Section. The request forms indicate that the results were reported to $D$. Boyer and are in chronological order. The series also includes photographs of the radiographs. Isotopes include Rubidium-106, Sb-125, and Cs-137 soil samples. Titles of plates include "Stack Gas Filter" and "Fallout Plate." Plates from 1959 to 1974 have been destroyed; thus records documenting intentional releases as part of the Controlled Environmental Release Tests (CERT) 1963 through 1968 are not included.

LOCATION OF Federal Records Center

RECORDS Seattle, WA 98115 
SEAIES TILE PhIips Petroleum Company health fhysics and neactor background Radiation Logs and heports

INCLUSIVE DATES 1951-1964

ARRANGEMENT Within the logs, chronological; otherwise none

VOLUME 5 cubic feet

DESCRIPTION The bulk of these records are logs kept by the Materials Test Reactor ${ }_{3}$ Health Physics Section. Since 1951, a continuous survey of background radiation was kept at the Idaho National Engineering Laboratory by the Health Physics section or the Health and Safety Division of the Phillips Petroleum Company. The survey was maintained in these logbooks. Start-up logs appear to be the first logs kept of a reactor. The logs record the background radiation day by day. Information includes the location, date, time of day the reading was taken, the background radiation count, and narrative comments. Health Physics logs were also recorded by date and shift, and include the work done by employees, and the names of employees in each area of the reactor. They also include records of isotopes acquired. There is some mention of System for Nuclear Auxiliary Power (SNAP) tests. Also included are Radioactivity Incident Reports which include the supervisor's name, the names of personnel involved, the date and time of the incident, the material involved, narratives of the incidents, graphs, records of medical examinations conducted, and tissue or excreta samples collected and examined. These reports include thyroid exposure data for the iodine exposure incident in 1958. There are also logbooks of hot-waste-water storage tank samples and safe work permits.

LOCATION OF Federal Records Center

RECORDS Seattle, WA 98115 


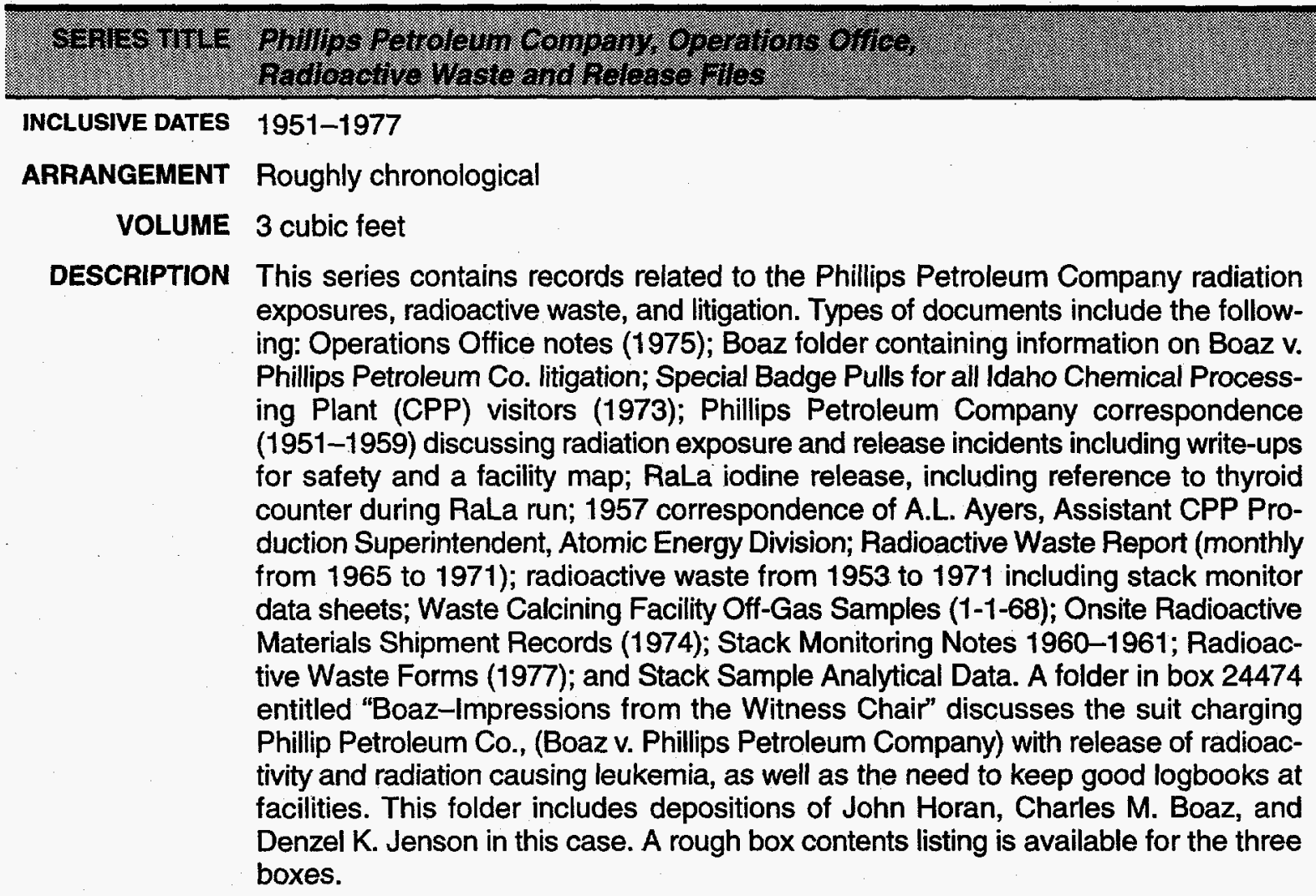

LOCATION OF Federal Records Center

RECORDS Seattle, WA 98115

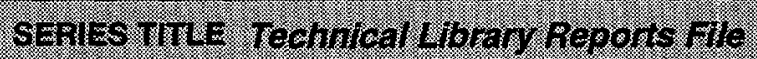

INCLUSIVE DATES 1950-present

ARRANGEMENT Report type; thereunder by report number

VOLUME approximately 300 cubic feet

DESCRIPTION This series consists of a collection of reports and publications maintained in the INEL Technical Library. There are approximately 800,000 reports on film and 200,000 in hard copy. INEL staff members are allowed to check out these reports for their personal use so some may be missing at any given time. Included are DOE Idaho numbered reports, Health and Safety Division annual reports, and the Radiological and Scientific Laboratory (RESL) annual reports.

LOCATION OF University Place

RECORDS Idaho Falls, ID 83401 
Lawrence Berkeley Laboratory

\section{The Site Today}

LAWRENCE BERKELEY LABORATORY (LBL) is a multiprogram research facility in Berkeley, CA. The University of California (UC) operates the Laboratory under a managing and operating contract with DOE. The Laboratory employs about 3,500 people and has an annual budget of about $\$ 250$ million. Research at LBL focuses on energy technology and biological sciences. The Laboratory operates unique national scientific facilities, including the Advanced Light Source and the $\mathrm{Na}$ tional Tritium Labeling Facility. LBL trains scientists and engineers and is involved in advanced technology transfer. LBL is also now expanding work in health sciences, environmental restoration, waste management, and energy efficiency.

\section{Site History}

The Laboratory has played an important role in the development of modern science and technology. Current ideas about using large teams to run complex equipment and explore interdisciplinary scientific issues originated at Berkeley. Many prominent scientists have worked at the Laboratory, nine of whom have won the Nobel Prize.

Current ideas about using large teams to run complex equipment and explore interdisciplinary scientific issues originated at Berkeley.

The origin of the Laboratory is traced to the arrival of Ernest $O$. Lawrence at UC Berkeley in 1928. Lawrence was a pioneer in nuclear physics: he built the world's first cyclotron at Berkeley in 1930. This machine accelerated nuclear particles in a predictable path by means of magnetic and oscillating electrical fields. The resulting beam of high-speed particles could disintegrate atomic nuclei and produce radioactive isotopes. The cyclotron opened new research opportunities in physics, chemistry, biology, and medicine. An adept entrepreneur, Lawrence met with steady success in convincing funding institutions of the scientific and practical benefits of his ideas. He won formal establishment of a UC Radiation Laboratory in 1936.
Lawrence, who served as Laboratory Director until his death in 1958, established a method of research known as "big science." Before establishment of the Radiation Laboratory, individual scientists had conducted research using simple equipment that they operated and built themselves. The cyclotron, however, was a large and complex machine that required the steady attention of many skilled people. The multiple uses to which a cyclotron could be put also led to the use of interdisciplinary research teams. This collaboration spawned significant technological developments, including powerful $x$-ray machines, new radioactive isotopes, and improved understanding of atomic and biological processes

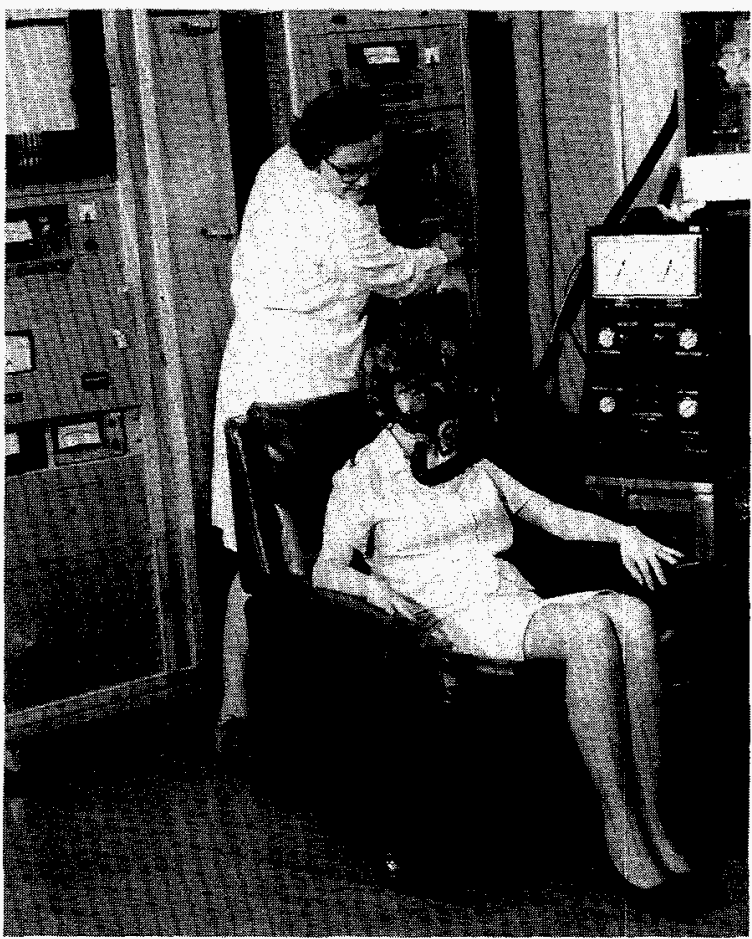

Figure 25. Respiration analysis using injected radioactive tracers at Donner Laboratory (circa 1968).

The Radiation Laboratory continued to grow with cyclotron advancement. Development ran from the 37 -inch and 60 -inch cyclotrons during the 1930s, the 184-inch cyclotron during the 1940 s, and the various specialized accelerators and other machines such as the Super-Hilac, the Bevatron, and the Advanced Light Source during 
the decades after the Second World War. Upon Lawrence's death, the facility was renamed Lawrence Radiation Laboratory. The University assigned the present title, Lawrence Berkeley Laboratory, in 1971.

Lawrence and his Laboratory were deeply involved in the war effort. Lawrence himself was one of the first scientists to believe that atomic weapons were feasible. His advocacy contributed to the creation of the Manhattan Engineer District, which assumed responsibility for the Laboratory's research in 1943. During this period, the Laboratory focused on developing a process for electromagnetic separation of a fissionable uranium isotope (uranium-235) for use in an atomic bomb. Using cyclotron technology and chemical processing techniques, the Laboratory produced the first samples of uranium-235. Berkeley participated in the design and construction of the electromagnetic separation plant $(Y-12)$ in Oak Ridge, TN. When the plant became operational, Lawrence and his staff devoted considerable time to resolving practical engineering issues and training the hundreds of people needed to operate the equipment.

Lawrence and his Laboratory were deeply involved in the war effort.

The Laboratory's scientific infrastructure supported important work in nuclear chemistry, including the discovery of many new transuranic elements. Laboratory researchers had discovered the first such element, neptunium, in 1940. Glenn T. Seaborg continued this work with the discovery of plutonium and played a key role in the discovery of over half a dozen new elements through the 1950s.

Work at the Laboratory also gradually expanded into other areas. A materials science center, established in 1961, studied the fundamental nature of materials at the molecular and atomic levels. By the 1970s, a major chemical biodynamics program was exploring green-plant photosynthesis and the chemical events that preceded the origin of life on Earth. The energy crises of the 1970 s led to work on fusion, geothermal, and solar energy technologies.

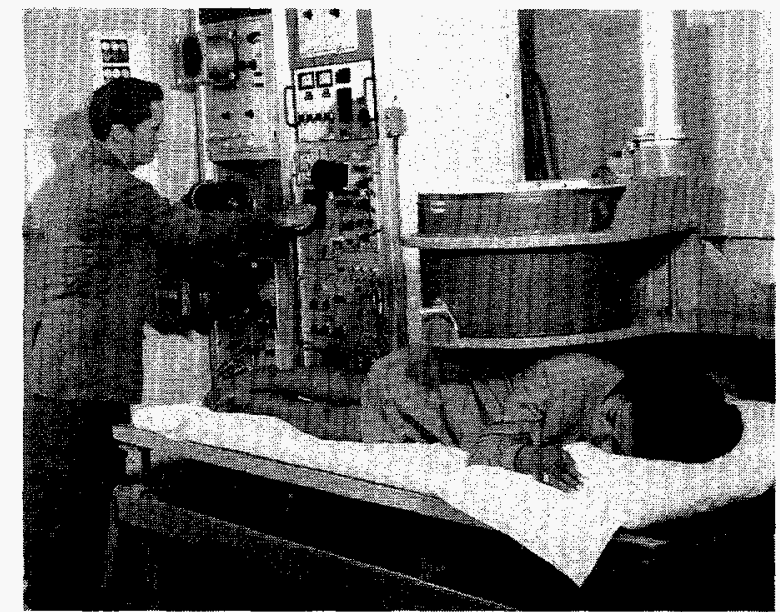

Figure 26. A patient under a positron camera. The camera was a diagnostic tool developed at Donner Laboratory, Berkeley, to photograph radioactive tracer concentrations. Unlike a whole body scanner, this device photographs a single, specific area of the body.

\section{Site Human Radiation Experiments}

The Laboratory has a long history of biomedical research involving radiation. Ernest Lawrence quickly realized the potential of radiobiology both for advancing science and for obtaining funding. Soon after creation of the Laboratory, he formed a Medical Physics Section. During the war, he established the Donner Laboratory specifically for this work. Early practitioners of radiation experiments at the Laboratory included John Lawrence, Paul Aebersold, Robert Stone, and Joseph Hamilton; all these individuals became major figures in radiobiology research.

Starting in the 1930s, biomedical researchers used the Laboratory's new equipment (such as particle beam accelerators and more powerful $x$-ray tubes) and substances (radioactive isotopes) to do experimental work on animals and people. The work on people centered on trial therapies for various medical conditions, especially cancer. Much of this medical treatment took place under the auspices of the UC hospital and medical school in San Francisco, and advanced the understanding of polycythemia rubra vera, leukemia, thyroid disorders, and other diseases. While this work was important from a scientific perspective, the practices surrounding patient consent and selection are unclear. Stone and Hamilton initiated these studies during the 1930 s, and both played key roles in controversial wartime human experiments with plutonium and other radioactive substances. 
During the war, the Laboratory curtailed its experimental treatment of disease and centered its biomedical research on issues associated with production of fissionable materials. While such materials were known to be harmful, production for the atomic bomb required hundreds of workers to labor with and possibly receive high exposure from them. Critical areas of concern were the effects of radioactive substances when they were inhaled, ingested, or entered the bloodstream through the skin.

During the war, the Laboratory centered its biomedical research on issues associated with production of fissionable materials.

While health protection was an overarching concern, other factors were apparent as well. Stafford Warren, head of the MED Health Section, noted that health and safety measures were needed to keep workers healthy and on the production lines. Security considerations also played a role in the desire to limit occupational illnesses and offsite radiation releases.

Working under the Health Section of the University of Chicago's Metallurgical Laboratory, the Radiation Laboratory was uniquely positioned to help the Manhattan Project. During the 1930s, Joseph Hamilton had established the Nation's first systematic radiation health and safety program at the Laboratory, and Warren applied Hamilton's ideas throughout the Manhattan Project.

Hamilton and some colleagues were also experienced in conducting experimental procedures involving radiation and radioactive substances. Berkeley medical staff injected three people with plutonium and one with americium at the UC hospital as part of the controversial human plutonium experiments.

Beyond the plutonium studies, Stone, Hamilton, and other laboratory researchers such as Cornelias Tobias, Bertram Low-Beer, and John Gofman conducted experiments with fission products and other radioactive substances during the war and immediately thereafter. There was also interest in the metabolism of thorium, protactinium, uranium, and yttrium. Most of this

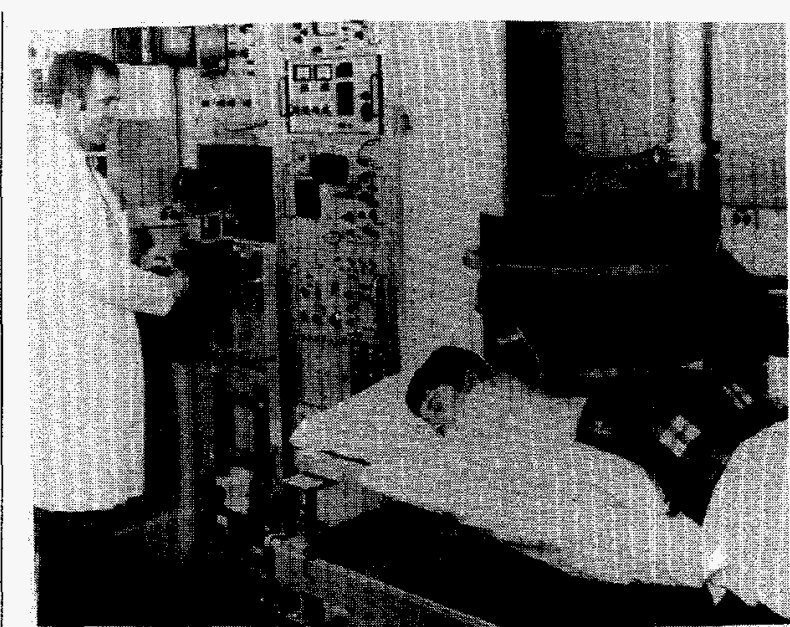

Figure 27. A kidney examination using a scintillation camera at Donner Laboratory, Berkeley.

research involved the use of animals, although Hamilton conducted studies involving the inhalation of zirconium oxides by human subjects.

Limited consent documentation is available for these early human studies. The therapeutic intent of this work is also unclear.

Other human studies involved the therapeutic and experimental use of radioactive potassium, tritium, iron, astatine, and carbon. Particle beams and other external radiation sources were also used. These studies had multiple, sometimes overlapping, purposes. They were conducted to treat disease, to understand biological processes, and to refine radiation dose/response information. As noted earlier, limited consent documentation is available for these early human studies. The therapeutic intent of this work is also unclear. While there was interest in treating cancer, for example, there was also strong interest in learning more about the body and how it was affected by radiation.

Other Laboratory biomedical research projects from the 1950s through to the present day include genetic mapping and sequencing, structural and molecular biology, biology of human disease, and bimolecular design. Researchers have had success in learning about cancer, arteriosclerosis, and blood disorders. The laboratory has in 
recent decades developed sophisticated medical imaging equipment, including Positron Emission Tomography and Computed Tomograph diagnostic scanners. While currently verified site experiments are detailed in Chapter 3, DOE expects to identify and describe additional Berkeley-related experiments in the near future.

\section{Site Records Collections}

Of all DOE facilities, LBL has done the best work in placing its records under intellectual control. The key to this success is a comprehensive inventory the laboratory has prepared for its active and inactive records. This inventory covers records of potential value for human ra-

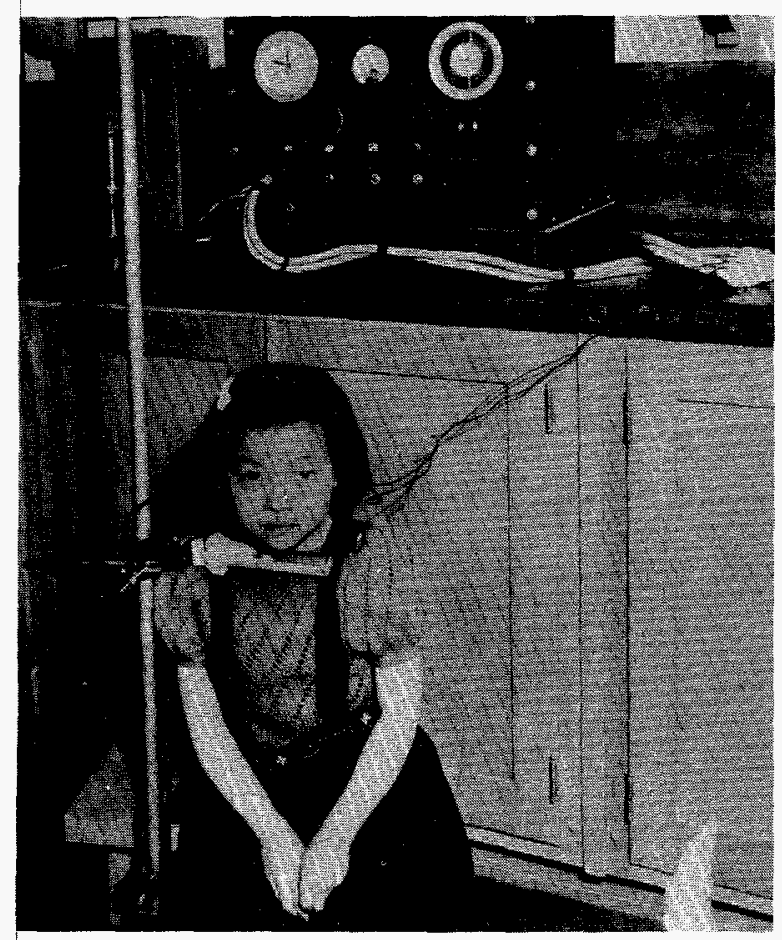

Figure 28. Early use of a Geiger-Müller counter to test thyroid function at Lawrence Radiation Laboratory.

diation experiments, as well as all other laboratory records. Space does not permit inclusion of the total inventory here. In addition, LBL archivists and records managers are working to identify and describe records relating to human radiation experiments at other sites including University of California facilities in San Francisco and
Los Angeles. DOE will make the results of this work available when it is completed. Researchers should contact OHRE or LBL for further information and assistance.

Of all Department of Energy facilities, Lawrence Berkeley Laboratory has done the best work in placing its records under intellectual control.

There is much documentation at LBL of human radiation experimentation from the 1930s to the present. Records detailing the work of Joseph Hamilton, Cornelius Tobias, E.O. and John Lawrence, John Gofman, Patricia Durbin, and other scientists are available. Experiments and other activities are discussed in files of the Crocker Laboratory, Donner Laboratory, and LBL Biology and Medicine Division. Topics covered include development of human use protocols, and specific isotope tracer and total body irradiation studies. Nearly all Laboratory records are unclassified or have been declassified. The location, content, and availability of especially pertinent records series are described are described below. 
Lawrence Berkeley Laboratory (LBL)

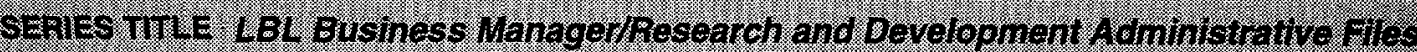

INCLUSIVE DATES 1946-1988

ARRANGEMENT Subject, thereunder chronologically

VOLUME 281 cubic feet

DESCRIPTION This series contains administrative documents, including materials relating to patents and inventions, purchasing operations, security, foreign visitors and building maintenance, construction, furnishings and equipment, materials pertaining to various accelerators, weapons tests, computers, miscellaneous personnel files, and files pertaining to finances. There are also files concerned with industrial hygiene and accidental exposure to radiation of staff members. The files include correspondence, reports, photographs, blueprints, and handbooks. The files were created during the administrations of multiple Lab directors.

LOCATION OF Lawrence Berkeley Laboratory

RECORDS Archives and Records Office Berkeley, CA 94720

Federal Records Center 1000 Commodore Drive San Bruno, CA 94066

\section{SERIES TILE LIfe Sciences DIViston-Administrative FIles of Bard Whaley Admmistrator}

INCLUSIVE DATES 1947-1988

ARRANGEMENT None

VOLUME 137 cubic feet

DESCRIPTION This series documents administrative activities of the Life Sciences Division. Documents include project correspondence, program proposals, human use information, budget information, annual reports, and building and equipment additions/maintenance. Subjects include NASA, LRL, and Atomic Energy Commission proposals; human use protocol development and specific program protocols; Bevalac planning, space allocation, and funding; Electron Linac and 184-inch Cyclotron administrative and project development information; fiscal year funding, budget, and recharge documentation; and Donner Laboratory historical administrative information, including Human Use Committee (of LBL) and Committee for the Protection of Human Subjects (of UCB) correspondence and protocol development with the Department of Health, Education, and Welfare and the National Institutes of Health. The records also contain correspondence documenting the establishment of biomedical research units at hospitals in Thailand and India.

LOCATION OF Lawrence Berkeley Laboratory

RECORDS Archives and Records Office Berkeley, CA 94720
Federal Records Center

1000 Commodore Drive

San Bruno, CA 94066 
INCLUSIVE DATES 1946-1987

ARRANGEMENT Reverse chronological order Subject

VOLUME 38 cubic feet

DESCRIPTION This series consists of administrative records created by various Administrative Assistants (among them: Igor Blake, R.A. San Souci, and Baird Whaley) in the course of their work for various Directors of the Biology and Medicine Division and Donner Laboratory (among them: John Lawrence, and James Born). Records include historic documents chronicling the planning, building, and funding of Donner Laboratory, Donner Annex, and Donner Pavilion; Director's Funds Research Proposals; correspondence; account ledgers; manuals; news clippings; blueprints and floor plans; animal care expenditures and inventories; Lab population lists; reprints of journal articles; Field Task Proposals; grant files; photographs; newsletters; organizational charts; purchase orders; and invoices. Correspondence sometimes contains descriptions of human experiments conducted or planned, including isotopes used and patient/subject selection.

LOCATION OF Lawrence Berkeley Laboratory

RECORDS Archives and Records Office

Federal Records Center

Berkeley, CA 94720 1000 Commodore Drive San Bruno, CA 94066

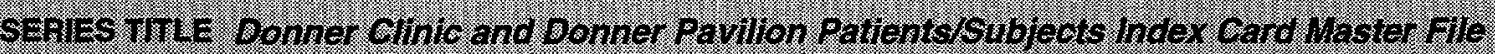

INCLUSIVE DATES $1938-75$

ARRANGEMENT Alphabetical by patient name

VOLUME 3.75 cubic feet

DESCRIPTION This series documents patients and subjects treated at the Donner Pavilion and Donner Clinic between 1938 and 1975. The index was created to keep track of and assist in locating medical charts for patients and subjects treated at the two Donner facilities. This is a semiactive records series maintained at Donner Pavilion, Life Sciences Division. These records contain: clinic number; patient, address, referring physician, referral diagnosis, date first seen, birth date, and death date. On some of the cards, the Patient Identification Number has been handwritten on the card.

RESTRICTIONS This series contains privacy material.

LOCATION OF Lawrence Berkeley Laboratory

RECORDS Archives and Records Office Berkeley, CA 94720
Federal Records Center 1000 Commodore Drive San Bruno, CA 94066 


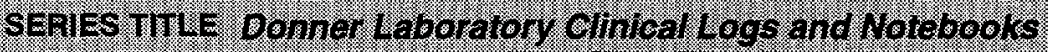

INCLUSIVE DATES ca. 1946-1977

ARRANGEMENT Record type

VOLUME 10 cubic feet

DESCRIPTION This series is comprised of patient appointment books, blood and bone marrow data, iron studies data, and miscellaneous clinical information pertaining to platelets, hematocrits, electrophoresis, and osmotic fragility. The majority of the information in this series is kept in small, bound logs or notebooks. Appointment books contain patient name, procedures, and physician name. Blood counts and bone marrow data include patient name, date of count, raw data, and occasional notes. Iron studies include patient name, weight, date, diagnosis and radioactivity injected, plus graphs and data relating to iron--59 injections. Several binders labeled "Blood Volumes" contain sheets listing patient name, weight, height, references to iodine-131 and date, time, and volume of injection. There are 13 sheets here that include the notation "San Quentin" after the patient name. These "San Quentin" sheets date from February and March of 1950. Miscellaneous clinical entries include patient name, date, and raw data.

RESTRICTIONS This series contains privacy material.
LOCATION OF Lawrence Berkeley Laboratory
RECORDS Archives and Records Office
Berkeley, CA 94720
Federal Records Center
1000 Commodore Drive
San Bruno, CA 94066

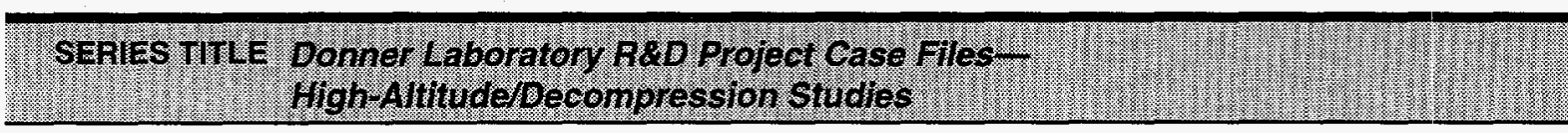

INCLUSIVE DATES $1940-1954$

ARRANGEMENT Varies

VOLUME 17 cubic feet

DESCRIPTION This series documents the research and activities of the Donner Laboratory, Aviation Medicine and High Altitude Physiology staff during WWII. The aim of these studies was to determine the effects of decompression on the human body for flight personnel. The series includes records documenting the experimental procedures performed on Peruvian, Army, Navy, Air Force, ROTC, and civilian subjects, as well as animals, in the decompression chamber and during flights out of the San Diego Aviation field. Radioactive isotopes were used as tracers in many of these studies. The series contains Committee on Aviation Medicine (CAM) reports, experimental notes, procedures performed on individual subjects, correspondence, individual scientist's files and notes (Hardin Jones and John Lawrence), $x$ rays of the knees and craniums of subjects, collected reference articles, photographs, graphs, charts, and original signed consent forms for underage subjects involved in these studies.

RESTRICTIONS This series contains a small amount of classified information.
LOCATION OF Lawrence Berkeley Laboratory
Federal Records Center
RECORDS Archives and Records Office
1000 Commodore Drive
Berkeley, CA 94720
San Bruno, CA 94066 


\section{SERIES TITLE Patient Medical Records}

INCLUSIVE DATES $1936-1983$

ARRANGEMENT Disease name; thereunder alphabetical by patient name

VOLUME 149 cubic feet

DESCRIPTION This series documents treatment of patients at the Donner Laboratory. Records consist of information and patient history forms, blood counts, urinalyses, correspondence with referring doctors and with patients, photographs, graphs, electrocardiographs, tomographic scans, notes, isotope therapy records, daily observations, and lists of dosages; in some cases consent forms are also present. Diseases documented include Hodgkin's disease, lymphatic leukemia, multiple myeloma, polycythemia rubra vera, thyroid problems, and acromegaly. Most pre-1950s cases appear to have involved John $\mathrm{H}$. Lawrence. Cases from 1950 and beyond involved other researchers at Donner Laboratory; Lawrence continued to oversee patient cases through the 1960s, when cases were seen by John A. Linfoot. Some records pertain to experimental work with radioactivity, and document treatment with $\mathrm{x}$ rays, radioactive phosphorus and strontium, iron, and radioactive yttrium for above-mentioned diseases. An index of diseases and cartons in which they are found is available.

RESTRICTIONS This series contains privacy material.

LOCATION OF Lawrence Berkeley Laboratory

RECORDS Archives and Records Office

Federal Records Center

Berkeley, CA 94720

1000 Commodore Drive

San Bruno, CA 94066

\section{SERIES TILE Research Mediche and Fadiaton Blophysics Hstorical Files}

INCLUSIVE DATES $1957-1979$

ARRANGEMENT Varies

VOLUME 11 cubic feet

DESCRIPTION This series documents development of nuclear radiation techniques for medical research at Donner Laboratory. Included are slides of experiments, grant proposals (both funded and not funded from 1966 to 1974), and films of Donner research, for both public and medical audiences. The grant proposal folders contain UC Request for Report of Inventions, Notice of Grants Awarded by the Dept. of Health, Education and Welfare, detailed budget sheets, Application for Research Grant Continuation Support, Summary Progress Reports, Notice of Research Project, and Committee for the Protection of Human Subjects approval memos. It appears that human involvement in these studies is limited to blood plasma/lipoproteins studies, but the project descriptions are lacking in some of these folders. Photographs of Donner staff from the 1950s, funding source lists, and articles are also present.

LOCATION OF Lawrence Berkeley Laboratory

RECORDS Archives and Records Office Berkeley, CA 94720
Federal Records Center 1000 Commodore Drive San Bruno, CA 94066 


\title{
SERIES TILLE Statistical Summaries
}

INCLUSIVE DATES $1937-1989$

ARRANGEMENT Varies

VOLUME 1.2 cubic feet

DESCRIPTION These files consist of statistical summaries of patients/subjects treated at the Donner Pavilion and Donner Clinic and in the several programs in Research Medicine since 1975. The records are primarily typescript pages that are maintained in three-ring binders and provide chronological statistical summaries of the treatment of patients/subjects at LBL by nuclear and radiological therapies. The format of the summary reports in each binder changes over time. These records were created and maintained for both their statistical summary function as well as a finding aid to be used in conjunction with the various card indexes for keeping track of biomedical charts for patients and subjects treated in the various Research Medicine Programs. Included are listings of all Donner patients/subjects; listings of new patients and deaths; survival lists of patients/subjects treated with alpha-particle irradiation organized by diagnosis, including but not limited to acromegaly, Nelson's Syndrome, Diabetic Retinopathy, Breast Cancer and prolactin-secreting pituitary adenoma; and lists of potential patients. A finding aid is available.

RESTRICTIONS This series contains privacy material.
LOCATION OF Lawrence Berkeley Laboratory
RECORDS Archives and Records Office
Berkeley, CA 94720
Federal Records Center 1000 Commodore Drive San Bruno, CA 94066

\section{SEAIES TILE Thomas Budinger files}

INCLUSIVE DATES 1961-1983

ARRANGEMENT Varies

VOLUME 27 cubic feet

\begin{abstract}
DESCRIPTION This series documents the research and activities of Budinger (Medical Director of Donner Laboratory from 1967 to 1978), from 1950 to 1984. Included are the following: original correspondence for Donner Medical Lab research; experimental/equipment development such as Positron Emission Tomography (PET), scanning techniques, and camera studies; patient files, including photographs of whole body, head, and hand scans and procedures performed; correspondence about patients/research subjects; proposals to, and the protocol of, the Human Use Committee; Budinger's notes; copies of reference articles; conferences/workshops attended and organized; notes on student experimental activities; and copies of grant proposals to various organizations submitted to Budinger for review. The series contains records related to experiments on humans and animals using many radioactive isotopes. The series is composed primarily of paper records, but also includes Laboratory photographs of scans.
\end{abstract}

LOCATION OF Lawrence Berkeley Laboratory

RECORDS Archives and Records Office

Berkeley, CA 94720
Federal Records Center

1000 Commodore Drive

San Bruno, CA 94066 


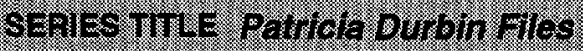

INCLUSIVE DATES 1940-1994

ARRANGEMENT Chronological by project or topic

VOLUME 89 cubic feet

DESCRIPTION This series consists of correspondence, abstracts, project descriptions, progress reports, original and final drafts of papers, grant proposals, notebooks, animal protocols, visual records, research specimens, and reference files created and maintained by Durbin. The files dating from 1940 to 1957 are research records from the Crocker Laboratory that were inherited by Durbin and are maintained by her as part of this series; these particular files have been microfilmed. Crocker Laboratory files dating from 1940 to 1957 include some files created or maintained by Joseph Hamilton. There is some variation in the format of the paper records, particularly in the reference files, which contain index cards and complete sets of animal progress reports of other biology groups in other national laboratories. Visual records $(35 \mathrm{~mm}$ slides, lantern slides, auto radiographs) total 2.75 feet and research specimens (microscope slides, bone blocks, bone bottles) total 5.25 feet.

LOCATION OF Lawrence Berkeley Laboratory

RECORDS Archives and Records Office

Berkeley, CA 94720

\begin{abstract}
Federal Records Center 1000 Commodore Drive

San Bruno, CA 94066
\end{abstract}

\section{SERIES TILE John W Cotman Files}

INCLUSIVE DATES $1950-1959$

ARRANGEMENT Varies

VOLUME 4 cubic feet

DESCRIPTION This series documents Gofman's research, which included thyroid studies, cancer and drug research, studies of lipoproteins and atherosclerosis, as well as his professional activities, such as University of California committee work. Records consist of correspondence, patient data, group progress reports, proposals, drafts, papers, questionnaires, follow-up forms, blood shipment lists, case report forms, and references. They are arranged loosely by study, so that most data pertaining to a particular experiment or study in a project is kept in one folder; blood sample information appears to be arranged by source (e.g., doctor providing the blood; other records, such as correspondence and reports, are not arranged systematically).

LOCATION OF Lawrence Berkeley Laboratory

RECORDS Archives and Records Office Berkeley, CA 94720
Federal Records Center 1000 Commodore Drive San Bruno, CA 94066 
SARES TIILE Josesh C. MamILon Records

INCLUSIVE DATES 1943-1975

ARRANGEMENT Varies

VOLUME 12 microfilm reels

DESCRIPTION These records have been copied from various collections to form an artificial collection of records pertaining to Hamilton. Many of these records were created by Hamilton and transferred to the LBL Archives and Records Office in 1957. Patricia Durbin used the files for her follow-up study of the 1945-1947 plutonium injections. Attached to each reel are file folder listings, a biographical sketch of Joseph G. Hamilton, and a scope and content note. Some notable projects represented here include Dugway bomb tests, and Project Sunshine, a study of the effects of strontium-90. Other records from the 1950s seem to be more directly related to Durbin's research or to the research of other, newer members of the research group. They document Durbin's early work with radioactive materials in animals and in some cases with humans. Human studies include a study of astatine in patients with goiter or adenoma and a study of milk and baby food (tracing natural levels of strontium and other elements). Durbin's follow-up studies of people injected with plutonium or americium in the 1940s include some correspondence, notes, and data. A finding aid with reel and microfilm frame numbers is available.
LOCATION OF Lawrence Berkeley Laboratory
RECORDS Archives and Records Office
Federal Records Center
Berkeley, CA 94720 1000 Commodore Drive
San Bruno, CA 94066

\section{SERIES TILLE Joseph G. Hamilton Matertals: EdWin M. MCMilan Papers}

INCLUSIVE DATES 1938-1973

ARRANGEMENT None

VOLUME 0.2 cubic foot

DESCRIPTION This series contains correspondence, article reprints, reports, newspaper clippings, photographs, and transparencies pertaining to the work of Joseph G. Hamilton. The series documents use of human subjects in Hamilton's radiation experiments with photographs of human tissue and charts recording human metabolism of radioisotopes. While the photographs of human tissues do not reference particular experiments, they are consistent with other records that document human subject radiation research by Hamilton. The series was created during the directorships of Edwin McMillan and E.O. Lawrence, and has no particular arrangement.

\section{LOCATION OF RECORDS}

Lawrence Berkeley Laboratory

Archives and Records Office

Berkeley, CA 94720

\author{
Federal Records Center \\ 1000 Commodore Drive \\ San Bruno, CA 94066
}




\section{SEniEs ThLE Wardh Jones tiles}

INCLUSIVE DATES 1940-1978

ARRANGEMENT Author name

VOLUME 3 cubic feet

DESCRIPTION This series is composed primarily of article reprints from the files of Hardin Jones, but it also contains some correspondence, papers and reports. The articles come from a number of medical joumals, mostly American, but European as well. They pertain to a variety of medical disciplines, but many are about experimental procedures and radiology. Topics include Laguna-Honda Hospital human studies and Donner Clinic metabolic studies. Experiments located at Laguna-Honda include a $I^{131}$ uptake study, and an electrolyte metabolism study in patients with malignancies using $\mathrm{Na}^{24}$ and $\mathrm{K}^{42}$. The hospital also studied leukemic children treated with radiation, use of tagged substances in the study of afferent arteries, and radiation to the pituitary in cancer patients. In addition to experiments with radiation, patients at Laguna-Honda Hospital were used for experimental drug and chemical therapies outlined in other funding proposals in this file.

LOCATION OF Lawrence Berkeley Laboratory

RECORDS Archives and Records Office Berkeley, CA 94720

Federal Records Center 1000 Commodore Drive San Bruno, CA 94066

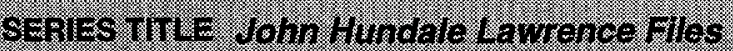

INCLUSIVE DATES 1932-1986

ARRANGEMENT Varies

VOLUME 65 cubic feet

DESCRIPTION This series chronicles the personal and professional life of Lawrence (1904-1991). Considered one of the pioneers in the field of nuclear medicine, Lawrence was the brother of LBL's first Director, Ernest O. Lawrence. John Lawrence served as Director of Donner Laboratory (1948-1970), Professor of Medical Physics at the University of California at Berkeley (1950-1970), Physician-in-Chief, Donner Pavilion (1954-1970), Associate Director, Lawrence Radiation Laboratory (1959-1970), and Regent of the University of California (1970 to early 1980s). The series contains correspondence; photographs; 35mm and lantern slides; preprints and reprints; newspaper clippings; negatives; charts; graphs; data; manuscripts; course materials; curricula vitae; floor plans; protocols; records of invention; viewgraphs; speeches and talks; sound recordings; and travel plans. These records clearly depict the scientific and social milieu in which Lawrence operated. The correspondence documents the growth of Lawrence's international reputation in nuclear medicine; his personal, religious, and political beliefs; Lawrence family history; and the history of Donner Lab, Donner Pavilion, and the Metabolic Unit at Cowell Hospital.

RESTRICTIONS This series contains privacy material.

LOCATION OF Lawrence Berkeley Laboratory

RECORDS Archives and Records Office

Berkeley, CA 94720
Federal Records Center 1000 Commodore Drive San Bruno, CA 94066 


\section{SERIES TITLE John Rundale Lavienco Rosearch Subject files}

INCLUSIVE DATES 1962-1975

ARRANGEMENT None

VOLUME 0.3 cubic foot

DESCRIPTION This series documents the research and administrative activities of Lawrence (1904-1991), brother of founder of LBL, Ernest O. Lawrence. In 1935 John Lawrence joined Ernest in Berkeley and became interested in the use of artificially produced radioisotopes and nuclear radiation in medicine. In 1936 Lawrence founded the Donner Laboratory within the Radiation Laboratory. Lawrence retired from Donner in 1969. He served as a University of California (UC) regent from 1970 to 1983 and was president of the Society of Nuclear Medicine in 1966-1967. This series is composed of two subseries: subject files in labeled file folders and a binder labeled Slides JHL.

RESTRICTIONS This series contains privacy material.

LOCATION OF Lawrence Berkeley Laboratory

RECORDS Archives and Records Office

Federal Records Center

Berkeley, CA 94720 1000 Commodore Drive San Bruno, CA 94066

\section{SERIES TITLE Thornton Sargent Administrative Files}

INCLUSIVE DATES 1961-1994

ARRANGEMENT Subject

VOLUME 11.5 cubic feet

DESCRIPTION Dr. Thornton Sargent is a biophysicist at Donner Laboratory whose research involves using radioisotopes in human and animal subjects to study physiologic processes. This series contains correspondence; grant proposals; personnel records, such as dosimetry, student assistant files by name; Donner staff committee meeting records; budget and funding information; safety data; radiation safety; administrative materials relating to whole body counter; pharmaceuticals; experimental proposals for projects that didn't get done; Donner administration materials; and travel. This series contains a file on human use protocols, filed by study name, and a file on consent forms and human use protocols that were in effect at the time human subject studies were approved.

LOCATION OF Donner Laboratory

RECORDS LBL Archives and Records Office

Berkeley, CA 94720 


\section{SERIES ThLE Thornton Sargent Patient Medical Case Flles}

INCLUSIVE DATES $1959-1994$

ARRANGEMENT Study

Patient name

VOLUME 17 cubic feet

DESCRIPTION This series contains patient case files relating to Sargent's studies using radioisotopes in human subjects to study physiologic processes. The files include raw data measurements and medical evaluation of subjects for the following studies: studies of calcium/strontium metabolism in patients with acromegaly and bone cancer (19641969); cobalt studies of subjects with $B_{12}$ deficiency v. normal subjects; chromium-51 studies of subjects with diabetes and hemochromatosis (1970s); iron studies of patients injected with thorotrast to compare iron absorption in normal v. iron deficient subjects; brain metabolism studies using iodine-122, filed by type of patient, e.g., depression, schizophrenia; brain imaging studies using bromine isotope for brain scanning on laboratory personnel, and zinc studies of mostly normal subjects (mid1960s). Patient records note name, weight, height, date of birth, employee number, work location, phone, date and results of urine bioassay test, dates of whole body counts, calculation of actual exposure, spectra of detected activity in both tabular and graphic forms, list of isotopes with which employee regularly works, patient's uptake level (if known), and suspected location of exposure, and either referral letter from outside physician or from Environmental Health \& Safety Division of LBL. There are also records for patients, referred by outside physicians, who may have been exposed to dangerous levels of radiation (e.g., as a result of Chernobyl nuclear reactor accident). Records of experimental exposures note isotope used, amount injected, daily counts, and final analysis.

RESTRICTIONS This series contains privacy material.

LOCATION OF Donner Laboratory

RECORDS LBL Archives and Records Office

Berkeley, CA 94720 


\section{SERIES TILLE Thomton Sargent Publication Working Files}

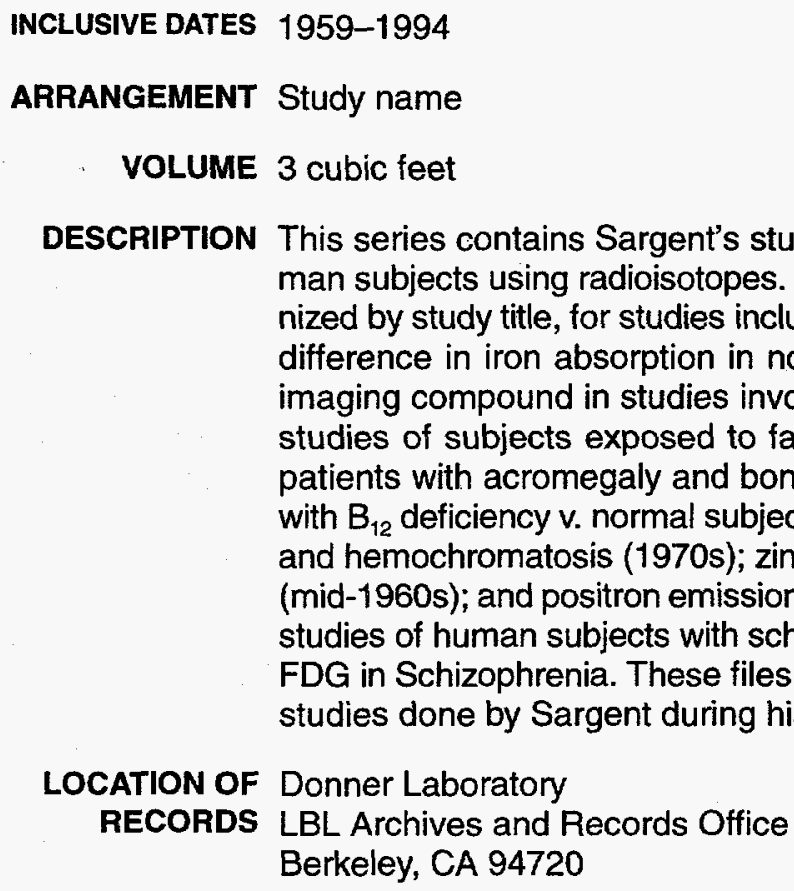

DESCRIPTION This series contains Sargent's studies of physiological processes in animal and human subjects using radioisotopes. Files in this series contain analyses of data, organized by study title, for studies including: subjects injected with thorotrast to evaluate difference in iron absorption in normal v. iron deficient subjects; bromine as brain imaging compound in studies involving lab personnel; cesium-137 and cesium-132 studies of subjects exposed to fallout; studies of calcium/strontium metabolism in patients with acromegaly and bone cancer (1964-1969); cobalt studies of subjects with $B_{12}$ deficiency $v$. normal subjects; chromium -51 studies of subjects with diabetes and hemochromatosis (1970s); zinc studies (unpublished) of mostly normal subjects (mid-1960s); and positron emission tomography (PET) 280 fluorodeoxyglucose (FDG) studies of human subjects with schizophrenia. Titles in this series include: Iron Paper, FDG in Schizophrenia. These files provide a fairly complete overview of the types of studies done by Sargent during his years at LBL.

ARRANGEMENT None

VOLUME 0.2 cubic foot

DESCRIPTION This series consists of a single file that contains an incomplete, 70 page transcript of an oral history interview of Kenneth Scott conducted by Sally Hughs on December 17, 1979. References to humans treated or experimented with radiation include treating leukemia patients with radioactive phosphorous in 1937; there are also references to the plutonium injection experiments.

\author{
LOCATION OF Lawrence Berkeley Laboratory \\ RECORDS Archives and Records Office \\ Berkeley, CA 94720
}

\author{
Federal Records Center \\ 1000 Commodore Drive \\ San Bruno, CA 94066
}


INCLUSIVE DATES 1945-1989

ARRANGEMENT Chronological

VOLUME 11.5 cubic feet

DESCRIPTION This series contains files relating to the research of William Siri who was a physicist at Donner Laboratory. Topics covered are human body composition, including studies of total body water, hydrogen exchange, acromegaly, and hypoxia. Files include LBL interoffice correspondence, and correspondence with outside colleagues; records relating to biophysics conferences and presentations; committees on which Siri served, such as Energy and Environment Division Council, and National Research Council; manuscripts and abstracts in draft, published form, grant applications and annual reports; drawings and plans for mass spectroscope, and altitude and low pressure chambers; and patient and human subject charts and graphs. Patient and human subject documentation includes raw data, cardiograms, notebooks for tritium studies, and studies using radioisotopes such as carbon-14, potassium-40, chromium-57, and iron-59. This series contains records of high altitude studies conducted in Peru in 1952, Bolivia in 1957, and relating to the American Mount Everest Expedition (AMEE) in 1963, using radioisotopes on human subjects. Files are arranged chronologically by subject in three-ring binders and folders. This series contains videotapes of heart flow and monkey studies, and 21 rolls of numbered electrographs.

LOCATION OF Federal Records Center

RECORDS LBL Archives and Records Office

Berkeley, CA 94720 


\section{SERES THLE Comenos A. TOblas TIES}

INCLUSIVE DATES 1937-1991

ARRANGEMENT Varies

VOLUME 105 cubic feet

DESCRIPTION This series documents Tobias' work as Professor of Medical Physics at the University of California at Berkeley, as well as his administration of the Radiation Biophysics Group at Donner Lab. Primary subseries include: subject and author literature searches; scientific journal reprints and preprints by both Tobias and others; correspondence; grant applications, research proposals and reports; instructional material; student theses and dissertations; recommendations for students, faculty and staff; experimental data; materials related to various Lawrence Berkeley Laboratory (LBL) organizations; LBL publications; documents related to Tobias' committee work on the Light Ion Biomedical Research Accelerator (LIBRA) and his Directorship at the Advanced Biomedical Science and Treatment Center (ABC); and Biology and Medicine Division staff files. This series also includes bibliographies, curricula vitae, journals, catalogs, technical reports and papers, patents, notebooks, experimental logbooks, and transcriptions of Sally Smith Hughs' oral history interviews of Tobias in $1979-1980$.

RESTRICTIONS This series contains privacy material.
LOCATION OF Lawrence Berkeley Laboratory
RECORDS Archives and Records Office
Berkeley, CA 94720
Federal Records Center
1000 Commodore Drive
San Bruno, CA 94066

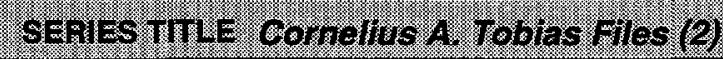

INCLUSIVE DATES 1943-1970

ARRANGEMENT Record type; alphabetical/chronological thereunder

VOLUME 38 cubic feet

DESCRIPTION This series documents Tobias' work as a Radiation Biophysicist at Donner Lab and LBL, as well as his professional association with various national and international committees, hospitals, and research facilities. Types of documents included are: drafts and final, scientific reports; AEC reports on experimentation with plutonium and $\mathrm{I}^{131}$ (Project 48A); scientific notes and correspondence related to radiation experimentation; slides, charts, and analysis of the uptake and desaturation curves of humans and animals used in radioactive tracer experiments; photographs of Donner personnel, scientific projects, and equipment; student information; curriculum vitae of physicists considered for jobs at LBL/Donner; Tobias' notes from classes taken as a graduate student, including copies of his thesis; publication correspondence; correspondence relating to applications for human use; correspondence with other facilities in a consultative capacity for cyclotrons and isotope techniques; blueprints for scientific equipment; patent files and applications; and copies of notes used for presentations and talks at seminars and conferences. The series also includes some of Tobias' personal correspondence and photographs. The series as a whole gives an overview of Tobias' career and his interaction with the international scientific community.

\section{LOCATION OF Lawrence Berkeley Laboratory \\ RECORDS Archives and Records Office Berkeley, CA 94720}

Federal Records Center 1000 Commodore Drive San Bruno, CA 94066 


\section{SERIES TILE Dorate Von DYte Flls}

INCLUSIVE DATES 1957-1975

ARRANGEMENT Varies

VOLUME 10 cubic feet

DESCRIPTION This series documents Van Dyke's work on blood and bone marrow studies. Particular fields of research included studies of human erythropoietic activity in plasma, cardiac evaluation from radioisotope dynamics, and blood transport through bone marrow. Studies include both animal and human experimentation, chiefly for the advancement of research on forms of leukemia, myeloma, and anemia. Techniques included induced parabiosis in animals (fusion of two animals to study passage of solutes from one to the other); skin grafts; spinal cuts; exposure to light and dark, and in both humans and animals, fluorokinesis, assays using radioactive iron, use of alpha-corticotrophin, ACTH, EHDP, and synthetic calcitonin; and studies of iron involved femur injections. The series consists of notebooks, data, graphs, manuscripts, drafts, references, photographs, negatives, $x$ rays, correspondence, magnetic tapes of data, and conference planning materials. Some subjects were prisoners and were recruited from the United States Public Health Service or San Francisco Public Health Service; work was also done on patients from San Francisco General Hospital. Human subjects included normal controls and patients, both adults and children. Correspondence and administrative records have gaps.

RESTRICTIONS This series contains privacy material.
LOCATION OF Lawrence Berkeley Laboratory
RECORDS Archives and Records Office
Berkeley, CA 94720
Federal Records Center 1000 Commodore Drive San Bruno, CA 94066


Lawrencel Lvermore National Laboratory

\section{The Site Today}

HISTORICALLY, THE PRIMARY mission of Lawrence Livermore National Laboratory has been nuclear weapons research and design. Livermore now supports other programs as well, including arms control and verification, fusion, lasers, materials research, and general energy research. The Laboratory is situated on $\mathbf{8 2} \mathrm{I}$ acres in Livermore, CA, about 50 miles east of San Francisco. In 1992, Livermore had an operating budget of over $\$$ I billion and employed approximately 8,000 people. It operates the National Energy Research Supercomputer Center, the National Genome Research Center, and other specialized facilities. Since Livermore's establishment in 1952, the University of California has run the Laboratory under a managing and operating contract with DOE.

\section{Site History}

After the Soviet Union detonated a nuclear device in 1949, the United States launched a program to develop a hydrogen bomb. Lawrence Livermore National Laboratory grew out of debates within the atomic energy and defense communities about the adequacy of the resources devoted to the hydrogen bomb program. The AEC was initially reluctant to create another nuclear weapons laboratory in addition to Los Alamos. Pressure from the joint Committee on Atomic Energy and the Department of Defense, as well as the adrocacy of physicist Edward Teller, led the AEC to build a second weapons laboratory. The facility was placed at Livermore, which was then the site of an abortive effort to build a prototype particle accelerator to produce plutonium or tritium.

Lawrence Livermore National Laboratory grew out of debates about the adequacy of resources devoted to the hydrogen bomb program.

Initially, Livermore was a branch of Ernest O. Lawrence's Radiation Laboratory in Berkeley. When Livermore opened in 1952, it employed 123 people, many of them still working in Berkeley.
Broadly speaking, Livermore addressed aspects of designing and testing thermonuclear weapons and related research, notably controlled fusion research that became part of the AEC's Project Sherwood.

The 1963 test ban treaty and technical difficulties derailed plans to use nuclear explosives to excavate a new Atlantic-Pacific canal through Central America.

The first efforts of Livermore's bomb designers proved disappointing, although this did not slow laboratory growth. Weapons design breakthroughs came in 1955 during Operation Teapot and in 1956 during Operation Redwing. In 1955, Livermore received its first weapon development assignment, the warhead for the Navy's Regulus II cruise missile. Two years later the Navy commissioned Livermore to design and develop warheads for its new Polaris missiles. Two other large development projects also began in 1957: Project Pluto to develop nuclear ramjets and Project Plowshare to develop peaceful nuclear explosives.

From its inception, Livermore had supported research on magnetic fusion. Under the auspices of the AEC's Project Sherwood, several other laboratories were also looking for practical methods of confining a fusion reaction to produce useful energy. The laboratory also began its long involvement with high-powered computing in its early days; the first UNIVAC arrived in 1953 and was used for fusion and weapons research.

A moratorium on nuclear weapons testing went into effect in November 1958, lasting almost 3 years. Despite questions raised about the future of the laboratory - it was hardly certain that nuclear weapons testing would ever resumeLivermore continued rapid growth. During the moratorium, Livermore scientists pursued some weapons design work using computers. Stimulated by their desire to understand the physics of nuclear explosions, weapons designers developed increasingly complex computer models. Livermore has become known for its efforts to 
understand many complex phenomena through computer modeling.

During the 1960s, the laboratory's nuclear weapons design program centered largely on requirements for strategic missile systems. The laboratory developed warheads for the secondgeneration Polaris and its successor, Poseidon. While the Air Force continued to rely heavily on Los Alamos to develop bombs and some missile warheads, it increasingly assigned warhead development for its intercontinental ballistic missiles, notably Minuteman, to Livermore. By the end of the decade, most of the warheads in the $\mathrm{Na}$ tion's strategic nuclear weapons stockpile were Livermore designs. Livermore also designed several tactical weapons systems for the Army, among them short-range Lance missiles, groundlaunched cruise missiles, and nuclear artillery.

Initially focused on large-scale earthmoving, or nuclear excavation, the Plowshare project-the peaceful nuclear explosives program-became one of Livermore's major programs through the 1960s. The 1963 test ban treaty and technical difficulties, however, derailed plans to use nuclear explosives to excavate a new Atlantic-Pacific canal through Central America. A reoriented program focused on using nuclear explosives to free natural gas from rock formations, but ambiguous experimental results and the environmental legislation of the late 1960s spelled the end of Plowshare.

Livermore has become known for its efforts to understand many complex phenomena through computer modeling.

In June 1971, Livermore became independent from Berkeley. Responding in part to campus protest, the Lawrence Radiation Laboratory divided into the Lawrence Berkeley Laboratory and the Lawrence Livermore Laboratory, with Livermore continuing its nuclear weapons activity and Berkeley focusing on unclassified research. In 1980, Congress gave the laboratory a new name: Lawrence Livermore National Laboratory.

By the mid 1970s, Livermore had become a center for agency fusion research. The invention of the laser offered a potential avenue toward the goal of controlled fusion. For Livermore, laser fusion had an additional advantage: laser-generated thermonuclear microexplosions allowed access to new kinds of weapons physics study. Beginning in the early 1970s, the Laboratory developed a series of neodymium-glass lasers, each more powerful than its predecessor.

\section{Site Human Radiation Experiments}

Livermore was the site of few known human radiation experiments. To date, three human experiments have been identified at this site. In 1963, a biomedical division was established at Livermore, headed by John Gofman, formerly of the Berkeley laboratory. This was consistent with the agency's decision to expand biomedical research activities into hazards of radioactive fallout. The AEC and the laboratory also wanted the Livermore unit to characterize the radioactive hazards that might arise from Project Plowshare. Livermore biomedical program personnel engaged in human radiation experiments during the early 1970s. Two of the Livermore human radiation experiments were designed to calibrate a biomedical research instrument, the whole body counter. The third involved the use of radioisotopes to study decompression sickness. Individual site experiments are detailed in Chapter 3.

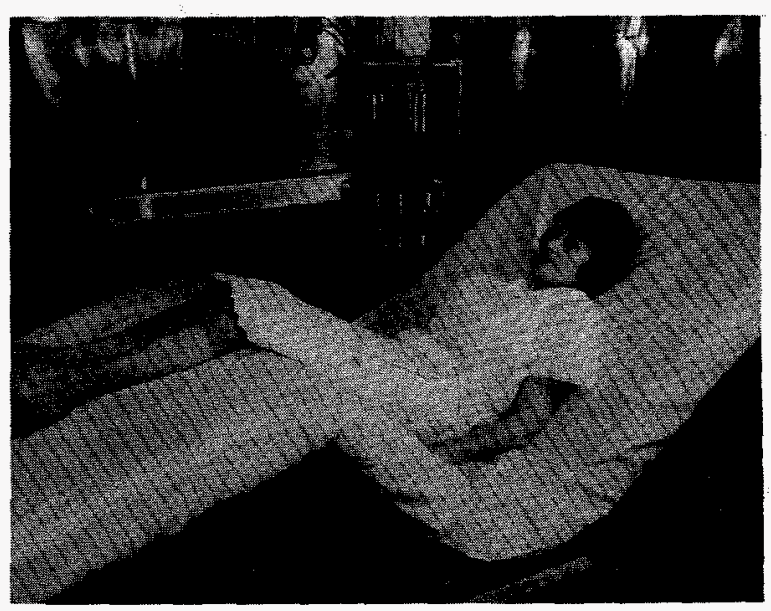

Figure 29. A conventional whole body counter (circa 1964). 


\section{Site Records Collections}

Livermore's known involvement in human experimentation is limited, as is the material thus far found. Many records collections that contain information pertinent to human radiation experiments have been consolidated into artificial groups. The series descriptions reflect Livermore's limited intellectual control over its records in contrast to the other laboratories run by the University of California. Although none of the series described here contain classified records, it should be noted that the facility itself is classified; access is difficult and must always be arranged in advance. One important group, which did not conform to the descriptions standards of this project and is not included below, is a 2,200-cubic-foot collection of laboratory historical records in the custody of the Laboratory historian. Livermore does have an archival facility, but has not traditionally used it to provide extensive material to the public. 
Chapter 2. Narratives and Records Series-Institutional Areas: Lawrence Livermore National Laboratory

\section{Lawrence Livermore National Laboratory (LLNL)}

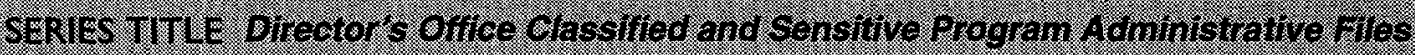

INCLUSIVE DATES 1979-present

ARRANGEMENT Alphabetical by subject

VOLUME 348 cubic feet

DESCRIPTION This record series functions as record of accomplishments, and provides background information as a basis for evaluating alternatives, as well as providing documentation of the actions taken by the Director's Office and the Laboratory. It is used for reference, documentation and tracking activities and consists of budget files, personnel awards, contracts, reviews, logs, correspondence, memorandums, photographs, travel files, and videos. Includes are mail logs, UC Contract 48, incoming and outgoing DOE and UC correspondence, and UC Regents Meeting Minutes.

LOCATION OF Lawrence Livermore National Laboratory

RECORDS Records Management Group 7000 East Avenue, L-511 (Vault)

Livermore, CA 94550

\section{SERIES TITLE Laboratory Counsels Legal Subjeot Fibs}

INCLUSIVE DATES 1970-present

ARRANGEMENT Alphabetical by subject

VOLUME 75 cubic feet

DESCRIPTION This series documents the Laboratory Counsel's legal and administrative functions. The records delineate the role of the Laboratory Counsel in dealing with a wide range of issues having to do both with internal laboratory personnel, equipment, procedures and policies as well as with external institutions and individuals. These records consists of correspondence; memorandums; reports; policies and procedures; opinions; and research materials. Subjects in this record series include Safeguards and Security, Drug Testing files, Human Subject files, and Health Services files.

LOCATION OF Lawrence Livermore National Laboratory

RECORDS Building 253, Room 1717

Berkeley, CA 94720 


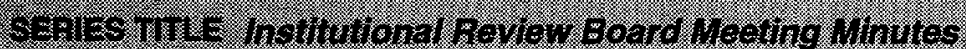

INCLUSIVE DATES $1975-1994$

ARRANGEMENT Chronological

VOLUME 4 cubic feet

DESCRIPTION The series consists of the minutes which are the collected notes of the proceedings of the Institutional Review Board (IRB). The IRB is the LLNL entity that has the responsibility for reviewing and approving requests for the use of humans as subjects in experiments or research activities. Records for each protocol describe the involvement of human subjects and the risks, if any, to which they are exposed. The minutes include the meeting date; location; members present; matters considered, including old business, new business, and minutes approval; and the record of votes taken as to whether the protocol being discussed should be approved. Related documents are attached to the minutes. The official copies of the minutes are maintained in hard copy by the Secretary to the Chairman of the IRB. A database of the minutes also provides summary information for the following categories: meeting date, IRB Project Number, title of project discussed at the IRB meeting, name of researcher, status of action, result (indicates whether or not the project was approved), and comments on whether or not the protocol was used subsequent to its approval. Three protocols involve experiments in which consenting human subjects were intentionally exposed to radiation.

RESTRICTIONS This series contains privacy material.

LOCATION OF Lawrence Livermore National Laboratory

RECORDS Building 361, Room 1134, 1 c.f.; Room 1063, 3 c.f.

Berkeley, CA 94720

\section{SEFlES TITLE Instutional Review Board protodol Flles}

INCLUSIVE DATES 1972-1994

ARRANGEMENT Active and inactive files; thereunder alphabetical by principal investigator

VOLUME 3 cubic feet

DESCRIPTION The series contains documentation of requests to use human subjects in scientific experiments which are submitted to the LLNL Institutional Review Board (IRB) in the form of protocols. Records for each protocol describe the involvement of human subjects and the risks, if any, to which they are exposed. The protocols are reviewed and discussed by the IRB and approved or rejected. The types of documents found in this collection include project summary sheets, consent forms, and correspondence and memorandums. The series contains one file folder entitled "Research on Human Subjects, 1972-1984," which contains University of California memorandums and correspondence.

RESTRICTIONS This series contains privacy material.

LOCATION OF Lawrence Livermore National Laboratory

RECORDS Building 361, Room 1134 and 1063

Berkeley, CA 94720 


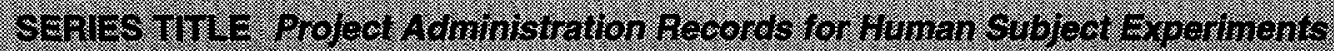

INCLUSIVE DATES 1978-1990

ARRANGEMENT None

VOLUME approximately 1.5 cubic feet

DESCRIPTION Records in this series document the work of the Whole Body Counter (WBC) staft in conjunction with: three phantom validation studies using niobium- $92 \mathrm{~m}\left(\mathrm{Nb}^{92 m}\right)$ to simulate inhaled plutonium; related studies using barium and strontium; and project administration records, including interaction with the LLNL Institutional Review Board (IRB). Subjects included in the collection are lung calibration/validation using the LLNL Humanoid lung, assistance with a British program to establish changes in lung counter calibration for $\mathrm{Nb}^{92 \mathrm{~m}}$, the use of $\mathrm{Ba}^{13}$ and $\mathrm{Sr}^{85}$ in tests conducted with a small number of human subjects, discussion of issues relating to use of human subjects, and request to Human Subjects Committee to allow participation of LLNL employees in the niobium inhalation study. Types of records in this series include memorandums, correspondence, journal articles, reports, raw scientific data, messages, handwritten notes, and photos. The series also includes a collective group of calibration data relating to the three validation studies, and the studies done with $\mathrm{Ba}^{133}$ and $\mathrm{Sr}^{85}$. For these same studies, raw scientific data is stored on magnetic disks, which is not readily accessible under current Whole Body Counter computer systems. The contents of this series are more fully described in the following subseries which are interfiled together: Subject Files for Inhalation Study Using 5-Micron-Diameter Niobium-92m; Subject Files for Inhàlation Study Using 3.5-Micron-Diameter Niobium$92 \mathrm{~m}$; and Records Relating to the Counting of Human Subjects Using Niobium-92m, $\mathrm{Ba}^{133}$, and $\mathrm{S}^{85}$ (IRB No. 88-101).

RESTRICTIONS This series contains privacy material.

LOCATION OF Lawrence Livermore National Laboratory

RECORDS Building 253, Room 1719

Berkeley, CA 94720

(Raw data is on magnetic tape; and calibration records are stored in the Control Room.) 


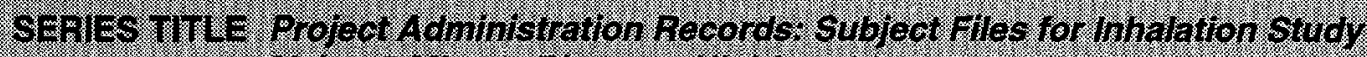
Using 5 Wroron Dhameter Notwm-g2m

INCLUSIVE DATES 1979-1982

ARRANGEMENT Alphabetical by subject name

VOLUME approximately 0.5 cubic foot

DESCRIPTION This series contains files for human subjects who participated in a study by the Whole Body Counter staff. The phantom validation study involved eight male subjects, five British and three American, who inhaled 5-micron-diameter niobium-92m. The study was initiated by the United Kingdom to evaluate the Humanoid phantom as a calibration tool for measuring plutonium in the lungs and was approved by review boards in the U.K. and U.S. After inhalation, subjects visited several laboratories for "counting." Records for individual subjects are maintained in notebooks. Typical record types in the series include forms, raw data, photos, and lung clearance graphs. This series is interfiled with Project Administration records and records of the other two validation studies.

RESTRICTIONS This series contains privacy material.

LOCATION OF Lawrence Livermore National Laboratory

RECORDS Building 253, Room 1719

Berkeley, CA 94720

(Raw data is on magnetic tape; calibration records are stored in the Control Room.) 


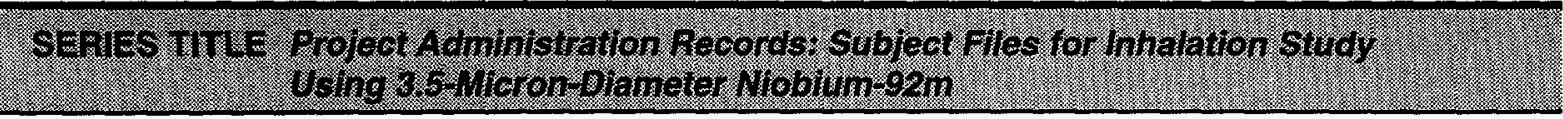

INCLUSIVE DATES 1983-1985

ARRANGEMENT Alphabetical by subject name

VOLUME approximately 0.5 cubic foot

DESCRIPTION This series contains files for human subjects who participated in a study by the Whole Body Counter staff. This series contains records of the second validation study, which involved 11 women who inhaled 3.5-micron-diameter niobium-92m-labeled microspheres to determine the suitability of the Humanoid phantom as a lung calibration medium for females. Subject files in this series were created by the Whole Body Counter staff in conjunction with their work on this study. The study was initiated by the United Kingdom to evaluate the Humanoid phantom as a calibration tool for measuring plutonium in the lungs and was approved by review boards in the U.K. and U.S. After inhalation, subjects visited several laboratories for "counting." Records for individual subjects are maintained in notebooks. The notebooks contain personal information about the subjects, biometric data and x-ray counts, and correspondence. Files contain records types such as photos, lung clearance graphs, raw data, handwritten notes, and charts. This series is interfiled with Project Administration records and records of the other two validation studies.

RESTRICTIONS This series contains privacy material.

LOCATION OF Lawrence Livermore National Laboratory

RECORDS Building 253, Room 1719

Berkeley, CA 94720

(Raw data is on magnetic tape; calibration records are stored in the Control Room.) 


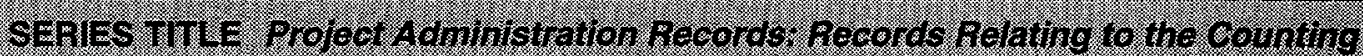

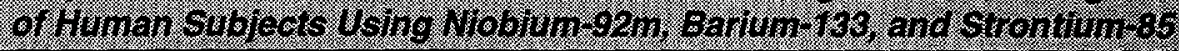

INCLUSIVE DATES $1988-1990$

ARRANGEMENT Alphabetical by subject name

VOLUME approximately 0.5 cubic foot

DESCRIPTION This series (IRB No. 88-01) contains records of a third validation study where five of the original eight male participants inhaled niobium and of studies where two subjects were injected with $\mathrm{Ba}^{133}$ and $\mathrm{Sr}^{85}$. The files for the niobium study pertain to subjects such as detector geometry, visits by foreign nationals, personal information on individual subjects, biometric data for the subject, and x-ray counts. Types of documents included are copies of the "Experimental Subject's Bill of Rights," signed consent forms, photos, tables, graphs, test results, and memorandums. The five British volunteers were also participants in the first study, so some folders for individual subjects may contain information from both the first and the third validation study. This series also contains subject file information for individual subjects who participate in studies relating to the use of $\mathrm{Ba}^{133}$ and $\mathrm{Sr}^{85}$. Two subjects received an injection of barium, and one of these subjects later received an additional administration of strontium. Some personal and medical information is available for subjects involved in these two studies. This series is interfiled with Project Administration records and records of the other two validation studies.

RESTRICTIONS This series contains privacy material.

LOCATION OF Lawrence Livermore National Laboratory

RECORDS Building 253, Room 1719

Berkeley, CA 94720

(Raw data is on magnetic tape; calibration records are stored in the Control Room.) 
INCLUSIVE DATES $1972-1976$

ARRANGEMENT None

VOLUME 1.5 cubic feet

DESCRIPTION This series contains information on the inter-laboratory comparison of three British subjects (all male) who inhaled palladium-103 (as a "mock" plutonium) and chromium51. Subjects were counted by at least eight laboratories in the U.S., including LLNL. The overall purpose of this experiment was to improve methods of in vivo bioassay for accidentally inhaled long-lived isotopes. An additional purpose was to establish analyses capabilities on an international level. The experiment was especially notable as there had been a significant problem in conducting accurate external measuring of heavy elements, particularly plutonium, in the human lung. The series documents the experiments and the measurement of the human subjects, which took place 1972-1976. Most of the series is comprised of scientific data relating to measurements taken on the subjects at LLNL and to subsequent analyses. Type of records included in the series are calibration data, tables, graphs, charts, handwritten notes, correspondence, memorandums, reports, draft reports, and technical reference material. The correspondence, in part, represents a discussion with other laboratories about the importance and uniqueness of this experiment.

RESTRICTIONS This series contains privacy material.

LOCATION OF Lawrence Livermore National Laboratory

RECORDS Building 253, Room 1717

Berkeley, CA 94720

\section{SERIES TILL Records Relating to Proposed Technetwi gs Counthg Program}

INCLUSIVE DATES 1975-1976

ARRANGEMENT None

VOLUME 0.3 cubic foot

DESCRIPTION The purpose of this proposed experiment was to study the use of technetium-99 to simulate inhaled plutonium-239 aerosol in the lungs. The series contains information such as discussions between LLNL and LBL about the project, including the development of protocols for the experiment, a statement that all 15 adult volunteers would be from LLNL or LBL, and preparation of operating safety procedures that would incorporate protocols for the experiment. Types of records in the collection include raw data, correspondence, and memorandums. This experiment was never carried out.

RESTRICTIONS This series contains privacy material.

LOCATION OF Lawrence Livermore National Laboratory

RECORDS Building 253, Room 1717

Berkeley, CA 94720 


\section{The Site Today}

LOS ALAMOS NATIONAL LABORATORY (LANL) is a multiprogram facility whose original mission was nuclear weapons research, development, and testing. Current laboratory work includes nuclear weapons safety, nonproliferation and counterproliferation, and environmental restoration. Los Alamos also provides technical assistance and basic research including energy and environmental technologies. In addition, the Laboratory possesses extensive capabilities in highperformance computing and human genome studies.

Los Alamos operates 20 major research facilities, among them the Clinton P. Anderson Meson Physics Facility, the National Genetic Sequences Data Bank, the lon Beam Materials laboratory, the Weapon Neutron Research Facility, and a Center for Human Genome Studies. The University of California manages the laboratory, which employs over 7,500 individuals and has a budget of about $\$ 1$ billion.

\section{Site History}

The Manhattan Project established Los Alamos-originally known as Project $Y$-under the University of California in 1943 to design and build a fission bomb. Although staff and equipment were in place by the summer of 1943, production of fissionable material at Oak Ridge and Hanford proved slower than hoped, limiting Oppenheimer and his staff to work with small quantities. Only in mid-1945 was enough fissionable material available to build the first two bombs, Fat Man and Little Boy.

Oppenheimer originally organized the laboratory into four technical divisions, each headed by a division leader: Theoretical Physics ( $T$ ), Experimental Physics (P), Chemistry and Metallurgy $(\mathrm{CM})$, and Engineering Ordnance (E). Each division contained several specialized groups, each group headed by a group leader. While individual scientists and group leaders had access to Oppenheimer, reporting was normally made to a division leader. These individuals, in turn, reported either to Oppenheimer or to committees created to monitor specific work, such as the "Cowpuncher Committee" created to "ride herd" on the implosion (Fat Man) design.

Oppenheimer also created an Administrative Division (A) for such activities as health, procurement, and patents. The first health group, A-6, was headed by Louis Hempelmann. Hempelmann, one of a few American physicians at the time with knowledge of radiation, came to Los Alamos from Washington University in St. Louis. He had worked with noted radiation biomedical scientists John Lawrence and Robert Stone and had served as a staff physician at the Malinckrodt Institute at Washington University.

Only in mid-1945 was enough fissionable material available to build the first two bombs, Fat Man and Little Boy.

The initial tasks of the Health Group were to define occupational health standards for special hazards and to monitor for radiation exposures. Although biological and physical research on health problems related to radioactive materials had been assigned elsewhere in the Manhattan Project, Hempelmann and Oppenheimer found that they could not always get the precise information they felt was needed. Consequently, Los Alamos undertook some health-related activities.

Since very little fissionable material was available during the first year of operations, the earliest work of the Health Group centered on the hazards related to accelerators and small sources of radioactive materials. In the spring of 1944, larger quantities of plutonium began arriving, generating increased health concerns. Hempelmann and his staff were entering new territory, since the only accepted standards for radiation exposure had been set in 1928 and were based on the health effects of radium. By August 1944, the Health Group were investigating biological methods for testing exposures to radioactive poisons.

Acting with the concurrence of Oppenheimer, Hempelmann urged the Manhattan Project to undertake human experiments to measure the excretion patterns of plutonium. Such experimentation became feasible when a young 
chemist, Wright Langham (Figure 30), developed a method of measuring small amounts of plutonium in excreta. Subsequent studies by the Manhattan Project were undertaken to establish the excretion and retention rates of plutonium in the human body. Such information was needed to estimate internal uptake of plutonium in workers. Langham's method became the standard for making such measurements for the next two decades.

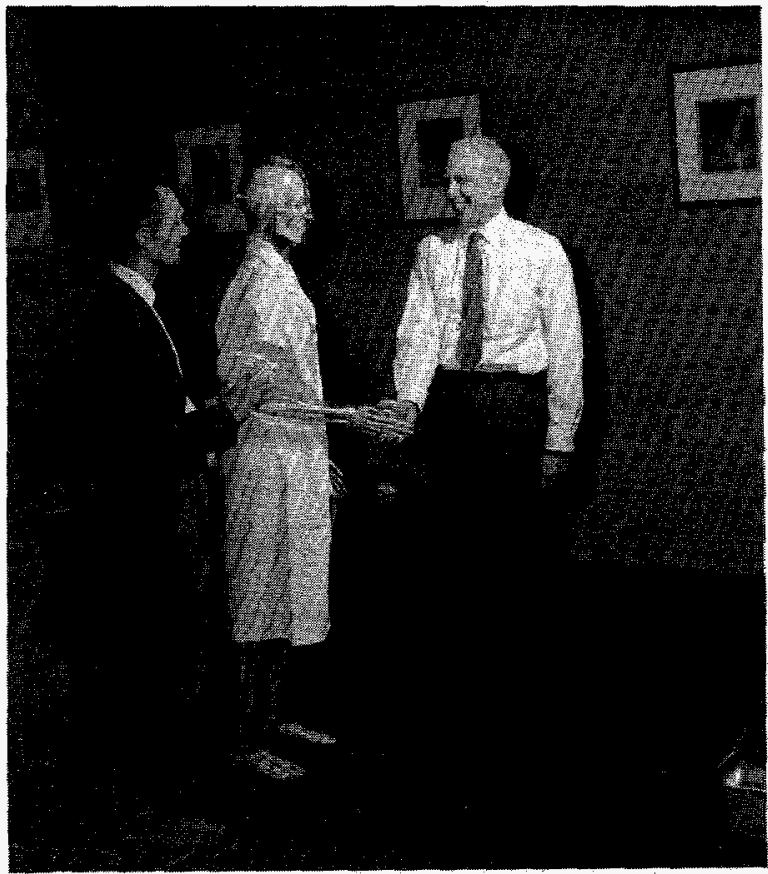

Figure 30. Wright Langham (/eft) introduces the "plastic man" to Los Alamos Director Norris Bradbury. The figure was used to simulate human radiation exposures.

After the first Soviet nuclear detonation, President Truman ordered the AEC to develop a thermonuclear bomb. Los Alamos scientists produced the first workable design, which culminated as the 1952 Mike test at the Enewetak Atoll in the Pacific. By the 1960s, the U.S. possessed a large arsenal of nuclear weapons, including gravity bombs, missile warheads, artillery shells, atomic demolition devices, torpedo warheads, and antisubmarine missiles. Many nuclear components for these systems were designed at Los Alamos.

After the 1963 atmospheric test ban treaty, the Laboratory conducted nuclear underground weapons tests. In addition, the Laboratory designed systems for satellites that could detect nuclear tests conducted in violating the agreement. The test ban negotiations also led the Laboratory to undertake projects in areas outside nuclear weapons research. One of the first such projects, Rover, was aimed at the development of nuclear rocket engines. Laboratory-designed prototype rocket engines were tested in the Jackass Flats area of the Nevada Test Site.

Los Alamos scientists also designed and operated a facility at the laboratory to evaluate the use of molten plutonium as a reactor fuel. A small experimental reactor was built to test fuel that might be used in a commercial high-temperature, gas-cooled reactor. In addition, work was done on the design of small reactors that might be used to power satellites.

Hempelmann and his staff were entering new territory, since the only accepted standards for radiation exposure had been set in 1928 and were based on the health effects of radium.

Later, the Laboratory was selected as the site for an accelerator, subsequently called the Clinton $P$. Anderson Meson Physics Facility, which could be used for basic nuclear research. With the end of the Cold War, the Laboratory shifted its research emphasis to such areas as stockpile stewardship, high-performance computing, and environmental remediation. Los Alamos is also transferring technology to private industry.

\section{Site Human Radiation Experiments}

In the autumn of 1945, changes were made to the Laboratory's organizational structure. In October 1945, Norris Bradbury became Director. In an effort to shape the Laboratory's structure to the postwar environment, Bradbury immediately altered the composition and charters of many divisions and groups. The health group and its functions remained intact. The group designation of $A-6$, however, was changed to $A-10$ in December 1945. The Group Leader continued to report directly to the Laboratory Director, the only group leader to do so. After Bradbury's organizational changes, the Laboratory's 
structure remained essentially the same for the rest of his Directorship, which lasted until 1970.

During 1945 and into 1946, Langham and others were deeply involved in analyzing samples obtained from the plutonium injection experiments. (See the Human Plutonium Injection Experiments narrative.)

During the latter half of 1945 and into 1946, Langham and others were deeply involved in analyzing samples obtained from the plutonium injection experiments.

Hempelmann relinquished his role as Health Group leader in 1946, to serve as a consultant to the Crossroads nuclear test in the Pacific. Shortly after these tests, the Manhattan Project passed its nuclear responsibilities on to the newly created AEC. The Interim Medical Committee of the AEC inherited the biomedical component of the Manhattan Project and saw a continuing need for clinical testing of radioactive materials with human subjects. Los Alamos was involved in these efforts.

In August 1945, the first of three fatal criticality accidents at the Laboratory occurred when a physicist dropped a tungsten carbide brick, causing an assembly experiment to become criti$\mathrm{cal}$ - that is, to begin a chain reaction. He died shortly afterward. The second accident occurred less than a year later. An individual received a lethal dose of ionizing radiation when his screwdriver slipped and two pieces of reflector came together. While they were not human experiment subjects, these individuals were carefully monitored after their exposures. The accidents provided some of the earliest data regarding high-dose radiation effects.

Group A-10 provided the basis for a new Health Division $(H)$ in May 1947. The new division had responsibility for a much broader range of health activities, including radiological safety, health physics, and industrial health. The $\mathrm{H}$ division also monitored exposures and was responsible for safety for all weapons tests conducted by the Laboratory. The research functions of A-10 became the responsibility of a new group, $\mathrm{H}-4$ (Radiobiology), under the direction of Wright Langham. During the late 1940s and early 1950s, research with human subjects at Los Alamos was limited to tritium studies. The human subjects were researchers in Group H-4. In 1949, the group's name was changed from Radiobiology to Bio-Medical Research. Wright Langham headed this group from 1947 until his death in 1972. At the time of Langham's death, $\mathrm{H}-4$ had grown to 70 staff members working in molecular radiobiology, cellular radiobiology, mammalian biology, biophysics, and veterinary biology, and pathology.

In 1956 the nature of human studies at Los Alamos changed dramatically when the first whole body radiation counter became operational. The sensitivity and noninvasiveness of this radiation counter made possible studies at levels 10 to 100 times below established limits of exposures. Using this new capability, tracer studies-research involving small amounts of radioactive substances that could be tracked in the body with instruments - were conducted at Los Alamos from 1956 through the 1960s. The subjects used in this research included Laboratory employees and their family members, as well as hospital patients. The patients were referred by attending physicians at the local hospital.

Using this new capability, tracer studiesresearch involving small amounts of radioactive substances that could be tracked in the body with instruments-were conducted at Los Alamos from 1956 through the 1960s.

A July 1956 memorandum from Health Division Leader Thomas Shipman enunciated "guiding principles and limiting rules" for human tracer studies. These rules, developed with guidance from the AEC Division of Biology and Medicine, stated that "[all] subjects will be bona fide volunteers who are fully informed as to the procedure to be carried out." The memo did not require that written consent be obtained from the subjects, but did call for written approval from the Health Division Leader, and to be based on a statement of the maximum dose to be administered. It further provided that all doses be given by a licensed physician. 


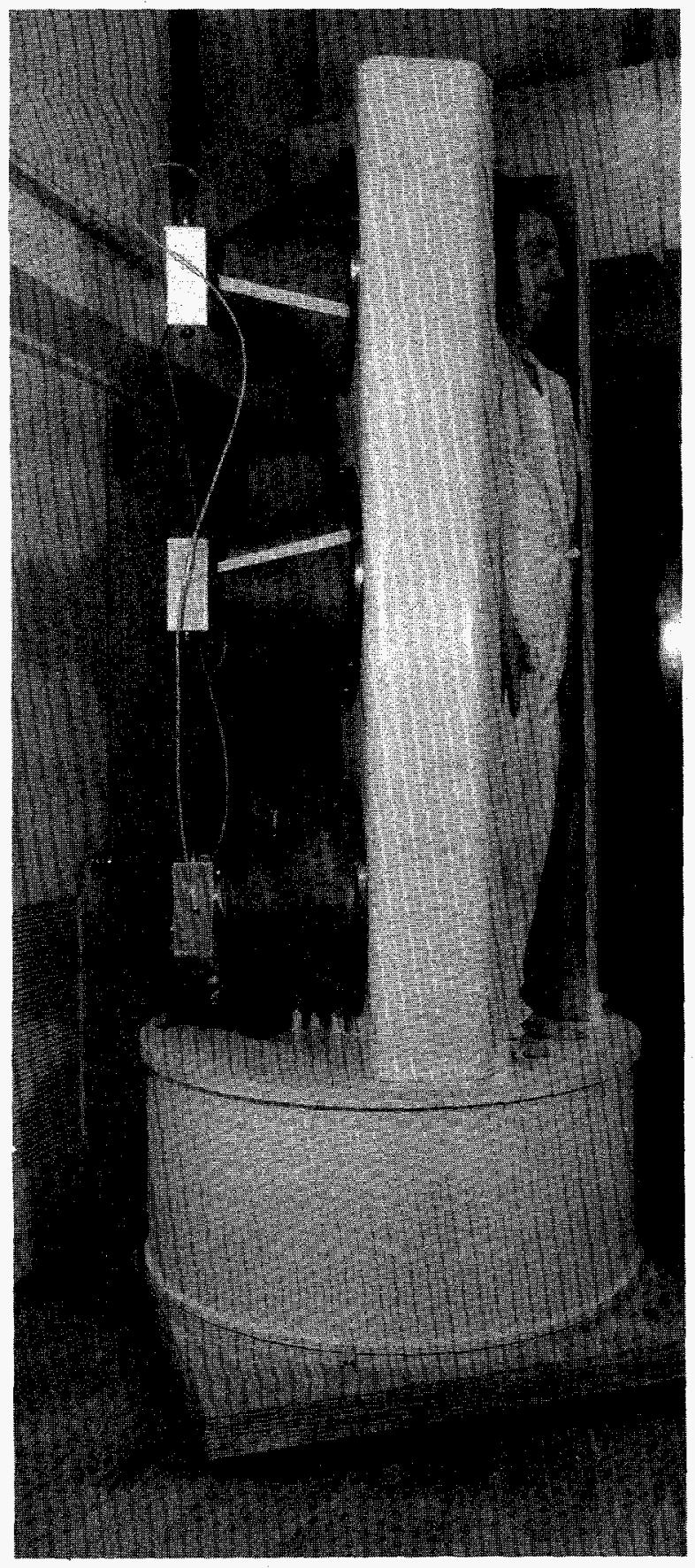

Figure 31. A whole body radiation counter at Los Alamos (circa 1958).

Among the tracer studies accomplished with the whole-body counter were iron absorption studies involving children and pregnant women. This study disproved the theory that intestinal absorption of iron is correlated with iron levels in the blood. Another of the tracer studies conducted in the late 1950s helped researchers assess the danger of fallout from open-air weapons testing. The ratio of radioactive iodine in eight children was measured to obtain accurate uptake and retention data as a benchmark for measuring thyroid doses from fallout. This study also improved counting methods for diagnostic uptake studies and provided data that enhanced knowledge about the thyroid gland. One of the last human studies conducted at Los Alamos took place in 1962 when cobalt tracers were used for diagnosing pernicious anemia. Site experiments are detailed in Chapter 3.

In December 1958, a Laboratory technician received a lethal dose of radiation when a plutonium recovery process accidentally went critical.

The last of the fatal criticality accidents at Los Alamos occurred in December 1958. A Laboratory technician received a lethal dose of radiation when a plutonium recovery process accidentally went critical. As in the previous cases, the course of the technician's condition was closely followed. His death also led to the establishment of the Los Alamos Human Tissue Analysis Project. Between 1959 and 1978, the Laboratory analyzed tissues of workers exposed to actinides (the group of radioactive chemicals between 89 and 103 on the table of elements), as well as tissues from the general population of the Nation. The successor to this program, now known as the Transuranium Registry, is currently run by Washington State University under a DOE grant.

After the National Institutes of Health adopted procedures for medical studies in 1966, the AEC began changing to a committee system for approval of medical research projects. The University of California also responded, calling for formalized procedures for such research. In 1971, Los Alamos established a Human Use Review Committee to oversee such research. By the mid 1970s, medical research at Los Alamos had entered an era where committees, not individuals, would shape research projects. 


\section{Site Records Collections}

Practically all Laboratory records remain on site. Of these, the inactive records are well organized, controlled, and stored. Most inactive records are maintained in the Laboratory's records center and archives building. Custody of the inactive files in the records center and archives is divided between records managers and archivists. Both staffs make documentation from collections available to researchers and maintain folder title listings to collections.

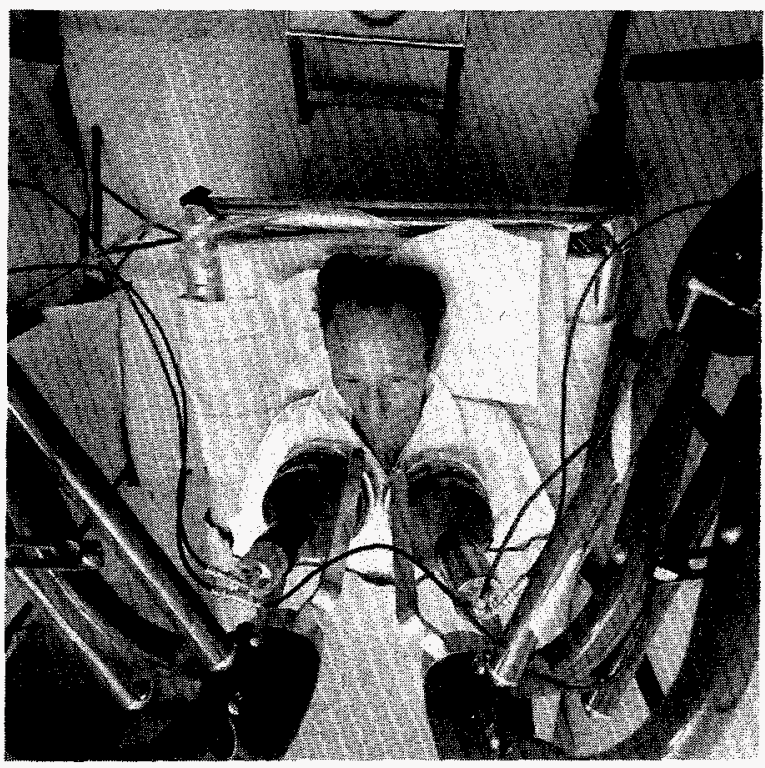

Figure 32. A counter being used at Los Alamos to measure plutonium in the lung.

The Laboratory has maintained a records management program since 1943 and an archival program since 1982. The completeness of the Laboratory's inactive records and the degree of intellectual control over them reflect a significant investment of resources in preserving its older records. Consistent with the Laboratory's primary mission of nuclear weapon research, Laboratory records collections contain many classified documents. Some records are also closed because of Privacy Act restrictions. The Laboratory states that all its documents relating to human radiation experiments either are unclassified or have been declassified. These documents are maintained in a public reading room.
As noted, the series described below contain documentation pertinent both to individual experiments themselves and to the site institutional milieu in which they took place. For the institutional framework, researchers will find the Laboratory Director's files especially useful. Researchers should note that the Laboratory Director's files on microfilm do not duplicate those on paper. Records about individual human radiation experiments can be found in most of the other series.

Practically all Laboratory records remain onsite. Of these, the inactive records are well organized, controlled, and stored.

In response to research interests of the Advisory Committee on Human Radiation Experiments, Los Alamos staff also reviewed and provided some documents residing in the records of the Los Alamos Test Division (J-Division). Some series descriptions are therefore included for those records, although the Laboratory states that these series do not contain material about human subject research. 


\title{
Los Mlamos National Laboratory (LANL)
}

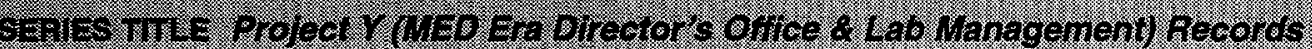

INCLUSIVE DATES 1942-1946

ARRANGEMENT War Department Dewey Decimal Filing System

VOLUME 33 cubic feet

DESCRIPTION These files document the founding of the Los Alamos National Laboratory and its subsequent work to develop fission bombs for use in WWII. These files contain some information on the biological effects of uranium-235 and plutonium-240, the earliest known references to the possibility of human experimentation by the Manhattan Engineer District, and the creation of RaLa Testing Program. These records were compiled by the Laboratory during WWII as the primary documentation of the Laboratories' wartime activities. As such they document technical, administrative, and policy decisions related to the development of the first nuclear bombs. The Project $Y$ files consist of technical and administrative files of memorandums, letters, and reports. They are organized by major organizational units of the Laboratory. A folder title listing is available. Collection number A-84-019.

RESTRICTIONS This series contains privacy material and classified information.

\author{
LOCATION OF Los Alamos National Laboratory \\ RECORDS Building 1001 \\ PO Box 1663 \\ Los Alamos, NM 87545
}




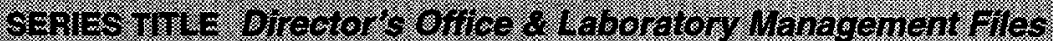

INCLUSIVE DATES $1945-1970$

ARRANGEMENT War Department Dewey Decimal Filing System

VOLUME 260 cubic feet

DESCRIPTION These records document laboratory management, administration, and director's policy decisions. The series consists of the office files of the second Director of Los Alamos, Norris Bradbury. The Director's files contain staff papers, progress reports, correspondence, and meeting minutes of all major lab work conducted during this period. They contain documentation of all major laboratory programs including RaLa, Rover, and weapons tests. Moreover they include administrative correspondence regarding day to day operations, policy decision making, and other correspondence. They consist of correspondence files of memorandums, letters, reports, and data. A folder title listing is available. The collection is known as B-9.

RESTRICTIONS This series contains privacy material and classified information.

LOCATION OF Los Alamos National Laboratory

RECORDS Building 1001

PO Box 1663

Los Alamos, NM 87545

\section{SERIES TILE Difeotors Office \& Laboratory Management Files (microflim)}

INCLUSIVE DATES $1945-1970$

ARRANGEMENT War Department Dewey Decimal Filing System

VOLUME 10 cubic feet

DESCRIPTION The documents captured on microfilm do not duplicate the Director's office series of textual files. These records document laboratory, management, administration, and Director's policy decisions. These files were the office files of the second Director of Los Alamos, Norris Bradbury. The microfilm Director's files contain staff papers, progress reports, correspondence, and meeting minutes of all major laboratory work. They include documentation on Project Sunshine and RaLa tests. The series consists of technical and administrative files of memorandums, letters, reports, and data. A folder title listing is available. The collection is known as B-9 microfilm.

RESTRICTIONS This series contains privacy material and classified information.

LOCATION OF Los Alamos National Laboratory

RECORDS Building 1001

PO Box 1663

Los Alamos, NM 87545 


\title{
SERES TILE Robert Undehill Files
}

\begin{abstract}
INCLUSIVE DATES 1943-1978
ARRANGEMENT Subject

VOLUME 6 cubic feet

DESCRIPTION These files were kept by Robert Underhill, Secretary to the University of California Board of Regents, and contain information on the operation of Los Alamos, particularly its administration. The files are most useful for documenting the contractual relationship of the University of California to the Government for operating the laboratory. They include information on laboratory overtime pay, insurance matters, hazardous work, and other administrative matters. The Robert Underhill records consist of contracts, correspondence, memorandums, and reports. A folder title listing is available. Collection number A-83-033.
\end{abstract}

RESTRICTIONS This series contains privacy material.

LOCATION OF Los Alamos National Laboratory

RECORDS Building 1001

PO Box 1663

Los Alamos, NM 87545

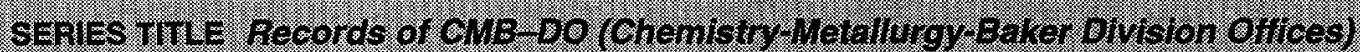

INCLUSIVE DATES $1956-1969$

ARRANGEMENT Chronological

VOLUME 16 cubic feet

DESCRIPTION This series consists of the monthly progress reports of the CMB-DO. The reports document chemical and metallurgical research at Los Alamos, including the metallurgical research of plutonium. These reports also include abstracts of research initiatives and data. Progress reports for the 1950s contain information on fabricating RaLa sources. A folder title listing is available. Collection number A-89-068.

RESTRICTIONS This series is entirely classified.

LOCATION OF Los Alamos National Laboratory

RECORDS Building 1001

PO Box 1663

Los Alamos, NM 87545 

Test Records

INCLUSIVE DATES 1944-1963

ARRANGEMENT Topical subseries

VOLUME 2 cubic feet

DESCRIPTION These files document the work of the laboratory organization responsible for planning and carrying out the RaLa experiments at Bayo Canyon, near Los Alamos. The records in this series document many of the RaLa experiments, including information on experimental design and data analysis. The series includes correspiondence, reports, photographs, and meeting minutes. A folder title listing is available. Collection number A-84-018.

RESTRICTIONS This series contains classified information.

LOCATION OF Los Alamos National Laboratory

RECORDS Building 1001

PO Box 1663

Los Alamos, NM 87545

\section{SERIES ThI E Wealh Division Central A dimistrative Records}

INCLUSIVE DATES $1943-1979$

ARRANGEMENT Subject

Chronological

VOLUME 100 cubic feet

DESCRIPTION This series contains the administrative files of the Laboratory's Health Division. These files were generated and kept as the division monitored the health and safety of laboratory workers. They also capture the division's involvement in decision making in matters concerning possible exposure to radioactive materials, health and safety aspects of the RaLa program, and biological work of Group $\mathrm{H}-4$. The records of the Health Division consist of organizational charts, reports, contracts, questionnaires, correspondence, memorandums, and progress reports. A folder title listing is available. Collection numbers A-89-118, TR-6704, TR-1133.

RESTRICTIONS This series contains privacy material and classified information.

LOCATION OF Los Alamos National Laboratory

RECORDS Building 1001

PO Box 1663

Los Alamos, NM 87545 
INCLUSIVE DATES 1953-1955

ARRANGEMENT Subject

VOLUME 1.5 cubic feet

DESCRIPTION These files document the work of the biomedical research group at Los Alamos. As such, they are similar to the records in the Wright Langham Papers. These files include policy decisions and basic correspondence. They contain information on a criticality fatality, gamma radiation, iodine-131, beta radiation, and tracer studies. They consist of memorandums, correspondence, and reports. A folder title listing is available. Collection number A-92-096.

RESTRICTIONS This series contains privacy material and classified information.

LOCATION OF Los Alamos National Laboratory

RECORDS Building 1001

PO Box 1663

Los Alamos, NM 87545

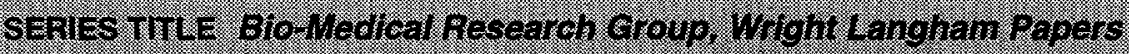

INCLUSIVE DATES $1950-1971$

ARRANGEMENT Subject

VOLUME 1.5 cubic feet

DESCRIPTION These records document the activities of Wright Langham and were created during his tenure as leader of the Biomedical Research Group. They contain documentation on the organization and technical work of the group, including animal studies and the Cecil Kelley accident. These files contain information related to Langham's research interest in gamma radiation and his leadership of a multidiscipline biomedical research group. However they are not as extensive as the $\mathrm{H}-4$ subdivision records. The Wright Langham Papers consist of correspondence, memorandums, and reports on health research, particularly gamma radiation. A folder title listing is available. Collection number A-92-095.

RESTRICTIONS This series contains privacy material and classified information.

LOCATION OF Los Alamos National Laboratory

RECORDS Building 1001

PO Box 1663

Los Alamos, NM 87545 


\section{SERES ThLE Records or.J-Division (Weapons Testing), Central Administrotive Files}

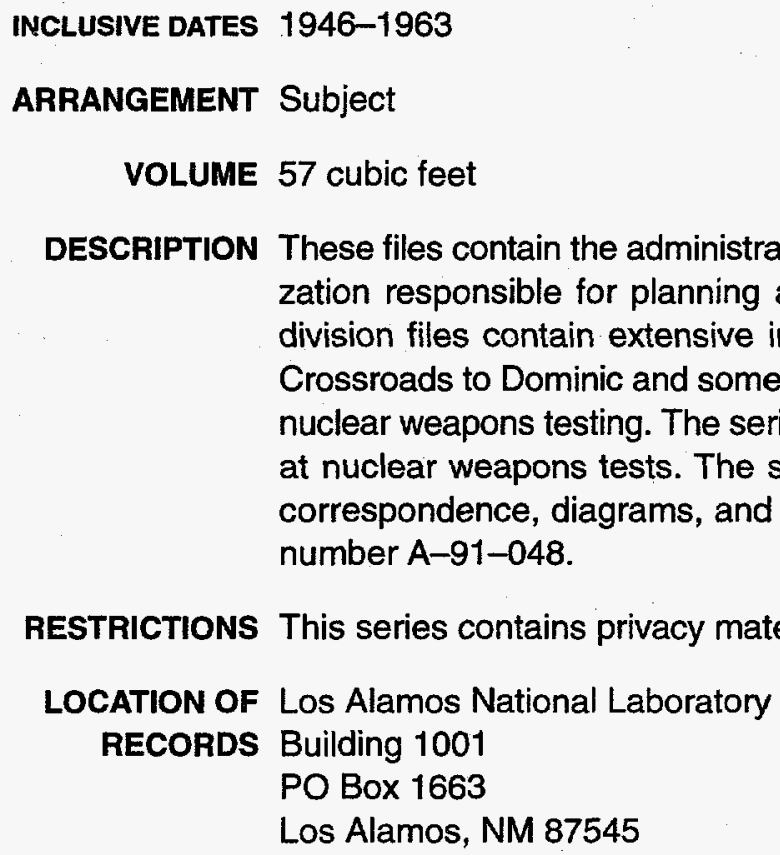
number A-91-048.

LOCATION OF Los Alamos National Laboratory

RECORDS Building 1001

PO Box 1663

Los Alamos, NM 87545

DESCRIPTION These files contain the administrative and technical records of the Laboratory organization responsible for planning and carrying out nuclear weapons tests. The test division files contain extensive information on each weapons test from Operation Crossroads to Dominic and some information on the Geneva Conference on limiting nuclear weapons testing. The series may contain information on human testing done at nuclear weapons tests. The series contains planning papers, meeting minutes, correspondence, diagrams, and reports. A folder title listing is available. Collection

RESTRICTIONS This series contains privacy material and classified information.

INCLUSIVE DATES $1956-1975$

ARRANGEMENT Subject

VOLUME 40 cubic feet

DESCRIPTION This series documents the central administration of N-Division's Rover Program, including the policies, organization, and activities regarding the program. The records in it document work on the Kiwi reactor, the Nevada Test Site, space and nuclear propulsion, and the Laboratory Rover Committee. It also includes studies on the dispersion of radioactive particles that might occur if a nuclear rocket accidentally reentered the earth's atmosphere and disintegrated, and of the transit time of large radioactive particles through the human gastrointestinal tract. The series consists of reports, correspondence, memorandums, technical data, and meeting minutes. A folder title listing is available. Collection numbers $A-86-017, A-88-007, A-89-083$, A-93-003, A-93-070, A-94-020.

RESTRICTIONS This series contains classified information.

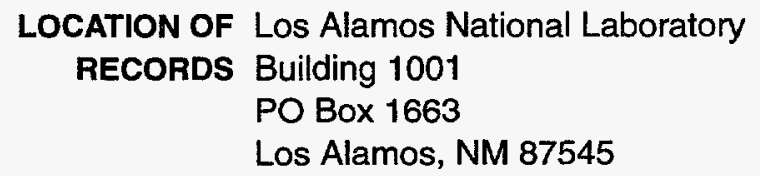


INCLUSIVE DATES $1965-1987$

ARRANGEMENT Subject

VOLUME 90 cubic feet

DESCRIPTION This series contains the technical and administrative records of the Medium Energy Physics Division, which conducted basic physics research in collaboration with universities throughout the world. Most of the collection deals with basic physics research, however, some information on biomedical research, particularly a pion therapy program is included. Pion therapy was a treatment at the Los Alamos Mason Physics Facility (LAMPF) using subatomic particles called pions to treat 225 cancer patients between 1974-1981. The series contains project proposals, construction records, and biomedical research records. A folder title listing is available. Collection number A-91-011.

RESTRICTIONS This series contains privacy material.

LOCATION OF Los Alamos National Laboratory

RECORDS Building 1001

PO Box 1663

Los Alamos, NM 87545

INCLUSIVE DATES $1945-1959$

ARRANGEMENT Topical subseries

VOLUME 2 cubic feet

DESCRIPTION The series documents the dissemination of information to the public. It includes information on the 1958 criticality accident in which laboratory technician Cecil Kelley was killed. The series contains news releases, reference material, news clippings, and information on special projects. A folder title listing is available. Collection number A-83-005.

LOCATION OF . Los Alamos National Laboratory

RECORDS Building 1001

PO Box 1663

Los Alamos, NM 87545 


\section{SERIES TILLE LAboratory Progress peports}

INCLUSIVE DATES 1945-1975

ARRANGEMENT Laboratory Organizational Units

VOLUME 100 cubic feet

DESCRIPTION The Laboratory Progress Reports consist of the formal reports written monthly by the laboratory's technical divisions and groups. They contain summary information and technical information on laboratory work such as that in physics, chemistry, and metallurgy. A listing is available. Collection number $\mathrm{A}-86-016$.

RESTRICTIONS This series contains privacy material and classified information.

LOCATION OF Los Alamos National Laboratory

RECORDS Building 1001

PO Box 1663

Los Alamos, NM 87545

\section{SERIES THLE REOORS Collection}

INCLUSIVE DATES $1943-1994$

ARRANGEMENT Chronological, by report number

VOLUME 7,000 cubic feet

DESCRIPTION These reports document all of the technical work of the Laboratory. Within these reports, there is documentation of various experiments, (e.g., the plutonium injection experiments, tracer studies, releases, weapons testing). Since 1943, the Laboratory has maintained a central repository for technical reports. The series contains annual and quarterly progress reports as well as those on specific experiments. A listing is available.

RESTRICTIONS This series contains privacy material and classified information.

LOCATION OF Los Alamos National Laboratory

RECORDS Building 207

PO Box 1663

Los Alamos, NM 87545 


\section{SERIES TITLE Laboratory Notebooks}

INCLUSIVE DATES $1942-1990$

ARRANGEMENT Numeric

Sequential

VOLUME 1,500 cubic feet

DESCRIPTION The Laboratory Notebooks consist of hardbound notebooks used by the scientific staff to record experimental and technical data. Each notebook was assigned to an individual scientist. The notebooks contain experimental data, calculations, and sketches of equipment and apparatus. They include experimental information including data related to early human plutonium studies, tracer studies, and RaLa research. A listing is available.

RESTRICTIONS This series contains privacy material and classified information.

LOCATION OF Los Alamos National Laboratory

RECORDS Building 1001

PO Box 1663

Los Alamos, NM 87545

\section{SERIESTTLE Litgation SUppert Database}

INCLUSIVE DATES $1943-1994$

ARRANGEMENT Subject

VOLUME not applicable

DESCRIPTION The records in this series were originally collected from various Laboratory offices to support the laboratory's litigation efforts. Records collected document a wide range of Laboratory activities including human studies and exposures to ionizing radiation and toxic substances. The series consists of correspondence, memorandums, and reports collected throughout the Laboratory to support ongoing litigation. Indices can be generated on request.

RESTRICTIONS This series contains privacy material and attorney-client privileged information.

LOCATION OF Los Alamos National Laboratory

RECORDS Building 1001

PO Box 1663

Los Alamos, NM 87545 
The Oak Ritesites

\section{The Sites Today}

THE OAK RIDGE COMPLEX consists of five major facilities located in or near Oak Ridge, TN: the DOE Oak Ridge Operations Office, Oak Ridge Institute for Science and Education (ORISE), Oak Ridge National Laboratory (ORNL), K-25 site, and $Y-12$ plant.

The Operations Office provides DOE oversight for the other facilities, which are Government owned and contractor operated. Oak Ridge Associated Universities (ORAU) is the operating contractor for ORISE; Martin Marietta Energy Systems runs the remaining facilities. The Oak Ridge sites have a combined annual budget exceeding $\$$ I billion and employ more than 14,000 people.

ORISE conducts programs in science and engineering education, training and management, and medical sciences, including basic research in biochemistry and cytogenetics. ORISE also operates the Radiation Internal Dose Information Center, the Center for Epidemiological Research, the Radiation Emergency Assistance Center/Training Site, and the Center for Human Reliability Studies.

ORNL focuses on basic and applied research in energy technology and conducts research in the physical, chemical, materials, computational, biomedical, earth, environmental, and social sciences. The Laboratory also operates 20 major research facilities, including the Holifield Heavy Ion Research Facility, the Oak Ridge Linear Accelerator, and the High Flux Isotope Reactor.

The $\mathrm{K}-25$ site, once a gaseous diffusion plant site for the production of uranium-235, now serves as headquarters for the Oak Ridge Environmental Restoration and Waste Management Office and for the High Temperatures Materials Laboratory. The $Y-12$ plant was originally built to produce uranium-235 through an electromagnetic process. Later the plant was converted to a nuclear weapons component manufacturing plant and now serves as a weapons disassembly site.

\section{Site History}

Oak Ridge Site selection-Wartime atomic planners first looked to the Oak Ridge area during the spring of 1942. A site was needed to build industrial facilities for production of plutonium and uranium-235, the principal materials required for an atomic bomb. The only production process then known created minute amounts of fissionable materials in experimental laboratories. Scientists such as E.O. Lawrence of the University of California and Arthur $\mathrm{H}$. Compton of the University of Chicago were confident, however, that experimental techniques could be translated into large-scale production facilities. This confidence, coupled with the Government's urgent desire to develop an atomic weapon, led the Manhattan Project to launch a crash production program.

Residents of the sparsely populated area were paid for their property and ordered to leave within a few weeks.

The program required large parcels of land to house sprawling plants, support facilities, and worker communities. Another requirement for industrial production of fissionable materials was relative isolation, both to ensure secrecy and to reduce danger to civilian populations. Abundant supplies of cooling water and electricity were also needed. The Manhattan Project determined that a 56,000-acre tract of land in eastern Tennessee met these requirements, and the Federal government moved to acquire what became known as the Oak Ridge reservation through eminent domain proceedings in September 1942. Residents of the sparsely populated area were paid for their property and ordered to leave within a few weeks.

General Leslie Groves and other Manhattan Project leaders identified four potential techniques for producing fissionable material at Oak Ridge. The reactor (or pile) process called for a controlled nuclear chain reaction to irradiate uranium, which could then be chemically processed to separate plutonium. Three processes were considered for producing the required quantities of weapons-grade uranium (uranium-235): electromagnetic separation, based on E.O. Lawrence's cyclotron research; gaseous diffusion, based on the research of Harold Urey of Colum- 
bia University; and liquid thermal diffusion, based on the ideas of Philip Abelson of the Naval Research Laboratory.

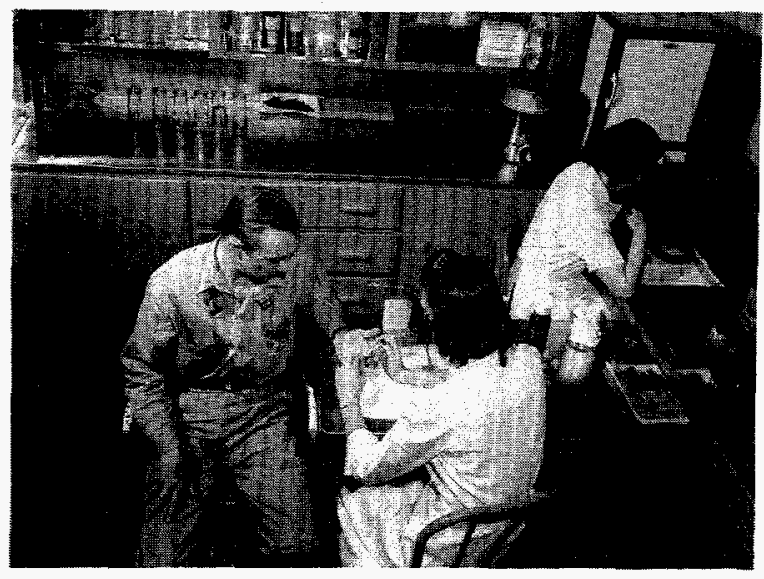

Figure 33. An Oak Ridge National Laboratory employee having a blood test to detect radiation exposure (circa 1950).

Since none of the methods had been proven on anything like the scale required, and there was no sure basis to choose among them, Groves pursued them all at once. This required construction of four separate and unique industrial plants, as well as the roads, housing, schools, and other infrastructure needed to support thousands of workers.

The $Y-12$ Plant-By 1942, work of Ernest Lawrence at the University of California in Berkeley suggested that the electromagnetic process was a feasible production method. The process was so inefficient, however, that it would require an enormous industrial plant to produce appreciable quantities of uranium-235. The Government contracted with Tennessee Eastman, a subsidiary of Eastman Kodak, to build and operate the Oak Ridge electromagnetic plant. Construction began on what was called Y-12 Plant in February 1943 on a site a few miles southwest of the town of Oak Ridge. Using 14,700 tons of silver borrowed from the U.S. Bullion Depository to substitute for scarce wartime copper, the plant was operating by early 1944. Yet the many new and complex machines caused electrical and mechanical problems to plague the facility. These problems, coupled with the success of the gaseous diffusion process, led to the discontinuance of the electromagnetic process after the war.
The $K-25$ Site-As the Government moved to acquire the Oak Ridge site, atomic planners were confident that the gaseous diffusion production method would succeed. The Special Alloy Material Laboratories at Columbia University had proved the practical application of the technology in 1942.

Groves engaged the M.W. Kellogg Company, operating as the Kellex Corporation, to design an industrial gaseous diffusion plant, which became known as $\mathrm{K}-25$. The J.A. Jones Construction Company contracted to build the facility, and the Carbide and Carbon Corporation, a subsidiary of the Union Carbide and Carbon Corporation, was designated as the operator. Construction began around June 1943 at a site some 15 miles southwest of the town of Oak Ridge. Initial testing started during the spring of 1944, and productive operation began about a year later. A related plant, known as $\mathrm{K}-27$, was built nearby to produce slightly enriched uranium used as feed material for the gaseous diffusion process.

Gaseous diffusion proved the best of the three production processes. The AEC turned to this technology when uranium-235 production capacity expanded to meet Cold War demands. More gaseous diffusion plants were built near $\mathrm{K}-25$ and also in Paducah, $\mathrm{KY}$ and Portsmouth, $\mathrm{OH}$. When the AEC moved to reduce production of fissionable material in 1964, the agency stopped operations at the $\mathrm{K}-25$ and $\mathrm{K}-27$ plants and gradually reduced operations at the remaining gaseous diffusion plants. Eventually the AEC used the plants to produce enriched uranium for commercial nuclear power plant fuel.

The Oak Ridge National Laboratory-The Manhattan Project originally intended to use the Tennessee site for all production work, but research at the Metallurgical Laboratory in Chicago showed that the pile process (the first nuclear reactor technology) would generate far more heat and radioactivity than scientists had previously believed. Consequently, the Project selected the Hanford site in eastern Washington, a much larger and even more isolated site than Oak Ridge, for plutonium production. A pile semiworks-a test plant that would move from the research stage to large scale productionwas, however, built in Oak Ridge. The E.I. du Pont de Nemours Company built the test pile 
plant, designated $X-10$ (Figure 34). Construction of the $X-10$ reactor began at a site 10 miles southwest of Oak Ridge during March 1943. The reactor was ready for full-scale operations by January 1944. The University of Chicago, through its Met Lab, operated the plant.

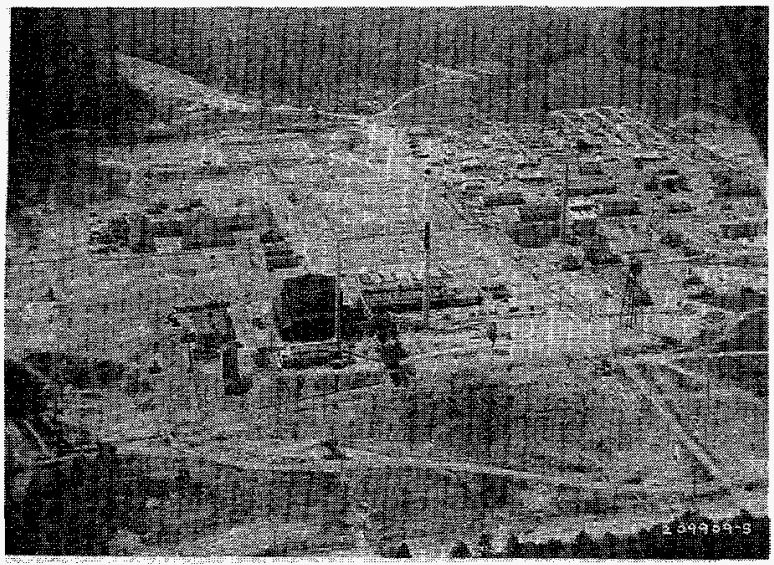

Figure 34. Aerial view of the Oak Ridge $X-10$ facility (1945), which served as a pilot for the Hanford plutonium production reactors. After World War II, the facility produced isotopes for national distribution. (PHOTO: U.S. ARMY)

A research facility designated as the Clinton Lab oratories was built during the war to support $X-10$ reactor activities. By 1944, Clinton Laboratories had chemistry, health, and engineering divisions. In 1947, the entire Oak Ridge complex, including the Clinton Laboratories, passed from the Manhattan Engineer District to the newly formed Atomic Energy Commission. Scientists at Clinton, meanwhile, were engaged in transforming the laboratory from a war production facility to a nuclear research center. Clinton Laboratories pushed for a substantial role in building an experimental materials testing reactor. The AEC, however, assigned the project to Argonne National Laboratory outside Chicago, which likewise had hopes of serving as a reactor development center. Around the same time, the Monsanto Chemical Company announced its withdrawal as the operating contractor for the Oak Ridge Laboratory. That contract was transferred to the Union Carbide and Carbon Corporation, which already ran the gaseous diffusion plants. In January 1948, the AEC changed the name of Clinton Laboratories to Oak Ridge $\mathrm{Na}$ tional Laboratory (ORNL). ORNL scientists set out to build a multiprogram research laboratory.
They used the $X-10$ reactor to produce the radioisotopes that the AEC distributed to scientists and physicians worldwide. In the early postwar years, the isotope distribution program was the AEC's most visible and touted "atoms for peace" program. Researchers also conducted homogenous reactor experiments, and worked on a nuclear reactor to power long-range bombers. In 1946, the Laboratory divided its health division into divisions of biology, medicine, and health physics. Divisions of metallurgy, physics, solid-state materials, mathematics, engineering physics, and electronuclear projects were added shortly afterwards. ORNL also organized units for reactor development and fusion research.

In 1955, ORNL began to broaden its work beyond issues of interest to the AEC alone. By the 1960s ORNL was the most diversified of the AEC research laboratories. The Laboratory also continued to engage in a wide array of AEC research. The High Flux Isotope Reactor for the production of transuranic elements was sited at Oak Ridge. The Laboratory became the primary technical support organization for AEC nuclear desalting projects, directed toward the development of reactors to supply both electric power and desalinated sea water.

In the early postwar years, the isotope distribution program was the Atomic Energy Commission's most visible and touted "atoms for peace" program.

ORNL also undertook extensive reactor safety work, investigating fission product release from reactor fuel elements and heavy-metal fabrication processes used to create reactor pressure vessels. Fusion research work continued, and the Laboratory built an experimental fusion device, the Oak Ridge Tokamak, and other experimental fusion devices. The Laboratory also conducted some research for the liquid-metal fast breeder reactor program, and was chosen as the site for the Clinch River Breeder Reactor, a project that was ultimately canceled.

The S-50 Plant - The Manhattan Project originally planned to construct only three Oak Ridge process plants. A fourth technology, liquid thermal diffusion, was initially considered but 
was rejected because of its apparent inefficiency. By June 1944, however, concerns about reaching needed production levels for uranium-235 led to a decision to construct a liquid thermal diffusion plant in Oak Ridge. The primary purpose of the plant was to enrich uranium feed material for the $Y-12$ electromagnetic facility. Using technology employed by a Navy pilot plant at

Anacostia Station in Washington, DC, the H.K.

Ferguson Company, operating as the Fercleve Corporation, quickly built the plant. Designated as $S-50$, the facility was near the $K-25$ gaseous diffusion plant. The $\mathrm{S}-\mathbf{5 0}$ plant operated for a year before it was shut down in September 1945.

After the war, the U.S. Government was concerned that a shortage of trained nuclear scientists, physicians, and other specialists could imperil plans to expand nuclear programs.

The Oak Ridge Institute of Nuclear Studies (ORINS) After the war, the U.S. Government was concerned that a shortage of trained nuclear scientists, physicians, and other specialists could imperil plans to expand nuclear programs. Many universities were establishing instructional courses, but rigid security requirements limited the information that these institutions could distribute. At the same time, the Government was

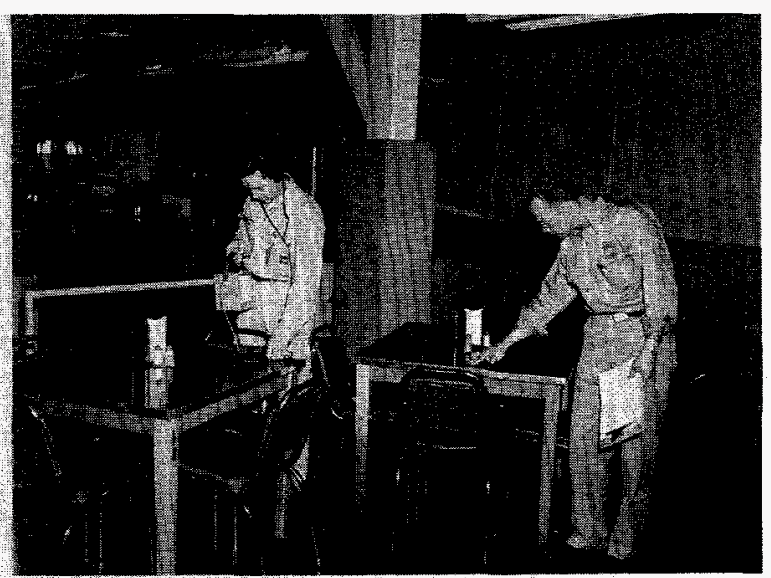

Figure 35. Oak Ridge health physics technicians monitoring a cafeteria for radiation. eager to train practitioners in what it viewed as the beneficial side of nuclear energy, particularly the use of radiation for biomedical research and treatment of disease. The Government concluded that it needed dedicated facilities for this purpose. The first such facility established was the Institute of Nuclear Studies at the University of Chicago.

Inspired by the Chicago institute, in 1946 the University of Tennessee and a consortium of southeastern universities persuaded the MED to establish the Oak Ridge Institute of Nuclear Studies (ORINS). Operating under a Manhattan Project (and later AEC) contract, ORINS was responsible for selecting both students and established scientists for fellowships and other temporary research assignments. The ORINS isotope training program, established in 1948, initially offered three 4-week summer courses covering radiation, instrumentation, tracer applications, and experimental procedures. These courses were immediately filled with scientists from diverse fields eager to use isotopes in their research. The AEC mandated such training before doctors or researchers could be licensed to use isotopes.

The hospital operated until 1974, when it and the other Atomic Energy Commission research hospitals were shut down.

In 1948, the AEC asked ORINS to establish a clinical research facility as part of a national program to address public and scientific interest in using radiation to treat cancer. ORINS established a Medical Division to operate the hospital and conduct biomedical research. It was assigned space in the former Manhattan Project hospital at Oak Ridge. In 1950, ORINS began accepting patients referred by private physicians for experimental cancer therapy. A board of medical consultants from southern medical schools was assembled to oversee the clinical research program. The hospital operated until 1974, when it and the other AEC research hospitals were shut down. By that time, many private hospitals around the country were offering high-quality nuclear medicine facilities. ORINS medical personnel continued treating patients on an outpatient basis. 
In 1966 ORINS became known by the name of its operating contractor, Oak Ridge Associated Universities. During the early 1990s the facility was renamed the Oak Ridge Institute for Science and Education (ORISE). ORAU currently remains the managing and operating contractor.

\section{Site Human Radiation Experiments}

ORINS and ORNL performed all identified human radiation experiments at Oak Ridge except for one plutonium injection experiment: the first in the series done at various sites. A Manhattan Project physician administered the injection in April 1945 at the Oak Ridge hospital. Clinton Laboratories personnel also constructed mathematical models based on the excretion data from this and three other plutonium injection experiments.

The ORINS Medical Division conducted clinical experiments using radionuclide and total body irradiation therapies to develop cancer diagnosis and treatment. ORNL personnel performed a few clinical experiments and conducted three intentional radiation releases as part of radiological warfare field tests. Most human radiation studies undertaken at Oak Ridge were performed by ORINS Medical Division personnel through the cancer research hospital and a related biomedical research program. Individual clinical experiments are detailed in Chapter 3, while the ORNL environmental releases are discussed in the Environmental Radiation Releases narrative.

Most human radiation studies undertaken at Oak Ridge were performed by ORINS Medical Division personnel through the cancer research hospital and a related biomedical research program.

ORINS radiation experiments-ORINS human radiation experiments involved the use of radiation and radioisotopes in the study of cancer, specifically in cancer biology and treatment. The main areas of experimentation related to five concerns:

- total body irradiation in the treatment of leukemia, lymphoma, and polycythemia rubra vera (a condition in which too many red blood cells are formed);
- the development and evaluation of teletherapy (Figure 36);

- the effects of radiotherapy on the blood;

- the development of other uses of radiation and isotopes in cancer treatment; and

- the study of other therapy-related biologic effects.

Much time and effort was devoted to determining the biological, physiological, and clinical effects of total body irradiation.

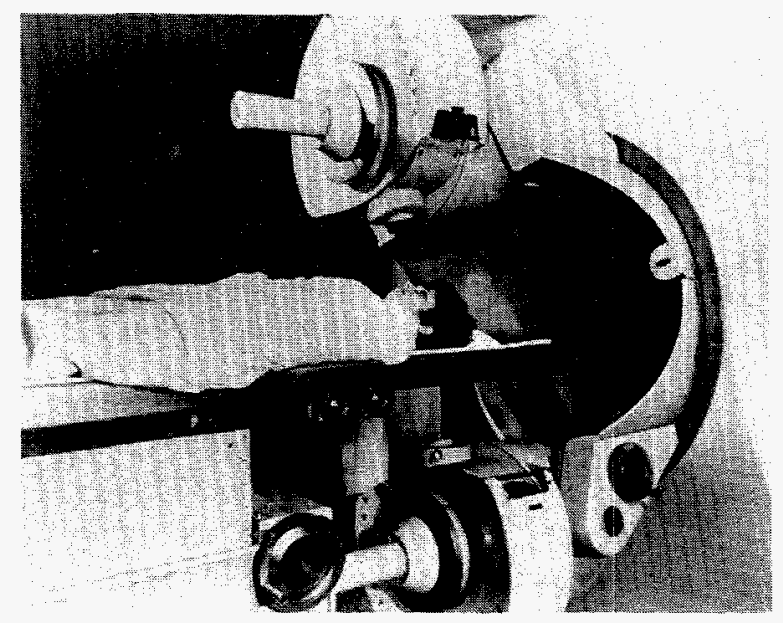

Figure 36. Cobalt- 60 teletherapy conducted for cancer treatment at the Oak Ridge Institute for Nuclear Science (1972). (PHOTO: F.W. HOFFMAN, AEC OAK RIDGE OPERATIONS OFFICE)

Patients meeting predetermined disease criteria were accepted into the research hospital on the recommendation of the medical schools of ORINS member institutions. About 3,000 patients participated in the program from 1950 through 1974, when the hospital was closed. ORINS Medical Division personnel required patients to sign consent forms before undergoing treatment. Patients were provided with a booklet describing radiation generally, the nature of the program, and the nature of the experimental program in which they would participate. The Medical Division staff as a group reviewed proposed experimental treatments until 1967. That year, following the example of the National Institutes of Health and acting on AEC recommendations, ORINS formed an institutional review board that examined proposals for research using human subjects. 
Total body irradiation had been employed for cancer treatment beginning in the 1930s, but until the late 1950s the instruments available did not provide uniform radiation fields. ORINS addressed this problem by designing and constructing a room to hold eight radiation sources that delivered a uniform dose at a moderate rate. The facility-called the Medium Exposure Total Body Irradiator, or METBI-went into use in 1960. In 1967, the Low Exposure Total Body Irradiator (LETBI) was built. Between I 960 and 1974, some 200 cancer patients received experimental treatment in these facilities.

The National Aeronautics and Space Administration (NASA) found LETBI patient data useful in assessing risks that astronauts might face from radiation in space or nuclear-powered spacecraft. Accordingly, in 1963, the AEC asked ORINS to assist NASA in assessing the health risks that astronauts might face from radiation in space. In response, ORINS conducted a retrospective study of acute radiation-induced effects among patients who had been exposed to radiation previously in hospitals throughout the country. NASA also funded some LETBI work and data from patients receiving cancer treatment were used to address NASA questions.

ORNL-ORNL/Clinton Laboratories scientists conducted comparatively few human radiation experiments. Laboratory experimentation was episodic and determined by the research interests of individual scientists. Examples include two 1945 radiation skin absorption experiments, a 1963 experiment in which an investigator put radioactive silver on his own arm, and an early 1960 s experiment in which five male subjects ingested radioiodine. The Laboratory helped with analyses of body fluids and autopsy materials of II patients injected with uranium at Massachusetts General Hospital during the early 1950s. In 1948, ORNL also conducted the three radiological warfare tests noted earlier. These tests apparently did not involve intentional human radiation exposures.

\section{Site Records Collections}

Oak Ridge presents a challenge to the researcher. The site has many valuable records collections that document its history and the history of other MED and AEC sites. However, many of these collections are currently hard to use. The difficulties are illustrated by the inactive records of the DOE operations office. Nearly all these records-some 7,000 cubic feet encompassing everything from 1940 s site construction plans to 1990s travel vouchers-are stored in a single records-holding area.

During the 1940s and 1950s, Oak Ridge served as a central records-collection point for other MED and AEC facilities. At one time, the records were carefully organized and indexed. But after years of inattention, there are today more than 1,000 boxes of fragmented and disorganized records dating from 1965 or before. Some important unclassified files were transferred to the custody of the National Archives and Records Administration (NARA). However, since NARA would not manage DOE classified records, classified segments were removed from many collections transferred to archival custody. These segments remain in the Oak Ridge holding area, separated from their parent series.

Starting in 1987, NARA and the DOE Oak Ridge Operations Office began working to characterize the records in the holding area and to transfer permanently valuable series to archival custody. Many significant files were transferred, but neither NARA nor DOE could provide adequate resources to finish the job. Listed below are records series that remain in Oak Ridge; it should be remembered, however, that these materials often represent fragments of larger series that either are at NARA or have been scattered, lost, or destroyed.

The site has many valuable records collections that thoroughly document its history and the history of other MED and $A E C$ sites. However, many of these collections are currently hard to use.

Among the most potentially valuable of these records are more than 600 cubic feet of contract files dating to the early days of the MED. Considering that records retention guidelines call for such documents to be destroyed after only 6 years, the fact that this material survives at all is remarkable. Another important body of records is the Records Holding Task Group (RHTG) Files, which consists of nearly 300 
boxes of classified documents removed from other collections. In archival terms, this is an artificial collection-one whose documents have lost all association with their original series.

The records situation for the Oak Ridge contractor sites is better. ORISE has many important records series documenting activities of the Medical Sciences Division, although the parent organization has only recently begun a systematic program to manage and control all its records. Of particular value are the ORISE medical files (for which personal privacy restrictions apply) and a full set of periodic reports from the start of the facility. ORNL has a huge volume of records contained in the various elements of its designated central files, which include correspondence, reports, and laboratory notebooks. Both $Y-12$ and $K-25$ have a smaller volume of records. DOE plans to continue its efforts to identify records holding at all of these sites and to pursue avenues for archival preservation of permanently valuable series. For additional Oak Ridge records, see the series listed under the National Archives and Records Administration. 


\title{
Oak Ridge Operations Office
}

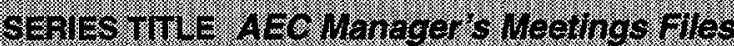

\author{
INCLUSIVE DATES $1957-1965$ \\ ARRANGEMENT Chronological \\ VOLUME 1 cubic foot

\section{LOCATION OF Oak Ridge Operations Office \\ RECORDS Building $2714 \mathrm{~J}$ \\ 200 Administration Road \\ Oak Ridge, TN 37831}

DESCRIPTION These records consist of Oak Ridge Operations Office Manager Sam Sapirie's files relating to annual Washington meetings of AEC field operations office managers. These meetings covered broad aspects of AEC policies and operations, including security, budgets, public relations, congressional legislation, and civil defense. Records for each meeting are filed together. Included are agendas, minutes, reports, correspondence, directives, and other material relating to individual meetings. Also present are Sapirie's notes and correspondence relating to meeting activities.

\section{SERIES TITLE Classfication Office Ries}

INCLUSIVE DATES $1956-1971$

ARRANGEMENT Subject

VOLUME 2 cubic feet

DESCRIPTION The series consists of documents compiled by the Classification Office showing classification policies and directives. It includes information on classification of nuclear weapons programs, nuclear production activities, and nuclear reactors. The series consists of letters, memorandums, and bulletins.

LOCATION OF Oak Ridge Operations Office

RECORDS Building 2714J

200 Administration Road

Oak Ridge, TN 37831 


\title{
SERES ThLE Contract DWision insurance Files
}

\author{
INCLUSIVE DATES 1948-1965 \\ ARRANGEMENT Chronological \\ VOLUME 1 cubic foot \\ collection that existed at one time. \\ LOCATION OF Oak Ridge Operations Office \\ RECORDS Building $2714 \mathrm{~J}$ \\ 200 Administration Road \\ Oak Ridge, TN 37831
}

DESCRIPTION Contained in these records are insurance policy files for AEC contractors, including Mallinckrodt Chemical Works, H.K. Ferguson Co., and Oak Ridge Institute of Nuclear Science (ORINS). Policy files detail liability coverage and premiums for staff, facilities, and automobiles; information regarding workmen's compensation is also present. The ORINS file documents issues such as medical malpractice and clinical activities, including patient treatment and autopsy. Correspondence is present to and from the Oak Ridge Division of Research, Oak Ridge Insurance Branch, AEC Insurance Section, and Office of the Comptroller in Washington, DC. Correspondence subjects include insurance coverage and premiums, public liability, workmen's compensation, and levels of needed coverage. These records appear to be fragments of a larger

\section{SERIES TITLE Chief Counsel Dtice, SUbjear Files}

INCLUSIVE DATES $1949-1987$

ARRANGEMENT AEC Subject/Numeric Filing System

VOLUME 28 cubic feet

DESCRIPTION The series was compiled by chief counsel staff to document litigation and other legal activities. It contains documentation on operations office legal matters and includes information on lawsuits, discrimination, procurement, and contract matters. These files contain letters, memos, reports, affidavits, depositions, and other legal documents. The series includes data on releases at the Portsmouth Plant.

LOCATION OF Oak Ridge Operations Office

RECORDS Building $2714 \mathrm{~J}$

200 Administration Road

Oak Ridge, TN 37831 


\section{SERIES TILE Decatur Area OTIce Files}

INCLUSIVE DATES 1944-1945

ARRANGEMENT Subject

VOLUME 1 cubic foot

DESCRIPTION The series consists of fragments of correspondence files pertaining to the manufacturing operation of the Houdaille Hershey Plant. The series consists of letters, memorandums, and reports that were maintained as an office subject file.

RESTRICTIONS This series contains a small amount of classified information.

LOCATION OF Oak Ridge Operations Office

RECORDS Building 2714J

200 Administration Road

Oak Ridge, TN 37831

\section{SEnIES TTLE Feed Materials Drvision, Lockand Area Othee, and Persorner Flles}

INCLUSIVE DATES 1943-1962

ARRANGEMENT Subject

VOLUME 45 cubic feet

DESCRIPTION The series consists of correspondence files from three organizations. The Feed Materials division files ( $26 \mathrm{cu}$. $\mathrm{ft}$.) cover uranium ore refining and assay activities at Oak Ridge and at the Mallinckrodt Chemical Works, Harshaw, Linde Air Products, and other plants. The Lockland Area office files (11 cu. ft.) cover attempts to develop nuclear reactors for the propulsion of aircraft. The personnel files $(8 \mathrm{cu}$. ft.) contain organization charts, directives, and files on personnel. The series consists of letters, memorandums, reports, charts, and directives. The Feed Materials files are arranged according to a Dewey Decimal System; the Lockland files by the AEC Subject/Filing System; and the personnel files by subject. The personnel files contain early Oak Ridge organization charts and a file on medical activities for 1943-1946.

LOCATION OF Oak Ridge Operations Office

RECORDS Building 2714J

200 Administration Road

Oak Ridge, TN 37831 


\section{SERIES TILLE Fhance DHistor Flles}

INCLUSIVE DATES 1944-1986

ARRANGEMENT Subject

VOLUME 11 cubic feet

DESCRIPTION This series was compiled by Oak Ridge personnel to capture data needed for financial oversight of contractors. The series contains documentation on financial policy implementation, contractor financial matters, audits, cost accounting methods, and uranium purchases. The series consists of letters, memorandums, reports, invoices, purchase orders, and cost accounting records. The series contains some files on the origins of the division.

RESTRICTIONS This series contains a small amount of classified information.

LOCATION OF Oak Ridge Operations Office

RECORDS Building 2714J

200 Administration Road

Oak Ridge, TN 37831

\section{SERES TITLE Mdividual hury Reports ond hedical file- Varbus MES dreas}

INCLUSIVE DATES $1943-1947$

ARRANGEMENT Location

VOLUME 1 cubic foot

DESCRIPTION This grouping consists of compensation claim files and occupational injury records from locations such as Brookhaven, Chicago, Colorado, Columbia, Hanford, Madison Square, New York, Santa Fe Safety Branch, and the Division of Engineering and Production. Compensation files are arranged alphabetically by name of employee. Included is correspondence describing injuries written by the District Safety Engineer and area medical officials to the U.S. Employee Compensation Commission.

RESTRICTIONS This series contains privacy material.

LOCATION OF Oak Ridge Operations Office

RECORDS Building $2714 \mathrm{~J}$

200 Administration Road

Oak Ridge, TN 37831 
INCLUSIVE DATES $1957-1979$

ARRANGEMENT Site or work location

VOLUME 11 cubic feet

DESCRIPTION The series consists of reports, contracts, and correspondence relating to employee salaries, strikes, retirement, grievances, insurance, and workmen's compensation. Also present is information about job descriptions, recruitment and regulatory programs, organizational structure, labor laws, compliance with the Davis-Bacon Act, and National Labor Relations Board Activities. Contractors covered include University of Puerto Rico, National Lead of Ohio, University of Tennessee, and Martin Marietta. Specified sites include the Portsmouth and Paducah gaseous diffusion plants. A file listing is available.

\section{LOCATION OF Oak Ridge Operations Office \\ RECORDS Building 2714J \\ 200 Administration Road \\ Oak Ridge, TN 37831}

\section{SERIES TIIE INWW and Compensation clam Files}

INCLUSIVE DATES $1943-1950 ; 1961-1976$

ARRANGEMENT Record type

VOLUME 12 cubic feet

DESCRIPTION These files document reports of employee job injuries and claims for compensation. Content, scope, and coverage vary within the files. Most of the files consist of individual employee injury reports created by the MED/AEC Oak Ridge Safety Branch. These reports include the name of the injured party, along with the type of injury, its severity, where it occurred, and if it occurred as a result of unsafe practices or conditions. Statements of the injured party as well as their supervisors are included. Monthly summary reports of site injuries are present, mostly for Oak Ridge although some other sites are represented as well. Compensation claim files also include injury reports along with correspondence with claimants, doctors, and insurance representatives. Transmittal memos to the AEC Insurance Section are included. These records consist of file fragments, and gaps are apparent.

RESTRICTIONS This series contains privacy material.

LOCATION OF Oak Ridge Operations Office

RECORDS Building 2714J

200 Administration Road

Oak Ridge, TN 37831 
INCLUSIVE DATES $1957-1971$

ARRANGEMENT Chronological

VOLUME 1 cubic foot

DESCRIPTION Records created and maintained by Joseph A. Lenhard, an AEC Oak Ridge employee. Lenhard was a health physicist who was employed by the Biology Branch of the Oak Ridge Operations Office Research Division. In 1967, Lenhard became Director of the Oak Ridge Safety Division, and later served as Director of the Safety and Environmental Control Division. The files document effluent and other pollution control, compliance with environmental protection laws, occupational health and safety, fire protection, waste disposal, isotopes handling and radiological safety, procedures for handling contaminated ORINS patients, and fallout reports. Much of the documentation consists of occupational correspondence with other AEC officials and with Oak Ridge contractors.

LOCATION OF Oak Ridge Operations Office

RECORDS Building $2714 \mathrm{~J}$

200 Administration Road

Oak Ridge, TN 37831

\section{SERIES TITLE KR-25 Insurance Branch Flles}

INCLUSIVE DATES 1944-1953

ARRANGEMENT AEC Subject/Numeric Filing System

VOLUME 0.5 cubic foot

DESCRIPTION The series contains seven files on the following subjects: insurance code classifications for some individual workers, a summary of health and accident reports for the site, and automobile accident reports at Oak Ridge. This series contains organization and personnel monthly status reports for the period June 1950 to October 1951 . Several of these reports have short sections on insurance activities, which contain claims and pending litigation against Oak Ridge Operations Office for work-related disabilities.

RESTRICTIONS This series contains privacy material.

LOCATION OF Oak Ridge Operations Office

RECORDS Building 27145

200 Administration Road

Oak Ridge, TN 37831 


\title{
SERIES TILE NeW Bunswick Area OTrce mles
}

\author{
INCLUSIVE DATES 1956-1958 \\ ARRANGEMENT AEC Subject/Numeric Filing System \\ VOLUME 1 cubic foot \\ files. \\ LOCATION OF Oak Ridge Operations Office \\ RECORDS Building $2714 \mathrm{~J}$ \\ 200 Administration Road \\ Oak Ridge, TN 37831
}

DESCRIPTION The series consists of fragments of correspondence files compiled to document the activities of the area office. They contain documentation pertinent to ore assay activities. The records include memorandums, letters, and reports organized into subject

\section{SEPIES TITLE NeW Vork Operations OtfCe FTlE:}

INCLUSIVE DATES $1943-1944 ; 1951-1957 ; 1964-1972$

ARRANGEMENT Subject

VOLUME 6 cubic feet

DESCRIPTION The series was compiled by New York Operations Office staff to assist in oversight of contractor operations. It contains documentation on plant operations, fuel element fabrication, Rochester worker badges, the Middlesex sampling plant, and the Fernald plant. The series contains letters, memorandums, reports, notebooks, handwritten notes, and badges.

RESTRICTIONS This series contains a small amount of classified information.

LOCATION OF Oak Ridge Operations Office

RECORDS Building 2714J

200 Administration Road

Oak Ridge, TN 37831 


\title{
SERIES TITLE NeW York Operations Office Contract Illes
}

\author{
INCLUSIVE DATES 1943-1950 \\ ARRANGEMENT Record type \\ VOLUME 37 cubic feet \\ LOCATION OF Oak Ridge Operations Office \\ RECORDS Building $2714 \mathrm{~J}$ \\ 200 Administration Road \\ Oak Ridge, TN 37831
}

DESCRIPTION These records consist of documents related to contracts managed by the MED/AEC New York Operations Office. Contractors include private corporations such as Brush Beryllium, Electro Metallurgical, and Radium Chemical. Federal agencies, including the Navy Department, Bureau of Federal Supply, and War Assets Administration, are also represented by contracts in the files.

\section{SERIES TILE Oak RIdge Comtract Flles}

INCLUSIVE DATES ca. 1943-ca. 1978

ARRANGEMENT Contract number

VOLUME approximately 650 cubic feet

DESCRIPTION This series consists of procurement files containing forms, reports, and correspondence associated with specific Oak Ridge-related contracts. The bulk of the files consist of routine financial and administrative materials relating to contract negotiation, awards, and financial accounting. The most substantive information is located in narrative statements included in project proposals, correspondence, and periodic reports, which are not always present in the files for each contract. The contracts relate to all areas of MED/AEC/DOE activities, including construction, manufacturing, administration, and research and development. Some human experimentation activities are detailed. The quantity and type of information varies among the files. For each contract file the volume of material ranges from a few pages to more than a cubic foot. There are significant gaps in the files, and it is not known where the misising files are located. An index to contractors is available.

LOCATION OF Oak Ridge Operations Office

RECORDS Building 2714J

200 Administration Road

Oak Ridge, TN 37831 


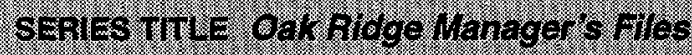

INCLUSIVE DATES 1951-1953

ARRANGEMENT Subject

VOLUME 7 cubic feet

DESCRIPTION The records appear to be the official files created and maintained in the office of the AEC Oak Ridge Operations Office Manager. This series covers a broad range of subjects relating to Oak Ridge facilities. Topics include: budget, accounting, and finance; community management; contracts; industrial research and application; information and publications; medicine, health and safety; organization and management; and research and development. While these files appear to be complete for the period covered, the location of similar material dating before and after is not known. A file listing is available.

LOCATION OF Oak Ridge Operations Office

RECORDS Building $2714 \mathrm{~J}$ 200 Administration Road

Oak Ridge, TN 37831

\section{SERIES TILE PUbIC Information Otice Files}

INCLUSIVE DATES 1971-1973

ARRANGEMENT Subject

VOLUME 21 cubic feet

DESCRIPTION These records are the central subject files for the Oak Ridge Public Information Office. A broad range of subjects are covered, including news releases, press interviews, radio and television stories, motion picture scripts, labor relations, procurement and contracts, and reactor development. Some information pertaining to medicine, health, and safety issues, including accidents, environment, and "special cases" of radiation exposure is present. Speeches of the Operations Office Manager are also included. While the files appear complete for the years covered, these records may be fragments of a larger collection that has yet to be located. A file folder listing is available for the 1971 records.

LOCATION OF Oak Ridge Operations Office

RECORDS Building 2714J

200 Administration Road

Oak Ridge, TN 37831 


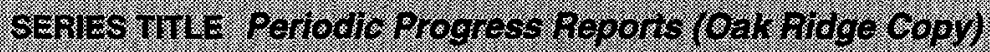

INCLUSIVE DATES $1948-1973$

ARRANGEMENT Report type; chronologically thereunder

VOLUME 8 cubic feet

DESCRIPTION The series consists of the Oak Ridge manager's office copy of the following formal reports: reports of the Oak Ridge operations office; monthly reports to the General Advisory Committee; quarterly progress reports to the Joint Committee on Atomic Energy; Hanford Operations Office reports; and Savannah River Operations Office reports. The series does not contain a complete set of any of these types of reports. Some reports contain information on AEC biomedical programs and activities.

RESTRICTIONS This series contains classified information.

LOCATION OF Oak Ridge Operations Office

RECORDS Building 2714J

200 Administration Road

Oak Ridge, TN 37831

\section{SERIES TITLE Personal hsurance Reoord Cards}

INCLUSIVE DATES 1943-1944

ARRANGEMENT Alphabetical by name

VOLUME 1 cubic foot

DESCRIPTION These records consist of four trays of 3- by 5-inch cards. The trays are labeled University of California, Clinton Laboratories, and University of Chicago. Each card contains the name of contractor, name of insured, date effected, premium amount, date canceled, and details regarding claims. Names are included under name of insured; these individuals were likely employees of the designated contractor. These cards likely are fragments of a larger collection of records that no longer exists.

RESTRICTIONS This series contains privacy material.

LOCATION OF Oak Ridge Operations Office

RECORDS Building 2714J

200 Administration Road

Oak Ridge, TN 37831 


\section{SERIES MTLE RW Cook OfTCE FIES}

INCLUSIVE DATES $1947-1951$

ARRANGEMENT Subject

VOLUME 1 cubic foot

DESCRIPTION The series was compiled by Cook's office to document his activities as manager of the operations office. It includes documentation on security, budget, and Clinton Laboratory matters. The series contains letters, memorandums, and reports arranged by subject.

RESTRICTIONS This series contains a small amount of classified information.

LOCATION OF Oak Ridge Operations Office

RECORDS Building $2714 \mathrm{~J}$

200 Administration Road

Oak Ridge, TN 37831

\section{SERIES TITLE Records Holding Task Group (RHTC) Files}

INCLUSIVE DATES $1942-1980$

ARRANGEMENT Sequential by assigned document number

VOLUME 290 cubic feet

DESCRIPTION The series consists entirely of classified documents removed from other files. This is an artificial collection created for classified document accountability purposes. The documents were produced by many parent Oak Ridge offices, including those concerned with MED biomedical programs. The files cover a variety of subjects from biomedical research to the production of special nuclear materials. File contents were assembled with classified documents removed from Oak Ridge records collections, some of which are now in the custody of the National Archives. An item index, which is itself classified, has been prepared as a listing of the documents in the collection.

RESTRICTIONS This series contains classified information.

LOCATION OF Oak Ridge Operations Office

RECORDS Building $2714 \mathrm{~J}$

200 Administration Road

Oak Ridge, TN 37831 


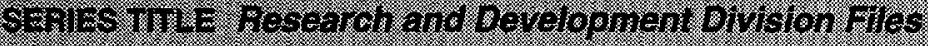

INCLUSIVE DATES $1943-1957 ; 1962-1967$

ARRANGEMENT None

VOLUME 5 cubic feet

DESCRIPTION The series was compiled by operations office staff to provide oversight of contractor operations. It includes materials on $\mathrm{K}-25$ plant operations and medical reports and files similar to records found in Oak Ridge Operations Office collections in the $\mathrm{Na}$ tional Archives field branch in East Point, GA. The series contains letters, proposals, blueprints, construction notebooks, memorandums, and reports.

RESTRICTIONS This series contains classified information.

LOCATION OF Oak Ridge Operations Office

RECORDS Building 2714J

200 Administration Road

Oak Ridge, TN 37831

\section{SERIES TILE RESearch and Mediche DWision Flles}

INCLUSIVE DATES 1944-1948

ARRANGEMENT Subject

VOLUME 3.5 cubic feet

DESCRIPTION The series consists of letters, memorandums, and reports compiled by the office to administer MED/AEC biomedical programs. Included is documentation, much of it declassified, on MED and early AEC biomedical programs and policies. The series has material pertaining to the interim medical advisory committee, extensive material pertaining to radioisotope distribution, and other documentation pertinent to human radiation experimentation. The series is closely related to the Oak Ridge Operations Office Research and Medicine Division files in the custody of the National Archives.

\section{LOCATION OF Oak Ridge Operations Office \\ RECORDS Building $2714 \mathrm{~J}$ 200 Administration Road Oak Ridge, TN 37831}


Chapter 2. Narratives and Records Series-Institutional Areas: Oak Ridge Operations Office

\section{SERIES TITLE St. Louis Area OHfice FIles}

INCLUSIVE DATES 1946-1965

ARRANGEMENT Subject

VOLUME 2 cubic feet

DESCRIPTION The series consists of fragments of correspondence files compiled to document the activities of the area office. Included are personnel and security subject files; materials supply reports; plant and equipment diagrams; communications security files; and materials control files. The series consists of letters and memorandums organized into subject files.

LOCATION OF Oak Ridge Operations Office

RECORDS Building 2714J

200 Administration Road

Oak Ridge, TN 37831 


\section{Oak Ridge Institute for Science and Education (ORISE)}

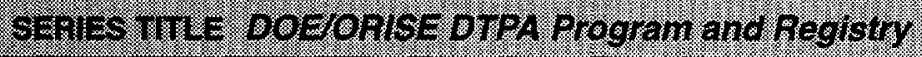

INCLUSIVE DATES $1959-$ present

ARRANGEMENT Record type

VOLUME 12 cubic feet

DESCRIPTION The series consists of correspondence, reports, publications, and patient registries (electronic as well as hard copy) relating to efforts to reduce transuranic body burdens through chemical chelation. These burdens typically were acquired by nuclear workers who had inhaled or ingested materials such as plutonium. Chelation is a process that attempts to speed excretion of materials such as plutonium and other transuranics through administration of chemical compounds. DTPA is approved by FDA as an Investigational New Drug (IND) for chelation of selected transuranic elements such as plutonium. Subjects covered include human use protocols, informed consent, and patient response, as well as general administration of the program. Also included are historical AEC business files for the DTPA program that document activities occurring prior to ORAU's involvement in 1978.

RESTRICTIONS This series contains privacy material.

LOCATION OF Oak Ridge Institute for Science and Education

RECORDS Medical Sciences Division

150 East Road, Room A

Oak Ridge, TN 37830

\section{SERIES TILE HWhan Radiation Studtes Intormation}

INCLUSIVE DATES $1943-1986$

ARRANGEMENT Record type

VOLUME 1 cubic foot

DESCRIPTION This is a reference file containing publications and other documents relevant to reports of human radiation experiments. Included are 1984 project summaries prepared by $A E C$ in response to queries from Congressman R.L. Ottinger and $A B C$ News, as well as the 1986 congressional report American Nuclear Guinea Pigs: Three Decades of Radiation Experiments on Citizens. Also present are several nuclear medicine publications that discuss aspects of ORINS/ORAU medical studies.

LOCATION OF Oak Ridge Institute for Science and Education

RECORDS Medical Sciences Division

140 East Vance Road, Room 202A

Oak Ridge, TN 37830 


\section{Seriles truL hathional sushoss Thes and roporto}

INCLUSIVE DATES 1945-1954

ARRANGEMENT Chronological

VOLUME 1 cubic foot

DESCRIPTION This grouping consists of three bound volumes of original correspondence documenting the establishment and early operations of ORINS. Also included are photographs, press reports, and the original ORINS letter contract. The compilation was assembled along with detailed written commentary in observance of the tenth ORINS anniversary. Note: these are official ORAU records.

LOCATION OF Oak Ridge Institute for Science and Education

RECORDS Medical Sciences Division

140 East Vance Road, Room 202A

Oak Ridge, TN 37830

\section{SERIES TILE Medical Correspondence and Commiter hlos}

INCLUSIVE DATES $1947-1993$

ARRANGEMENT Record type

VOLUME 4 cubic feet

DESCRIPTION This collection consists of several small bodies of documents relating to ORINS/ORAU medical policies, including use of human subjects. The AEC Medical Division Correspondence (1947) pertains to clinical testing and legal responsibilities. Clinical conference announcements (1951-1957) document periodic hospital staff discussions relating to patients and pertinent study findings. Minutes of the Teletheraphy Committee (1951-1960) discuss development of new instruments and techniques for medical use of external radiation. The Committee on Human Studies proposals (1967-1993) cover review of proposals to conduct studies involving human subjects at the facility. Medical Radionuclide Committee/Committee on Human Studies proposals (1966-1981) cover review of proposals for the administration of radioactive materials to human subjects involved in research.

RESTRICTIONS This series contains privacy material.

LOCATION OF Oak Ridge Institute for Science and Education

RECORDS Medical Sciences Division

140 East Vance Road, Room 202A

Oak Ridge, TN 37830 


\section{SERIES TILE Newstettors and Revorts}

INCLUSIVE DATES 1947-present

ARRANGEMENT Record type

VOLUME 5 cubic feet

DESCRIPTION This collection consists of assorted ORINS/ORAU compilations and issuances intended for external use. Included are ORAU annual reports (1960-1991); Newsletters (1948-1974); Employee News and Notes (1965-1970); Medical Division monthly highlights (1959-1971); and bibliographies (1950-1992). These documents include information relevant to ORINS/ORAU clinical research program (1950-1986).

LOCATION OF Oak Ridge Institute for Science and Education

RECORDS Medical Sciences Division

140 East Vance Road, Room 202A

Oak Ridge, TN 37830

\section{SEnies TITE Patient Medical Charts}

INCLUSIVE DATES $1950-1986$

ARRANGEMENT Alphabetical by patient name

VOLUME 93 cubic feet

DESCRIPTION This series covers the central in and outpatient medical records (in original hard copy and/or microfiche forms) for the ORINS/ORAU Hospital. Charts may contain admittance and agreement sheets, medical histories, medical reports, clinical laboratory results, diagnostic radiology reports, photographs, death certificates, autopsy reports, consent forms, discharge summaries, nurse/physician notes, physician's orders, reports, and correspondence, for visits to ORINS/ORAU clinical research program. Also included are treatment protocols, including application of internal or external radiation. All documents relating to an individual patient are compiled as one chart. Records dating from after the closure of the in-patient treatment facility in 1974 document ongoing or new outpatient visits.

RESTRICTIONS This series contains privacy material.

LOCATION OF Oak Ridge Institute for Science and RECORDS Education Medical Sciences Division Collection 230 Warehouse Road Records Holding Area Room 506, Boxes 1-93

Oak Ridge, TN 37830
Oak Ridge Institute for Science and Education Medical Science Division 150 East Vance Road Room A Oak Ridge, TN 37830 


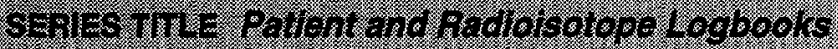

INCLUSIVE DATES $1950-1986$

ARRANGEMENT Record type

VOLUME 3 cubic feet

DESCRIPTION Included here are summaries of ORAU patient treatments as well as of ORAU receipt and/or use of radiation sources. Present is a set of patient registry logs that provide patient name, admission date, chart number, sex, age, address, and referring physician/university. For the ca. 1977-1986 period, the registries cover outpatients only. No information regarding medical condition or treatment is provided. Separate logs detail various uses of internal and external radiation. Included are logs for applications of gallium, carbon-11, valine, tryptophan, lanthanum, iodine-131, phosphorous-32, and other substances. These records generally include protocols and patient information such as name, date of admission and of procedure, diagnosis, dosage, and results. Logs for linear and other total body scans include similar information.

RESTRICTIONS This series contains privacy material.

LOCATION OF Oak Ridge Institute for Science and Education

RECORDS Medical Sciences Division

140 East Vance Road, Room 202A

Oak Ridge, TN 37830

\section{SERIES TILE Yiman Total Eody Iradiation Program Intormation Repors}

INCLUSIVE DATES $1948-1974$

ARRANGEMENT Record type

VOLUME 1 cubic foot

DESCRIPTION This is a collection of reports and other documents relating to operation and investigation of the ORAU total body irradiation (TBI) program. Present are fact sheets and technical documents (including reports associated with summary studies of TBI at 45 institutions), articles and tape recordings relating to the D. Sexton litigation, and reports and other documents pertaining to the 1981 congressional investigation of the TBI program (Gore hearings).

LOCATION OF Oak Ridge Institute for Science and Education

RECORDS Medical Sciences Division Collection

230 Warehouse Road

Records Holding Area, Room 506, Box 571

Oak Ridge, TN 37830 


\section{Oak Ridge National Laboratory (ORNL)}

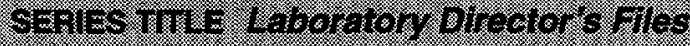

INCLUSIVE DATES 1948-present

ARRANGEMENT Subject; thereunder chronological

VOLUME 150 cubic feet

DESCRIPTION These records consist of correspondence and other documents received and sent by ORNL directors and associate directors. Nearly all operations of the Laboratory are covered, including budgets, classification/declassification, accounting, health protection (including health physics), industrial relations, protection services, and research and development (including much reactor research). Records types include minutes, research proposals, budget analyses, data, and manuscripts.

LOCATION OF Oak Ridge National Laboratory

RECORDS ORNL Records Vault Oak Ridge, TN 37831

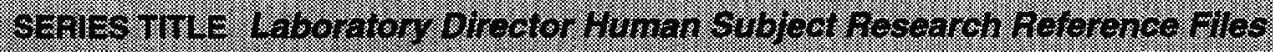

INCLUSIVE DATES 1984-present

ARRANGEMENT Chronological

VOLUME 3 cubic feet

DESCRIPTION These records include project summaries of current DOE-sponsored research activities involving human subjects. Information in the file includes annual funding, principal investigators, collaborating institutions, types of review, vulnerable population involvement, research type, and study objectives and methodology. "Protecting Human Subjects" forms are included.

LOCATION OF Oak Ridge National Laboratory

RECORDS Building 4500-N, Room H-205 (Vault)

Oak Ridge, TN 37831 


\section{SERES TILE Central Fles: Central heport File}

INCLUSIVE DATES 1943-present

ARRANGEMENT Prefix; thereunder by number

VOLUME 1,200 cubic feet

DESCRIPTION Central files at ORNL consist of multiple series maintained at a single location in the Laboratory since its inception. This central filing unit has provided individual document control and currently serves as a report clearance mechanism. This series is a master file for ORNL reports in all areas of research and development. There are approximately 75 different prefixes for reports in this file; each relates to a specific topical area. ORNL prefixed reports, for example, are official institutional reports, while MON reports were generated by Monsanto Corporation when it operated the laboratory. Various indexes are available. The DOE Office of Scientific and Technical Information (OSTI) indexes the reports from 1974 forward.

RESTRICTIONS This series contains a small amount of classified information.

LOCATION OF Oak Ridge National Laboratory

RECORDS Building 4500-N, Room H-205 (Vault)

Oak Ridge, TN 37831 
INCLUSIVE DATES 1943-present

ARRANGEMENT Chronological

VOLUME 400 cubic feet

DESCRIPTION Central files at ORNL consist of multiple series maintained at a single location in the Laboratory since its inception. This CF (central files) prefixed series includes both correspondence and unpublished reports, and other internal unpublished material that has been collected and given a report number. After the 1970s correspondence is generally not included, but for the early period there is a considerable volume. There is a small amount of material relating to University of Chicago activities prior to establishment of the Oak Ridge site. Approximately 30 cubic feet of the central files are classified and are maintained separately. Handwritten chronological logs, including classified as well as unclassified entries, list the assigned report number and brief information about the document. These listings, verified against the documents, have been put into an unclassified computerized database that currently goes through 1949. The records document the full range of activities and interests of Laboratory personnel. Included are documents from the 1940s relating to Nuclear Energy for the Propulsion of Aircraft (NEPA); documents relating to field tests, using radioactive lanthanum, that were carried out in order to provide a basis for recommendations by the joint AEC-National Military Establishment Panel on Radiological Warfare; and documents relating to isotope production.

RESTRICTIONS This series contains a small amount of classified information.

LOCATION OF Oak Ridge National Laboratory

RECORDS Building 4500-N, Room H-205 (Vault)

Oak Ridge, TN 37831

INCLUSIVE DATES 1943-present

ARRANGEMENT Numeric

VOLUME 29.5 cubic feet

DESCRIPTION Central files at ORNL consist of multiple series maintained at a single location in the Laboratory since its inception. This series consists of reports published by the MED Metallurgical Laboratory, as well as reports issued by the lab's successor, Argonne National Laboratory. Some of these reports include data regarding human health and protection. These records constitute a complete set of reports published by the Metallurgical Laboratory. An index and brief history is available.

LOCATION OF Oak Ridge National Laboratory

RECORDS 4500-N, H-205 (vault)

Oak Ridge, TN 37831 


\title{
SERIES TILE ORML Central Flles. Technical Research Notebooks
}

\author{
INCLUSIVE DATES 1943-present
}

ARRANGEMENT Numeric by notebook

VOLUME 420 cubic feet

DESCRIPTION Central files at ORNL consists of multiple subseries maintained at a single location in the Laboratory since its inception. Technical and research notebooks are used to record data on research and development work and for establishing patent or invention rights. They are also used to document the detailed information regarding and progress achieved on completed research. These are bound notebooks issued to researchers which are numbered sequentially.

RESTRICTIONS This series contains classified information.

LOCATION OF Oak Ridge National Laboratory

RECORDS ORNL Records Center

Building 4500-N, Room H-205 (vault)

Oak Ridge, TN 37831

INCLUSIVE DATES 1943-1958

ARRANGEMENT None

VOLUME 12 cubic feet

DESCRIPTION This series consists of a broad range of general correspondence files including housing and telephone allocations, incident reports, health physics reports, and meeting minutes.

RESTRICTIONS This series contains privacy material.

LOCATION OF Oak Ridge National Laboratory

RECORDS Building 4500N, Room A224

Oak Ridge, TN 37831 


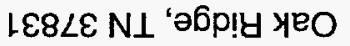

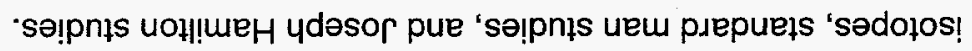

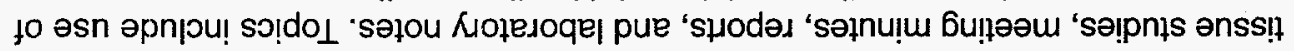

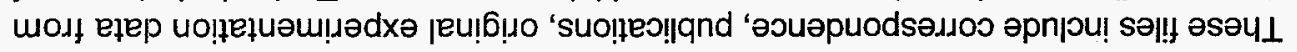

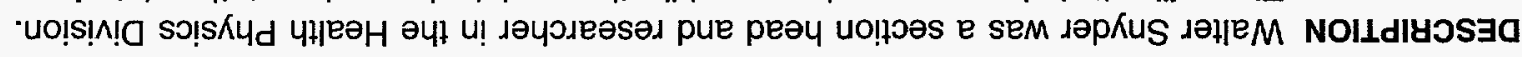

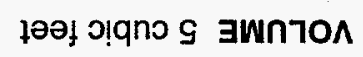

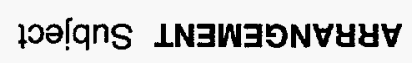

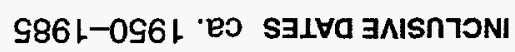
1.:

\author{
IE8 $\angle \varepsilon N$ 'әбр!y yео \\ O!HY 'S-00St Gu!p!ng sayoogy

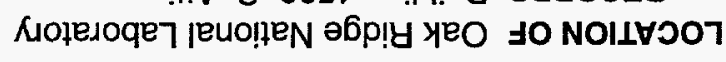

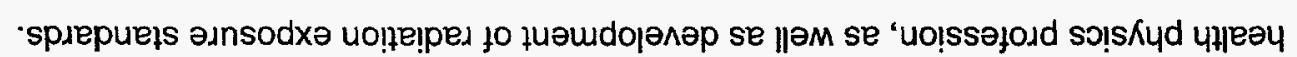

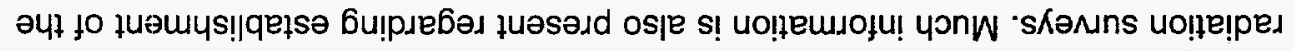

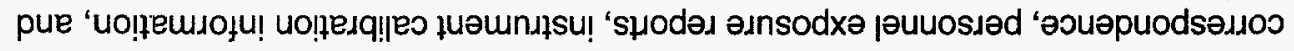

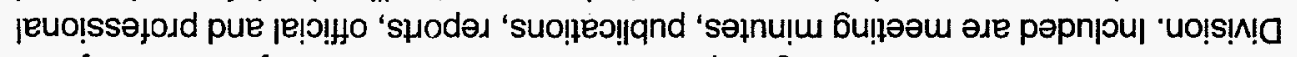

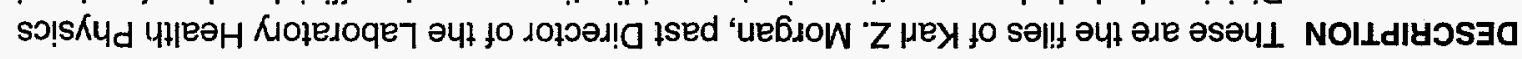

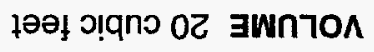

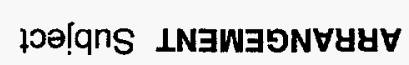

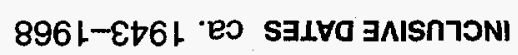




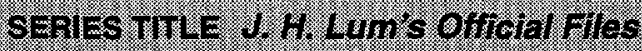

\author{
INCLUSIVE DATES $1940-1948$ \\ ARRANGEMENT Subject \\ VOLUME 13 cubic feet \\ RESTRICTIONS This series contains privacy material. \\ LOCATION OF Oak Ridge National Laboratory \\ RECORDS Building 4500-N, Room A224 \\ Oak Ridge, TN 37831
}

DESCRIPTION This series contains records of J.H. Lum who was the Deputy Director of Oak Ridge National Laboratory. It consists of administrative records which include information on staffing, housing, travel, budget, and similar topics.

\section{SERIES TTLE Boston Oak Ridge URanium Study Files}

INCLUSIVE DATES 1953-1958

ARRANGEMENT Numerical (patient records)

None (other files)

VOLUME 3 cubic feet

DESCRIPTION This series consists of records sent from Dr. Sweet at Massachusetts General Hospital, Boston, to the Health Physics Division at ORNL. They relate to a study in which eleven patients with inoperable brain tumors were injected with a uranium solution to determine its usefulness in therapeutic treatment. The injections took place at Massachusetts General Hospital and the uranium solution preparation and tissue analysis was done at ORNL. The series includes a correspondence file, medical notes on patients, and autopsy reports. There are logbooks for each patient that include analysis of data. Also included is data on animal experimentation with uranium.

RESTRICTIONS This series contains privacy material.

LOCATION OF Oak Ridge National Laboratory

RECORDS 1060 Commerce Park, Room 253

Oak Ridge, TN 37831 
INCLUSIVE DATES 1948-present

ARRANGEMENT Chronological

VOLUME 2.2 cubic feet

DESCRIPTION This record series documents the research and experiment activities of the Biology Division at ORNL. The documents are periodic reports consisting of abstracts of research and experiments that were performed by scientists within the biology division. In addition to the abstract there are also bibliographic citations if publication resulted from the research. The reports also contain information on various animal experiments.

\section{LOCATION OF Y-12 Plant}

RECORDS Building 9207, Annex (Hall and Room 7-24)

Oak Ridge, TN 37831 


\section{K-25 Site}

\section{SERIES TIIL Techncal and Research Notebooks}

INCLUSIVE DATES 1944-present

ARRANGEMENT Numeric

VOLUME 307 cubic feet

DESCRIPTION These notebooks and logs record technical operations and research relating to both daily operations and to special research activities. Present are daily notes for checks of plant operations, as well as research progress. Notebooks are issued to specific individuals and are used for different purposes, including to record data for establishing patent or invention rights.

RESTRICTIONS This series contains a small amount of classified information.

\section{LOCATION OF K-25 Facility}

RECORDS Building 1034-A, Plant Records Vault

Oak Ridge, TN 37831 


\section{Y-12 Plant}

\section{SEnIES TILE Cental Files Reports}

INCLUSIVE DATES 1947-present

ARRANGEMENT Alphanumeric

VOLUME 523 cubic feet

DESCRIPTION This file contains classified and unclassified research and development, administrative, and progress reports related to the activities of this plant and other installations.

RESTRICTIONS This series contains classified information.

LOCATION OF Y-12 Plant

RECORDS Building 9711-5, Room 109 (Vault)

Oak Ridge, TN 37831

\section{SERES TILE Laboratory Technical files}

INCLUSIVE DATES 1951-present

ARRANGEMENT Numeric by notebook number

VOLUME 142 cubic feet

DESCRIPTION The records in this series document the content and direction of research performed at the facility. Technical and research notebooks are used to record data on research and development work and for establishing patent and invention rights. They contain detailed information regarding progress achieved on completed research. The series consists of bound notebooks issued to researchers which are numbered sequentially.

RESTRICTIONS This series contains classified information.

LOCATION OF Y-12 Plant

RECORDS Building 9711-5, Room 109 (Vault)

Oak Ridge, TN 37831 


\section{The Site Today}

THE UNIVERSITY OF CHICAGO is a major academic and research institution. Founded in 1891 by John D. Rockefeller, the university includes an undergraduate college as well as ten graduate programs and schools. In addition, the university plays an active role in biomedical, physics, and nuclear-studies research through its contract with DOE to operate Argonne National Laboratory (ANL). More than II,000 people are employed by the University through its schools and hospitals, and its annual budget is more than $\$ 770$ million.

\section{Site History}

The Metallurgical Laboratory-During World War II the Federal government sponsored substantial scientific research at the University. The premier facility was the Metallurgical Laboratory (Met Lab), established on-campus in 1942. This laboratory was responsible for designing the first nuclear reactors to produce fissionable plutonium for the atomic bomb. In 1946, the Met Lab became Argonne National Laboratory, and the university continued to operate the facility under contract with the Government. ANL remains by far the largest and most significant Government nuclear facility associated with the university. (See the section on Argonne National Laboratory.) The university has, however, conducted other nuclear-related contractual work.

The premier wartime facility was the Metallurgical Laboratory (Met Lab), established on-campus in 1942.

The Chicago Toxicity Laboratory-Chicago ran a toxicity laboratory for the U.S. Army Chemical Corps during World War II to conduct chemical warfare research. From 1948 until 1951, the AEC used the facility for radiological warfare research. In 1948, the AEC worked with the Army and the university on a research program for the laboratory that focused on the poisonous effects of radiation exposure. Animal research was conducted on the local effects and general toxicity of radioisotopes considered for use as radiological warfare agents. Some coincidental work was also done with ANL on developing occupational safety practices for radiation handling. When interest in radiological warfare began to decrease in 1951, the AEC considered ending its association with the laboratory. Evidence suggests that the laboratory was under the control of the U.S. Air Force by 1952.

Animal research was conducted on the local effects and general toxicity of radioisotopes considered for use as radiological warfare agents.

Project Sunshine-Willard F. Libby, a Nobel laureate, held an appointment at the university's Enrico Fermi Institute for Nuclear Studies. In 1953, he began AEC-sponsored biomedical research for Project Sunshine, which studied the worldwide distribution and health hazards of fallout. The project examined movement of fallout through the atmosphere, its deposition on soil and vegetation, and its uptake into the human body. Researchers collected and measured radiation levels in soil, plant, and animal samples, and in samples of human tissues and bones, including some from the bodies of stillborn babies.

Project Sunshine research was initially conducted at the University of Chicago, the AEC Health and Safety Laboratory, and the Columbia University Lamont Geological Observatory. Fallout generated by 1954 AEC nuclear tests led to greatly increased funding for Project Sunshine. By 1957, nearly 50 institutions and Federal agencies were participating in the project. The project yielded important data that allowed the estimates for worldwide fallout levels. The AEC curtailed Project Sunshine work at the university in 1958.

The Argonne Cancer Research Hospita/- During the immediate postwar years, there was great interest in exploring the potential biomedical uses and effects of radiation. The Argonne Cancer Research Hospital was one of three clinical facilities created by the AEC in 1948. The hospital was originally intended to be part of Argonne National Laboratory, but the University of Chicago ultimately contracted to run it as a separate institution. While the AEC owned the 
hospital, the university medical school administered and staffed the facility. Construction began in 1950 and the hospital admitted its first patient in January 1953.

Fallout led to greatly increased funding for Project Sunshine. By 1957, nearly 50 institutions and Federal agencies were participating in the project.

The hospital was equipped with 58 patient beds and facilities for animal research. In addition, it had contemporary state-of-the-art therapeutic and diagnostic equipment for experimental cancer treatment and research using radioactive materials. Members of the medical school faculty, as well as physicians and scientists from Argonne National Laboratory and various other institutions, used the hospital for research (Figure 37). Patients were admitted on a selective basis, with doctors choosing persons whose condition best suited the hospital's research and treatment applications. In 1973, the university changed the name of the hospital to the Franklin McLean Memorial Research Institute. The AEC terminated its contract with the hospital in 1974.

\section{Site Human Radiation Experiments}

The Argonne Cancer Research Hospital undertook many experiments focusing on the internal use of radioisotopes. Examples include use of carbon- 13 labeled glycine to investigate multiple myeloma; application of yttrium-90 for intracavity therapy; and chromium-5I as a labeling technique to study red cells. In addition, the hospital conducted many tracer studies and studies of radioactively labeled compounds to determine metabolic rates. Individual site experiments are detailed in Chapter 3.

\section{Site Records Collections}

The university provided helpful assistance for the DOE search, although records relating to the Manhattan Project and successor agencies are seemingly not abundant. The university has no central records-management program, and academic departments, institutes, and Argonne Cancer Research Hospital have preserved or destroyed records as they saw fit. As a result, many potentially useful records have been destroyed over the years.

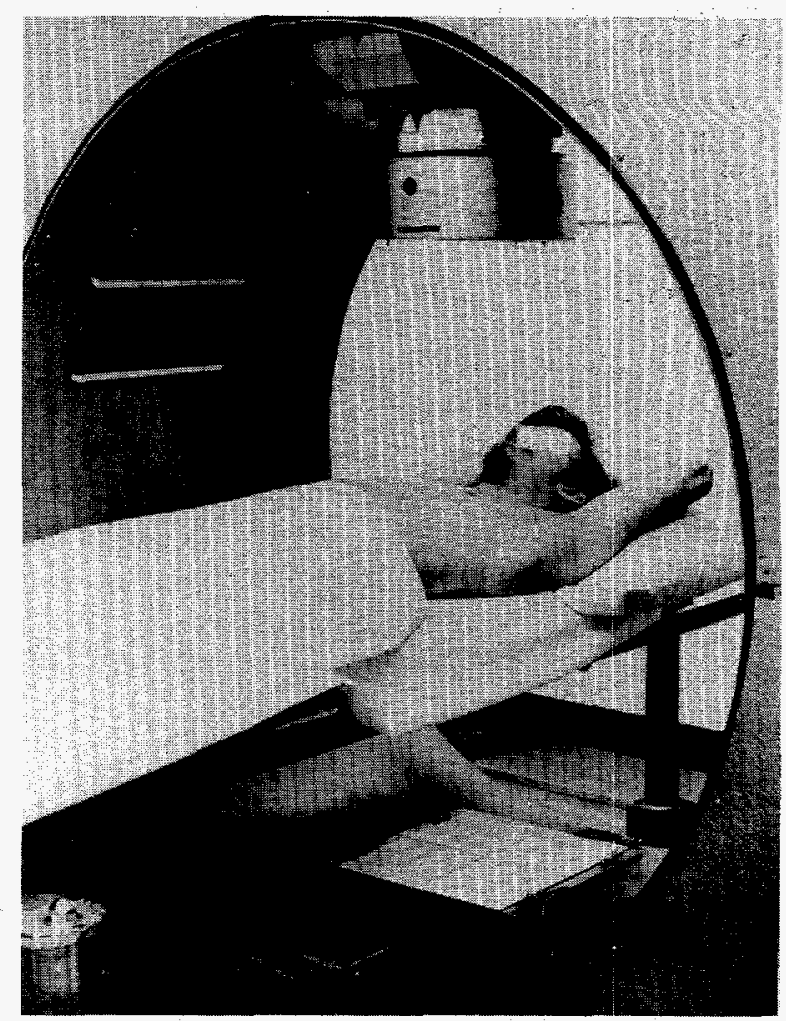

Figure 37. The automatic contouring system used at Argonne Cancer Research Hospital to determine how much radiation will penetrate to cancer tumors.

The Joseph Regenstein Library has a few pertinent records collections. Except for two collections, these holdings present little documentation pertinent to this project. Those seeking to document the university's role in human radiation experiments will find only a small part of the story here.

The Argonne Cancer Research Hospital undertook many experiments focusing on the internal use of radioisotopes.

Researchers should know that two access policies are in place at the university. The Joseph

Regenstein Library collections are easily accessible through routine archival procedures. Records in the General Counsel's Office, however, are not in archival custody and require advance permission for use. Use of records currently in the Public Affairs Office also require special permission. 


\section{University of Chicago}

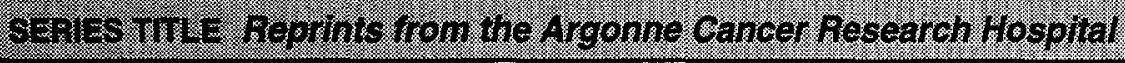

INCLUSIVE DATES 1954-1973

ARRANGEMENT Chronological

VOLUME 4 cubic feet

DESCRIPTION This series documents the medical, research and experimentation activities of the Argonne Cancer Research Hospital (ACRH). It includes articles on animal and human subject research at the ACRH as well as data on radium watch dial painter studies. The series consists entirely of 16 volumes of published articles and abstracts. An index is available.

LOCATION OF The University of Chicago

RECORDS Office of Legal Counsel

5801 Ellis Avenue

Chicago, llinois 60637

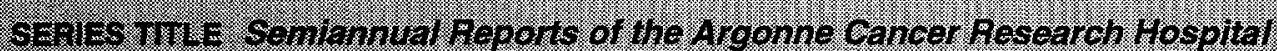

INCLUSIVE DATES $1954-1973$

ARRANGEMENT Chronological

VOLUME 1 cubic foot

DESCRIPTION This series documents the medical, research and experimentation activities of the Argonne Cancer Research Hospital. It includes information on both animal and human radiation experiments carried out by the Argonne Cancer Research Hospital as well as its assistance in Argonne National Laboratory radium and other radiation studies. The series consists entirely of bound volumes of semiannual and annual reports. A brief index to the reports is available.

LOCATION OF The University of Chicago

RECORDS Office of Legal Counsel

5801 Ellis Avenue

Chicago, IL 60637 


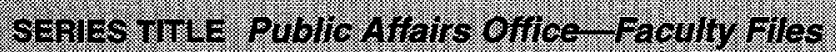

INCLUSIVE DATES 1924-present

ARRANGEMENT Alphabetical

VOLUME 70 file drawers

DESCRIPTION This series documents the lives and careers of past and present University of Chicago faculty. It was created to serve as a resource of the Public Affairs Office. It includes biographical, bibliographical, and professional information and contains files on Austin Brues, Arthur Compton, Lowell Coggeshall, Robert Hasterlik, Leon Jacobson, Robert Stone, Leo Szilard, and Raymond Zirkle. The series consists of resumes, obituaries, bibliographies, journal articles, speeches, press releases, news clippings, correspondence, and publicity materials created for special events. No index is available.

LOCATION OF University of Chicago

RECORDS Administration Building, Public Affairs Office 5801 Ellis Avenue

Chicago, IL 60637

\section{SERIES TITLE PUblic 4tairs Reterence Files}

INCLUSIVE DATES 1944-1993

ARRANGEMENT Subject

VOLUME 150 cubic feet

DESCRIPTION The series documents publicity given to University of Chicago projects and faculty. It includes files on biological sciences; hospitals and clinics; institutes; centers; nuclear energy; foundations; pharmacology and radiation; Fermi Memorial; inhalation therapy; Cancer Research Center; and Fermi National Accelerator Laboratory. It also contains issue papers and President's files, and a post-1987 collection of biographies and publications. The series consists primarily of press releases and news clippings. A finding aid is available.

LOCATION OF University of Chicago

RECORDS Administration Building, Public Affairs Office

5801 Ellis Avenue

Chicago, IL 60637 
INCLUSIVE DATES 1892-1988

ARRANGEMENT Subject

VOLUME Approximately 42 cubic feet

DESCRIPTION This series documents the activities of organizations, institutions, and committees associated with the University of Chicago. It includes information on AIDS Task Force; American Meat Institute Foundation; Argonne Universities Association; Argonne Cancer Research Hospital; Chicago Lying-in Hospital; Hospitals and Clinics; Coggeshall Report; Biological Sciences Division; Council on Medical and Biological Research; and Pharmacology Department. It does not appear to contain specific information on human radiation experiments. The series consists of reports, publications, press releases, and pamphlets. A finding aid is available.

LOCATION OF The University of Chicago

RECORDS Department of Special Collections

The Joseph Regenstein Library, Room JRL-130

1100 E. 57th Street

Chicago, IL 60637

\section{SERIES TITLE UhVersty Mscellaneous Archival Files.}

INCLUSIVE DATES 1939-1974

ARRANGEMENT Alphabetical by name

VOLUME Approximately 12 cubic feet

DESCRIPTION This series documents selected information concerning individuals of importance to the University of Chicago. It contains collections of papers, such as those of George V. LeRoy and Robert J. Hasterlik, as well as collections of publications and speeches. The series consists of articles, speeches, press releases, letters, and memorandums. An index is available.

LOCATION OF The University of Chicago

RECORDS Department of Special Collections

The Joseph Regenstein Library, Room JRL-130

1100 E. 57th Street

Chicago, IL 60637 


\section{SERIES THLE Physics Deparment Papers}

INCLUSIVE DATES $1937-1947$

ARRANGEMENT Subject

VOLUME 13 cubic feet

DESCRIPTION This series documents teaching and other activities of the Physics Department of the University of Chicago. It includes correspondence files, departmental records, reprints, textbook and course materials, the papers of A. E. Shaw, and documentation on the Cosmic Ray Study in Boxes 27-37. The series consists of letters, memorandums, reports, reprints, personnel and health charts, navigation logs, charts, graphs, magnetic observatory data tables, lecture notes, class records, and experimental results. A finding aid is available.

LOCATION OF The University of Chicago

RECORDS Department of Special Collections

The Joseph Regenstein Library, Room JRL-130

1100 E. 57th Street

Chicago, IL 60637

\section{SERES TITLE Records of the Office of the Vice President, Special Projects}

INCLUSIVE DATES $1940-1966$

ARRANGEMENT Subject

Chronological

VOLUME 27 cubic feet

DESCRIPTION This series documents the activities of the Office of the Vice President for Special Projects, which managed projects outside of the responsibilities of established schools and academic departments. It includes files on contracts with various Federal agencies, including the Departments of Agriculture, Health Education and Welfare, and Defense (Army, Air Force, and Navy), the Office of Scientific Research and Development, the Atomic Energy Commission, Argonne National Laboratory, the Clinton Laboratory, du Pont and Monsanto Chemical Companies, and various construction companies. It also contains two files on Project Sunshine. The series consists of letters, memorandums, and reports. A finding aid is available.

LOCATION OF The University of Chicago

RECORDS Department of Special Collections

The Joseph Regenstein Library, Room JRL-130

1100 E. 57th Street

Chicago, IL 60637 


\section{The University of Rochester}

\section{The Site Today}

THE UNIVERSITY OF ROCHESTER is a private, independent institution on a 534-acre campus in Rochester, NY. Rochester has about 8,500 enrolled students and is among the top 25 American universities in Federal funding for research and development. Technical research centers include the Institute of Optics, the Laboratory for Laser Energetics, and the Strong Memorial Hospital. Other specialties include schools of music, management, medicine, and nursing.

\section{Site History}

From 1850 through 1918 , the institution was a liberal arts college. In 1918, it became a university and established professional schools and doctoral programs. The university invested in state-of-the art scientific instruments, including a cyclotron and a million-volt $x$-ray machine. These developments brought several prominent scholars to Rochester, including Lee A. DuBridge in physics, W. Albert Noyes in chemistry, and Curt Stern in biology. In 1925, Stafford L. Warren began his service at the University of Rochester School of Medicine and Dentistry, where he served as the Department of Radiology chief.

The Manhattan Project looked to the university to provide extensive research and support for medical aspects of the bomb program.

During World War II the university undertook several military research projects. A major client was the U.S. Office of Scientific Research and Development (OSRD), which contracted with Rochester for more than a hundred projects in chemistry, physics, biology, medicine, and psychology. The Manhattan Project, successor to the OSRD in supporting atomic research, looked to the university to provide extensive research and support for medical aspects of the bomb program. This program began in 1943 when Stafford Warren was appointed first as a consultant and later as Chief of the Manhattan Project Medical Section. Apart from Warren's expertise, Rochester was selected as a medical research center because of the extensive biological studies with cyclotron-produced radioactive isotopes conducted at the medical school. A contract established a formal Manhattan Project program at the university. This program grew rapidly, and by the end of the war the total staff size reached about 350 .

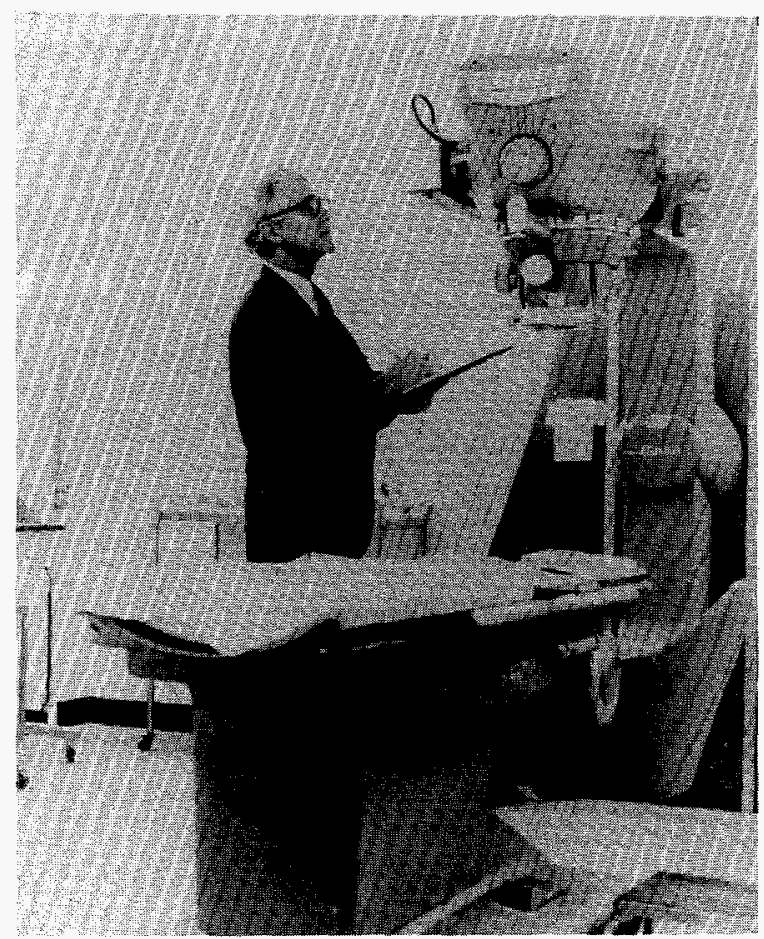

Figure 38. An AEC inspector checking radiation equipment for safety at Oakland Navy Hospital (circa 1973).

The Rochester project supported two basic activities. The first consisted of technical services, including analysis of periodic medical examination reports for all personnel employed at Manhattan Project facilities. Rochester also advised these facilities on employee health protection issues and developed radiation measurement instruments, and staff traveled to various Manhattan Project sites to measure radiation and toxic dusts.

The second service Rochester provided to the Manhattan Project was biomedical research. Much of this work focused on biological studies of polonium, radium, and plutonium and was 
intended to establish occupational radiation exposure standards. Rats and other animals were used as subjects in many experiments designed principally to measure bodily distribution and excretion of these substances. Human beings were also used as experimental subjects. Most wartime activities at Rochester were secret and related documentation was classified.

The second service Rochester provided to the Manhattan Project was biomedical research.

After the war, Rochester received a substantial AEC contract to operate an Atomic Energy Project (AEP). The university created a Department of Radiation Biology at the medical school to administer this contract. With all of its former technical services now performed by the AEC Health and Safety Laboratory in New York, Rochester focused on research and education activities related to the biomedical aspects of nuclear energy. Security eased to the point were nearly all AEP projects where unclassified by 1950 . Most wartime research was also declassified and published in the open scientific literature.

Through the Atomic Energy Project, the university established a preeminent program in radiation biology. In 1950, Rochester offered the first doctorate degree in radiation biology, and many influential scientists passed through this program. During the 1950s, research emphasis shifted from acute radiation effects to molecular aspects of radiation damage in biological systems. Activities under the AEP also fostered extensive work involving nuclear materials in pharmacology and biochemistry.

Until the early 1960s, the AEC funded all activities of the university's Department of Radiation Biology through the Atomic Energy Project. Limitations on AEC funds led Rochester in 1963 to solicit funding from the National Institutes of Health and the National Science Foundation. Despite this shift, AEP research interests remained focused in areas that originated during the war or shortly thereafter: aerosols, cancer research, internal emitters, and basic radiobiology. AEC commitment to the program, however, declined and successor agencies also had limited interest in the AEP. During the 1980s DOE terminated the project and turned all facilities over to the university.

\section{Site Human Radiation Experiments}

As noted, Rochester was a hub for Manhattan Project biomedical research. As part of this activity, the University also served as a major center of human radiation experiments. Documents suggest that Stafford Warren arranged a cooperative experimentation plan involving the Rochester and Los Alamos projects. This plan called for separate human metabolism studies with at least five different substances: plutonium, uranium, polonium, and radioactive lead, each with 10 subjects; and radium, with 5 subjects. Rochester selected the subjects, arranged for their stay at the university hospital, administered the substances, and collected samples of blood and excreta. Los Alamos analyzed the samples, determined concentrations of the administered substances, and determined rates of excretion. The stated purpose of these experiments was to gain knowledge about the behavior of the substances in the body so that researchers could establish standards for Manhattan Project workers.

Rochester was a hub for Manhattan Project biomedical research and also served as a major center of human radiation experiments.

Evidence suggests that studies involving at least three of these substances took place at Rochester from 1945 through 1947: Eleven people received plutonium injections; 5 received doses of polonium (four injections and one oral dose); and 6 received injections of uranium. Apparently these individuals were Strong Memorial Hospital patients who were selected on the basis of their medical condition. For the plutonium injections, documents show that Rochester personnel carefully selected each subject and prepared separate protocols for each injection. A 1974 AEC investigation of the plutonium injections was unable to find documentary evidence that the university obtained consent from these subjects.

After 1947, biomedical aspects of the Rochester Atomic Energy Project focused primarily on 
animal studies, although human subjects were used on occasion. Individual site experiments are detailed in Chapter 3.

\section{Site Records Collections}

Documents have been found that shed light on Rochester's role in biomedical support for the MED or its successors, but these materials are primarily in files focusing on other topics. No body of records for the Rochester project have been found within DOE, although documents have been found in other files that discuss activities at the university during the war and afterwards. Of particular value are Rochester-related documents in the Plutonium Injection Investigation Files and the Ottinger/Markey Investigation Files (listed earlier under the headquarters series), which document aspects of the Rochester human radiation experiments occurring during and just after the war. Additional documents have been found in series at Oak Ridge, Lawrence Berkeley Laboratory, and the National Archives.

DOE has contacted Rochester to learn what records the university may have relevant to human radiation experiments. The university is involved in litigation in this area and has shown caution in communicating the contents of its records holdings. Rochester states that it has not found a body of records relating to either wartime or Atomic Energy Project activities connected with human radiation experiments. The university also states that it has searched the potentially relevant files of its president, treasurer, and medical school dean. DOE did obtain one cubic foot of AEP periodic reports dating from about 1948 to about 1968 from the university.

A DOE staff member traveled to Rochester to discuss the university's search and to examine special collections holdings of the Edward $G$. Miner Library. Two collections of personal papers were examined: the Joe W. Howland Papers and the Louis H. Hempelmann, Jr. Papers. Both individuals participated in the plutonium injection experiments and later joined the Rochester medical school staff. DOE intends to continue efforts to review Rochester's records holdings. 


\section{University of Rochester}

\section{SEAIES TILE ATomic Energy Project Reports}

INCLUSIVE DATES 1948-1954

\section{ARRANGEMENT Chronological}

VOLUME 1 cubic foot

DESCRIPTION These records consist of periodic technical reports from the Rochester Atomic Energy Project (AEP) to the AEC. Topics cover most aspects of AEP activities, including biomedical studies of $x$ rays, uranium, beryllium, thorium, fluoride, and fallout. Information is also present regarding chemical toxicity, health physics, and educational programs. Some gaps are apparent in the reports. The wartime origins and activities of the project are not covered extensively in this material; the location of reports from this era is unknown. Bibliographic listings and indexes are available.

LOCATION OF University of Rochester

RECORDS School of Medicine and Dentistry

Rochester, NY 14642

\section{SERIES TILE Louis H Kempelmann, Ur. Papers}

INCLUSIVE DATES 1948-1973

ARRANGEMENT Record type; chronological thereunder

VOLUME 1 cubic foot

DESCRIPTION These records consist of three subgroups: correspondence and research grants of the university medical school Division of Radiation Therapy; correspondence, research grants, and budgets of the Division of Diagnostic Radiology; and annual reports to the dean of the medical school. Hempelmann was an instructor in Radiology at Washington University from 1942 to 1946 , and served as Heath Division Leader at Los Alamos from 1947 to 1948 . He came to the Rochester medical school as a professor of experimental biology in 1950. He later served as Chairman of the Department of Radiology at Rochester. These papers contain no information pertaining to Hempelmann's activities prior to coming to Rochester in 1951, his involvement with the MED or AEC, or his research activities at Rochester. A finding aid is available for this collection.

LOCATION OF University of Rochester

RECORDS Edward G. Miner Library

School of Medicine and Dentistry

Rochester, NY 14642 


\section{SERIEST TLE Uoe W. Howland Papers}

INCLUSIVE DATES $1949-1973$

ARRANGEMENT Record type; chronological thereunder

VOLUME 10 cubic feet

DESCRIPTION These records consist of four subgroups: the Atomic Energy Project (AEP); AEP Medical Division; Health and Safety; and Howland (personal papers). The materials document early research in radiation toxicity and also illustrate operation of the AEP, which was funded by the U.S. Atomic Energy Commission, at Rochester. Included are Proposals for Research and Development (Form 189s); copies of the AEP Quarterly Review; administrative records; research correspondence and reports; and educational materials. Documentation is also available concerning Howland's activities as a consultant on radiation exposure, occupational safety, and civil defense. Information pertaining to the use of isotopes at Rochester and the university's role in allocating isotopes to regional hospitals is also present. Howland worked at the Rochester School of Medicine and Dentistry from 1938 to 1965, ending as a professor of radiation biology. He was on a leave of absence from 1944 to 1947 when he served in the medical organization of the MED. A finding aid is available for this collection.

LOCATION OF University of Rochester

RECORDS Edward G. Miner Library

School of Medicine and Dentistry

Rochester, NY 14642 


\section{National Archives and Records Administration}

The NATIONAL ARCHIVEs and Records Administration (NARA) is the Federal agency responsible for overseeing the creation, management, storage, and final disposition of the Federal government records. NARA provides two types of facilities and services for physical custody of records:

- records centers-For inactive records (older records that usually receive minimal use), Federal agencies are permitted to use various NARA Federal Records Centers located around the country. Records in these centers remain under the legal custody and control of the agency that sent them. Most of these records are slated for eventual destruction according to terms of legally approved disposition authorities.

- permanent archives-Separate archival repositories preserve and service records judged to warrant permanent retention for their historical value. Records in these repositories have been legally transferred to NARA ownership and control. NARA's job is to protect the records and make them available to individuals who wish to use them. NARA maintains archival repositories in Washington, DC, and College Park, MD, as well as in 12 regional repositories across the Nation.

Most of the Department of Energy's historical records lie beyond NARA control.

While some important files from DOE and its predecessors have been transferred to NARA archival custody, most of the agency's historical records lie beyond NARA control. This is due partially to classification issues, but the most substantial barrier to transfer is the poor intellectual control of DOE records. It should be noted, however, that this issue goes beyond DOE.
There is a critical need to use innovative efforts to manage and preserve Post-War Federal records. Failure to do so will mean the effective loss of the Cold War historical record.

NARA has had limited success managing permanent records dating from the postwar period, particularly those relating to science and technology. The great volume of these materials, their technical complexity, and their disorder and decentralization have presented archival obstacles that the Federal government as a whole has yet to overcome. As the human radiation experiments project has proven, however, there is a critical need to use innovative efforts to manage and preserve these records. Failure to do so will mean the effective loss of the Cold War historical record. 
Chapter 2. Narratives and Records Series - Institutional Areas: NARA Records Relating to the MED

National Archives Records Relating to the Manhattan Engineer District

\section{SERIES TILE Central Files}

INCLUSIVE DATES $1942-1947$

ARRANGEMENT War Department Dewey Decimal Filing System

VOLUME 60 cubic feet

DESCRIPTION This series documents the work of the MED, which was headquartered in Oak Ridge, except for a short initial period in New York. It has information on the range of activities involved in the supervision of sites and contractors across the country, including the construction and operation of the Oak Ridge and Hanford facilities. A preliminary search revealed some references to the plutonium injection experiments and to the polonium work at Rochester The records include extensive discussions of worker hazards and occupational health issues and discussions of the urgent need to set safe standards based on research with ionizing radiation and toxic chemicals. The series consists of correspondence files of reports, letters, memorandums, studies, meeting minutes, and telegrams. Classified documents have been removed from the files and retained in Oak Ridge Operations. Collection number 4NN-326-8505.

LOCATION OF National Archives-Southeast Region

RECORDS 1557 St. Joseph Street

East Point, GA 30344 


\section{National Archives Records Relating to the Atomic Energy Commission}

\section{SAnIES TILE RESearch BWIston Correspondence Flles}

INCLUSIVE DATES 1944-1962

ARRANGEMENT AEC Subject/Numeric Filing System (exceptions noted below)

VOLUME 66 cubic feet

DESCRIPTION The series documents agency and site biomedical and basic research programs. It is especially valuable for documenting biomedical policies (1944-1950), the interim medical advisory committee, and policies for the medical use of radioisotopes. It contains files on plant and animal studies, information related to human experimentation, and files on worker exposures and environmental emission monitoring. The series contains subsections devoted to University of Tennessee, Oak Ridge Institute of Nuclear Studies, and aircraft nuclear propulsion program biomedical activities. Also included are subsections of access permits (filed by permit number), directives (filed by directive number), and contracts (filed by contract number). A detailed folder title inventory to series is available. The series consists of correspondence files of memorandums, letters, meeting minutes, handwritten notes, TWXs, drawings, charts, and some photographs. Classified documents have been removed from the files and retained in Oak Ridge Operations Office RHTG (Records Holding Task Group) Files. Collection number 68A1096.

LOCATION OF National Archives-Southeast Region

RECORDS 1557 Street Joseph Street

East Point, GA 30344 


\section{SERES TITLE Research and Developrent Division Correspondence Files:}

INCLUSIVE DATES $1947-1963$

ARRANGEMENT AEC Subject/Numeric Filing System (Part)

Subject (Part)

VOLUME 44 cubic feet

DESCRIPTION The series was assembled by Oak Ridge officials of the division in implementing agency reactor development and other programs. It contains information on reactor programs, isotope production, aircraft nuclear propulsion programs, other developmental programs and some information on radiological warfare and RaLa programs. There may be data in environmental emissions in the series. Boxes 12 \& 13 contain some biomedical program data for the 1944-1946 period. The series consists of correspondence files of memorandums, letters, meeting minutes, and handwritten notes. Classified documents have been removed from it and retained in the Oak Ridge Operations Office Records Holding Task Group (RHTG) Files. A folder title inventory to the series is available. Collection number $4 \mathrm{NN}-326-87-6$.

RESTRICTIONS This series contains privacy material.

LOCATION OF National Archives-Southeast Region

RECORDS 1557 St. Joseph Street

East Point, GA 30344

\section{SERIES TITL Research and Mediche Division Cortespondence Files}

INCLUSIVE DATES Ca.1944-1950

ARRANGEMENT Alphabetical by subject (partially by AEC Subject/Numeric Filing System)

VOLUME 20 cubic feet

DESCRIPTION The series documents the Oak Ridge administration of MED/AEC biology and medicine programs. It contains significant information relating to all aspects of MED/AEC biology and medical programs, including research activities, health effects of radioactive and other materials, animal studies, some experiments with human subjects, worker exposures to radiation, isotopes distribution, and plant and environmental emission monitoring. The series includes correspondence, budget documents, reports, medical and other topical case files, directives, meeting agendas and minutes, and policy development documents. Classified documents have been removed from the files and retained in the Oak Ridge Operations Office RHTG (Records Holding Task Group) Files. A detailed file folder listing is available. Collection number 326-68A588.

RESTRICTIONS This series contains privacy material.

LOCATION OF National Archives-Southeast Region

RECORDS 1557 St. Joseph Street

East Point, GA 30344 
SERIES TITE Metallurgical Laboratory/Argonne National Laboratory. Classitied Correspondence Fites

\begin{abstract}
INCLUSIVE DATES $1942-1965$
ARRANGEMENT Chronological

VOLUME 158 cubic feet

DESCRIPTION The series was compiled to document laboratory research and administration activities. It includes information on the design and construction of plutonium production reactors, health and safety problems associated with them, other laboratory reactor development activities, laboratory biomedical activities, research into fission products and their health hazards, and work on separating plutonium from waste fission products. It also includes information on radiological warfare activities, may contain information on clinical human radiation experiments, and contains a set of MED $N$ and $C$ series of technical reports. The series contains some Walter Zinn reader files from his tenure as laboratory director. The series consists of letters, memorandums, technical reports, charts, graphs, and handwritten notes. A general box index is available. Collection number E-74.
\end{abstract}

RESTRICTIONS This series contains classified information.

LOCATION OF National Archives at College Park

RECORDS 8601 Adelphi Road

College Park, MD 20740

SERIES TITLE Gak RIOge Diaries

INCLUSIVE DATES 1943-1972

ARRANGEMENT Chronological

VOLUME 14 cubic feet

DESCRIPTION This series consists of the daily diaries of the managers of the MED/AEC Oak Ridge Operations Office. The diaries may contain brief references to radiological warfare or to human experimentation. The diaries consist of notebooks containing typewritten notes of telephone conversations, meetings, and significant events which took place during the course of the day. No index is available. Collection number E-81.

RESTRICTIONS This series is entirely classified.

LOCATION OF National Archives at College Park

RECORDS 8601 Adelphi Road

College Park, MD 20740 
INCLUSIVE DATES 1946-1958

ARRANGEMENT Dewey Decimal Filing System (1946-1951 portion)

AEC Subject/Numeric Filing System (1951-1958 portion)

VOLUME 146 cubic feet

DESCRIPTION These files were compiled by the Secretary to the Atomic Energy Commission (AEC) to create the official record of agency policies, origins, structure, functions, missions, controversies, and activities at the highest level of the agency. These portions of the files document AEC operational activities. They include agency policy formulation on budgets, contractor oversight, nuclear weapons programs, nuclear reactor programs, the hydrogen bomb program, special nuclear materials production programs, biomedical programs, Project Sunshine, the nuclear waste programs, contracts, and security matters. They contain information on agency policies and standards for human experimentation. They also include files on radiological warfare policy decisions and programs. The Secretary's files contain some meeting minutes and most letter reports of the Advisory Committee on Biology and Medicine. The 1946-1951 portion contains materials on the interim medical advisory committee. The series contains AEC information and decision staff papers, letters and memorandums showing implementation of policy decisions, and excerpts of minutes of Commission meetings. Collection numbers $E-78$ and $E-79$.

RESTRICTIONS This series contains classified information.

LOCATION OF National Archives at College Park

RECORDS 8601 Adelphi Road

College Park, MD 20740 


\section{SERIES TILE Whutes of the Meetings of the AEC}

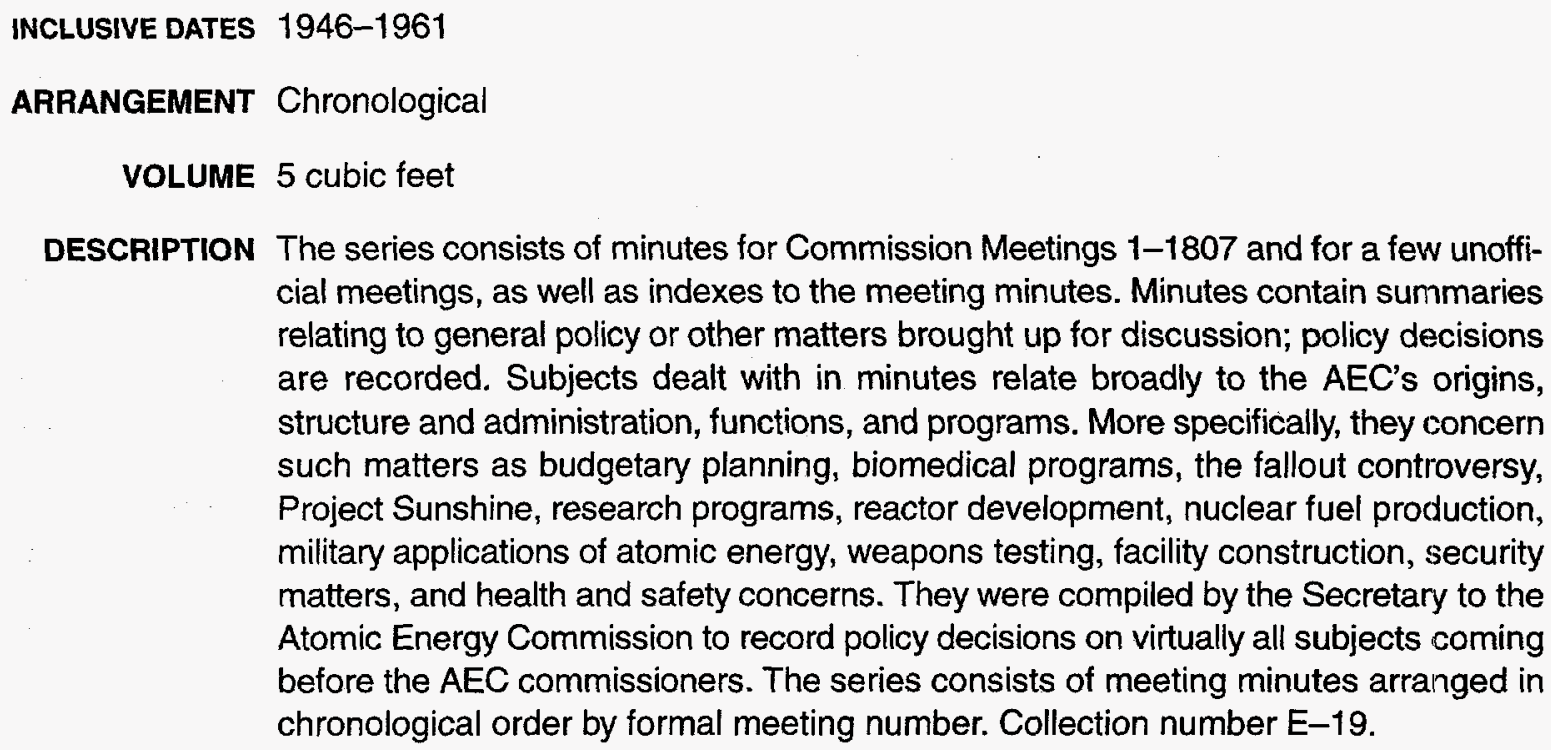
cial meetings, as well as indexes to the meeting minutes. Minutes contain summaries relating to general policy or other matters brought up for discussion; policy decisions are recorded. Subjects dealt with in minutes relate broadly to the AEC's origins, structure and administration, functions, and programs. More specifically, they concern such matters as budgetary planning, biomedical programs, the fallout controversy, Project Sunshine, research programs, reactor development, nuclear fuel production, military applications of atomic energy, weapons testing, facility construction, security matters, and health and safety concerns. They were compiled by the Secretary to the Atomic Energy Commission to record policy decisions on virtually all subjects coming before the AEC commissioners. The series consists of meeting minutes arranged in chronological order by formal meeting number. Collection number E-19.

RESTRICTIONS This series contains classified information.

LOCATION OF National Archives at College Park

RECORDS 8601 Adelphi Road

College Park, MD 20740

\section{SERIES TILE Nicrofilm Copies of Transcripts of the Meetings of the AEC}

INCLUSIVE DATES 1954-1957

ARRANGEMENT Chronological

VOLUME 0.3 cubic foot

DESCRIPTION The series consists of verbatim transcripts of the proceedings of commission regular meetings, executive session meetings, and informal meetings. The series was compiled by the AEC Secretary to create a supplemental record of agency policy decisions. The series contains verbatim discussions of a wide range of subjects; for example, the J.R. Oppenheimer security clearance decision, the fallout controversy, biomedical programs, nuclear weapons programs, special nuclear materials production programs, basic research programs, civilian nuclear power programs, regulatory programs, and Atoms for Peace programs. The series consists entirely of transcripts arranged in chronological order.

RESTRICTIONS This series is entirely classified.

LOCATION OF National Archives at College Park

RECORDS 8601 Adelphi Road

College Park, MD 20740 


\section{SEAIES TILE Minutes and Reports of Meetings of the General 4 disory Connituo (c)}

INCLUSIVE DATES $1947-1974$

ARRANGEMENT Chronological by date of meeting

Numerical sequence by meeting number

VOLUME 6 cubic feet

DESCRIPTION The series consists of summaries of GAC meetings prepared by the Committee Secretary. It contains minutes and related records that document the GAC's involvement in administrative and policy matters relating to basic research, reactor development, weapons development and testing, research performed by Atomic Energy Commission national and other laboratories, special nuclear materials production programs, test ban and disarmament negotiations, and the hydrogen bomb decision and program. Because the General Advisory Committee rarely considered biomedical topics, the series contains little, if anything, directly pertinent to human radiation experiments. The series contains meeting minutes, agendas, letter reports of meetings, and some special subcommittee reports. Collection number E-70.

RESTRICTIONS This series contains classified information.

LOCATION OF National Archives at College Park

RECORDS 8601 Adelphi Road

College Park, MD 20740

INCLUSIVE DATES $1946-1973$

ARRANGEMENT Subject

VOLUME 22 cubic feet

DESCRIPTION The series consists of correspondence files and data files created by the fallout studies branch and other units of the Atomic Energy Commission's division of biology and medicine. It contains extensive documentation on fallout controversy of the 1950 s, including files on Project Sunshine, the investigation of sheep losses after the 1953 test series, and the controversy over Harold Knapp's analysis of iodine-131 doses to residents of St. George, Utah. The series is arranged into subject files, but they are not grouped according to a single filing system. The series contains technical reports, Project Sunshine bulletins, speeches, memorandums, letters, transcripts of interagency conferences, data files, handwritten notes, published articles, and photographs. Collection number E-73.

RESTRICTIONS This series contains classified information.

LOCATION OF National Archives at College Park

RECORDS 8601 Adelphi Road

College Park, MD 20740 


\section{Topical Areas}

$\mathbf{T}$ HREe TOPICAL NARRATIVES dealing with areas of special interest are included here:

I. Radiation, Biomedical Science, and Distribution of Isotopes;

2. Plutonium Injection Experiments; and

3. Intentional Radiation Releases.

Because these topics cut across sites and other structural arrangements, records series for these narratives are not listed. Series that are pertinent to the topics are, however, listed under the site narratives.
Human radiation experiments encompass many additional topics beyond those presented here. Yet the three that are discussed are of particular relevance to DOE and sufficient information is available about them to tell a meaningful story. As with the other topical areas covered in this report, the broad outlines of what took place are provided with particular attention to organizational context.

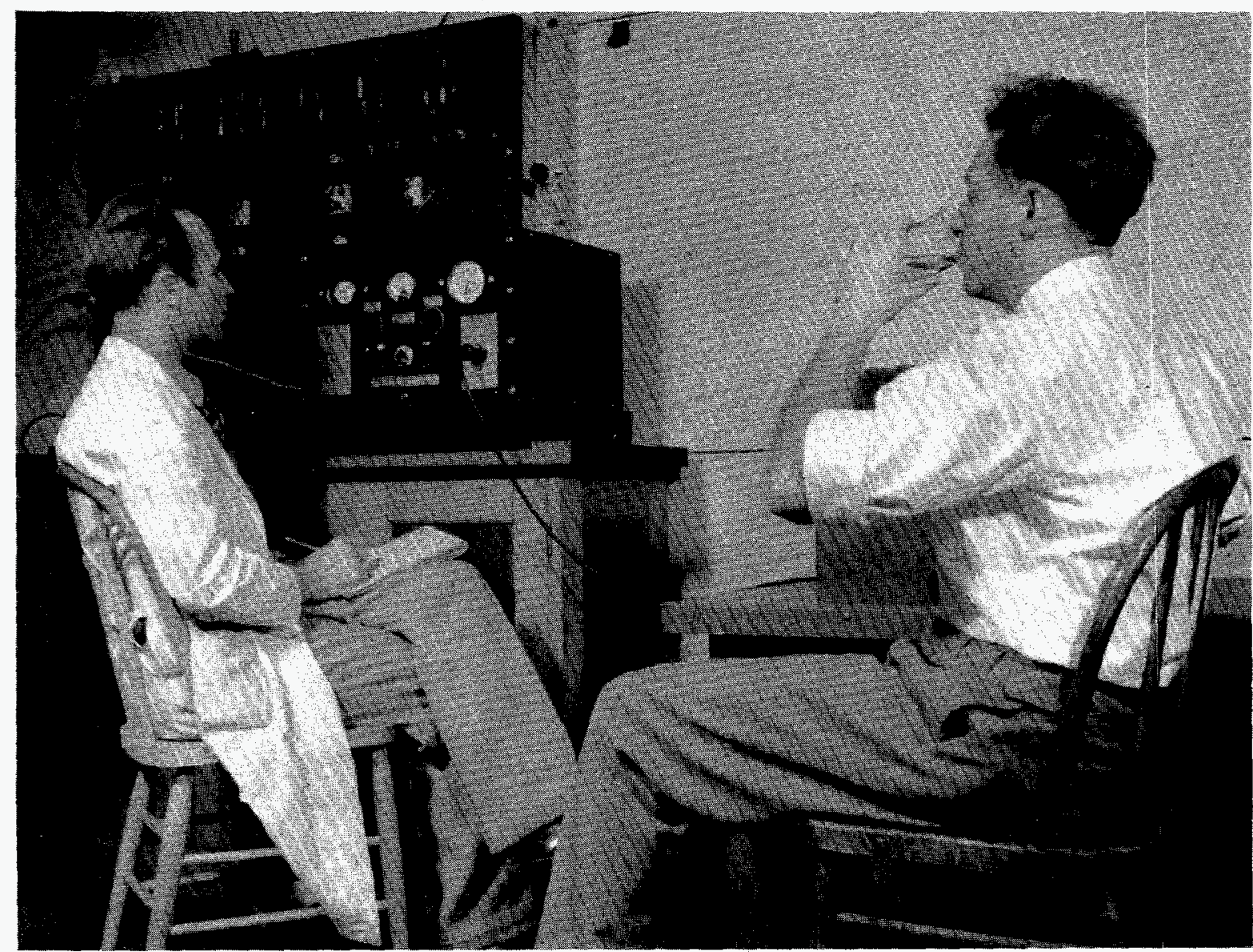

Figure 39. Joseph Hamilton (/eft) conducting one of the first isotope metabolism studies during the 1930s. The study took place at the Lawrence Radiation Laboratory (now Lawrence Berkeley Laboratory). 


\section{Introduction}

GOVERNMENT-SPONSORED hUman radiation eXperiments occurred in the broader context of biomedical science, which encompassed experimental research as well as medical diagnosis and treatment.

Biomedical use of radiation began before the Manhattan Project. This use, moreover, has grown into accepted practices of modern nuclear medicine that today take place with only limited Government involvement. The Manhattan Project and its successors (AEC and DOE) played a key role in advancing the scientific use of radiation. This role ran from developing critical research tools to supporting pioneering cancer therapy. The role also included questionable and controversial activities, such as wartime human experiments.

\section{Background}

Before 1930, scientists were aware that multiple versions of some elements existed in nature.

Such versions of a single element, known as isotopes, shared the same chemical properties.

Some of these isotopes had unstable nuclei that gave off radiant energy-radioactivity-as they disintegrated.

Radioactive isotopes had value for biological research because a researcher could measure their movement through living organisms. In 1923, the first use of radioactivity in biological study took place when a radioactive isotope of lead was employed to study bean root absorption. Shortly afterward, radioactive isotopes of lead and bismuth were used in animal studies. During the late 1920s, Herman Blumgart of Harvard University extended this work by injecting isotopes into humans to study physiological processes.

Initially, the major limitation to research use of isotopes was the scarcity of naturally occurring radioactive elements. This stricture began to loosen in 1934, when Irène Curie and Jean Frédéric Joliot announced they had produced a new radioisotope by striking target metals with alpha radiation. During the same year, physicists working under Ernest $O$. Lawrence at the University of California in Berkeley announced they, too, had produced isotopes. The Berkeley group used Lawrence's cyclotron to bombard a variety of elements with atomic particles, which proved to be a highly effective method of producing various new isotopes.

Radioactive isotopes had value for biological research because a researcher could measure their movement through living organisms.

John Lawrence, Joseph Hamilton, and other Berkeley biomedical researchers working with E.O. Lawrence quickly grasped the value of radiation and radioactive materials for human experiments. Hamilton used radioactive sodium to study blood circulation. John Lawrence used an isotope of phosphorous in experimental treatments for leukemia and polycythemia rubra vera. Robert Stone pioneered the use of external radiation sources for experimental treatment of human cancer patients. Other researchers at various institutions also used radioactive materials to make significant advances in scientific knowledge during the 1930s.

These developments led to optimism (and increased funding) for the biomedical use of radiation. Universities such as Harvard, Rochester, and the Massachusetts Institute of Technology acquired cyclotrons and $x$-ray equipment to pursue studies of plants, animals, and humans. Yet despite the cyclotron and other means of producing radioactive materials, the total amount available for research remained small. One consequence of this was limited knowledge of the potential harm from radiation. It was known that some industrial dial painters who inadvertently ingested radium during earlier decades had contracted bone cancers and other maladies; radiologists of the era were aware that too much $x$-ray radiation would cause damage. But the overall hazards of radiation, both immediate and long term, were not well understood. 


\section{World War II and the Manhattan Project}

Early in 1942, officials of the Manhattan Project realized they needed a special medical program associated with the secret project to build an atomic bomb. Work was underway to construct mammoth industrial facilities to produce plutonium and uranium-235, key bomb materials.

These materials existed in minute quantities to that point, but successful operation of the new plants would result in massive production. Many scientists and thousands of workers would be exposed to exotic new materials, some of which were extremely toxic. The health effects from such exposures were unknown. There were many reasons to worry about possible adverse health effects. There were humanitarian concerns for personnel safety, but two other issues also loomed large:

- If knowledgeable personnel were disabled or killed from exposures, keeping the project secret would be impossible, as would maintaining the bomb schedule.

- If excessive radioactivity spread from production facilities, it might be detected through adverse health effects. This detection, likewise, threatened to compromise secrecy.

To avert these risks, the MED in 1943 asked Stafford Warren, professor of radiology at the University of Rochester School of Medicine and Dentistry, to serve as Chief of the Manhattan Project Medical Section. Along with industrial safety and medical care, the Medical Section was responsible for funding and coordinating university biomedical research programs. Most of these research programs were carried out in a select group of universities-particularly Berkeley, Rochester, and Chicago- that had been active before the war in radiation research.

Until the war, biomedical researchers at these universities had used radiation as a tool to study biological systems and disease. The Manhattan Project shifted this research to study the metabolism and health effects of radiation itself. For example, experiments at Rochester included studies of chronic low levels of radiation and development of improved detection instruments.

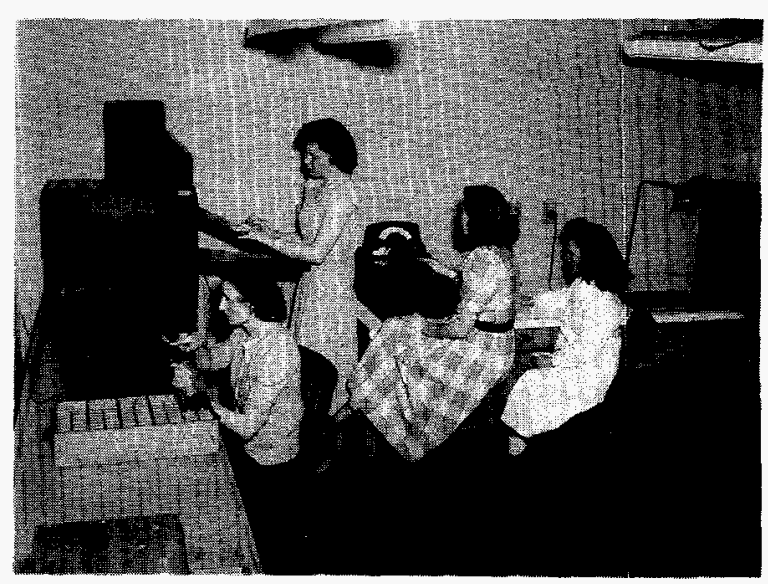

Figure 40. Oak Ridge technicians reading dosimeters to detect worker radiation exposures.

At the Chicago Met Lab, a group headed by Robert Stone worked to define the mechanisms of radiation injury from internal and external exposure in the hope of detecting early damage and providing remedial treatment. The Berkeley group studied the effects of internal depositions of fission products and came to focus on the actinides, especially plutonium.

Early in 1942, officials of the Manhattan Project realized they needed a special medical program associated with the secret project to build an atomic bomb.

Inhalation, ingestion, and injection of radioactive materials were studied at all three universities under Manhattan Project contracts. Most of these studies involved animals, and their chief purpose was to determine where in the body these materials collected and at what rate the materials were excreted. This information was needed to judge the radiation dose from the material and the estimate corresponding hazard.

While the animal studies provided important data, MED researchers wanted precise human data to establish firm radiation exposure guidelines. As a result, human studies were authorized. Some researchers used themselves as subjects: six researchers at the Met Lab drank solutions of plutonium to study excretion rates. Other studies used hospital patients, and 
included injections of radioactive polonium and uranium in patients at Rochester's Strong Memorial Hospital. Plutonium was also injected into subjects in the Oak Ridge hospital, the University of Chicago Billings Hospital, the University of California Medical School, and Strong Memorial Hospital.

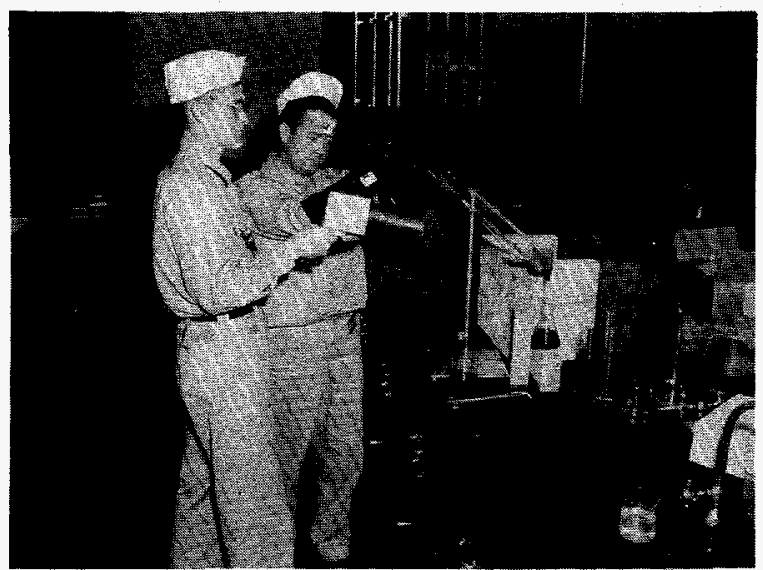

Figure 41. An Oak Ridge isotope worker (right) and a health physics technician (circa 1950)

The Manhattan Project shifted the focus of biomedical research to study the metabolism and health effects of radiation itself.

Data from these human experiments and related research were used to set worker exposure standards. These standards, in turn, were used to analyze the various industrial processes to set needs for shielding, ventilation, and other worker-safety measures. The principle behind these practices was to control exposures from external radiation, and from internal radioactive emitters entering the body from inhalation, ingestion, or wounds. Initially, these standards were implemented from headquarters in Oak Ridge or from the university research programs that developed them. But as the production facilities grew more familiar with the standards, responsibility for managing them became more localized. Inspection teams still visited the plants periodically, but the expectation was that each facility would operate health and safety programs based on established standards.

\section{Postwar Research}

After the war, there was a great deal of interest in conducting further biomedical research with radiation. This interest correlated with a vastly enhanced knowledge of radioactive materials and the recently developed ability to produce large volumes of radioisotopes in nuclear reactors.

Scientists who had used radiation for metabolic studies or for medical diagnosis and treatment before the war now envisioned broad new avenues of radiation research. The U.S. Government shared this view, as did the public. Impressed with the remarkable success of the Manhattan Project and awed by the power of the atomic bomb, the nation was receptive to using radioactivity to solve problems. There was also a new willingness for Government to fund and support research. As a result, the Manhattan Project and later the AEC moved aggressively into civilian biomedical research while continuing defense-related applications.

Researchers used isotopes in many areas, including industrial, agricultural, and chemical research. By far the largest area of use was biomedical research. Isotopes were ideal tools for learning about basic functions, particularly the normal chemical activities-metabolism-of biological systems. Researchers wanted to know more about metabolism to understand the many complex mechanisms involved. This understanding would be of particular value for epidemiologists, immunologists, and others interested in learning about why and how disease interferes with the system.

Scientists who had used radiation for metabolic studies or for medical diagnosis and treatment before the war now envisioned broad new avenues of radiation research.

A disease of major interest to biomedical research was cancer. Cancer was a focal point because it was widespread and because radiation had shown early promise as a possible treatment and diagnostic tool. Some cancer tumors could be destroyed or greatly reduced by radiation; if 
effective doses could be delivered to a cancerous spot, patients could be helped. lodine-I3I, for example, was an effective treatment for some thyroid cancers because the isotope had a great affinity for locating in the thyroid gland. Isotopes were also useful in diagnosing system abnormalities associated with cancer.

Along with a rise in scientific interest in using radiation to battle cancer, there was also some related political interest during the postwar years. In 1948, for example, Congress earmarked $\$ 5$ million for AEC-sponsored cancer research. As a result, the AEC could provide research grants to various universities and was also able to establish its own cancer research hospitals at the University of Chicago, Oak Ridge Institute of Nuclear Studies, and Brookhaven National Laboratory.

The years immediately after the war were characterized by optimism that radionuclides could combat diseases, particularly cancer.

These special hospitals admitted patients through physician referrals. Most of these people had illnesses that had resisted conventional treatment, and the avowed concept was to use experimental treatments to help the patient and to gather information that might help other patients. Since knowledge about effective treatment doses from and specific physical reactions to isotopes was still limited, much experimental work went into developing methodologies and techniques. Many internal and external radiation applications were tested until the AEC closed the hospitals in 1974. This work laid the foundations for modern nuclear medicine.

J. Newell Stannard, in Radiation and Health: $A$ History, describes two distinct periods in the history of nuclear medicine. He cites an "era of therapeutic intent" occurring from about 1948 to 1965. This was replaced by an "era of ever more scanning and ever shorter half-life radionuclides," which continues today. As noted above, the years immediately after the war were characterized by optimism that radionuclides could combat diseases, particularly cancer. The AEC, through its support for cancer research and its isotopes distribution program, played a critical role during this period. This role grew even larger with the initiation of the U.S. "Atoms for Peace" program during the mid-1950s.

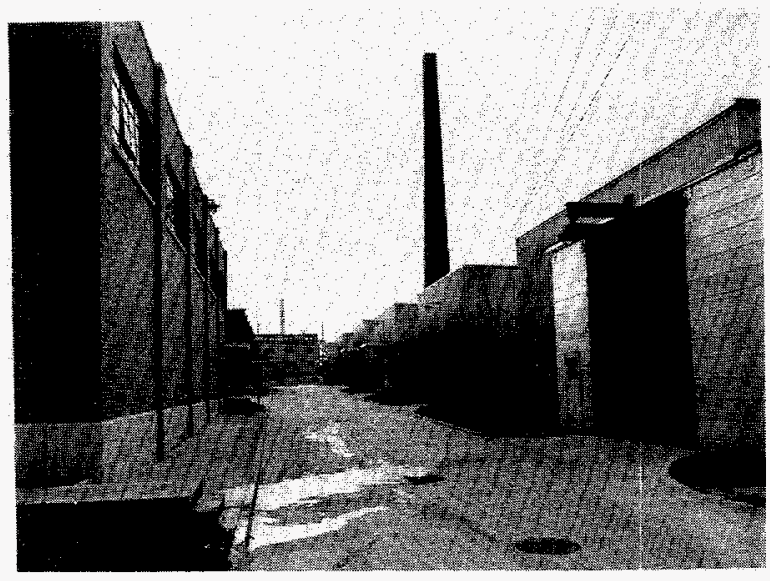

Figure 42. Isotope processing buildings, Oak Ridge.

Atoms for Peace aimed to promote a wide range of nonmilitary nuclear applications, including civilian power generation; mining and excavating; and agricultural production. Interest in medical uses for radiation, already booming, grew still larger. Ambitious studies were underway using radioiodine and astatine for thyroid problems, gallium for bone tumors, and radioactively labeled antibodies for various tumors. Boron neutron capture therapy, a process involving localization of boron in brain tumors and irradiation with reactor neutrons, was tried on more than 40 patients.

Many of these applications ultimately proved disappointing, and by the mid-1960s medical use of radionuclides was shifting away from therapy and toward diagnosis. Stannard notes that unlike the earlier era, AEC and Government laboratories have played a limited role in these later nuclear medicine applications. This is chiefly attributable to the proven success of modern nuclear medicine and its ability to support itself through patient medical fees. Much of this success came through first radioiodine, and later technetium, for diagnostic scanning of various organs and tissues. 


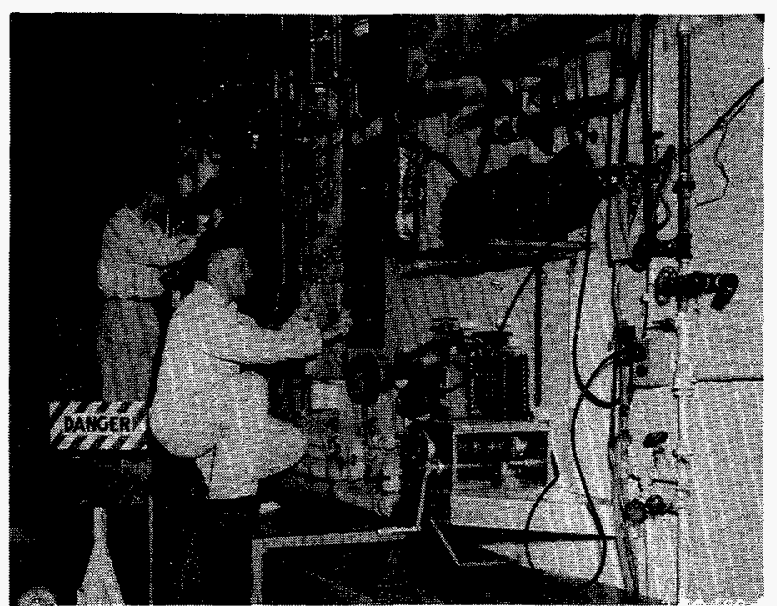

Figure 43. Production of isotopes at Oak Ridge National Laboratory, ca. 1946.

\section{Isotope Distribution Program}

A major reason for the postwar boom in isotope use was the establishment of an isotopes distribution program. In 1946, Paul Aebersold, formerly a scientist at the Berkeley Radiation Laboratory and at Los Alamos, came to Oak Ridge to establish an Isotopes Branch. Official announcement of the isotope distribution program was made in a June 1946 issue of Science, 100 available isotopes were listed. The Isotopes Branch received many applications. The first isotope recipient was the Bernard Free Skin and Cancer Hospital in St. Louis, which had requested carbon- 14 for cancer research. Over the rest of the year, the branch received several hundred requests. Many of these initial applications were delayed, however, because the requesting facilities lacked personnel with radiation training.

Officials were not surprised by the need for radiation training. While Manhattan Project staff had received extensive instruction, no similar teaching was available elsewhere. Eager to train practitioners in the use of radiation, the Manhattan Project established the Oak Ridge Institute of Nuclear Science (ORINS) in 1946. Initially, the facility focused on establishing resident fellowship programs for work at the Oak Ridge Laboratory. In 1948, ORINS began a nonresident isotope training program. Many physicians and scientists eager to use isotopes attended these courses. The training consisted of lectures and laboratory work focusing on various aspects of physics, instrumentation, tracer applications, and experimental procedures. These and related offerings have proved of enduring popularity.

Initial development and oversight of the isotope distribution program fell to an Interim Advisory Committee on Isotope Distribution Policy. This committee worked with the Clinton Laboratories (predecessor to the Oak Ridge National Laboratory) to set up production and distribution schedules. The committee also recommended that the MED take four steps:

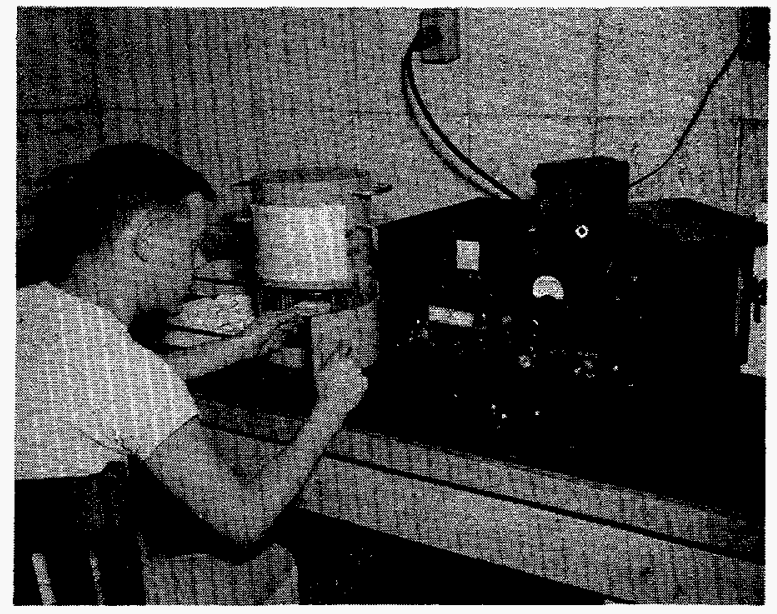

Figure 44. Measuring beta radiation from a sample of phosphorous-32 at Oak Ridge.

I. Appoint a Subcommittee on Allocation and Distribution of Isotopes to judge the merits of each request,

2. Appoint a Subcommittee on Human Applications to review requests for use of isotopes on humans,

3. Make isotopes available only through qualified institutions, and

4. Establish priorities for allocation, to be based on perceived value for publishable research and human therapeutic uses.

These recommendations were accepted by the Manhattan Project and its successor, the AEC. Meeting later in 1946, the Subcommittee on Human Applications affirmed that its primary responsibility would be to review and approve isotope requests involving human research. The group also decreed that it would steer production efforts to emphasize isotopes needed for human therapeutic and diagnostic applications, 
with an emphasis on cancer. In addition, the subcommittee endorsed the following policies:

- Create an official list of medical schools, hospitals, and clinics prepared to receive isotopes.

- Appoint a local committee at each listed facility to review all isotopes requests.

- Direct requests to the Isotopes Division from these local committees for all proposed human uses.

- Appoint knowledgeable physicians and radiologists to the local committees.

The AEC issued policies for the use of isotopes in human studies. A primary control involved the requirement that each requesting institution set up a local isotope committee to evaluate all proposals for use of isotopes on humans. These committees were to include physicians trained in internal medicine and hematology, and someone experienced in protecting personnel against ionizing radiation. Qualified physicists and therapeutic radiologists were to be members of such committees or available in a consulting capacity. Only after approval by its local committee could a requesting organization apply to the Isotopes Division for an allocation.

In completing Form AEC-313, "Application for Radioisotope Procurement," applicants had to provide the name of the institution and the name of the individual who would use or directly supervise the material. Details regarding the proposed use were also required, including:

- approval of the local isotopes committee,

- the types of cases for which materials would be administered,

- the number of patients receiving materials,

- the frequency of treatment per patient,

- the nature of samples to be taken for measurement, and

- radiation instruments and health protection facilities.

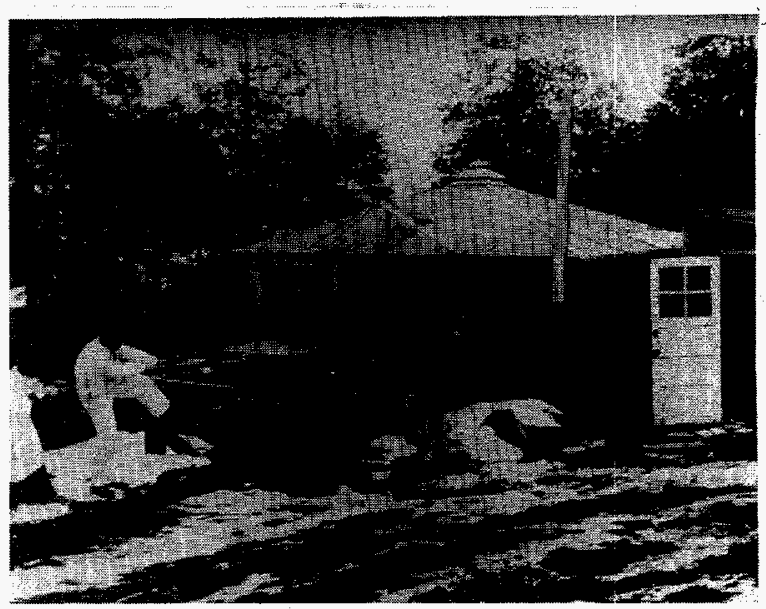

Figure 45. Early method of handling radioactive sources at Los Alamos.

The $A E C$ required that each institution requesting isotopes have a local isotope committee to evaluate all proposals for use of isotopes on humans.

Under the original policy, the Isotopes Division would submit all applications involving the use of humans to the Subcommittee on Human Applications for review. But in 1948, the AEC Advisory Committee on Biology and Medicine concluded that the subcommittee would only review applications for the first human use of a particular isotope. If the first use was approved, future uses of the isotope would not require subcommittee review.

How much success the AEC had in implementing and enforcing policies for application of isotopes to humans is unclear. Records indicate that some local isotopes committees functioned according to AEC guidelines. In addition, the Isotopes Division produced detailed published accounts of its operations regarding isotope authorizations and their intended purpose, including human use. (For an example, see lsotopes: An Eight Year Summary of Distribution and Utilization, U.S. AEC, 1955.) The agency also placed a heavy emphasis on training practitioners in isotope use and safety practices.

On the other hand, no files documenting AEC audits of isotope recipients have been found. There is evidence that the AEC had reason to 
enforce its rules. In a 1949 letter to all agency National Laboratories, Shields Warren, Director of the AEC Division of Biology and Medicine, reminded managers that "the same clearances for the use of isotopes should be obtained from [the Subcommittee on Human Applications] as would be required by the work to be done in an institution not connected with an atomic energy installation."

Aebersold followed up with a memorandum to the AEC New York Operations Office Manager noting that full application, including Subcommittee approval, was needed in all proposed human uses, even in cases where the isotope was made in the laboratory where it was to be used. Noting that "this procedure has not been uniformly followed in the past," he enclosed application forms and instructions.

\section{Other Aspects of Biomedical Research}

The major pursuit in radiation biomedical research during and after World War II focused on health effects in the interest of basic science and therapeutic medical applications. The MED and its successors also had related interests, including radioecology, radiological warfare, civil defense, nuclear fallout, and special technologies such as nuclear-powered aircraft. Occasionally, biomedical topics were studied in conjunction with other activities. For example, the agency studied radioecology - how radiation affects and moves through the environment-with nuclear weapons tests. On other occasions, officials ordered separate studies, such as radiological warfare tests or "Project Sunshine" fallout tissue research.

In some cases, however, the connection between mainstream activities such as cancer research and the various other government re-search interests was less clear. Knowledge gained from therapeutic trials of a radionuclide, for example, might have application to civil defense planning. Similarly, results noted from clinical treatments with external radiation might be useful in designing shielding for a nuclear aircraft engine.
Extensive radiation-related biomedical research occurred from 1946 onward in both public and private organizations. This is reflected partly in

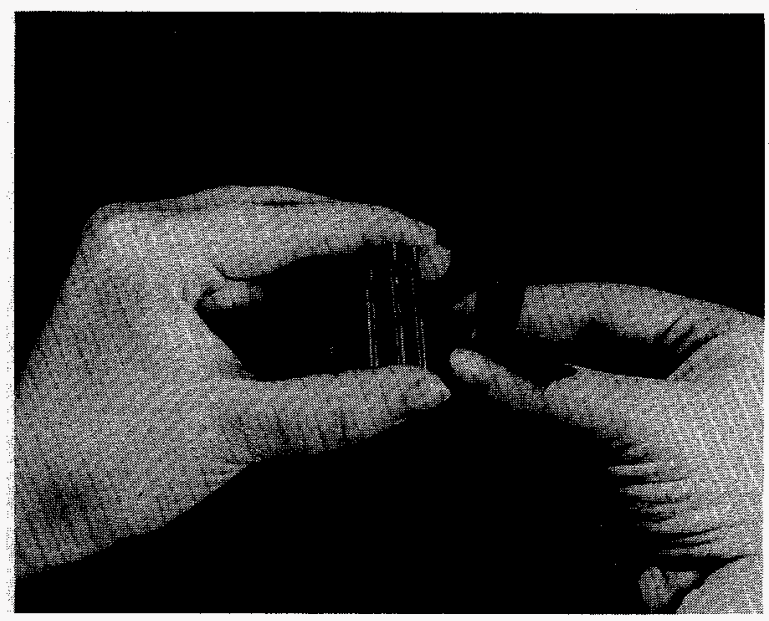

Figure 46. Experimental cardiac pacemaker powered by plutonium, ca. 1968.

isotope distribution statistics. Five years after the start of distribution in 1946, the AEC had issued more than 13,000 procurement authorizations to more than 600 institutions. By the end of 1954, the number of authorizations exceeded 37,000 , and the institutions that received them numbered over 2,400. By 1966, the AEC had sent more than 200,000 isotope shipments to a host of national and international entities. The Manhattan Project and its successors played a key role in developing and supporting biomedical research, much as other Government agencies stimulated various other scientific research during the same era. 


\section{Human Plutonium Injection Experiments}

\section{The Manhattan Project and Plutonium Health Hazards}

DisCOVERED IN I94I by Glenn Seaborg and others at Berkeley, plutonium supported nuclear fission, a process that split atoms and released tremendous energy. Plutonium became an urgently needed material for one variety of atomic bomb; uranium-235, the fissionable isotope of natural uranium, was used in the other bomb type.

The first appreciable quantities of plutonium became available by January 1944. At that time, Seaborg warned of its potential health hazards and suggested immediate studies to learn its biological behavior. This was a critical issue: the longer the material stayed in the body, the more damage it could do. Hundreds of workers would soon be exposed to plutonium, and exposure standards were necessary. Overexposure would not only hurt workers; it could compromise secrecy and disrupt production schedules.

Sentiment grew among project medical staff to administer known amounts of plutonium to humans to derive precise excretion data.

About 10 percent of the plutonium supply was allocated for animal studies in January 1944. By the summer of that year, those studies provided enough information about plutonium retention to justify removal of several Los Alamos workers with high previous exposures from further work with the material. Los Alamos had already had several accidental human exposures to plutonium, and the imminent prospect of working with far larger quantities increased the desire for even more metabolic information.

The early animal studies showed that different species excreted known amounts of plutonium at different rates. This meant that there was no accurate way to correlate animal excretion data to humans. As a result, sentiment grew among project medical staff to administer known amounts of plutonium to humans to derive precise excretion data. However, it was not until the winter of 1944 that Los Alamos Health
Group personnel developed methods to detect tracer-level concentrations of plutonium in excreta. In February 1945, this group, headed by Louis Hempelmann and supervised by Wright Langham, used the procedure to monitor workers for accidental plutonium uptake.

The Manhattan Project was asked to consider "that a hospital patient at either Rochester or Chicago be chosen for injection from 1 to 10 micrograms of material [plutonium]."

With a proven method to detect small amounts of plutonium in excreta, Los Alamos personnel met on March 23, 1945, with Robert

Oppenheimer and Colonel Hymer Friedell of the Manhattan Engineer District (MED) to discuss "the medical problems of this project and their relationship to the Medical Research Program of the Manhattan District." In a memorandum written three days after the meeting, Louis Hempelmann stated that the Manhattan Project was asked to consider "that a hospital patient at either Rochester or Chicago be chosen for injection from I to 10 micrograms of material [plutonium] and that the excreta be sent to this laboratory for analysis." The Manhattan District was also asked to help make arrangements for this "human tracer experiment." Such arrangements were made, and an MED medical officer administered the first human plutonium injection on April 10, 1945, at the Oak Ridge Hospital.

\section{The Experiments, Part 1}

How all the injections were coordinated-or even if they were coordinated-is unclear. Following the Oak Ridge test, injections were given at the Billings Hospital at the University of Chicago on April 26, 1945, and at the University of California Hospital in San Francisco on May 14, 1945. By late June, Manhattan Project contractors at the University of Rochester's Strong Memorial Hospital developed a detailed plan for "rapid (I year) Completion of Human Tracer Studies." These studies were to include plutonium, uranium, polonium, and radioactive lead. 

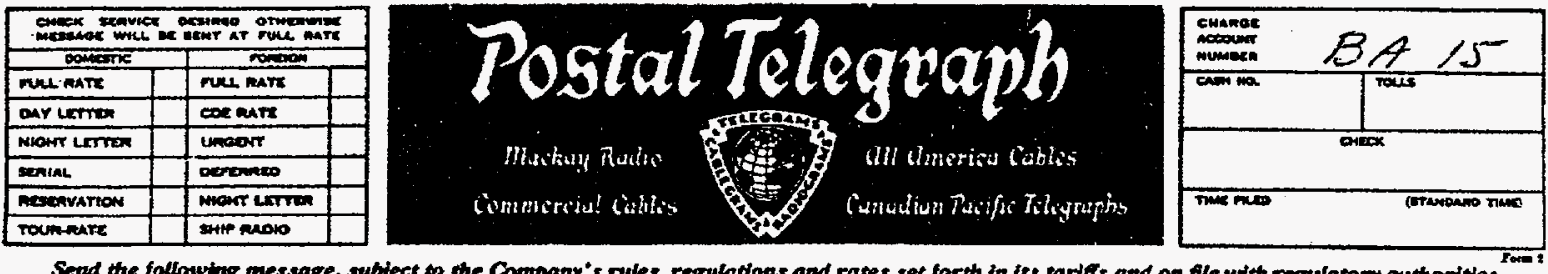

Send the following message, subject to the Company's rules, regulations and rases set forth in tiss tartfif and on file with regularory austionities

$$
\begin{aligned}
& \text { Dr. Wright Langhan } \\
& \text { c/o D. L. Hempelman } \\
& \text {-H.P. }-3 \text { and H.P. }-4 \text { INJECTED TUESAAY, NOVEMBIA TINTYSSEV GNTH. } \\
& \text { H. P. }-5 \text { INJECT\$D FRIDAY, NOVEVBER THIRTIETH. } \\
& \text { II-130.4- 5? - } \\
& 11 / 30 / 45
\end{aligned}
$$

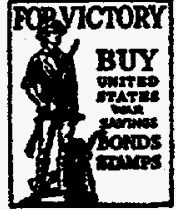

$3,4,5$

Robert M. Fink

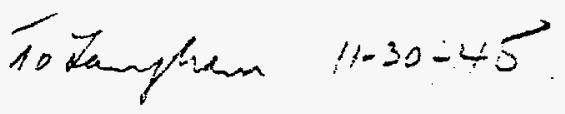

Figure 47. Telegram from University of Rochester notifying Los Alamos of three plutonium injections, 1945.

Over the next several months this plan was revised, and on September 18, 1945, Wright Langham sent the most recent version to Colonel Stafford Warren, Chief of the Manhattan District Medical Section, noting that "you and Col. Friedell, will of course, have final say as to whether or not the experiment goes through in accordance with this plan."

The Rochester plutonium experiment protocol called for 10 subjects to be admitted to the Strong Memorial Hospital metabolism ward in groups of four per month for the first two months and two for the third month. After injection, samples of blood, urine, and feces were to be shipped to Langham at Los Alamos for analysis. Documents show that, from October 1945 to July 1946, Rochester injected II patients. One of the later patients (designated as HP-1I) died of pneumonia and other preexisting ailments 6 days after his February 20 injection. Samuel Bassett at Rochester described this as an "acute experiment" that did not involve collection of excreta, but that did yield organs and other autopsy material that was sent to Los Alamos for study.
When notified of HP-I I, Langham told Bassett, "If you should decide to do another terminal case, I suggest you use 50 micrograms [of plutonium] instead of 5. This would permit the analysis of much smaller samples and make my work considerably easier." Langham also stated, "I have just received word that Chicago is performing two terminal experiments using 95 micrograms each. I feel reasonably certain there would be no harm in using larger amounts of material if you are sure the case is a terminal one."

Langham told Bassett, "If you should decide to do another terminal case, I suggest you use 50 micrograms [of plutonium] instead of 5. This would permit the analysis of much smaller samples and make my work considerably easier."

The two Chicago experiments took place at Billings Hospital on December 27, 1945. Both subjects died of preexisting ailments shortly after injections of 94.91 micrograms of plutonium. 
Experimental protocols exist for the Rochester studies. Langham and others who directed the research also described in broad terms how subjects were to be selected. Generally, the choice fell on older individuals ( 13 of whom were 45 or older) with limited life expectancy. (Ten of the 16 who were tracked died within 10 years.) Four subjects did, however, live more than 20 years after the experiments.

Although several research reports by others appeared earlier, Langham and several colleagues at Los Alamos compiled the most substantial account of the plutonium injection experiments. They based their conclusions chiefly on the Rochester study. Issued as Los Alamos report LA-II5I in September 1950, Distribution and Excretion of Plutonium Administered Intravenously to Man described the experiments, tabulated the data on plutonium metabolism, and derived an empirical formula for calculating retained plutonium from urinalysis. Although LA-I I 5 I itself remained restricted until 1980 , information about the plutonium studies made its way into the scientific literature shortly after the injections took place.

Efforts to find and study surviving patients from the experiments of the $1940 \mathrm{~s}$ ultimately triggered controversy.

\section{The Experiments, Part 2}

During the early 1970s, Patricia W. Durbin, a biophysicist at the Lawrence Radiation Laboratory, reevaluated Langham's plutonium excretion data. One reason Durbin could improve on Langham's results was the unexpected availability of data from long-term survivors. During her research, she learned that one subject had lived for $\mathbf{2 0}$ years after being injected. Painstaking detective work revealed that four other subjects were also still alive in the early 1970s. With the AEC's approval, support from the Center for Human Radiobiology at Argonne National Laboratory, and cooperation from the University of Rochester's Strong Memorial Hospital, three of the four survivors were reexamined in 1973. Researchers gathered and promptly published new data on long-term patterns of plutonium retention and excretion.
Efforts to find and study these surviving subjects ultimately triggered controversy. In the time since the work had been done, the Government had adopted requirements mandating that subjects give informed consent as a condition of research. Questions arose whether the plutonium subjects provided consent for the original experiments or for the 1973 follow-up examinations. The ensuing investigation resulted in two internal AEC reports issued in August 1974. Both concluded that only one subject may have provided any kind of consent. The other 17 participated with little verifiable knowledge of the experiment or its risks. Moreover, the reports found that the 1973 follow-up studies were also not done with informed consent from the subjects. The three subjects were not told they had been injected with plutonium for experimental purposes, nor why they had been asked to return to the hospital.

Although the AEC did not publicly release these reports, the agency's successor, the Energy Research and Development Administration, issued a fact sheet on the matter in 1976. This issuance provided details on the experiments and briefly discussed results from the 1974 AEC inquiry on informed consent.

\section{The Plutonium Experiments and the Public}

Publications based on the plutonium studies began to appear in the medical literature as early as 1948. In several articles during the 1950s and early 1960s, Langham explained the technique for measuring excreted plutonium and referred to the validating research on plutonium metabolism in humans. Some information, however, remained classified for a number of years afterward.

What the scientific literature and other information about the experiments did not provide was the names of the subjects or their personal stories.

The public first learned about experiments in 1976, after ERDA issued the fact sheet noted above. Several newspapers carried stories emphasizing the absence of informed consent 
and raising questions about medical ethics, but the issue seemed to arouse little public concern. Ten years later, a congressional committee issued a report that criticized the plutonium injections and about 30 other Federal human radiation experiments. Commonly known as the Markey report after subcommittee chairman Edward J. Markey (D-Mass.), this document again stimulated only limited media attention at the time.

What the scientific literature and other information about the experiments did not provide was the names of the subjects or their personal stories. This approach was pursued by Eileen Welsome of the Albuquerque Tribune, who in November 1993, published a series on the experiments and its subjects. The author had hunted through government reports, scientific journals, and newspaper files to piece together facts about the experiments, including the names and other personal details of several subjects.
At a December 1993 press conference, Secretary of Energy Hazel R. O'Leary discussed the plutonium experiments in conjunction with releasing much formerly classified information on a variety of subjects. As part of a new policy of openness, she also committed the Department to revealing the full scope and details of human radiation experiments done by the agency and its predecessors. The story of the experiments received extensive national attention and led to public demands that the Federal government make full disclosure on the topics.

One year after the Secretary's commitment, the Department has found, declassified, and made available much documentation relating to the plutonium injections and other human radiation experiments. Now under investigation by the Advisory Committee on Human Radiation Experiments and others, this information will provide the basis for a comprehensive ethical analysis of these studies. 
Environmental Releases of Radiation

\section{Introduction}

GENERALLY SPEAKING, these releases do not fit the definition of human experimentation, in that they were not undertaken with the intent of testing the effects of radiation in humans or designed to measure human exposure.

The scope of DOE's document search has encompassed numerous environmental radiation releases. In looking for pertinent records, it has become apparent that such releases were typically conducted as site projects, meaning that pertinent records often still reside at the sites. Record series for releases are therefore found under the section dealing with the site where they were conducted. For example, the Green Run series are described in the Hanford section. This narrative outlines the history of the pertinent DOE and predecessor agency environmental radiation releases, including radiological warfare activities.

Some of these events fit the definition of a human radiation experiment, while others do not. Some are ambiguous.

In November 1993, the U.S. General Accounting Office (GAO) released a Fact Sheet entitled "Examples of Post World War II Radiation Releases at U.S. Nuclear Sites." The report focused on three occurrences:

- the 1949 Green Run test at Hanford,

- radiation warfare tests at Oak Ridge and the Dugway Proving Grounds from 1948 to 1952, and

- the 1950 atmospheric radiation-tracking tests at Los Alamos.

Section 2(b) of the January 15, 1994, Executive Order establishing the Advisory Committee on Human Radiation Experiments directed the committee to evaluate the radiation releases outlined in the GAO Fact Sheet, and "[a]ny other similar experiment that may later be identified."

A subsequent memorandum from the Secretary of the Cabinet directed several agencies, including
$D O E$, to find and inventory records related to human radiation experiments, including those related to intentional environmental releases, defined in Paragraph 2(a)(1) as

[e]xperiments involving intentional environmental releases of radiation that $(A)$ were designed to test human health effects of ionizing radiation; or (B) were designed to test the extent of human exposure to ionizing radiation.

The environmental releases described below are grouped into two main categories:

- Releases associated with military purposes - this category includes radiological warfare, nuclear-powered aircraft, the Green Run, and the Los Alamos Bayo Canyon tests.

- Nonmilitary programs, including various reactor-related tests.

Many of these releases are now under study by entities other than DOE to arrive at independent conclusions regarding potential health effects.

Some of these events fit the definition of a human radiation experiment, while others do not. Some are ambiguous. Yet rather than choose among these releases, DOE has taken an inclusive approach. The releases described below, therefore, include events where individuals were purposefully exposed to radiation, events where such exposures were inadvertent or incidental, and events with no known human exposures. Please note, however, that this listing is by no means a full accounting of all agency environmental radiation releases.

\section{Radiation Releases for Military Purposes}

The first National nuclear undertakingdevelopment of the atomic bomb-focused exclusively on military objectives. The Atomic Energy Act of 1946 called for the development of an atomic energy program "subject at all times to the paramount objective of assuring the common defense and security." Through the mid-1950s, AEC activities continued to focus on atomic energy for weapons development and for 
other military purposes. Early AEC intentional releases of radioactivity included testing for radiological warfare and for other purposes; all but a handful of these tests were originally secret. Known intentional releases for military purposes are described below.

Radiological warfare: An overview-The Manhattan Project and its successors investigated various aspects of radiological warfare, which would use radioactive sources to contaminate a targeted area. Nuclear explosions would not be involved. Rather, radioactive material would be placed in a casing for battlefield dispersal. Among the purposes envisioned for these weapons were to injure enemy soldiers, block troop advances, and contaminate enemy cities. Radiological warfare weapons also were conceived as a tool to instill fear in adversaries and to serve as a deterrent to their use against America.

Ideas about radiological warfare surfaced even before the U.S. began its atomic bomb program. Key atomic scientists Ernest $O$. Lawrence and Arthur Holly Compton proposed a top priority program to develop radioactive weapons in 1941. An atomic bomb program was actually given a lower priority at that point, in part because it was far more complex than producing fission products for use on a battlefield or an enemy city. While most attention soon shifted to the bomb program, anxieties persisted that Germany might develop radiological weapons for use against American or English cities. The Manhattan Project even sent radiation detection instruments to Washington, New York, Chicago, and other cities to prepare for such an attack.

Serious consideration was given to radiological warfare after the war. There was concern that a foreign power, frustrated in its attempt to develop an atomic bomb, might instead turn to radiological warfare. In 1947, the Armed Forces Special Weapons Project of the Department of Defense (DOD) asked the AEC to form a committee to study the subject. A year later, following the recommendations of its General Advisory Committee and the Advisory Committee on Biology and Medicine, the AEC committed to further investigations. Areas of study included laboratory research on radiological agents, field toxicology studies on animals and vegetation, and methods of producing and dispersing radiological agents.

In 1948, AEC and DOD formed a special panel to study defensive and offensive radiological warfare. This panel became known by the name of its chairman, W.A. Noyes, Jr. Defensive aspects included assessment of potential radiological agents, including delivery systems and biological effects. Methods of medical treatment and public education were also considered. Offensive aspects focused on the potential use of radioisotopes to deny an enemy the use of an area for a period of time. The Noyes panel was set up to help define the AEC radiological warfare program, particularly the production of radioactive sources and the study of biomedical effects. Within the military, the Army Chemical Corps assumed responsibility for dissemination methods and protection measures, including design, selection, and testing of tactical weapons.

Anxieties persisted that Germany might develop radiological weapons for use against American or English cities.

Also in 1948, a study panel chaired by Franklin McLean of the University of Chicago was established. This panel differed from the Noyes group in that it focused solely on biological and medical aspects of radiological warfare. The Chicago Toxicity Laboratory, an Army Chemical Corps contractor, helped in reviewing literature and in suggesting the necessary experimental work. Using animals, the laboratory studied the toxicity of radioactive zirconium, tantalum, columbium, and lanthanum following inhalation, bloodstream absorption, and ingestion. Plans were made to coordinate this research with work at other AEC facilities, such as the research in diagnosis and treatment of radiation sickness and deposition of radioactive materials in tissue.

The Noyes panel functioned until November 1950, when it voted to disband. The committee recommended a low priority for radiological warfare, citing the need for bomb production and the limited success in producing waste fission products in amounts that could be useful for radiological warfare. The panel saw some 
limited cases where radiological warfare offered potential advantages over the atomic bomb, such as for use against targets where it might be desired to preclude human presence for some time while avoiding permanent destruction. The panel also recommended consolidation of radiological warfare and atomic bomb civil defense programs. AEC continued some research and production of potential radiological agents until all such work was ended in 1954. Army Chemical Corps radiological research and development ended in 1953.

\section{Oak Ridge radiological warfare releases - in} 1948, Oak Ridge National Laboratory (ORNL) conducted three field experiments to support the Noyes panel. ORNL was responsible for testing radioactive lanthanum ( $\mathrm{RaLa}$ ) and radio. active tantalum, and also for working with Hanford to develop potential agents such as tantalum, zirconium, and columbium. For the RaLa tests, a strip was cleared in a field near the $X-10$ reactor area. Sources were placed and measurements taken at varying distances. The first test used three sources of approximately 1280,100 , and 20 curies each. The second test used only the 1280 curie source. Upon completion of the tests, the sources were removed.

A test involving radioactive tantalum was conducted shortly afterward. The experiment was conducted in a rectangular plot near the $\mathrm{K}-25$ gaseous diffusion plant and involved over 250 tantalum wires placed in a grid pattern. ORNL took measurements of radiation intensities at various points and removed the wires. None of these tests were designed to yield biomedical information.

Radiological warfare releases at Dugway Proving Ground-The AEC worked with the Army Chemical Corps and the Air Force to develop munitions for radioactive warfare products. Munitions field testing took place at the Dugway Proving Ground in Utah, which was established by the Army in 1942 for biological and chemical warfare tests. Between 1949 and 1952, there were at least 14 radiological tests at Dugway. Dispersal tests measured the rate and extent of the spread of radioactive material following a release. Contamination tests focused on the effect of radioactivity on land and structures. Decontamination tests evaluated the effectiveness of cleansing methods. Documentation uncovered in DOE's search does not show a biomedical research component of AEC participation in these tests.

The tests usually involved an air release of radioactive material followed by analysis of the test area. Data from measuring devices placed at various heights and distances were collected to evaluate weapons strategy and tactics. Precautions were taken against off-site contamination, including scheduling tests when wind conditions were most favorable.

The documents found by DOE do not show that human experimentation was involved in the Dugway tests.

The Dugway test series began late in 1949. The purpose of the first tests was to study ballistic dispersal from an air-dropped device. Particles of tantalum- 132 were prepared for the tests by Oak Ridge National Laboratory and loaded into cluster devices. The Air Force dropped the devices, which dispersed material within a square mile. Additional testing continued from 1950 through 1952 to evaluate explosives used to disperse radioactive agents, primarily tantalum. Decontamination studies were also conducted.

AEC's primary responsibilities for these tests continued to be the provision of nuclear materials. By late 1950, tantalum was scarce and was replaced by zirconium-niobium as the primary radiological testing agent. The documents found by DOE do not show that human experimentation was involved in the Dugway tests. The only known evidence of human exposure reviewed involves a crane operator accidentally exposed during a tantalum test.

The Green Run-The Air Force and the AEC conducted a test at Hanford in December 1949 to test a methodology for monitoring the emerging Soviet nuclear program. Known as the Green Run, the test aimed to learn if nuclear materials could be detected at long distances from their source. There was a strong desire to answer this question because the Soviets had tested their first atomic bomb in August 1949 and the government wished to gather data about Soviet capabilities. 


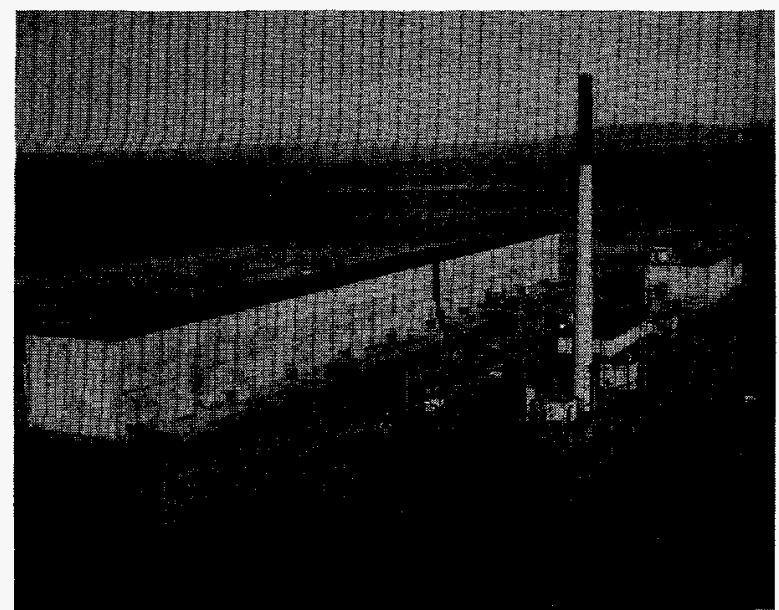

Figure 48. Plutonium separation building ("canyon") at Hanford.

The term "Green Run" refers to the use of "green" irradiated reactor fuel cooled (allowed to become less radioactive through atomic decay) for only sixteen days-instead of the usual ninety to one hundred days - before processing. The fuel was dissolved in nitric acid and the solution processed to separate plutonium. Dissolution of this "green" fuel resulted in the discharge of much larger quantities of radioactive iodine and xenon than would result from the processing of a like amount of older fuel. The plant's off-gas scrubbers, which in normal operations substantially reduced the release of radioactive iodine from the stacks, were intentionally shut down.

The official test account issued in May 1950 reports that about 7,800 curies of iodine and 20,000 curies of xenon were released into the atmosphere in Southeast Washington and Oregon. This iodine release was almost twice the pre-test projection. Weather conditions at the time of the test were unfavorable, and radioactive gases were dispersed over populated areas. Radioactive iodine was detected on the ground, vegetation, and water. Although the amount of the release was not deemed unsafe at the time, the Health Instruments Division stated in a 1950 report that "the resultant activity came close enough to significant levels, and its distribution differed enough from simple meteorological predictions that [we] would resist a proposed repetition of the test." Radioactivity released during the Green Run was, however, dwarfed by the amount of radioactive materials released during routine production activities at Hanford in the 1944-1948 period, before the installation of emission reduction equipment.

Weather conditions at the time of the Green Run test were unfavorable, and radioactive gases were dispersed over populated areas.

DOE has declassified all technical data associated with the test and DOD conducted a declassification review in 1994 that released additional information. Only a few details remain classified by DOD: The December 1993 GAO Fact Sheet noted that GAO had reviewed the classified material and believed that it contained no documentation showing that "the test was intended to be a radiation warfare experiment or a field test of radiobiological effects on humans." Both OHRE and the Advisory Committee on Human Radiation Experiments staff with security clearances have also reviewed the classified material. The test did result in the exposure of populated areas near the site. These exposures, and exposures resulting from other Hanford emissions, have been estimated through work of the Hanford Environmental Dose Reconstruction Project, a multi-year undertaking managed by the U.S. Centers for Disease Control and Prevention.

\section{Los Alamos Bayo Canyon RaLa tests-From} 1944 to 1962, Los Alamos conducted 254 openair implosion physics tests in Bayo Canyon. The purpose of the program was to test weapons designs using conventional high explosives and radioactive lanthanum (RaLa), a short-lived but intense radioactive source. Tests were performed specifically to diagnose material motion and compression through high-speed $\mathrm{x}$-ray photographs of the earliest moments of the implosion. The sources involved contained from around a hundred to several thousand curies of lanthanum-140; some strontium-90 impurities were also present.

Design details of the RaLa test device and the implosion process remain classified because the information is judge to be of potential use to a nuclear proliferator. Data on how much RaLa 
was used in each test is, however, unclassified and has been made public. While the highest concentration of radioactivity after a test was around the site of detonation, offsite contamination was periodically detected. Los Alamos $\mathrm{Na}$ tional Laboratory has an effort underway to estimate the offsite doses resulting from the Bayo Canyon tests.
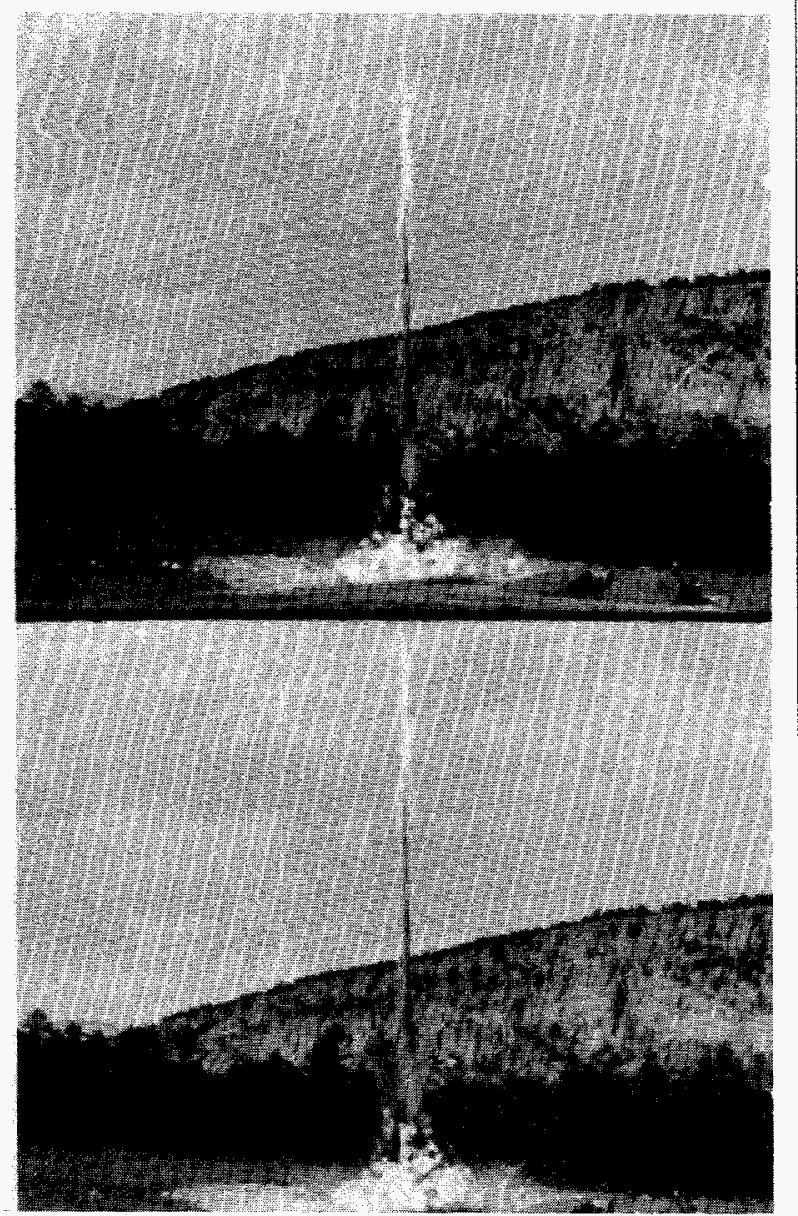

Figure 49. (top and bottom) A Los Alamos Radioactive Lanthanum (RaLa) test in Bayo Canyon.

Los Alamos Atmospheric Tracking Tests-The 1993 GAO report listed four tracking tests conducted at Los Alamos in 1950. The report stated that the tests were conducted by Los Alamos and the U.S. Air Force to track radioactive clouds using an experimental aircraft instrument. Two of these tests were conducted during RaLa implosion tests. The Air Force Cambridge Research Laboratories used an aircraft to evaluate an experimental instrument for measuring atmospheric electrical conductivity in an attempt to measure airborne radioactivity. These tests took place during March and April of 1950. A third detection study was scheduled during a RaLa test, but was canceled when the test cloud drifted over restricted airspace.

The fourth event, conducted by the Air Force in July 1950, also focused on measuring atmospheric electrical conductivity. This test used a lanthanum-I 40 source to test air conductivity in a static known radiation field. The test involved no explosives or release of radioactive material. At the completion of the experiment the source was removed.

\section{The Aircraft Nuclear Propulsion Program} (ANP)-General Electric ran the aircraft nuclear propulsion program (ANP) for the U.S. Air Force. Its goal was to design a nuclear reactor suitable for use in aircraft. The program was a follow-on to the unsuccessful Nuclear Engine for the Propulsion of Aircraft (NEPA) program of the late 1940s and early 1950s. Safety concerns and engineering problems led to the cancellation of this program as well in the early 1960s.

Three major test series at the AEC National Reactor Testing Station in Idaho were conducted for the ANP program. The first were the Initial Engine Tests (IET), designed to test reactor assemblies. At least 26 of these tests were conducted from 1955 to 1961, most of which involved some release of radioactivity into the environment. There were, however, no known biomedical aspects of these tests. The most significant releases took place during Initial Engine Test \#3. During this test, damage to the fuel elements resulted in the release of about 300 curies of iodine- $|3|$.

General Electric ran the aircraft nuclear propulsion program (ANP) for the U.S. Air Force.

The second series was the Fuel Element Burn Tests A and B, conducted in March 1957. Nuclear fuel assemblies were heated to determine fission product release in the case of aircraft crash and resulting fire. The tests were not classified and 
may have resulted in some off site exposures. The third test series, the Fission Product Field Release Tests (FPFRT), took place from July through September 1958. Nine tests were undertaken to measure fission product release, diffusion of radioactivity in the air, deposition of radioactivity on vegetation and the ground, and uptake by animals and plants, including possible biological effects. All of the experiments were done with extensive field monitoring to verify predicted test behavior. The tests included a biological component run by the University of Rochester, which used dogs, rabbits and rats. No intentional exposure of human subjects to radiation is suggested in the documents reviewed.

Additional fission product field release tests took place at the Dugway Proving Grounds in Utah. The tests were conducted in essentially the same manner as those done in Idaho and involved some intentional environmental release of radiation. These tests are separate from the radiological warfare experiments described above that took place at Dugway in the early 1950 s.

\section{Radiation Releases for Nonmilitary Purposes}

In 1954, the Atomic Energy Act was amended and the AEC given authority to declassify certain areas of nuclear technology to promote commercial nuclear power and international peaceful atomic energy activities. Concurrent with the development of these applications, public concern about the hazards of fallout from atmospheric nuclear weapons testing was increasing. The releases discussed below are closely tied to these concerns and include analysis of fallout effects, reactor safety testing, nuclear rocket and aircraft tests, and plant safety testing. With one exception, these experiments were not classified.

In 1962 and 1963, Hanford intentionally released small amounts iodine-131 to study the dispersion of radioactive iodine into the air and soil.

Hanford: 1962 and 1963 releases-In 1962 and 1963, Hanford intentionally released small amounts of iodine-|3| to study the dispersion of radioactive iodine into the air and soil. These tests were related to AEC biomedical studies of fallout. The 1962 release involved 8.3 curies of iodine-131 emitted from the Hanford Redox Plant, a plutonium processing facility. During the emission, the plume trajectories were plotted from meteorological data and samples were collected across the predicted plume trajectories at several altitudes and at distances up to $\mathbf{5 0}$ miles from the plant.

Following the emission, sets of vegetation and milk samples were collected. Designed to study the spread and behavior of iodine- 131 released to the atmosphere, the 1963 test provided data to estimate the hazards potentially associated with weapons testing or nuclear accidents. The test released 120 millicuries of iodine-131. Two human volunteers, Hanford employees, stood in the path of the release to obtain data on inhalation uptake. Air, soil and plant data were collected and dogs were also used to measure inhalation.

The Controlled Environmental Release Tests involved intentional releases to measure released radionuclides in the air, vegetation, cows, and milk.

Idaho National Engineering Laboratory (INEL): Controlled Environmental Radioiodine Tests (CERT)-The CERT activities involved intentional releases of radioiodine to the environment and were intended to evaluate the health hazards of reactor accidents. Twenty-four tests undertaken from 1963 to 1968 were designed to develop models for predicting movement of radioiodine through the air-vegetation-cow-milkhuman food chain. CERT tests I, 2, 7, 10, and II involved human volunteers breathing air or drinking milk containing small amounts of radioiodine. In the first test, seven people had their thyroids measured after drinking milk from cows that had grazed in a pasture with radioiodine deposits. In the remaining four tests, individuals were exposed during radioiodine release over the pasture and their inhalation uptake was measured. The experimental design for the other CERT tests apparently did not involve exposure of human subjects. 


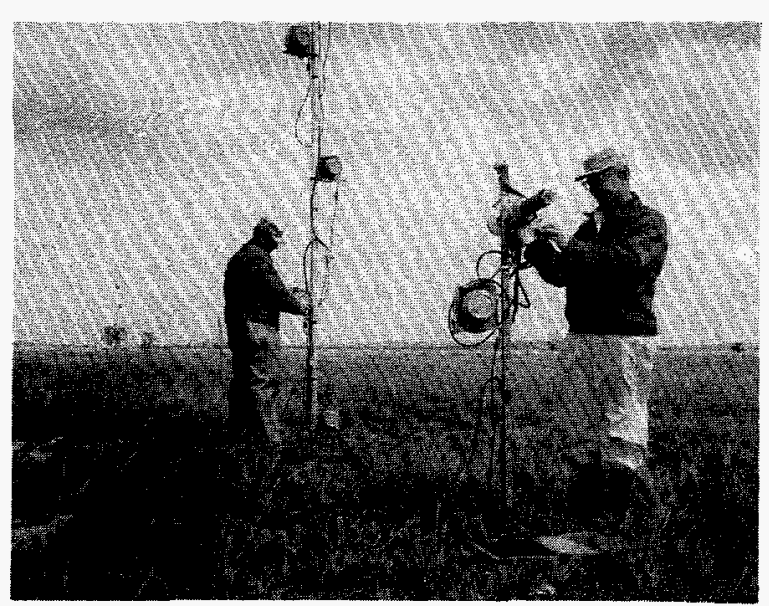

Figure 50. Measuring intentional radiation releases at the Idaho experimental dairy farm (circa 1964).

\section{INEL: Controlled Environmental Release Tests} (CERT)-This test series, also known as CERT, involved intentional releases with isotopes other than radioiodine and, like those described above, were designed to measure released radionuclides in the air, vegetation, cows, and milk. The radionuclides released in this series, running from 1968 through 1977, included sulphur-35, chromium-5I, potassium-42, cesium- 134 , and cerium-|4|. The experimental design involved no intentional exposure of humans radiation.

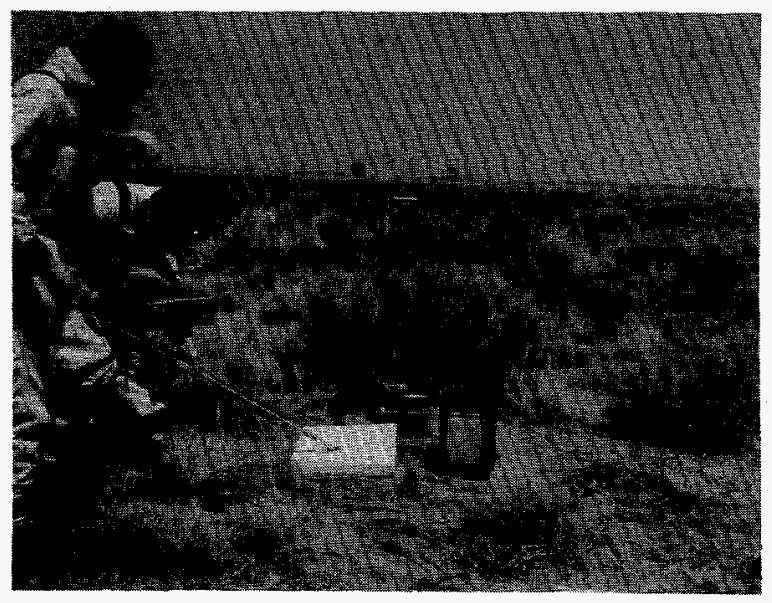

Figure 51. Checking radioactivity after a Controlled Environmental Radioiodine Test (CERT) in 1966.

INEL: Special Power Excursion Reactor Tests (SPERT) - When the AEC began to promote commercial nuclear power during the mid-1950s, it initiated reactor safety research programs at INEL. Initial concerns focused on the hazards of a nuclear excursion, or runaway chain reaction. The Special Power Excursion Reactor Tests (SPERT) at Idaho included destructive tests in which reactor cores were intentionally damaged by nuclear excursions. These tests resulted in limited releases of radioactive materials into the environment. The SPERT-I testing program consisted of three series of tests done in 1962 through 1964 to evaluate the factors involved in two actual test reactor accidents. Exposure to humans was not planned and no exposure is suggested in documents collected.

INEL: Loss of Fluid Test (LOFT)-The LOFT series involved eight power reactor safety-related tests conducted under the direction of the Organization for Economic Cooperation and Development, an international group. The final testing simulated a small-break, loss-of-coolant accident in a commercial reactor similar to the 1979 Three Mile Island accident. The test resulted in fuel meltdown and release of fission products to the primary coolant system. Following the test, leakage from the fission product monitoring system and the primary coolant system allowed some fission products into the reactor building and subsequently was released through a monitored pathway to environment

The Loss of Fluid Test resulted in fuel meltdown and release of fission products to the primary coolant system.

INEL: Systems for Nuclear Auxiliary Power (SNAP) program-The SNAP program was designed to develop small, lightweight nuclear power sources for satellites, spacecraft, Antarctic weather stations, and navigation buoys. The SNAP IOA transient (SNAPTRAN) Test series was conducted to evaluate radiation safety problems of small space reactors. A test version of the reactor was destroyed during SNAPTRAN-3 in 1964 to determine the radiological consequences of immersion of a SNAP reactor in water or wet earth. The test was conducted with extensive radiological and meteorological support, surveillance and controls; small amounts of radioactive material 
were released. SNAPTRAN-2, conducted in 1966, provided data on the dynamic response, fuel behavior, and inherent shutdown mechanisms of the reactors in the open air. The experiment did not involve intentional exposure of people to radiation.

INEL: Diffusion tests with the National Oceanic and Atmospheric Administration (NOAA)NOAA conducted a meteorological research program with the $A E C$ to improve the characteriza-

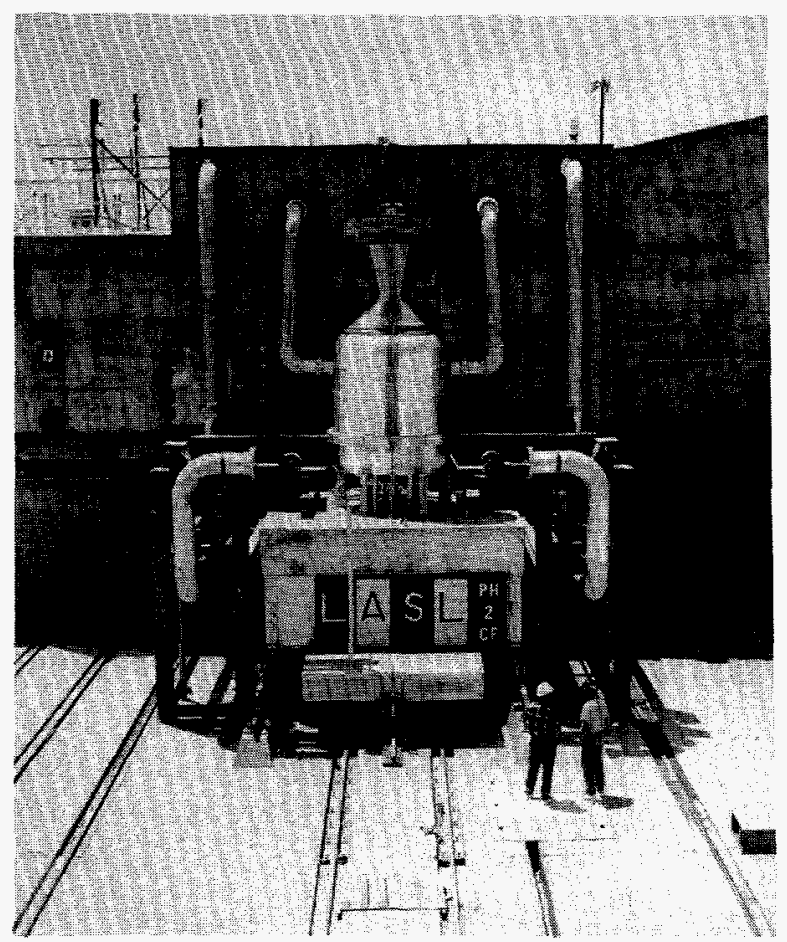

Figure 52. A nuclear reactor sitting on a test cell pad prior to preliminary tests at the Nevada Test Site (circa 1968). This Phoebus 2 design was part of the Rover project to develop a nuclear-propelled rocket capable of interplanetary travel. (PHOTO: LOS ALAMOS SCIENTIFC LABORATORY)

tion of the transport and diffusion of pollutants in the atmosphere. These studies focused on determining the differences in urban and rural diffusion patterns. NOAA conducted four Relative Diffusion Tests (RDT) from 1967 through 1969 using small amounts of radioactive tracers.

The Long Distance Diffusion Tests (LDDT) were jointly conducted by the National Oceanic and Atmospheric Administration and the AEC Health Services Laboratory. Taking place in 1971 and 1972, these tests involved measurements of controlled releases. Known quantities of radioactive and non-radioactive tracers were released from the INEL Chemical Processing Plant under monitored meteorological conditions. Air concentrations were measured at distances up to 80 kilometers from the release point.

INEL: Other tests-The Organic Moderated Solvent Burning Experiment (OMRE) tested the feasibility of open-air incineration of contaminated solvents. Conducted in 1960, the test burned about 400 gallons of diesel oil, xylene, methylchor, and water. Small amounts of radiation were released. The Experimental Cloud Exposure Study (EXCES) was conducted from 1968 to 1970 and involved release of xenon- 133 and sodium-24 with the subsequent measurement of exposure rates at several downwind distances.

Nevada Test Site: Kiwi tests-Kiwi was the name given to the reactors designed and tested by Los Alamos for the space program known as Rover. Rover began in 1955, and reactor testing took place at the Nevada Test Site between 1959 and 1966. The Kiwi tests included plume sampling done by the Air Force to measure radioactive reactor effluent. During a Kiwi test, aircraft crews participated in tests to measure thermal neutrons. Prior to the test, some crew members swallowed gamma measuring film capsules. During the test, crews wore different types of gamma film badges and flew in planes equipped with various measuring devices. After the test, the measuring films were analyzed and some crew were given whole body counts.

The Kiwi Transient Nuclear Test simulated a worst case accident occurring during the launch of a nuclear-powered spacecraft.

The Kiwi Transient Nuclear Test (TNT), conducted in 1965, simulated a worst case accident occurring during the launch of a nuclear-powered spacecraft. The test involved a controlled nuclear excursion resulting in partial vaporization of the reactor core. This created a radioactive plume that, while low in radioactivity, was detectable far off-site. Los Alamos collected environmental data from the test point to approximately 50 miles 
downwind. The U.S. Public Health Service monitored the cloud to beyond 200 miles downwind, which extended to Los Angeles and the Pacific Ocean.

Paducah, KY, Gaseous Diffusion Plant: uranium hexafluoride tests-Four deliberate releases of uranium hexafluoride $\left(\mathrm{UF}_{6}\right)$ were made to the atmosphere at the Paducah Gaseous Diffusion Plant. Two occurred in 1955; the other two took place in 1974. The tests were conducted to study the airborne behavior of $\mathrm{UF}_{6}$. There is no record of human experimentation associated with these tests.

Oak Ridge K-25 Plant: UF outleakage testsDuring 1976, fifty-seven tests were conducted at the Oak Ridge K-25 plant, resulting in the release of uranium hexafluoride into the environment. The purpose was to evaluate the plant detectors in conjunction with a plant operation upgrade. The releases were considered small in comparison to routine production releases at the facility.

Oak Ridge environmental research areas-The Oak Ridge Health Physics Division established various environmental research areas to evaluate the behavior of radionuclides in the environment. These areas functioned in conjunction with a radioecology program begun in 1954. Laboratory and field studies used 18 different radionuclides to study the uptake, accumulation, and movement of isotopes in terrestrial and aquatic food chains; rates of translocation in plants; consumption of food and turnover of isotopes by terrestrial and aquatic insects and other invertebrates, fish and, mammals; and reentry of isotopes into the soil through fungi, bacteria, and soil animals.

Thirty-eight different environmental research areas have been identified at Oak Ridge. Various types of trees were inoculated and sprayed with cesium isotopes to simulate fallout, and the material tracked through the leaves and roots to the soil and to foliage-feeding insects. Radiocesium was also applied to grass and agricultural plants, such as soybeans, sorghum, and peanuts for transport evaluation. Rodents and arthropods were also studied in this manner.

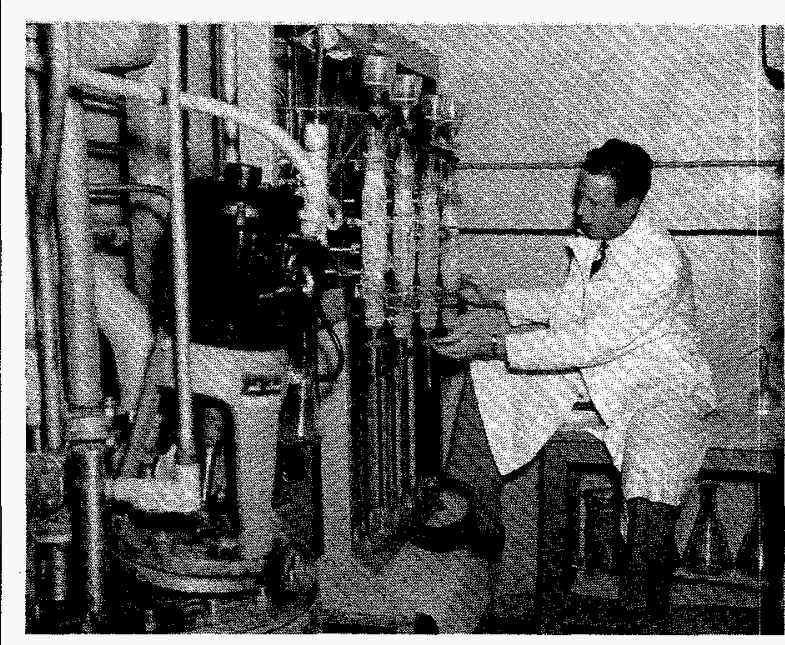

Figure 53. Separating radioactive carbon from material bombarded in the Oak Ridge nuclear reactor.

In addition, a field study of stream flow generation using natural and injected tracers was conducted with the Massachusetts Institute of Technology. The study focused on two forested watersheds, the Bickford Watershed in central Massachusetts and the West Fork of the Walker Branch Watershed in eastern Tennessee. A major objective of the study was the development of a methodology to use naturally occurring radon-222 as a tracer. 


\section{Chapter 3:}

\section{Human Radiation Experiments Associated With DOE and Its Predecessors}

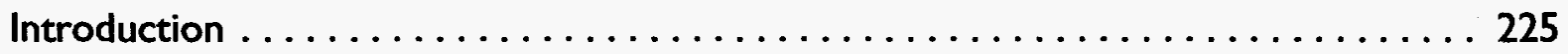

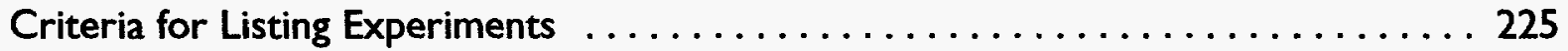

Basic Categories of Human Radiation Experiments $\ldots \ldots \ldots \ldots \ldots \ldots \ldots \ldots 226$

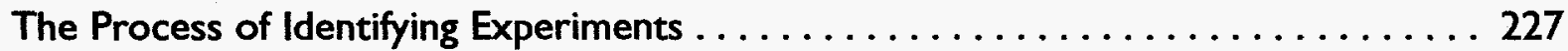

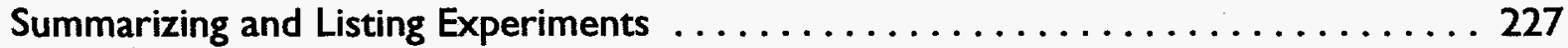

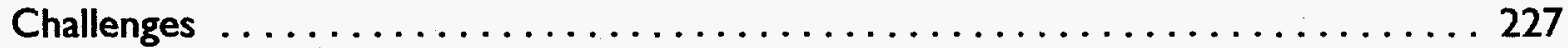

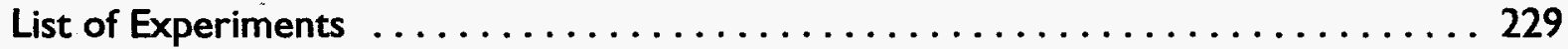

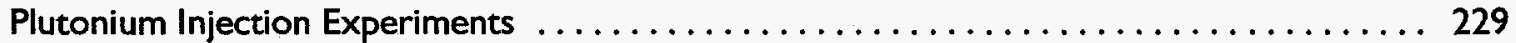

Argonne National Laboratory . . . . . . . . . . . . . . . . . . . . . . . . 229

Brookhaven National Laboratory ............................... 23 I

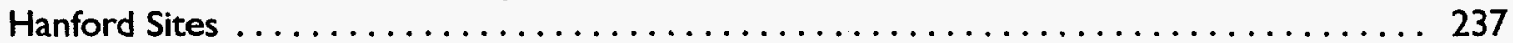

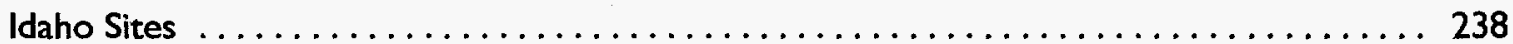

Lawrence Berkeley Laboratory . . . . . . . . . . . . . . . . . . . . . . . . . . . 239

Lawrence Livermore National Laboratory . . . . . . . . . . . . . . . . . . . . . 249

Los Alamos National Laboratory ................................... 251

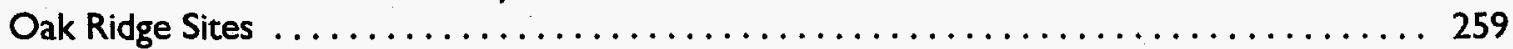

University of Chicago-Argonne Cancer Research Hospital $\ldots \ldots \ldots \ldots \ldots \ldots \ldots \ldots . \ldots \ldots$

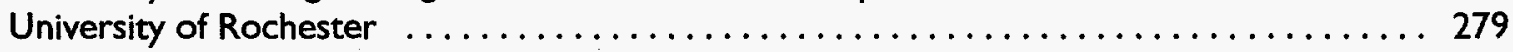

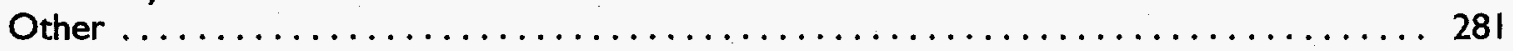


224 


\section{Chapter 3. Human Radiation Experiments Associated With DOE and Its Predecessors}

\section{lintroduction}

$\mathbf{T}$ HIS SECTION CONTAINS a listing, description, and selected references for documented human radiation experiments sponsored, supported, or performed by the Department of Energy or its predecessors. The list represents work completed by the Office of Human Radiation Experiments through December 1994, and is a work in progress. Additional experiments will be added as they are identified, documented, and confirmed. The experiment list is available on the Internet and will be updated over time. This list includes experiments released at Secretary O'Leary's June 1994 press conference, as well as additional studies identified during the six months that followed. Cross-references are provided for experiments originally released at the press conference. Some of the 48 experiments released in June 1994 are not listed here, as continuing research is necessary. In the interest of assembling the most comprehensive information possible, a list of experiments described in the 1986 congressional report entitled American Nuclear Guinea Pigs: Three Decades of Radiation Experiments on U.S. Citizens is provided as an appendix. It should be noted that information about some studies in American Nuclear Guinea Pigs has been updated and included in the current DOE list; further update efforts are ongoing.

The experiment list is available on the Internet and will be updated over time.

Basic guidance for identifying experiments is contained in Executive Order 12891 issued January 15, 1994, and in a January 19, 1994 White House memorandum entitled "Retrieval and Inventory of Records of Human Radiation Experiments." These authorities define human radiation experiments as:

Experiments on individuals involving intentional exposure to ionizing radiation. This category does not include common and routine clinical practices, such as established diagnosis and treatment methods, involving incidental exposures to ionizing radiation; and

Experiments involving intentional environmental releases of radiation that $(A)$ were designed to test human health effects of ionizing radiation; or (B) were designed to test the extent of human exposure to ionizing radiation.

\section{Criteria for Listing Experiments}

SEVERAL ADDITIONAL CRITERIA were used in compiling the list. First, clear evidence that an experiment took place was required. Given the fragmented and highly disparate nature of the documentation, this was often a challenge. Many documents refer to proposed studies, and in other cases documents provide inconclusive leads that require further research. The experiments listed below have been confirmed through research in primary and secondary sources.

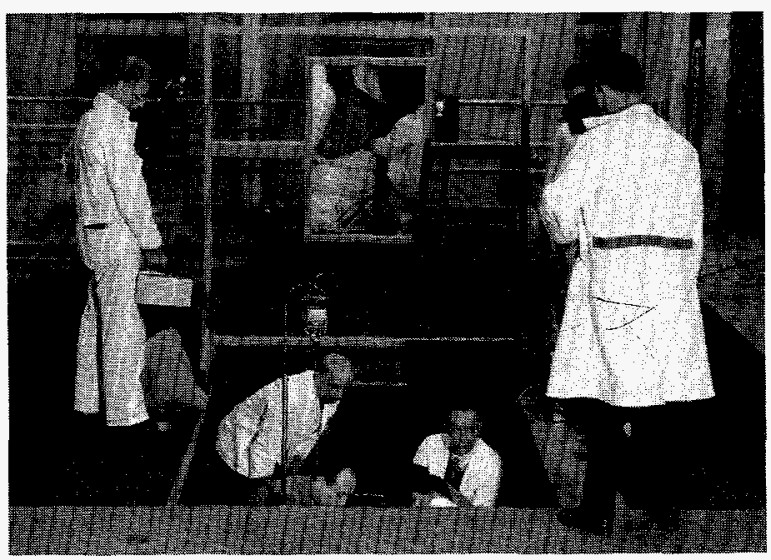

Figure 54. The first patient to receive boron neutron capture therapy at Brookhaven National Laboratory (1951). The patient is under the blanket visible in the mirror (top center).

Second, the list is limited to experiments conducted or supported by DOE, its predecessor agencies, or agency contractors. Starting in the late 1940s, hundreds of hospitals and other 
institutions did work with scores of radionuclides and radioactively labeled compounds. Much of this work involved human radiation experiments. Yet apart from distributing licenses and isotopes, DOE and its predecessors had no active role in most of these experiments. Yet the agency did operate its own cancer hospitals and other research facilities where human subjects were used in radiation research. Moreover, the agency contracted with universities and other institutions for human radiation research. Such experiments are included.

The third consideration for inclusion on the list was evidence that an experiment involved exposure of human subjects to radiation. Studies involving only human tissue samples were not included. Research involving various drugs, hormones, minerals, or other substances also were not included unless radiation was involved.

In judging if a procedure was a "common and routine clinical practice," the following guidelines were used. A human radiation experiment included any of the following situations where radiation was administered

- without realistic expectation of a benefit to the subject;

- to test or determine the potential usefulness of a treatment for other individuals;

- to healthy human subjects;

- to an individual to calibrate radiation detection instruments.

Several types of procedures did not fall within the scope of human radiation experiments.

These included procedures where:

- workers occupationally exposed to radiation were measured for potential internal or external radiation exposure by routine dosimetry, bioassay, or whole body counting methods;

- workers were assayed after accidental internal or external radiation exposures;

- individuals were treated with chelating agents for removal of accidental or occupational internal contamination;

- patients were measured for internal radioactivity as part of a legitimate medical, diagnostic or therapeutic process;
- preexisting internal deposition of radionuclides were assessed, measured, or studied in body fluids, excreta, blood, cells, or tissue samples.

\section{Basic Categeries of Human Ratation Experiments}

THERE ARE SEVERAL common and recurring categories of human radiation experiments. Tracer studies involved use of radioisotopes as tools to learn more about the properties of other biological compounds, transport pathways, and processes in the body. Tracer studies also involved using isotopes as labeling agents where a drug was labeled with a radioactive isotope, including studies conducted to gain knowledge of the effect of radiation upon humans.

Many of the experimental treatment therapies moved from the experimental stage to the routine. The point at which they ceased to be experimental may be difficult to draw with precision.

All radionuclide metabolism studies in human subjects were considered as human radiation experiments. These tests involved the study or analysis of radioisotope uptake, retention, and excretion, and were done to learn more about the specific behavior of elements in the body.

Biological effects of radiation were often determined during dose response studies.

Radionuclides were used in diagnostic studies to research human physiological conditions, or to calibrate radiation detectors or imaging systems.

Finally, experimental treatments for disease, cancer perhaps the most prominent, involved the use of various radiations and radioactive materials. Over time, many of these therapies moved from the experimental stage to the routine. The point at which they ceased to be experimental may be difficult to draw with precision. The reviewers have used their best judgment in listing those treatments that appear to have been experimental at the time they were administered. 


\section{The Process of ldentifying} Experiments

SEVERAL STEPS were involved in locating and reviewing documentary evidence related to human radiation experiments. To start, DOE Office of Human Radiation Experiments (OHRE) staff other personnel searched records with information of potential value. This selective search covered records in work spaces, offices, Federal Records Centers, the U.S. National Archives, and other archival repositories.

References usually contain fragmentary information, and considerable research in primary and secondary sources is often necessary to verify and describe a specific experiment.

When documents were found that might contain information related to human radiation experiments, the documents were copied and provenanced. Provenancing involves noting the location of the original document (site, series, box, and folder). The copies were sent to OHRE through a document processing facility, the Coordination and Information Center ( $\mathrm{ClC}$ ). The $\mathrm{ClC}$ numbered and indexed the documents, optically scanned them, and produced copies for distribution to DOE public reading rooms and other interested parties, including the Advisory Committee on Human Radiation Experiments. About 150,000 documents are included in this system. The basic document indexes are now available electronically, including through the Internet. Work is underway to provide enhanced searching capabilities and access to document images through the Internet World Wide Web.

Many varieties of documents reference experiments. These include reports from laboratories or contract correspondence between researchers and agency officials, researcher notes, medical files, experiment protocols and proposals, and research bibliographies. References usually contain fragmentary information, and considerable research in primary and secondary sources is often necessary to verify and describe a specific experiment. This research involved gathering all documents related to a particular experiment and comparing the information with published journal literature. Much of the information on human radiation experiments was published in the open scientific literature.

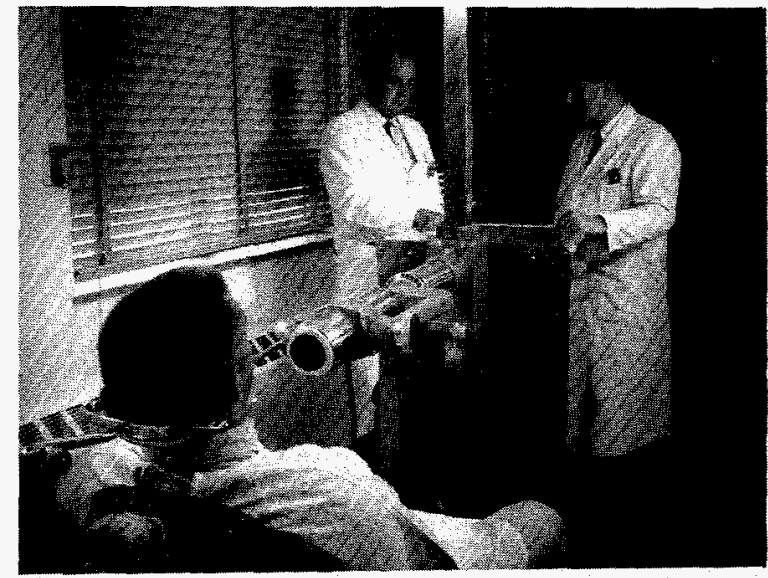

Figure 55. Diagnostic test of iodine-131 thyroid uptake at Brookhaven National Laboratory.

\section{Summarizing and Listing Experiments}

THE EXPERIMENT sUmmaries provide a concise description of what occurred based on the information that could be found. The focus has been on learning when and where the experiment took place; type and dosage of radiation used; how radiation was administered; why the experiment was conducted; numbers and types of subjects involved; experimental results; and funding sources for the experiment. Each experiment summary is followed by a reference section which lists citations to information sources. In addition, case files have been prepared with information concerning each experiment listed.

\section{Challenges}

IN PREPARING THIS LIST, and in continuing the work to find experiments, a variety of challenges have been encountered. One issue relates to subject populations. With some exceptions, little evidence exists about how researchers chose experimental subjects or what factors went into such decisions. More details are often available about the composition of subject populations, but information in this area is hardly complete. 
Another obstacle is dating: references to experiment dates are often incomplete, as some studies were conducted over several years. Occasionally, the date given in the experiment summary is an estimated date based on available information.

The use of informed consent-or any degree of consent at all-is also very difficult to document for many experiments dating before the standard requirements issued by the National Institutes of Health in 1974. Contemporary professional literature typically did not provide much detail about consent issues, nor do contracts, progress reports, or other information sources.
In addition, it can be difficult to determine the role of the Federal government in some experiments. Studies occurring at AEC research hospitals or other agency facilities have an obvious connection to the Government. Yet experiments done in private hospitals often do not. The AEC provided grants, contracts, and other forms of direct support for human radiation experiments, and examples are included in the list. Funding status, however, is not always clear. Where available, funding information is provided.

Finally, this list does not constitute a comprehensive compilation of all human radiation research in which DOE and its predecessors were involved. As indicated above, the work of collecting, assessing, researching, and confirming continues. 
Plutonium Injection Experiments

\section{P1.1. Plutonium Injection Studies}

DURING 1945 to 1947, 18 persons were injected with amounts of plutonium at the Manhattan Engineer District Hospital in Oak Ridge, TN (1 patient), at Strong Memorial Hospital in Rochester, NY (11 patients), at Billings Hospital of the University of Chicago (3 patients), and at the University Hospital of the University of California in San Francisco (3 patients). Excreta were obtained from patients and sent to Los Alamos for plutonium analysis. These data were used to establish mathematical equations describing plutonium excretion rates.

This research was funded by the Manhattan Engineer District; follow-up studies were supported by the U.S. Atomic Energy Commission and the Energy Research and Development Administration. (This experiment was referenced in the Markey report. See Chapter 2 of this Roadmap for further information about this experiment.)

\section{References}

Durbin, P.W. Plutonium in Man: A Twenty-Five

Year Review. Berkeley: Lawrence Radiation Laboratory, UCRL-20850, 1971.

Durbin, P.W. "Plutonium in Man: A New Look at the Old Data." Chapter 7.2 in Radiobiology of Plutonium, edited by B.J. Stover and W.S. Jee. Salt Lake City: The J.W. Press, 1972. pp. 469-530.

Langham, W.H., H. Bassett, P. S. Harris, and R.E. Carter. Distribution and Excretion of Plutonium Administered Intravenously to Man. Los Alamos: Los Alamos Scientific Laboratory, LA-1151. Republished in Health Physics. Vol. 38, 1980, pp. 1,031-1,060.

Stannard. J.N. Radioactivity and Health: A History. Office of Scientific and Technical Information. 1988 , p. 350-355.

\section{Argonne National Laboratory}

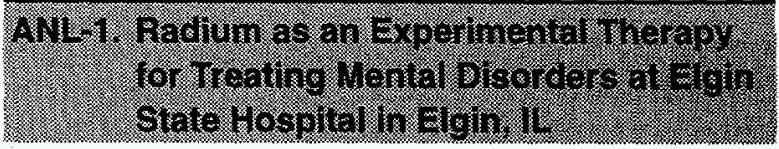

PATIENTS In A state mental hospital were injected with radium as an experimental therapy for mental disorders. The experiment appears to have been conducted at the Elgin State Hospital, in Elgin, IL, between 1931 and 1933. Documents indicate that 70 to 450 micrograms of radium-226 $\left(R a^{226}\right)$ were injected. This experiment occurred prior to the establishment of the Argonne National Laboratory and the U.S. Atomic Energy Commission. Argonne National Laboratory later collected records and attempted to locate the subjects. Researchers believed that if the patients could be located and body content measurements made in the 1950 s, a valid retention curve for radium in humans over several decades could be constructed. Argonne National Laboratory made all later measurements. This information was useful for radiation protection guidelines for alpha particle emitters.

The records contain information regarding radium content of the located subjects, medical information relating to the subjects' admission to the hospital, periodic medical examination results, and causes of death and death certificates for deceased subjects. (Previously described in \#31 on the original list of 48 experiments released by DOE in June 1994)

\section{References}

Rowland, R.E., A.F. Stehney, and H.F. Lucas. "Dose-Response Relationship for Radium-Induced Bone Sarcomas." Health Physics. Vol. 44 (Suppl. 1), 1983, pp.15-31.

Looney, W.B., R.J. Hasterlik, and A.M. Brues. "A Clinical Investigation of the Chronic Effects of Radium Salt Administered Therapeutically." American Journal of Roentgenology, Radium Therapy, and Nuclear Medicine. Vol. 73, 1955, pp. 1,006-1,037. 
Norris, Speckman, and Gustafson. "Studies of the Metabolism of Radium in Man." American Journal of Roentgenology, Radium Therapy, and Nuclear Medicine. Vol. 73, 1955, p. 785.

Miller, C.E., R.J. Hasterlik, and A.J. Finkel. The Argonne Radium Studies: Summary of Fundamental Data. Chicago: Argonne National Laboratory and Argonne Cancer Research Hospital. ANL-7531 and ACRH-106.

\section{ANL2 Etrect of Dhosphorous 82 on themoglo bin Metabolism in Polycy thema Rubra Vera}

THIS STUDY was conducted by the Health Division of the Metallurgical Laboratory at the University of Chicago at the University Hospital's Hematology Clinic (six patients) and at the University of Minnesota (one patient). Five patients were administered 15 to 40 microcuries of phosphorus$32\left(\mathrm{P}^{32}\right)$, and two patients were injected with undetermined amounts of $P^{32}$ in a study of the metabolism of hemoglobin in man. These experiments took place between October 1944 and June 1945. This study was supported by the U.S. Atomic Energy Commission. (Previously described in \#10 on the original list of 48 experiments released by DOE in June 1994)

\section{References}

Schwartz, S., E.J. Katz, L.M. Porter, L.O. Jacobson, and C.J. Watson. Studies of the Hemolytic Effect of Radiation. Chicago: Metallurgical Laboratory, $\mathrm{CH}-3760$, July 10, 1946. National Archives and Records Administration, Record Group 326, U.S. Atomic Energy Commission, MED/AEC, Metallurgical Laboratory/Argonne National Laboratory, Classified Correspondence Files, Box 23X, 2 of 4, Folder 651.

\section{ANL-3. Plitionium ingestion Study}

IN MAY 1946, six male employees of the Metallurgical Laboratory of the Manhattan Engineer District in Chicago drank a water solution containing about 0.18 nanocurie of plutonium-239 $\left(\mathrm{Pu}^{239}\right)$. The purpose of this study was to investigate the gastrointestinal absorption and fecal excretion rate of ingested plutonium. Researchers also hoped to use the results to improve the interpre- tation of previously collected data on persons occupationally exposed to plutonium. Participation in this experiment was voluntary, and the amounts of plutonium ingested were sufficiently low to be barely detectable in urine and feces with instrumentation available in 1946. At least two of the subjects were still alive in 1994. (Previously described in \#7 on the original list of 48 experiments released by DOE in June 1994)

\section{References}

Memorandum. E.R. Russell to J.J. Nickson. June 20, 1946. U.S. Department of Energy, Chicago Operations, Center for Human Radiobiology, Plutonium Documents.

\section{ANI-4. Arsenic-76 Biodistitbution and Excretion Studies}

THIS STUDY WAS CONDUCTED by the Argonne National Laboratory in 1947 in Chicago. Twelve hospital patients were injected intravenously with arsenic-76 $\left(\mathrm{As}^{76}\right)$, administered as potassium arsenite, to study the uptake, retention, distribution, and excretion of arsenic. The subjects included five males and seven females, all between the ages of 18 and 67 years and hospitalized with leukemia, Hodgkin's disease, polycythemia rubra vera, melanocarcinoma, and carcinoma of the parotid. Amounts of $\mathrm{As}^{76}$ administered were 0.5 to 15.4 millicuries. This study showed that $\mathrm{As}^{76}$ rapidly distributed throughout the body, failed to localize in tumors or lymphatic tissue, and was rapidly excreted in urine and via the intestinal tract. The study was supported by the U.S. Atomic Energy Commission. (Previously described in \#11 on the original list of 48 experiments released by DOE in June 1994)

\section{References}

Neal, W.B., L.O. Jacobson, H. Ducoff, and T. Kelly. Arsenic-76 Preliminary Studies Progress Report. Chicago: Argonne National Laboratory, Biology Division, CH-3830, June 1, 1947, pp.1-16. National Archives and Records Administration, Record Group 326, U.S. Atomic Energy Commission, MED/AEC, Metallurgical Laboratory'Argonne National Laboratory, Classified Correspondence Files, Box 23, Box 3 of 5, Folder 699. 


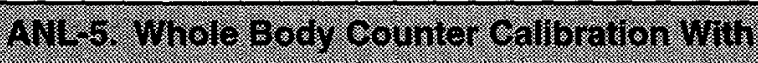
sodium 24

THIS STUDY WAS CONDUCTED at Argonne National Laboratory, in the early 1950 s, to test and calibrate a sodium iodide scintillation counter. Three individuals ingested a few microcuries of sodium$24\left(\mathrm{Na}^{24}\right)$ and the sodium iodide scintillation counter apparatus was used to determine the gamma-ray activity of $\mathrm{Na}^{24}$ in the subjects. The three subjects were Argonne employees.

\section{References}

Marinelli, L.D., C.E. Miller, P.F. Gustafson, and R.E. Rowland. "The Quantitative Determination of Gamma-Ray Emitting Elements in Living Persons." American Journal of Roentgenology, Radium Therapy, and Nuclear Medicine. Vol. 73, No. 4, April 1955, p. 661-666.

\section{AML 6. Uptake of hadieactive Thymidine by} Muman Trmor

IN 1962, A STUDY was conducted on the uptake of thymidine labeled with tritium $\left(\mathrm{H}^{3}\right)$ by human tumors. This study was a cooperative effort between the Departments of Pathology and Surgery, Northwestern University Medical Hospital, Chicago, and Argonne National Laboratory. Four male patients, between the ages of 54 and 69 years old, were included in the study. Three were in the terminal stages of various forms of cancer. All subjects were injected with 10 microcuries of $\mathrm{H}^{3}$-labeled thymidine prior to their previously scheduled surgery. Samples consisting of tumor and normal abdominal tissues were removed during surgery. Samples were also collected during the autopsies of the terminal subjects. The results showed similar growth in both cancerous and noncancerous cells, a finding that was in agreement with previous animal studies. This project was partly funded by the U.S. Atomic Energy Commission. (Previously described in \#9 on the original list of 48 experiments released by DOE in June 1994)

\section{References}

Baserga, R., G.C. Henegar, W.E. Kisieleski, and $\mathrm{H}$. Lisco. "Uptake of Tritiated Thymidine by Human Tumors In Vivo." Laboratory Investigation. Vol. 11, No. 5, May 1962, pp. 360-364.

\section{Brookhaven National Laboratory}

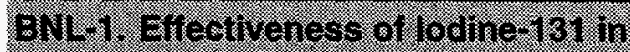
Diagnosing and Treating Craves:

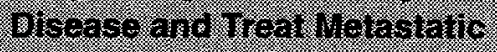
Carchoma of the Thyroid

IN 1950, BrookHAVEN National Laboratory conducted a study on the use of iodine-131 $\left({ }^{131}\right)$ to treat patients with metastatic carcinoma of the thyroid or with Graves' disease. Patients for the study were sent to Brookhaven from Memorial Hospital in New York City. In the study, a therapeutic dose of 4 to 360 millicuries of $I^{131}$ was given to patients; the exact dose depended in part on the number of metastases and on previous radiation treatment. Graves' disease patients who were unsuitable for surgical therapy were treated with $1^{131}$ in doses of 6 to 20 millicuries. The patients were monitored for hematological damage. Metabolic studies were also conducted, including study of the effects of radiation dose on renal tubular function. Twelve patients participated in the study, ranging in age from 15 to 63 years old. Of the 12 patients, 8 were females. The study was conducted in conjunction with the Memorial Hospital and was funded by the U.S. Atomic Energy Commission.

\section{References}

Memorandum. L.E. Farr to BNL Committee on Use of Radioactive Isotopes in Human Studies. January 20, 1950. Brookhaven National Laboratory Project $\mathrm{H}-1$. Brookhaven National Laboratory, Clinical Research Center, Bldg. 490, Human Medical Research Protocols.

Memorandum. BNL Committee on Use of Radioactive Isotopes in Human Studies. January 20, 1950. Brookhaven National Laboratory Project $\mathrm{H}-1$. Brookhaven National Laboratory, Clinical Research Center, Bldg. 490, Human Medical Research Protocols.

Farr, L.E. "Observations of Renal Function in Patients Receiving Internally Administered Radioactive Isotopes." from Symposium on Radiobiology, A.A.A.S., Cleveland, Ohio. December 30, 1950. 


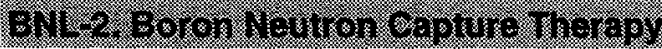

BrookHAVEN National LaBoratory conducted boron neutron capture therapy (BNCT) on 45 patients from 1951 to 1961 . The patients all were suffering from aggressive and otherwise untreatable types of brain tumors, such as glioblastoma multiforme or malignant glioma; all had received conventional radiation treatments. The purpose of BNCT was to attack more precisely the tumors with radiation, destroying the tumor cells. The patients were injected with a discrete amount of boron that was intended to deposit in the tumor. The tumors were then bombarded with a beam of neutrons that was directed to the boron and thus aimed at destroying the tumor. The results of this therapy were unsuccessful. Patients who were treated with BNCT generally lived only as long as those patients, with the same types of brain tumors, who were treated with conventional radiation therapies.

This work was funded by the U.S. Atomic Energy Commission. Currently, advances in technology allowing for greater precision in this technique have brought about the return of BNCT. As a result, Brookhaven is currently performing the therapy. (BNCT was referenced in the Markey report.)

\section{References}

Slatkin, D. N. "A History of Boron Neutron Capture Therapy of Brain Tumors." Brain. Vol. 114, 1991, pp. 1,609-1,629.

Lippincott, S.W., Y. L. Yamamoto, and L.E. Farr, "Radiation Effects of Neutron-Capture Therapy on a Malignant Vascular Neoplasm of the Cerebellum." A.M.A. Archives of Pathology. Vol. 69, January 1960, pp. 44-54.

Farr, L.E., S.W. Lippincott, W. Kahle, W.B. Haymaker, and P. Yakovlev. "The Neuropathological and Topographical Study of Whole Brains Following Neutron Capture Therapy for Glioblastoma Multiforme" in Proc. III Congress Int'l de Neuropathologie, Acta Medica Belgica., 1958, pp. 227-228.

Farr, L.E., J.S. Robertson, and E. Stickley. "Use of the Nuclear Reactor for Neutron Capture Therapy of Cancer" from International Conference on the Peaceful Uses of Atomic Energy. June 23, 1955.
Godwin, J. T., L E. Farr, W.H. Sweet, and J.S. Robertson. "Pathological Study of Eight Patients with Glioblastoma Multiforme Treated by Boron Neutron Capture Therapy Using Boron 10." Cancer, Vol. 8. No. 3, May-June 1955, pp. 601-615.

Farr, L.E., W.H. Sweet, L.B. Locksley, and J.S. Robertson. "Neutron Capture Therapy of Gliomas Using Boron." Transactions of the American Neurological Association. 1954, pp. 110-113.

Memorandum. L.E. Farr. February 26, 1951. Brookhaven National Laboratory Project $\mathrm{H}-15$. Brookhaven National Laboratory, Clinical Research Center, Bldg. 490, Human Medical Research Protocols.

Letter. D.L.Sutherland to L.E. Farr. May 23, 1953. Brookhaven National Laboratory Project $\mathrm{H}-15$. Brookhaven National Laboratory, Clinical Research Center, Bldg. 490, Human Medical Research Protocols.

\section{BNI -3. todine-1at Used to Measure Thyroid Funetion hn Young childon with Verhrotic Symurome}

SCIENTISTS AT BrooKhAVEN National Laboratory conducted a series of experiments using a group of young children suffering from nephrotic syndrome (kidney disease). In 1951, eight of these children, aged 2 to 6 years, with renal functions varying from 14 to 225 percent normal and with varying degrees of edema or lack thereof, were studied after administration of iodine-131 $\left(1^{131}\right)$.

A uniform ability by the thyroid gland to extract radioactive iodine from the blood was noted. The maximum uptake by the gland varied from 30 to 60 percent of the administered doses, which ranged from 3 to 5 microcuries. The data was evaluated against comparable data obtained in normal children. The scientists concluded that there is no impairment of the thyroid gland in its ability to take up iodine in young children with the nephrotic syndrome.

\section{References}

Farr, L.E., J.L. Gamble, C.G. Foster, and J.S. Robertson. "Thyroid Function in Young Children with Nephrotic Syndrome." Quarterly Progress Report April 1-June 30, 1951. Upton: Brook- 
haven National Laboratory, p. 119. Brookhaven National Laboratory, BNL Medical Dept., Bldg. 490, Annual Periodic Reports.

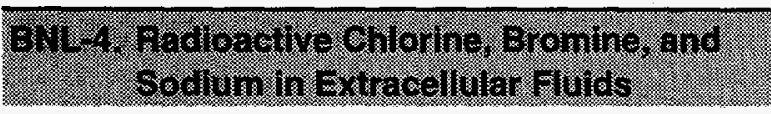

From 1952 to 1953, the total volume of extracellular fluids in 15 humans was studied at Brookhaven National Laboratory. Five chronically ill hospital patients were injected with chlorine-38 $\left(\mathrm{Cl}^{38}\right)$ and sodium-24 $\left(\mathrm{Na}^{24}\right)$. Ten other patients were injected with $\mathrm{Cl}^{38}$ and bromine- $82\left(\mathrm{Br}^{82}\right)$. Total radiation doses were planned so that the weekly dose limit of $0.3 \mathrm{rad}$ would not be exceeded. Blood samples were drawn at various times after injection and the radioactivity measured. During the course of this experiment, urine, red blood cells, pleural fluid, gastrointestinal fluid, and spinal fluid were also measured for $\mathrm{Cl}^{38}$ and $\mathrm{Br}^{82}$. The subjects were considered to be "normal" for purposes of this study. The U.S. Atomic Energy Commission funded this study. (Previously described in \#3 on the original list of 48 experiments released by DOE in June 1994)

\section{References}

Gamble, J.L., J.S. Robertson, C.A. Hannigan, C.G. Foster, and L.E. Farr. Chloride, Bromide, Sodium, and Sucrose Spaces in Humans. Upton: Brookhaven National Laboratory, BNL-1326, February 3, 1953. U.S. Department of Energy Archives, Record Group 326, U.S. Atomic Energy Commission, Division of Biology and Medicine, Box 3358, Folder 14.

\section{bIVL.5. Measurement of the Tumover Rate of So.dium in Vephrotio children Using Soditin 24}

BrookHaVen National LaBoratory conducted an experiment in 1954 on nephrotic children to study the rates of exchange of sodium in edema fluid, in ascitic fluid, and in the blood plasma. Sodium-24 $\left(\mathrm{Na}^{24}\right)$ as sodium chloride was injected intravenously and the plasma $\mathrm{Na}^{24}$ disappearance curve was analyzed and compared to the $\mathrm{Na}^{24}$ appearance curves in the two fluids. It was found that in both fluids the ratio of (a) the rate of change of the $\mathrm{Na}^{24}$ concentration to (b) the difference between the $\mathrm{Na}^{24}$ concentration in the plasma and that in the fluids increased with time during the first few hours after injection.

\section{References}

Robertson, J.S. "The Turnover Rate of Sodium in Edema Fluid and Ascites." in Federation Proceedings of the American Society for Experimental Pathology. Vol. 13, March 1954, p. 442.

Robertson, J.S. "The Turnover Rate of Sodium in Edema Fluid and Ascites." Quarterly Progress Report April 1-June 30, 1954. Upton, NY: Brookhaven National Laboratory, p. 50. Brookhaven National Laboratory, BNL Medical Dept., BIdg. 490, Annual Periodic Reports.

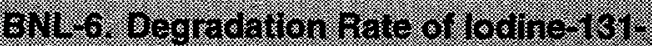 Libeled rormal abumin Using the Whole Body Camma Soerromots:}

IN 1954, Brookhaven National Laboratory conducted metabolic studies in humans with I $^{131}$. tagged serum albumin. In prior studies, plasma protein fractions labeled with $I^{131}$ had been administered to both normal subjects and to patients. A gamma spectrometer was constructed to determine transfer rates of locally injected $I^{131}$ serum albumin and other substances tagged with gamma-emitting isotopes.

In this study, the biological half-life of $\mathrm{I}^{131}$-labeled human albumin was determined by two methods. The first method was the calculation from serum and urine samples following injection of 59 microcuries of $\mathrm{I}^{131}$. The second method used the whole body gamma spectrometer to measure the amount of label present in the body at stated intervals following injection of 6.6 microcuries of $\mathrm{I}^{131}$. Plasma-specific activity and urinary excretion were followed up to 60 days following injection. The rate of disappearance of the labeled albumin was measured in two patients. The first was a 49-year-old woman with chronic cystic mastitis; the second was a 40-year-old woman who had previously had a mastectomy. This research was supported by the U.S. Atomic Energy Commission.

\section{References}

Lippincott, S.W., S.H. Cohn, J.S. Robertson, and L.E Farr, "In Vivo Measurement by the Whole 
Body Gamma Spectrometer of the Degradation Rate of $\mathrm{I}^{131}$ Labeled Normal Albumin." Laboratory Investigation. Vol. 10, Pt. 1, May-June 1961, pp. $481-491$.

Lewallen, C.G. "Studies in Humans with $\mathrm{I}^{131} \mathrm{Se}-$ rum Albumin." Quarterly Progress Report July 1-September 30, 1954. Upton, NY: Brookhaven National Laboratory, p. 51. Brookhaven National Laboratory, BNL Medical Dept., Bldg. 490, Annual Periodic Reports.

Cohn, S.H. "Whole body Counting." Quarterly Progress Report April 1-June 30, 1959. Upton, NY: Brookhaven National Laboratory, pp. 41-42. Brookhaven National Laboratory, BNL Medical Dept., Bldg. 490, Annual Periodic Reports.

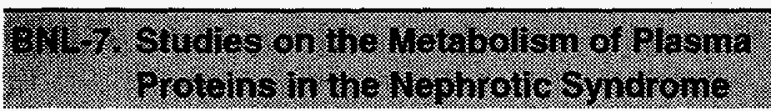

THIS STUDY WAS conducted at Brookhaven National Laboratory from 1955 to 1956 . The subjects were six children in various phases of the nephrotic syndrome, including one child who had recovered from the illness, and nine normal subjects, consisting of 8 men and one woman, all between the ages of 21 and 29 . These subjects were given intravenous tracer doses of radioiodinated human plasma albumin and radioiodinated human gammaglobulin. Three of the children were then given intravenous injections of radioiodinated human iron-binding globulin. The amount of activity administered was not to exceed 1.5 microcuries per kilogram of body weight.

The disappearance of specific radioiodinated plasma protein from circulation and its cumulative appearance in the urine were studied; the urinary excretion of nonprotein radioiodine was also investigated. This study was supported by grants from the National institutes of Health, the United States Public Health Service, the Muscular Dystrophy Association of America, the Playtex Park Research Institute, and the U.S. Atomic Energy Commission.

\section{References}

Gitlin, D., D.G. Cornwell, D. Nakasato, J.L. Oncley, W.L. Hughes, and C.A. Janeway. "Studies on the Metabolism of Plasma Proteins in the Nephrotic Syndrome: The Lipoproteins." Journal of Clinical Investigation. Vol. 37, No. 2, February 1958, pp. 172-184.

Gitlin, D., C.A. Janeway, and L.E. Farr. "Studies on the Metabolism of Plasma Proteins in the Nephrotic Syndrome: Albumin, Gamma-Glabulin and Iron-Binding Globulin." Journal of Clinical Investigation. Vol. 35, January-June 1956, pp. 44-56.

Gitlin, D., C.A. Janeway, and L.E. Farr. "Studies on the Metabolism of Plasma Proteins in the Nephrotic Syndrome. I. Albumin, Gammaglobulin, and Iron-Binding Globulin." Quarterly Progress Report January 1-March 31, 1956. Upton, NY: Brookhaven National Laboratory, p. 52. Brookhaven National Laboratory, BNL Medical Dept., Bldg. 490, Annual Periodic Reports.

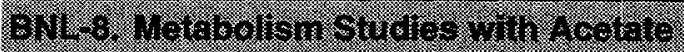
Iabelea whi Caroon th

IN 1957, AT Brookhaven National Laboratory, studies were carried out to investigate carbon acetate metabolism. Forty to 100 microcuries of 1- $\mathrm{C}^{14}$-labeled acetate or 2-C $\mathrm{C}^{14}$-labeled acetate were intravenously injected into human subjects. Diabetics, who had fasted and were denied insulin on the day of the experiment, served as subjects. Both stable and unstable diabetics were used in this experiment, including a 12-year-old girl who had fasted for 15 hours and had received no insulin on the day of the experiment.

After medical staff administered the intravenous trace dose of $\mathrm{C}^{14}$-labeled acetate, metabolism products as triglycerides, cholesterol, ketone bodies, glucose, pyruvic and alpha-ketoglutaric acids, and carbon dioxide were isolated from the blood, urine, and breath, and analyzed by $\mathrm{C}^{14}$ content. The study was supported by the U.S. Atomic Energy Commission.

\section{References}

Hennes, A.R. and W.W. Shreeve. "Hormonal Effects on $\mathrm{C}^{14}$ Acetate Metabolism in the Human." in Proceedings of the Society for Experimental Biology and Medicine. Vol. 100, February 1959, pp. 246-250.

Shreeve, W.W. and A.R. Hennes. "Effect of Adrenal Steroid Hormones on the Metabolic Fate of $\mathrm{C}^{14}$-Labeled Acetate in Human Subjects." Quar- 
terly Progress Report July 1-September 30, 1957. Upton, NY: Brookhaven National Laboratory, $p$.

36. Brookhaven National Laboratory, BNL Medical Dept., Bldg. 490, Annual Periodic Reports.

Shreeve, W.W. and A.R. Hennes. "Effect of Adrenal Steroid Hormones on the Metabolism of 2-C ${ }^{14}$ Pyruvate in Diabetic Humans." Quarterly Progress Report July 1-September 30, 1957. Upton: Brookhaven National Laboratory, pp. 36-37. Brookhaven National Laboratory, BNL Medical Dept., Bldg. 490, Annual Periodic Reports.

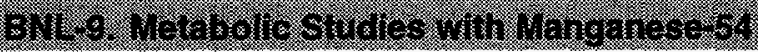

IN 1957, Brookhaven National Laboratory conducted human metabolic studies with the isotope manganese-54 $\left(\mathrm{Mn}^{54}\right)$. This study was the first to use $\mathrm{Mn}^{54}$ in human subjects. Manganese had been assumed to participate indirectly in hematopoiesis (blood formation). Two or more patients were injected with $\mathrm{Mn}^{54}$ and followed to determine body surface, blood radioactivity, and excretion rates. Blood taken from one of the patients 66 days after injection contained almost the entire radioactivity in the red cell fraction. This research was supported by the U.S. Atomic Energy Commission.

\section{References}

Borg, D.C. and G.C. Cotzias. "Incorporation of Manganese into Erythrocytes as Evidence for a Manganese Porphyrin in Man." Nature. Vol. 182, December 13, 1958, pp. 1,677-1,678.

Borg, D.C., G.C. Cotzias, and M. Birnbaum. "Basic Physiology of Manganese." Quarterly Progress Report July 1-September 30, 1957. Upton, NY: Brookhaven National Laboratory, p. 41. Brookhaven National Laboratory, BNL Medical Dept., Bldg. 490, Annual Periodic Reports.

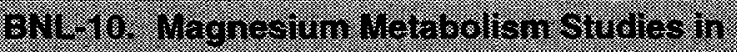 tumans with Yagnestum-28}

IN 1959, Brookhaven National Laboratory used magnesium-28 $\left(\mathrm{Mg}^{28}\right)$ to study the in vivo distribution and retention function of magnesium in man. Ten adults- 3 males and 7 females-were studied at the metabolic wards of the Brookhaven Medical Research Center Hospital. All but one of the male subjects suffered from hypertension. Nine of the subjects received intravenous injections of the isotope; two were studied after oral administration of $\mathrm{Mg}^{28}$. The intravenous dosages, which ranged from 20 to 104 microcuries, were slowly administered to prevent toxic symptoms. Excretion rates were analyzed by measuring $\mathrm{Mg}^{28}$ in urine and stool specimens. This study was conducted with support from the U.S. Atomic Energy Commission.

\section{References}

Silver, L.J. Robertson and L.K. Dahl. "Magnesium Turnover in the Human Studied with $\mathrm{Mg}^{28}$." Journal of Clinical Investigation. Vol. 39, February 1960 , pp. $420-425$.

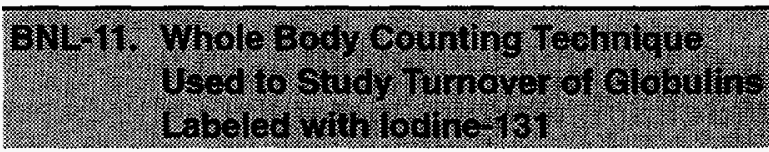

IN 1959, Brookhaven National Laboratory conducted studies on the turnover of beta- and gamma-globulins labeled with iodine-131 $\left(1^{131}\right)$. The investigators used both the conventional method of blood and urine sampling and a new technique that used the whole body gamma spectrometer. The new device allowed scientists. to measure the retention of labeled globulins over long periods of time following administration of low levels of isotopes, particularly internally deposited gamma emitters.

One patient participated in these studies; he was placed in the whole body counter 34 times. The subject was a multiple myeloma patient who was injected with the $\mathrm{I}^{131}$-labeled globulins on three occasions. The amount of iodine activity in the labeled globulins ranged from 17 to 50.16 microcuries. The study was supported by the U.S. Atomic Energy Commission.

\section{References}

Lippincott, S.W., S.H. Cohn, H. Hamel, S. Fine, and $\mathrm{S}$. Korman. "Determination of Radioactively Labeled Globulin Turnover by the Direct Whole body Counting Technique." Journal of Clinical Investigation. Vol. 40, January-June 1961, pp. 697-702. 
Lippincott, S.W., W.L. Hughes, and S. Korman. "Turnover of Labeled Globulins as Correlated with Serum Electrophoretic Pattern in Multiple Myeloma." Bulletin of the Medical Department July 1, 1959. Upton, NY: Brookhaven National Laboratory, p. 16. Brookhaven National Laboratory, BNL Medical Dept., Bldg. 490, Annual Periodic Reports.

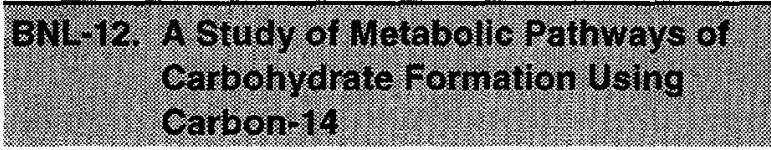

STUDIES WERE carried out at Brookhaven National Laboratory to study the metabolic pathways by which human subjects in various metabolic states form glucose. In this study, the subjects were three men with bronchogenic carcinoma, three male diabetics, and one 13-year-old female diabetic.

On the day of the experiment, the subjects were denied food and insulin and then were injected with $\mathrm{C}^{14}$-acetate. Carcinoma patients received 200 microcuries; diabetic patients received from 40 to 100 microcuries as a single 1 - to 2-minute injection. Breath samples were collected and analyzed. Some of these patients participated in multiple studies.

In a related study, two moderately diabetic subjects fasted and were given by mouth $0.5-1.0$ grams of $\mathrm{C}^{14}$-labeled ethanol per kilogram of body weight. The blood and urinary glucose were isolated. The results indicated that in one patient about 1 percent as much $\mathrm{C}^{14}$ was present in total body glucose as had been excreted as $\mathrm{CO}_{2}$ after $21 / 2$ hours. In the other patient about 2 percent as much was present. Both patients had excreted about 25 percent of the total administered $\mathrm{C}^{14}$ by the end of 24 hours. This research was partly supported by the U.S. Atomic Energy Commission.

\section{References}

Shreeve, W.W., A.R. Hennes, and R. Schwartz. "Production of $\mathrm{C}^{14} \mathrm{O}_{2}$ from 1- and 2-C $\mathrm{C}^{14}$-Acetate by Human Subjects in Various Metabolic States." Metabolism. Vol. 8, September 1959, pp. 741-756.

Shreeve, W.W. and M. Conovitz. "A Study of Metabolic Pathways of Carbohydrate Formation in Diabetes by Means of Carbon-14." Quarterly Progress Report July 1-September 30, 1955. Upton, NY: Brookhaven National Laboratory, p. 45. Brookhaven National Laboratory, BNL Medical Dept., Bldg. 490, Annual Periodic Reports.

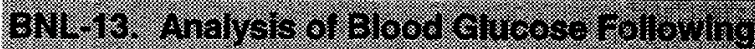 intravenous hjecton of chron.t4:}

IN 1959, at Brookhaven National Laboratory, diabetic and nondiabetic patients were given intravenous injections of 40 to 150 microcuries of lactate or pyruvate labeled with carbon-14 $\left(\mathrm{C}^{14}\right)$. The injections were followed by serial analysis of blood glucose for $\mathrm{C}^{14}$ content. Subsequently, glycogen was injected in an attempt to estimate relative glycogen labeling. Seven diabetic and three nondiabetic subjects were used in this study. The effects of insulin, tolbutamide, and glucose load were also studied in the same patients. This study was funded by the U.S. Atomic Energy Commission.

\section{References}

De Meutter, R.C. and W.W. Shreeve. "Conversion of DL-Lactate-2- $\mathrm{C}^{14}$ or $-3-\mathrm{C}^{14}$ or Pyruvate-2$\mathrm{C}^{14}$ to Blood Glucose in Humans: Effects of Diabetes, Insulin, Tolbutamide, and Glucose Load." Journal of Clinical Investigation. Vol. 42, No. 4, 1963, pp. 525-533.

Schwartz, R., R.C. DeMuetter, and W.W. Shreeve. "Dynamics of Bicarbonate Movement and Turnover in Humans." Quarterly Progress Report April 1-June 30, 1959. Upton, NY: Brookhaven National Laboratory, p. 52. Brookhaven National Laboratory, BNL Medical Dept., Bldg. 490, Annual Periodic Reports.

\section{BML-14. The Verbiblsm and Fate of Thished Thuridine tiv Nan}

THIS STUDY WAS CONDUCTED in 1959, at Brookhaven National Laboratory as part of an investigation of $\mathrm{H}^{3}$-thymidine as a label for DNA of proliferating cells in vivo and in vitro systems. In this study, $\mathrm{H}^{3}$-thymidine metabolism was studied in selected patients following intravenous injection. All patients were beyond reproductive age and were judged to have short life expectancies. In two control patients with normal hematopoiesis 
(blood-formation), $\mathrm{H}^{3}$-thymidine rapidly cleared the plasma and distributed in a volume as large as total body water within a few minutes after injection. Two of the subjects selected for this initial investigation were patients with brain tumors, judged to have short life expectancies and to be in hemopoietic equilibrium at the time of study. This research was supported by the U.S. Atomic Energy Commission.

\section{References}

Rubini J.R., E.P Cronkite, V.P. Bond, and T.M. Fliedner. "The Metabolism and Fate of Tritiated Thymidine in Man." Journal of Clinical Investigation. Vol. 39, June 1960, pp. 909-918.

Cronkite, E.P., J.R. Rubini, S.A. Killmann, V.P. Bond, J. Bateman, L. Feinendegen, E. Adamik, L. Wood, M. Canner, M. Pavelec, and C. Sipe. "Metabolism of $\mathrm{H}^{3}$-Thymidine and $\mathrm{H}^{3}$-Labeled DNA." Quarterly Progress Report April 1-June 30, 1959. Upton, NY: Brookhaven National Laboratory, pp. 55-56. Brookhaven National Laboratory, BNL Medical Dept., Bldg. 490, Annual Periodic Reports. $\square$

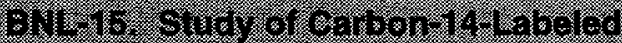

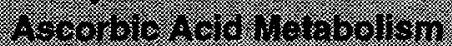

A RESEARCH COLLABORATION in the early 1970 s between Brookhaven National Laboratory and Verwoerd Hospital in Pretoria, South Africa, resulted in a study of ascorbic acid (Vitamin C) labeled with carbon-14 $\left(\mathrm{C}^{14}\right)$ metabolism in Bantu tribesmen with a disease called hemosiderosis. This disease is similar to scury and is common among the South African Bantu. It involves excessive iron accumulation and failure to utilize ascorbic acid. This research was conducted to determine the metabolism of ascorbic acid. Four adult Bantu men who had been diagnosed with hemosiderosis and scurvy participated in this study. Ascorbic acid labeled with carbon-14 was given orally, after which blood samples, urine samples, and respiratory $\mathrm{CO}_{2}$ samples were collected and analyzed. The results indicated that most of the $\mathrm{C}^{14}$ was excreted primarily by respiration and secondarily in the urine. This work was jointly supported by the U.S. Atomic Energy Commission and the South African Atomic Energy Board.

\section{References}

Hankes, L.V., C.R. Jansen, and M. Schmaeler. "Ascorbic Acid Catabolism in Bantu with Hemosiderosis (Scurvy)." Biochemical Medicine. Vol. 9, 1974, pp. 244-255.

\section{Hanford Sites}

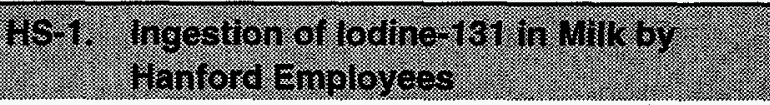

IN 1963, MILK from dairy cows fed iodine-131 $\left({ }^{131}\right)$ was consumed by eight General Electric/Hanford workers either as a single dose or as several daily doses. During the study, the amount of iodine in the cows' diet was increased from 5 milligrams per day to 2 grams per day. The resulting uptake by the human thyroid was determined in Hanford's whole body counter facility. Participants were Hanford scientists who volunteered to drink the milk and be counted over a period of about one month. This work was supported by the U.S. Atomic Energy Commission. (Previously described in \#41 on the original list of 48 experiments released by DOE in June 1994)

\section{References}

Watson, E.C., I.C. Nelson, D.H. Wood, R.O. McClellan, and L.K. Bustad. "Effect of Varying Stable lodine in Diets of Cows Fed $I^{131}$ on Uptake of $\mathrm{I}^{131}$ in Man Drinking the Milk-An Abstract." in Biology of Radioiodine: Proceedings of the Hanford Symposium on the Biology of Radioiodine, Richland, Washington, July 17-19, 1964. Oxford: Pergamon Press, 1964, p. 339.

Handwritten Monthly Report. J.K. Soldat to R.F. Foster. July 1963. Washington State University Tri-Cities Campus, PNL, DOE Richland Public Reading Room, $\mathrm{I}^{131}$, Open Shelving, PNL-9369-DEL.

\section{S.2. Intentional Relezse of lodine-131 at Hanford in 1968}

IN JULY 1963, Hanford Laboratory conducted a study that involved the release of 120 microcuries of iodine-131 $\left({ }^{131}\right)$ into the environment. These releases were designed to characterize 
the dispersion of radiation to the environment. The purpose of the experiment was to enable scientists to study how the radioactive iodine spread in turn through the air, soil, and vegetation, and how it affected animals. Two volunteer human subjects (Hanford employees), were stationed in the expected path of the radiation cloud. These subjects intentionally inhaled $\mathrm{I}^{131}$ from the release and were subsequently measured for thyroidal uptake of $\mathrm{I}^{131}$. These experiments were performed under contract with the U.S. Atomic Energy Commission.

\section{References}

Gamertsfelder, C.C. "Plans and Hazard Analysis for the First Hanford I ${ }^{131}$ Field Release Test." Richland, WA: Hanford Atomic Products Operation, Physics and Instruments Laboratory, HW-78312, July 19, 1963. Washington State University Tri-Cities Campus, PNL, DOE Richland Public Reading Room, $1^{131}$, Open Shelving.

Handwritten Monthly Report. J.K. Soldat to R.F. Foster. July 1963. Washington State University Tri-Cities Campus, PNL, DOE Richland Public Reading Room, $I^{131}$, Open Shelving, PNL-9369-DEL.

Monthly Report. Senior Engineer to R.F. Foster. August 23, 1963. Washington State University Tri-Cities Campus, PNL, DOE Richland Public Reading Room, $\left.\right|^{131}$, Open Shelving, PNL-9370.

\section{Idaho Sites}

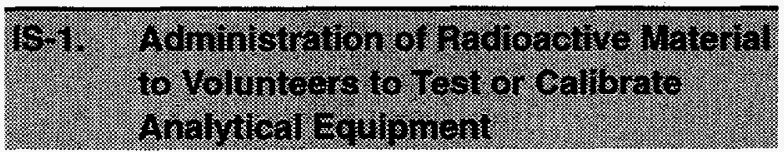

From 1965 to 1972, as many as 18 employees at the U.S. Atomic Energy Commission's Health Services Laboratory at the National Reactor Testing Station in Idaho voluntarily swallowed radioactive material, or inhaled radioactive noble gases, prior to being placed in whole body counters. The following radionuclides were used in the experiments: $\mathrm{Ar}^{41}, \mathrm{~K}^{42}, \mathrm{Mn}^{54}, \mathrm{Co}^{60}, \mathrm{Zn}^{65}, \mathrm{Kr}^{85 m}$, $\mathrm{Zr}^{95} / \mathrm{Nb}^{95}, \mathrm{Ru}^{106}, \mathrm{Ag}^{110 \mathrm{~m}}, \mathrm{I}^{131}, \mathrm{Cs}^{132}, \mathrm{Xe}^{133}, \mathrm{Cs}^{137}$, and $\mathrm{Ce}^{144}$. In most of the ingestion cases, the radioactive material was encapsulated in plastic so that no radioactive material was absorbed into body tissues. These measurements were performed to develop and evaluate new whole bodycounting equipment and to calibrate that equipment. The whole body-counting equipment was used to measure the amount of radioactivity inside the body of occupational radiation workers exposed to radioactive material. Policies for conducting these experiments limited radiation doses to volunteers to levels below the occupational radiation-protection guidelines in effect at the time. (This experiment was referenced in the Markey report.)

\section{References}

Anderson, J.I. and D.G. Olson. "A Rotational Technique for Assessing Quantity and Distribution of Body Radioactivity." Health Physics. Vol. 13, 1967, p. 719.

Olson, D.G. "A Direct Calibration Using Gamma Spectrometry for Measuring Radioactivity in $\mathrm{Hu}-$ mans." Health Physics. Vol. 14, 1968, p. 438.

Howard, L.E., J.H. Spikard, and M. Wilhelmsen. "A Human Radioactivity Counter and Medical Van." Health Physics. Vol. 21, 1971, p. 417.

Anderson, J.I. and D.G. Olson. "Computerized Helical Scanning to Determine the Location of Specific Nuclides in the Human Body." Health Physics. Vol. 23, 1972, p. 325.

Sill, C.W. Some Guidelines for Studies Involving Internal Administration of Radioactive Materials to Human Volunteers. Idaho Falls: Idaho Operations Office, U.S. Atomic Energy Commission, IDO-12058, October 1966.

\section{IS2 Conirollod Envionmental} Radiotodine Tests (C)FT)

ATOMIC EnERGy Commission scientists and other professionals at the National Reactor Testing Station in Idaho conducted the Controlled Environmental Radioiodine Tests (CERT) to study the transport of radioiodine through the air-vegetationcow-milk-human food chain from 1963 through 1968. Five of the 24 CERT tests involved exposure of volunteers to iodine-131 to study the transport of radioiodine to and through the human body. 
In the first test-CERT No. 1-seven individuals consumed milk from a cow that had grazed in a pasture where the radioiodine was deposited, and their uptake of radioiodine was determined by thyroid gland monitoring. Average thyroid dose was 0.39 rad; the maximum thyroid dose was 0.63 rad. In CERT Nos. 2, 7, and 10, three individuals, seven individuals, and one individual, respectively, were reportedly exposed during radioiodine releases over the pasture to determine their uptake by inhalation. The number of individuals involved in a similar inhalation experiment during CERT No. 11 was not listed in published reports; however, whole body-counting logs indicate that 10 individuals were apparently involved. Thyroid doses from inhalation during CERT No. 2 were no greater than $0.015 \mathrm{rad}$, and the reported thyroid activity observed during CERT No. 7 was about the same as that in CERT No. 2. Thyroid doses to volunteers were not reported for CERT Nos. 10 and 11. The volunteers were employees of the U.S. Atomic Energy Commission. (This experiment was referenced in the Markey report.)

\section{References}

Hawley, C.A., C.W. Sill, G.L. Voelz, and N.F. Islitzer. Controlled Environmental Radioiodine Tests at the National Reactor Testing Station. Idaho Falls: Idaho Operations Office, U.S. Atomic Energy Commission, IDO-12035, June 1964.

Hawley, Jr., C.A., Editor. Controlled Environmental Radioiodine Tests at the National Reactor Testing Station 1965 Progress Report. Idaho Falls: Idaho Operations Office, U.S. Atomic Energy Commission, IDO-12047, February 1966.

Bunch, D.F., Editor. Controlled Environmental Radioiodine Tests Progress Report Number Two. Idaho Falls: Idaho Operations Office, U.S. Atomic Energy Commission, IDO-12053, August 1966.

Bunch, D.F., Editor. Controlled Environmental Radioiodine Tests, Progress Report Number Three. Idaho Falls: Idaho Operations Office, U.S. Atomic Energy Commission, IDO-12063, Januany 1968.
Lawrence Berkeley Laboratory

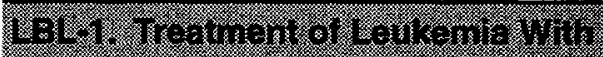

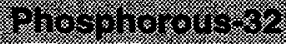

BETWEEN 1936 AND 1947, patients with various types of leukemia were treated with phosphorous-32 $\left(\mathrm{P}^{32}\right)$ with and without supplemental x-ray treatments. Approximately 129 patients with chronic myelogenous leukemia and 100 patients with chronic lymphatic leukemia were treated at the Radiation Laboratory and the Donner Laboratory of the University of California in Berkeley and San Francisco. Previously it had been demonstrated that radiophosphorous concentrated in the bone marrow and soft tissue of leukemic mice. Therefore, it was expected that $\mathrm{P}^{32}$ would provide a highly localized radiation source for human leukemic patients.

Both studies employed similar average doses of 1 to 2 microcuries per week for 4 to 8 weeks, although higher doses were also included. Approximately half of the patients studied previously received $x$-ray treatment. It was found that $P^{32}$ treatment increased the quality of life for chronic myelogenous leukemic patients, but did not prolong the duration of life. In the case of chronic lymphatic leukemia patients, the quality of life was improved and the duration was prolonged. Based on these findings, an unspecified number of chronic lymphatic patients were treated with $P^{32}$ through 1960 . This research was partly supported by grants from the International Cancer Research Foundation.

\section{References}

Lawrence, J.H., R. L. Dobson, B.V.A. Low-Beer, and B.R. Brown. "Chronic Myelogenous Leukemia." Journal of the American Medical Association. Vol. 136, 1948, pp. 672-677.

Lawrence, J.H., B.V.A. Low-Beer, and J.W.J. Carpender. "Chronic Lymphatic Leukemia." Journal of the American Medical Association. Vol. 140, 1949, pp. 585-588. 


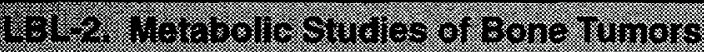 18 sing Strontium 69}

AN EXPERIMENT WAS conducted in 1942 at the Radiation Laboratory of the University of California, Berkeley, on the uptake of radiostrontium by bone tumors. Strontium- $89\left(\mathrm{Sr}^{89}\right)$ was administered to six subjects prior to biopsy or amputation. Tissue samples were collected and analyzed to determine the $\mathrm{Sr}^{89}$ uptake. The subjects consisted of five males and one female, ranging in age from 9 to 54 years. Five of the subjects received intravenous injection solutions which ranged from 326 to 1,462 microcuries. The sixth subject was given 1,183 microcuries of $\mathrm{Sr}^{89}$ orally. This experiment showed that $\mathrm{Sr}^{89}$ had therapeutic value in treating certain types of bone cancers. Some of these cancer patients also received therapeutic amounts of $\mathrm{Sr}^{39}$ (a few millicuries), but details are not available. This research was supported by the Rockefeller Foundation and the Columbia Fund for Medical Physics.

\section{References}

Treadwell, A. de G., B.V.A. Low-Beer, H. L. Friedell, and J.H. Lawrence. "Metabolic Studies on Neoplasm of Bone with the Aid of Radioactive Strontium." American Journal of the Medical Sciences. Vol. 204, 1942, pp. 521-523.

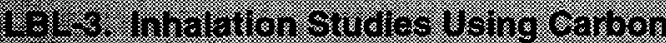

From 1944 ro 1945, the Aero Medical Laboratory, University of California, Berkeley and the Department of Physiology, Columbia University, conducted a collaborative study using carbon. The radioactive carbon was used as a tracer to determine whether in the human body carbon monoxide (CO) oxidizes to carbon dioxide $\left(\mathrm{CO}_{2}\right)$. The subjects consisted of four men, including three of the researchers conducting the experiment. The four men inhaled a relatively large dose of CO labeled with carbon, subsequent to which they breathed oxygen. During this time, their expired $\mathrm{CO}_{2}$ was collected and measured for radioactivity, the presence of which would prove that the human body could convert $\mathrm{CO}$ to $\mathrm{CO}_{2}$. Geiger counters were placed over various parts of the body (thigh, chest, spleen, and liver) to measure the uptake and elimination of $\mathrm{CO}_{2}$.
The $\mathrm{CO}$ oxidized to $\mathrm{CO}_{2}$ by the body amounted to less than 0.1 percent of the $\mathrm{CO}$ lost from the blood. This work was supported by the U.S. Atomic Energy Commission.

\section{References}

Tobias C.A., J.H. Lawrence, F.J.W. Roughton, W.S. Root, and M.I. Gregersen. "The Elimination of Carbon Monoxide from the Human Body with Reference to the Possible Conversion of $\mathrm{CO}$ to $\mathrm{CO}_{2}$." American Journal of Physiology. Vol. 145, No. 2, December 1945, pp. 253-263.

Lawrence, J.H. "Positron Emitting Isotopes: Investigative and Diagnostic Studies," pp.

247-262. Lawrence Berkeley Laboratory, John Hundale Lawrence Files, Accession 434-92-0066, File Code 19-14-6, Carton 15, Folder Positron Emitting Isotopes.

\section{BI-4. Thalawon of Zircomum: 89 on Smoke Porticlos.}

INHALATION STUDIES were conducted at Lawrence Berkeley Laboratory in about 1945 using an active smoke containing zirconium-89 $\left(\mathrm{Zr}^{\mathrm{Bg}}\right)$. One member of the research team was the only human subject. The purpose of this experiment was to determine the degree of retention by the lungs of very finely divided active smoke suspended in air. The results showed that almost 100 percent of the inhaled activity (about 0.5 microcurie of $\mathrm{Zr}^{39}$ ) was retained within the lungs and upper respiratory tract. This work was supported by the U.S. Atomic Energy Commission. (Previously described in $\# 30$ on the original list of 48 experiments released by DOE in June 1994)

\section{References}

Scott, K.G., D. Axelrod, J. Crowley, and J.G. Hamilton. "Deposition and Fate of Plutonium, Uranium and Their Fission Products Inhaled as Aerosols by Rats and Man." Archives of Pathology. Vol. 48, No. 1, July-December 1949, pp. 31-54.

\section{LBL. 5. Ridroactive Phosphorous as a

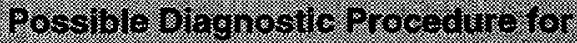 sreast Tumors}

In 1946, the University of California Hospital, San Francisco, employed phosphorous-32 $\left(\mathrm{P}^{32}\right)$ in 
tracer studies to develop a new diagnostic procedure for distinguishing between malignant and benign breast tumors. Twenty-five female patients with breast tumors were included in the study. All patients had been scheduled for surgery. Each patient was intravenously administered 300 to 500 microcuries of $P^{32}$ as sodium phosphate 24 or 48 hours prior to surgery. Surface measurements were made over the tumor and over a control area on the opposite normal breast, 2, 4, 6, and 20 hours after the injection of $P^{32}$. An increase in counts was found over the surface of malignant tumors, whereas counts were not elevated over benign tumors. The malignancy of the tumor was determined by surgery. Results indicated that $P^{32}$ might be used as a diagnostic procedure for breast cancer, except for very slow-growing or deep-seated cancers.

\section{References}

Low-Beer, B.V.A., H.G. Bell, H.J. McCorkle, R.S. Stone, H.L. Steinbach, and W.B. Hill. "Measurement of Radioactive Phosphorus in Breast Tumors in Situ: a Possible Diagnostic Procedure." Radiology. Vol. 47, pp. 429-496.

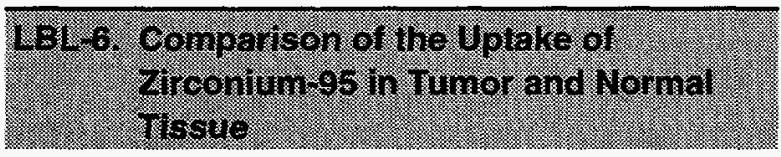

IN 1946, at the University of California San Francisco and the Crocker Radiation Laboratory, University of California, Berkeley research was carried out to study the deposition of zirconium in a human subject. The subject, a 55-year-old female patient with a reticulo endothelial tumor that had arisen in the spleen and then metastasized to the liver and left leg, was given a test dose of $\mathrm{Zr}^{95}$. This was administered intravenously as an isotonic saline solution 24 hours prior to a midthigh amputation of the left leg. This subject was administered 1.76 millicuries of $\mathrm{Zr}^{95}$ in saline by intravenous injection 24 hours prior to a scheduled midthigh amputation of the left leg. Samples of the tumor, as well as normal tissue, were later obtained from the limb for $\mathrm{Zr}^{95}$ assay. The tumor was found to have greater uptake of $\mathrm{Zr}^{95}$ than the normal tissues of the body. External counting 2 hours after the $\mathrm{Zr}^{95}$ injection showed that the liver contained about 90 percent of the total measurable deposition and the tumor had about 10 percent of the total deposition. This study was supported by the U.S. Atomic Energy Commission.

\section{References}

Low-Beer B.V.A., K.G. Scott, J.G. Hamilton, and R.S. Stone. "Comparative Deposition of $\mathrm{Zr}^{95}$ in a Reticulo Endothelial Tumor to Normal Tissues in a Human Patient." Berkeley: University of California Radiation Laboratory, UCRL-68.

\subsection{L7. Auteradiggraphe Stulles of the Distribution or Reatrolabeled Levistre aro Wustard C.s on Sik.}

THIS EXPERIMENT was conducted in 1947 at the Crocker Radiation Laboratory, University of California, Berkeley and the University of California Medical School in San Francisco. The experiment sought to determine the distribution of mustard and lewisite in skin and eye tissues. These two chemical-warfare gases were labeled with radioactive sulfur $\left(\mathrm{S}^{35}\right)$ and radioactive arsenic $\left(\mathrm{As}^{74}\right)$. Small areas of the skin of four normal subjects were exposed to the two labeled gases. Two experiments were performed with mustard gas labeled with $S^{35}$. The first involved a 10-minute exposure to 475 micrograms of labeled chemical; the second, a 15-minute exposure to 475 micrograms. In both cases, the exposed area was 0.43 square centimeter and biopsy specimens of these areas were taken 24 hours after exposure.

Two experiments were also performed on lewisite labeled with 10 micrograms of $\mathrm{As}^{74}$; the first involved a 10 -minute exposure to 475 micrograms of lewisite; the second, a15-minute exposure to $\mathbf{4 7 5}$ micrograms. The new technique of autoradiography was used to determine the skin layer at which the fixation took place on the biopsied human skin samples. Lewisite was found to fix primarily in the epidermis and mustard gas fixed in both the epidermis and dermis.

\section{References}

Axelrod, D.J. and J.G. Hamilton. "Radio-Autograph Studies of the Distribution of Lewisite and Mustard Gas in Skin and Eye Tissues." American Journal of Pathology. Vol. XXIII, 1947, pp. 389-411. 


\section{LDL-8. Injection of Anericium 24}

ON JUNE 10, 1947, at the University of California San Francisco, a 16-year-old Chinese male patient of Chinese Hospital in San Francisco, identified as Cal-A, with osteogenic sarcoma of the left femur, and general metastases, received an intramuscular injection of americium-241 $\left(\mathrm{Am}^{24}\right)$. Estimated dose is around 0.2 microcurie. The same day, two rats were given intramuscular injections of $1 \mathrm{cc}$ of solution made from the same specifications as the Cal-A injection. Readings of the human subject's urine and feces were collected through at least June 24,1947 . On June 12,1947 , the subject was amputated at the left midthigh. Samples of the amputation tissue were dissected the next day. The samples were read for isotope uptake, as the tumor was expected to have higher uptake than normal body tissues. Studies were made of the tumor; the bone tissue in which the tumor was found; the surrounding tissues, both bone and connective; and the muscles. Measurements from the amputated tissues were compared with the rat data; the patient was discharged on July 27,1947 . Rat data showed considerable uptake by the liver; human data appears to show 13 to 20 percent uptake by the bone. The patient died of preexisting ailments on June 15, 1948. The experiment appears to have been done as a comparison to previous human subjects studies involving plutonium, as data sheets for Cal-A show standards for measurements set against Cal-1 (a human injected with plutonium-238).

\section{References}

Lawrence Berkeley Laboratory, Joseph G. Hamilton Records, Archives and Records Office, Folder No: Am H (95H).

\section{LBL-9. Uptake of lodine-13i in thy rolds of Psychratrc Pattents}

From JULY 1949 To APRIL 1950 a cooperative research project was conducted by the Departments of Psychiatry, Radiology and Medicine at the University of California Medical School and the Langley Porter Clinic in San Francisco. The objective of this project was to determine whether thyroid function was normal or abnormal in persons with mental illness. Sixty-five subjects were selected from the regular in-patient group at the Langley Porter Clinic. Among the subjects were patients with schizophrenia, manic-depression, mixed psychoneurosis, and anorexia nervosa. A control group was selected of volunteers from the clinics, clerical, and medical staff. Subjects were injected with 150 microcuries of iodine-131 $\left(1^{131}\right)$; subsequently, the concentration of $\mathrm{I}^{131}$ in the thyroid was then measured six times over a 72-hour period. The test and control groups underwent medical and psychiatric evaluations, including serum-bound iodine, basal metabolism, plasma cholesterol, and electroencephalogram. No abnormal thyroid function was found in the group with mental illness and no significant differences were detected between the patients and the controls in this study. This study was partly funded by the U.S. Atomic Energy Commission. (Previously described in \#2 on the original list of 48 experiments released by DOE in June 1994)

\section{References}

Stone, R.S. Biological Effects of Radiations from External and Internal Sources, Progress Report July 1, 1949 to April 15, 1950. San Francisco: University of California Radiation Laboratory, April 1950. U.S. Department of Energy Archives, Record Group 326, U.S. Atomic Energy Commission, Box 3358, Folder 22.

Bowman, K.M., E.R. Miller, M.E. Dailey, A. Simon, B. Frankel, and G.W. Lowe. "Thyroid Function in Mental Disease Measured with Radioactive lodine, $\mathrm{I}^{131}$." The American Journal of Psychiatry. Vol. 106, No. 7, February 1950.

\section{L-10. Sodium-24 Uptake STudies on Patients with hhoumatold A whitis}

DURING THE MID 1940s to the early 1950s, the University of California Lawrence Berkeley Laboratory conducted studies on the uptake of sodiurn-24 $\left(\mathrm{Na}^{24}\right)$ to evaluate vascular abnormalities in persons with rheumatoid arthritis. Sodium-24 was administered by intravenous injection, usually in 50-microcurie amounts. Systemic transport of $\mathrm{Na}^{24}$ was followed using two gamma Geiger counters: one in the subject's hand, the other placed under a knee. The results showed an impeded blood flow in diseased areas of the body. Uptake of $\mathrm{Na}^{24}$ in 
the knee joint was also studied after three patients drank a solution of sodium chloride labeled with $\mathrm{Na}^{24}$ in water.

\section{References}

Tobias, C. "Sodium Uptake Studies." Lawrence Berkeley Laboratory, Cornelius A. Tobias Papers, Accession 434-89-100, File Code 10-08-063, Carton 25/38, Folder Sodium Uptake Studies.

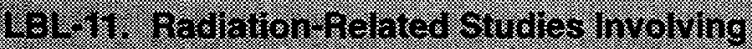 inmates at San Guentin Pitson}

From 1949 TO THE LATE 1950s, the University of California conducted studies involving radioactive isotopes using inmates at San Quentin Prison as volunteer subjects. Studies included the following: (a) 1949 to 1951: studies on red blood cell production-Blood was drawn from participants, labeled with iron-59 $\left(\mathrm{Fe}^{59}\right)$, and reinjected into the respective subjects. Four samples were drawn at specific intervals over the next 2 hours. The procedure was repeated for 4 successive days, during which $\mathrm{Fe}^{59}$-labeled red blood cells were counted.

(b) 1950: studies on blood volume-At least 13 participants had blood drawn, labeled with phosphorus-32 $\left(\mathrm{P}^{32}\right)$, and reinjected. Blood volume in the subject was subsequently measured. (c) late 1950s: Studies on red cell volume-chromium-51 $\left(\mathrm{Cr}^{51}\right)$ was used as a label to measure red blood cell volume in 201 healthy participants.

\section{References}

Letter. J.H. Lawrence to Mr. J.H. Corley. August 17, 1949. Lawrence Berkeley Laboratory. Administrative Files of Administrative Assistants to the Directors of the Biology and Medicine Division and Donner Laboratory, Accession 434-90-0209, File Code 16-5-22, Carton 2, Folder "Historical Donner Laboratory."

Donner Laboratory Clinical Books, 1946-1977. Patient Sheets from February to March 1950, noted "San Quentin" after patient's name. Lawrence Berkeley Laboratory. Donner Laboratory Clinical Logs and Notebooks, Accession 439-89-0151, File Code 8-2-2, Carton 7/10, Binder No. 2.

Wennesland, R., E. Brown, J. Hopper, Jr., J.L. Hodges, Jr., O.E. Guttentag, K.G. Scott, I.N.
Tucker, and B. Bradley. "Red Cell, Plasma, and Blood Volume in Healthy Men Measured by Radiochromium $\left(\mathrm{Cr}^{51}\right)$ Cell Tagging and Hemocrit." The Journal of Clinical Investigation. Vol. 38, No. 7, July 1959, pp. 1,065-1,077.

\section{L6L.12. Blood and Tissue studies Whih 1ron:59}

THIS RESEARCH was conducted at the Donner Laboratory, University of California at Berkeley, in the early 1950s. The purpose of this study was to investigate the rates and pathways of iron transport in the human body, including the differences in iron turnover rates between normal individuals and patients with anemia. The subjects consisted of 22 individuals with anemia and other diseases and 16 normal individuals. From 5 to 30 microcuries of radioactive iron $\left(\mathrm{Fe}^{59}\right)$ globulin was injected intravenously to label the circulating plasma iron globulin. External radiation measurements were made on the liver, spleen, and bone marrow using a gamma-fluorescence detector. In addition, plasma and whole blood samples were analyzed for $\mathrm{Fe}^{59}$ content. The results showed that iron turnover rates varied, the exact rate depending on the disease state of the patient. This research was partly funded by the U.S. Atomic Energy Commission.

\section{References}

Elmlinger P.J., R.L. Huff, C.A. Tobias, and J.H. Lawrence. "Iron Turnover Abnormalities in Patients Having Anemia: Serial Blood and In Vivo Tissue Studies with $\mathrm{Fe}^{59}$." Acta Haematologica. Vol. 9, No. 2, February 1953, pp. 73-96.

Huff, R.L., C.A. Tobias, and J.H. Lawrence. "A Test for Red Cell Production." Acta Haematologica. Vol. 7, No.3, March 1952, pp. 129-143.

\section{BL-16: Sodim-24 Uptake Studies on Padents. Wit Rheumatoid Arthrits}

DURING THE MID-1940s to the early 1950s, the University of California Lawrence Berkeley Laboratory conducted studies on the uptake of sodium-24 $\left(\mathrm{Na}^{24}\right)$ to evaluate vascular abnormalities in persons with rheumatoid arthritis.

Sodium ${ }^{24}$ was administered by intravenous injection, usually in 50-microcurie amounts. Systemic transport of $\mathrm{Na}^{24}$ was followed using two gamma 
Geiger counters: one in the subject's hand, the other placed under a knee. The results showed an impeded blood flow in diseased areas of the body. Uptake of $\mathrm{Na}^{24}$ in the knee joint was also studied after three patients drank a solution of sodium chloride labeled with $\mathrm{Na}^{24}$ in water.

\section{References}

Tobias, C. "Sodium Uptake Studies." Lawrence Berkeley Laboratory, Cornelius A. Tobias Papers, Accession 434-89-100, File Code 10-08-063, Carton 25/38, Folder Sodium Uptake Studies.

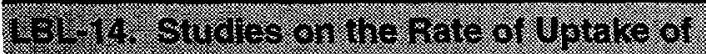 loone-131 in the Thyraid}

IN THE EARLY 1950s, studies were conducted at the University of California, San Francisco on various aspects of thyroid function in patients with normal and abnormal thyroid glands. At least 427 subjects were studied; of these, at least 25 healthy individuals served as controls, $122 \mathrm{pa}$ tients had normal thyroid function, and $110 \mathrm{pa}$ tients had various thyroid problems. After the subjects drank a solution containing approximately 100 microcuries of iodine-131 $\left(1^{131}\right)$, an external gamma counter was placed over the thyroid to measure the uptake of radioiodine. A good correlation was found between high rates of uptake and hyperthyroidism and between lower rates and absence of hyperthyroidism.

Further research was also conducted to study aspects of the physiology of the thyroid and other endocrine glands. Studies were conducted on obese patients, and on adult and child hyperthyroid patients requiring thyroid stimulating hormone. This research was funded by the U.S. Atomic Energy Commission.

\section{References}

Miller, E.R., M.E. Dailey, A.V. Holmes, G.L. Alexander, and G.E. Sheline. "Studies with Radioiodine: I. Function and Rate of $\mathrm{I}^{131}$ Uptake of Thyroid." Radiology. Vol. 57, No.1, July 1951, pp. 37-47.

Annual Report of Cancer Activities of the Radiological Laboratory. San Francisco: University of California School of Medicine, 1953, pp.1-9.
Special Collections, The Library, University of California, San Francisco.

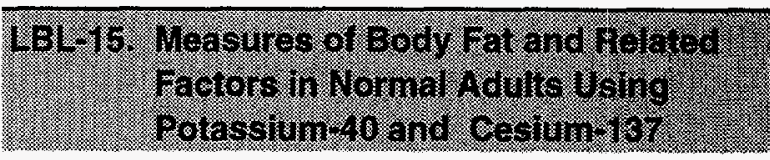

From 1950 To 1960 , the Donner Laboratory at the University of California, Berkeley, in collaboration with the California State Department of Public Health and the Bureau of Public Health Nutrition, conducted a series of experiments using potassium-40 $\left(\mathrm{K}^{40}\right)$ and cesium-137 $\left(\mathrm{Cs}^{137}\right)$ to measure body composition. The experiments were designed to accurately determine the human body's total water content, body fat, protein content, and bone mineral content. In all, 2,301 healthy volunteers were used for these experiments. These individuals each received a letter describing the purpose of the study and the parameters to be measured. The laboratory analyses included measurements of total body water after an oral tracer dose of tritium, analysis of specific gravity by the helium dilution technique, and whole body counting of $\mathrm{K}^{40}$. This study was partly supported by a grant from the National Institutes of Health.

\section{References}

Steinkamp, R.C., N.L. Cohen, W.R. Gaffey, T. McKey, G. Bron, W.E. Siri, T.W. Sargent, and E. Isaacs. "Measures of Body Fat and Related Factors in Normal Adults-II." Journal of Chronic Diseases. Vol. 18, 1965, pp. 1,279-1,289.

\section{LBL-16. Study of Ascilic Fluid Using Tition} Labeted Water and Phosphorts-82

DURING 1951 AND 1952, the University of California Donner Laboratory and the Highland-Alameda County Hospital, Oakland, CA, conducted experiments to determine the total of ascitic fluids in humans. Tritium $\left(\mathrm{H}^{3}\right)$ was used to trace the flow of water into, and out from, the peritoneal cavity. Six patients with ascites (a condition characterized by fluid buildup in the peritoneal cavity) were injected with 2 microcuries of tritium-labeled water; either intravenously or intraperitoneally. Samples of blood and ascitic fluid were taken over the following 7 to 24 hours. Blood samples were labeled 
with phosphorus-32 $\left(\mathrm{P}^{32}\right)$ and one $\mathrm{cc}$ of the labeled blood was injected into the peritoneal cavity. This study showed that the water content of ascitic fluid entered and left the peritoneal cavity at a very rapid rate. It also showed that the peritoneal surfaces of both normal and diseased subjects reabsorbed large volumes of fluid. This work was supported by the U.S. Atomic Energy Commission and the Life Insurance Medical Research Fund.

\section{References}

Prentice, T.C., W. Siri, and E.E. Jones. "Quantitative Studies of Ascitic Fluid Circulation with Tritium-Labeled Water." American Journal of Medicine. Vol. 13, No. 6, December 1952, pp. 668-673.

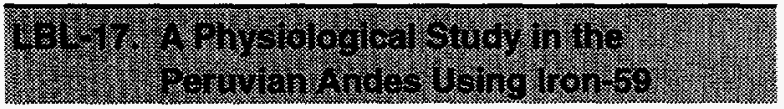

The Donner Laboratory of Medical Physics, University of California, Berkeley, used iron-59 $\left(\mathrm{Fe}^{59}\right)$ in high-altitude studies similar to the previously conducted studies using tritium $\left(\mathrm{H}^{3}\right)$. The purpose of these experiments was to investigate the physiology of reduced barometric pressure, particularly as seen in high-altitude flights, and the physiology and treatment of various hematopoietic (blood-forming) disorders, especially polycythemia rubra vera, leukemia, and aplastic anemia. In these studies, reported in 1952, healthy subjects (medical students from the University of San Marcos, Lima, Peru) and native Peruvians in the Andes mountains were studied. Four Andean natives suffering from pulmonary silicosis (as well as high-altitude polycythemia rubra vera) were also studied. A few micrograms of $\mathrm{Fe}^{59}$ were incubated for 20 minutes with 10 to 20 milliliters of the subject's plasma and then injected into the subjects. After injection, $\mathrm{Fe}^{59}$ analysis was made on plasma samples taken at hourly intervals for 4 to 5 hours. Acclimatization to high altitude was found to be related to changes in blood volume, plasma volume, and red blood-cell mass. Post-plasma-iron turnover rates and red cell renewal rates increased to roughly twice their normal values in less than 12 hours at high altitude. This study was supported by the U.S. Atomic Energy Commission, United States Navy and the United States Air Force.

\section{References}

Lawrence, J.H., R.L. Huff, W. Siri, L.R. Wasserman, and T.G. Hennessy. "A Physiological Study in the Peruvian Andes." Acta Medica Scandinavica. Vol. CXLII (II), 1952, pp.117-133.

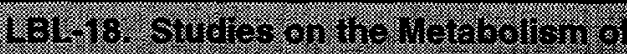

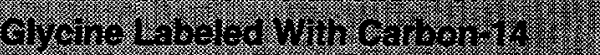

IN EXPERIMENTS REPORTED in 1952 and 1953, nine terminally ill patients received intravenous injections of 100 microcuries of glycine labeled with carbon-14 $\left(\mathrm{C}^{14}\right)$ in an attempt to determine the urinary excretion of $\mathrm{C}^{14}$, the elimination of $\mathrm{C}^{14}$ in the breath, the tissue distribution levels of $\mathrm{C}^{14}$, and the life span of red blood cells in leukemia and polycythemia rubra vera. For four patients, autopsies were carried out within 12 hours after death. Of these patients, the first was autopsied 57 days after administration of the isotope, the second after 105 days, the third after 152 days, and the fourth after 526 days. The study was conducted by the Section on Experimental Medicine, Donner Laboratory of Medical Physics and the Radiation Laboratory, University of California, Berkeley. It was supported by the U.S. Atomic Energy Commission.

\section{References}

Berlin, N.I., B.M. Tolbert, and C. Lotz. "Studies in Glycine-2-C ${ }^{14}$ Metabolism in Man. II. Tissue Distribution." Journal of Clinical Investigation. Vol. 31, 1952, pp. 335-337.

Berlin, N.I., B.M. Tolbert, and H.C. Lee. "The Metabolism of Glycine-2- $C^{14}$ in Man. III. The Urinary Excretion of $\mathrm{C}^{14}$ and Cumulative Radiation Dosimetry." Journal of Clinical Investigation. Vol. 32,1953 , pp. 1-4.

\section{B.}

THE OBJECTIVE of this experiment was to test the uptake of astatine-211 $\left(\mathrm{At}^{211}\right)$ and to evaluate its potential benefits in the treatment of thyroid diseases. Eight human subjects were injected with 50 microcuries of the 7-hour half-life alpha emitter $\left.\mathrm{At}^{211}\right)$. These experiments were conducted at the University of California Hospital during early 
1954. (Previously described in \#37 on the original list of 48 experiments released by DOE in June 1994)

\section{References}

Hamilton, J.G., P.W. Durbin, and M.W. Parrott. "Accumulation of Astatine by Thyroid Gland in Man." in Proceedings of the Society for Experimental Biology and Medicine. Vol. 86, 1954, pp. 366-369.

Hamilton, J. G., P.W. Durbin, and M.W. Parrott. "Comparison of Acute and Chronic Changes Produced in Rats by $\mathrm{I}^{131}$ and $\mathrm{At}^{211}$ at Lethal Levels. Preliminary Data on the Uptake of $\mathrm{At}^{211}$ in Patients with Thyroid Disease." Chapter 24 in Proceedings of the 2nd Radioisotope Conference in Oxford, England, July 1954. London: Butterworth Scientific Publications, pp. 219-231.

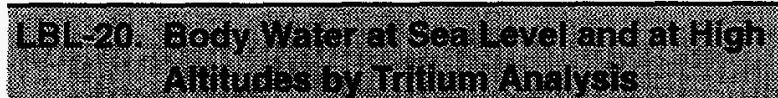

IN 1954, SCIENTISTS from the Donner Laboratory, University of California, Berkeley, and the Instituto de Biologia Andina, Lima, Peru, used tritium $\left(H^{3}\right)$ to determine changes in weight and total body water for subjects living in Lima at high altitudes and at sea level. Two groups of subjects were studied. The first group consisted of 15 young male medical students; the second group consisted of 13 normal male Peruvian Indian mine workers. The tritium was administered both orally and intravenously. The mean values of body water for the two groups was normal for their age range and occupations. This research was supported by the Public Health Service, the U.S. Atomic Energy Commission, and the U.S. Air Force.

\section{References}

Siri, W.E., C. Reynafarje, N.I. Berlin, and J.H. Lawrence. "Body Water at Sea Level and at Altitude." The Journal of Applied Physiology. Vol. 7, No. 3, November 1954, pp. 333-334.

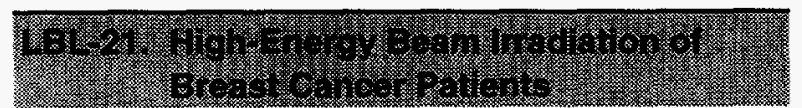

ABout 1955, the University of California Radiation Laboratory conducted studies on high-energy proton beam irradiation of the human pituitary gland, using breast cancer patients as subjects. The purpose of the studies was to determine whether irradiation of the pituitary gland would cause regression of tumor growth. Twenty-six patients with metastatic breast carcinoma and ranging in age from 27 to 70 participated in the study. Patients came from all parts of the United States, traveling to the Donner Laboratory in Berkeley for treatment. Cumulative doses ranged from 9,000 to 32,000 rads. During the course of the study, patients were irradiated in small doses three times per week. As the study progressed and the effects were observed, individual and cumulative dose levels were increased, and the time required for the entire course or irradiation was decreased. The first patient received 14,000 rads over a 63-day period. Later patients received as much as 30,000 rads in six sessions within 2 weeks. Pituitary function was assessed by measuring thyroid uptake of radioiodine (iodine-131) and by measuring 24-hour pituitary hormone excretion in the urine. The studies demonstrated decreased pituitary function and both gross and microscopic damage to the pituitary gland. A few of the patients studied showed clinical evidence of improvement. At about the same time; four additional cancer patients were similarly irradiated in a separate study, but results were not reported with those of the breast cancer patients. This work was supported by the U.S. Atomic Energy Commission.

\section{References}

Tobias, C.A., J.H. Lawrence, J.L. Born, R.K. McCombs, J.E. Roberts, H.O. Anger, B.V.A. Low-Beer, and C.B. Huggins. "Pituitary Irradiation with High-Energy Proton Beams: A Preliminary Report." Cancer Research. Vol. 18, No. 2, February, 1958, pp. 121-134.

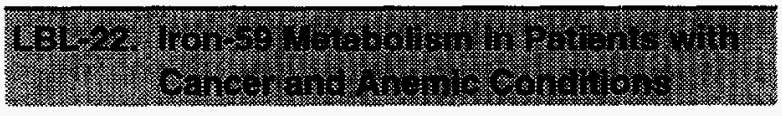

STUdies Were CONDUCTEd in 1959 at the University of California Lawrence Radiation Laboratory, on the metabolism of iron in humans using iron-59 $\left(\mathrm{Fe}^{59}\right)$ as a tracer. The aim of these studies was to determine the effects of age, gender, and health status on iron metabolism in humans. Approximately 80 cancer patients and subjects with various anemias, hemochromatosis (a disease 
characterized by an excessive absorption of iron), and iron deficiencies were used in these studies. The rate of hemoglobin synthesis, mean redblood-cell life span, and mean time required for hemoglobin formation within the total red-cell volume were measured. Gastrointestinal bleeding was correlated with iron and red cell movement in seven human subjects. This work was supported by the U.S. Atomic Energy Commission.

\section{References}

Polycove, M. and J.H. Lawrence. "Iron Metabolism." University of California Lawrence Radiation Laboratory Project Description. June 30, 1959. Lawrence Berkeley Laboratory, Cornelius A. Tobias Papers, Accession 434-92-0154, File Code 19-14-43, Carton 21, Folder Program Book.

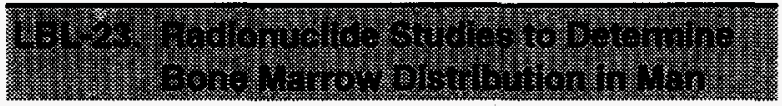

IN THE EARLY 1960s, at the Donner Laboratory and the Lawrence Radiation Laboratory, University of California, Berkeley, iron-52 $\left(\mathrm{Fe}^{52}\right)$, iron-59 $\left(\mathrm{Fe}^{59}\right)$ and technetium-99m ( $\mathrm{Tc}^{99 \mathrm{~m}}$-sulfur colloids were administered to study marrow distribution.

The marrow, liver, and spleen were then imaged, using conventional scanners or scintillation cameras. Administered activities ranged from 3 to 100 microcuries. Samples of bone marrow, plasma, red cells, and liver were analyzed to determine tissue activity over time. Subjects included hospital patients and normal volunteers, including children. This work was supported in part by the U.S. Atomic Energy Commission and in part by a grant from the National Cancer Institute of the National Institutes of Health.

\section{References}

Van Dyke D.C., H.O. Anger, and Y. Yano. "Progress in Determining Bone Marrow Distribution In Vivo." Progress in Atomic Medicine. Vol. 2, 1968, pp. 65-84.

Lawrence, J.H. "Positron Emitting Isotopes: Investigative and Diagnostic Studies." pp. 247-262. Lawrence Berkeley Laboratory, John Hundale Lawrence Files, Accession 434-92-0066, File Code 19-14-6, Carton 15, Folder Positron Emitting Isotopes.

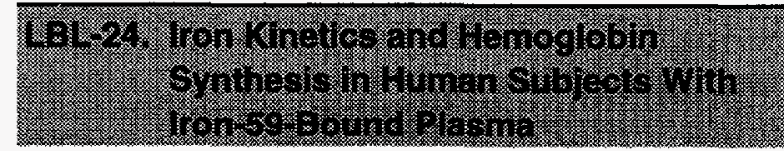

THIS STUDY WAS conducted in about 1959 at the University of California, Berkeley, in collaboration with the Veterans Administration in Boston. Its purpose was to develop a suitable mathematical model of hemoglobin synthesis, using sequential measurements of iron-59 present in human blood plasma, red cells, and peripheral blood. Data were obtained from 13 normal, healthy subjects ( 1 female and 12 male volunteers) between the ages of 24 and 72 years, plus 6 male hospital patients with endogenous hemochromatosis. Five to 20 milliliters of plasma labeled with 10 to $\mathbf{4 0}$ microcuries of iron-59 $\left(\mathrm{Fe}^{59}\right)$ were intravenously injected into the subjects. Plasma and erythrocyte radioactivity were measured with a scintillation counter. This study was supported by the U.S. Atomic Energy Commission with partial support by a grant from the U.S. Public Heath Service.

\section{References}

Pollycove, M. and R. Mortimer. "The Quantitative Determination of Iron Kinetics and Hemoglobin Synthesis in Human Subjects." Journal of Clinical Investigation. Vol. 40, 1961, pp. 753-772.

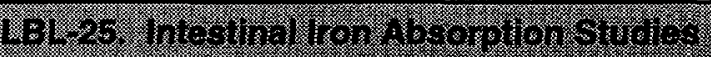

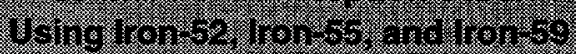

IN A STUDY CONDUCTED at the Donner Laboratory, University of California, Berkeley, in 1966, radioactive isotopes of iron were used to measure the rate of iron absorption into the plasma and its distribution in the gastrointestinal tract. Forty microcuries of iron-52 ( $\left.\mathrm{Fe}^{52}\right)$ were administered orally to 6 fasting normal subjects. Just prior to the oral dose, iron turnover studies were performed using 2 microcuries of transferrin-bound iron-59 $\left(\mathrm{Fe}^{59}\right)$ injected intravenously; the subjects were then whole body counted. For the iron turnover studies, 20 to 30 microcuries of iron-55 $\left(\mathrm{Fe}^{55}\right)$ were injected into the same subjects. Photoscans of the abdomen using the Anger Positron Camera were taken throughout the study. The maximum rate of intestinal iron absorption was found to occur at the time when iron was in the upper gastrointestinal tract. This work was supported by the U.S. Atomic Energy Commission. 


\section{References}

Fawwaz, R.A., H.S. Winchell, M. Pollycove, T. Sargent, H. Anger, and J.H. Lawrence. "Intestinal Iron Absorption Studies Using Iron-52 and Anger Positron Camera." Journal of Nuclear Medicine. Vol. 7, 1966, pp. 569-576.

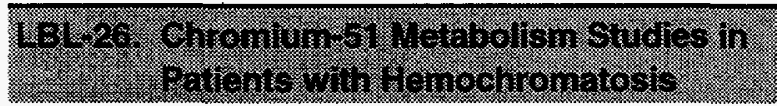

Chromium-51 metabolism studies were conducted at Lawrence Berkeley Laboratory on healthy males and on patients with hemochromatosis (a disease characterized by an excessive absorption of iron). Five normal, male subjects were injected with 100 microcuries of chromium51 to study the retention of chromium. This study was conducted to show that homochromatic diabetes was due to the exclusion of chromium from either the carrying agent or from the liver because of saturation by iron. Eleven subjects were injected with $\mathrm{Cr}^{51}$-chloride. Among the subjects were patients with varying degrees of hemochromatosis, including two hemochromatotic patients depleted of excess iron and two subjects with excess iron but no clinical disease. All of the subjects were followed by whole body counting for up to 6 months. The results showed that the exclusion of chromium occurs principally at binding sites in the liver. Two further studies were conducted on chromium metabolism using plasma analysis, $\mathrm{Cr}^{51}$ clearance rates, the whole body scanner, and the whole body counter. This work was supported by the U.S. Department of Energy.

\section{References}

Sargent T. W. and H.H. Stauffer. "Human in Vivo Kinetics of Radionuclide Trace Metals in Health and Disease." University of California Lawrence Berkeley Laboratory Project Description. May 1, 1976. Lawrence Berkeley Laboratory, Cornelius A. Tobias Papers, Accession 434-32-0154, File Code 19-14-43, Carton 22, UCLBL Project Descriptions.

Lim, T.H., T. Sargent, and N. Kusubov. "Kinetics of Trace Element Chromium (III) in the Human Body." American Journal of Physiology. Vol. 244, Vol. 4, April 1983, pp. R445-454.

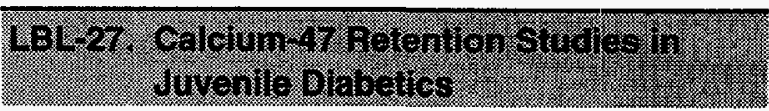

THIS RESEARCH was conducted at the Berkeley Donner Laboratory in the early 1970 s. This study was undertaken to determine the rate of uptake and retention of calcium- $47\left(\mathrm{Ca}^{47}\right)$ in juvenile diabetics. The subjects consisted of eight healthy individuals, of various ages and diets, and three juvenile diabetics (ages 23, 26, and 26). One to 25 microcuries of $\mathrm{Ca}^{47}$ was intravenously administered and the retention of $\mathrm{Ca}^{47}$ in the whole body was determined by direct in vivo counting. The whole body retention of $\mathrm{Ca}^{47}$ did not significantly vary over the wide range of calcium and protein intakes and ages of healthy subjects. Diabetics excreted $\mathrm{Ca}^{47}$ at a higher rate. This work showed a decreased rate of bone mineralization in diabetics. The research was supported by the Energy Research and Development Administration.

\section{References}

Sargent, T., J. Linfoot, and H. Stauffer. "Decreased Whole Body Retention of $\mathrm{Ca}^{47}$ in Juvenile Diabetics." IRCS Medical Science Journal. Vol. 4, 1976, p. 58.

Sargent T. W. and H.H. Stauffer. "Human In Vivo Kinetics of Radionuclide Trace Metals in Health and Disease." University of California Lawrence Berkeley Laboratory Project Description. May 1, 1976. Lawrence Berkeley Laboratory, Cornelius A. Tobias Papers, Accession 434-32-0154, File Code 19-14-43, Carton 22, UCLBL Project Descriptions.

\section{LBL 28. Whole Body Colming Studies on the Retertion or Copper-67 and Phosphorus-32}

IN THE MID- TO LATE 1970S, the University of California Lawrence Berkeley Laboratory conducted studies on the retention of radionuclides in humans. The subjects were healthy individuals and patients with a variety of diseases. The protocol for each study with each isotope was separately approved by the Lawrence Berkeley Laboratory for Safeguards in Human Research on Human Subjects. Four subjects were injected with 100 microcuries of copper-67 $\left(\mathrm{Cu}^{67}\right)$ to determine 
copper uptake, retention, and excretion rates. Of the four subjects, three were healthy, and one had a copper storage disease. The results showed that there is no abnormality of total body turnover of copper when iron stores are normal. Results also showed that for the subject with the copper storage disease, the excretion of copper was slower than for normal subjects by a factor of two. Six subjects with diseases related to bone marrow production were injected with 1 to 5 millicuries of phosphorus-32 $\left(\mathrm{P}^{32}\right)$ to determine excretion rates. This was one of the first published studies on human whole body phosphorus turnover. This work was supported by the U.S. Department of Energy.

\section{References}

Sargent, T. W. and H. Stauffer. "Whole body Counting of Retention of $\mathrm{Cu}^{67}, \mathrm{P}^{32}$, and $\mathrm{Cr}^{51}$ in Man." International Journal of Nuclear Medicine and Biology. Vol. 6, 1979, pp. 17-21.

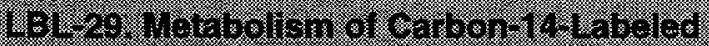 Methioninoth Sch12ojohionies}

THIS RESEARCH was conducted in the 1980 s at the Lawrence Berkeley Laboratory. Researchers suspected that a defect in the methyl-carbon metabolic pathway was a causative factor in schizophrenia. Methionine labeled with carbon-11 $\left(C^{11}\right)$ or carbon-14 $\left(\mathrm{C}^{14}\right)$ was administered to both schizophrenics and healthy subjects to test this hypothesis. The oxidation of methionine was studied in seven unmedicated schizophrenics, and the effect of high and low methionine in the diet was studied in control subjects. This research was supported by the National Institute of Mental Health, the Donner Laboratory, and the U.S. Department of Energy.

\section{References}

Sargent, T.W., N. Kusubov, S. Taylor, and T.F. Budinger. "Tracer Kinetic Evidence for Abnormal Methyl Metabolism in Schizophrenia." Biological Psychiatry. Vol. 32, 1992, pp. 1,078-1,090.

Sargent, T.W. "Metabolism in Brain Disorders." U.S. Department of Energy Field Task Proposal/Agreement. April 1, 1982. Lawrence Berkeley Laboratory, Cornelius A. Tobias Papers, Accession 434-92-0154, File Code 19-14-43,
Carton 21, Field Task Proposals/Agreements.

Sargent, T.W. "Metabolism of [14-C-Methy]-Methionine in Schizophrenia and Affective Disorders." Public Health Service, Food and Drug Administration, Radioactive Drug Research Committee, Report on Research Use of Radioactive Drug Study Summary. Lawrence Berkeley Laboratory, Director's Office-LBL Associated Lab, Director for Administration R\&D Files1981-1987, Accession 434-91-0176, File Code 13-11-14, Carton 58/58, Folder Biology/Medicine General FY87.

\section{Lawrence Livermore National Laboratory}

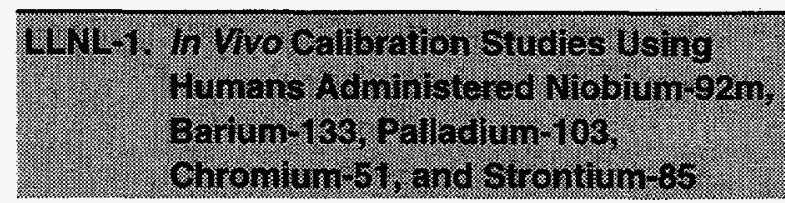

THE PURPose of these studies was to develop accurate calibration factors for in vivo counting equipment and to cross-calibrate the various U.S. and European counting centers. Volunteer subjects were administered radionuclides at Harwell Laboratory (United Kingdom) and were whole-body or chest counted at the Lawrence Livermore National Laboratory and at other Department of Energy contractor in vivo counting facilities in the U.S. Two subjects were from Lawrence Livermore Laboratory and the remainder were from the United Kingdom.

This study was broad in scope and spanned several years. From 1972 to 1976 , three males inhaled palladium-103 $\left(\mathrm{Pd}^{103}\right)$ and chromium-51 $\left(\mathrm{Cr}^{51}\right)$-labeled microspheres and were counted in 14 labs in Europe and the United States. From 1979 to 1982,18 men inhaled niobium-92m $\left(\mathrm{Nb}^{22 m}\right)$-labeled microspheres and were counted at several labs. During the 1988 to 1990 period, five males, who earlier had inhaled $\mathrm{Nb}^{92 \mathrm{~m}}$, were again exposed to $\mathrm{Nb}^{92 m}$ and counted. Two of these five were injected with barium-133 $\left(\mathrm{Ba}^{133}\right)$ in March 1986 and one of those two was injected with strontium-85 $\left(\mathrm{Sr}^{85}\right)$ in June 1987. This research was jointly sponsored by the Atomic Energy Research Establishment-Harwell, British 
Nuclear Fuels, the General Electricity Generating Board, the International Atomic Energy Agency, and the U.S. Department of Energy (and its predecessor agencies). (Previously described in \#15 on the original list of 48 experiments released by DOE in June 1994)

\section{References}

Newton, D., F.A. Fry, B.T. Taylor, M.C. Eagle, and R.C. Sharma. "Intralaboratory Comparison of Techniques for Measuring Lung Burdens of LowEnergy Photon Emitters." Health Physics. Vol. 35, 1978, pp. $751-777$.

Dean, P.N., R.V. Griffith, and A.L. Anderson. "Design Criteria for Phantoms for Calibration of External Detectors for the In Vivo Assay of Plutonium." Lawrence Livermore National Laboratory, UCRL-76411, November 17, 1975.

Anderson, A.L. and G.W. Campbell. "LLL Plutonium Lung Counter Calibration and Discussion of Errors." Lawrence Livermore National Laboratory, UCRL-78409, June 20, 1976.

Swinth, K.L., W.J. Bair, P.N. Dean, J. Rundo, and F.K. Tomlinson. "Status and Trends in the External Counting of Inhaled Heavy Elements Deposited In Vivo." Lawrence Livermore Laboratory, UCRL-83949, February 5, 1980.

Newton, D., G.W. Campbell, A.L. Anderson, and J.C. Fisher. "Consistent X-Ray Counting Efficiencies for Plutonium In Lungs, Derived by Independent Methods." Lawrence Livermore Laboratory, UCRL-83946, February 4, 1980.

Campbell, G.W., A.L. Anderson, F.A. Fry, D. Newton, and D. Ramsden. "Calibration of Phoswich Detectors for Assessment of Plutonium in Lungs: The Methods of Four Laboratories Compared." Lawrence Livermore Laboratory, UCRL-84516, June 11, 1980.

\section{L.ML2. Orone Etrects on overall and Feshonal Ling Furtion}

IN THIS COLLABORATION between the University of Washington (Seattle) and Lawrence Livermore Laboratory, the impact of ozone on the human lungs was studied. The objective was to determine the functional changes that might result from low ozone levels in smog. Four healthy, male subjects were exposed to low (0.4 part per million by volume) concentrations of nonradioactive ozone for a total of $\mathbf{2 . 5}$ hours. Periods of exercise and rest were alternated during the exposure. The subjects then inhaled small quantities of radioisotope-labeled gas mixtures for the purpose of measuring lung function. The first mixture was a blend of 20 percent oxygen and 80 percent nitrogen-15 $\left(N^{15}\right)$, intended to simulate air. The second mix contained 10 percent carbon-15 labeled carbon dioxide $\left(\mathrm{CO}_{2}\right)$ in air. The results of this test suggested that ozone caused nonuniform mechanical alteration to the central and peripheral airways. The study was performed under a contract from the U.S. Department of Energy from 1977 to 1978 and in part by a grant from the National Heart, Lung, and Blood Institute. (Previously described in \#16 on the original list of 48 experiments released by DOE in June 1994)

\section{References}

Meyer, P. "Ozone, Respiration, and the Bends." Energy and Technology Review. Lawrence Livermore Laboratory, UCRL-52000-81-12, December 1981, pp. 22-31.

"Ozone Effects on Overall and Regional Lung Function." Lawrence Livermore National Laboratory Review Board File. LLNL B361 Rm. B940A, Institutional Review Board, IRB Protocol File, ACtive Grants-Collaborative, University of Washington Ozone Effect on Overall Lung Function.

\section{LLVL 3. Decompression Sickness Studies} Using Whog gh 15 ahd irgen-4

A JOINT STUDY between the Lawrence Livermore National Laboratory and the U.S. Navy was conducted during the 1980 s, using the radionuclide tracers nitrogen-15 $\left(\mathrm{N}^{15}\right)$ and argon-41 $\left(\mathrm{Ar}^{41}\right)$ to determine information on the uptake and clearance of nitrogen gas in man. This research was necessary to better understand decompression sickness of deep-sea divers, which results from excessive accumulation of inert gases (stable nitrogen and argon) in divers' bodies. Mlore than one experiment was conducted during this collaboration. In one such study, nine normal, healthy human subjects (Navy volunteers) breathed air containing $\mathrm{N}^{15}$ and $\mathrm{Ar}^{41}$ and then 
waited 40 to 100 minutes to allow redistribution and washout. The subjects were then monitored using positron detectors to determine the concentration of $\mathrm{N}^{15}$ and $\mathrm{Ar}^{44}$ remaining in the body.

The amounts of $\mathrm{N}^{15}$ and $\mathrm{Ar} \mathrm{r}^{41}$ inhaled depended on the amounts breathed by the subjects. This air contained about one microcurie of $\mathrm{N}^{13}$ and 24 microcuries of $A r^{41}$ per liter of breathing air. Absorbed doses to subjects were estimated to be about 0.3 to 0.5 rad to the lungs and trachea and $0.01 \mathrm{rad}$ to the whole body. The experiment met the requirements of both the Navy's and Lawrence Livermore National Laboratory's human subjects committees. This work was supported by the Naval Medical Research Institute and the U.S. Department of Energy. (Previously described in \#14 on the original list of 48 experiments released by DOE in June 1994)

\section{References}

Weathersby, P.K., P. Meyer, E.T. Flynn, L.D. Homer, and S. Survanshi. "Nitrogen Gas Exchange in the Human Knee." Journal of Applied Physiology. Vol. 61, No. 4, October 1986, pp. 1,534-1,545.

Meyer, P. "Ozone, Respiration, and the Bends." Energy and Technology Review. Lawrence Livermore National Laboratory, UCRL-5200081-12, December 1981, pp. 22-31.

\section{Los Alamos National Laboratory}

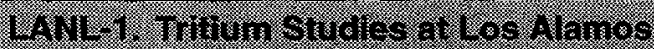
Setenmit Laboratory

DURING THE EARLY 1950s, Los Alamos Scientific Laboratory conducted studies on the human uptake, distribution, and retention of tritium $\left(\mathrm{H}^{3}\right)$. Three volunteers, all researchers working on the studies, participated as subjects. In one experiment, a male subject immersed his arm up to the elbow in water containing 0.1 millicurie of tritium per cubic centimeter.

This study showed that the rate of absorption through the skin was too slow to pose a hazard. The whole body would have to be immersed for more than an hour before an Atomic Energy Commission recommended exposure limit was reached. In another study, all three subjects inhaled for 4 to 5 minutes oxygen that was saturated with tritium water vapor (HTO) which, when condensed, contained 1.16 millicuries of tritium per milliliter of water. Results showed that 98-99 percent of the tritium was retained in the body after inhalation.

In a third study, the three subjects drank water containing tritium. Water volumes ranged from 100 to 1,000 milliliters ( $1 / 3$ to 4 cups) and level of activity ranged from 1,640 to 2,920 microcuries. These studies showed that water absorption from the gastrointestinal tract begins 2 to 9 minutes after ingestion, that absorption is a linear function of time, and that it is proportional to the amount ingested. All these studies were used to establish standards for occupational exposure to tritium. This work was supported by the U.S. Atomic Energy Commission. (These experiments were referenced in the Markey report.)

\section{References}

Pinson, E.A. The Body Absorption, Distribution, and Excretion of Tritium in Man and Animals. Los Alamos: Los Alamos Scientific Laboratory, LA-1218, March 12, 1951.

Pinson, E.A. Lung Absorption of HTO by Man Upon Inspiration of HTO Water Vapor. Los Alamos: Los Alamos Scientific Laboratory, LA-1465, June 1952.

Pinson, E.A. The Body Absorption of Ingested Tritium Water and the Water Dilution Volume of Man. Los Alamos: Los Alamos Scientific Laboratory, LA-1464, June 1952.

\section{NL2. Metabollsm of EOTA in Himmis}

IN 1953, Los Alamos Scientific Laboratory conducted studies on the human metabolism of the chelating agent ethylenediaminetetraacetic acid (EDTA) labeled with carbon-14. The purpose was to gain information that would help establish optimum dosage schedules and identify any harmful effects. Twelve young adult healthy males served as subjects in four groups of three. One group was administered an intravenous injection of 2.2 milligrams of $C^{14}$-labeled EDTA; the second received an intramuscular injection of 2.2 milligrams; the third received oral administration 
of 1.5 milligrams; and the fourth group had 2.0 milligrams applied directly to the skin.

The studies showed that EDTA passed through the body essentially unchanged and that it was excreted primarily by the kidney within 1 hour of intravenous injection and 1.5 hours of intramuscular injection. It is poorly absorbed in the gastrointestinal tract and practically not at all through the skin. This work was supported by the U.S. Atomic Energy Commission. (Previously described in \#43 on the original list of 48 experiments released by DOE in June 1994)

\section{References}

Foreman, H. and T.T. Trujillo. "The Metabolism of $\mathrm{C}^{14}$ Labeled Ethylenediaminetetraacetic Acid in Human Beings." The Journal of Laboratory and Clinical Medicine. Vol. 43, No. 4, pp. 566-571.

Biomedical Research Group of the Health Division Annual Report 1953. Los Alamos: Los Alamos Scientific Laboratory, LA-1690, 1954, p. 17.

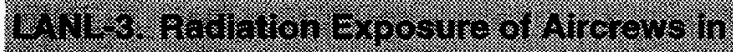

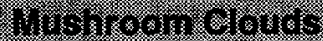

DURING THE 1955 TEAPOT and the 1956 REDWING nuclear test series, manned aircraft were used to map the amount and distribution of radiation within some of the resulting "mushroom". clouds. The objective was to obtain information needed to plan for the safe and effective use of military aircraft in cloud areas during combat operations. Studies conducted in 1953 using animal subjects in drone aircraft had previously shown that it would be safe for manned aircraft to enter atomic clouds relatively soon after detonation. Penetrations of clouds from low-yield detonations were made during Operation TEAPOT in 1955. Penetrations of the larger clouds from high-yield detonations were made during Operation REDWING in 1956. Special radiation exposure limits, in excess of the usual 3.9 roentgens Maximum Permissible Exposure, were established for some of these flight crews. During Operation TEAPOT, 4 Air Force officers were permitted to receive up to 15 roentgens, and 2 received this amount. Exposures of up to 25 roentgens were permitted during Operation REDWING, but no one received this amount; the largest doses were approximately 15 roentgens for three officers. Pre- and postmission urine tests and evaluation in whole body counters showed no significant internal deposition of fission products or unfissioned plutonium. This work was supported by the U.S. Atomic Energy Commission. (This experiment was referenced in the Markey report.)

\section{References}

Headquarters Field Command. "The Radiation Hazards to Personnel Within an Atomic Cloud." Report of Operation UPSHOT/KNOTHOLE Project 4.1. Armed Forces Special Weapons Center, WT-743. Reynolds Electrical and Engineering Co., Inc., Coordination and Information Center, Las Vegas, NV, CIC Document 40992.

Headquarters Field Command. "Manned Penetration of Atomic Clouds." Report of Operation TEAPOT Project 2.8a. Armed Forces Special Weapons Center, WT-1156. Reynolds Electrical and Engineering Co., Inc., Coordination and Information Center, Las Vegas, NV, CIC Document 12800.

Headquarters Field Command. "Early Cloud Penetrations." Report of Operation REDWING Project 2.66a. Armed Forces Special Weapons Center, WT-1320. Reynolds Electrical and Engineering Co., Inc., Coordination and Information Center, Las Vegas, NV, CIC Document 68117.

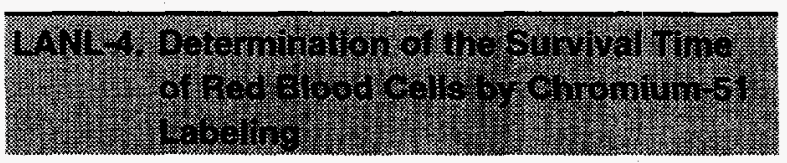

A study was conducted by Los Alamos Scientific Laboratory in 1957 to determine the survival times of circulating blood red blood cells in healthy and diseased subjects. Thirty-two human subjects ( 7 healthy and 25 diseased) received intravenous injection of samples of their own red blood cells that had been previously removed and tagged with radioactive chromium-51 $\left(\mathrm{Cr}^{51}\right)$. After tagging, the red cells were injected back into the donor, and the person's uptake and radioactivity was assessed in the whole body counter. Half-times for the survival of the chromium tag were determined. Large volumes of urine were also obtained from the subjects and counted to determine excretion rates. This research was supported by the U.S. 
Atomic Energy Commission. (Previously described in \#26 on the original list of 48 experiments released by DOE in June 1994)

\section{References}

"Application of Low Level In Vivo Counting Techniques to Clinical Investigations." H-Division Progress Report August 20, 1948-September 20, 1948. Los Alamos: Los Alamos Scientific Laboratory, LAMS-790, pp. 62-63.

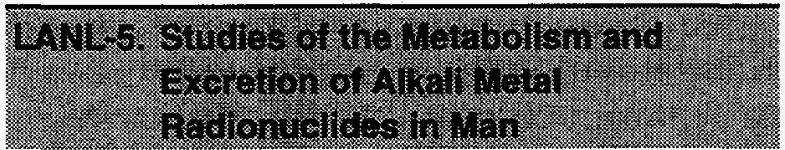

Scientists at THE Los Alamos Scientific Laboratory conducted a series of studies to determine the metabolism and excretion of alkali metals as part of a general research program on the retention, excretion, and absorption of radioactive materials in humans. Sodium-22 $\left(\mathrm{Na}^{22}\right)$, potassium$42\left(\mathrm{~K}^{42}\right)$, and rubidium-86 $\left(\mathrm{Rb}^{86}\right)$ were administered orally to 10 normal, healthy human subjects and were measured at various times thereafter in the whole body counter. The distribution and retention patterns for these materials were determined periodically for about 1 year. Radiocesium $\left(\mathrm{Cs}^{134}\right.$ or $\left.\mathrm{Cs}^{137}\right)$ was also administered and measured. These experiments are described separately, under LANL-8. This research was supported by the U.S. Atomic Energy Commission. (Previously described in \#25 on the original list of 48 experiments released by DOE in June 1994)

\section{References}

Richmond, C.R. "Retention and Excretion of Radionuclides of the Alkali Metals by Five Mammalian Species." Biological and Medical Research Group of the Health Division Semiannual Report July-December 1959. Los Alamos: Los Alamos Scientific Laboratory, LAMS-2445, 1960, pp. 71-79.

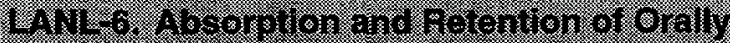 Aominstered 1ronso in Homans}

THIS STUDY WAS conducted at Los Alamos Scientific Laboratory in 1959. The purpose was to determine the absorption and retention of orally administered iron in human subjects. A second objective was to evaluate the whole body counting technique and equipment as a tool for measuring iron in the human body. Sixty-six subjects were part of this test, including 1 pregnant woman and 4 children. Also included in the study were hospital patients with anemia, leukemia, or polycythemia rubra vera. Each of the study participants ingested 0.5 to 0.7 microcuries of iron$59\left(\mathrm{Fe}^{59}\right)$ as ferrous citrate in water. The oral dose was followed with an additional 100 to 200 milliliters of tap water to wash the radioactive iron into the stomach. Body counting and fecal bioassay were used to determine the relationship between ingested, retained, and excreted iron.

The study showed that there was an apparent lack of iron absorption with leukemia and infection. Also, the pregnant woman absorbed larger amounts of iron. This study was supported by the U.S. Atomic Energy Commission. (Previously described in \#40 on the original list of 48 experiments released by DOE in June 1994)

\section{References}

Lushbaugh, C.C. and D.B. Hale. "Clinical Applications of Whole body Counting: A Clinical Comparison of the Absorbability of Ferrous versus Ferric Salts in Normal Human Subjects." Biological and Medical Research Group of the Health Division Semiannual Report July 1961-June 1962. Los Alamos: Los Alamos Scientific Laboratory, LAMS-2780, 1962, pp. 337-347.

\section{WWL7. Determing Thy oro Uphake and Retentor or lowine-181}

IN 1959, Los Alamos Scientific Laboratory conducted studies on whole body measurement techniques for determining thyroid uptake of iodine-131 $\left(1^{131}\right)$. Seventeen normal or ill male or female patients ranging in age from 10 to 57 drank water solutions containing 1.5 to 3.0 microcuries of $I^{131}$ as sodium iodide. Study results showed that the whole body liquid scintillometer measurement technique provided a simple, valid means of determining thyroid uptake and thyroid function. Additional studies were conducted to address how thyroid retention changed with disease, chemotherapy, and metabolic status. These studies involved some of the same patients, but added others, as well. Six children 
whose thyroid gland had been removed were added, as was one patient with an overactive thyroid and one patient with an underactive thyroid. A total of 63 patients were administered $\mathrm{I}^{131}$ either orally or intravenously in these studies. These studies showed that retention rates in diseased patients varied widely from normal rates, and that retention was influenced by therapy. This work was supported by the U.S. Atomic Energy Commission. (Previously described in \#45 on the original list of 48 experiments released by DOE in June 1994)

\section{References}

Lushbaugh, C.C. and P.S. New. "Clinical Applications of Whole Body Scintillometry. II. A Comparison of Three Different Methods of Determining Retention and Thyroid Uptake of Orally Administered I'131."Biological and Medical Research Group of the Health Division Semiannual Report JulyDecember 1959. Los Alamos: Los Alamos Scientific Laboratory, LAMS-2445, 1960, pp. 348-360.

Lushbaugh, C.C. and D.B. Hale. "Clinical Applications of Whole Body Scintillometry. III. Whole Body Retention of lodine-131 as a Method of Studying Thyroid Function in Man." Biological and Medical Research Group of the Health Division Semiannual Report July-December 1959. Los Alamos: Los Alamos Scientific Laboratory, LAMS-2445, 1960, pp. 361-373.

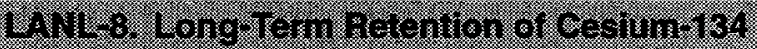 and Cestun- ith in tivmans}

FROM ABOUT 1959 to 1961, a study was conducted at the Los Alamos Scientific Laboratory on the long-term retention of radioactive cesium (Cs) in humans. Four healthy, adult males participated in this study. Two of subjects received oral doses of 1 and 1.4 microcuries cesium- $134\left(\mathrm{Cs}^{134}\right)$ as cesium chloride. The subjects were followed by whole body counting for 106 and 910 days, respectively, to determine the gastrointestinal tract uptake and whole body retention with time. The other two subjects were administered about $1 \mathrm{mi}-$ crocurie $\mathrm{Cs}^{137}$ and were followed by whole body counting for about 500 days. This study showed that the biological retention half-time of cesium in man was about 137 days. This work was supported by the U.S. Atomic Energy Commission.
(Previously described in \#25 on the original list of 48 experiments released by DOE in June 1994)

\section{References}

Richmond, C.R., J.E. Furchner, and W.H. Langham. "Long-Term Retention of Radiocesium by Man." Biological and Medical Research Group of the Health Division Semiannual Report JanuaryJune 1961. Los Alamos: Los Alamos Scientific Laboratory, LAMS-2627, 1961, pp. 163-174.

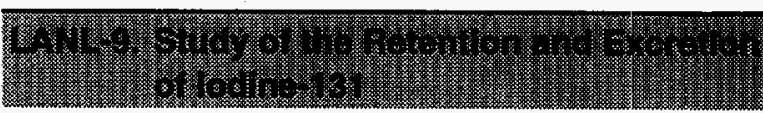

A STUdY WAS PERFORMED at Los Alamos Scientific Laboratory, in 1960 to determine the retention and excretion of iodine-131 $\left({ }^{131}\right)$ by humans. Twenty-six normal subjects, including 17 women, 3 men, 3 girls, and 3 boys, participated in the study. Each volunteer was given an oral dose of liquid containing 8 microcuries of $\mathrm{I}^{131}$ as sodium iodide, then measured for whole body and thyroid content of $I^{131}$ within 1 hour. Additional measurements were made on the 1st, 2nd, 3rd, 4th, 7th, 10 th, 14th, and 18th days following the ingestion. This study showed that approximately 20 percent of the ingested $\mathrm{I}^{131}$ was taken up by the thyroid gland, and the remaining 80 percent excreted by the kidneys by the urine. This research was supported by the U.S. Atomic Energy Commission. (Previously described in \#19 on the original list of 48 experiments released by DOE in June 1994)

\section{References}

Lushbaugh, C.C., D.B. Hale, and C.R. Richmond. "Clinical Applications of Whole Body Scintillometry. IV. Turnover Rate of Protein-Bound lodide." Biological and Medical Research Group of the Health Division Semiannual Report January-June 1960. Los Alamos: Los Alamos Scientific Laboratory, LAMS-2455, 1960, pp. 364-371.

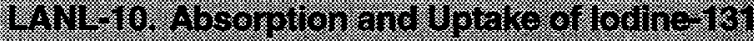 and Soollin. 24 in tumans}

IN 1960, an experiment was conducted at Los Alamos Scientific Laboratory to determine the feasibility of in vivo measurements to study the absorption of radionuclides through the skin. Liquid solutions of sodium-24 (10 microcuries) or 
iodine-131 (51 microcuries) were placed on the palms of two volunteer subjects employed at the Laboratory. After allowing absorption to occur, the palms were washed and the subjects were counted periodically in the Laboratory's whole body counter to determine the fraction of either radionuclide absorbed through the skin.

In a second experiment, two volunteer subjects ingested 0.18 microcurie of sodium-24 or 0.14 microcurie of iodine-131 to determine the gastrointestinal absorption and whole body retention of these radionuclides. This research was supported by the U.S. Atomic Energy Commission. (Previously described in \#27 on the original list of 48 experiments released by DOE in June 1994)

\section{References}

Van Dilla, M.A. , C.R. Richmond, and J.E. Furchner. "Cutaneous Absorption by Human Subjects, I. Studies with Sodium-24 and lodine-131." Biologi$\mathrm{cal}$ and Medical Research Group of the Health Division Semiannual Report July-December 1960. Los Alamos: Los Alamos Scientific Laboratory, LAMS-2526, 1961, pp. 164-171.

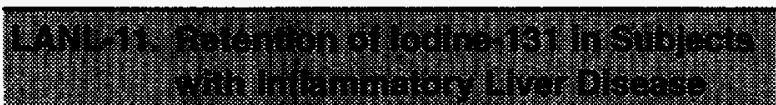

IN 1960, a study was conducted at Los Alamos Scientific National Laboratory on the use of an iodine-131 $\left(1^{131}\right)$ labeled blood dye in determining liver function. Ten normal subjects and 18 persons suffering from inflammatory hepatic disease were injected intravenously with 10 microcuries of $1^{131}$-labeled dye (rose bengal). The timeactivity curves for retention of $I^{131}$ in the blood stream were determined using the Los Alamos arm counter. The blood retention curve was found to be a better measurement of function than the clearance rate of labeled rose bengal dye measured in urine. This research was supported by the U.S. Atomic Energy Commission. (Previously described in \#28 on the original list of 48 experiments released by DOE in June 1994)

\section{References}

Lushbaugh, C.C., D.B. Hale, and R. McGill. "The Use of the Arm Counter to Determine the Degree of Hepatic Function." Biological and Medical Research Group of the Health Division, Semiannual
Report January-June 1960. Los Alamos: Los Alamos Scientific Laboratory, LAMS-2455, 1960, pp. 223-229.

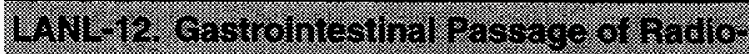 active Far Hille:}

IN THE EARLY 1960s, Los Alamos Scientific Laboratory conducted studies on the passage of radioactive particles through the human gastrointestinal tract. These studies addressed the issue of reentry and destruction of nuclear-powered space vehicles in the earth's atmosphere and subsequent ingestion of the resulting particles by humans. Fifty-seven normal adults participated. Each swallowed a gelatin capsule containing three radioactive particles. One particle was ceramic, about 150 microns in diameter, and contained approximately 150 picocuries of manganese-54. The other two particles were uranium carbide, about 175 microns in diameter, and contained an unspecified amount of uranium-235 activity.

The total calculated radiation dose delivered to the gastrointestinal tract in these studies was extremely low-well below the maximum permissible level for these materials. Several subjects repeated the ingestion at different times of day to estimate the time-of-day variable in the study. One subject repeated the test 10 different times to estimate the variation within a single individual. The studies showed that particle density did not influence passage rate and that there was no significant holdup of particles in the digestive system. Transit times corresponded more to bowel movement habits than a normal distribution. This work was supported by the U.S. Atomic Energy Commission. (This experiment was referenced in the Markey report.)

\section{References}

\section{Some Biological Aspects of Radioactive} Microspheres. Los Alamos: Biological and Medical Research Group, Los Alamos Scientific Laboratory, LA-3365-MS, June 20, 1965.

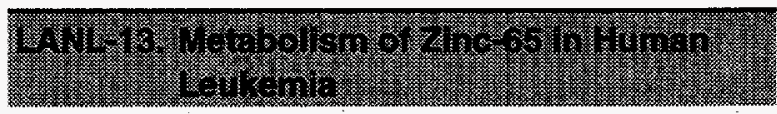

A sTUdY WAS CONDUCTED at Los Alamos Scientific Laboratory in early 1961 on the metabolism of 
zinc-65 $\left(\mathrm{Zn}^{65}\right)$ in human cancer patients with chronic leukemia. This experiment involved a single subject. A 15-year-old female patient with chronic myelogenous leukemia was given a oral dose of 0.6 microcurie of zinc-65 $\left(\mathrm{Zn}^{65}\right)$ as zinc chloride 137 days prior to death. One hour after administration and on days $1,2,3,20$, and 137 the subject was studied for whole body $\mathrm{Zn}^{65}$ in the Los Alamos human counter. Also, tissue samples were removed at autopsy and sampled for zinc-65. The findings of this study showed that $\mathrm{Zn}^{65}$ was retained less tenaciously by the leukemia patient than by normal subjects. This work was supported by the U.S. Atomic Energy Commission. (Previously described in \#32 on the original list of 48 experiments released by DOE in June 1994)

\section{References}

Richmond, C.R., J.E. Furchner, and G.A. Trafton. "Long Term Retention of Zinc-65 by Man." Biological and Medical Research Group of the Health Division Semiannual Report July-December 1960. Los Alamos: Los Alamos Scientific Laboratory, LAMS-2526, 1961, pp. 15-20.

Furchner, J.E., C.R. Richmond, and G.A. Trafton. "Metabolism of Zinc-65 in Humans." Biological and Medical Research Group of the Health Division Annual Report July 1961-July 1962. Los Alamos: Los Alamos Scientific Laboratory, LAMS-2780, 1962, pp. 66-77.

Furchner, J.E. and C.R. Richmond. "Effect of Dietary Zinc on the Absorption of Orally Administered $\mathrm{Zn}^{65}$." Health Physics. Vol. 8, 1962, pp. 35-40.

Richmond, C.R., J.E. Furchner, G.A. Trafton, and W.H. Langham. "Comparative Metabolism of Radionuclides in Mammals-I: Uptake and Retention of Orally Administered $Z^{65}$ by Four Mammalian Species." Health Physics. Vol. 8, 1962, pp. 481-489.

Richmond, C.R., C.C. Lushbaugh, M.W. Rowe, and M.A. Van Dilla. "Metabolism of Zinc-65 in a Terminal Leukemia Case." Biological and Medical Research Group of the Health Division Semiannual Report January-June 1961. Los Alamos: Los Alamos Scientific Laboratory, LAMS-2627, 1960, pp. 263-269.

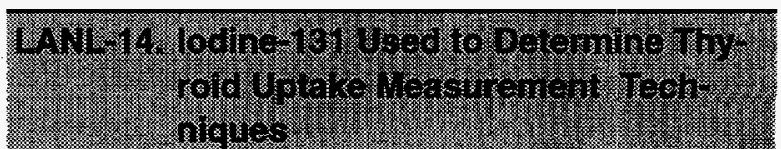

IN 1961, Los ALAmos Scientific Laboratory conducted studies intended to improve the accuracy of whole body counting techniques for determining thyroid uptakes. Previous experience had shown that body mass influenced overall absorption and affected the accuracy of thyroid uptake measurements. An unspecified number of subjects received oral administration of 8 microcuries of iodine-131. A "mock iodine" mixture of barium-133 and cesium-134 equal to 2.48 microcuries was also administered to establish a control standard. The results of these studies were used to develop standards in establishing normal human absorption values for men, women, and children of various ages. (Previously described in \#45 on the original list of 48 experiments released by DOE in June 1994)

\section{References}

Lushbaugh, C.C. "Progress in Refinement of the Whole Body Counting Technique for Determining Thyroid Uptake." Biological and Medical Research Group of the Health Division Semiannual Report January-June 1961. Los Alamos: Los Alamos Scientific Laboratory, LAMS-2627, 1961, pp. 291-297.

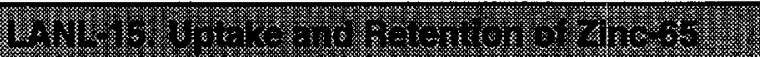

DURING 1961 AND 1962, a study was conducted at Los Alamos Scientific Laboratory, NM on the uptake and retention of radioactive materials by mammals. Three males and one female between the ages of 31 and 48 received a single oral dose of 0.6 to 1.0 microcurie as zinc chloride in water. The subjects were evaluated for whole body distribution and retention of $\mathrm{Zn}^{65}$ with time. These measurements were made in the Los Alamos whole body center. Urine and feces were also obtained and analyzed for $\mathrm{Zn}^{65}$. Measurements continued out to 416 to 664 days after administering $\mathrm{Zn}^{65}$. These data were used to determine the retention and excretion of $\mathrm{Zn}^{65}$ in men and women for comparison with other animal species. This study was supported by the U.S. 
Atomic Energy Commission. (Previously described in \#32 on the original list of 48 experiments released by DOE in June 1994)

\section{References}

Richmond, C.R., J.E. Furchner, G.A. Trafton, and W.H. Langham. "Comparative Metabolism of Radionuclides in Mammals-I: Uptake and Retention of Orally Administered $\mathrm{Zn}^{65}$ by Four Mammalian Species." Health Physics. Vol. 8, 1962, pp. 481-489.

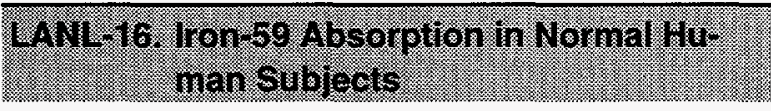

From MID-1961 to mid-1962, a study was conducted at the Los Alamos Scientific Laboratory on the absorption of iron by normal human subjects. The objective of the study was to determine whether the ferrous or ferric form was more readily absorbed. A group of volunteers composed of 20 normal men and 30 normal women was included in the study. The subjects were divided randomly into two subgroups. Each subject received 0.27 microcurie of iron orally. Some received the iron in the form of ferrous citrate labeled with iron-59 $\left(\mathrm{Fe}^{59}\right)$. The others received the iron in the form of ferric chloride labeled with $\mathrm{Fe}^{59}$. A whole body count was performed immediately after ingestion and again 7 days later. At the time of the second body count, blood samples were withdrawn and characterized. No difference was found in human uptake between the ferrous and ferric forms of iron. This study was supported by the U.S. Atomic Energy Commission. (Previously described in \#40 on the original list of 48 experiments released by DOE in June 1994)

Lushbaugh, C.C. and D.B. Hale. "Clinical Applications of Whole body Scintillometry I. Retention of Orally Administered Iron." Biological and Medical Research Group of the Health Division Semiannual Report July-December 1959. Los Alamos: Los Alamos Scientific Laboratory, LAMS-2445, 1960, pp. 337-347.

\section{LANL-17: Ctranoous Absorption of Stortlum 85}

From 1961 to 1962, Los Alamos Scientific Laboratory conducted studies on the absorption of strontium-85 $\left(\mathrm{Sr}^{85}\right)$ through human skin. Radioactive strontium chloride was applied in a gauze patch to the forearm of two subjects and held in place with adhesive tape. The amount of $\mathrm{Sr}^{85}$ administered was about 70 microcuries. After 2 days, one subject had absorbed 0.2 percent and the other had absorbed 0.6 percent. The study showed that absorption through the skin occurred, but at very low levels. This work was supported by the U.S. Atomic Energy Commission. (Previously described in \#44 on the original list of 48 experiments released by DOE in June 1994)

\section{References}

Van Dilla, M.A., C.R. Richmond, J.E. Furchner, and M.W. Rowe. "Cutaneous Absorption of Radionuclides by Human Subjects. Il. Strontium-85." Biological and Medical Research Group of the Health Division Annual Report July 1961-June 1962. Los Alamos: Los Alamos Scientific Laboratory, LAMS-2780, 1962, pp. 154-157.

\section{LANL-18. Retention of Strontium-85}

From 1961 to 1962, Los Alamos Scientific Laboratory conducted studies on the whole body retention of strontium-85 $\left(\mathrm{Sr}^{85}\right)$ in humans. Three male laboratory employees ingested 1.07 microcuries of $\mathrm{Sr}^{85}$ in 100 milliliters of tap water. The studies showed that $\mathrm{Sr}^{85}$, with its 65-day half-life, is suitable for studying short-term retention of fallout but not appropriate for long-term retention studies. This work was supported by the U.S. Atomic Energy Commission. (Previously described in \#44 on the original list of 48 experiments released by DOE in June 1994)

\section{References}

Furchner, J.E., M.A. Van Dilla, M.W. Rowe, and C.R. Richmond. "Retention of Strontium-85 by Man." Biological and Medical Research Group of the Health Division Annual Report July 1961-June 1962. Los Alamos: Los Alamos Scientific Laboratory, LAMS-2780, 1962, pp. 43-49.

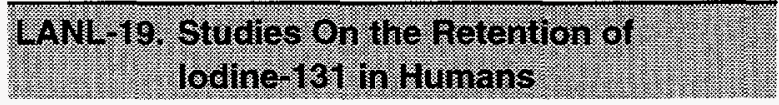

IN 1961 To 1962, the Los Alamos Scientific Laboratory conducted studies on the retention of 
radioiodinated paratoluidine polyvinylpyrrolidone, also known as PVP-13i. The purpose of the study was to determine whether PVP-| ${ }^{131}$ could be used to detect the presence of vascular leaks into the gastrointestinal or renal excretory tracts. Eight adults were injected intravenously with 0.7 microcurie of PVP- $\left.\right|^{131}$. Four of the subjects had medical conditions that included known internal bleeding. The study showed that the bleeding subjects lost the iodine more rapidly than the nonbleeding subjects-in one case, almost twice as fast-indicating that PVP-1 ${ }^{131}$ was an effective detector of internal bleeding.

In a related study, one of these subjects drank a water solution containing 0.06 microcurie of PVP- $\left.\right|^{131}$ to determine retention in the thyroid gland. The study showed little retention, indicating that PVP-1 ${ }^{131}$ is not readily absorbable. This work was supported by the U.S. Atomic Energy Commission. (Previously described in \#45 on the original list of 48 experiments released by DOE in June 1994)

\section{References}

Lushbaugh, C.C. and D.B. Hale. "Clinical Applications of Whole body Counting: Retention of Raovin lodine-131 as a Measure of Serum or Blood Loss." Biological and Medical Research Group of the Health Division Annual Report July 1961-June 1962. Los Alamos: Los Alamos Scientific Laboratory, LAMS-2780, 1962, pp. 188-193.

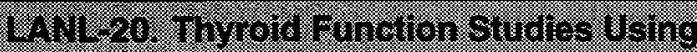 Sodium toulde-13i}

From 1961 to 1962, Los Alamos Scientific Laboratory conducted studies on human thyroid function using iodine-131 $\left({ }^{131}\right)$ administered as sodium iodide. At least two adult females received 0.5 microcurie by oral administration. Tests were repeated several times in combination with various drugs and uptakes were measured and compared. These studies showed which drug therapies were most effective in treating thyroid disorders. This work was supported by the U.S. Atomic Energy Commission. (Previously described in \#45 on the original list of 48 experiments released by DOE in June 1994)

\section{References}

Lushbaugh, C.C. and D.B. Hale. "Clinical Applications of Whole body Counting: Determination of Thyroidal Activity from Sodium lodine-131 Retention Measurements with Humco II." Biological and Medical Research Group of the Health Division Annual Report July 1961-June 1962. Los Alamos: Los Alamos National Laboratory, LAMS-2780, 1962, pp. 181-187.

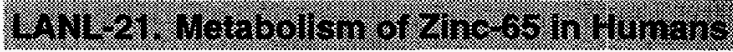

A study of the metabolism of zinc-65 was conducted at Los Alamos Scientific Laboratory in 1962 to evaluate the gastrointestinal absorption, distribution in the body, retention time, and excretion rates. The study involved four laboratory employees-three male and one female - between 29 and 48 years of age. The subjects were given an oral dose of 0.6 to 1.0 microcurie of $\mathrm{Zn}^{65}$ in the form zinc chloride, in water and were studied by whole body counting. Urinary and fecal samples were also obtained and counted to measure the excretion rates of $Z \mathrm{n}^{65}$ from the subjects. Their study was supported by the U.S. Atomic Energy Commission. (Previously described in \#18 on the original list of 48 experiments released by DOE in June 1994)

\section{References}

Richmond, C.R., J.E. Furchner, G.A. Trafton, and W.H. Langham. "Comparative Metabolism of Radionuclides in Mammals: Uptake and Retention of Orally Administered $\mathrm{Zn}^{65}$ by Four Mammalian Species." Health Physics. Vol. 8, 1962, pp. 481-489.

\section{W.WL-22. Cesium-182 Metabolism in humans}

From 1962 To 1963, a study was conducted at Los Alamos Scientific Laboratory to determine the retention and excretion of cesium-132 $\left(\mathrm{Cs}^{132}\right)$ in humans. The subjects were three male and one female normal, young adults in good health. These subjects were injected intravenously with 0.65 microcurie of $\mathrm{Cs}^{132}$ as cesium chloride. Three of the subjects were counted approximately 30 times over a 45 -day period. Whole body retention of $\mathrm{Cs}^{132}$ was determined by measurements of the subjects in the Laboratory's 
whole body counters. This research was supported by the U.S. Atomic Energy Commission. (Previously described in \#25 on the original list of 48 experiments released by DOE in June 1994)

\section{References}

Richmond, C.R., J.E. London, and J.E. Furchner. "Retention of Intravenously Administered Cesium- 132 by Man." Biological and Medical Research Group of the Health Division Annual Report July 1962-June 1963. Los Alamos: Los Alamos Scientific Laboratory, LAMS-3034, 1963, pp. 21-33.

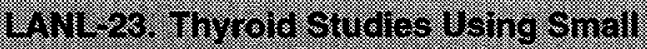 Amounts of Padloadive lodine}

IN ABOUT 1963, the Los Alamos Scientific Laboratory conducted studies on thyroid metabolism, using very small amounts of iodine-125 $\left(1^{125}\right)$ and iodine-131 $\left(\left(^{131}\right)\right.$. The purpose was to determine the retention of iodine in the thyroid as a function of time, with a particular interest in radioiodine metabolism in children. Nineteen normal male and female subjects ranging in age from 4 to 46 drank approximately 10 nanocuries each of $\mathrm{I}^{125}$ and $\mathrm{I}^{131}$ mixed together in water. Subsequent measurements showed that there was no difference in radioiodine metabolism between children and adults. This work was supported by the U.S. Atomic Energy Commission. (Previously described in \#45 on the original list of 48 experiments released by DOE in June 1994)

\section{References}

Van Dilla, M.A. and M.J. Fulwyler. "Thyroid Metabolism in Children and Adults Using Very Small (Nanocurie) Doses of lodine-125 and lodine-131." Health Physics. Vol. 9, 1963, pp. 1,325-1,331.

Van Dilla, M.A. and M.J. Fulwyler. "Radioiodine Metabolism in Children and Adults After the Ingestion of Very Small Doses." Science. Vol. 144, No. 3614, April 1964, pp.178-179.

\section{Oak Ridge Sites}

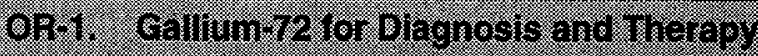
at oak Riuge

From 1949 то 1951, the Oak Ridge Institute of Nuclear Studies conducted studies on the therapeutic use of gallium-72 $\left(\mathrm{Ga}^{72}\right)$. More than 50 patients with various kinds of bone cancer participated. The patients were divided into two groups: one in which a therapeutic effect was attempted, and another in which only gallium uptake and localization were studied with no therapeutic effect attempted. All patients, except one, had fatal cancers that were not amenable to surgery or radiotherapy. The radiogallium was administered intravenously in doses ranging from 10 to 100 millicuries. Most patients tolerated two to four injections of less than 70 millicuries. Further doses or higher level doses caused anorexia, nausea, vomiting, and severe mental depression, with later appearance of skin reactions, diarrhea, and serious bone marrow depression. These studies showed that $\mathrm{Ga}^{72}$ was not suitable as a therapy or tracer because of its toxicity in humans. As a result, subsequent studies focused on other isotopes, such as $\mathrm{Ga}^{67}$ or gallium- 68 $\left(G a^{68}\right)$. This work was supported by the U.S. Atomic Energy Commission.

\section{References}

Brucer, G. M., G.A. Andrews, and H.D. Bruner. "A Study of Gallium." Radiology. Vol. 61, No. 4, 1954, pp. 534-613.

"Gallium." Medical Division Annual Report June 1951. Oak Ridge: Oak Ridge Institute of Nuclear Studies, pp. 16-20. Oak Ridge Institute of Nuclear Studies, ORAU Medical Science Division, Vance Road Facility, Room 202A, ORAU-30022.

Nelson, B., R.L. Hayes, C.L. Edwards, R.M. Kniseley, and G.A. Andrews. "Distribution of Gallium in Human Tissues After Intravenous Administration." Journal of Nuclear Medicine. Vol. 13, 1972, pp. 92-100.

\section{1-2. Colloidal Cold-198 Studies at Oak} Ridge

COLLOIDAL GOLD-198 was studied in the 1950s at Oak Ridge Institute of Nuclear Studies for 
potential diagnostic and therapeutic applications in nuclear medicine. Gold-198 $\left(\mathrm{Au}^{198}\right)$ was used intravenously in an experiment involving terminal cancer patients. Four males and three females with different types of cancer were included in this study between 1949 and 1953. $\mathrm{Au}^{198}$ was administered in various amounts over the course of the patient's disease in the hope of demonstrating a therapeutic effect. In addition, activities of 2.3 to 33 millicuries were administered just prior to death to enhance the isotope concentrations in tissues and to study the biodistribution at time of autopsy. Colloidal $\mathrm{Au}^{198}$ was also employed in intracavitary infusions to study and treat patients with tumors of the chest or abdomen. These studies were supported by the U.S. Atomic Energy Commission. (Previously described in \#12 on the original list of 48 experiments released by DOE in June 1994)

\section{References}

Root, S.W., G.A. Andrews, R.M. Kniseley, and M.P. Tyor. "The Distribution and Radiation Effects of Intravenously Administered Colloidal $\mathrm{Au}^{198}$ in Man." Cancer. Vol. 7, No. 5, September 1954, pp. 856-866.

Kniseley, R.M. and G.A. Andrews. "Pathological Changes Following Intracavitary Therapy with Colloidal Au ${ }^{198}$." Cancer. Vol 6., No. 2, March 1953, pp. 303-312.

\section{Or.3. Use of Serum Albumin Labeled With lodine- 181}

IN THE EARLY 1950s, the Oak Ridge Institute for Nuclear Studies conducted experiments on the transfer of labeled serum albumin between the peritoneal cavity (within the abdominal cavity) and the blood vessels. Eleven women hospitalized for ascites (accumulation of fluid in the peritoneal cavity) were the subjects of this study; 9 had abdominal carcinomatosis and 2 had cirrhosis of the liver. These patients were injected either intraperitoneally or intravenously with human serum albumin labeled with 200 to 300 microcuries of iodine-131 $\left(1^{131}\right)$. Samples of ascitic fluid and blood were analyzed for $I^{131}$-labeled human serum albumin content. The results showed complete equilibrium of the injected tagged albumin between compartments, and that a similar mechanism was involved in the accumulation of ascitic fluid in the two diseases studied. This work was supported by the U.S. Atomic Energy Commission.

\section{References}

Tyor, M.P. "Human Serum Albumin Tagged with lodine-131 in Patients With Ascites Caused by Abdominal Carcinomatosis and Portal Cirrhosis: The Rates of Interchange Between the Vascular Compartment and Peritoneal Cavity." Journal of Laboratory and Clinical Medicine. Vol. 44, No. 1, July 1954, pp. 110-117.

\section{OR.4. Iodine-139 In the Treativent of Mallonant Meraroma}

AN EXPERIMENT CONDUCTED at the Oak Ridge Institute of Nuclear Studies in 1951 investigated the use of iodine-131 $\left({ }^{131}\right)$ in the treatment of malignant melanoma. A secondary objective was to determine the distribution of $\mathrm{I}^{131}$ in patients with this type of tumor both in the presence and in the absence of functioning thyroid tissue. Two experimental subjects were studied. The first subject was a 37-year-old man in the terminal stages of metastatic malignant melanoma of the liver. $\mathrm{He}$ received 100 microcuries of $\mathrm{I}^{131}$ orally. Three days later, the subject was given $\mathbf{5 7 . 6}$ millicuries of $\mathrm{I}^{131}$ orally. Tissue samples were obtained during the autopsy, 6 days after ingestion of the $\mathrm{I}^{131}$ The second subject was a 43-year-old woman with malignant melanoma of the arms and legs. This patient received three oral doses of $\mathrm{I}^{131}$ (305 millicuries, 69.7 millicuries, and 69.7 millicuries). Tissues samples were obtained by biopsy after each dose. $I^{131}$ failed to localize the tumor and was judged ineffective for therapy. This work was supported by the U.S. Atomic Energy Commission.

\section{References}

Andrews, G. A. and M. Brucer. "Radioactive lodine in Malignant Melanoma." Medical Division Quar. terly Report October 1-December 31, 1953. Oak Ridge: Oak Ridge Institute of Nuclear Studies, pp. 12-16. Oak Ridge Institute of Nuclear Studies, ORAU Medical Science Division, Vance Road Facility, Room 202A, ORAU-30022. 
Chapter 3. Human Radiation Experiments-Oak Ridge Sites

67.5. Use of inadiolodine In Sugleal Removol or Thyold Cancers

BetWEen 1950 AND 1974, 117 patients admitted to the Oak Ridge Institute of Nuclear Studies, Oak Ridge Associated Universities, with cancer of the thyroid received at least one dose of therapeutic iodine-131 $\left(1^{131}\right)$ as part of their therapy in addition to surgery. The project was started before the formation of the ORAU/ORNL Committee on Human Studies in 1967. However, prior to 1967 , experimental protocols were reviewed by all members of the clinical staff, with consensus required for approval. The project was terminated in October 1974 and ORAU personnel began compiling data and evaluating the clinical course of the patients. Eighty-seven of these patients were still alive at that time. This work was supported by the U.S. Atomic Energy Commission.

\section{References}

"Use of Radioiodine in Surgical Removal of Thyroid Cancers." Oak Ridge Associated Universities, Medical Division, Committee on Human Studies File (Project No. 5). 1973. Oak Ridge Institute for Science and Education. Medical Sciences Division. ORAU/ORNL Committee. Vance Road Facility, Room 202A, ORAU-30016, File 1.

\section{PR-6. Comparison of the Metabolism of Rubidium 86 and Potassium-42}

IN 1953, Four patients at Oak Ridge Institute for Nuclear Studies with leukemia and carcinoma participated in tracer experiments to determine whether rubidium- $86\left(\mathrm{Rb}^{86}\right)$ could be used as an analog for potassium- $42\left(\mathrm{~K}^{42}\right)$ in studying biological systems. Simultaneous intravenous injections of $\mathrm{K}^{42}$ and $\mathrm{Rb}^{86}$ were administered to the experimental subjects. Multiple samples of plasma, red cells, and urine were obtained and analyzed from each patient. The researchers concluded that $\mathrm{Rb}^{86}$ was a satisfactory substitute for $\mathrm{K}^{42}$ in biological studies. This work was funded by the U.S. Atomic Energy Commission.

\section{References}

"Potassium-42 and Rubidium-86 Studies." Medical Division Quarterly Report October 1-December 31, 1953. Oak Ridge: Oak Ridge Institute of Nuclear Studies, pp. 10-11. Oak Ridge Institute of
Nuclear Studies, ORAU Medical Science Division, Vance Road Facility, Room 202A, ORAU-30022.

Tyor, M. P. and J.S. Eldridge. "A Comparison of the Metabolism of $R b^{86}$ and $K^{42}$ Following Simultaneous Injection into Man." Abstract of paper presented to American Society for Clinical Investigation, Atlantic City, April 1954.

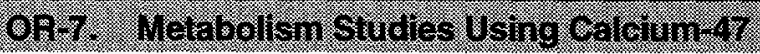

THE METABOLISM OF CALCIUM in humans was studied at the Oak Ridge Institute of Nuclear Studies in 1959. Eleven patients with various diseases, including bone lesions and breast cancer, were given calcium- $47\left(\mathrm{Ca}^{47}\right)$. Analyses for $\mathrm{Ca}^{47}$ were then conducted on blood, urine, feces, and saliva. Whole body retention of $\mathrm{Ca}^{47}$ was also determined. Two patients were administered 70 microcuries intravenously and two patients received oral dosages of 138 and 104 microcuries, respectively. One patient received both an intravenous and an oral dose. Comparisons were made between intravenous and oral routes of administration. This research was funded by the U.S. Atomic Energy Commission.

\section{References}

Monthly Highlight Report of the Oak Ridge Institute of Nuclear Studies, Medical Division. June 1960. NARA Atlanta Archives, RG 326-68A1096, OR Research Division, Organization and Management-5, Box 400, Folder Organization and Management-8, Reports-ORINS.

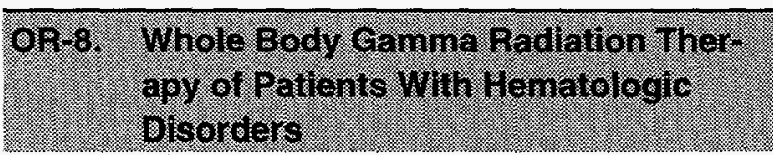

From 1956 To 1973, the Oak Ridge Institute for Nuclear Studies/Oak Ridge Associated Universities Medical Division conducted studies on the efficacy of total body irradiation (TBI) for the treatment of hematologic disorders, particularly leukemia, polycythemia rubra vera, and lymphoma. The purposes were to develop better irradiation methods for therapy, improve methods for assessing and treating accidental gamma and neutron radiation, compile and evaluate related data, and devise new and more precise endpoints that define human radiation dose-response. 
The 194 male and female patients, all diagnosed with some kind of hematologic malignancy, ranged in age from 12 to 86 years. They were exposed to totals of 50 to 250 roentgens $(R)$ per treatment series. However, in 1970, one patient was exposed to $500 \mathrm{R}$ in conjunction with an attempted bone marrow graft. The external gamma radiation sources were either cobalt-60 $\left(\mathrm{Co}^{60}\right)$ or cesium-137 $\left(\mathrm{Cs}^{137}\right)$ used in three types of facilities: a medium-exposure-rate total body irradiator (METBI) providing $1.5 \mathrm{R} / \mathrm{min}$ and two lowexposure-rate total body irradiators (LETBIs) providing $1.5 \mathrm{R} / \mathrm{hr}$ and $0.8 \mathrm{R} / \mathrm{hr}$.

The therapeutic total body irradiation project was discontinued after 194 patients received exposures to $250 \mathrm{R}$ in METBI or LETBI. However, there was a higher frequency of remissions at $150 \mathrm{R}$ compared to $250 \mathrm{R}$, which occurred because of excessive marrow suppression at the higher exposure rates. Survival data indicated that TBI patients survived about as long as, but not significantly longer than, patients treated by other methods. The program, which was discontinued in 1974, was funded by the U.S. Atomic Energy Commission. (TBI was referenced in the Markey report.)

\section{References}

Monthly Highlight Report of the Oak Ridge Institute of Nuclear Studies, January 1960-Medical Division. February 3, 1960, p. 2.

Edwards, C.L., C.C. Lushbaugh, H. Vodopick, F.A. Goswitz, B. Nelson, R.M. Kniseley, and G.A. Andrews. "Studies of Total-Body Irradiation in Patients with Hematological Disorders." Application for Use of Humans As Experimental Subjects, Medical Division, Oak Ridge Associated Universities, Committee on Human Studies and Related Documentation (Project No. 10). 1969. Oak Ridge Institute for Science and Education. Medical Sciences Division. ORAU/ORNL Committee. Vance Road Facility, Room 202A, ORAU-30016, File 1.

"Radiation Effects and Related Topics: Clinical Total-Body Irradiation." 1970 Research Report. Oak Ridge: Medical Division, Oak Ridge Associated Universities, ORAU-113, p. 4.

"Clinical Observations: Therapeutic Total-Body Irradiation." 1972 Research Report. Oak Ridge:
Medical Division, Oak Ridge Associated Universities, ORAU-122, pp. 6-14.

"Radiation Effects and Related Topics." 1973 Research Report. Oak Ridge: Medical Division, Oak Ridge Associated Universities, ORAU-123, pp. 4-12.

Andrews, G.A., F.V. Comas, C.L. Edwards, R.M. Kniseley, C.C. Lushbaugh, and H. Vodopick. "Hematologic and Therapeutic Effect of TBI in Patients with Malignant Lymphoma, Chronic Lymphocytic and Granulocyte Leukemias, and Polycythemia Vera." Washington, D.C.: U.S. Atomic Energy Commission, ORAU-112, 1970.

Andrews, G.A., C.C. Lushbaugh, R.M. Kniseley, D. White, and B.I. Friedman. "Hematological Effects of Whole body Irradiation in the Human Being." in IAEA Panel: Effects of lonizing Radiation on the Hematopoietic Tissue. Vienna: International Atomic Energy Agency, 1970, pp. 75-83.

Andrews, G.A., R.M. Kniseley, H. Vodopick, P.E. Bergner, and C.C. Lushbaugh. "Hematologic Responses to Total-Body Irradiation." in Radioisotope in Pharmakokinetick und Klinischer Biochemie, edited by G. Hoffman and H.A. Ladner, pp. 517-27. Stuttgart: Nuklear Medizin, 1966.

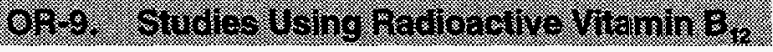

THIS RESEARCH, CONDUCTED in the early 1960s, was a collaborative effort between the Oak Ridge Institute of Nuclear Studies, the Long Island Jewish Hospital (Jamaica, NY), South Nassau Communities Hospital (Oceanside, NY), and Brookhaven National Laboratory. A series of experiments was conducted to study the plasma clearance of vitamin $\mathrm{B}_{12}$ labeled with cobalt- $57\left(\mathrm{Co}^{57}\right)$. The studies sought to determine why the serum and plasma levels of vitamin $B_{12}$ were elevated in patients with chronic myelocytic leukemia. In one study, three patients in remission were intravenously administered 0.13 microcurie of vitamin $B_{12}$ labeled with cobalt- 57 . The procedure was repeated twice in the same patients, after administration of loading doses of stable vitamin $B_{12}$.

In another study, 10 patients with various degrees of chronic myelocytic leukemia and 5 healthy individuals each received 3 or more intravenous injections of $\mathrm{Co}^{57}$ labeled $\mathrm{B}_{12}$. This 
research was supported by the U.S. Atomic Energy Commission and by a grant from the National Cancer Institute.

\section{References}

Meyer L.M., L.M. Schiffer, D.A. White, and E.P. Cronkite. "The Plasma Disappearance of Radioactive Cyanocobalamin: Effect of Prior Administration of Vitamin $B_{12}$ Analogues." British Journal of Hematology. Vol. 11, No. 3, May 1965, pp. 370-379.

Monthly Highlight Report of the Oak Ridge Institute of Nuclear Studies, Medical Division. December 1962. NARA Atlanta Archives, RG 326-68A1096, OR Research Division, Organization and Management-5, Box 400, Folder Organization and Management-8, Reports-ORINS.

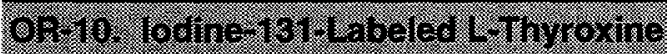
THover by Whole Body counting

DURING 1966 AND 1967, a study was conducted by the Oak Ridge Institute of Nuclear Studies/Oak Ridge Associated Universities to compare the turnover of L-thyroxine (thyroxine is the active iodine compound existing normally in the thyroid gland) in subjects with hyperthyroidism, hypothyroidism, and normal thyroid functions. Ten patients with abnormal L-thyroxine metabolism were compared against a control group of five normal subjects. All subjects received 20 to 40 microcuries of iodine-131 $\left(1^{131}\right)$-labeled L-thyroxine intravenously. Body counting was conducted twice on the first day after the $1^{131}$-labeled L-thyroxine was administered and daily thereafter. Daily thyroid counts were made on the subjects by standard methods. In addition, blood samples were obtained from five patients to compare blood turnover rates to whole body counts. This study showed that whole body counting provided quantitative information on the turnover of L-thyroxine. This work was funded by the U.S. Atomic Energy Commission.

\section{References}

Bird, E. D. and W.D. Gibbs. "L-thyroxine Turnover by Whole body Counting in Patients Receiving Exogenous Thyroid Hormone." 1968 Research Report. Oak Ridge: Medical Sciences Division, Oak Ridge Associated Universities, pp.
223-227. Oak Ridge Institute for Science and Education, ORAU Medical Sciences Division, ORAU-30002, Part 3 of 6.

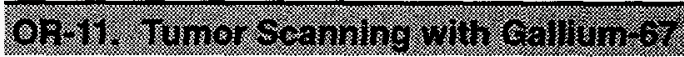

From 1969 Through 1977, Oak Ridge Associated Universities conducted studies on the use of gallium-67 $\left(\mathrm{Ga}^{67}\right)$ as a tumor-scanning agent in humans. Participating were 357 male and female patients ranging in age from 6 to 83 years. All had known, viable bone or soft tissue tumors associated with a wide variety of cancers. All patients received at least one intravenous injection of 70 microcuries of $\mathrm{Ga}^{67}$ per kilogram of body weight up to a total dose of 6 millicuries. Thirty-four of these patients received more than one injection. Several received a series of injections to study the therapeutic effect and to look for recurrence of disease.

In a related study, four patients were administered $\mathrm{Ga}^{67}$ by injection into the lymphatic structure of the feet. These studies showed that gallium does not collect equally in all types of tumors. Rather, it collects in tumors of specific cellular types. The lymphatic injections showed no advantage to this approach, even in identifying tumors along the lymphatic vessels. In May 1976, the U.S. Food and Drug Administration approved $\mathrm{Ga}^{67}$ citrate for general diagnostic use. This work was supported by the U.S. Atomic Energy Commission.

\section{References}

Edwards, C. L., R.L. Hayes, N. Tehranian, R. Kniseley, F. Goswitz, R. Tanida, and H. Vodopick. "Tumor Scanning with Gallium-67." Application for Use of Humans As Experimental Subjects, Medical Division, Oak Ridge Associated Universities, Committee on Human Studies and Related Documentation (Project No. 9). 1969. Oak Ridge Institute for Science and Education. Medical Sciences Division. ORAU/ORNL Committee. Vance Road Facility, Room 202A, ORAU-30016, File 1.

"Tumor Scanning with Gallium-67." 1970 Research Report. Oak Ridge: Medical Sciences Division, Oak Ridge Associated Universities, pp. 100-105. Oak Ridge Institute for Science and Education, ORAU Medical Sciences Division, ORAU-30002, Part 3 of 6. 
Nelson, B., R.L. Hayes, C.L. Edwards, R.M. Kniseley, and G.A. Andrews. "Distribution of Gallium in Human Tissues After Intravenous Administration." Journal of Nuclear Medicine. Vol. 13, 1972, pp. 92-100.

\section{Of-12. Therapeitic Allogenic Transplantation of human Bone Marroy}

From 1970 to 1973, Oak Ridge Associated Universities conducted a study to evaluate the effectiveness of combining high-dose total body irradiation (TBI) with antilymphocyte-globulin as an immunosuppressive regimen to induce tolerance to a foreign bone marrow graft in humans. Three patients were involved initially. Each was exposed to 500 roentgens $(R)$, which corresponded to an average total body absorbed dose of approximately 370 rads. Subsequent bone marrow grafts were successful in two patients. Failure of the graft in the third patient was determined to have resulted from an insufficient radiation dose. Accordingly, researchers requested and received approval to increase the exposure level to deliver an absorbed dose of $800 \mathrm{rads}$ at the rate of $40 \mathrm{R} / \mathrm{min}$.

The original protocol limited patients to those with acute leukemia. Researchers also requested and received approval to extend the procedure to patients with aplastic anemia. A fourth patient, with acute leukemia, was treated in 1973. This patient was exposed to a $694 \mathrm{R}$ to the total body irradiation, but developed an unexplained severe graft-versus-host reaction that prevented a successful marrow transplant.

The Oak Ridge Institute of Nuclear Studies conducted a related study beginning in 1971 that was designed to identify objective signs and distinguish early graft-versus-host reactions from drug reactions, infections, and other complications related to or incidental to the marrow transplant/TBI procedure. In this study, skin biopsies were obtained from four patients or volunteers, without further exposing them to radiation of any kind. This work was supported by the U.S. Atomic Energy Commission. (TBI was referenced in the Markey report.)

\section{References}

"Allogenic Marrow Transplantation in Man." 1971 Research Report. Oak Ridge: Medical Division, Oak Ridge Associated Universities, ORAU-116, pp. 65-70.

"Therapeutic Allogenic Bone-Marrow Transplantation." 1973 Research Report. Oak Ridge: Medical Division, Oak Ridge Associated Universities, ORAU-123, pp. 39-43.

Gengozian, N., C. L. Edwards, H. Vodopick, and K. Hubner. "Therapeutic Allogenic Transplantation of Human Bone Marrow." Application for Use of Humans As Experimental Subjects, Medical Division, Oak Ridge Associated Universities, Committee on Human Studies and Related Documentation (Project No. 13). 1970. Oak Ridge Institute for Science and Education. Medical Sciences Division. ORAU/ORNL Committee. Vance Road Facility, Room 202A, ORAU-30016, File 1.

Nelson, B. and L. Edwards. "Histologic Changes in the Skin Related to the Graft vs Host (GVH) Reaction After Marrow Transplantation." Application for Use of Humans As Experimental Subjects, Medical Division, Oak Ridge Associated Universities, Committee on Human Studies and Related Documentation (Project No. 15). 1970. Oak Ridge Institute for Science and Education. Medical Sciences Division. ORAU/ORNL Committee. Vance Road Facility, Room 202A, ORAU-30016, File 1.

Andrews. G.A. "The Therapeutic Use of BoneMarrow Transplantation." in Proceedings of the International Conference on Leukemia-Lymphoma, edited by C.J.D. Zarafonetis, pp. 423-432. Philadelphia: Lea and Febiger, 1968. $\square$

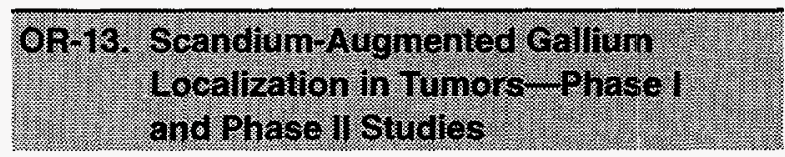

From 1972 то 1973, Oak Ridge Associated Universities conducted a study to determine whether intravenous administration of stable (nonradioactive) scandium citrate along with radioactive gallium increases the relative concentration of the gallium in tumors. The study protocol proposed administration of scandium in doses ranging from 0.005 to 1.0 milligram per kilogram of body 
weight, followed by 100 microcuries of gallium- 67 $\left(\mathrm{Ga}^{67}\right)$ to 21 patients with known malignancies. The first patient to be treated experienced an adverse reaction to the scandium citrate but made a satisfactory recovery. Testing was suspended pending further investigation. There is no indication of further activity. This work was supported by the U.S. Atomic Energy Commission.

\section{References}

Hayes, R.L., C.L. Edwards, and B.M. Nelson. "Scandjum-Augmented Gallium Localization in Tumors-Phase I and Phase II Studies." Application for Use of Humans As Experimental Subjects, Medical Division, Oak Ridge Associated Universities, Committee on Human Studies and Related Documentation (Project No. 18). 1971. Oak Ridge Institute for Science and Education. Medical Sciences Division. ORAU/ORNL Committee. Vance Road Facility, Room 202A, ORAU-30016, File 1.

Hayes, R.L. and C.L. Edwards. "The Effect of Stable Scandium on Red Blood Cells and the Retention and Excretion of $\mathrm{Ga}^{67}$ in Humans." Southern Medical Journal. Vol. 66, 1973, pp. 1,339-1,340.

\section{or-14. Cinical Testing of Strontium-85in as a Borle Scaming Agent}

From 1972 To 1975, Oak Ridge Associated Universities conducted a study of strontium- $85 \mathrm{~m}$ $\left(\mathrm{Sr}^{85 \mathrm{~m}}\right)$ as a bone scanning agent. Patients with known malignant tumors or suspected metastatic disease of the bone were administered up to 30 microcuries of $\mathrm{Sr}^{85 \mathrm{~m}}$ per kilogram of body weight (approximately 2 microcuries per patient) by intravenous infusion. Results of the $\mathrm{Sr}^{85 \mathrm{~m}}$ scans were compared with subsequent scans using strontium-85, fluorine-18 $\left(\mathrm{F}^{18}\right)$ or technetium-99m $\left(T e^{99 m}\right)$. Four patients were involved in the study. This work was supported by the U.S. Atomic Energy Commission.

\section{References}

"Clinical Testing of Strontium-85m as a Bone Scanning Agent," Application for the Use of Humans as Experimental Subjects, Medical Division, Oak Ridge Associated Universities, Committee on Human Studies and Related Documen- tation (Project No. 25). 1972. Oak Ridge Institute for Science and Education, Medical Sciences Division, ORAU/ORNL Committee, Vance Road Facility, Room 202A, ORAU-30016, File 1.

\section{OR-15. Comparison of hdium-111 and} Btsmuth-2066 with Gallum 67 as: rimor Scaming Agents

From 1972 To 1978, Oak Ridge Associated Universities conducted a study to determine the relative merits of indium-111 $\left(\ln ^{111}\right)$ and bismuth-206 $\left(\mathrm{Bi}^{206}\right)$ when compared to gallium-67 $\left(\mathrm{Ga}^{67}\right)$ as tumor imaging agents. In actual application, the study was limited to evaluating $\operatorname{In}^{111}$ and $G a^{67}$. In 1973 , six cancer patients received simultaneous injections of $\ln ^{111}$ (0.011 microcurie per kilogram of body weight) and $\mathrm{Ga}^{67}$ (0.045 microcurie $/ \mathrm{kg}$ ). Three additional patients were studied during 1974. The study showed that $\mathrm{Ga}^{67}$ was a better tumor scanning agent than $\mathrm{In}^{\mathrm{tt}}$. After July 1974, no patients were scanned with In $^{111}$ at Oak Ridge. This work was supported by the U.S. Atomic Energy Commission.

\section{References}

"Comparison of Indium-111 and Bismuth-206 with Gallium-67 as Tumor Scanning Agents." Application for Use of Humans As Experimental Subjects, Medical Division, Oak Ridge Associated Universities, Committee on Human Studies and Related Documentation (Project No. 22). 1972. Oak Ridge Institute for Science and Education. Medical Sciences Division. ORAU/ORNL Committee. Vance Road Facility, Room 202A, ORAU-30016, File 1.

"Indium-111 and Ga ${ }^{67}$ for Tumor Scanning." 1973 Research Report. Oak Ridge: Medical Division, Oak Ridge Associated Universities, ORAU-123, pp. 77-82.

\section{OR-16. Use of an External Gadolmum 153 Source for Tining the Cardiac Cvele}

From 1972 тo 1975, Oak Ridge Associated Universities conducted a study to determine the effectiveness of gadolinium-153 $\left(\mathrm{Gd}^{153}\right)$ as a noninvasive technique for evaluating specific stages of the cardiac cycle, notably the left ventricular ejection time. A fine beam of gamma 
radiation from a $\mathrm{Gd}^{153}$ source, which was placed on the subject's back, was directed through the heart to a detector on the subject's chest. At least six patients were subjected to a radiation exposure of approximately 0.2 roentgen over a 1 inch-diameter area on their backs. The passage of blood through the left ventricle was determined by measuring the blockage of gamma rays emitted by the $\mathrm{Gd}^{153}$. This work was supported by the U.S. Atomic Energy Commission.

\section{References}

Oder, C., A.C. Morris, L. Edwards, and J. Berger. "Use of External Gadolinium-153 Source for Timing of Parts of Cardiac Cycle." Application for the Use of Humans as Experimental Subjects, Miedical Division, Oak Ridge Associated Universities, Committee on Human Studies and Related Documentation (Project No. 23). 1972. Oak Ridge Institute for Science and Education, Medical Sciences Division, ORAU/ORNL Committee, Vance Road Facility, Room 202A, ORAU-30016, File 1.

\section{Off 17. Dysprosium 157 as a Clinical linaging Agent ror Sollo tumbro}

From 1973 to 1977, Oak Ridge Associated Universities conducted a study to determine whether dysprosium-157 (Dy ${ }^{157}$ ) could be used effectively as a tumor localizing agent in humans. Both tumors and soft-tissue tumors were considered. Thirty-four patients with known cancer were included. This study was discontinued in 1977 after the investigators found that $\mathrm{Dy}^{157}$ did not provide better images of solid tumors than the technetium$99 \mathrm{~m}\left(\mathrm{Te}^{99 \mathrm{~m}}\right)$ phosphate compounds did for bone scans, nor was it better than gallium-67 $\left(\mathrm{Ga}^{67}\right) \mathrm{ci}$ trate for soft tissue tumors. This work was supported by the U.S. Atomic Energy Commission.

\section{References}

Edwards, C.L., R.L. Hayes, and J.K. Poggenburg. "Dysprosium-157 as a Clinical Scanning Agent for the Detection of Osseous and Nonosseous Tumors," Application for the Use of Humans as Experimental Subjects, Medical Division, Oak Ridge Associated Universities, Committee on Human Studies and Related Documentation (Project No. 35). 1973. Oak Ridge Institute for Science and Education, Medical Sciences Division, ORAU/
ORNL Committee on Human Studies, Vance Road Facility, Room 202, ORAU-30017, File 2.

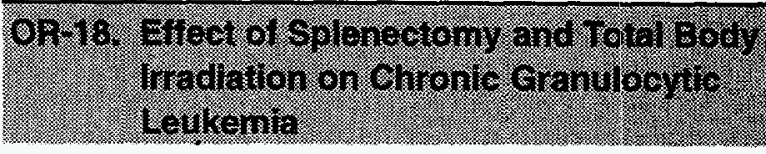

IN 1974, OAK RIDGE Associated Universities conducted a study to determine the effect of splenectomy (surgical removal of the spleen), with or without total body irradiation (TBI), on the onset of blast crisis and overall survival in leukemia patients. The blast crisis occurs when a patient, previously in remission, begins to produce large quantities of immature white blood cells (called "blast cells"). The blast crisis is usually a terminal condition. The spleen becomes enlarged during the blast crisis and causes the patient considerable discomfort. The researchers were studying whether removal of the spleen, with or without TBI, might postpone the onset of blast crisis. The study protocol called for radiation exposure of 100 to $250 \mathrm{R}$, depending on the white cell count of the patient. Only one patient was treated in the study. The patient was not kept in remission after the splenectomy and required subsequent suppressive therapy. The study was canceled in January 1975 and the patient was no longer followed by ORAU. This work was supported by the U.S. Atomic Energy Commission. (TBI was referenced in the Markey report.)

\section{References}

Goswitz, F.A., C.L. Edwards, H. Vodopick, and G. Littlefield. "Effect of Splenectomy and TBI on Onset of Blast Crisis and Survival in Chronic Granulocytic Leukemia." Application for the Use of Humans as Experimental Subjects, Medical Division, Oak Ridge Associated Universities, Committee on Human Studies and Related Documentation (Project No. 29). 1973. Oak Ridge Institute for Science and Education, Medical Sciences Division, ORAU/ORNL Committee, Vance Road Facility, Room 202A, ORAU-30016, File 1. 


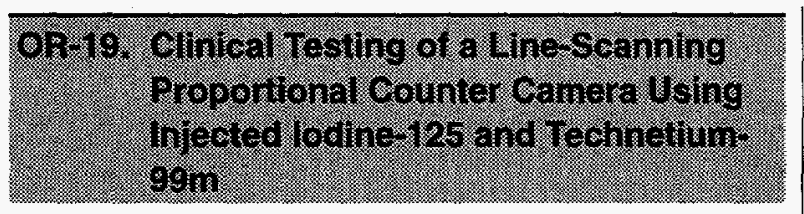

DIAGNOSTIC DOSES OF IODINE-125 and technetium$99 \mathrm{~m}\left(\mathrm{TC}^{99 \mathrm{~m}}\right)$ were administered to selected patients referred to Oak Ridge Associated Universities from the Oak Ridge Methodist Hospital for thyroid evaluation. The quality of images obtained with the two radioisotopes with the camera was evaluated and compared. Although these subjects were evaluated for preexisting disease, certain aspects of this study were experimental, and the objective was development of instrumentation and techniques for evaluating human thyroids. An estimated 100 subjects were studied. This study was conducted between August 27, 1975, and September 29, 1977. The protocol was approved by the Oak Ridge Associated Universities/Oak Ridge National Laboratory Institutional Review Board. (Previously described in \#33 on the original list of 48 experiments released by DOE in June 1994)

\section{References}

Andrews, G.A., W. Gibbs, C. Borkowski, K. Hubner, and J. Harter. "Clinical Testing of a Line Scanning Proportional Counter Camera." Application for Use of Humans As Experimental Subjects, Medical Division, Oak Ridge Associated Universities, Committee on Human Studies and Related Documentation (Project No. 41). 1975. Oak Ridge Institute for Science and Education. Medical Sciences Division. ORAU/ORNL Committee on Human Studies, Vance Road Facility, Room 202A, ORAU-30017, File 2.

Brill, A.B. "Radioisotope Studies Utilizing a Low Level Whole Body Counter and Clinical Applications of Activation Analysis." ERDA Progress Report. Nashville: Vanderbilt University, April 30, 1975, p. 75. Oak Ridge Operations Office, Records Holding Area, Documents 1944-1994, Box H-101-12, Bldg. 2714-H, Folder 2401, Reports May/July 1976, Vanderbilt University.

Brill, A.B "Radioisotope Studies Utilizing a Low Level Whole Body Counter and Clinical Applications of Activation Analysis." ERDA Progress Report. Nashville: Vanderbilt University, July 31, 1977. Oak Ridge Operations Office, Records
Holding Area, Documents 1944-1994, Box $\mathrm{H}-101-12$, Bldg. 2714-H, no folder.

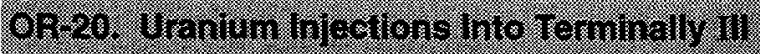 cancer pationts}

From 1953 то 1957, Oak Ridge National Laboratory and Massachusetts General Hospital conducted a cooperative study on the distribution and excretion of uranium in humans using terminally ill brain cancer patients as subjects. Participants included male and female patients ranging in age from 26 to 63 years. All were near death (in a coma or semicoma) prior to injection and were receiving usual hospital care for comatose patients. Subjects were intravenously administered uranium-233 $\left(U^{233}\right)$ or uranium-235 $\left(U^{235}\right)$ as either uranyl nitrate hexahydrate (9 patients) or uranium tetrachloride (2 patients) in amounts ranging from 4 to 50 milligrams. The subjects expired from their brain cancer within several months of injection. Study results indicated that 99 percent of the injected uranium cleared the blood within 20 hours, either depositing in the skeleton and kidneys or exiting through urine. This work was supported by the U.S. Atomic Energy Commission. (This experiment was referenced in the Markey report.)

\section{References}

Bernard, S.R. "Maximum Permissible Amounts of Natural Uranium in the Body, Air and Drinking Water Based on Human Experimental Data." Health Physics, Vol. 1, 1958, pp. 288-305.

Bernard, S.R., J.R. Muir, and G.W. Royster, Jr. "The Distribution and Excretion of Uranium in Man." in Proceedings of the Health Physics Society, June 1956, pp. 33-48.

Luessenhop, A.J., J.C. Gallimore, W.H. Sweet, E.G. Struxness, and J. Robinson. "The Toxicity in Man of Hexavalent Uranium Following Intravenous Administration." American Journal of Roentgenology, Radium Therapy and Nuclear Medicine. Vol. 79, No. 1, 1958, pp. 83-100.

Struxness, E.G., A.J. Luessenhop, S.R. Bernard, and J. C. Gallimore. "The Distribution and Excretion of Hexavalent Uranium in Man." in Proceedings of the International Conference on the Peaceful Uses of Atomic Energy. New York: United Nations, 1956, pp. 186-196. 


\section{University of Chicago- Argonne Cancer Research Hospital}

UC. 1. Chromim-51 and ron-59 Used to Sturd Red Blood Cell Production

STUdies Were CARRIED OUT in the early 1950 s at the Argonne Cancer Research Hospital to determine the rate of red cell production and destruction in healthy and anemic subjects. Two to four microcuries of iron-59 $\left(\mathrm{Fe}^{59}\right)$ was added to 20 milliliters of plasma and injected into the arms of the subjects. Several days after the administration of the $\mathrm{Fe}^{59}$, the procedure was repeated using chromium-51 $\left(\mathrm{Cr}^{51}\right)$-labeled plasma. The subjects were six healthy individuals and two anemic individuals. The combined use of $\mathrm{Cr}^{51}$ and $\mathrm{Fe}^{59}$ provided an indicator of red cell survival and total blood volume in humans. This work was carried out under a contract between the Office of the Surgeon General, the United States Army, and the Department of Medicine of the University of Chicago. The U.S. Atomic Energy Commission provided funding to the Argonne Cancer Research Hospital through the University of Chicago, its operating contractor.

\section{References}

Weinstein, I.M. and E. Beutler. "The Use of $\mathrm{Cr}^{51}$ and $\mathrm{Fe}^{59}$ in a Combined Procedure to Study Erythrocyte Production and Destruction in Normal Human Subjects and in Patients with Hemolytic or Aplastic Anemia." Semiannual Reports to the U.S. Atomic Energy Commission, Vol. 1, Parts 1-6, 1954 to 1956. Chicago: Argonne Cancer Research Hospital, pp. 70-75. The University of Chicago, Office of Legal Counsel, Semiannual Reports of the Argonne Cancer Research Hospital.

\section{UC2. Studies on the elinical Application of Tritum-90}

IN 1953, AT the ARgonne Cancer Research Hospital, preliminary studies were carried out with yttrium-90 $\left(Y^{90}\right)$ to determine whether $Y^{90}$ might be used for intracavitary therapy. A patient in the terminal stage of carcinomatosis was injected intrapleurally with a solution containing about 1,350 microcuries of $Y^{90}$. Samples of fluid were withdrawn from the pleural cavity at 3,24 , and 48 hours and at autopsy, which was 7 days after the administration of $Y^{90}$. The study found that $Y^{90}$ had a half-time of 30 to 36 hours. The U.S. Atomic Energy Commission provided funding to the Argonne Cancer Research Hospital through the University of Chicago, its operating contractor.

\section{References}

LeRoy, G.V., R.W. Wissler, and D.W. Talmage. "Preliminary Studies on the Clinical Application of Yttrium-90 for Intrapleural Therapy." Serniannual Reports to the U.S. Atomic Energy Commission, Vol. 1, Parts 1-6, 1954 to 1956. Chicago: Argonne Cancer Research Hospital, pp. 1-4. The University of Chicago, Office of Legal Counsel, Semiannual Reports of the Argonne Cancer Research Hospital.

UC 3. Rediedetive Sodum2 Chromate Used: to Study Primaquine Sensitivity

IN 1953, THE UNIVERSITY of Chicago and the Argonne Cancer Research Hospital conducted studies to determine the hemolytic defect that develops during primaquine administration. Primaquine is an anti-malarial drug that induces an acute hemolytic anemia in some people, mainly members of heavily pigmented races. The subjects for this study were healthy, male inmates from the Illinois State Penitentiary at Statesville. None of the inmates had ever had malaria. All of the primaquine-sensitive subjects were AfricanAmericans and the primaquine-nonsensitive subjects included both African-American and Caucasian subjects. There was also one subject who was a student at the University of Chicago, who was included in the study because he had been splenectomized two years prior to the initiation of this research. Blood labeled with 200 to 300 microcuries of sodium chromate $\left(\mathrm{Na}^{2} \mathrm{Cr}^{51} \mathrm{O}_{4}\right)$ was injected into both the normal subjects and the group of primaquine-sensitive subjects. Subsequently, primaquine was administered to subjects in both groups. Blood samples showed that the primaquine-sensitive subjects developed a severe anemia, which was attributed to a urique susceptibility of their red blood cells. This study was carried out under a contract between the Department of Medicine at the University of Chicago and the Office of the Surgeon General for 
the United States Army. The radiochromium was obtained under an authorization from the Isotopes Division of the U.S. Atomic Energy Commission at Oak Ridge, TN. The Argonne Cancer Research Hospital was operated by the University of Chicago, which was funded by the U.S. Atomic Energy Commission.

\section{References}

Dern, R.J., I.M. Weinstein, D.W. Talmage, G.V. LeRoy, and A.S. Alving. "Studies on the Mechanism of Hemolysis in Primaquine-Sensitive Negroes." Semiannual Reports to the U.S. Atomic Energy Commission, Vol. 1, Parts 1-6, 1954 to 1956. Chicago: Argonne Cancer Research Hospital, pp. 37-41. The University of Chicago, Office of Legal Counsel, Semiannual Reports of the Argonne Cancer Research Hospital.

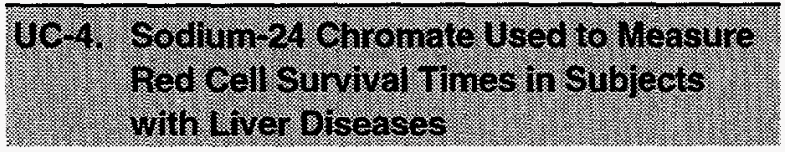

In 1953, AT the ARgonne Cancer Research Hospital, sodium chromate labeled with sodium-24 $\left(\mathrm{Na}^{24}\right)$ was used to measure the red cell survival time of patients with liver disease. The subjects in this study were 19 patients with various types of liver disease. Liver biopsies were taken from all cases, except from 4 patients with bleeding tendencies. The results indicated an abnormal red cell survival time in these patients. This study was supported in part by the Office of the Surgeon General, United States Army. The Argonne Cancer Research Hospital was operated by the University of Chicago, which was funded by the U.S. Atomic Energy Commission.

\section{References}

Jones, P.N., I.M. Weinstein, R.H. Ettinger, and R.R. Capps. "Decreased Red Cell Survival Times Associated with Liver Diseases As Measured with Radioactive Sodium Chromate." Semiannual Reports to the U.S. Atomic Energy Commission, Vol. 1, Parts 1-6, 1954 to 1956. Chicago: Argonne Cancer Research Hospital, pp. 42-46. The University of Chicago, Office of Legal Counsel, Semiannual Reports of the Argonne Cancer Research Hospital.

\section{UC-5. Radioactive Carbon in Studies of Cholesterol Metabolism in Man}

IN 1955, A STUDY on the metabolism of cholesterol was reported by the Department of Medicine and the Argonne Cancer Research Hospital of the University of Chicago and the Los Alamos Scientific Laboratory. The objective of the study was to determine the rate at which cholesterol labeled with carbon-14 $\left(\mathrm{C}^{14}\right)$ appeared in the plasma and to determine now much of the $\mathrm{C}^{14}$ was incorporated. This study was conducted on patients admitted to the research wards of the Argonne Cancer Research Hospital. Thirty-four subjects with various forms of cancer were studied. Both male and female subjects were included; their ages ranged from 23 to 71 years.

Patients received 100 or 200 microcuries of $C^{14}$. labeled sodium acetate. The $\mathrm{C}^{14}$ labeled acetate was administered either orally or intravenously, and in some cases by both routes. Larger amounts were given to patients having the shortest life expectancies. Blood was withdrawn at a time point ranging from 30 minutes to several weeks after administering the $\mathrm{C}^{14}$ acetate. Some patients were subjected to additional tests to determine the amount of $\mathrm{C}^{14}$ lost from the body by respiration or excretion. This study was funded by the U.S. Atomic Energy Commission, the Damon Runyon Memorial Fund, and the American Cancer Society. (Previously described in \#23 on the original list of 48 experiments released by DOE in June 1994)

\section{References}

Gould, R.G., G.V. LeRoy, G.T. Okita, J.J. Kabara, P. Keegan, and D.M. Bergenstal. "The Use of $C^{14}$-Labeled Acetate to Study Cholesterol Metabolism in Man." The Journal of Laboratory and Clinical Medicine. Vol. 46, No. 3, September 1955, pp. 372-384.

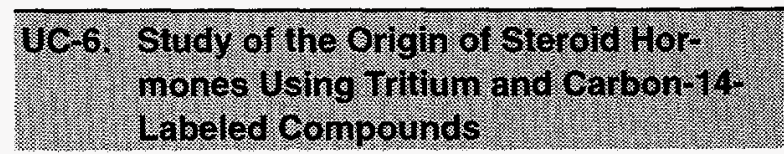

IN 1955, A STUDY was conducted at the Argonne Cancer Research Hospital, in collaboration with scientists at the Los Alamos Scientific Laboratory, to determine the relationship between 
dietary cholesterol and the synthesis of hormones in the body. Seven patients who were to have their adrenal glands surgically removed or who were scheduled to have a therapeutic abortion were fed 50 microcuries of tritium-labeled $\left(\mathrm{H}^{3}\right)$ cholesterol seven days prior to surgery. An additional amount of 10 microcuries $\mathrm{H}^{3}$-labeled cholesterol was administered orally each succeeding day before surgery. During the surgery the patient was given 100 microcuries of acetate labeled with carbon-14 $\left(\mathrm{C}^{14}\right)$ by intravenous injection. The aborted fetuses, the removed adrenal gland, and other biopsy tissue samples were analyzed for $\mathrm{C}^{14}$ - and $\mathrm{H}^{3}$-labeled cholesterol and steroid-based hormones. This study showed that dietary cholesterol was rapidly converted to steroid hormones and that $\mathrm{C}^{14}$ from the acetate source was also incorporated into hormones. The research was supported by the U.S. Atomic Energy Commission. (Previously described in \#23 on the original list of 48 experiments released by DOE in June 1994)

\section{References}

Langham, W.H. and J.B. Storer. Biomedical Research Group of the Health Division Annual Report 1954. Los Alamos: Los Alamos Scientific Laboratory, LA-1889, 1955, p. 24-25.

\section{UC7. Sodium Chromate Used to Sudy Red albod Colls}

THIS RESEARCH WAS CARRIED OUT at the Argonne Cancer Research Hospital in the mid 1950s. This study was the first to use the chromium-51 $\left(\mathrm{Cr}^{51}\right)$ labeling technique to study red cell survival in patients with abnormal hemoglobin syndrome. The subjects were 11 black patients with various blood disorders, including 4 with sickle cell anemia, and 2 healthy black subjects. One hundred milliliters of blood were withdrawn from each patient, labeled with 200 microcuries of $\mathrm{Cr}^{51}$, and reinjected. Samples of blood and feces were collected and analyzed to determine red cell survival times. The study showed that there was a decreased survival of erythrocytes (red blood cells) in patients with sickle cell anemia. The U.S. Atomic Energy Commission provided funding to the Argonne Cancer Research Hospital through the University of Chicago, its operating contractor.

\section{References}

Weinstein, I.M., C.L. Spurling, H. Klein, and T.F. Necheles. "Radioactive Sodium Chromate for the Study of Survival of Red Blood Cells III. The Abnormal Hemoglobin Syndromes." Semiannual Reports to the U.S. Atomic Energy Commission, Vol. 1, Parts 1-6, 1954 to 1956. Chicago: Argonne Cancer Research Hospital, pp. 47-53. The University of Chicago, Office of Legal Counsel, Semiannual Reports of the Argonne Cancer Research Hospital.

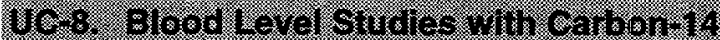
bieritoxin

IN THE MID-1950s, studies were conducted at the Argonne Cancer Research Hospital on the uptake and retention of digitoxin labeled with carbion-14 $\left(\mathrm{C}^{14}\right)$. Digitoxin is a drug used in the treatment of cardiac failure. This study sought to determine the rate of disappearance of unchanged digitoxin and to determine the conversion products arising from the parent drug. Eight subjects with congestive heart failure were given an intravenous injection of 0.5 to 1.5 milligrams of 0.36 to 0.65 microcurie per milligram of radioactive $\mathrm{C}^{14}$-digitoxin. Digitalis medication had been withheld from 14 to 34 days prior to the injection and none was given after the injection. Subsequent to the injection, several 10- to 20-milliliter blood samples were withdrawn in a 96hour period.

The same researchers conducted another study, using three terminal patients. The purpose of the second study was to determine the distribution of digitoxin in various tissues of the body and to determine the pathway by which the drug is removed from the body. The radioactive digitoxin was isolated from digitalis plants that had been grown in an atmosphere of $\mathrm{C}^{14}$. The specific activity of the drug ranged from 0.48 to 0.65 microcurie per milligram. For three terminal patients, multiple doses were intravenously administered to maintain an adequate concentration in the tissues. Tissue samples were taken after the patients died. These tissues were analyzed for digitoxin content. Further research was conducted where radioactive metabolites of digitoxin were studied following the administration of single intravenous doses of digitoxin labeled with $\mathrm{C}^{14}$ or 
with $\mathrm{H}^{3}$. This research determined the reactions that digitoxin undergoes in humans. The Argonne Cancer Research Hospital was operated by the University of Chicago, which was funded by the U.S. Atomic Energy Commission.

\section{References}

Okita, G.T., P.J. Talso, J.H. Curry, F.D. Smith, and E.M.K. Geiling. "Blood Level Studies of $\mathrm{C}^{14}$ Digitoxin in Human Subjects with Cardiac Failure." Semiannual Reports to the U.S. Atomic Energy Commission, Vol. 1, Parts 1-6, 1954 to 1956. Chicago: Argonne Cancer Research Hospital, pp. 69-73. The University of Chicago, Office of Legal Counsel, Semiannual Reports of the Argonne Cancer Research Hospital.

Okita, G.T., P.J. Talso, J.H. Curry, F.D. Smith, and E.M.K. Geiling. "Metabolic Fate of Radioactive Digitoxin in Human Subjects." Semiannual Reports to the U.S. Atomic Energy Commission, Vol. 1, Parts 1-6, 1954 to 1956. Chicago:

Argonne Cancer Research Hospital, pp. 62-68. The University of Chicago, Office of Legal Counsel, Semiannual Reports of the Argonne Cancer Research Hospital.

Okita, G.T. and J.H. Curry. "Metabolism of Radioactive Digitoxin in Man." Semiannual Reports to the U.S. Atomic Energy Commission, Vol. 3, Part 101, 1961 and Parts 11 to 15,1959 to 1961. p. 101. The University of Chicago, Office of Legal Counsel, Semiannual Reports of the Argonne Cancer Research Hospital.

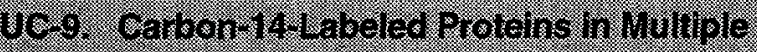 Mrelona}

THIS RESEARCH WAS CARRIED OUT at the Argonne Cancer Research Hospital in the early to mid 1950s. A total of 5.41 grams of carbon-14 $\left(C^{14}\right)$ labeled glycine were given orally in divided doses over an 11-hour period to a patient suffering from multiple myeloma, a malignant neoplasm that originates in the bone marrow and is characterized by abnormalities in formation of plasma protein. The myeloma cells produce abnormal proteins in the serum and urine. Blood samples were withdrawn and 24-hour urine collections were analyzed to determine the rate of synthesis and the possible precursor relationships of my- eloma globulins and Bence-Jones proteins.

The same researchers conducted further experiments with another patient who had different pathological proteins and graver clinical conditions. The subject of this experiment was a 70year-old male with multiple myeloma. The patient was given 20.94 grams of stable nitrogen-15-labeled glycine. The results of this later experiment showed the direct interaction of the Bence-Jones proteins with the metabolic pool of nitrogen.

In a third experiment, a 64-year-old female patient was injected with $\mathrm{C}^{14}$-labeled lysine to determine the rate of synthesis and excretion of the Bence-Jones protein. On the day of the experiment, a catheter was inserted and the patient was injected with 300 microcuries of L-lysine labeled with $\mathrm{C}^{14}$. Urine and respiration were analyzed and two dialysis experiments were performed on the patient. The patient died of uremia 2 months after admission to the hospital. Another patient, a 67-year-old male who was admitted to the Argonne Cancer Research Hospital for treatment and terminal care was injected with 450 microcuries of carbon-14 glutamic acid. One reason for conducting this last experiment was to learn whether glutamic acid might be a better compound to use to study protein synthesis than lysine or glycine. This research was supported by grants from the National Cancer Institute, National Institute of Health and the American Cancer Society. The Argonne Cancer Research Hospital was operated by the University of Chicago, which was funded by the U.S. Atomic Energy Commission.

\section{References}

Putnam, F.W. and Hardy, S. "Proteins in Multiple Myeloma III. Origin of Bence-Jones Protein." Semiannual Reports to the U.S. Atomic Energy Commission, Vol. 1, Parts 1-6, 1954 to 1956. Chicago: Argonne Cancer Research Hospital, pp. 74-76. The University of Chicago, Office of Legal Counsel, Semiannual Reports of the Argonne Cancer Research Hospital.

Hardy, S. and F.W. Putnam. "Proteins in Multiple Myeloma IV. Interaction with Metabolic Nitrogen." Semiannual Reports to the U.S. Atomic Energy Commission, Vol. 1, Parts 1-6, 1954 to 1956. Chicago: Argonne Cancer Research Hospital, 
pp. 77-80. The University of Chicago, Office of Legal Counsel, Semiannual Reports of the Argonne Cancer Research Hospital.

Putnam, F.W., F. Meyer, and A. Miyake. "Proteins in Multiple Myeloma V. Synthesis and Excretion of Bence-Jones Protein." Semiannual Reports to the U.S. Atomic Energy Commission, Vol. 1, Parts 1-6, 1954 to 1956. Chicago:

Argonne Cancer Research Hospital, pp. 31-37. The University of Chicago, Office of Legal Counsel, Semiannual Reports of the Argonne Cancer Research Hospital.

Putnam, F.W. and A. Miyake. "Proteins in Multiple Myeloma. VIII. Biosynthesis of Abnormal Proteins." Semiannual Reports to the U.S. Atomic Energy Commission, Vol. 2, Part 100, 1956 and Parts 7-10, 1957 to 1958. Chicago: Argonne Cancer Research Hospital, p. 27. The University of Chicago, Office of Legal Counsel, Semiannual Reports of the Argonne Cancer Research Hospital.

Putnam, F.W., A. Mikaye, and F. Meyer. "The Metabolism of DL-Glutamic Acid-1-C ${ }^{14}$ in Man." Semiannual Reports to the U.S. Atomic Energy Commission, Vol. 2, Part 100, 1956 and Parts 7-10, 1957 to 1958. Chicago: Argonne Cancer Research Hospital, pp. 35-43. The University of Chicago, Office of Legal Counsel, Semiannual Reports of the Argonne Cancer Research Hospital.

VC. 10 . Carbon-14.Labeled Digitoxin Administered to Pregnant Womento Determine Fetal Distribution

THIS STUDY WAS CONDUCTED at the Argonne Cancer Research Hospital in the mid-1950s. The purpose of the study was to investigate the transfer of digitoxin across the placental barrier of pregnant women and to determine the relative concentration of the unchanged drug and its metabolic products in various fetal organs. The subjects were four pregnant women who were hospitalized at the Chicago Lying-in Hospital. Three of the women had abortions; the fourth delivered an anencephalic baby. Three to 5 hours before hysterotomy, three of the women were intravenously given from 0.25 to 0.5 milligram of digitoxin labeled with carbon- 14 $\left(\mathrm{C}^{14}\right)$ at a concentration of 0.25 to 0.5 microcurie per milligram. The fourth woman was given 0.5 milligram of the radioactive drug 2 to 3 hours be- fore the expected time of delivery. The Algonne Cancer Research Hospital was operated by the University of Chicago, which was funded by the U.S. Atomic Energy Commission.

\section{References}

Okita, G.T., E.J. Plotz, and M.E. Davis. "Placental Transfer of Radioactive Digitoxin in Fregnant Women and its Fetal Distribution." Semiannual Reports to the U.S. Atomic Energy Commission, Vol. 1, Parts 1-6, 1954 to 1956. Chicago:

Argonne Cancer Research Hospital, pp. 26-30. The University of Chicago, Office of Legal Counsel, Semiannual Reports of the Argonne Cancer Research Hospital.

UC- 11. Wuman Tracer Studies Using Tritum and Carbon-14.Labeled Cholusterol

IN 1957, AN EXPERIMENT was conducted at the Argonne Cancer Research Hospital, using radioactively labeled cholesterol. A 60-year-old man with chronic arthritis was the subject of this study. $\mathrm{He}$ received an intravenous injection containing 33.8 microcuries of tritium-labeled $\left(\mathrm{H}^{3}\right)$ cholesterol and 4.3 microcuries of cholesterol labeled with carbon-14 $\left(\mathrm{C}^{14}\right)$. Blood samples were withdrawn at various times starting about 4 hours after injection and continuing periodically for 10 days. Urine samples were also collected and analyzed for $\mathrm{C}^{14}$ - and $\mathrm{H}^{3}$-labeled cholesterol and steroid hormones. This experiment showed the advantages of using $\mathrm{H}^{3}$ and $\mathrm{C}^{14}$ in humans. It also showed the distribution of $\mathrm{C}^{14}$ and $\mathrm{H}^{3}$ in hormones synthesized from cholesterol. This study was funded by the Damon Runyon Memorial Fund and the U.S. Atomic Energy Commission. (Previously described in \#23 on the original list of 48 experiments released by DOE in June 1994)

\section{References}

Werbin, H., D.M. Bergenstal, R.G. Gould, and G.V. LeRoy. "Evaluation of Tritium Cholesterol as a Tracer in Man." The Journal of Clinical Endocrinology and Metabolism. Vol. 17, No. 3, March 1957, pp. 337-345. 


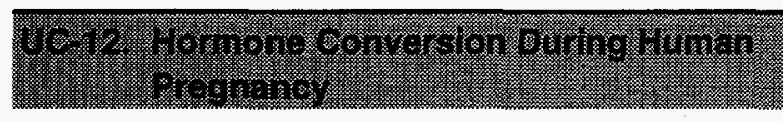

THIS STUDY WAS CONDUCTED by the Argonne Cancer Research Hospital in the mid- to late 1950s. The purpose of the study was to determine whether acetate and cholesterol are precursors of estrone in pregnant women. The subject was a 36-year-old white woman who underwent a thyroidectomy prior to pregnancy. An intramuscular injection of 35.09 microcuries of testosterone-4- $\mathrm{C}^{14}$ was administered during the 7 th week of pregnancy and an abortion was performed 4 days after the injection. About 55 percent of the radioactivity derived from the labeled testosterone was eliminated from the body by way of the kidney. The results of this experiment demonstrated the conversion of testosterone to estrone during the course of human pregnancy. The U.S. Atomic Energy Commission provided funding to the Argonne Cancer Research Hospital through the University of Chicago, its operating contractor.

\section{References}

Ejarque, P., E.J. Plotz, and M.E. Davis. "Conversion of Testosterone-4-C $C^{14}$ into Esterone- $C^{14}$ During Human Pregnancy." Semiannual Reports to the U.S. Atomic Energy Commission, Vol. 2, Part 100, 1956 and Parts 7-10, 1957 to 1958. Chicago: Argonne Cancer Research Hospital, pp. 61-65. The University of Chicago, Office of Legal Counsel, Semiannual Reports of the Argonne Cancer Research Hospital.

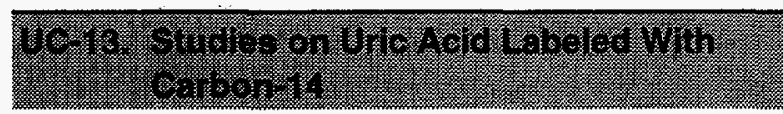

IN THE LATE 1950s, studies were carried out at the Argonne Cancer Research Hospital to investigate the metabolism of uric acid in humans. Uric acid labeled with carbon-14 $\left(\mathrm{C}^{14}\right)$ was intravenously injected into five individuals, consisting of two healthy subjects, two gouty subjects, and one patient with arteriosclerotic heart disease. Urine samples were analyzed for $\mathrm{C}^{14}$ content. For three individuals, after the administration of the carbon14-labeled uric acid, samples of expired air were collected and radioassayed. The expired air from all three patients showed that some of the injected uric acid had been degraded to carbon dioxide and ammonia. Saliva, gastric juice, and bile were also radioassayed to determine the amount of uric acid excreted into the intestine.

To verify the role of the intestinal flora on uricolysis, the degradation of intravenously administered uric acid $\mathrm{C}^{14}$ was studied before and after a high degree of intestinal bacteriostasis had developed. The subject was a healthy 57 -year-old male, who was kept on a diet during the study and for 10 days prior to the study. After intravenous administration of 33.23 milligrams of uric acid containing 35 microcuries of $\mathrm{C}^{14}$, urine and expired-air samples were collected for 10 days. On the 11th day, three types of antibiotics were orally administered and after establishing the desired bacteria level in the intestinal tract, 35 microcuries of $\mathrm{C}^{14}$-labeled uric acid was intravenously injected. This research found that intestinal flora play a prominent role in the degradation of uric acid in humans. The Argonne Cancer Research Hospital was operated by the University of Chicago and supported by the U.S. Atomic Energy Commission.

\section{References}

Sorensen, L.B. "The Degradation of Uric Acid in Man." Semiannual Reports to the U.S. Atomic Energy Commission, Vol. 2, Part 100, 1956 and Parts 7-10, 1957 to 1958. Chicago: Argonne Cancer Research Hospital, pp.1-20. The University of Chicago, Office of Legal Counsel, Semiannual Reports of the Argonne Cancer Research Hospital.

Sorensen, L.B. "Studies on Purine Metabolism: Uric Acid Metabolism." Semiannual Reports to the U.S. Atomic Energy Commission, Vol. 3, Part 101, 1961 and Parts 11-15, 1959 to 1961. Chicago: Argonne Cancer Research Hospital, pp. 96-98. The University of Chicago, Office of Legal Counsel, Semiannual Reports of the Argonne Cancer Research Hospital.

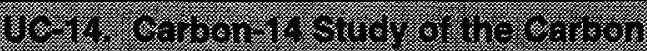 bojife peolin Wh}

THIS RESEARCH WAS CONDUCTED in the late 1950s at the Argonne Cancer Research Hospital. Since many materials labeled with carbon-14 $\left(\mathrm{C}^{14}\right)$ are oxidized to carbon-dioxide-labeled $\mathrm{C}^{14}$, this research sought to determine the metabolic pool of 
carbon dioxide in humans. A solution of $\mathrm{NaHC}^{14} \mathrm{O}_{3}$ was given intravenously at a constant rate for a period of two to four hours, while the one subject breathed continuously through a beta-particle chamber. The Argonne Cancer Research Hospital was operated by the University of Chicago which was funded by the U.S. Atomic Energy Commission.

\section{References}

Okita, G.T., P. Meir, and G.V. LeRoy. "The Carbon Dioxide Pool in Man." Semiannual Reports to the U.S. Atomic Energy Commission, Vol. 3, Part 101, 1961 and Parts 11-15, 1959 to 1961. Chicago: Argonne Cancer Research Hospital, pp. 19-21. The University of Chicago, Office of Legal Counsel, Semiannual Reports of the Argonne Cancer Research Hospital.

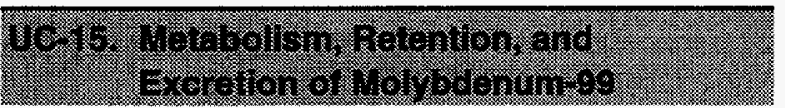

IN THE LATE 1950s, the Argonne Cancer Research Hospital conducted studies on the absorption and excretion patterns by means of molybdenum-99 $\left(\mathrm{Mo}^{99}\right)$. The studies were carried out on healthy subjects to determine the role of molybdenum in the oxidation of hypoxanthine and xanthine (precursors of uric acid). The urinary excretion rate of molybdenum in normal subjects was determined. Molybdenum was readily absorbed from the gastrointestinal tract. Seventy-five percent of ingested $\mathrm{Mo}^{99}$ was recovered in the first 24-hour urine sample. The Argonne Cancer Research Hospital was operated by the University of Chicago, which was funded by the U.S. Atomic Energy Commission.

\section{References}

Sorenson L.B. "Determination of Molybdenum in Biological Material." Semiannual Reports to the U.S. Atomic Energy Commission, Vol. 3, Part 101, 1961 and Parts 11-15, 1959 to 1961. Chicago: Argonne Cancer Research Hospital, p. 99. The University of Chicago, Office of Legal Counsel, Semiannual Reports of the Argonne Cancer Research Hospital.

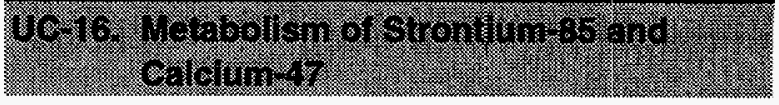

In 1960, AT the ARgonne Cancer Research Hospital, tracer amounts of strontium-85 $\left(\mathrm{Si}^{85}\right)$ as strontium chloride, in doses from 26 to 40 microcuries, were administered intravenously to seven adult subjects (six male and one female). Measurements were made of blood specimens, urine specimens, and total body gamma activity. The subjects included a woman with moderate osteoporosis, a 66-year-old male with multiple myeloma, and 2 males in the 60-year age group.

The research found that strontium is retained with greater avidity where there is deossification of the skeleton (skeletal disease). One other patient with metastatic parathyroid carcinoma was intravenously administered $\mathbf{5 0}$ microcuries of $\mathrm{S}^{85}$, and total body counting was performed over a 238-day period. Studies on the metabolism of calcium were carried out using calcium- $47\left(\mathrm{Ca}^{47}\right)$. Sixteen hospitalized patients were counted in the whole body counting facility following a single 20microcurie dose of $\mathrm{Ca}^{47}$. The Argonne Cancer Research Hospital was operated by the University of Chicago, which was funded by the U.S. Atomic Energy Commission.

\section{References}

Hasterlik, R.J. "Metabolic Studies of Alkaline Earth Metals: Metabolism of Strontium and Calcium in the Human." Semiannual Reports to the U.S. Atomic Energy Commission, Vol. 3, Part 101, 1961 and Parts 11-15, 1959 to 1961. Chicago: Argonne Cancer Research Hospital, pp. 11-13. The University of Chicago, Office of Legal Counsel, Semiannual Reports of the Argonne Cancer Research Hospital.

Hasterlik, R.J., G.V. LeRoy, and C.M. Newton. "The Argonne Cancer Research Hospital TotalBody Counter." Semiannual Reports to the U.S. Atomic Energy Commission, Vol. 5, Parts 21-25, Parts 102-104, 1964 to 1966. Chicago: Argonne Cancer Research Hospital, pp. 70-72. The University of Chicago, Office of Legal Counsel, Semiannual Reports of the Argonne Cancer Research Hospital. 


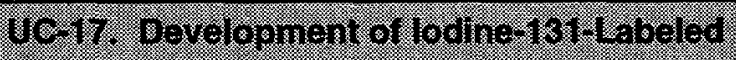
Fivorescernas a Brain Trmor Iraging agent

THIS STUDY WAS CONDUCTED in 1960 at the Argonne Cancer Research Hospital. Fluorescein labeled with radioiodine $\left(1^{131}\right)$ was developed to diagnose tumors of the central nervous system. Information obtained included the rate of disappearance from the blood, the rate of excretion, distribution in tissues, and comparison of concentrations in brain tumors and in normal brain tissue. Patients suspected of having brain tumors were selected for studies on the localization and retention of $\mathrm{I}^{134}$-fluorescein. Urine and stool samples were also collected from six patients over a 48-hour period for $\mathrm{I}^{131}$ analysis. Two normal volunteers were also injected with 5.7 microcuries of $1^{131}$-fluorescein. A total of 102 patients were injected. This research was supported in part by a grant from the American Cancer Society. The Argonne Cancer Research Hospital was operated by the University of Chicago, which was funded by the U.S. Atomic Energy Commission.

\section{References}

Tocus, E.C., G.T. Okita, J.P. Evans, and S. Mullan. "The Localization of Octoiodofluorescein$1^{131}$." Semiannual Reports to the U.S. Atomic Energy Commission, Vol. 3, Part 101, 1961 and Parts 11-15, 1959 to 1961. Chicago: Argonne Cancer Research Hospital, pp. 104-113. The University of Chicago, Office of Legal Counsel, Semiannual Reports of the Argonne Cancer Research Hospital.

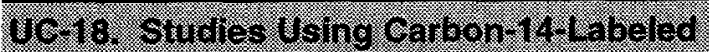 Compounds in Patents. Whit Gout}

StUdies Were Conducted by the Argonne Cancer Research Hospital in the early 1960 s on patients with gout to determine the metabolism of uric acid in humans. This research was conducted to determine whether patients with various degrees and types of gout had an increased incorporation of glycine into uric acid. Gout is an inherited metabolic disorder characterized by chronic arthritis and usually by an elevated uricacid blood level. Twelve patients with gout were intravenously administered glycine labeled with carbon-14 $\left(\mathrm{C}^{14}\right)$ over a period of 60 minutes. The results of these experiments demonstrated that excessive incorporation of glycine into uric acid is usually confined to gouty subjects with abnormally high urinary outputs of uric acid. Three of the subjects who were overproducers of uric acid were studied in detail to determine the pathway whereby glycine is incorporated into uric acid more promptly than in normal humans.

Two of the healthy subjects and one other patient with gout, who did not overproduce uric acid, were also part of this study. These individuals were administered azathioprine, a cytotoxic and immunosuppressive agent, for 7 to 10 days prior to the intravenous administration of 100 microcuries glycine labeled with $\mathrm{C}^{\dagger 4}$. This research found that when azathioprine was given to subjects who overproduce uric acid, their urinary uric acid fell to normal values. The Argonne Cancer Research Hospital was operated by the University of Chicago, which was funded by the U.S. Atomic Energy Commission.

\section{References}

Sorensen L.B. "The Pathogenesis of Gout." Semiannual Reports to the U.S. Atomic Energy Commission, Vol. 4, Parts 16-20, 1961 to 1963. Chicago: Argonne Cancer Research Hospital, pp. 23-40. The University of Chicago, Office of Legal Counsel, Semiannual Reports of the Argonne Cancer Research Hospital.

Sorensen L.B. "Suppression of the Shunt Pathway in Primary Gout by Azathioprine." Semiannual Reports to the U.S. Atomic Energy Commission, Vol. 5, Parts 21-25, Parts 102-104, 1964 to 1966. Chicago: Argonne Cancer Research Hospital, pp. 56-61. The University of Chicago, Office of Legal Counsel, Semiannual Reports of the Argonne Cancer Research Hospital.

\section{VC. 10. Use of Molybelenum 99 for L V Ver Scatinng Studies}

Molybdenum-99 was used as a tracer agent in the early 1960s, at the Argonne Cancer Research Hospital, to image the liver and to determine the disappearance from the blood of intravenously injected molybdenum- $99\left(\mathrm{Mo}^{99}\right)$. Both normal subjects and patients with liver disease were administered between 40 and 100 
microcuries of $\mathrm{Mo}^{99}$ by intravenous injection. Liver scans were performed at the Argonne Cancer Research Hospital's whole body counting facility. Subjects included normal volunteers and one patient with viral hepatitis. Approximately 100 liver scans were performed using $\mathrm{Mo}^{99}$ as a tracer. The Argonne Cancer Research Hospital was operated under contract by the University of Chicago which was funded by the U.S. Atomic Energy Commission.

\section{References}

Sorensen, L.B. and M. Archambault. "Visualization of the Liver by Scanning Using $\mathrm{Mo}^{99}$ (Molybdate) as Tracer." Semiannual Reports to the U.S. Atomic Energy Commission, Vol. 4, Parts 16-20, 1961 to 1963. Chicago: Argonne Cancer Research Hospital, pp. 57-68. The University of Chicago, Office of Legal Counsel, Semiannual Reports of the Argonne Cancer Research Hospital.

\section{VC 20. Metabolism of LThoeholie 4de Laheled wh carbon-14}

THESE STUDIES WERE carried out by the Argonne Cancer Research Hospital in the early 1960 s to determine the metabolism of lithocholic acid. Lithocholic acid, a steroid produced by the human body, is found in human bile and feces. A dose of eleven microcuries of lithocholic acid labeled with carbon-14 $\left(\mathrm{C}^{14}\right)$ was orally administered to four patients, 20 to 72 hours before elective gallbladder surgery for gallstones. Two other patients with functioning gallbladders were studied after oral administration of 50 microcuries of lithocholic acid labeled with $\mathrm{C}^{14}$. Bile was obtained during their gallbladder operations and analyzed for $\mathrm{C}^{14}$. The Argonne Cancer Research Hospital was operated under contract by the University of Chicago which was funded by the U.S. Atomic Energy Commission.

\section{References}

Norman, A. and R.H. Palmer. "Metabolites of Lithocholic Acid-24-C ${ }^{14}$ in Human Bile and Feces." Semiannual Reports to the U.S. Atomic Energy Commission, Vol. 5, Parts 21-25, Part 102-104, 1964 to 1966. Chicago: Argonne Cancer Research Hospital, pp. 65-81. The University of Chicago, Office of Legal Counsel, Semiannual Reports of the Argonne Cancer Research Hospital.
Palmer R.H. "The Formation of Bile Acid Sulfates: A New Pathway of Bile Acid Metabolism in Humans." Semiannual Reports to the U.S. Atomic Energy Commission, Vol. 6, Parts 26-33. Chicago: Argonne Cancer Research Hospital, pp. 71-75. The University of Chicago, Dffice of Legal Counsel, Semiannual Reports of the Argonne Cancer Research Hospital.

WC-21. Preliminary Tracer Studies Using Techrotin $99 \mathrm{~m}$

STUDIES WERE CONDUCTED in 1961 at the Argonne Cancer Research Hospital on the use of technetium-99m $\left(\mathrm{Tc}^{99 \mathrm{~m}}\right)$ as a tracer and imaging agent for nuclear medicine. Scans of human subjects were made with a Picker Magnascanner 30 minutes after intravenous injection of $T c^{99 m}$. One white female received an intravenous injection of 1 millicurie of $\mathrm{Tc}^{99 \mathrm{~m}}$. Thyroid scans were conducted on a clinically normal white male $30 \mathrm{~min}$ utes after intravenous injection of $\mathrm{Tc}^{99 \mathrm{~m}}$ and the results were compared with scans conducted after iodine-131 $\left(\left(^{131}\right)\right.$ administration. The urinary and fecal excretion of $\mathrm{Tc}^{99 \mathrm{~m}}$ pertechnate was studied in four patients. At least two normal subjects, including a healthy African-American male, were administered 440 microcuries of $7 c^{99 m}$ in order to analyze radiocardiograms. Another male subject was administered 1 millicurie of $T c^{99 m}$ and dose calculations were made for the total body, stomach, and thyroid. The purpose of this research was to determine the biological retention half-time, and suitability as an imaging agent, of $\mathrm{TC}^{99 \mathrm{~m}}$. With a biological retention half-tirne of 48 hours, $\mathrm{Tc}^{99 \mathrm{~m}}$ was found to be a suitable imaging agent . The Argonne Cancer Research Hospital was operated under contract by the University of Chicago, which was funded by the U.S. Atomic Energy Commission.

\section{References}

Harper P.V., G. Andros, and K. Lathrop. "Preliminary Observations on the Use of Six-Hour $\mathrm{Tc}^{99 \mathrm{~m}}$ as a Tracer in Biology and Medicine." Semiannual Reports to the U.S. Atomic Energy Commission, Vol. 4, Parts 16-20, 1961 to 1963. Chicago: Argonne Cancer Research Hospital, pp. 76-88. The University of Chicago, Office of Legal Counsel, Semiannual Reports of the Argonne Cancer Research Hospital. 
Harper P.V., K.A. Lathrop, R.J. McCardle, and G. Andros. "The Use of $\mathrm{TC}^{99 \mathrm{~m}}$ as Pertechnetate for Thyroid Liver and Brain Scanning." Semiannual Reports to the U.S. Atomic Energy Commission, Vol. 5, Parts 21-25, Part 102-104, 1964 to 1966. Chicago: Argonne Cancer Research Hospital, pp. 119-133. The University of Chicago, Office of Legal Counsel, Semiannual Reports of the Argonne Cancer Research Hospital.

Harper P.V. and K. Lathrop. "Technetium-99m as a Scanning Agent." Semiannual Reports to the U.S. Atomic Energy Commission, Vol. 5, Parts 21-25, Part 102-104, 1964 to 1966. Chicago: Argonne Cancer Research Hospital, pp. 96-98. The University of Chicago, Office of Legal Counsel, Semiannual Reports of the Argonne Cancer Research Hospital.

Harper P.V. and K. Lathrop. "The Pharmacodynamics of Technetium Pertechnetate $\left(99 \mathrm{~m}-\mathrm{TCO}_{4}\right)$." Semiannual Reports to the U.S. Atomic Energy Commission, Vol. 5, Parts 21-25, Part 102-104, 1964 to 1966. Chicago: Argonne Cancer Research Hospital, pp. 97-98. The University of Chicago, Office of Legal Counsel, Semiannual Reports of the Argonne Cancer Research Hospital.

UC 22. Melabollsmand $A$ bsoription of SMh Medications Labeled Win Carbon-14

THIS RESEARCH WAS CONDUCTED by the Argonne Cancer Research Hospital in the mid-1960s. Eleven normal and nine psoriatic Caucasian volunteers served as experimental subjects. Palmitic acid containing 1 microcurie of carboxyl carbon $\left(\mathrm{C}^{14}\right)$ label dissolved in petroleum ether was dripped onto each of two demarcated areas of lesion-free skin on the back of each subject. After 2.5 hours, the skin was wiped with petroleum ether-soaked cotton. The entire study was repeated in four additional normal volunteers following the application of an ointment comparable to the standard treatment for psoriasis. The study was also repeated in one other normal volunteer and in two patients with minor eczema. The Argonne Cancer Research Hospital was operated under contract by the University of Chicago, which was funded by the U.S. Atomic Energy Commission.

\section{References}

Gara, A., E. Estrada, S. Rothman, and A.L. Lorincz. "Deficient Cholesterol Esterifying Ability of Lesion-Free Skin Surfaces in Psoriatic Individuals." Semiannual Reports to the U.S. Atomic Energy Commission, Vol. 5, Parts 21-25, Part 102104, 1964 to 1966. Chicago: Argonne Cancer Research Hospital, pp. 62-69. The University of Chicago, Office of Legal Counsel, Semiannual Reports of the Argonne Cancer Research Hospital.

Lorincz, A.L. "Specific Metabolic Processes in Skin." Semiannual Reports to the U.S. Atomic Energy Commission, Vol. 5, Parts 21-25, Part 102104, 1964 to 1966. Chicago: Argonne Cancer Research Hospital, p. 75. The University of Chicago, Office of Legal Counsel, Semiannual Reports of the Argonne Cancer Research Hospital.

16-28. Studies on the Use or lodine-181 Aititibrinogen

ThIS WAS A COLLABORATIVE study between the Argonne Cancer Research Hospital and the University of Rochester conducted in the mid-1960s. Its purpose was to determine the diagnostic and therapeutic potential of antifibrinogen labeled with iodine-131 $\left(1^{131}\right)$, which was thought to combine with circulating fibrinogen and to localize in tumors. In half of the tumors studied, localization allowed for clear visualization on scanning.

An antibody was intravenously administered. This procedure was carried out in two patients. Although some tumors imaged, this study was not successful in treating cancer because of poor localization of the antifibrinogen label with $^{131}$. The Argonne Cancer Research Hospital was operated under contract by the University of Chicago, which was funded by the U.S. Atomic Energy Commission.

\section{References}

Harper, P.V. and I. Spar. "I ${ }^{131}$-Antifibrinogen." Semiannual Reports to the U.S. Atomic Energy Commission, Vol. 5, Parts 21-25, Part 102-104, 1964 to 1966. Chicago: Argonne Cancer Research Hospital, pp. 98-100. The University of Chicago, Office of Legal Counsel, Semiannual Reports of the Argonne Cancer Research Hospital. 
UC-24. Bone-tissue Radlography Using and External Source of looine-125

A METHOD WAS DEVELOPED at the Argonne Cancer Research Hospital in Chicago to measure bone mineral content in animals or humans, using an external iodine-125 $\left(\left(^{125}\right)\right.$ source. Bone mineral was determined by transmitting a small beam of photon radiation from an $\mathrm{I}^{125}$ source through a single human finger bone, capturing an image of the finger on radiographic film. Mineral content was determined by analyzing the image density. This technique was tested on a group of postmenopausal women (with ovaries removed) who were estrogen deficient to determine the beneficial effects of estrogen therapy on bone mineralization. Another group of postmenopausal women with ovaries and no hormone therapy was also studied, again using finger bone radiography. $A$ group of premenopausal women served as controls. One hundred patients participated in this study. The study showed that hormone therapy had a beneficial effect on bone mineral content in women. The Argonne Cancer Research Hospital was operated by the University of Chicago and supported by the U.S. Atomic Energy Commission.

\section{References}

Lanzl, L.H. and N.M. Strandjord. "Measurement of Bone Mineral Content Using a Radioactive Device." Semiannual Reports to the U.S. Atomic Energy Commission, Vol. 5, Parts 21-25, Part 102-104, 1964 to 1966. Chicago: Argonne Cancer Research Hospital, pp. 141-142. The University of Chicago, Office of Legal Counsel, Semiannual Reports of the Argonne Cancer Research Hospital.

\section{UC-25. Retention of Iron-59 in the Lungs}

THIS STUDY WAS CONDUCTED at the Argonne Cancer Research Hospital in 1967. This study compared the amount of blood lost from the body to that retained from the lungs in a menopausal woman with pulmonary hemosiderosis, a disease characterized by expectoration of blood from the lungs or bronchial tubes. This was the first study in which linear profile scanning of iron-59 $\left(\mathrm{Fe}^{59}\right)$ was used for this purpose. When the patient was in remission from the disease, 10 microcuries of $\mathrm{Fe}^{59}$ were injected intravenously. Analysis was done on plasma iron clearance, serial body surface counting rates, erythrocyte incorporation, and linear profile scanning of $\mathrm{Fe}^{59}$. The Argonne Cancer Research Hospital was operated under contract by the University of Chicago which was funded by the U.S. Atomic Energy Commission.

\section{References}

DeGowin, R.L., L.B. Sorensen, D.B. Charleston, A. Gottschalk, and J.H. Greenwald. "Retention of Radioiron in the Lungs of a Woman with Idiopathic Pulmonary Hemosiderosis." Semiannual Reports to the U.S. Atomic Energy Commission, Vol. 6, Parts 26-33, 1966 to 1970. Chicago:

Argonne Cancer Research Hospital, pp. 28-37. The University of Chicago, Office of Legal Counsel, Semiannual Reports of the Argonne Cancer Research Hospital.

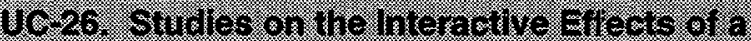

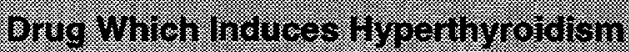

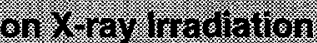

THIS RESEARCH WAS CONDUCTED by the Argonne Cancer Research Hospital in the late 1960s to determine whether induced hyperthyroidism increased the sensitivity of tumors to therapeutic $x$ rays. The subjects of this experiment were patients with advanced cancer who could tolerate an elevated metabolic rate caused by oral doses of triiodothyronine. $X$ rays were also administered in daily fractionated doses. In two patients with bronchogenic carcinomas, after induction of the hyperthyroid condition, the metastases on one side was treated and the other side was treated only after the BMR had been allowed to return to normal. At autopsy, 3 months after the treatment, the side treated with the drug and the $x$ rays showed only fibrosis while the tumor was still present in the side treated by $x$ rays alone. Another patient with lung metastasis due to melanoma was subjected to the combined treatment with no response. In two patients with adenocarcinoma brain metastases and unknown primary lesions, the combined therapy was effective on the brain lesions but not on the primary lesions. The U.S. Atomic Energy Commission provided funding to the Argonne Cancer Research Hospital through the University of Chicago, its operating contractor. 


\section{References}

Griem M.L. and J.A. Stein. "The Effect of L-triiodothyronine on Radiation Sensitivity." Semiannual Reports to the U.S. Atomic Energy Commission, Vol. 3, Part 101, 1961 and Parts 11-15, 1959 to 1961. Chicago: Argonne Cancer Research Hospital, pp. 52-54. The University of Chicago, Office of Legal Counsel, Semiannual Reports of the Argonne Cancer Research Hospital.

\section{0-27. Wotebollon and fotemion Studies} Voing Selentum 75

THESE STUDIES WERE carried out in the late $1960 \mathrm{~s}$ at the Argonne Cancer Research Hospital to determine the organ uptake of selenium-75 $\left(\mathrm{Se}^{75}\right)$. Four subjects were intravenously injected with $\mathrm{Se}^{75}$. The first was a male with a varicose ulcer who was administered 100 microcuries. The second was a male with mild diabetes who was administered 200 microcuries on one occasion and was subsequently administered 220 microcuries. Subjects were followed by whole body counting for up to 30 months. The biological half-time was found to be about 80 days. The results of this study found that after a single injection of $\mathrm{Se}^{75}$, one-half of the $\mathrm{Se}^{75}$ was eliminated from the body after 80 days. The Argonne Cancer Research Hospital was operated under contract by the University of Chicago, which was funded by the U.S. Atomic Energy Commission.

\section{References}

Lathrop, K.A., P.V. Harper, and F.D. Malkinson. "Human Total-Body Retention and Excretory Routes of $\mathrm{Se}^{75}$ from Selenomethionine." Semiannual Reports to the U.S. Atomic Energy Commission, Vol. 6, Parts 26-33, 1966 to 1970. Chicago: Argonne Cancer Research Hospital, pp. 49-57. The University of Chicago, Office of Legal Counsel, Semiannual Reports of the Argonne Cancer Research Hospital.

\section{WC 28. Comparison of CaWlun 68 .

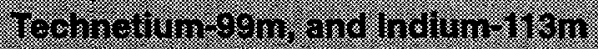 10r. Diagnosis of Tumors}

IN THE LATE 1960s, the Argonne Cancer Research Hospital conducted studies to determine the combination of radionuclide preparation and imaging system with the best lesion-detection capabilities per unit radiation dose. Preparations of gallium-68 $\left(\mathrm{Ga}^{68}\right)$, technetium-99m ( $\left.\mathrm{Tc}^{99 m}\right)$, and indium-113m $\left(\mathrm{ln}^{113 \mathrm{~m}}\right)$ were used to detect lesions in the brain, kidney, liver, and lung. Biological half-times in humans were compared with those in mice by measuring radioactivity in the excreta. The Argonne Cancer Research Hospital was operated under contract by the University of Chicago, which was funded by the U.S. Atomic Energy Commission.

\section{References}

Lathrop, K.A., T.D. Cohen, R.N. Beck, and P.V. Harper. "Comparison of Gallium-68, Technetium$99 \mathrm{~m}$, and Indium-113m Used with the Gamma Camera and the 3-Inch and 5-Inch Scanners for Visualization of Lesions in the Brain, Kidney, Liver, and Lung." Semiannual Reports to the U.S. Atomic Energy Commission, Vol. 6, Parts 26-33, 1966 to 1970. Chicago: Argonne Cancer Research Hospital, pp. 1-13. The University of Chicago, Office of Legal Counsel, Semiannual Reports of the Argonne Cancer Research Hospital.

\section{University of Rochester}

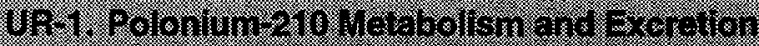 Stuby}

DURING THE EARLY 1940s, the University of Rochester in New York conducted studies on the retention, excretion, and gastrointestinal tract absorption of polonium-210 ( $\left.\mathrm{Po}^{210}\right)$ in humans, using patients at Strong Memorial Hospital in Rochester, NY as subjects. The purpose of the study was to determine occupational exposure limits for use in radiation protection programs. Five patients with advanced lymphoma or leukemia participated. Four were administered an intravenous injection of 8 to 23 microcuries of $\mathrm{Po}^{210}$ and one patient was orally administered 18.5 microcuries of $\mathrm{Po}^{210}$ in tap water. Urine samples were subsequently collected and analyzed for $\mathrm{Po}^{210}$. All subjects died of preexisting ailments shortly after the administrations. Tissues were obtained at autopsy and examined for $\mathrm{Po}^{210}$ concentration. This research was supported by the Manhattan Engineer District. (This experiment was referenced in the Markey report.) 


\section{References}

Fink, R.M. "Biological Studies with Polonium, Radium, and Plutonium." National Nuclear Energy Series. Div. VI, Vol. 3. New York: McGraw-Hill, 1950.

Stannard. J.N. Radioactivity and Health: A History. Office of Scientific and Technical Information. 1988, p. 213-214.

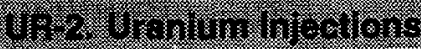

From August 1946 to January 1947, the University of Rochester conducted toxicity studies on uranium, using hospital patients as subjects. The purpose of the studies was to determine the dose level at which renal injury is first detectable, measure the rate at which uranium is eliminated from the body once it enters the bloodstream, and observe the effect of measures intended to alter the excretion rate. Human subjects included four males and two females, all with good kidney function, ranging in age from 24 to 61 years. All had medical conditions, such as undernutrition, alcoholism, or heart disease. Highly enriched uranium (uranium-234 and uranium-235) was administered intravenously as uranyl nitrate in amounts ranging from 6.4 to 70.9 micrograms per kilogram of body weight. At levels approaching 50 micrograms per kilogram, the preparation was diluted with natural uranyl acetate $\left(U^{238}\right)$ to limit the potential radiotoxicity associated with systemic enriched uranium. Five subjects received a single injection and experienced no kidney damage. The sixth subject experienced slight kidney tissue toxicity at the 70.9 micro$\mathrm{gram} / \mathrm{kg}$ level, suggesting that the human tolerance level had been reached. This patient was administered ammonium chloride to induce an acidosis condition (a decrease in alkali relative to acid in bodily fluids), then received a second injection of uranyl nitrate at a dose of 56.6 microgram per kilogram.

These studies showed that the tolerance level for uranium in the human circulation was about 70 micrograms per kilogram of body weight, that uranium excretion occurred mainly through urine, that 70 to 85 percent was eliminated in the first 24 hours, and that acidosis decreased the rate of uranium excretion. This research was supported by the Manhattan Engineer District. (This experiment was referenced in the Markey report.)

\section{References}

Bassett, S.H., A. Frankel, N. Cedars, H. Van Alstine, C. Waterhouse, and K. Cusson. The Excretion of Hexavalent Uranium Following Intravenous Administration. II. Studies on Human Subjects. Rochester: The University of Rochester, UR-37, June 1948.

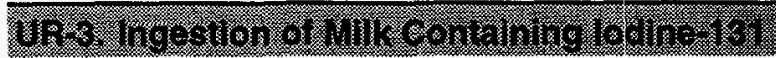

THIS STUDY WAS CONDUCTED in 1963 by a graduate student at the University of Rochester to investigate the human body's metabolism of radioiodine found in dairy products. The research sought to determine if iodine found in milk was transferred to the thyroid in the same quantities as the inorganic iodide commonly used in medical studies. As much as 40 percent of the iodine found in milk was found to be protein bound. The study focused on the range of uptake percentages in children of various ages. Subjects for the experiment were chosen with an emphasis on the younger age groups, since the majority of known research had been conducted on adults. The subjects ranged in age from 6 years to 50 years; seven were less than 21 years old. The milk used for this study was obtained from Cornell University's Department of Veterinary Medicine, where a cow had been fed iodine-131 $\left(1^{131}\right)$ so as to produce 5,000 to 10,000 picocuries per liter in its milk. All subjects were put on an iodine restricted diet prior to the study and then were fed the $\mathrm{I}^{131}$ milk for a minimum of 14 days. One of the children in this study subsequently developed thyroid carcinoma. The research was performed under a contract with the U.S. Atomic Energy Commission.

\section{References}

Cuddihy, R.G. "Hazard to Man from I"131 in the Environment." Health Physics. Vol. 12, 1966, pp. $1,021-1,025$.

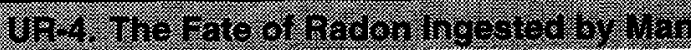

IN 1964, the Department of Radiation Biology at the University of Rochester conducted a study on the fate of radon ingested by humans. Two male 
subjects, one 56 and the other 36 , participated. On two occasions, each subject drank approximately 1 microcurie of radon-222 $\left(\mathrm{Rn}^{222}\right)$ in equilibrium with its decay products in 100 milliliters of water. On three separate days, the ingestions of radon were followed by a normal breakfast; the fourth followed a larger breakfast high in fat. The subject's respired air, blood, and urine were obtained and sampled for $\mathrm{Rn}^{222}$ activity. This study provided rates at which the body loses radon and the impact of stomach contents on the rate of loss. The research was supported by the U.S. Atomic Energy Commission. (Previously described in \#29 on the original list of 48 experiments released by DOE in June 1994)

\section{References}

Hursh, J.B., D. A. Morken, T.P. Davis, and A. Lovaas. "The Fate of Radon Ingested by Man." Health Physics. Vol. 11, 1965, pp. 465-476.

\section{Other}

\section{ort. Study or blosd Volumes Wh 18.the-13t-Tag ged Plasina Proteh}

Case Western Reserve University conducted this study in 1950. Blood volume determinations were made on 76 ambulatory hospital patients who exhibited normal fluid and protein balance. The subjects were injected with plasma protein tagged with iodine-131 $\left({ }^{131}\right)$ while they were fasting. They were confined to bed until the experiment was completed. Approximately 40 to 60 microcuries of $I^{131}$ were intravenously injected. Twelve patients who were to receive spinal anesthesia were also given radioactive iodinated protein at various intervals, preceding the administration of the anesthesia. No radioactivity was detected in the spinal fluid of these patients. The studies on the patients confined to bed showed that an average of 8 to 12 percent of the injected radioactive iodine was found in the urine within 24 hours of the injection. This research was partly supported by an Atomic Energy Commission contract.

\section{References}

Storaasli, J.P., H. Krieger, H.L. Friedell, and W.D. Holden. "The Use of Radioactive lodinated Plasma Protein in the Study of Blood Volume." American Journal of Obstetrics \& Gynecology. Vol. 91, October 1950, pp. 458-464.

Storaasli, J.P., H. Krieger, H.L. Friedell, and W.D. Holder. The Use of Plasma Protein Tagged lodine-131 in the Study of Blood Volumes. Cleveland: Western Reserve University, NYO-1608, July $6,1950$.

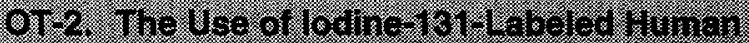

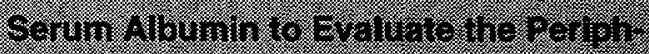 eral clrculaton}

THIS RESEARCH WAS carried out in 1952 at Case Western Reserve University. Human serum albumin labeled with iodine-131 $\left({ }^{131}\right)$ was injected into 77 subjects and a scintillation counter was used to determine cardiac output and to observe peripheral vascular flow. Approximately 150 microcuries of radioiodinated albumin were injected into the subjects. A series of these experiments were performed on young subjects with normal circulation. Four of the young subjects had one foot immersed in hot water for $20 \mathrm{~min}$ utes before the labeled albumin was injected into them. In two other subjects, the foot was immersed in ice water for 10 minutes before the test was performed. The study was carried out under contract with the U.S. Atomic Energy Commission.

\section{References}

Krieger, H., J.P. Storaasli, W.J. Macintyre, W.D. Holden, and $\mathrm{H}$. Friedell. "The Use of Radioactive lodinated Human Serum Albumin in Evaluating the Peripheral Circulation." Annals of Surgery, Vol. 136, No. 3, September 1952, pp. 357-365.

Maclntyre, W.J., J.P. Storaasli, H. Krieger, W.H. Pritchard, and H.L. Friedell. ${ }^{131}$ Labelled Serum Albumin-Its Use in the Study of Cardiac Output and Peripheral Vascular Flow. Cleveland: Western Reserve University, NYO-1642, March 11, 1952. 


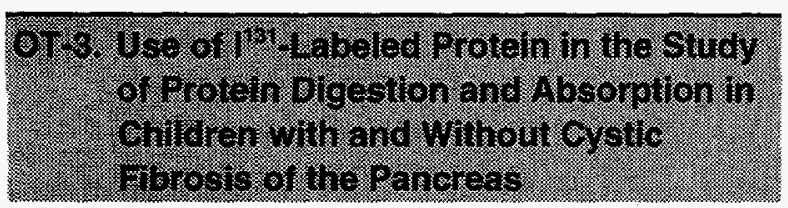

THIS STUDY WAS PERFORMED in 1952 at Case Western Reserve University. During the two decades prior to the study, several studies of protein digestion and absorption were carried out both in normal individuals and in patients with various diseases. This study describes a simple and accurate method to determine the efficiency of protein digestion and absorption, by measuring the isotope content of the feces after oral ingestion of protein labeled with iodine-131 $\left(1^{131}\right)$. The subjects were 10 children with diseases that did not specifically involve the gastrointestinal tract and 5 children with cystic fibrosis of the pancreas. These patients fasted for 12 hours before the experiment; then, a test meal containing $1^{131}$ was orally administered in place of breakfast. The test meal contained approximately 1 microcurie of labeled protein per kilogram of body weight. In the five children with cystic fibrosis of the pancreas, pancreatin was withheld for 3 days prior to and during the initial test. The subjects ranged in age from 1.6 years to 9 years. The research demonstrated a diminished retention of dietary protein in cystic fibrosis of the pancreas. This research was supported by a U.S. Atomic Energy Commission contract.

\section{References}

Lavik P.S., L.W. Matthews, G.W. Buckaloo, F.J. Lemm, S. Spector, and H.L. Friedell. "Use of I"131 Labeled Protein in the Study of Protein Digestion and Absorption in Children with and without Cystic Fibrosis of the Pancreas." Pediatrics. Vol. 10, 1952, p. 667-675.

Lavik, P.S., L.W. Matthews, G.W. Buckaloo, S. Spector, and H.L. Friedell. Use of $r^{131}$ Labeled Protein in the Study of Protein Digestion and Absorption in Children with and without Cystic Fibrosis of the Pancreas. Cleveland: Western Reserve University, NYO-4025, August 15, 1952.

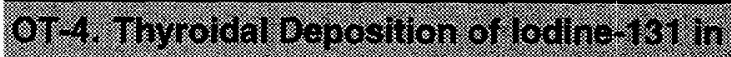
Wan Par and Bog. From Mrend: Normin Sources

IN 1963, Cornell UnIVERSITY conducted studies on the comparative uptake of iodine from ingested water and milk, using human and animal subjects. Eleven healthy male volunteers ranging in age from 26 to 52 years participated and ingested 0.1 liter of milk containing iodine-131 $\left(1^{131}\right)$. The study used milk obtained from cows that had been fed $\mathrm{I}^{131}$ two days prior to milk collection. The milk contained approximately 2.5 microcuries of $I^{131}$ per liter. Inorganic $\mathrm{I}^{131}$ was administered with 100 milliliters of water containing about 0.26 microcurie of ${ }^{131}$. Results of the study indicated that there was no significant difference in the uptake of iodine in humans when obtained through milk or water. This work was supported by the U.S. Atomic Energy Commission. (Previously described in \#47 on the original list of 48 experiments released by DOE in June 1994)

\section{References}

Comar, C.L., R.A. Wentworth, and J.R. Georgi. "Thyroidal Deposition in Man, Rat and Dog of Radioiodine from Milk and Non-Milk Sources." Health Physics. Vol. 9, 1963, pp. 1,249-1,252.

\section{OT-5 plasma Volumo STucles Using Chromum 51 - Chloride}

THIS RESEARCH WAS CONDUCTED at the Biophysical Laboratory and the Department of Medicine at Harvard Medical School and the Medical Clinic at Peter Bent Brigham Hospital in Boston. Approximately 100 microcuries of chromium- 51 $\left(\mathrm{Cr}^{51}\right)$ as chromium chloride were intravenously injected into 26 normal adults ( 5 women and 21 men). After allowing 5 minutes for mixing within the circulation, researchers drew four samples of blood and analyzed them in a gamma counter to determine plasma volumes. The plasma volumes were determined by this method. In some subjects, a second study was also performed. This method was further tested by measuring the plasma volume before and after transfusion or hemorrhage of between 250 and 500 milliliters of 
plasma in hospital patients and volunteer subjects. This research was supported in part by the U.S. Atomic Energy Commission and in part by the United States Public Health Service.

\section{References}

Frank, H. and S.J. Grey. "The Determination of Plasma Volume in Man with Radioactive Chromic Chloride." Journal of Clinical Investigation, Vol. 32, No.10, 1953, pp. 991-999.

\section{OT-6. Iodine-131. U.jake by the Muman innorio}

IN 1953, STUDIES were conducted at the University of lowa, lowa City, on the uptake of iodine$131\left(1^{131}\right)$ in thyroids of human embryos in utero. Pregnant women scheduled for therapeutic abortions were given dosages of 100 to 200 microcuries of $I^{131}$. Some time later, the abortions were performed. The aborted embryos were sectioned and autoradiographed. The human embryos showed thyroid uptake at 4 weeks, nearly one month earlier than was previously known. This finding was useful in understanding the transfer of radioiodine across the placental barrier. This study showed that it would not be prudent to administer $\mathrm{I}^{131}$ to pregnant women for diagnostic or therapeutic purposes. The number of subjects is not known. This work was funded by the U.S. Atomic Energy Commission. (Previously described in \#5 on the original list of 48 experiments released by DOE in June 1994)

\section{References}

U.S. Atomic Energy Commission. Monthly Status and Progress Report Division of Biology and Medicine. June 1953. U.S. Department of Energy Archives, Record Group 326, Division of Biology and Medicine, Box 3363, Folder 23.

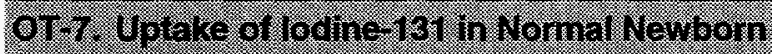 inaris in lova ely}

THE UPTAKE OF IODINE-131 $\left(1^{131}\right)$ was st udied in $^{\text {in }}$ newborn infants at the University of lowa, lowa City, in 1963. Twelve male and 13 female infants were included in this study. All were less than 36 hours old, weighted between 5.5 and 8.5 pounds, and were considered to be healthy and normal.
Less than 1 microcurie of $\mathrm{f}^{131}$ was administered to each newborn. Eight received the radioiodine orally and 17 by intramuscular injection. The concentration of $l^{131}$ in the thyroid was measured using a thyroid gamma probe. Measurements were continued at intervals of 2 to 8 hours for 3 to 4 days. This study showed that $\mathrm{I}^{131}$ was taken up by the thyroid at a higher level and more rapidly when administered by injection rather then ingestion. This study was supported by the U.S. Atomic Energy Commission and the American Cancer Society. (Previously described in \#4 an original 48 experiments released by DOE in June 1994)

\section{References}

Morrison, R.T., J.A. Birkbeck, T.C. Evans, and J.I. Routh. "Radioiodine Uptake Studies Newborn Infants." Journal of Nuclear Medicine. Vol. 4, 1963, pp.162-166.

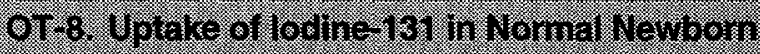 intants in Nebraska}

THE THYROID FUNCTION of infants was studied jointly by the Veterans Administration Hospital, Omaha, NB, and the Department of Radiology, University of Nebraska, College of Medicine, in 1960. Twenty-eight normal, healthy infants from the nursery at the College of Medicine, including 16 males and 12 females ranging in age from 72 to 180 hours, were involved in the experiment. The newborn infants were given 5 microcuries of iodine-131 $\left(1^{131}\right)$ through a gastric tube. The concentration of $I^{131}$ in the thyroid was measured 24 hours later. This study showed the thyroid of a newborn functioned similarly to those of adult thyroids. The subject's sex and weight were not related to thyroid function. (Previously described in \#4 on original 48 experiments released by DOE in June 1994)

\section{References}

Ogborn, R.E., R.E. Waggener, and E. VanHove. "Radioactive-lodine Concentration in Thyroid Glands of Newborn Infants." Pediatrics. Vol. 26, November 1960 , pp. 771-776. 


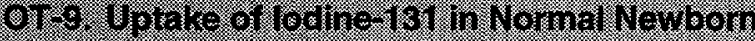 intants in Wemphis}

IODINE-131 $\left(I^{131}\right)$ WAS USED to stu dy the uptake of iodine in normal, newborn infants at the University of Tennessee, Memphis, in 1954. Seven male infants (one white and six black) between 2 and 3 days old were injected intravenously with 1 to 1.5 microcuries of $1^{131}$. The concentration of $I^{131}$ in the thyroid was measured 24 hours after injection. Absorbed doses to the infant thyroids were estimated to be about 60 rads. The $1^{131}$ uptake of the thyroid of the subjects was found to lie within the range of values that would be found in hyperthyroid adults. This study was supported by a grant from the U.S. Atomic Energy Commission. (Previously described in \#4 on the original list of 48 experiments released by DOE in June 1994)

\section{References}

Middlesworth, L.Van. "Radioactive lodide Uptake of Normal Newborn Infants." AMA American Journal of Diseases of Children. Vol. 88, October 1954, pp. 439-442.

\section{T-10. Radioactive ISotope Studies at Tulane}

IN THE LATE 1940s and early 1950s, a series of metabolic experiments was conducted at Charity Hospital and Tulane University School of Medicine, New Orleans, LA. The focus of the experiments was to investigate the role of electrolytes in normal humans and in patients with congestive heart failure. The total number of subjects is not specified, but as many as 269 people could have been included in the study. Some of these subjects may have participated in more than one study. The radioisotope studies examined retention times, excretion rates, biologic decay rates, and a variety of other physiological parameters. The radioisotopes used included: mercury-203 $\left(\mathrm{Hg}^{203}\right)$, mercury-205 $\left(\mathrm{Hg}^{205}\right)$, chlorine-36 $\left(\mathrm{Cl}^{36}\right)$, sodium-22 $\left(\mathrm{Na}^{22}\right)$, sodium-24 $\left(\mathrm{Na}^{24}\right)$, rubidium-86 $\left(\mathrm{Rb}^{86}\right)$, potassium-39, $\left(\mathrm{K}^{39}\right)$, and potassium -42 $\left(K^{42}\right)$. One subject received only $X$ rays to determine the effects of radiation on humans. (Previously described in \#8 on the original list of 48 experiments released by DOE in June 1994)

\section{References}

Burch, G.E., S.A. Threefoot, J.A. Cronvich, and P. Reaser. "Theoretic and Experimental Considerations of Biological Decay Periods: Studies in Man with the Use of $\mathrm{Na}^{22}$." in Cold Spring Harbor Symposia On Quantitative Biology. Vol. 13, 1948, pp. 63-74.

Burch, G.E., P. Reaser, and J. Cronvich. "Rates of Sodium Turnover in Normal Subjects and in Patients with Congestive Heart Failure." The Journal of Laboratory and Clinical Medicine. Vol. 32, No. 10, 1947, pp. 1,169-1,191.

Burch, G.E., R.S. Sohal, S. Sun, G.C. Miller, and H. L. Colcolough. "Effects of Radiation on the Human Heart." Archives of Internal Medicine. Vol. 221, 1968, pp. 230-234.

Burch, G.E., S.A. Threefoot, and P.B. Reaser. "Some Aspects of Renal Excretion of $\mathrm{Na}^{24}$ by Normal Subjects and by Patients with Congestive Heart Failure." Stanford Medical Bulletin. Vol. 6, No. 1, 1948, pp. 81-87.

Burch, G.E., S.A. Threefoot, and P.B. Reaser. "Aspects of the Biological Decay Periods of Sodium in Normal and Diseased Men." Science. Vol. 107, 1948, pp. 91-92.

\section{7-11. Iron Metabolism in Human Pregnancy as Studied Whit the Rodioactive isotope tron-59}

From 1945 THROUGH 1949, Vanderbilt University Hospital conducted studies on iron absorption in pregnant women. Participants in the study were part of a larger nutrition survey conducted by the hospital. In all, 829 normal, healthy, pregnant women ingested radioactive iron-59 $\left(\mathrm{Fe}^{59}\right)$ in an amount ranging from 1.8 to 120 milligrams. The $\mathrm{Fe}^{59}$ was administered at various times in the gestation period ranging from fewer than 10 to more than 35 weeks. Radioactivity in the blood was measured 2 weeks and, again, 3 weeks after administration. The study showed that iron uptake is related to both dosage level and gestation period. The percentage of absorption decreased as the amount administered went up, while the actual amount of iron absorbed increased. Also, uptake increased later in the gestation period. At 30 weeks, three times as much 
iron was absorbed as at 15 weeks. This research was supported by the Nutrition Foundation, Inc., The Rockefeller Foundation, and the Tennessee State Department of Health.

From 1964 to 1967, Vanderbilt University School of Medicine conducted a follow-up study on the children born to these women. The study included 679 children of mothers who had been fed $\mathrm{Fe}^{59}$ and 705 children of mothers in the original study control population. One case of leukemia and two cases of sarcoma were discovered in the $\mathrm{Fe}^{59}$ population. There were no malignancies in the control population. Compared to an expected incidence of less than one, the three cases are statistically significant. There were no differences in malignancies among the mothers, congenital defects among the children, or congenital defects among subsequent children between the two populations. This follow-up work was supported by the U.S. Public Health Service and the U.S. Atomic Energy Commission. (Previously described in \#1 on the original list of 48 experiments released by DOE in June 1994)

\section{References}

Hahn, P.F., E.L Carothers, W.J. Darby, M. Martin, C.W. Sheppard, R.O. Cannon, A.S. Beam, P.M. Densen, J.C. Peterson, and G.S. McClellan. "Iron Metabolism in Human Pregnancy as Studied with the Radioactive Isotope, $\mathrm{Fe}^{59}$." American Journal of Obstetrics and Gynecology. Vol. 61, No. 3, March, 1953, pp. 477-486.

Hagstrom, R.M., S.R. Glasser, A.B. Brill, and R.M. Heyssel. "Long Term Effects of Radioactive Iron Administered During Human Pregnancy." American Journal of Epidemiology. Vol. 90 , No. 1, pp. 1-10.

\section{Or-12. Sodum-24 Used to Study Exchange- able Sodtum in Relation to the Men. struar crole}

THIS STUDY WAS CONDUCTED in 1969 at Vanderbilt University. Six healthy female volunteers, between the ages of 19 to 44 years, with no history of hypertension and with normal blood pressure, were fed a constant sodium diet for 30 to 45 days. After administration of a 10 microcuries oral dosage of sodium-24 $\left(\mathrm{Na}^{24}\right)$, exchangeable sodium spaces were measured during the follicular phase and the luteal phase of the menstrual cycle. The subjects were followed daily at the Clinical Research Center for excretion of sodium, potassium and creatinine, urine volume, body weight, and basal body temperature. This research was funded by grants from the Public Health Service, the American Heart Association, and the U.S. Atomic Energy Commission.

\section{References}

Michelakis, AM., E.G. Stant, and A.B. Brill. "Sodium Space and Electrolyte Excretion During the Menstrual Cycle." American Journal of Obstetrics \& Gynecology. Vol. 109., No. 1, January 1, 1971, pp. 150-154.

Brill, A.C. AEC Progress Report: Radiation Dosimetry and Biological Turnover of Radionuclides Used in Nuclear Medicine in Prenatal and Postnatal Subjects Using Stable and Radioactive Tracer. Nashville: Vanderbilt University, October 31, 1969. Oak Ridge Operations Office, Public Reading Room/Public Information Office, RHA Shipment 9162, Box 6 and 7, New York Times FOIA Requests 88-91.

\section{OT-17. Chromum-50-Laheled Red Cell Studies in Newborn hrtants With Hyalne Merbiane Drsease}

IN 1969, AT VANDERBILT UNIVERSITY, chromium-50 $\left(\mathrm{Cr}^{50}\right)$ was used to label red cells in studies of newborn infants with the hyaline membrane disease. The studies were performed with a twotold purpose: (1) to determine the blood volume in these children, and (2) to determine, for those who died, whether hemorrhage had occurred prior to or after $\mathrm{Cr}^{50}$ labeling. Measurements of red blood cell volumes were made on 86 newborn infants with respiratory distress. Of these infants, 28 were found to have intracranial hemorrhage at autopsy and 22 had their major bleeding episode after they were tagged with the $\mathrm{Cr}^{50}$. Large quantities of blood were drawn from these infants for extensive diagnostic studies and the replacement transfusions of donor blood was labeled with $\mathrm{Cr}^{50}$.

The researchers also conducted further studies on one infant and three adult patients using dual 
tracers of chromium-51 $\left(\mathrm{Cr}^{51}\right)$ and $\mathrm{Cr}^{50}$ and measuring blood volume. This study was supported in part by an Atomic Energy Commission contract and in part by a grant from the National Heart Institute.

\section{References}

Dyer, N.C., A.B. Brill, G. Faxelius, and M. Stahlman. "Blood Volume and Hemorrhage Timing in Newborn Infants with Respiratory Distress using the Stable Tracer $\mathrm{Cr}^{50}$." in Neutron Sources and Applications: Proceedings of the Nuclear Society National Topical Meeting in Augusta, Georgia, April 19-21, 1971. April 18, 1971, pp. V-46-V-52.

Brill, A.B. AEC Progress Report Radiation Dosimetry and Biological Turnover of Radionuclides Used in Nuclear Medicine in Prenatal and Postnatal Subjects Using Stable and Radioactive Tracers. Nashville: Vanderbilt University, October 31, 1969. Oak Ridge Operations Office, Public Reading Room/Public Information Office, RHA Shipment 9162, Box 6 and 7, New York Times FOIA Requests 88-91.

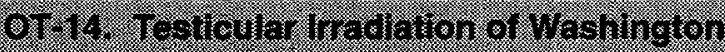
Stute Prisonithities

From 1963 To 1973, the University of Washington conducted studies on the effects of radiation on human testicular function using inmates at the Washington State Prison in Walla Walla, WA, as subjects. Initially, 232 healthy volunteers were accepted into the study program. Sixty were subsequently irradiated with acute doses of $x$ rays, ranging from 7.5 to 400 rads to the testes. Four other participants went through an identical procedure, but received no radiation. Forty-three were released from the program for a variety of reasons. The remaining 125 inmates served as control subjects in the study. Each inmate selected for the study had expressed a desire to undergo a vasectomy at the conclusion of the study. Fifty-three subjects received post-study vasectomies. The other 11 subjects either declined the procedure or did not receive vasectomies. Tissue samples were analyzed at the Biology Division of Oak Ridge National Laboratory, whose participation was reviewed and approved by an institutional review board.
These studies showed that doses of 7.5 rads had no adverse affect on testicular function, that doses of 27 rads inhibited generation of sperm cells, that doses of 75 rads destroyed existing sperm cells, and that doses of 100 to 400 rads produced temporary sterility. All subjects of the study eventually recovered to their normal preirradiation condition prior to vasectomy. Study results showed that adult males are very radiosensitive to temporary sterility, but also radioresistant to complete sterility. This work was supported by the U.S. Atomic Energy Commission. (This experiment was referenced in the Markey report.)

\section{References}

Paulsen, C.A. The Study of Irradiation Effects on the Human Testis: Including Histologic, Chromosomal and Hormonal Aspects. Terminal Report, AEC Contract \#AT(45-1)-2225. Seattle: University of Washington School of Medicine, January 31, 1973.

Thorslund, T.W. and C.A. Paulsen. "Effects of $X$-Ray Irradiation on Human Spermatogenesis." in Proceedings of the National Symposium on Natural and Man-Made Radiation in Space. E.A. Warman, ed. NASA Document TM X-2440, 1972, pp. 229-232.

\section{0r-15. Radlosctive tron in Mumans}

IN THE EARLY 1950s, a study was conducted at University Hospital at the University of Washington on the iron metabolism and the production of red blood cells. Iron-55 $\left(\mathrm{Fe}^{55}\right)$ and iron-59 $\left(\mathrm{Fe}^{59}\right)$ were injected into either normal subjects or anemic subjects. Approximately 20 subjects received $\mathrm{Fe}^{55}$; another 60 to 80 received $\mathrm{Fe}^{59}$ in amounts ranging from 5 to 10 microcuries. Blood samples were drawn at different times and counted to determine radioiron content. This study was supported by the U.S. Atomic Energy Commission. (Previously described in \#40 on the original list of 48 experiments released by DOE in June 1994)

\section{References}

Giblett, E.R., D.H. Coleman, G. Pirzio-Biroli, D.M. Donohue, A.G. Motulsku, and C.A. Finch. "Erythrokinetics: Quantitative Measurements of Red Cell Production and Destruction in Normal 
Subjects and Patients with Anemia." Blood. Vol. 1, 1956, pp. 291-309.

Finch, C.A., E.R. Giblett, D.M. Donohue, A.V. Hurtado, A.G. Motulsky, and R.H. Reiff. "Quantitative Aspects of Erythropoiesis in Man." Transactions of the Association of American Physicians. Vol. 69, 1956, pp. 149-154.

Sturgeon, P. and C.A. Finch. "Erythrokinetics in Cooley's Anemia." Blood. vol. 12, 1957, pp. 64-73.

Bothwell, T.H., A.V. Hurtado, D.M. Donohue, and C.A. Finch. "Erythrokinetics. IV. The Plasma Iron Turnover as a Measure of Erythropoiesis." Blood. Vol. 12, 1957, 407-427.

Letter. C.A. Finch to S. Marks. July 17, 1984. Pacific Northwest Laboratory General Human Subjects, Box Alan Rither, PNL-9055-DEL.

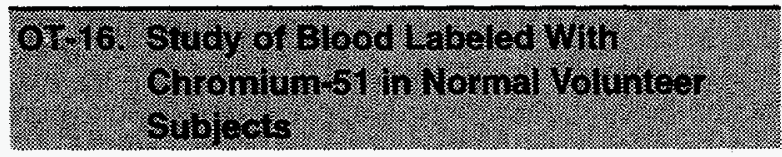

Chromium-51 Was used to tag red blood cells, which were then injected in normal volunteers in amounts similar to those used clinically in blood volume determinations. The number of volunteers was estimated to be 50 . These studies led to the use of adenine as a blood preservative. The University of Washington, Seattle, conducted the study prior to 1964 with funding from the U.S. Atomic Energy Commission. (Previously described in \#39 on the original list of 48 experiments released by DOE in June 1994)

\section{References}

Hennessey, M., C.A. Finch, and B.W. Gabrio. "Erythrocyte Preservation. VIII. Metabolic Degradation of Nucleosides In Vitro and In Vivo." Journal of Clinical Investigation. Vol. 36, 1957, pp. 429-433.

Donohue, D.M., B.W. Gabrio, F.M. Huennekens, and C.A. Finch. "The Metabolic Pathways of Purine Nucleosides and the Use of Inosine in Red. Cell Preservation." in International Society of Blood Transfusion: Proceedings of the 6th Congress. Basel: Karger, 1958, pp. 290-293.
Lange, R.D., W.H. Crosby, D.M. Donohue, C.A. Finch, J.G. Gibson, R.J. McManus, and M.M. Stumia. "Effect of Inosine on Red Cell Preservation." Journal of Clinical Investigation. Vol. 37, 1958, pp. 1,485-1,493.

Letter. C.A. Finch to S. Marks. July 17, 1984. Pacific Northwest Laboratory General Human Subjects, Box Alan Rither, PNL-9055-DEL. $\square$

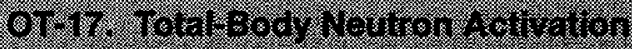
thatists

Between 1970 and 1973, studies on the potential usefulness of total body neutron activation analysis as a diagnostic tool were conducted at University Hospital, University of Washington, Seattle. In the first stage, $\mathbf{4 0}$ to $\mathbf{5 0}$ females were studied to develop the technique. All were over the age of 55 years and were afflicted with known bone-wasting diseases, such as osteoporosis. In the second stage, which used this new technique with human subjects, 25 chronically ill adults suffering from kidney failure were studied to evaluate calcium balance. Females in the second stage were beyond childbearing years. All subjects were exposed to uniform low-flux, high-energy neutrons. The total body dose to study participants was estimated to be 0.2 rad (neutrons). Initial subject were given a 1-year examination, but no longer-term follow-up was conducted. This study was funded by the U.S. Atomic Energy Commission. (Previously described in \#38 on the original list of 48 experiments released by DOE in June 1994)

\section{References}

Letter. W.B. Nelp to S. Marks. August 30, 1984. Pacific Northwest Laboratory, General Human Subjects, Box Alan Rither, PNL-9055-DEL. ㅁ

\section{Ot.18. Uah Strontumb5 Uababollsn Study}

THE UNIVERSITY OF UTAH Radiobiology Laboratoiy conducted a strontium-85 $\left(\mathrm{Sr}^{85}\right)$ metabolism study on human subjects in 1956 to determine the uptake, retention, and excretion of $\mathrm{Sr}^{85}$ in man. The study was conducted to learn more about the likely metabolism of strontium-90 $\left(\mathrm{Sr}^{90}\right)$ fallout from atomic testing. Subjects consisted of seven male patients at the Salt Lake Veterans 
Administration Hospital and two male staff members. Five of the patients had normal bone metabolism and two had osteoporosis. After intravenous injection of approximately 5 microcuries of $\mathrm{Sr}^{35}$, measurements were made over time to determine concentrations of $\mathrm{S}^{85}$ in blood plasma, urine, and feces. Bone tissue biopsy samples obtained from two osteoporotic patients and from two normal subjects were analyzed for $\mathrm{Sr}^{85}$ and calcium. In addition, several bone samples were obtained at autopsy from a tenth injected patient who was not bioassayed along with the other patients. This work showed that strontium cleared more efficiently than calcium from the blood and was excreted primarily in urine rather than feces. This study was part of Project Sunshine and was supported by the U.S. Atomic Energy Commission.

\section{References}

Van Dilla, M. A., S. Wallach, and J. S. Arnold. "Sr-85 Tracer Studies in Humans." Semiannual Progress Report. Salt Lake City: Radiobiology Laboratory, University of Utah, September 30 , 1956.

01719. Radiolsotope Studies at the Fernald Strte Schoor. Massachusetis

IN THE EARLY TO MID-1950s, various radiation-related studies were carried out at the Fernald State School in Waverly, MA, using students as subjects. In a study addressing calcium metabolism, nine adolescent males, institutionalized for mental inadequacy but otherwise physically normal, ranging in age from 10 to 15 years, and one 21-yearold male participated as subjects. The adolescents received 0.7 microcurie of calcium- $45\left(\mathrm{Ca}^{45}\right)$. The subjects were divided into two groups. One group was administered the $\mathrm{Ca}^{45}$ intravenously, the other received it orally. One month later, 0.74 microcurie was administered, but the means of administration was reversed between the groups. Two years later, 2.02 microcuries were administered to the 21-year-old subject. The studies showed that calcium is retained in the body for some time and that it is eventually excreted more through urine than feces.

A second study addressed thyroid function in Down's syndrome subjects and their parents.
Twenty-one male and female Down's sy'ndrome students ranging in age from 5 to 26 years participated, as did 5 female and 2 male normal parents of these students. The students were orally administered 70 microcuries of iodine-131 $\left(\left(^{131}\right)\right.$. The parents received 100 microcuries. Thyroid uptake, turnover, and urinary excretion were subsequently measured. Additionally, thyroxine metabolism was studied in two Down's syndrome students after intravenous injection of 55 microcuries of thyroxine labeled with ${ }^{131}$. These studies showed that iodine uptake was in the low-normal range and did not differ significantly from normal values; that the iodine turnover rate was significantly faster than normal; that the thyroxine turnover rate was normal; and that the uptake, turnover, and excretion rates in parents of Down's syndrome children was normal. These studies were supported in part by the U.S. Atomic Energy Commission.

\section{References}

Bronner, F., R.S. Harris, C.J. Maletskos, and C.E. Benda. "Studies in Calcium Metabolism. The Fate of Intravenously Injected Radiocalcium in Human Beings." Journal of Clinical Investigation. Vol. 35, 1956, pp. 78-88.

Kurland, G.S., J. Fishman, M.W. Hamolsky, and A.S. Freedberg. "Radioisotope Study of Thyroid Function in 21 Mongoloid Subjects Inclucling Observations in 7 Parents." Journal of Endocrino/ogy and Metabolism. Vol. 17, 1957, pp. 552-560.

OT-20. Uptake or lodine-13i by Prenatire inams in Dorroit

IN 1954, THE UPTAKE of iodine-131 by the thyroid gland of premature infants was studied by the Pediatric Division and the Radioisotope Laboratory of Harper Hospital, Detroit, MI. Sixty-five premature infants ranging in birth weight from 2.1 to $5.5 \mathrm{lb}$ were included in the study; 7 full-term infants were used for the control group. The premature infants were given 5 microcuries of $I^{131}$ orally. $1^{131}$ concentrations were then measured in the thyroid gland. It was found that the range of uptake of $\mathrm{I}^{131}$ in this series of infants was within the limits of normal as measured in studies of full-term children and adults. (Previously 
described in \#4 on original 48 experiments released by DOE in June 1994)

\section{References}

Martmer, E.E., K.E. Corrigan, H.P. Charbeneau, and A. Sosin. "A Study of the Uptake of lodine $\left({ }^{131}\right)$ by the Thyroid of Premature Infants." AMA American Journal of Diseases of Children. Vol. 17, 1955, pp. 503-509.

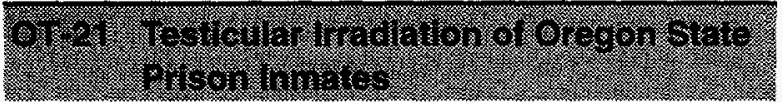

From August 1963 to May 1971, the Pacific Northwest Research Foundation in Seattle, WA, conducted studies on the effects of radiation on human testicular function using as subjects inmates at the Oregon State Prison in Salem, OR. The purposes of the study were to determine the effects of ionizing radiation on sperm production and to determine minimum dose levels for initial effect and permanent damage. Sixty-seven healthy volunteers ranging in age from 24 to 52 years were irradiated by $x$ rays at least once during the course of the study. Of these 67 subjects, 6 received a second irradiation, 1 received 3 irradiations, and 1 received a series of 11 weekly irradiations. Testicular absorbed doses ranged from 8 to 640 rads. Postirradiation studies included analysis of blood, urine, and seminal fluid, and biopsy of sperm-producing tissues. Subjects were compensated for their participation and for each biopsy. All subjects who had not been previously vasectomized agreed to undergo a vasectomy at the conclusion of the study. All did so and received additional compensation for the procedure. All subjects were volunteers. Inmates could withdraw from participation at any time. The study was reviewed at 3-month intervals by a review board, and three additional reviews were provided by a national ad hoc committee.

This study showed that a single testicular dose of 600 rads caused temporary disruption of testicular function. Recovery time was dose dependent: The higher the dose, the longer the time required for recovery. Subjects who were irradiated a second or third time had responses that were similar to their initial responses. This work was supported by the U.S. Atomic Energy Commission. (This experiment was referenced in the Markey report.)

\section{References}

Heller, C.G. Effects of lonizing Radiation on the Testicular Function of Man: 9 Year Progress Report. Seattle: Pacific Northwest Research Foundation, May 1972.

Heller, C.G., D.E. Dilaconi, and M.J. Rowley. Protection of the Rights and Welfare of Prison Volunteers: Policies Followed Throughout a 17-Year Medical Research Program. Seattle: Pacific Northwest Research Foundation.

Rowley, M.J., D.R. Leach, G.A. Warner, and C.G. Heller. "Effect of Graded Doses of lonizing Radiation on the Human Testis." Radiation Research. Vol. 59, 1974, pp. 665-678.

"Background Information on AEC Human Testicular Irradiation Projects in Oregon and Washington State Prisons." Information from ERDA. Washington, DC: Energy Research and Development Administration, March 1975.

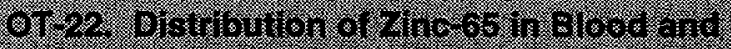 Organovin tha}

IN 1947, RESEARCHERS in Boston administered zinc-65 $\left(\mathrm{Zn}^{65}\right)$ to a 67 -year-old male suffering from myelogenous leukemia and to a nonleukemic, healthy subject. The purpose of this study was to determine how the content and distribution of zinc in blood and organs of the normal subject compared with the zinc content and distribution in the leukemia patient. $\mathrm{Zn}^{65}$ was injected intravenously as zinc chloride daily for several days and ranged in amounts ranging from 2 milligrams per day to "far in excess of this amount." Analysis occurred over a long period of time to monitor $\mathrm{Zn}^{65}$ retention.

This experiment showed that zinc plays an important role in the metabolism of tissues and biood cells. The work was supported by the U.S. Atomic Energy Commission. (Previously described in \#32 on the original list of 48 experiments released by DOE in June 1994)

\section{References}

Vallee, B.L., R.G. Fluharty, and J.G. Gibson. Distribution of Zinc in Normal Blood and Organs Studied by Means of $Z n^{65}$. 1947. Oak Ridge Operations 
Human Radiation Experiments: The DOE Roadmap to the Story and the Records

Office, (RHTG) Classified Docs 1944-1994, Records Holding Area-Bldg 2714-H Vault, Box RH H108-5, 1 of 2, Folder Advisory Committee.

Gibson, J.G., B.I. Vallee, R.G. Fluharty, and J.E.

Nelson. Studies of the Zinc Content of the Leucocytes in Myelogenous Leukemia. 1947. Oak Ridge Operations Office, (RHTG) Classified Docs

1944-1994, Records Holding Area-BIdg 2714-H Vault, Box RHA H108-5, 1 of 2, Folder Advisory Committee.

290 


\section{Abbreviations and Acronyms}

ABC-Advanced Biomedical Science and Treatment Center (at LBL)

ACRH-Argonne Cancer Research Hospital (University of Chicago)

ACTH-alpha-corticotrophin

AIW-a prototype Naval reactor (at INEL)

ADOCS - an INEL database)

AEC-[U.S.] Atomic Energy Commission

AEP-Atomic Energy Project (University of Rochester)

ALARA-as low as reasonably achievable

AUI-Associated Universities, Inc.

ANC-Aerojet Nuclear Company

ANL-Argonne National Laboratory (IL)

AWF-Argonne National Laboratory West Facility (ID)

BNL-Brookhaven National Laboratory (Upton, NY)

BORAX - Boiling Water Reactor Experiment (at INEL)

CAM-Committee on Aviation Medicine (of Donner Laboratory, Berkeley)

CDC-Centers for Disease Control and Prevention (of U.S. Department of Health and Human Services)

CERT-Controlled Environmental Radioiodine Tests (at INEL); a/so: Controlled Environmental Release Tests (at INEL)

CERTLE-CERT Laboratory Experiments

CF-central files (a prefix used in ORNL reports and correspondence)

CFA-Central Facilities Area (at ID)

CHR-Center for Human Radiobiology (at ANL)

$\mathrm{CIC}$-Coordinating and Information Center (Las Vegas)

CM-Chemistry and Metallurgy Division (at LANL)
CPP-Chemical Processing Plant

DBM-Division of Biology and Medicine (of the AEC)

DMA-Division of Military Applications (of AEC)

DOD-[U.S.] Department of Defense

DOE-[U.S.] Department of Energy

DTPA-diethylenetriamine penatacetic acid

E-Engineering Ordnance Division (at LANL)

EBR-1-Experimental Breeder Reactor I (at INEL)

EHS-Environmental Health Science (a type of appraisal conducted by AEC); see also RL

EIS-Environmental Impact Statement

EHDP-diophosphonate

EM-Environmental Management Division (at LANL)

EP-Experimental Physics Division (at LANL)

ER-Environmental Research Division (at ANL)

ERDA-Energy Research and Development Administration (successor to AEC)

EXCES-Experimental Cloud Exposure Study (at INEL)

FDG-fiuorodeoxyglucose

FFTF-Fast Flux Test Facility

FPFRT-Fission Product Field Release Tests

FRC-Federal Records Center

GAC-General Advisory Committee (of AEC)

GE-General Electric Company

GM-General Manager (of AEC)

GMX-5-Dynamic Weapons Testing Division (at LANL)

$\mathrm{H}$-Health Division (at LANL)

H-4-Biomedical Research Group of the Health Division (at LANL)

HEDR - Hanford Environmental Dose Reconstruction Project 
HEW-[U.S. Department of] Health, Education, and Welfare (preceded U.S. Department of Health and Human Services)

HR-Deputy Assistant Secretary for Human Resources (of DOE)

HS-Health and Safety Division (at LANL)

HSE-Health, Safety, and Environment Division (at LANL)

HTRE-Heat Transfer Reactor Experiments (at INEL)

ICPP_Idaho Chemical Processing Plant

IET-Initial Engine Test(s) [conducted at the AEC National Reactor Testing Station in Idaho for the ANP program]

IHDE-INEL Historical DOSE Evaluation

INEL-Idaho National Engineering Laboratory

IRB-Institutional Review Board

$\mathrm{K}-25-\mathrm{a}$ facility in Oak Ridge, TN, originally built as a gaseous diffusion plant site for producing $\mathrm{U}^{235}$

$\mathrm{K}-27$ - a gaseous diffusion plant built near $\mathrm{K}-25$

LAMPF-Los Alamos Meson Physics Facility

LANL-Los Alamos National Laboratory (NM)

LASL_Los Alamos Scientific Laboratory (an early name for LANL)

LBL-Lawrence Berkeley Laboratory (Berkeley, CA)

LDDT-Long Distance Diffusion Tests (at INEL)

LETBI-Low Exposure Total Body Irradiator (at Oak Ridge, TN); see also METBI

LIBRA-_Light Ion Medical Research Accelerator (at LBL)

LLNL_Lawrence Livermore National Laboratory (Livermore, CA)

LMFBR - Liquid Metal Fast Breeder Reactor

LOFT-Loss of Fluid Test Facility (at INEL)

LRL-Lawrence Radiation Laboratory

LS_Life Sciences Division (at LANL)

MED-Manhattan Engineer District-the Manhattan Project
METBI-Medium Exposure Total Body Irradiator (at Oak Ridge, TN); see also LETBI

Met Lab-Metallurgical Laboratory (at University of Chicago)

MH\&S-Medicine Health and Safety

M\&O-management and operating

MON-a prefix denoting reports generated by Monsanto Corporation when it operated ORNL

NARA-U.S. National Archives and Records Administration

NASA-National Aeronautics and Space Administration

NCEH-National Center for Environmental Health (of CDC)

N-Division-Nuclear Rocket Propulsion Division (of LASC)

NEPA-Nuclear Energy for the Propulsion of Aircraft

NIH-National Institutes of Health

NOAA-National Oceanic and Atmospheric Administration (of the U.S. Department of Commerce)

NRC-Nuclear Regulatory Commission

NRF-Naval Reactors Facility (ID)

NRTS-National Reactor Testing Station (early name for INEL)

OHRE-Office of Human Radiation Experiments

OMRE-Organic Moderated Solvent Burning Experiment (at INEL)

OPEC-Organization of Petroleum Exporting Countries

ORAU—Oak Ridge Associated Universities

ORINS-Oak Ridge Institute of Nuclear Studies

ORISE-Oak Ridge Institute for Science and Education

ORNL—Oak Ridge National Laboratory (TN)

ORO-Oak Ridge Operations Office (of DOE)

OSRD-[U.S.] Office of Scientific Research and Development 
OSTI-Office of Scientific and Technical Information (of DOE)

PET-positron emission tomography

PNL--Pacific Northwest Laboratory (Richland, WA)

RaLa-radioactive lanthanum; also known as radio lanthanum

RDT-Relative Diffusion Tests (at INEL)

RESL-Radiological and Environmental Sciences Laboratory (at INEL)

RHTG-Records Holding Task Group (of Oak Ridge Operations Office)

RL-Richland Operations Office; see also EHS

ROTC-Reserve Officers Training Corps

S1W-a prototype naval reactor (INEL)

S5G-a prototype naval reactor (at INEL)

S-50-the liquid thermal diffusion plant built at Oak Ridge, TN in 1944 to enrich uranium feed material for $Y-12$

SFPHS-San Francisco Public Health Service

SL-1-Stationary Low-Power Reactor No. I (at INEL)
SNAP-System(s) for Nuclear Auxiliary Power

SNAPTRAN-SNAP IOA Transient Test (at INEL)

SPERT-Special Power Excursion Reactor Tests (at INEL)

T-Theoretical Physics Division (at LANL)

TM-Technical Memoranda (an ORNL report series dating from 1974)

TNT-Transient Nuclear Test (at INEL)

TWX-Teletypewriter Exchange

UC-University of California

UCB-Committee for the Protection of Human Subjects (at Donner Laboratory, Berkeley); see also LRL.

USGS-U.S. Geological Survey

USPHS-United States Public Health Service

WBC - Whole Body Counter

$X-10$ - a test pile plant built at Oak Ridge

$Y-12$ - the industrial electromagnetic separation plant in Oak Ridge, TN, originally built to produce uranium-235 
D EFINED BELOW are some technical terms relating to radiation.

Radioactivity is the tendency of unstable atoms to undergo a spontaneous, energy-releasing change in their structure. The energy released is called radiation. It occurs at various energy levels. At a certain point, radiation energy is sufficient to strip electrons from the atoms in materials it strikes and is therefore called ionizing radiation. It is particularly dangerous for humans because these energy levels are such that they also can cause damage to living tissues.

lonizing radiation may involve alpha particles, beta particles, gamma rays, $x$ rays, or neutrons.

Alpha particles-An alpha particle is a high-energy particle with a very short range. It does not pose an external hazard because it cannot penetrate human skin. It may be stopped by a single sheet of paper. However, if inhaled or ingested, the particles come in direct contact with tissue cells and can cause severe damage. Accordingly, alpha particles present a serious internal hazard. Uranium, radium, and plutonium all emit alpha particles.

Beta particles-Beta particles exhibit a wide range of energy levels. Some have sufficient energy to penetrate human skin, and will cause skin burns. These particles can cause damage if inhaled or ingested. Beta particles can be stopped by plastic, aluminum, and wood. Tritium is one example of a beta emitter.

Gamma rays and $x$ rays - Both of these are high-energy emissions that easily penetrate the human body. They are, therefore, dangerous in high amounts as external radiation hazards. They can be stopped by dense materials, such as lead, concrete, or steel. Gamma rays are produced by isotopes such as lanthanum- 140 , cesium- 137 , and cobalt $-60 . X$ rays are produced by medical $x$-ray tubes and the $x$-ray machines used to examine carry-on baggage at airports.

Neutrons-A neutron is a component of the nucleus of an atom. Neutron radiation can be harmful to living things. Neutrons are liberated in great numbers in a nuclear reactor, but they do not present a hazard to humans because they are absorbed by the heavy shielding that encloses the reactor. Neutrons are also emitted during the spontaneous decay of certain radionuclides such as californium- 252 .

Amount of radiation is expressed in several ways. A curie is a measure of activity, or the rate of disintegration of atoms undergoing change. This unit of measure is often expressed as millicuries (thousandths of a curie) or microcuries (millionths of a curie). A roentgen is a measure of the ionization of air by $x$ rays or gamma rays.

Exposure refers to being placed in a field of radiation energy. Dose refers to energy imparted per unit mass of tissue. A rad is a measure of the absorbed dose to tissue from exposure to radiation; that is, the amount of energy deposited per unit mass of tissue. A rem is a measure of dose equivalent in man. It is the dose in rads multiplied by a weighting factor to account for the more damaging effects of alpha particles and neutron radiation.

Background radiation refers to the natural radiation to which people are exposed in daily life. It differs for different locations and different circumstances. Brick and wood homes emit different levels of background radiation. Cities at different elevations have different levels of background cosmic radiation. For example, the average annual dose from all sources to U.S. residents is estimated to be $\mathbf{2 0 0}$ millirems per year. However, the average dose to residents of Los Alamos, NM-a city at high elevation-is 330 millirems per year. A transcontinental airplane flight will result in a dose of about 4 millirems to a passenger. A standard chest $x$ ray will result in a dose of about 10 millirems.

Occupational dose refers to the dose that people receive in their workplace. To provide for the safety of workers, the International Commission on Radiological Protection has established certain standards to limit the dose received by workers. Standards for minors are 10 percent of the dose for adults. These annual dose limits for radiation workers are:

$\begin{aligned} \text { Whole body } & 5 \mathrm{rem} \\ \text { Skin or any extremities } & 50 \mathrm{rem} \\ \text { Eyes } & 15 \mathrm{rem} \\ \text { Embryo/fetus } & 0.5 \mathrm{rem}\end{aligned}$

By comparison, the annual dose limit for the general public (not radiation workers) set by the Commission is $0.1 \mathrm{rem}$. 


\section{Appendixa.Markey Repont "Expeniment List'}

$\mathbf{T}$ HE FOLLOWING is a category and title list of experiments taken from American Nuclear Guinea Pigs: Three Decades of Radiation Experiments on U.S. Citizens. This 1986 report was prepared by the Subcommittee on Energy Conservation and Power of the Committee on Energy and Commerce of the U.S. House of Representatives. Known as the Markey Report, the report arranges experiments into 12 categories. Individual experiments are discussed in some categories, and not in others. A number of these "Markey experiments" have been reworked with more current information and references, and included in Chapter 3. Others are included by reference as part of this appendix.

Category I: Metabolism and Biological Effects of Plutonium, Polonium, Thorium, Uranium, Radium, and Lead-2/2

- Plutonium Injections into Humans

- Administration of Radium and Thorium to Humans

- Polonium Administered to Humans

- Absorption of Lead-212 by Human Gastrointestinal Tract

- Some Biological Aspects of Radioactive Microspheres in Humans

- Injection of Uranium Salts

\section{Category 2: Testicular Irradiation}

- Testicular Irradiation of Inmates at Oregon State Prison

- Testicular Irradiation of Inmates at Washington State Prison

Category 3: Whole Body Irradiation for Treatment of Leukemia and Lymphoma

- Blood Changes in Human Beings Following Total Body Irradiation

Category 4: Teletherapy with Particular Beams

- Neutron Therapy Facility

- Biological Effects of Heavy lons on Human Nervous System and Vision

Category 5: Other Teletherapy Studies

Category 6: Treatment of Polycythemia

Category 7: Hematological Effects
Category 8: Neutron Capture Therapy

Category 9: Other Radiation Therapy

- Uranium Injected into Brain Tumor Patients

Category 10: Biological Effects of $I^{\prime 31}$

- Study of Changes in Thyroids Irradiated with Radioactive lodine

- Milk containing $\left.\right|^{|3|}$ Fed to Humans

- Planned Radioiodine Exposures to Humans

Category II: Other Biological Effects Studies

- Reactions of Human Skin to Beta Rays

- Studies of Radium applied to Human Skin

- Analysis of Illness of Children Receiving Fetal Irradiation

- Human Absorption of Tritium Oxide through Skin

- Effects of X Rays on Human Fingers

- Human Absorption and Excretion of Tritium

- Human Absorption of Tritium Liquid and Vapor

- Human Absorption of Tritium by Lung

- Human Absorption of Ingested Tritium Water

- Radiation Exposure of Aircrews in Mushroom Clouds

- Radioactive Material placed on Human Skin

- Medical Follow-up Studies

- Human Ingestion of Fallout

- Lanthanum-I40 Administered to Humans

Category 12: Metabolic and Physiological Studies

- Strontium and Calcium Injected in Terminal Cancer Patients

- Technetium Administered to Humans

- Promethium Administered to Humans

- Phosphorus-32 Injected into Humans

- Humans Inhaled Tritium

- Radioactive Material Administered to Humans to Calibrate Equipment 
$\mathbf{T}$ HIS BIBLIOGRAPHY lists a selection of the sources consulted for the overview history and the histories of individual sites. Note that many primary and secondary sources potentially useful for studying human radiation experiments exist apart from those listed here. All of the primary-source documents listed are available to the public. For copies, please mail requests to the following address:

Office of Human Radiation Experiments

I726 M Street N.W., Suite 200

Washington, DC 20036

Or call (202) 254-5020.

\section{Primary Source Documents}

\section{U. S. Congress}

Committee on Energy and Commerce, U.S. House of Representatives. Report. American Nuclear Guinea Pigs: Three Decades of Radiation Experiments on U.S. Citizens. November 1986.

Committee on Science and Technology, U. S. House of Representatives. Hearings on Human Total Body Irradiation (TBI) Program at Oak Ridge. September 23, 1981.

\section{U.S. Department of Energy. Archives}

Comptroller General of the United States. Report, Administration and Management of the Biology and Medicine Research Program, Atomic Energy Commission, April 16, 1969. U. S. Department of Energy Archives, Record Group 326, Atomic Energy Commission, Collection, Secretariat, Box 7827, Folder 10.

Letter, Carroll L. Wilson to Dr. Stafford L. Warren, April 30, 1947. U.S. Department of Energy Archives, Record Group 326, Atomic Energy Commission, Collection, General Manager, Box 550I, Folder April 1947 Reader File.

Letter, David Lilienthal to G.W. Beadle, August 6, 1947. U.S. Department of Energy Archives,
Record Group 326, U.S. Atomic Energy Commission, Collection, Biology and Medicine (II29), Box 1, Folder 2.

Letter, Carroll L. Wilson to Robert S. Stone, November 5, 1947. U. S. Department of Energy Archives, Record Group 326, Atomic Energy Commission, Collection, General Manager, Box 5501 , Folder 13.

Letter, Shields Warren to Leslie M. Redman, March 5, 1951. U. S. Department of Energy Archives, Record Group 326, Collection, Division of Biology and Medicine (I I 32), Box 3353, Folder 39.

Liverman, James L. Briefing on Plutonium Project, April 29, 1974. U.S. Department of Energy Archives, Record Group 326, U.S. Atomic Energy Commission, Collection, Secretariat, Box 7931, Folder 1.

Memorandum, O. G. Haywood, Jr. to File. Subject: Distribution of Report "The Distribution and Excretion of Plutonium in Two Human Subjects," March II, 1947. U. S. Department of EnergyArchives, Record Group 326, U. S. Atomic Energy Commission, General Manager, Box 5579, Folder Declassification General.

U. S. Atomic Energy Commission. Annual and Semiannual Reports to Congress, 1947-1975. U.S. Department of Energy Archives. Reference Collection.

U. S. Atomic Energy Commission. Report of the Board of Review, June 20, 1947. U.S. Department of Energy Archives, Record Group 326, U.S. Atomic Energy Commission, Collection, Division of Biology and Medicine (1 129), Box 1, Folder 2.

U.S. Atomic Energy Commission. Minutes of Limited Attendance Session 74-78A, May 14, 1974.

U.S. Department of Energy Archives, Record Group 326, U.S. Atomic Energy Commission, Collection, Secretariat, Box 7937, Folder 13.

U.S. Atomic Energy Commission. Minutes of Commissioners Executive Session, May 15, 1974.

U.S. Department of Energy Archives, Record Group 326, U.S. Atomic Energy Commission, 
Collection, Commission Minutes, Box 3738, Folder 3.

U. S. Atomic Energy Commission. Division of Inspection, Report 44-2-326, Division of Biomedical and Environmental Research, Headquarters Activities Involving Injection of Individuals with Plutonium, August 16, 1974. U. S. Department of Energy Archives, Record Group 326, Collection, Division of Biology and Medicine (1709), Box 4, Folder, MH\&S 3-9 Plutonium Injection Investigation.

U.S. Atomic Energy Commission. Information Report, August 13, 1974, SECY-75-130. U.S. Department of Energy Archives, Record Group 326, U.S. Atomic Energy Commission, Collection, Secretariat, Box 7979, Folder 12.

U. S. Atomic Energy Commission. "A Plan for the Expansion of Research in Biology and Medicine." A Report to the General Manager by the Director, Division of Biology and Medicine, AEC 604/35, August 4, 1958. U.S. Department of Energy Archives, Record Group 326, U.S. Atomic Energy Commission, Collection, Secretariat Files, Box 1360, Folder 1.

4. S. Department of Energy. Los Alamos National Laboratory

Memorandum, G.T. Seaborg to R.S. Stone, January 5, 1944. "Physiological Hazards of Working with Plutonium." Los Alamos Human Studies Project Team Release No. 94-365.

Letter, Thomas L. Shipman to Charles L. Dunham, June 18, 1956. Los Alamos National Laboratory Records Center, Collection TR-6704, Box G-3-236, Folder AEC Bio-Medical.

Letter, Charles L. Dunham to Thomas L. Shipman, July 5, 1956. Los Alamos National Laboratory Records Center, Collection, TR-6704, Box G-3-236, Folder AEC Bio-Medical.

\section{U. S. Department of Energy, Oak Filge Operations ontee}

Letter, O. G. Haywood, Jr. to Dr. Fidler, April 17, 1947. Oak Ridge Operations Office Records Holding Area, Collection RHTG Files, Box 603.
1. S. Depariment of Energy. Oak Ridge institute for Science and Education

Oak Ridge Institute of Nuclear Studies Medical Division, Information for Patients, n.d. but about 1952. Oak Ridge Institute for Science and Education, Collection, Medical Correspondence and Committee Files, ORAU Document No. 30052.

U. S. Departinent of Energy, Orice of Human Radiation Experiments

Memorandum, L.H. Hempelmann to R. J. Oppenheimer, March 26, 1945. "Meeting of Chemistry Division and Medical Group." Office of Human Radiation Experiments, Collection, Plutonium Injection Investigation Files, Box 3, Folder LA-I I 5 I Plutonium in Man, 1950, Langham.

Martin Marietta Systems, Inc., Chronological Listing of Radiation Research Involving Human Subjects and Deliberate Environmental Releases at the Sites Currently Managed for the U. S. Department of Energy, 1994. Office of Human Radiation Experiments, Collection, Retrieval Project Administrative Files, Drawer, Laboratory/Sites, Progress Reports, Retrieval Visits, Folder ORNL/ORISE Experiments Lists.

V.S. Department of Energy Pactic Nonthwest Laboratory

Jenne, D.E. and J.W. Healy. "Dissolving of Twenty Day Metal at Hanford," HW 17381. Richland, Washington: General Electric Nucleonics Department, May I, 1950.

Nationar Archtres and hecords Administration, Washington. DO

Warren, Stafford L. "Report of the January 23-24, 1947 Meeting of the Interim Medical Committee of the U.S. Atomic Energy Commission." National Archives and Records Administration, Record Group 326, U.S. Atomic Energy Commission, Collection, Secretary's General Correspondence File, 1946-1951, Box 22, Folder 337 (1-28-47), Interim Medical Advisory Committee Meetings and Agenda. 


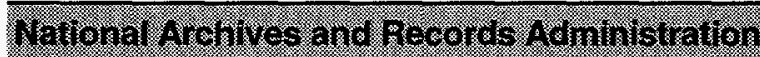

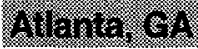

Interim Advisory Committee on Isotope Distribution Policy. Minutes of the Advisory Subcommittee on Human Applications of the Interim Advisory Committee on Isotope Distribution Policy, June 28, 1946. National Archives and Records Administration, Atlanta Archives, Collection 326-681096, Box 3, Folder Isotopes.

\section{University of Washington}

Memorandum, Stafford L. Warren to W.D. Fleming, September 9, 1946. "Recommendations of Medical Advisory Committee, September 5-6, 1946." University of Washington Manuscripts Division, Herbert M. Parker Papers, Accession 3616, Box 5, Folder 1949.

\section{Secondary Works}

\section{B.6.k.}

Ackerknecht, Erwin H., M.D. A Short History of Medicine. Baltimore: The Johns Hopkins University Press, 1992.

Brookhaven National Laboratory. The First Forty Years, 1947-1987. Upton, Long Island, New York: Associated Universities, Inc., no publication date given.

Cassedy, James H. Medicine in America: A Short History. Baltimore: The Johns Hopkins University Press, 1991.

Faden, Ruth R. and Tom L. Beauchamp. A History and Theory of Informed Consent. New York: Oxford University Press, 1986.

Hawkins, David. Project Y: The Los Alamos Story. Los Angeles: Tomash Publishers, 1983.

Hewlett, Richard G. and Jack M. Holl. Atoms for Peace and War. 1953-1961: Eisenhower and the Atomic Energy Commission. Berkeley: University of California Press, 1989.

Hewlett, Richard G. and Oscar E. Anderson Jr. The New World: A History of the United States Atomic Energy Commission, vol. 1, 1939-1946.
Washington, D.C.: U.S. Atomic Energy Commission, 1972.

Hewlett, Richard G. and Francis Duncan. Atomic Shield: A History of the Atomic Energy Commission, vol. 2, 1947-1952.

Washington, D.C.: U.S. Atomic Energy Commission, 1972.

Hoddeson, Lillian, et al. Critical Assembly: $A$ Technical History of Los Alamos during the Oppenheimer Years, 1943-1945. Cambridge: Cambridge University Press, 1993.

Jones, Vincent C. Manhattan: The Army and the Atomic Bomb, Special Studies, U.S. Army in World War II. Washington, D.C.: Government Printing Office, 1985.

Lawrence Livermore National Laboratory. Preparing for the 21st Century: 40 Years of Excellence. (Prepared for the U.S. Department of Energy by the Lawrence Livermore Laboratory, contract no. W-7405-ENG-48). No publication place or date given.

Mazuzan, George T. and J. Samuel Walker. Controlling the Atom: The Beginnings of Nuclear Regulation, 1946-1962. Berkeley: University of California Press, 1984.

Rothman, David J. Strangers at the Bedside: $A$ History of How Law and Bioethics Transformed Medical Decision Making. New York:

BasicBooks, 1991.

Stannard, J. Newell. Radioactivity and Health: $A$ History. Pacific Northwest Laboratory: Battelle Memorial Institute, 1988.

Walker, Samuel J. Containing the Atom: Nuclear Regulation in a Changing Environment, 1963-1971. Berkeley: University of California Press, 1992.

Warren, Stafford L. "The Role of Radiology in the Development of the Atomic Bomb," In Radiology in World War II, Medical Department, U.S. Army, ed. by Kenneth D. A. Allen. Washington, D.C.: Government Printing Office, 1966. 